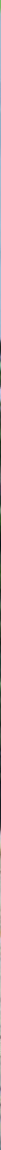

\title{
\begin{tabular}{r|l} 
Comunidades & Su rol en la conservación, \\
cales y pueblos & mantenimiento y creación de
\end{tabular} \\ \begin{tabular}{r|r} 
Comunidades & Su rol en la conservación, \\
locales y pueblos & mantenimiento y creación de
\end{tabular} indígenas $\mid$ áreas protegidas
}





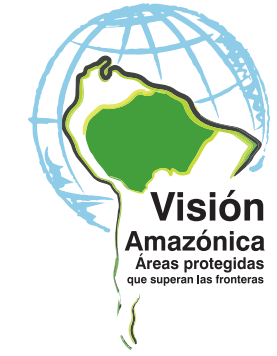

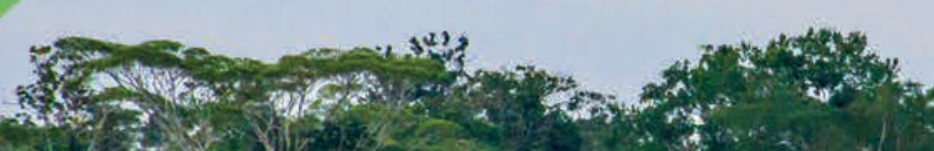
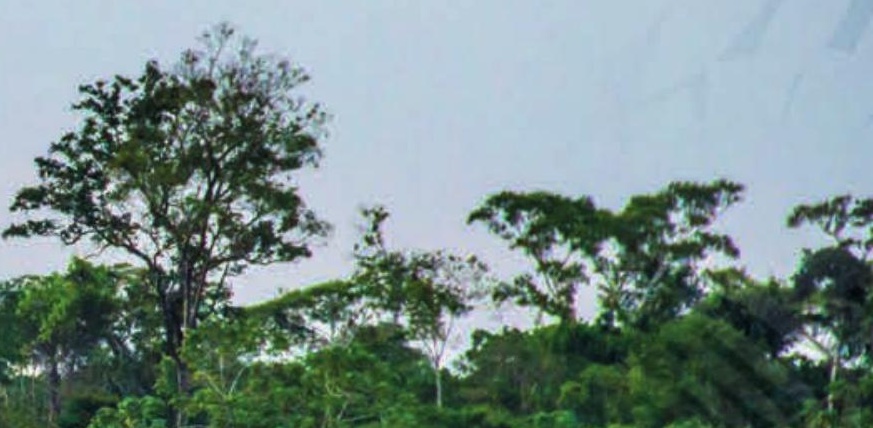

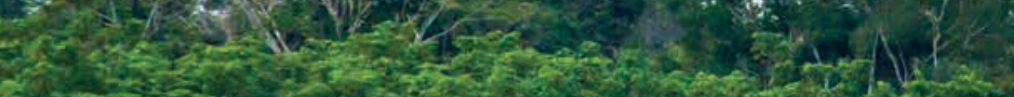

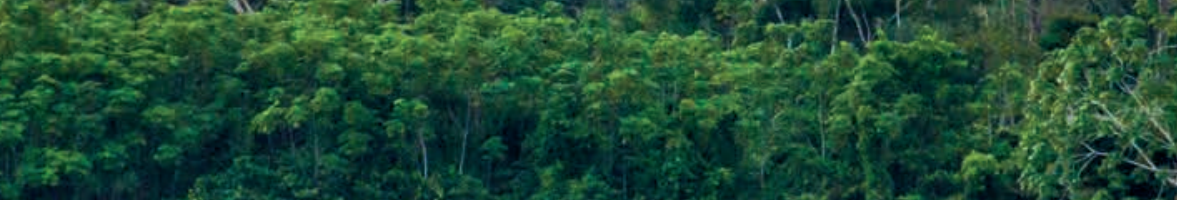

The

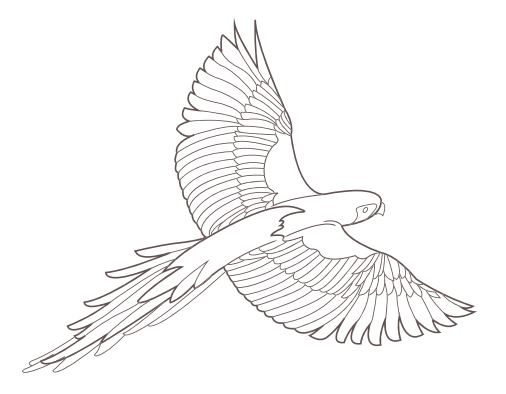

\section{Comunidades locales y pueblos indígenas}

Su rol en la conservación, mantenimiento y

creación de áreas protegidas

Martha Coronel Cisneros y Jéssica Solórzano Orellana

Donante

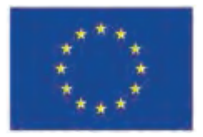

UNIÓN EUROPEA 
La presentación del material en esta publicación y las denominaciones empleadas para las entidades geográficas no implican en absoluto la expresión de una opinión por parte de la UICN, FAO, WWF, ONU Medio Ambiente, Unión Europea y Redparques sobre la situación jurídica de un país, territorio o zona, o de sus autoridades, o acerca de la demarcación de sus límites o fronteras.

Esta publicación ha sido desarrollada con el apoyo de la Unión Europea. Su contenido es responsabilidad única de Martha Coronel Cisneros y Jessica Solórzano. Los puntos de vista que se expresan en esa publicación no reflejan necesariamente los de la UICN, FAO, WWF, ONU Medio Ambiente, Unión Europea y Redparques

Esta publicación se desarrolla en el marco del proyecto Integración de las áreas protegidas del Bioma Amazónico - IAPA - Visión Amazónica (GCP/RLA/202/EC). Es financiado por la Unión Europea, Coordinado por la Organización de Naciones Unidas para la Alimentación y la Agricultura - FAO e implementado en conjunto con WWF, UICN, ONU Medio Ambiente y Redparques.

\section{Publicado por:}

Derechos reservados:

Citación:

ISBN:

DOI:

Fotografías:

Coordinación:

Fusión de documentos y revisión de estilo:

Diseño por:

Disponible en:
Oficina Regional para América del Sur de la Unión Internacional para la Conservación de la Naturaleza, Quito, Ecuador en colaboración con REDPARQUES, FAO, WWF, ONU Medio Ambiente y Unión Europea.

(c) 2017 Unión Internacional para la Conservación de la Naturaleza y de los Recursos Naturales.

Se autoriza la reproducción de esta publicación con fines educativos y otros fines no comerciales sin permiso escrito previo de parte de quien detenta los derechos de autor con tal de que se mencione la fuente.

Se prohíbe reproducir esta publicación para la venta o para otros fines comerciales sin permiso escrito previo de quien detenta los derechos de autor.

Coronel M. y Solórzano J. (2017). Comunidades locales y pueblos indígenas. Su rol en la conservación, mantenimiento y creación de áreas protegidas. Iniciativa Visión Amazónica. REDPARQUES, WWF, FAO, UICN, ONU Medio Ambiente. XV +192pp.

$978-2-8317-1860-6$

http://dx.doi.org/10.2305/IUCN.CH.2017.09.es

(C) Sergio Garrido García

Sergio Garrido García

Beatriz Herrero Mengod

Gorky Bonifaz / Babel diseño y comunicación

\section{Unión Internacional para la Conservación de la Naturaleza}

Av. República de El Salvador N34-127 y Suiza. Edificio Murano Plaza, piso 12; 170515

Quito, Ecuador, Telf. (593 2) 3330684

www.iucn.org/sur

www.portalces.org

Twitter: @UICN_SUR

Facebook UICN-Sur. facebook.com/UICN.SUR www.iucn.org

samerica@iucn.org 


\section{UICN}

La UICN es una Unión de Miembros compuesta por Estados soberanos, agencias gubernamentales y organizaciones de la sociedad civil. Cuenta con la experiencia, los recursos y el alcance de sus más de 1300 organizaciones Miembro y los aportes de alrededor de 15000 expertos. La UICN es la autoridad mundial en cuanto al estado de la naturaleza y los recursos naturales, así como las medidas necesarias para protegerlos.

\section{Sobre FAO}

La Organización de las Naciones Unidas para la Alimentación y la Agricultura - FAO, por sus siglas en inglés, es una organización intergubernamental creada en 1945, cuenta con 194 países miembros. Brinda sus servicios tanto a países desarrollados como a países en vías de desarrollo y actúa como un foro neutral donde todas las naciones se reúnen como iguales para negociar acuerdos y debatir políticas. Sus prioridades se centran en: 1) Ayudar a Eliminar el Hambre, la Inseguridad Alimentaria y la Malnutrición, 2) Fomentar la Agricultura, la Actividad Forestal y la Pesca más Productivas y Sostenibles, 3) Reducir la Pobreza Rural, 4) Crear un Entorno Propicio para el Establecimiento de Sistemas Agrícolas y Alimentarios y 5) Aumentar la Resiliencia en los Medios de Vida ante los Desastres.

\section{Sobre WWF}

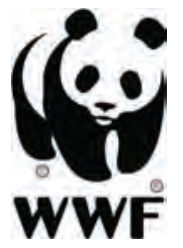

Es una de las organizaciones independientes de conservación más grandes y con mayor experiencia del mundo. WWF nació en 1961 y es conocida por el símbolo del Panda. Actualmente, cerca de 5 millones de personas cooperan con WWF, y cuenta con una red mundial que trabaja en más de 100 países. WWF trabaja por un planeta vivo, y su misión es detener la degradación del ambiente natural de la Tierra y construir un futuro en el que el ser humano viva en armonía con la naturaleza: conservando la diversidad biológica mundial, asegurado que el uso de los recursos naturales renovables sea sostenible y promoviendo la reducción de la contaminación y del consumo desmedido.

\section{Sobre ONU Medio Ambiente}

ONU Medio Ambiente, establecido en 1972, es la voz del medio ambiente en el sistema de las Naciones Unidas que actúa como catalizador, defensor, educador y facilitador para promover el uso sensato y el desarrollo sostenible del medio ambiente global. Es la autoridad ambiental líder en el mundo, que fija la agenda ambiental global, que promueve la aplicación coherente de las dimensiones ambientales del desarrollo sostenible en el marco del sistema de las Naciones Unidas, y que ejerce de defensor acreditado del medio ambiente global.

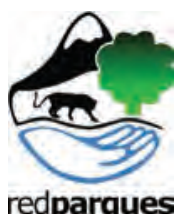

\section{Sobre REDPARQUES}

La Red Latinoamericana de Cooperación Técnica en Parques Nacionales, otras Áreas Protegidas, Flora y Fauna Silvestres, fue conformada hace más de 30 años por los representantes de los Sistemas de Áreas Protegidas de 19 países de la región, y supone un espacio técnico de intercambio de experiencias y trabajo común. Cuenta con tres sub-regiones: Centro América y Caribe, Andes Amazonía y América del Sur, siendo desde 2014 el SERNANP-Perú quien ejerce las funciones de Coordinación Regional.

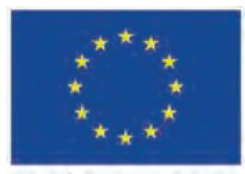

\section{Sobre Unión Europea}

La Unión Europea (UE), es una asociación económica y política única en su género, actualmente compuesta por 28 países, cuyo origen se encuentra en el periodo posterior a la Segunda Guerra Mundial. Sus primeros pasos consistieron en impulsar la cooperación económica con la idea de que, a medida que aumentara la interdependencia económica entre los países, disminuirían las posibilidades de conflicto. Lo que comenzó como una unión meramente económica ha evolucionado hasta convertirse en una organización activa en todos los frentes políticos, desde el clima hasta el medio ambiente y desde la salud hasta las relaciones exteriores y la seguridad, pasando por la justicia y la migración. Se basa en el Estado de Derecho y se rige por el principio de democracia representativa: Ios ciudadanos están directamente representados en el Parlamento Europeo, mientras que los Estados miembros tienen su representación en el Consejo Europeo y el Consejo de la UE. 


\section{Agradecimientos}

Este documento no habría sido posible sin los numerosos y valiosos aportes recibidos, la información proporcionada y los debates entablados con una gran variedad de personas e instituciones.

\section{Revisiones técnicas del texto}

\author{
Aracely Pazmiño Montero \\ Camila Romero Chica \\ Diana Castellanos Méndez \\ Jeferson Rojas Nieto \\ Jesús Rodrigues Domingos de Souza \\ Johana Deza Grados \\ Jose Antonio Gómez Díaz \\ Juan Eduardo Hernández Orozco
}

\section{Acompañamiento en salidas de campo y facilitación de informaciones}

REGIONAL
COICA
FAO
REDPARQUES
ICCA CONSOrtium

\section{PAISAJE NORTE}

\section{ACILAPP}

Asociación de mujeres "El Porvenir"

Asociación El Peregrino

Caiman Lodge

Campesinos de Aguas Negras

Campesinos de El Paraíso

Campesinos de Puerto Leguízamo

Cantón Cuyabeno

CEDIA

Comisaría de Policía Cuyabeno

Comuna Amena

Centro poblado Cabo Pantoja

Comunidad Playas de Cuyabeno

Comunidad Secoya Puerto Estrella

Comunidad San Victoriano

comunidad Zancudococha

Cuyabeno Lodge

Fundación Sobrevivencia Cofán

Ganaderos de Puerto Leguízamo

Grupo de Operadores Turísticos de Cuyabeno

Guacamayo Lodge

Guardaparques de la Reserva Comunal Airo Pa

Guardaparques de la RPF Cuyabeno

\author{
Juliana Vélez Gómez \\ Luis Borbor Laínez \\ Madelaide Morales Ruiz \\ Rosario Barrera Cáceres \\ Sergio Garrido García \\ Telma Elizabeth Paredes Martínez \\ Teófilo Torres Tuesta \\ Walter Cano Cardona
}

Guardaparques del PNN La Paya

Guardaparques del Parque Nacional Güeppí-

sekime

Jamu lodge

Jefatura del Parque Nacional Natural La Paya

Jefaturas de la RPF Cuyabeno

Junta Parroquial de Aguas Negras

Junta Parroquial Playas de Cuyabeno

Ministerio del Ambiente - Ecuador

Municipio de Puerto Leguízamo

Organización "Expreso de Oriente"

Parques Nacionales Naturales de Colombia

Profesionales del Parque Nacional Natural La Paya

Programa Sociobosque

Programa Trinacional

Resguardo Jiri-Jiri

Resguardo Lagarto Cocha

Servicio Nacional de Áreas Naturales Protegidas por el Estado de Perú

Siona Lodge

Técnicos de la RPF Cuyabeno

Tenencia Política de la Parroquia Yasuní

WWF - Colombia

WWF - Ecuado

WWF - Peru 
PAISAJE SUR

APECO

Autoridad Nacional del Agua - Perú

Barraca Puerto América

Barrio 2 de Mayo

Barrio Centroamérica

Barrio Nuevo Rosario

Comunidad Chivé

Comunidad Curichón

Comunidad Luz de América

Comunidad nativa Colombiana

Comunidad nativa Gastabala

Comunidad nativa Miguel Grau

Comunidad nativa Nueva Luz

Comunidad nativa Puija

Comunidad nativa San Ramón

Comunidad nativa Santa Clara

Comunidad nativa Santa Margarita

comunidad nativa Sepahua

Comunidad Núcleo de Cazumbá

Comunidad San Antonio

Comunidad Villa Florida

ECOPURUS

FECONAPU

FUNAI

Gerencia Subregional de Purús

Gobernación Regional de Ucayali - Subregión de Purús

Grupo de artesanas de la RESEX

Cazumbá-Iracema

Grupo de extracción de asaí de la RESEX

Cazumbá-Iracema

Grupo de jóvenes de la RESEX Cazumbá-Iracema

Guardaparques de la Reserva Comunal Purús

Guardaparques de la Reserva Comunal Purús

Guardaparques de la Reserva Nacional de Vida

Silvestre Amazónica Manuripi

Guardaparques del Parque Nacional Alto Purús

ICMBio

Jefatura de la Reserva Comunal Purús

Jefatura de la RESEX Cazumbá-Iracema

Jefatura del Parque Estadual Chandless

Jefatura del Parque Nacional Alto Purús

Jefatura de la RNVSA Manuripi

MABOSINFRON

Ministerio de Cultura - Perú

Ministerio do Meio Ambiente de Brasil
Monitores de Biodiversidad de la RESEX Cazumbá-

Iracema

Moradores del Parque Estadual Chandless

OSINFOR

Profesionales asociados al PE Chandless

Programa ARPA

Secretaría de Meio Ambiente de Acre - SEMA

Servicio Nacional de Áreas Naturales Protegidas por el Estado de Perú

Servicio Nacional de Áreas Protegidas de Bolivia

SETUL

Técnicos de la Reserva Comunal Purús

Técnicos de la RESEX Cazumbá-Iracema

Técnicos del Parque Nacional Alto Purús

Técnicos de la Reserva Nacional de Vida Silvestre

Amazónica Manuripi

Tierra Indígena Madijá Alto Purús

Trabajadores del Parque Estadual Chandless

WWF-Bolivia

WWF-Brasil

WWF-Perú

\section{EQUIPO PROYECTO IAPA}

Alberto Pacheco Capella

Ana Isabel Martinez Torres

Carolina del Lama Marques

Claudia Marín Daza

Emerson Devia Acevedo

Jose Antonio Gómez Diaz

Juliana Vélez Gómez

Miguel Avila Moraes

Mónica Salinas Venegas

Paula Andrea Bueno Martinez

Sergio Garrido García

Viviana Andrea Londoño Calle 


\section{Índice}

$$
\text { Pr }
$$

Presentación XIII

Introducción XIV

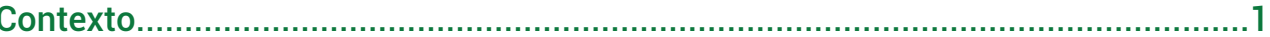

Áreas protegidas y categorías de manejo..........................................................

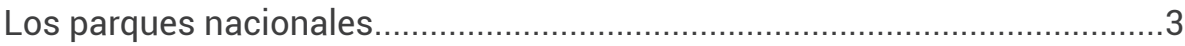

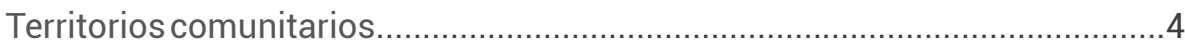

Forzantes para aprovechamiento de bienes y servicios ecosistémicos...........5

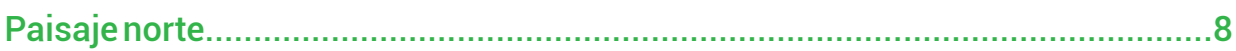

ReservadeProducción deFauna Cuyabeno(RPFCuyabeno)..........................13

Parque Natural Nacional La Paya (PNN La Paya).........................................18

Parque Nacional Güeppí-Sekime (PN Güeppí-Sekime) y

Reservas Comunales Airo Pai y Huimeki (RC Airo Pai y RC Huimeki)..........22

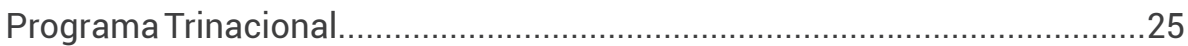

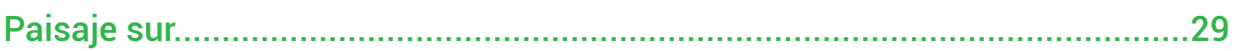

Reserva Nacional de Vida Silvestre Amazónica

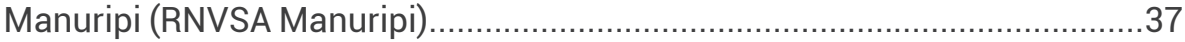

Las áreas protegidas de Brasil.......................................................................

Programas del Gobierno federal...................................................................4

Programas estatales en Acre............................................................. 45

Parque Estadual Chandless (PE Chandless)..............................................46

Reserva Extractivista Cazumbá-Iracema (RESEX Cazumbá-Iracema).........49

Parque Nacional Alto Purús (PN Alto Purús) ................................................53

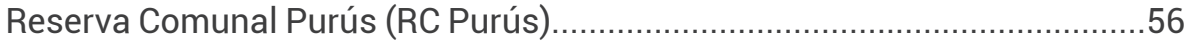

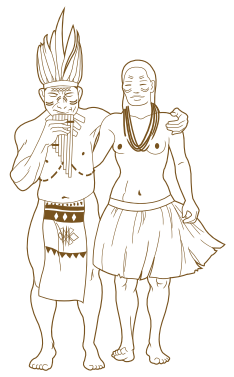

Iniciativas de gobernanza compartida a nivel de paisaje 60

Condiciones materiales de vida de la población de las áreas protegidas.

El papel de los pueblos indígenas y las comunidades locales para la conservación de las áreas protegidas 64

Metodología. 64

Temas abordados. 65

Paisaje norte. 66

Ambito ecológico.

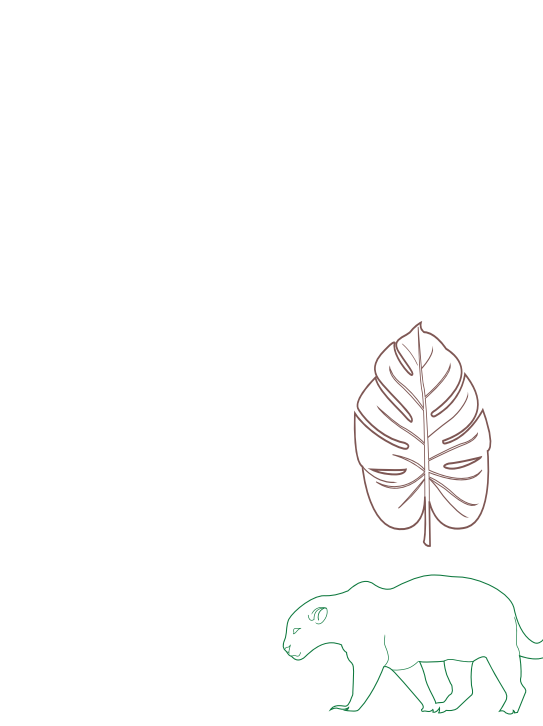

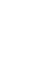

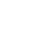

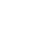

.

8

3

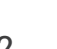
9 
Paiche y arawana, especies con manejo sostenible .66

Repoblamiento de tortugas charapas......................................................67

Pobladores locales monitoreando la biodiversidad....................................67

Control y vigilancia, un trabajo en equipo entre las áreas protegidas.........68

Incentivos para la conservación: Programa Socio Bosque...........................71

Ordenamiento territorial: iniciativas a nivel de paisaje ...............................72

Iniciativas de ordenamiento en las áreas protegidas......................................73

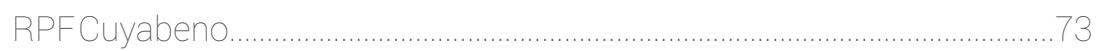

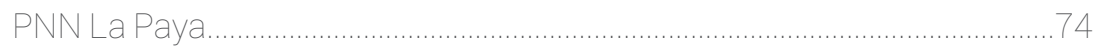

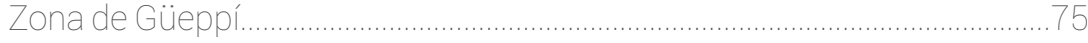

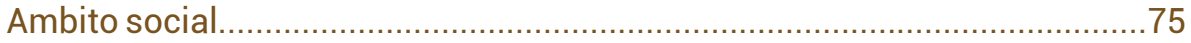

Las chacras, una prioridad de conservación................................................75

Principales actividades productivas sostenibles........................................77

Turismo en las áreas protegidas y el caso de gestión

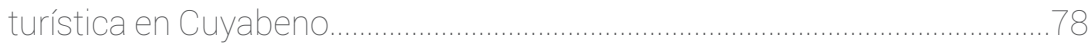

Mecanismos para disminuir la presión en las áreas

protegidas desde las zonas de amortiguamiento........

Formas de liderazgo y toma de decisión consuetudinarias. .82

Acuerdos de participación entre el Estado y los pueblos indígenas. 83

Comités de gestión como mecanismo de participación. 85

ConsultaPrevia .85

Ambito cultural

Aspectos que fortalecen los procesos culturales de los pueblos indígenas. .87

Canastos de Sabiduría

La cosmovisión de los muruis y su interrelación con el

manejo sostenible del bosque

Mujeres: guardianas del territorio. .90

Jóvenes actores en la conservación. 92

Retos en el ámbito artesanal....... .92

Interrelación de actores. .93 
Paisaje sur.

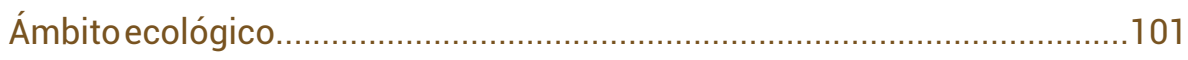

Gestión y conservación de la biodiversidad...............................................101

ElmonitoreocomunitarioenlaRESEXCazumbá-Iracema.........................102

Monitoreo integral en Manuripi................................................................... 104

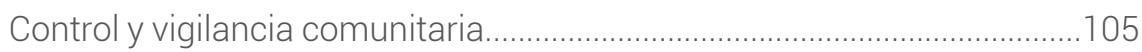

Ordenamiento territorial en las áreas protegidas del paisaje sur...............107

Acuerdos locales para el uso del territorio en el PE Chandless...................107

Ordenamiento participativo en la RESEX Cazumbá-Iracema....................108

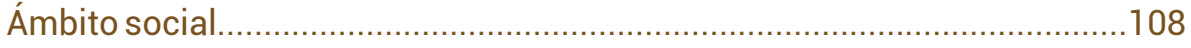

Participación comunitaria en las áreas protegidas.....................................108

Gestión compartida y participación en Manuripi..........................................108

Consejo Consultivo del PE Chandless................................................170

Participación en la RESEX Cazumbá-Iracema.....................................110

Comité de gestión del Parque Nacional Alto Purús....................................112

Contrato de administración para la participación

en la Reserva Comunal Purús...........................................................................173

Actividades productivas sostenibles......................................................... 114

Certificación de la castaña de Manuripi......................................................174

El asaí como una alternativa económica....................................................179

Charapas y taricayas para la conservación y

promoción de la economía local..............................................................120

Aprovechamiento y comercialización de semillas de caoba.......................121

Turismo científico en las áreas protegidas...............................................122

Otras alternativas sostenibles para aprovechar

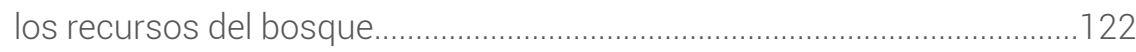

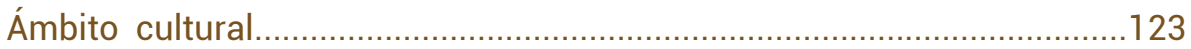

El rescate de la tradición de la goma.........................................................123

Las contribuciones de las mujeres a la conservación..................................125

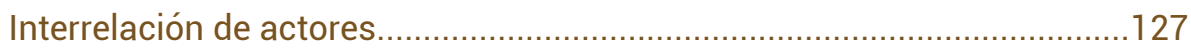


Costos y beneficios económicos de las áreas protegidas

para las poblaciones locales.

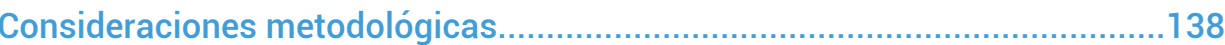

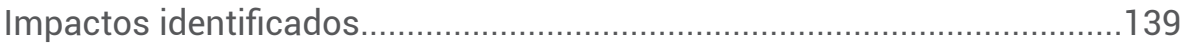

Valoración de costos y beneficios económicos..........................................141

Impacto por la creación de las áreas protegidas..........................................142

Construcción de gobernanza territorial local...........................................142

Modificación del aprovechamiento económico de los recursos del AP......146

Impactos por el funcionamiento de las áreas protegidas...............................149

Modificación del aprovechamiento de recursos del

territorio con criterios de sostenibilidad

Estímulo de procesos productivos para aprovechamiento sostenible y comercialización de productos del bosque.

Actividades productivas sostenibles en el paisaje norte..............................157

Parque Nacional Natural La Paya.........................................................157

Reserva de Producción de Fauna Cuyabeno..............................................158

PN Güeppí-Sekime y Reservas Comunales Airo Pai y Huimeki................161

Actividades productivas sostenibles en el paisaje sur.................................162

PN Alto Purús y RC Purús................................................................................. 162

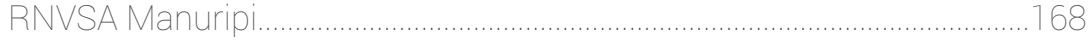

PE Chandless................................................................................................ 770

RESEX Cazumbá-Iracema........................................................................171

Transferencias económicas por actividades de conservación..................173

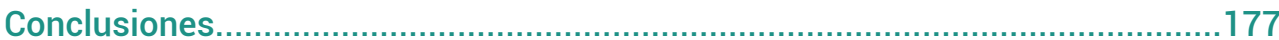

Sobre el aprovechamiento sostenible de los recursos

naturales de las áreas protegidas

Sobre la gobernanza territorial de las poblaciones

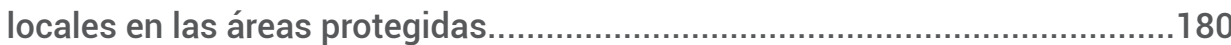

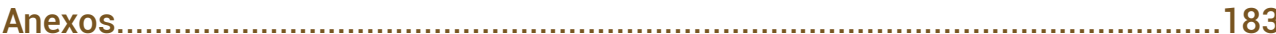

Bibliografía 


\section{Índice de mapas}

- Mapa 1: Paisaje norte 8

- Mapa 2: Reserva de Producción de Fauna Cuyabeno, Ecuador 13

- Mapa 3: Centros poblados de la zona alta de la Reserva de Producción de Fauna Cuyabeno

- Mapa 4: Pueblos indígenas en PNN La Paya

- Mapa 5: Parque Nacional Güeppí-Sekime y Reservas Comunales Airo Pai y Huimeki 22

- Mapa 6: Parque Nacional Güeppí-Sekime 23

- Mapa 7: Mapa del Corredor Trinacional Ecuador-Colombia-Perú 26

- Mapa 8: Paisaje sur 29

- Mapa 9: Reserva Nacional de Vida Silvestre Amazónica Manuripi 37

- Mapa 10: Reserva de Vida Silvestre Amazónica Manuripi 38

- Mapa 11: Parque Estadual Chandless 46

- Mapa 12: Parque Estadual Chandless 46

- Mapa 13: Reserva Extractivista Cazumbá-Iracema 49

- Mapa 14: Parque Nacional Alto Purús 53

- Mapa 15: Reserva Comunal Purús 56

\section{Índice de gráficos}

- Gráfico 1: Interrelación de actores en la

Reserva de Producción de Fauna Cuyabeno 94

- Gráfico 2: Interrelación de actores en PNN La Paya 98

- Gráfico 3: Interrelación de actores en PN Güeppí-Sekime,

RC Airo Pai y RC Huimeki 100

- Gráfico 4: Interrelación de actores en el paisaje norte 100

- Gráfico 5: Interrelación de actores del PE Chandless y

RESEX Cazumbá-Iracema

- Gráfico 6: Interrelación de actores Reserva Nacional de

Vida Silvestre Amazónica Manuripi

- Gráfico 7: Interrelación de actores PN Alto Purús y

Reserva Comunal Purús

- Gráfico 8: Interrelación de actores del paisaje sur 


\section{Îndice de tablas}

- Tabla 1: Paisajes priorizados y unidades de conservación XV

- Tabla 2: Áreas protegidas priorizadas para el proyecto IAPA XV

- Tabla 3: Categorías de manejo de las áreas protegidas según la UICN 3

- Tabla 4: Territorios comunitarios cercanos a las áreas protegidas seleccionadas 4

- Tabla 5: Descripción de forzantes relacionados con las áreas protegidas del paisaje norte 5

- Tabla 6: Descripción de forzantes relacionados con las áreas protegidas del paisaje sur 6

- Tabla 7: Características de las áreas protegidas del paisaje norte 9

- Tabla 8: Zonificación RPF Cuyabeno 15

- Tabla 9: Territorios indígenas en la Reserva de Producción de Fauna Cuyabeno 17

- Tabla 10: Zonificación PNN La Paya 20

- Tabla 11: Territorios comunitarios del Parque Nacional Natural La Paya 21

- Tabla 12: Zonificación PN Güeppí-Sekime 25

- Tabla 13: Características de las áreas protegidas del paisaje sur 30

- Tabla 14: Zonificación RNVS Manuripi 42

- Tabla 15: Zonificación PE Chandless 48

- Tabla 16: Zonificación RESEX Cazumbá-Iracema 52

- Tabla 17: Zonificación PN Alto Purús 55

- Tabla 18: PN Alto Purús

- Tabla 19: Zonificación Reserva Comunal Purús 58

- Tabla 20: Territorios comunitarios de la Reserva Comunal Purús 59

- Tabla 21: Servicios básicos en las áreas protegidas 61

- Tabla 22: Transferencias condicionadas 63

- Tabla 23: Descripción de actores de la RPF Cuyabeno 95

- Tabla 24: Descripción de actores de la PNN La Paya 96

- Tabla 25: Descripción de actores del PN Güeppí-Sekime y RC Airo Pai y Huimeki 99

- Tabla 26: Descripción de actores del PE Chandless y RESEX Cazumbá-Iracema 127

- Tabla 27: Descripción de actores del RNVS Manuripi 131

- Tabla 28: Descripción de actores del PN Alto Purús y RC Purús 133

- Tabla 29: Servicios ecosistémicos priorizados 138

- Tabla 30: Descripción y valoración cualitativa de los impactos en los paisajes norte y sur 140 
- Tabla 31: Sueldo básico nacional 156

- Tabla 32: Costos y beneficios, PNN La Paya 157

- Tabla 33: Beneficios por comercialización de cacao, comunidad Zancudo Cocha 158

- Tabla 34: Beneficios por comercialización de chocolate, Asociación El Porvenir 159

- Tabla 35: Ingresos para las comunidades por atención a turistas 160

- Tabla 36: Ingresos por Prestación de Servicios a Lodges 160

- Tabla 37: Costos y beneficios, PN Güeppí-Sekime 162

- Tabla 38: Ingresos por venta de tortugas, comunidades de la cuenca del río Curanja 164

- Tabla 39: Ingresos por venta de quelonios, comunidades de la cuenca del Río Alto Purús 165

- Tabla 40: Ingresos por comercialización de semillas de caoba

- Tabla 41: Ingresos individuales por trabajo en proyecto recolección de semillas de caoba 167

- Tabla 42: Costos y beneficios, RC Purús 167

- Tabla 43: Ingresos familiares por venta de castaña certificada de la RNVSA Manuripi 168

- Tabla 44: Costos y beneficios, PE Chandless 170

- Tabla 45: Ingresos económicos por venta de artesanías de caucho 171

- Tabla 46: Costos y beneficios RESEX Cazumbá-Iracema 172

- Tabla 47: Ingresos económicos por actividades de producción sostenible 178

- Tabla 48: Ingresos por actividades turísticas RPF Cuyabeno 179

- Tabla 49: Especies cultivadas 183

- Tabla 50: Frutos del bosque que se recolectan para consumo 183

- Tabla 51: Pescados de consumo local 183

- Tabla 52: Animales del bosque para consumo 184 


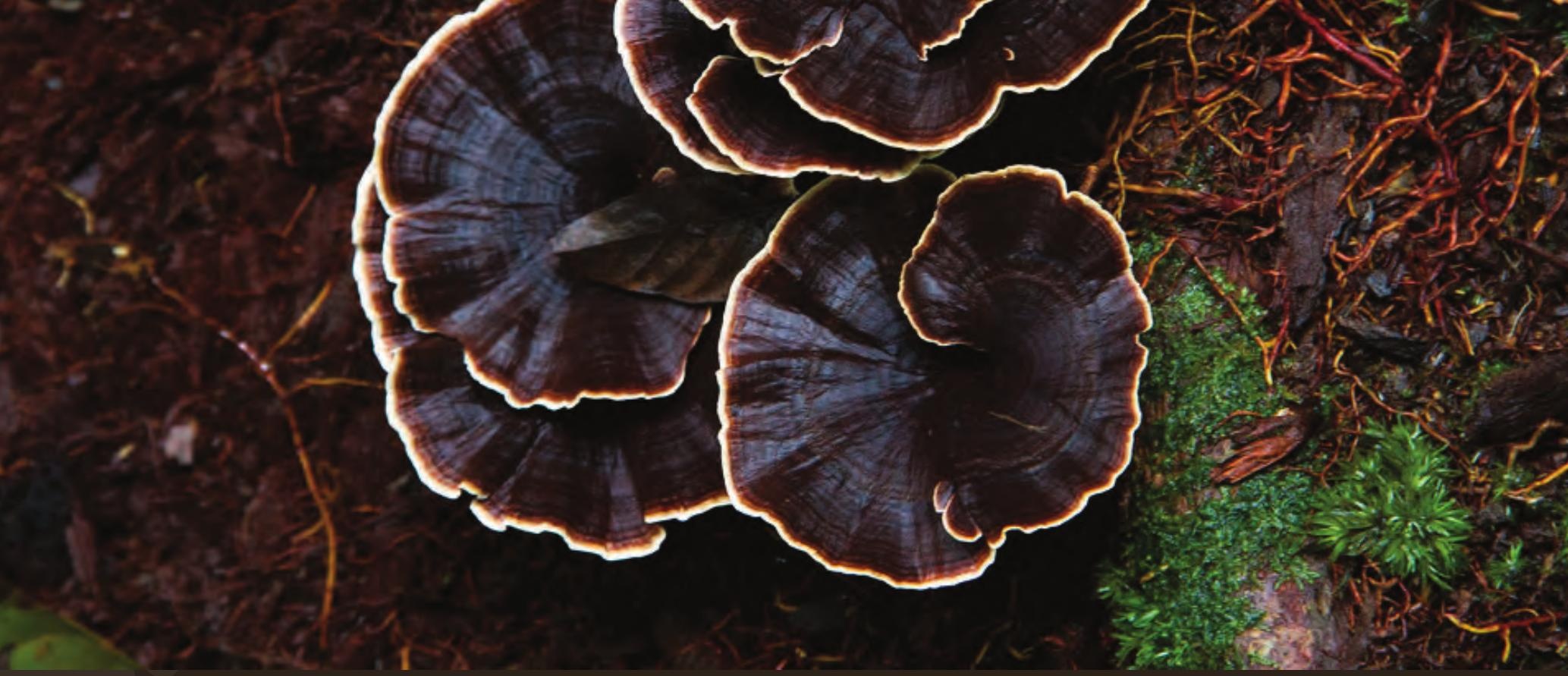

\section{Presentación}

El concepto de área protegida ha ido evolucionando a lo largo de estos últimos 60 años, su definición se ha ido adaptando a los diferentes paradigmas, visiones y entendimientos que han ido surgiendo en los diferentes foros, congresos y reuniones sobre todo de las Instituciones y agrupaciones internacionales como la UICN sobre la contribución de las áreas protegidas al bienestar humano sobre todo al de las poblaciones locales asentadas en su interior o en sus zonas de amortiguamiento. Desde los inicios, una idea rigurosamente conservacionista, trató de establecer parques y reservas nacionales que salvaguardasen únicamente los recursos naturales, sin ningún tipo de presencia o intervención humana.

Posteriormente, fuimos conscientes de que en muchos de estos espacios estaban anteriormente con ocupación humana, y en la gran mayoría, éstos tenían allí su residencia, haciendo uso de los recursos como medios de vida de sostenimiento. Por esto, se fueron actualizando los conceptos y cambiando las mentalidades hacia un concepto más social, donde la necesidad de proteger los bienes y servicios de la naturaleza no solo estuviese enfocada en la salvaguarda per sé de los recursos renovables, sino que se buscase también una protección de los servicios culturales y la integridad de las personas que anteriormente habían habitado en estas áreas.

En los últimos años, consideramos también como una modalidad de conservación aquellos otros espacios, que no necesariamente poseen un estatus legal para esto, y que en la mayoría de los casos se han mantenido ahí gracias a la gestión adecuada que las poblaciones tradicionales han sabido darle con su conocimiento sobre el manejo de la naturaleza y su permanencia a lo largo de las generaciones

En el presente documento se busca rescatar el aporte que las comunidades locales y los pueblos indígenas con sus saberes hacia la conservación y manejo de sus recursos naturales y a las diferentes modalidades de conservación adoptados. Asimismo el papel de otros actores que en ocasiones, han apoyado y fortalecido estas iniciativas, a veces propias, y otras veces aprendidas, pues el proceso de cambio y adaptación es otra lección necesaria para la conservación

Es innegable que la declaración de áreas protegidas por los estados ha tenido impactos sobre estas comunidades, la mayoría de veces positivos y en algunos casos, lamentablemente negativos. En el texto, también se ha buscado de alguna forma visibilizar, por lo menos parcialmente, los costos y beneficios económicos que esta medida ha podido generar. Sin considerar otras externalidades.

Esperamos que este documento sea de utilidad a la hora de declarar y gestionar sus áreas protegidas, considerando el mayor número de beneficios posibles a las poblaciones y actores locales y se busque incentivar aquellas actividades de conservación que estos actores tradicionalmente, ya han venido realizando a lo largo de su existencia.

Pedro Gamboa Moquillaza

Coordinador regiona Redparques

Director SERNANP 

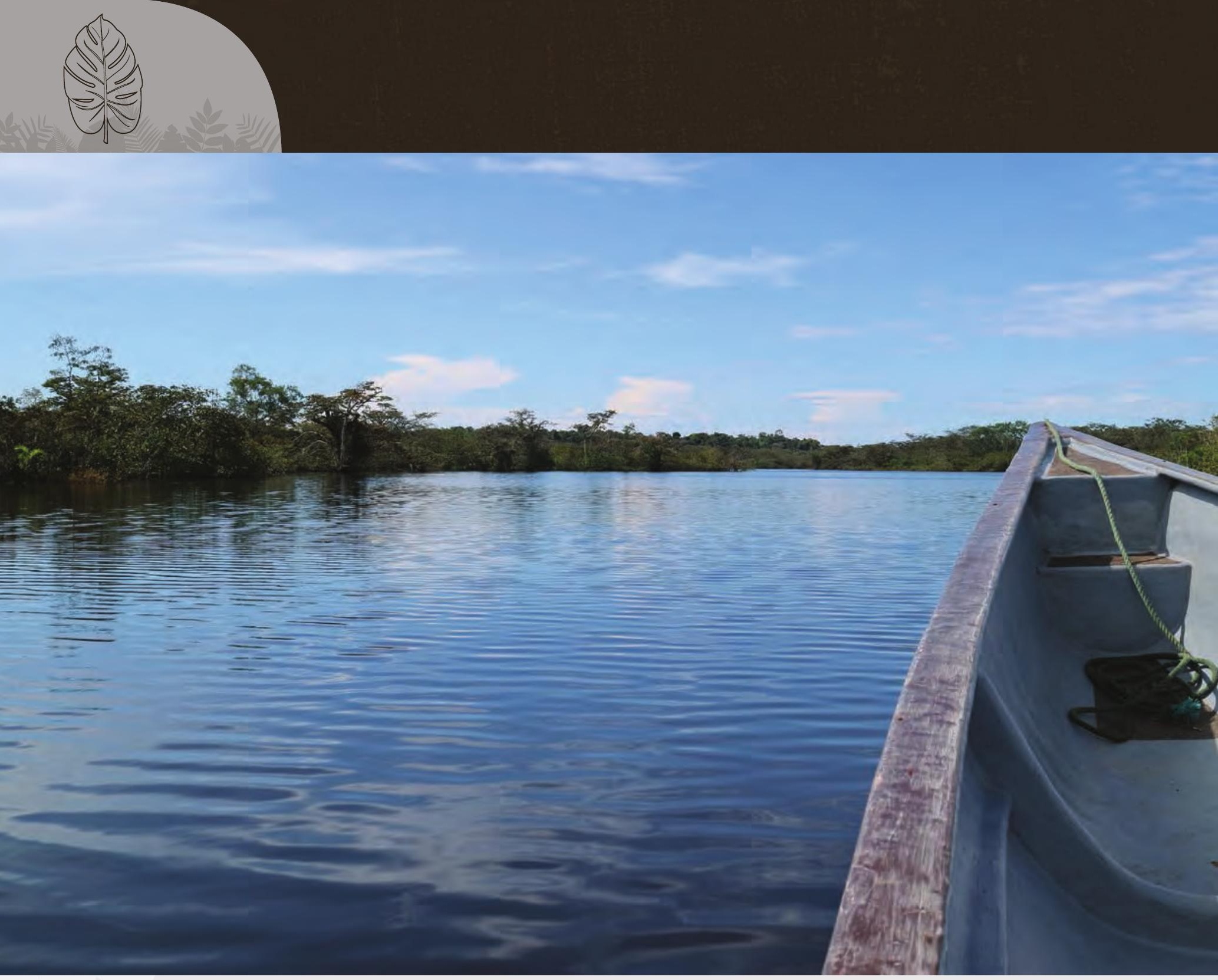

\section{Introducción}

El presente documento se enmarca en la iniciativa Visión Amazónica y en el proyecto "Integración de las áreas protegidas del Bioma Amazónico" (IAPA), financiado por la Unión Europea, coordinado por la Organización de Naciones Unidas para la Alimentación y la Agricultura (FAO) e implementado en conjunto con WWF, la Unión Internacional para la Conservación de la Naturaleza (UICN), el Programa de las Naciones Unidas para el Medio Ambiente (ONU Medio Ambiente) y la REDPARQUES.

El proyecto IAPA trabaja para mejorar la gestión de las áreas protegidas del bioma a través del fortalecimiento e integración de los sistemas nacionales de áreas protegidas de los países amazónicos, con el fin de incrementar la resiliencia de los ecosistemas frente al cambio climático.
La Unión Internacional para la Conservación de la Naturaleza (UICN) lidera, desde la Oficina Regional para América del Sur, el componente de gobernanza. Para ello, uno de los propósitos es evaluar el papel que cumplen los pueblos indígenas y las comunidades locales para la conservación en los aspectos ecológico, social y cultural en dos paisajes de la región amazónica e identificar cuáles han sido los costos y beneficios económicos, así como los impactos sociales y culturales que representan estas áreas protegidas para las poblaciones locales.

Entre las organizaciones cooperantes del proyecto IAPA y los representantes de los gobiernos nacionales que conforman el bioma amazónico, se definieron dos paisajes para la intervención del proyecto 


\section{Introducción}

\begin{tabular}{|c|c|c|}
\hline Paisaje & $\begin{array}{l}\text { País al que } \\
\text { pertenece }\end{array}$ & Unidades de conservación presentes en el paisaje \\
\hline \multirow{5}{*}{ Norte } & Colombia & Parque Nacional Natural La Paya \\
\hline & \multirow{3}{*}{ Perú } & Parque Nacional Güeppí-Sekime \\
\hline & & Reserva Comunal Huimeki \\
\hline & & Reserva Comunal Airo Pai \\
\hline & Ecuador & Reserva de Producción Faunística Cuyabeno \\
\hline \multirow{15}{*}{ Sur } & \multirow{12}{*}{ Brasil } & Área de Proteção Ambiental Igarape Sao Francisco \\
\hline & & Área de Proteção Ambiental Lago do Amapá \\
\hline & & Área de Relevante Interesse Ecológico Seringal Nova Esperança \\
\hline & & Terra Indígena Alto Río Purús \\
\hline & & Terra Indígena Mamoadate \\
\hline & & Terra Indígena Cabeceiras do Rio Acre \\
\hline & & Reserva Extractivista do Cazumbá-Iracema \\
\hline & & Reserva Extractivista Chico Mendes \\
\hline & & Floresta Nacional do Macaua \\
\hline & & Floresta Nacional de São Francisco \\
\hline & & Estação Ecológica Rio Acre \\
\hline & & Parque Estadual Chandless \\
\hline & \multirow{2}{*}{ Perú } & Reserva Comunal Purús \\
\hline & & Parque Nacional Purús \\
\hline & Bolivia & Reserva de Vida Silvestre Amazónica Manuripi \\
\hline
\end{tabular}

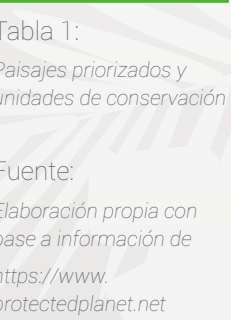

Dentro de estos dos paisajes existen, en total, veinte unidades de conservación con diferentes categorías de manejo. Para las intervenciones específicas que requiere el proyecto IAPA, se han priorizado diez áreas protegidas (AP) con el fin de focalizar la investigación y la ejecución final del proyecto.

\begin{tabular}{|c|c|}
\hline Paisaje & Área Protegida Priorizada \\
\hline \multirow{3}{*}{ Norte } & Parque Nacional Natural La Paya (Colombia) \\
\cline { 2 - 3 } & Parque Nacional Güeppí-Sekime (Perú) \\
\cline { 2 - 3 } & Reserva Comunal Huimeki (Perú) \\
\cline { 2 - 3 } & Reserva Comunal Airo Pai (Perú) \\
\hline \multirow{3}{*}{ Sur } & Reserva de Producción de Fauna Cuyabeno (Ecuador) \\
\cline { 2 - 3 } & Parque Nacional Alto Purús (Perú) \\
\cline { 2 - 3 } & Reserva Comunal Purús (Perú) \\
\cline { 2 - 3 } & Reserva Nacional de Vida Silvestre Amazónica Manuripi (Bolivia) \\
\hline Parque Estadual Chandless (Brasil)
\end{tabular}



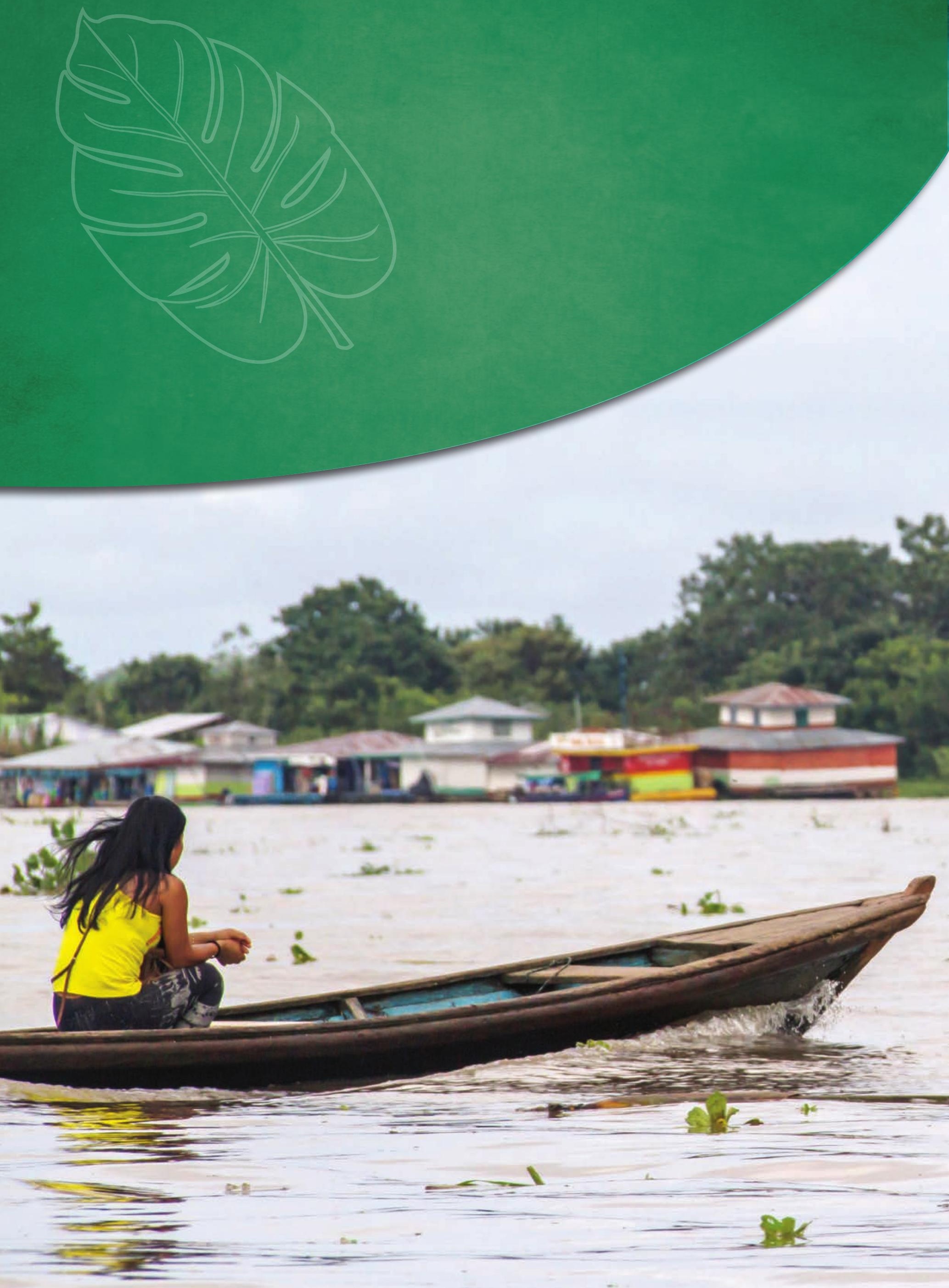


\section{Contexto}

La región amazónica alberga una gran riqueza de flora y fauna, pueblos indígenas y comunidades locales con formas de vida íntimamente ligadas a la naturaleza, al bosque y a sus recursos. Las prácticas tradicionales de autosustento de su población incluyen la caza, pesca, recolección de los recursos del bosque y la agricultura.

Anteriormente, los pueblos indígenas amazónicos se organizaban en grupos de familias extendidas que compartían una misma vivienda y migraban periódicamente para no desgastar el suelo, dejando que la flora y fauna del bosque se regenerasen por sí mismas. Estos pueblos conformaban clanes que se asentaban de manera dispersa, pero conectados entre sí por trochas, y que compartían espacios sagrados y territorios donde desarrollaban sus actividades tradicionales. Si bien eran pueblos itinerantes, sufrieron desplazamientos que los obligaron a reubicarse en otros lugares. En la época colonial (siglo XVII) fueron desplazados por la llegada de los misioneros franciscanos y capuchinos, seguida por el auge de la goma (caucho o siringa) desde finales del siglo XIX hasta la primera década del siglo XX. Esta actividad estuvo dominada por empresarios caucheros $^{1}$ que obligaron a los indígenas a trabajar en condiciones extremas. La bonanza de la goma duró hasta 1913, cuando decayó por el surgimiento de cultivos de goma en Asia con mano de obra más barata y, luego, por la aparición de la goma sintética. Así, la goma constituyó una parte importante pero dolorosa de la historia de los pueblos amazónicos y fue la modeladora de la estructura social, política, económica y cultural de estos pueblos.

Después de la goma, empezó el negocio de la explotación de madera, donde también los indígenas fueron requeridos como mano de obra. Las guerras entre países por nuevos límites territoriales obligaron a algunos indígenas a dispersarse a lo largo de las fronteras, ocasionando la separación de los grupos familiares.

Más tarde tuvo lugar la reforma agraria, que conllevó modificaciones estructurales de pro- piedad y producción de la tierra e incentivos a los campesinos por parte de los gobiernos para que ocupasen tierras amazónicas. En los años 70, la Amazonía cambió aún más con el auge del petróleo y la minería, lo que trajo consigo la apertura de nuevos caminos, causantes de la deforestación, colonización, aculturación y uso indiscriminado de los recursos, entre otros.

Años más tarde, por influencia de movimientos ecologistas a nivel internacional y local, los Estados establecieron áreas protegidas en sus territorios como una forma de proteger a los pueblos indígenas y los recursos de estas zonas tan vulnerables. Todos estos cambios obligaron a los indígenas a establecerse en un solo lugar, a demarcar su territorio y a llegar a acuerdos con el Estado para el manejo y uso de la tierra.

Hoy, los pueblos indígenas y las comunidades locales que conforman los paisajes del estudio, si bien tienen dinámicas distintas derivadas de los marcos políticos y la gobernanza propia de cada país, enfrentan amenazas comunes como actividades extractivas de petróleo, minería, extracción ilegal de madera, grupos armados ilegales, contrabando de combustible y gas, entre otras. Algunos de los pueblos indígenas tradicionales mantienen una lucha constante por preservar el bosque, su cultura y forma de vida desde sus espacios propios y prácticas cotidianas y, a la vez, por conseguir condiciones de vida occidental resultado de los procesos de aculturación.

Los logros alcanzados hasta el momento para la conservación de los bosques amazónicos a través de los distintos programas y proyectos se llevan a cabo mediante alianzas y el trabajo conjunto entre los pueblos indígenas y campesinos y el Estado, la empresa privada, organismos internacionales y ONG.

\footnotetext{
Entre estos se encuentran el magnate Nicolás Suárez en el Departamento del Beni (Bolivia) con su empresa Casa Suárez (la cual llegó a cubrir el 60 \% de la demanda mundial de goma) y Julio César Arana (Casa Arana), de nacionalidad peruana, político y cauchero.
} 


\section{Áreas protegidas y categorías de manejo}

\begin{tabular}{|c|c|c|c|}
\hline Paisaje & Área protegida & Nominación nacional & $\begin{array}{l}\text { Categoría de } \\
\text { Manejo según UICN }\end{array}$ \\
\hline \multirow{5}{*}{ Norte } & La Paya & Parque Nacional Natural & ॥ \\
\hline & Güeppí-Sekime & Parque Nacional & ॥ \\
\hline & Huimeki & Reserva Comunal & VI \\
\hline & Airo Pai & Reserva Comunal & VI \\
\hline & Cuyabeno & Reserva de Producción Faunística & No reportada \\
\hline \multirow{5}{*}{ Sur } & Alto Purús & Parque Nacional & $\|$ \\
\hline & Purús & Reserva Comunal & VI \\
\hline & Manuripi & $\begin{array}{l}\text { Reserva Nacional de vida silvestre } \\
\text { amazónica }\end{array}$ & No reportada \\
\hline & Chandless & Parque Estadual & ॥ \\
\hline & $\begin{array}{c}\text { Cazumbá-Irace- } \\
\text { má }\end{array}$ & Reserva Extractivista & VI \\
\hline
\end{tabular}

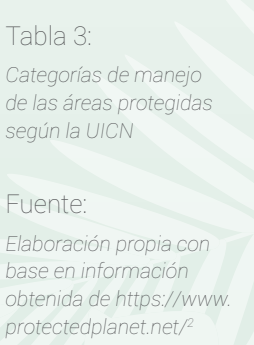

Aquellas áreas protegidas nominadas como parques nacionales (categoría II, según UICN) son zonas que no permiten el uso directo de los bienes y servicios ecosistémicos que están en estos espacios. En cambio, las AP nominadas como áreas de gestión de hábitats/especies o áreas protegidas con uso sostenible de los recursos naturales (categorías IV o VI, según UICN) son accesibles para una gestión directa del territorio por parte de pueblos indígenas o mestizos a través de la coordinación con las direcciones estatales de estas áreas, convirtiéndose en territorios de aprovechamiento comunitario.

\section{Los parques nacionales}

Los parques nacionales (categoría II, según UICN) son "extensas áreas naturales o casi naturales dedicadas a la protección de procesos ecológicos a gran escala, junto con el complemento de espacios y ecosistemas característicos del área, que también brindan el fundamento para oportunidades espirituales, científicas, educativas, recreativas y turísticas, ambiental y culturalmente compatibles" (Borrini et al., 2014).
En los parques nacionales se permite un aprovechamiento indirecto de los bienes ambientales que presta el área declarada. Esto quiere decir que solo se pueden realizar actividades recreativas, turísticas o de investigación en estas zonas, mientras que actividades de uso directo, como la extracción de materiales, quedan completamente limitadas. Solamente en aquellos parques nacionales donde se ha identificado la presencia de Pueblos en Aislamiento Voluntario (PIAV) existe un uso directo de los recursos. Este es el caso del Parque Nacional Alto Purús (Perú), en el que se encuentra a la población mashco piro y del Parque Estadual Chandless, donde residen 11 familias mestizas y donde también transitan diferentes pueblos indígenas en Aislamiento Voluntario, los mismos mencionados para el caso de Perú.

\footnotetext{
2. No reportada significa que, en la fuente oficial consultada, no se encuentra reportada la categoría de manejo que se corresponde con el AP. Sin embargo, para esta investigación se considera que las reservas comunales o reservas de vida silvestre, o de fauna, son similares a categorías IV o VI, según UICN, y que los parques nacionales y estaduales son categoría II de UICN.
} 
La declaratoria de parque nacional conlleva una fuerte restricción para el uso de los recursos por parte de las poblaciones locales que no están en aislamiento voluntario. Inicialmente, esta categoría de manejo supone territorios sin población, lo cual, en la mayoría de los casos, da cuenta de una planificación sin previo conocimiento de las características de poblamiento de la zona, pues todas las AP que son parte de esta investigación son espacios históricamente ocupados, ya sea por culturas indígenas amazónicas o poblaciones de mestizos colonos.

Un claro ejemplo de esta ocupación histórica son los territorios que han sido reconocidos, dentro o alrededor de los parques nacionales, como zonas de uso exclusivo de poblaciones indígenas y/o mestizas, llámense reservas comunales, resguardos indígenas o formas de organización territorial similares. Estas han asegurado el uso tradicional de los recursos y, a su vez, se han convertido también en zonas de protección de los SE (como los parques nacionales) que tienen un fuerte componente de uso sostenible y gestión participativa del territorio.

\section{Territorios comunitarios}

Todas las AP consideradas tienen territorios comunitarios, traslapados o alrededor de su territorio. En estos territorios se han generado procesos de concertación y participación efectiva con las poblaciones que históricamente han vivido en estas zonas. Sin embargo, por la declaratoria del territorio como AP, han visto modificada la forma de uso territorial. También han sido incluidas en estos procesos poblaciones colonas que llegan al territorio como parte de políticas de ampliación de la frontera agrícola y de creación de fronteras vivas, o por procesos de desplazamiento forzoso, como es el caso del Parque Nacional Natural La Paya.

Algunos de estos territorios comunitarios fueron reconocidos antes de la declaratoria de las AP, por lo que han tenido que realizar procesos de alineación con las directrices de las AP para compatibilizar y acordar el uso que se dará al territorio. En otros casos, estos territorios comunitarios se reconocieron al mismo tiempo de la declaratoria del AP.

\begin{tabular}{|c|c|c|c|}
\hline Paisaje & Área protegida & Territorio & Relación ${ }^{3}$ \\
\hline \multirow{4}{*}{ Norte } & \multirow{2}{*}{ Parque Nacional Natural La Paya } & Resguardos indígenas & Traslape parcial \\
\hline & & Veredas campesinas & Vecindad \\
\hline & Parque Nacional Natural Güeppí-Sekime & Reserva Comunal & Vecindad \\
\hline & $\begin{array}{l}\text { Reserva de Producción de } \\
\text { Fauna Cuyabeno }\end{array}$ & Territorios indígenas & Traslape total \\
\hline \multirow{8}{*}{ Sur } & \multirow{3}{*}{ Parque Nacional Alto Purús } & $\begin{array}{l}\text { Reserva Territorial } \\
\text { (PIAV) }\end{array}$ & Traslape total \\
\hline & & Reservas territoriales & Vecindad \\
\hline & & Reserva Comunal & Vecindad \\
\hline & \multirow{2}{*}{$\begin{array}{l}\text { Reserva Nacional de Vida Silvestre } \\
\text { Amazónica Manuripi }\end{array}$} & Comunidades & Traslape parcial \\
\hline & & Barracas & Traslape parcial \\
\hline & \multirow{2}{*}{ Parque Estadual Chandless } & Comunidad & Traslape parcial \\
\hline & & Tierra indígena & Vecindad \\
\hline & Reserva Extrativista Cazumbá-Iracema & Colocação Seringal & Traslape total \\
\hline
\end{tabular}

En términos generales, los territorios que están junto a los parques nacionales se convierten en zonas con un manejo ambiental especial, lo que impide que se intensifiquen las actividades productivas de las poblaciones que habitan estas zonas. De esta manera, se conforman grandes paisajes de conservación, combinando espacios sin aprovechamiento y espacios bajo sistemas de aprovechamiento sostenible beneficiosos para las poblaciones locales. 


\section{Áreas protegidas y categorías de manejo}

Forzantes para aprovechamiento de bienes y servicios ecosistémicos

Los elementos "forzantes" (también pueden ser interpretados como "motores") son aquellos elementos o procesos que son externos al área protegida y a los procesos (biológicos y de planificación del territorio) que en ella se desarrollan, pero que inciden en las funciones de los ecosistemas y en los servicios que brindan (Suarez y Cohanoff, 2012, p.16). En consecuencia, el aprovechamiento de los SE que brindan estas AP también se puede ver afectado.

Entre los forzantes que pueden causar variaciones en el aprovechamiento de los servicios ecosistémicos de las AP están: la existencia de vías de acceso, bloques hidrocarburíferos en el interior o alrededor de las AP, concesiones mineras y conflictos sociales vinculados a la deforestación y contaminación de fuentes de agua, entre otros.
Es bien conocido que, históricamente, la

Amazonía ha tenido una creciente presión

sobre los usos de bienes y servicios ecosistémicos a partir de procesos como: la colonización, la deforestación (por la expansión de la frontera agrícola y construcción de infraestructuras como carreteras) y la extracción de recursos no renovables (minería y petróleo). Estos factores aumentan progresivamente la vulnerabilidad del ecosistema amazónico y causan impactos, ya sean positivos o negativos, en las condiciones de generación de servicios por parte del ecosistema y en las posibilidades de aprovechamiento de estos, lo que conlleva costos y beneficios económicos para la población.

3. La relación del AP con territorios comunitarios se describe en función del traslape existente. Este traslape puede ser total (todo e territorio comunitario está dentro del AP) parcial (parte del territorio del AP es con vkuujvcsiderado territorio comunitario), o puede existir una relación de vecindad entre territorio comunitario y AP.

\begin{tabular}{|c|c|c|c|}
\hline Variable & \multicolumn{3}{|c|}{ Paisaje norte } \\
\hline Áreas protegidas & La Paya, Colombia & Cuyabeno, Ecuador & $\begin{array}{c}\text { Güeppí-Sekime, Perú } \\
\text { Reservas Comunales Airo Pai y } \\
\text { Huimeki }\end{array}$ \\
\hline $\begin{array}{l}\text { Vías de acceso } \\
\text { carreteable }^{4}\end{array}$ & Sí & Sí & No \\
\hline $\begin{array}{l}\text { Bloques petroleros } \\
\text { en el interior del AP }\end{array}$ & No & $\begin{array}{c}\text { "EDEN YUTURI" } \\
\text { "TARAPOA" } \\
\text { "CUYABENO TIPISHCA" }\end{array}$ & No \\
\hline $\begin{array}{l}\text { Bloques petroleros } \\
\text { rodeando el AP }\end{array}$ & $\begin{array}{l}\text { "PUT 14" } \\
\text { "PUT 15" } \\
\text { "PUT 23" } \\
\text { "TERECAY" } \\
\text { "TACACHO" } \\
\text { "CAG 3" }\end{array}$ & $\begin{array}{l}\text { "VINITA" } \\
\text { "ITT" } \\
\text { "NANTU" }\end{array}$ & No \\
\hline $\begin{array}{l}\text { Concesiones } \\
\text { mineras otorgadas } \\
\text { por el Estado }\end{array}$ & No & No & No \\
\hline Conflictos sociales & $\begin{array}{l}\text { Cultivos de uso ilícito } \\
\text { como la coca } \\
\text { (Falla, s/f) } \\
\text { Actores armados } \\
\text { al margen de la ley } \\
\text { (Falla, s/f) }\end{array}$ & $\begin{array}{c}\text { Derrames de petróleo } \\
\text { (RPFC, 2008) }\end{array}$ & $\begin{array}{l}\text { Actores armados al margen } \\
\text { de la ley provenientes de } \\
\text { Colombia (Rojas, 2007) } \\
\text { Potencialidad de explotación } \\
\text { petrolera (Rojas, 2007) } \\
\text { Minería ilícita de aluviales }\end{array}$ \\
\hline & Extra & de madera, tráfico de & רa, pesca ilegal \\
\hline
\end{tabular}


Variable

Áreas protegidas

Areas protegidas

Vías de acceso carreteable

Bloques petroleros en el interior del AP

Bloques petroleros rodeando el AP

Concesiones mineras otorgadas por el Estado

Tabla 6 scripción relacionados con las áreas protegidas de Paisaje sur Fuente Elaboración propia

\section{Conflictos} sociales

\begin{tabular}{|c|c|c|}
\hline Manuripi, Bolivia & $\begin{array}{l}\text { Alto Purús y Reserva } \\
\text { Comunal Purús, Perú }\end{array}$ & $\begin{array}{c}\text { Chandless y Reserva } \\
\text { Extractivista Cazumbá- } \\
\text { Iracema, Brasil. }\end{array}$ \\
\hline Sí & $\begin{array}{c}\text { Posible construcción } \\
\text { carretera Purús- } \\
\text { |ñapari }\end{array}$ & $\begin{array}{l}\text { PE Chandless No } \\
\text { RESEX CI Sí }\end{array}$ \\
\hline Sí & & No \\
\hline $\begin{array}{c}\text { Dos áreas de } \\
\text { exploración } \\
\text { autorizadas a } \\
\text { YPFB'. Bloques } \\
\text { "Nueva Esperanza" } \\
\text { y "Río Beni" }\end{array}$ & & No \\
\hline $\begin{array}{c}\text { Minería ilegal de } \\
\text { aluviales. } \\
\text { Existen siete } \\
\text { concesiones } \\
\text { mineras legales } \\
\text { para la explotación } \\
\text { de oro. } \\
\text { Se ha destinado } \\
\text { casi un } 49 \% \text { de } \\
\text { la reserva como } \\
\text { área de reserva }^{\text {para exploración }} \\
\text { hidrocarburífera }^{6} \text {. }\end{array}$ & $\begin{array}{l}\text { Minería ilícita de } \\
\text { aluviales en el río } \\
\text { Madre de Dios }\end{array}$ & No \\
\hline $\begin{array}{c}\text { Actividad } \\
\text { maderera ilícita } \\
\text { Contaminación de } \\
\text { río Madre de Dios } \\
\text { con mercurio } \\
\text { Asentamiento ilegal } \\
\text { de colonos }\end{array}$ & $\begin{array}{l}\text { Conflictos por tala } \\
\text { ilegal de madera }\end{array}$ & No \\
\hline
\end{tabular}

5. Fuente: htto://www hidrocarburosbolivia com/noticiasarchivadas/572-upstream-archivado/upstream-0107-2015-01-01-2016/71384-alistan-sismica-en-dosareas-junto-al-parque-manuripi.html

6. Fuente: Plan de manejo Manuripi
Paisaje sur

Chandless y Reserva

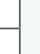

sible construcción era Purús

Chandless $\mathrm{No}$

RESEX CI Sí

uviales en el río 


\section{Áreas protegidas y categorías de manejo}

Las vías de acceso carreteable a las AP son elementos forzantes en la medida de su existencia, pues determinan el acceso de personas a los recursos del AP. Pueden proporcionar acceso a recursos como el turismo, que permite a las poblaciones locales diversificar sus ingresos, pero también proporcionan mayor acceso a productos maderables y fauna o flora para el comercio ilícito, lo cual se convierte en un perjuicio para la población y para la conservación de la biodiversidad si no hay capacidad para controlarlo.

La cercanía de las AP con la frontera hidrocarburífera se torna en otro forzante, ya que la existencia de bloques petroleros implica la apertura de trochas y vías, pero también se convierte en un factor de riesgo, pues eventuales derrames de petróleo podrían influir sobre la calidad de las fuentes hídricas de las AP, de las que dependen las poblaciones locales. Esto ya ha sucedido en Cuyabeno y, aunque las empresas hidrocarburíferas han realizado los procesos de remediación ambiental respectivos, el riesgo de contaminación siempre está presente (RPFC, 2008).

Las AP seleccionadas son parte de corredores que componen paisajes con gran diversidad ecológica y cultural. En general, los ecosistemas trascienden los límites políticos y administrativos de entidades territoriales y nacionales. En este sentido, el bioma amazónico es una unidad ecológica que funciona de forma integrada e interdependiente y alberga territorios de diferentes culturas, indígenas y mestizas, que han poblado históricamente esta zona.

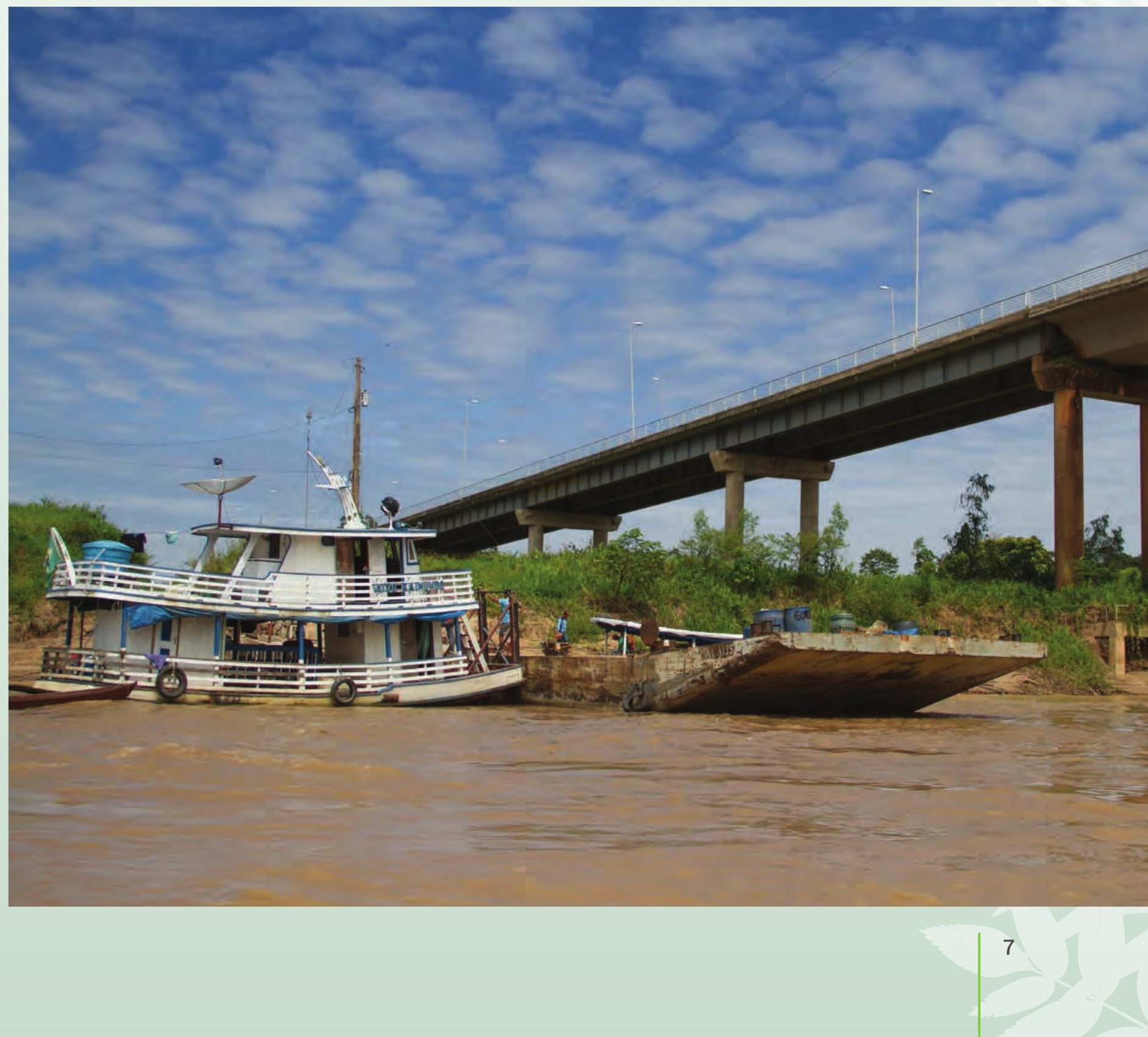




\section{Paisaje norte}

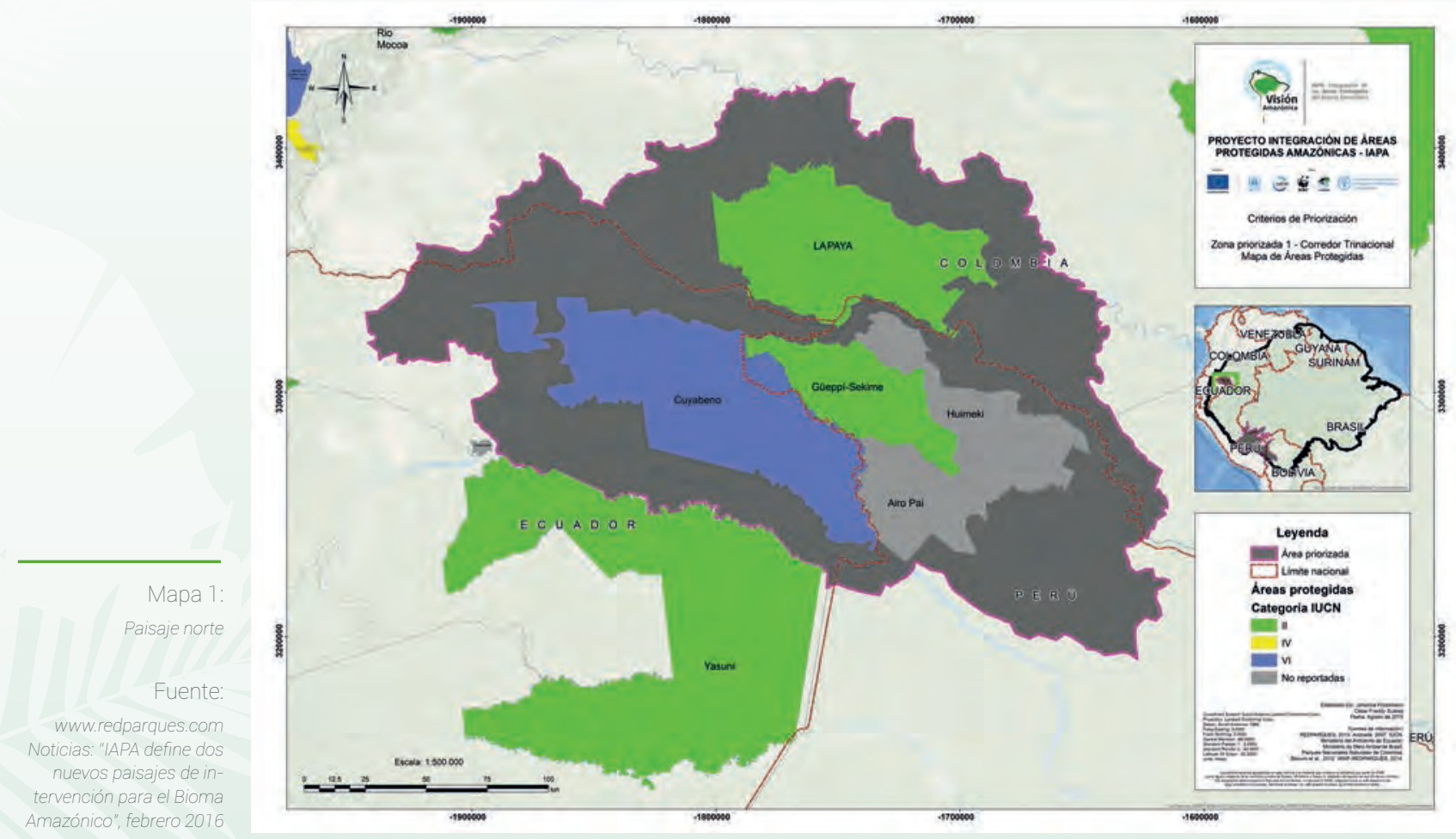

La zona correspondiente al paisaje norte se encuentra en la frontera compartida entre Ecuador, Colombia y Perú, en la cuenca media del río Putumayo, donde se ubica el Corredor Trinacional con una superficie aproximada de cuatro millones de hectáreas (40 817,25 km2). ${ }^{10}$ En ella habitan alrededor de: 5000 personas, entre campesinos, colonos mestizos y nueve pueblos indígenas ancestrales de las etnias:
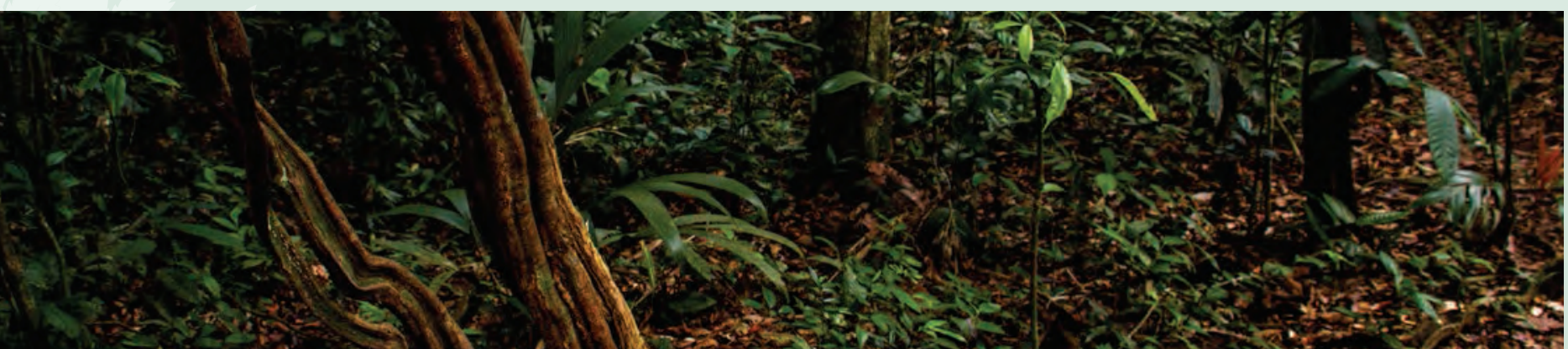

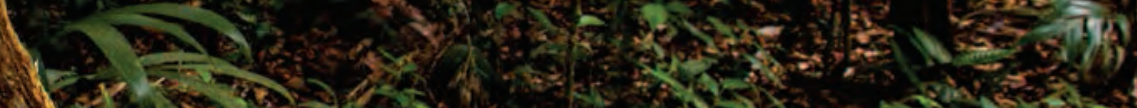

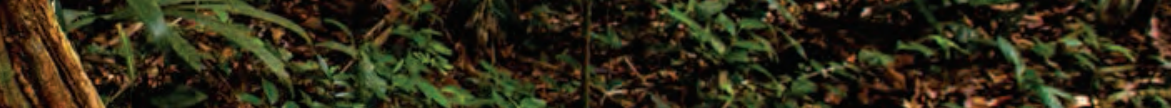

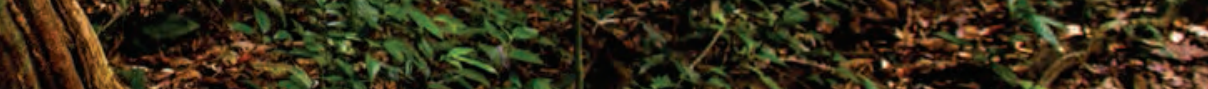

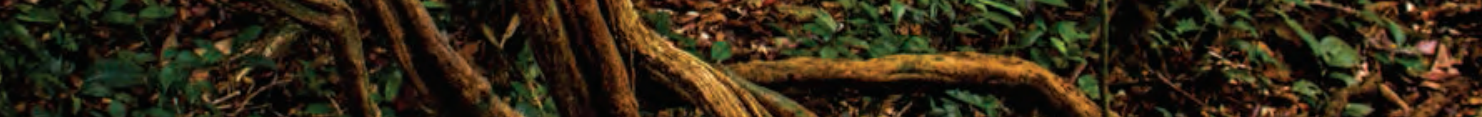

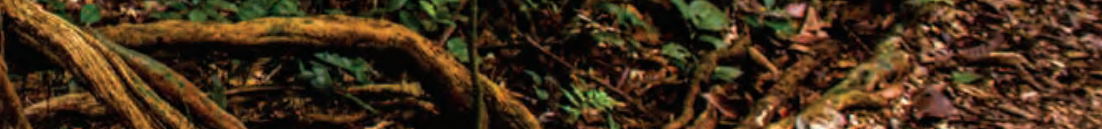

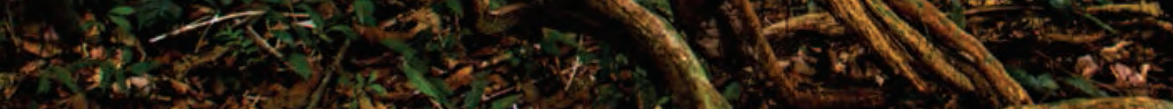

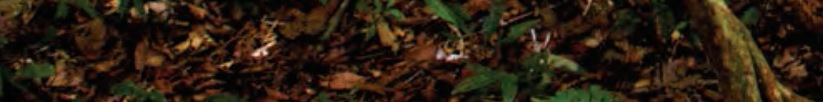

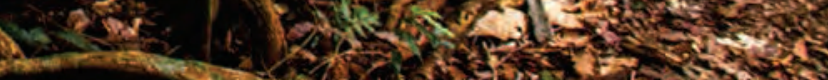

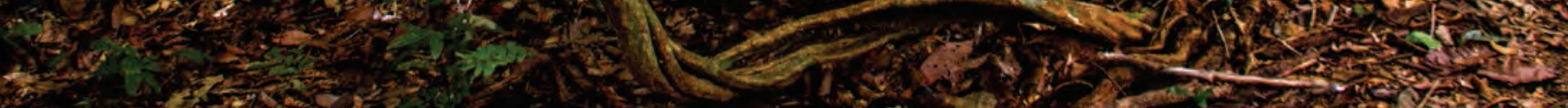

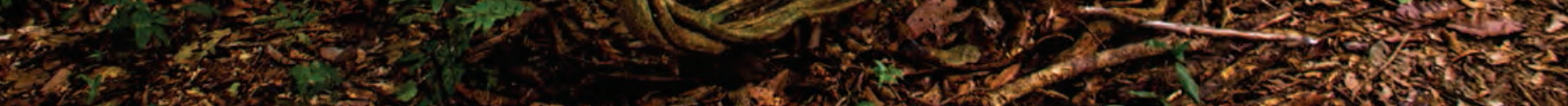


Etnias: cofán ${ }^{11}$, siona ${ }^{12}$, secoya ${ }^{13}$, kichwa ${ }^{14}$,

shuar $^{15}$, koreguaje ${ }^{16}$ y huitoto o muruil ${ }^{17}$, muina-

ne y nasa.

\begin{tabular}{|c|c|c|c|}
\hline $\begin{array}{l}\text { Nombre del } \\
\text { área protegida }\end{array}$ & $\begin{array}{l}\text { Reserva de Producción de } \\
\text { Fauna Cuyabeno }\end{array}$ & $\begin{array}{l}\text { Parque Nacional Natural } \\
\text { La Paya }\end{array}$ & $\begin{array}{l}\text { Parque Nacional } \\
\text { Güeppí-Sekime } \\
\text { Reserva Comunal Airo Pai } \\
\text { Reserva Comunal Huimeki }\end{array}$ \\
\hline $\begin{array}{c}\text { Año de } \\
\text { constitución }\end{array}$ & 1979 & 1984 & 2012 \\
\hline Ubicación & $\begin{array}{l}\text { Nueva Loja, provincias de } \\
\text { Sucumbíos y Orellana }\end{array}$ & $\begin{array}{c}\text { Municipio de } \\
\text { Puerto Leguízamo, } \\
\text { departamento } \\
\text { de Putumayo y } \\
\text { departamento de } \\
\text { Caquetá, municipio } \\
\text { de Solano, al sur de } \\
\text { Colombia }\end{array}$ & $\begin{array}{l}\text { En el extremo norte de } \\
\text { Perú, en los distritos de } \\
\text { Teniente Manuel Clavero y } \\
\text { Torres Causana, provincia } \\
\text { de Putumayo y Maynas, } \\
\text { departamento de Loreto }\end{array}$ \\
\hline Extensión total & 590112 ha & 422000 ha & $\begin{array}{l}\text { Reserva Comunal Airo Pai: } \\
247887,59 \text { ha } \\
\text { Reserva Comunal Huimeki: } \\
141234,46 \text { ha } \\
\end{array}$ \\
\hline $\begin{array}{l}\text { Extensión del } \\
\text { área traslapada }\end{array}$ & 80 \% del área & $\begin{array}{c}25000 \text { ha } \\
\text { aproximadamente } \\
\text { Los resguardos } \\
\text { indígenas ocupan un } 7 \\
\text { \% del total del AP }\end{array}$ & No hay datos \\
\hline Población & $\begin{array}{c}917 \text { personas } \\
11 \text { comunidades indígenas, } \\
600 \text { campesinos } \\
\text { En la zona de } \\
\text { amortiguamiento }^{18} \text { se estima } \\
\text { una población colona de más } \\
\text { de } 8000 \text { habitantes } \\
\text { (dato de } 2008)\end{array}$ & $\begin{array}{l}\text { Población indígena: } \\
903 \text { habitantes } \\
\text { aproximadamente }{ }^{19} \\
10 \text { resguardos indígenas } \\
\text { traslapados y } 2 \text { cabildos } \\
\text { indígenas en proceso } \\
\text { de constitución }{ }^{20} \\
\text { y } 40 \text { comunidades } \\
\text { establecidas }\end{array}$ & $\begin{array}{l}3000 \text { habitantes, } 722 \\
\text { familias distribuidas en } \\
29 \text { centros poblados. Los } \\
\text { indígenas están distribuidos } \\
\text { en } 23 \text { comunidades. }\end{array}$ \\
\hline
\end{tabular}

Tabla 7 :

Características de las

áreas protegidas del

Paisaje Norte

Fuente:

11. Los indigenas cofanes se autodenominan Ái que significa "gente de verdad". Habitan la zona entre los ríos Guamúes y Aguarico, hoy frontera entre Colombia y Ecuador. Su territorio está dentro de la RPF Cuyabeno.12. Fuente: Plan de manejo Manurip

2. Con la creación de la RPF Cuyabeno (1979), algunos sionas fueron trasladados hasta San Pablo, donde se asentaron familias sionas y secoyas de Ecuador y Perú. Sin embargo, algunos sionas se quedaron dentro de la reserva en Puerto Bolívar y en 1990 lograron la titulación y linderación de su territorio. Además, se encuentran en Colombia a orillas del río Putumayo, donde se los conoce como Zio Bain. 14.

13. Los secoyas ocupan la zona fronteriza entre Ecuador, Colombia y Perú desde hace 2000 años aproximadamente y se movilizaban en la zona interfluvial entre el Putumayo-Napo y Putumayo-Aguarico. Actualmente se encuentran en Ecuador y Perú, donde se conocen como los Airo Pai ("gente del monte")

14. Los kichwas se autodenominan Runa (persona). Se encuentran en los tres países que conforman este paisaje.
15. A los indígenas shuares se los conocía como yaguarzongos y bracamoros. Era un pueblo guerrero que acostumbraba a reducir las cabezas de sus enemigos como trofeo de guerra, conocidas como tzantzas. Habitan entre las selvas de Ecuador y Perú. Se encuentran en la RPF Cuyabeno, a orillas del río Aquarico.

16. El nombre korequaje significa "gente de tierra". Habitan en Colombia, en las riberas del río Mecaya en el departamento de Putumayo, municipio de Puerto Leguízamo, donde se ubica el resguardo indígena Koreguaje Consara-Mecaya.

17. Los huitotos se autodenominaban muruis. Se encuentran entre el río Putumayo y Lagartococha. Conforman la comunidad Santa Teresita en el río Peneya en Perú y los que se encuentran dentro del Parque La Paya se ubican en las cuencas de los ríos Caquetá, Caucaya y sobre el Putumayo.

18. Zonas con función amortiguadora (término utilizado en Colombia)

19. Fuente: Plan de Manejo del Parque Nacional Natural La Paya 20. Fuente: Modelo de Gestión Organizativa del PNN La Paya, 2013 


\begin{tabular}{|c|c|c|c|}
\hline $\begin{array}{l}\text { Nombre del } \\
\text { área protegida }\end{array}$ & $\begin{array}{c}\text { Reserva de Producción de } \\
\text { Fauna Cuyabeno }\end{array}$ & $\begin{array}{c}\text { Parque Nacional Natural } \\
\text { La Paya }\end{array}$ & $\begin{array}{c}\text { Parque Nacional } \\
\text { Güeppí-Sekime } \\
\text { Reserva Comunal Airo Pai } \\
\text { Reserva Comunal Huimeki }\end{array}$ \\
\hline $\begin{array}{l}\text { Pueblos } \\
\text { indígenas }\end{array}$ & $\begin{array}{c}\text { Siona, secoya, cofán, kichwa, } \\
\text { shuar }\end{array}$ & $\begin{array}{c}\text { Siona, koreguaje, huitoto- } \\
\text { murui, kichwa, nasa, } \\
\text { muinane }\end{array}$ & $\begin{array}{c}\text { Parque: Secoya } \\
\text { Reserva Comunal Airo Pai: } \\
\text { secoya, kichwa, mestizos- } \\
\text { ribereños de Cabo Pantoja } \\
\text { Reserva Comunal Huimeki: } \\
\text { kichwa, huitoto (murui) y } \\
\text { mestizos }\end{array}$ \\
\hline $\begin{array}{l}\text { Categoría de } \\
\text { manejo UICN }\end{array}$ & $\begin{array}{l}\text { Categoría VI: área protegida } \\
\text { con usos sostenibles de } \\
\text { recursos naturales }{ }^{21} \\
\text { (No reportado en } \\
\text { Protected Planet) }\end{array}$ & $\begin{array}{c}\text { Categoría II: } \\
\text { parque nacional }{ }^{22}\end{array}$ & $\begin{array}{l}\text { Categoría II: parque } \\
\text { nacional. Uso indirecto, } \\
\text { se respetan los usos } \\
\text { tradicionales de los } \\
\text { pueblos indígenas }\end{array}$ \\
\hline $\begin{array}{l}\text { Tipología de } \\
\text { gobernanza }\end{array}$ & Sí & $\begin{array}{c}\text { Gobernanza por parte } \\
\text { del gobierno } \\
\text { En proceso la } \\
\text { construcción de } \\
\text { acuerdos de manejo } \\
\text { de la zona de traslape } \\
\text { del área protegida; } \\
\text { unas ya han sido } \\
\text { establecidos y otros } \\
\text { están en construcción }\end{array}$ & $\begin{array}{c}\text { Gobernanza por parte } \\
\text { delgobierno, en la zona } \\
\text { del parque. } \\
\text { Gobernanza compartida, } \\
\text { en las reservas } \\
\text { comunales }\end{array}$ \\
\hline
\end{tabular}

En el paisaje norte, el AP más antigua es la Reserva de Producción de Fauna Cuyabeno seguida por el Parque Natural Nacional La Paya, siendo el Parque Nacional Güeppí - Sekime - con las Reservas Comunales Airo Pai y Huimeki - el más reciente en su creación.

La Reserva de Producción de Fauna Cuyabeno contiene cinco territorios indígenas dentro de todo el territorio del AP; parte de la población del PNN La Paya se encuentra asentada en veredas campesinas y resguardos indígenas traslapados con el territorio del AP; en GüeppíSekime la población está asentada en las Reservas Comunales Airo Pai y Huimeki.

Es importante considerar que estas tres AP son fronterizas, por lo que algunas de las culturas que aquí habitan son las mismas, aunque divididas por las líneas que definen los Estados Nación. Ejemplos de esto son las culturas Siona y Cofán - ubicadas en Ecuador y Perú - la cultura Secoya - ubicada en Ecuador y Perú - y los huitotos o muruis, habitantes de Perú y Colombia.

Las poblaciones colonas mestizas de estas tres AP son originarias de diferentes lugares de cada país pero, en general, tienen procesos de movilidad entre fronteras. Llegan a estos territorios por procesos de ampliación de la frontera agrícola, generación de fronteras vivas, procesos impulsados por los Estados, desplazamiento por conflictos, etc

\footnotetext{
21. Fuente: Ministerio del Ambiente de Ecuador, 2006. Políticas y Plan Estratégico del Sistema Nacional de Áreas
}

22. Fuente: www.protectedplanet.net 
La mayoría de las poblaciones indígenas que conforman el paisaje norte tienen una vinculación cercana y armónica con el bosque, mantienen sus prácticas tradicionales y utilizan el conocimiento ancestral para determinar el calendario de siembra, cosecha, caza, pesca, crecida y descenso de las aguas de los ríos y de la procreación de los peces y animales del bosque; esto a pesar de ciertas adaptaciones a las formas de uso de los recursos naturales y la aculturación por las poblaciones migrantes en la zona.

En las AP de este paisaje, la pesca es la actividad más practicada debido a la ubicación de las comunidades en las orillas de los ríos. Sin embargo, en la zona de Colombia, la pesca se practica cada vez menos debido a la contaminación de los ríos con mercurio, producto de la minería de aluvión.

En las AP, la caza está permitida solo para autoconsumo. Esta actividad es realizada exclusivamente por los hombres, quienes emplean escopetas y no las armas tradicionales (lanzas y cerbatanas) que eran elaboradas por ellos mismos. La caza se realiza esporádicamente dado que los cazadores prefieren capturar mamíferos grandes y almacenar la carne por semanas utilizando las técnicas tradicionales de preservación.

De acuerdo a conversaciones mantenidas con algunos indígenas, las chacras están siendo afectadas por los cambios en los ciclos de Iluvia y de sequía. Por ejemplo, los indígenas muruis (PNN La Paya) mencionan su preocupación por las alteraciones en el clima y ven la necesidad de rehacer el calendario de siembra y cosecha como también el de caza y pesca. Para los abuelos del resguardo murui Jiri Jirí "el aire se está calentando", lo que pone de manifiesto la importancia de mantener el bosque y la forma tradicional del uso de los recursos -tomando solo lo que se necesita -, respetar los tiempos de reproducción de las especies y los ciclos de la naturaleza.

Según conversaciones mantenidas con indígenas kichwas en la zona de Zancudo Cocha (Cuyabeno), los ciclos de lluvia y de sequía son considerados como un mecanismo de autorregulación de la naturaleza para equilibrar los eventos del planeta. Sin embargo, desde lo cotidiano, los indígenas de estas áreas protegidas perciben que ahora los veranos son más largos, hace más calor, los inviernos son más intensos y más fríos y las Iluvias y sequías llegan a destiempo.

Estos cambios a los que hacen referencia los indígenas se corroboran con la información de los guardaparques de la Reserva de Cuyabe$n \mathrm{O}^{23}$, quienes mencionan que en los últimos años se han visto cambios en las épocas secas y de lluvia. Resaltan que en el último año la reserva pasó 32 días seguidos sin Iluvia y que ahora la Laguna Grande de Cuyabeno (con 5 a 7 metros de profundidad, 2000 metros de largo y 300 metros de amplitud) se seca dos veces al año cuando antes se secaba solo una vez. Consideran que esto se da por la disminución de bosque alrededor de la reserva y la extensión de la frontera agrícola en la zona de amortiguamiento.

Debido a las demandas actuales impuestas por la lógica del mercado, las comunidades indígenas ubicadas dentro de las AP y las poblaciones de colonos en las zonas de amortiguamiento se dedican a diferentes actividades para generar ingresos económicos. Algunos emplean su mano de obra en trabajos relacionados con las actividades extractivas que se realizan en la zona.

En Cuyabeno, algunos indígenas trabajaban temporalmente en actividades relacionadas al petróleo pero, debido a la bajada del precio, están volviendo al trabajo en sus comunidades. Una actividad que tomó impulso en los últimos años y constituyó una fuente de ingreso para las familias en Cuyabeno fue el servicio de transporte por vía terrestre -con la compra de camionetas - y por vía fluvial - con canoas de fibra motorizadas-. Este servicio era ofrecido a las empresas petroleras de la zona. Ahora, al no tener contratos, este servicio se destina a los habitantes locales y como apoyo al sector turístico.

Algunos pobladores generan ingresos con la venta de los excedentes de sus chacras y el manejo de animales menores como aves de corral y, en menor cantidad, ganado. Cabo Pantoja (Perú) es la localidad donde se realizan las actividades comerciales de las comunidades cercanas a la RC Airo Pai. Los indígenas secoyas de Puer-

23. Reunión mantenida en el puesto de control de Lagartococha, marzo 2016 
to Estrella salen por el río en peque-peque ${ }^{24}$ una vez al mes para vender los excedentes de la chacra, la caza y la pesca y, así, aprovisionarse de artículos de primera necesidad ${ }^{25}$ La ley peruana establece un cupo de hasta 30 kilos mensuales por familia entre carne y pescado (a excepción del paiche que tiene otro tratamiento por ser considerada especie en peligro), lo que ha llevado a que, en algunos casos, las familias utilicen este cupo al máximo y vendan el excedente ${ }^{26}$

Los moradores de Cabo Pantoja comentan que los sábados se realizan ferias en la orilla del río Napo donde comerciantes ecuatorianos y peruanos abastecen a la población local y a los campamentos militares con carne de monte, tortugas y pescado.

En cuanto a educación, las comunidades, a nivel de paisaje, tienen escuelas unidocentes que, en la mayoría de casos, no se encuentran en buen estado. Para acceder a la educación secundaria, los jóvenes deben salir de sus comunidades hacia las ciudades más cercanas y muy pocos tienen acceso a estudios universitarios. Destaca la Unidad Educativa del Milenio en la comunidad Playas de Cuyabeno, a la cual se hace referencia más adelante.

Los principales problemas de salud en las áreas protegidas del paisaje están relacionados con la malaria, problemas digestivos, desnutrición, heridas por cortes y picaduras de culebras. En las comunidades, la medicina tradicional es importante y muy utilizada, sin embargo todos coinciden en la importancia de unir los conocimientos de la medicina tradicional con la occidental. Los indígenas usan las plantas medicinales que cultivan en sus chacras o que recogen del bosque para enfermedades comunes y, cuando requieren de asistencia médica especializada, salen al centro poblado más cercano. En la zona de Güeppí,

"Antes del establecimiento de la reserva pescábamos mucho paiche para vender, ahora por las prohibiciones de la reserva, la pesca del paiche ha disminuido. Lo mismo con la madera, ahora ya se controla el ingreso de la gente de Cabo Pantoja para sacar madera y eso es bueno para nosotros".

Indígena secoya de Puerto Estrella, marzo 2016. hay un puesto de salud y un promotor de salud en la comunidad Tres Fronteras. Tanto en esta comunidad como en Puerto Estrella, cuando se presentan problemas graves, llevan a los enfermos hasta Cabo Pantoja, desde donde pueden acceder al servicio de avioneta del Seguro Integrado de Salud (SIS), que traslada a los enfermos a Iquitos. Otros van a Puerto Leguízamo, Colombia. En Cuyabeno salen a Lago Agrio o Puerto El Carmen en busca de asistencia médica.

Entre las amenazas del paisaje norte se pueden mencionar las que se dan en las zonas de amortiguamiento, donde predominan actividades extractivas como el petróleo, la minería y la tala de madera. Dentro de la RPF Cuyabeno existen proyectos de prospección sísmica; en la zona del Parque Güeppí-Sekime, hasta 2012, había actividad petrolera (con la empresa Petrobras), que terminó a raíz de la declaración de parque nacional; en los ríos colindantes al PNN La Paya se realizan actividades ilegales de minería de aluvión.

En general, las comunidades indígenas que conforman el paisaje norte respaldan y reconocen el trabajo realizado por las distintas administraciones de las áreas protegidas y coinciden en que es más beneficioso estar dentro de estas áreas

Para los indígenas de la etnia murui (PNN La Paya), el establecimiento del AP les ha beneficiado con el control de la entrada a madereros y mineros ilegales ${ }^{27}$. Las comunidades indígenas en Cuyabeno se sienten respaldadas por contar con bosques bien cuidados para realizar proyectos de ecoturismo y otras actividades de aprovechamiento sostenible de los recursos. Además, mencionan que estar dentro de la reserva les facilita obtener certificaciones ambientales. Entre las desventajas, destacan las prohibiciones para construir carreteras, lo que dificulta la distribución de los productos en el mercado, y las limitaciones para acceder a créditos para inversión por no contar con títulos de propiedad de las tierras

\footnotetext{
24. Lancha de madera con un motor de dos tiempos adaptado que anda a una velocidad promedio de $14 \mathrm{~km} / \mathrm{h}$

25. Información proporcionada por los moradores de Puerto Estrella en la visita realizada a su comunidad.

26. Información proporcionada por los guardaparques de la Reserva Airo Pal

27. Conversación mantenida en la maloca de la comunidad Jiri Jirí con el Consejo de Abuelos en marzo, 2016. Fuente: Ministerio del Ambiente, 2012. Plan de Manejo de la Reserva de Producción de Fauna Cuyabeno. Quito, Ecuador, 56 p.
} 
Reserva de Producción de Fauna Cuyabeno (RPF Cuyabeno)
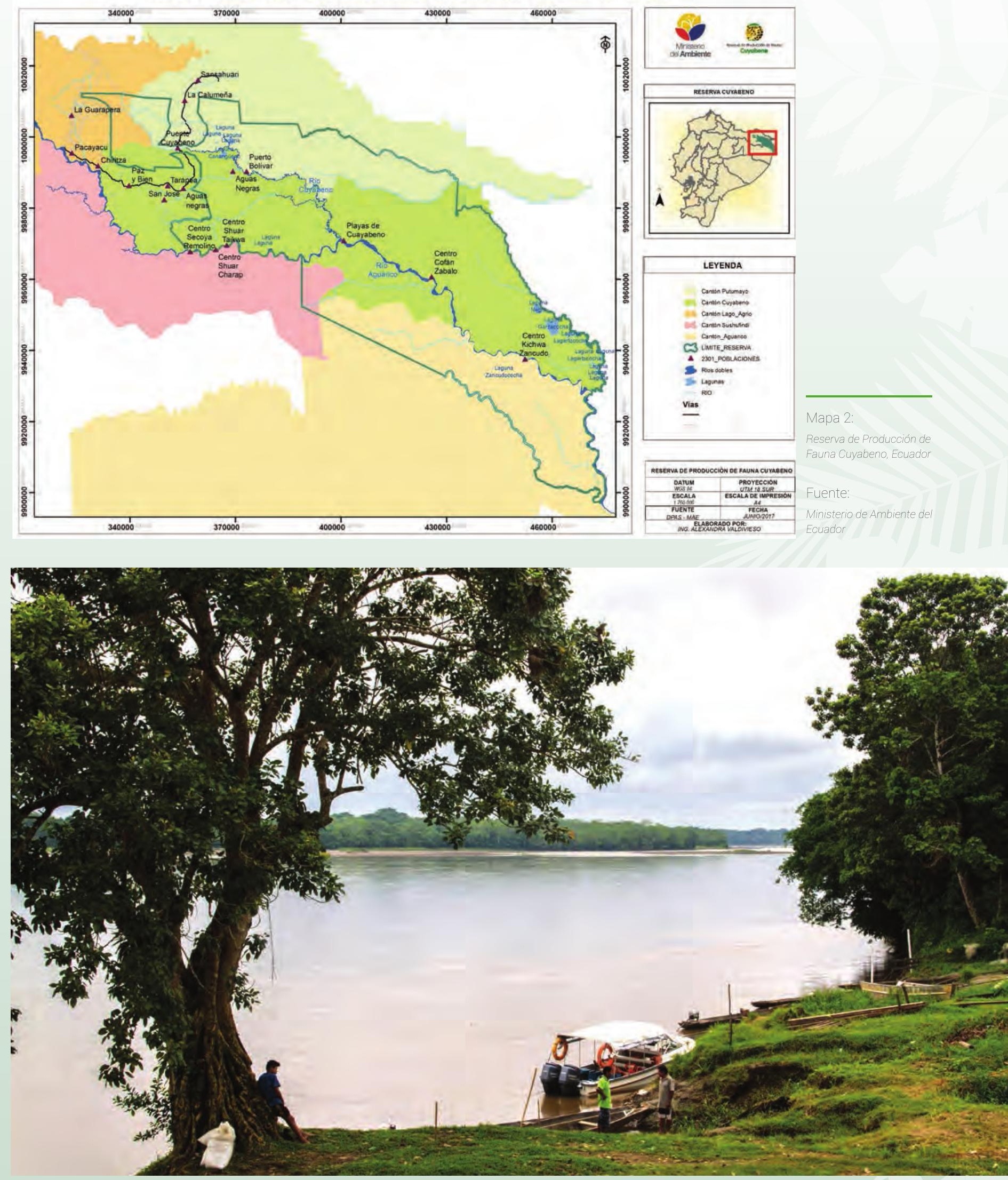

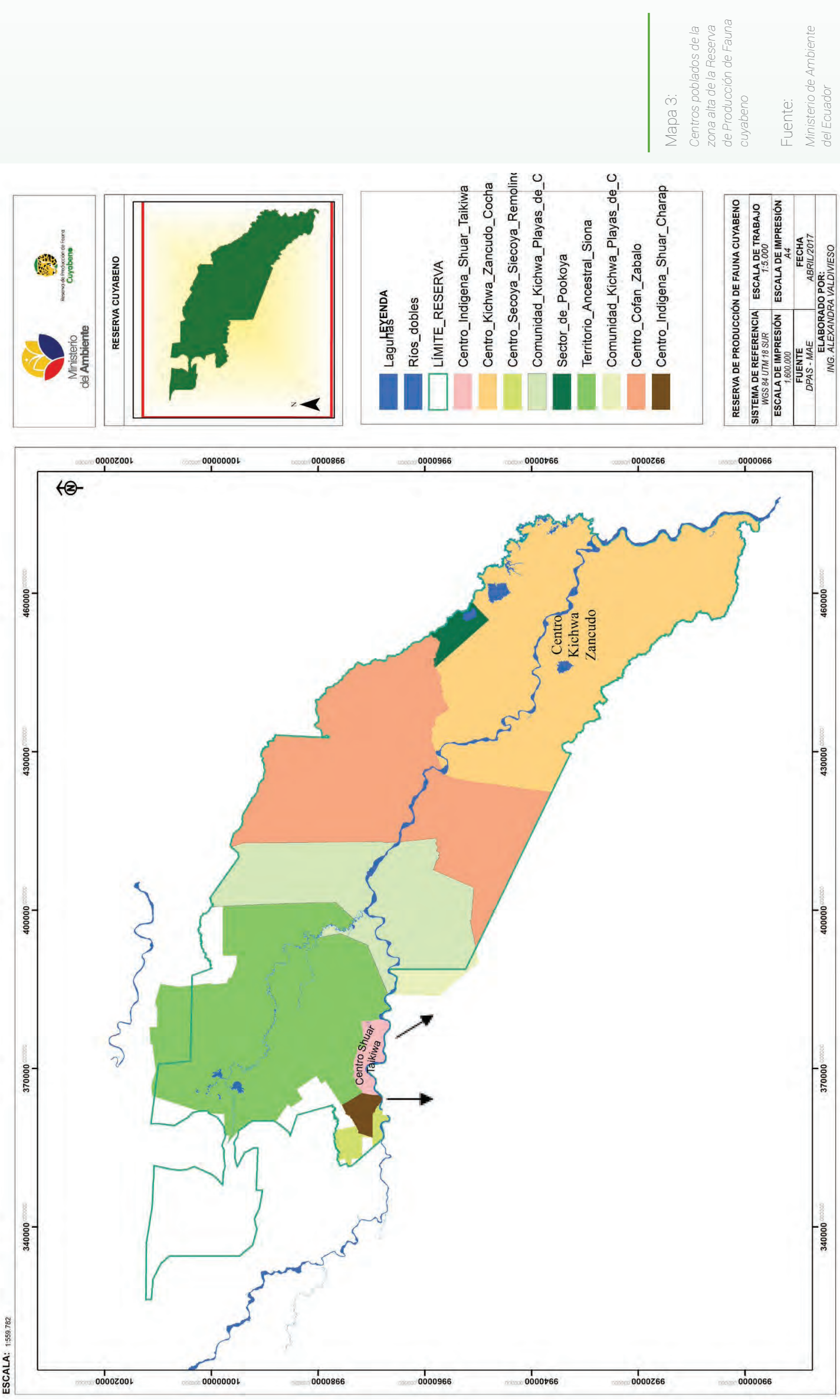
En Ecuador, la autoridad nacional competente en materia ambiental y administradora de las áreas protegidas es el Ministerio del Ambiente (MAE). La administración de la RPF Cuyabeno representa al MAE en Cuyabeno y maneja la relación con los actores involucrados, tanto en el interior de la reserva como en la zona de amortiguamiento. El MAE es la entidad referente en el área protegida; la mediadora cuando hay conflictos entre las comunidades y entre otros actores; la que brinda el apoyo técnico y financiero en la elaboración y actualización de planes de manejo; y la que mantiene las relaciones con las áreas protegidas de los otros países

En 2012, el MAE desarrolló el Plan de Manejo de la RPF Cuyabeno, que incluye los siguientes objetivos:

- Proteger la diversidad biológica y cultural de la reserva y su zona de amortiguamiento

- Consolidar la gobernanza en la protección del área protegida

- Promover el uso sostenible de los recursos naturales dentro y fuera de la reserva

- Contribuir a mejorar las condiciones de vida de las comunidades ancestrales y población local.
Dicho plan cuenta con un Sistema de Seguimiento y Evaluación (SSE) y el financiamiento proviene de fondos fiscales y de proyectos nacionales e internacionales. Sin embargo, según el jefe de la reserva, estos fondos son insuficientes para sus expectativas, por lo que la administración de la reserva busca fondos en otras fuentes para lograr sus objetivos.

Este plan fue un insumo importante para el Plan de Desarrollo del Cantón Cuyabeno, el cual contó con la asistencia técnica y financiera de la Secretaría Nacional de Planificación y Desarrollo (SENPLADES), la Asociación de Municipalidades del Ecuador y las juntas parroquiales. En la práctica, lo propuesto en el plan de desarrollo cantonal se concreta y ejecuta más ágilmente de lo que figura en el plan de manejo de la reserva, ya que cuenta con más presupuesto

La zonificación de la RPF Cuyabeno se estableció tomando en cuenta criterios físicos, climáticos, ecológicos, sociales y de uso, respetando la ocupación de las comunidades indígenas y su organización territorial. Dentro de la reserva hay ${ }^{28}$ :

28. Fuente: Ministerio del Ambiente, 2012. Plan de Manejo de la Reserva de Producción de Fauna Cuyabeno. Quito, Ecuador, $56 \mathrm{p.}$

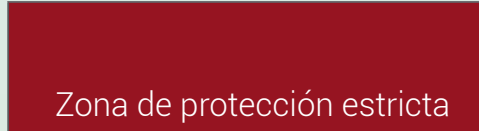

Zona de uso especial

Zona de uso turístico
y recreativo

Zona de recuperación

Zona de amortiguamiento
Zonas con acceso restringido donde solo se pueden realizar actividades de investigación científica y monitoreo de biodiversidad.

Zonas donde se permiten actividades de caza y pesca para autosustento por parte de las comunidades indígenas que habitan la reserva.

Zonas donde se permite la actividad turística con el cumplimiento de normas y estándares propios de la reserva.

Zonas para recuperación de ecosistemas degradados por actividades humanas.

Zonas alrededor de la reserva, donde se realizan actividades para mitigar las presiones y amenazas existentes. 
En la zona de Cuyabeno se ha realizado una importante inversión en programas educativos, de salud, infraestructura, etc. a raíz de las Reformas a la Ley de Hidrocarburos de Ecuador (2010), que establece que el $12 \%$ de las utilidades de los excedentes petrole- ros se deben invertir en las poblaciones aledañas a los proyectos hidrocarburíferos ${ }^{29}$. Así se construyó la Comunidad del Milenio en Playas de Cuyabeno, dentro de la reserva, a orillas del río Aguarico, inaugurada en el año 2013

\section{Comunidad del Milenio Playas de Cuyabeno}

Es un proyecto de vivienda para 80 familias que incluye todos los servicios básicos (agua potable, alcantarillado, electricidad, telefonía fija y móvil), internet, centro de salud, planta de tratamiento de aguas residuales, manejo de desechos sólidos, espacios públicos, cementerio, coliseo, mercado y muelle. Los habitantes crían animales menores y cultivan huertos.

La comunidad cuenta también con la Unidad Educativa del Milenio que ofrece instrucción primaria y secundaria, cuenta con 15 docentes y 180 alumnos de todas las comunidades de alrededor. Ofrece internado para los jóvenes de las localidades cercanas, que van a la escuela de domingo a viernes en una lancha del Ministerio de Educación. Actualmente hay 7 alumnos en el internado, pertenecientes las comunidades Tarapoa, Cascales y Gonzalo Pizarro
Petroamazonas EP, empresa pública dedicada a la exploración y producción de hidrocarburos, entregó formalmente la comunidad al Gobierno Autónomo Descentralizado (GAD) de Cuyabeno en 2014 y, a partir de ese momento, el GAD asumió su administración, que incluye el mantenimiento y el costo de uso de los servicios con los que cuenta. Dado que la comunidad está dentro de la Reserva Cuyabeno, sus habitantes, indígenas dedicados a actividades de autosustento (caza, pesca y agricultura), no están sujetos a pagar impuestos. El GAD Cuyabeno afirma que el manejo de la comunidad es complejo y costoso y que no cuentan con los recursos económicos para asumir estos gastos, por lo que ya han dejado de proveer a la comunidad con alguno de los servicios básicos.
En Playas de Cuyabeno, el grupo consultado manifiesta que, desde hace 5 años, los indígenas de la reserva y el municipio mantienen una relación de colaboración que antes no existía. Aducen que, antes, esta relación no era necesaria ya que la empresa petrolera les proveía de lo necesario, pero que esto cambió a raíz de la bajada del precio del petróleo. Sin embargo, este cambio también corresponde al nuevo marco legal ecuatoriano, como el Código Orgánico de Organización Territorial, Autonomía y Descentralización (COOTAD), el cual, entre otras cosas, "desarrolla un modelo de descentralización obligatoria, progresiva y definitiva de competencias, del Gobierno central, hacia los Gobiernos autónomos descentralizados, garantizándoles su autonomía política, administrativa y financiera"30.

El Municipio de Cuyabeno lleva adelante, desde 2014, el proyecto "Recolección fluvial de los desechos inorgánicos generados en las comunidades y prestadoras de servicios turís- ticos ubicados en las riberas de los ríos Aguarico y Cuyabeno". El proyecto busca la gestión integral de los residuos sólidos e incluye: separación por tipo de desecho, recolección, transporte, tratamiento y disposición final en el relleno. La recolección se realiza 1 ó 2 veces al mes en los lodges alrededor de la Laguna Grande de Cuyabeno y las comunidades indígenas ubicadas a las orillas del Aguarico y el río Cuyabeno ${ }^{31}$. Los lodges pagan una mensualidad por este servicio, mientras que las comunidades se benefician de este servicio de manera gratuita. Los operadores turísticos manifiestan que los tiempos de recolección son insuficientes por la cantidad de desechos que generan

\footnotetext{
29. Art. 94. El Estado ecuatoriano tiene la obligación de entregar e $12 \%$ de las utilidades de los trabajadores del sector petrolero a los Gobiernos Autónomos Descentralizados, para que ejecuten planes, proyectos, obras y servicios única y exclusivamente en inversión social en salud y educación.

30. Fuente: documentación.asambleanacional.gob.ec

31. Proyecto desarrollado con el apoyo técnico y financiero del Fondo Ítalo-ecuatoriano.
} 


\section{Paisaje norte}

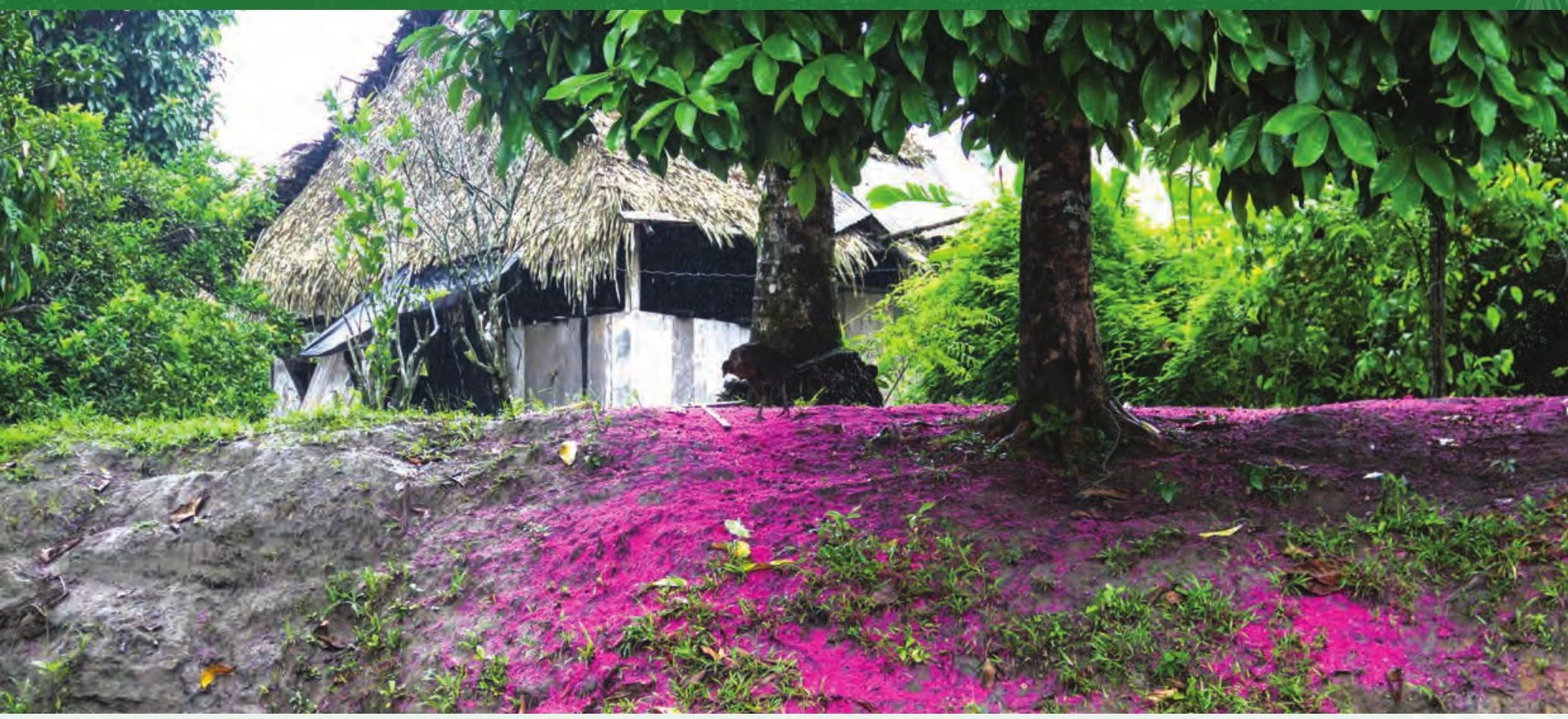

a diario y por la rápida descomposición de los mismos. La comunidad kichwa de Zancudo Cocha ve este proyecto con buenos ojos ya que manifiesta que antes se arrojaban los residuos al río, lo que resultaba en una mala calidad del agua. A raíz de la implementación de este proyecto, las enfermedades asociadas con temas digestivos y cálculos en los riñones han disminuido

En la RPF Cuyabeno y en la zona de amortiguamiento, el Municipio de Cuyabeno y el Gobierno provincial de Sucumbíos, en alianza con la entidad estatal Ecuador Estratégico ${ }^{32}$, están realizando obras de infraestructura: una construcción de vía dentro de la reserva y el "Proyecto de Captación de Agua Nueva Juventud", con el cual se quiere dotar de agua potable a 2000 personas ubicadas en las localidades de San José, 33 Tarapoa y Aguas Negras. El GAD reconoce que el proyecto genera impactos ambientales (por la captación de agua del río Bonito) pero que mejorará la calidad de vida de la población.

\begin{tabular}{|c|c|c|}
\hline \multirow{4}{*}{ Paisaje } & AP de referencia & Culturas \\
Norte & \multirow{4}{*}{ Cuyabeno } & Secoya \\
\cline { 3 - 3 } & & Siona \\
& & Cofán \\
& & Kichwa \\
& & Shuar \\
\hline
\end{tabular}

La Reserva de Producción de Fauna Cuyabeno acoge en su interior el territorio de cinco pueblos indígenas amazónicos, organizados en diferentes comunidades. El reconocimiento de estos territorios se dio a la par que se constituyó el AP y representa un traslape total del AP con estos territorios.

El reconocimiento de estos territorios dentro de la Reserva de Producción Faunística Cuyabeno ha sido un proceso sostenido y exitoso en la gestión de esta AP, ya que se logró, entre otras cosas: la delimitación completa de cada uno de los territorios con el acuerdo de la población, evitar la colonización ilícita de los territorios indígenas y frenar la expansión de la frontera agrícola (entrevista Luis Borbor, 2016). Además, la gestión actual ha reducido sensiblemente la caza de fauna para el comercio.

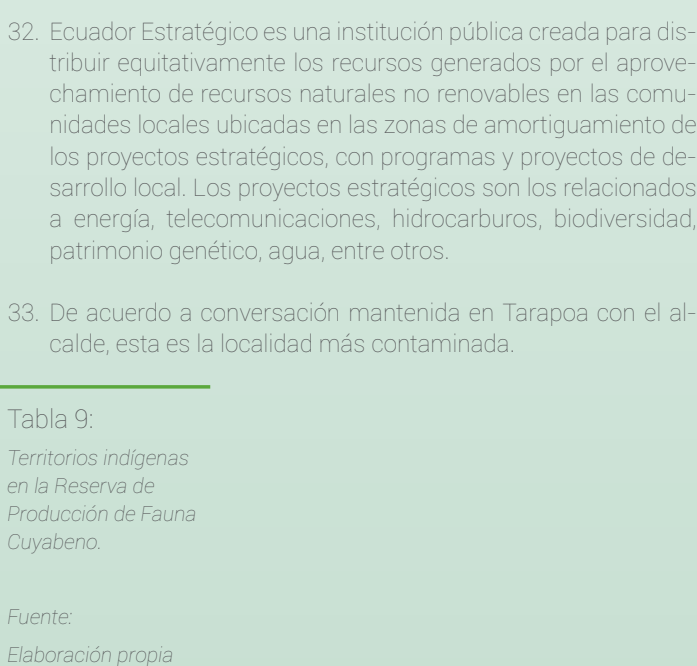




\section{Parque Natural Nacional La Paya (PNN La Paya)}

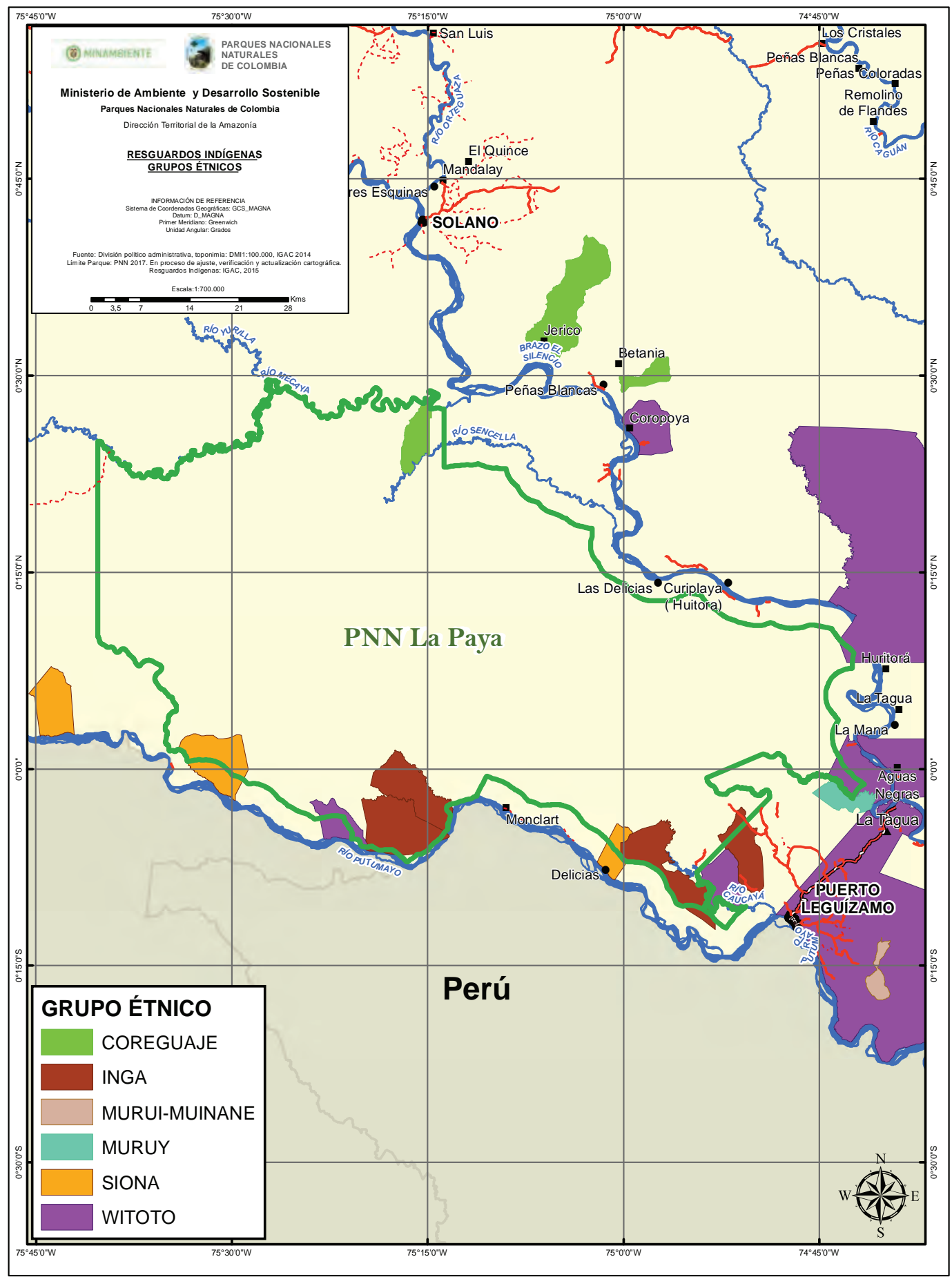




\section{Paisaje norte}

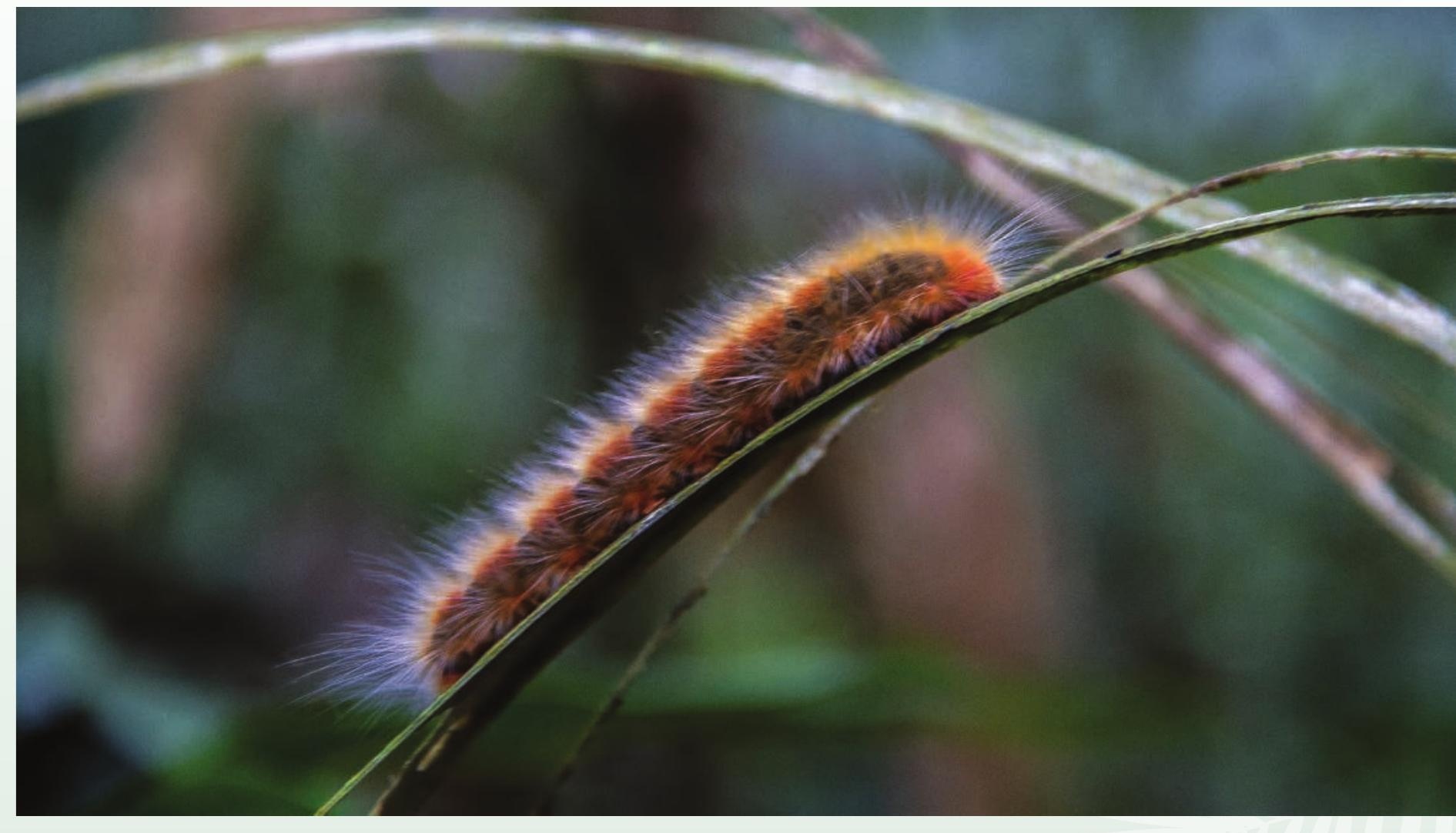

Parques Nacionales Naturales de Colombia (PNNC) es la instancia que administra el Sistema de Parques Nacionales Naturales de Colombia y coordina el Sistema Nacional de Áreas Protegidas (SINAP). La Dirección Territorial Amazonia (DTAM) es una dependencia del PNN que apoya la gestión de las áreas protegidas de la región amazónica colombiana y se encuentra formada por 11 áreas protegidas; así mismo, coordina el relacionamiento con las autoridades indígenas que forman parte de los resguardos indígenas legalmente conformados y las autoridades de pueblos vinculados a las áreas protegidas en su jurisdicción, con quienes construyen conjuntamente el Régimen Especial de Manejo (REM) para los resguardos indígenas que se encuentren traslapados con áreas protegidas de la Amazonía.

EI REM es un conjunto de reglas y procedimientos que permiten la planeación, implementación y seguimiento de las acciones coordinadas sobre el uso, control y coadministración de los recursos naturales entre las autoridades ambientales locales y las autoridades indígenas presentes en el área traslapada con resguardos indígenas o territorios ancestrales. Es el producto de un proceso participativo para llegar a acuerdos entre las autoridades locales, indígenas y la administración de las áreas protegidas, quienes conforman un comité coordinador para dirigir, evaluar y hacer seguimiento a los acuerdos establecidos.

El Plan de Manejo del PNN La Paya se desarrolló para el periodo 2007-2011 y constituyó un insumo para la concertación del REM con las comunidades y autoridades indígenas.

Entre los objetivos del Plan de Manejo del PNN La Paya destacan ${ }^{34}$.

- Construcción e implementación participativa de criterios y mecanismos que contribuyan al ordenamiento ambiental territorial del Parque Nacional Natural La Paya, en un contexto regional

- Formulación de un Régimen Especial de Manejo REM para las áreas de resguardos superpuestas con el PNN La Paya y definición de mecanismos de acuerdos para las áreas no superpuestas o de territorios ancestrales

- Mejorar el conocimiento y control sobre el PNN La Paya y su zona de amortiguamiento

34. Tomado del Plan de Manejo PNN La Paya 2007-2011 
- Posicionamiento y fortalecimiento del equipo de trabajo del PNN La Paya

El Plan de Manejo del PNN La Paya está siendo reformulado. Jefferson Rojas, jefe del parque, menciona la necesidad de hacer un proceso más participativo para que este sea legítimamente aceptado y para que los implicados se sientan identificados y lo asuman como propio.
En el PNN La Paya, de acuerdo a la normativa ambiental, se permiten actividades que no ocasionen alteraciones significativas al ambiente natural, estas son: actividades de conservación, de recuperación y control, investigación, educación, recreación y de cultura ${ }^{35}$.

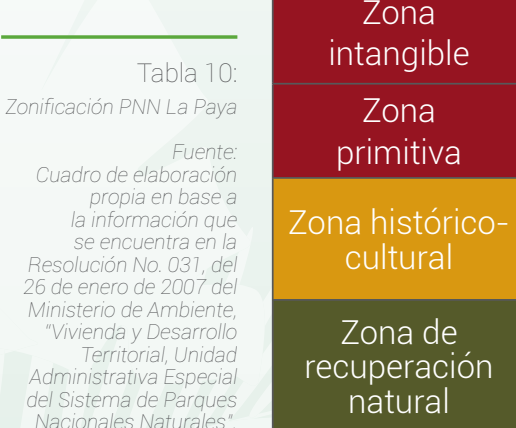

En el año 2009, la Corte Constitucional de Colombia emitió el Auto 2004, que busca la "protección y defensa de los derechos fundamentales de las personas y los pueblos indígenas desplazados por el conflicto armado o en riesgo de desplazamiento forzado ". El pueblo murui, ${ }^{36}$ ubicado en Putumayo y Caquetá, es uno de los 34 pueblos que conforman la lista de los que requieren atención inmediata del Gobierno nacional por estar considerados en peligro de desaparición tanto física como cultural.

En Colombia, desde septiembre de 2012, se está llevando a cabo el proceso de Acuerdo de Paz entre las Fuerzas Armadas Revolucionarias de Colombia (FARC) y el Gobierno de Juan Manuel Santos. Este proceso ha promovido algunos proyectos nacionales de reinserción para garantizar condiciones más estables a los ciudadanos. En la zona de amortiguamiento del PNN La Paya, el Gobierno nacional inició con las comunidades la construcción de Planes de Salvaguarda Étnica ante el conflicto armado y el desplazamiento forzado; estos incluyen el derecho a la consulta previa, libre e informada. Los planes de salvaguarda incluyen temas como territorio (plan de uso y manejo, restablecimiento de la conexión del territorio sagrado ancestral), soberanía alimentaria (recuperación de semillas, fortalecimiento de chacras), medioambiente (recuperación de plantas, reforestación) y gobierno propio (fortalecimiento del capital social).

De acuerdo a las personas consultadas, en Puerto Leguízamo la presencia del Estado es más recurrente en los últimos años. Anteriormente, la dinámica socioeconómica dependía de los militares que tienen sus bases y mucha presencia en el territorio. Además, desde enero de 2016, Puerto Leguízamo cuenta, por primera vez, con un alcalde indígena, Juan Carlos Paya, un joven murui exdirigente social. Hasta esta fecha siempre hubo representación mestiza a pesar de que la mayoría de la población es indígena. Actualmente existe una buena relación entre el PNN La Paya y el Municipio de Puerto Leguízamo, la cual se debe mantener, ya que el parque es un actor muy importante y además ocupa la mitad de la superficie total de dicho municipio.

En el Parque Nacional Natural La Paya, la forma de manejo territorial de los pueblos ancestrales se ha constituido a través de resguardos indígenas que bordean y se traslapan con el territorio de esta área protegida. Alrededor de este territorio hay aproximadamente treinta veredas mestizas con las que se ha trabajado la gestión del área. Este ordenamiento del

\footnotetext{
35. Artículo 331 y 332 de Código Nacional de Recursos Naturales Renovables y del Medio Ambiente.

36. Tomado de www.corteconstitucional.gov.co
} 
territorio, a través de resguardos y veredas, se realizó a partir de los años 1984 y 1986, como parte de los procesos de reforma agraria de Colombia.

Actualmente existe una buena relación entre el PNN La Paya y el Municipio de Puerto Leguízamo, la cual se debe mantener, ya que el parque es un actor muy importante y además ocupa la mitad de la superficie total de dicho municipio.

En el Parque Nacional Natural La Paya, la forma de manejo territorial de los pueblos ancestrales se ha constituido a través de resguardos indígenas que bordean y se traslapan con el territorio de esta área protegida. Alrededor de este territorio hay aproximadamente treinta veredas mestizas con las que se ha trabajado la gestión del área. Este ordenamiento del territorio, a través de resguardos y veredas, se realizó a partir de los años 1984 y 1986, como parte de los procesos de reforma agraria de Colombia.

\begin{tabular}{|c|c|}
\hline $\begin{array}{l}\mathrm{AP} \text { de } \\
\text { referencia }\end{array}$ & Territorios comunitarios \\
\hline \multirow{9}{*}{ La Paya } & Resguardo de Lagarto Cocha \\
\hline & Resguardo Tukunaré \\
\hline & Resguardo Jiri Jirí \\
\hline & Resguardo Aguas Negras \\
\hline & Resguardo Ceciliacocha \\
\hline & Resguardo La Paya \\
\hline & Resguardo El Hacha \\
\hline & Resguardo Comsara-Mecaya \\
\hline & Veredas mestizas ${ }^{37}$ \\
\hline
\end{tabular}

\footnotetext{
Tabla 11

Territorios comunitarios

del Parque Nacional

Natural La Paya

Fuente:

Elaboración propia
}

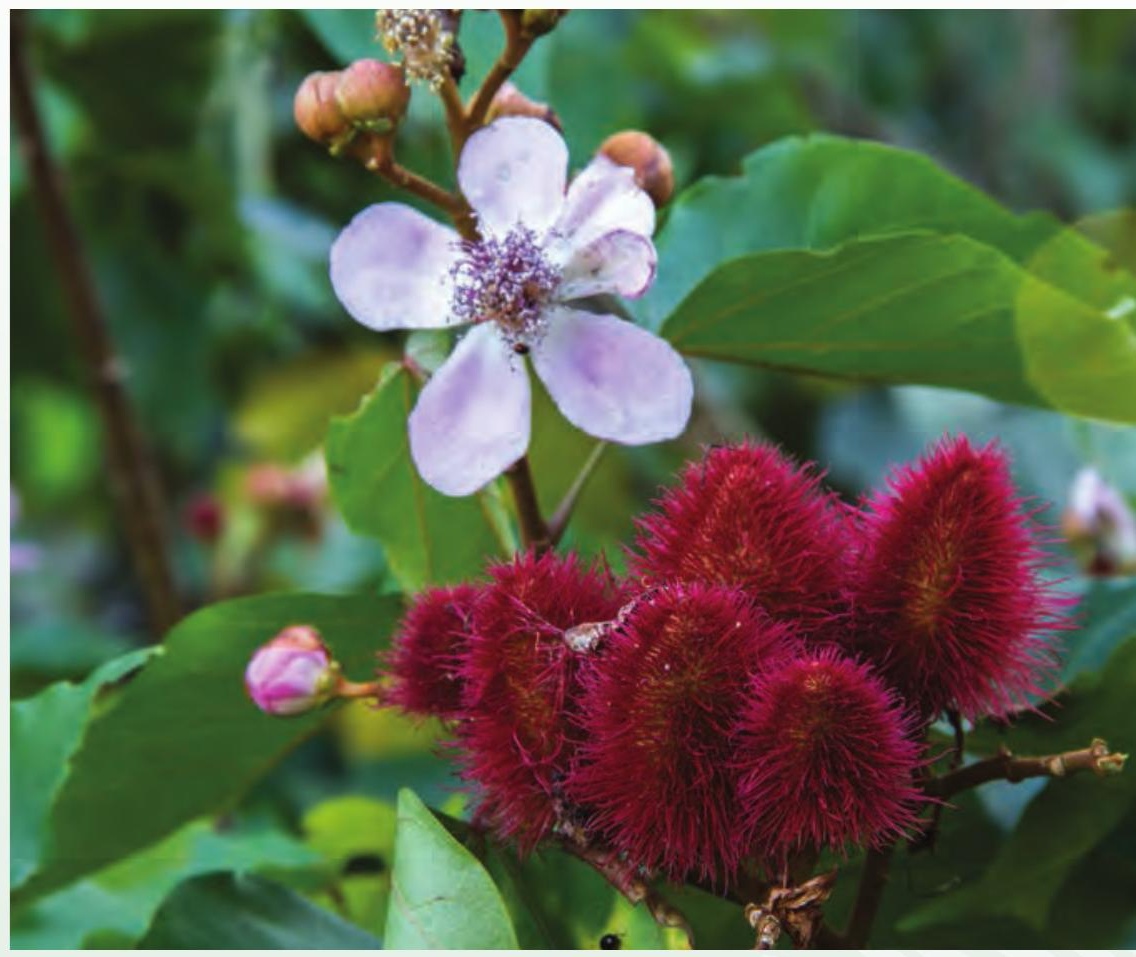

En esta misma época también se creó el Parque Nacional Natural La Paya, aunque su creación fue un proceso administrativo ligado a la misión institucional de Parques Nacionales Naturales de Colombia ${ }^{38}$, que implicó el traslape con resguardos indígenas. Desafortunadamente, y dado el mecanismo que existía en ese momento para adelantar la declaratoria de AP en el país, no fueron reconocidas las personas que ya se encontraban dentro de la zona delimitada como parque, por ejemplo, la zona del río Caucayá, que atraviesa la mitad el parque.

En esta zona se realizó, desde la jefatura del parque, un proceso de concertación para que estas personas se trasladasen a otros lugares y así mantener el estatus de parque nacional y sus restricciones de uso sin perjuicio de los medios de sustento de la población mestiza que se encontraba en este lugar.

37. Vereda, en Colombia, es la subdivisión territorial de un municipio, conformada por áreas rurales de propiedades privadas y otras situaciones de tenencia de la tierra. Cada vereda suele tener su propia escuela primaria y su expresión organizativa está institucionalizada en la Junta de Acción Comunal (JAC), (Ruiz, 2015)

38. Que establece en su misión y en el marco de ordenamiento ambiental del territorio, conservar in situ la diversidad biológica y ecosistémica representativa del país, proveer y mantener bienes y servicios ambientales, proteger el patrimonio cultural y el hábitat natural donde se desarrollan las culturas tradicionales como parte del Patrimonio Nacional (Programa Trinacional, 2016). 
Parque Nacional Güeppí-Sekime (PN Güeppí-Sekime) y Reservas Comunales Airo Pai y Huimeki (RC Airo Pai y RC Huimeki)

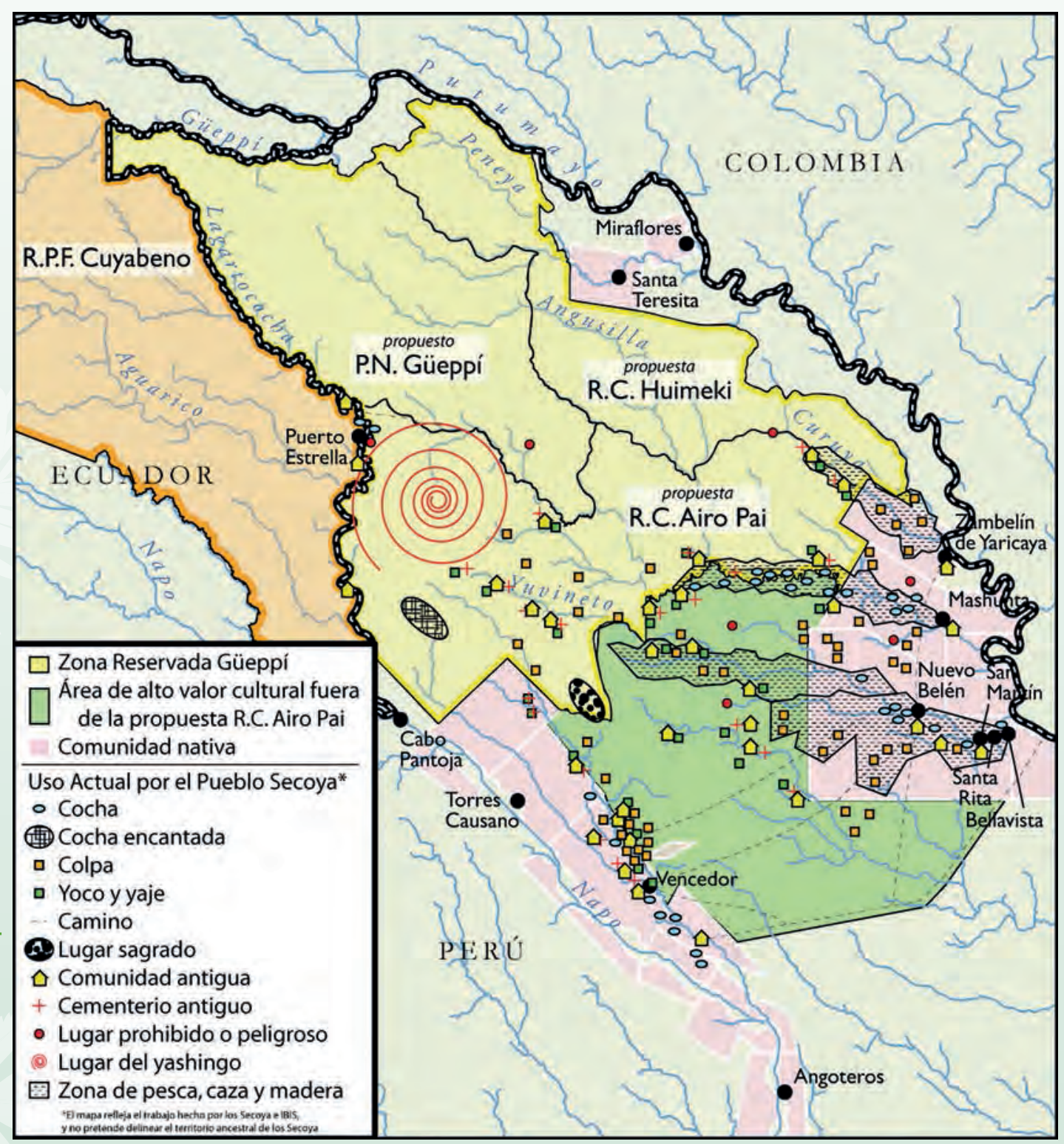




\section{Paisaje norte}

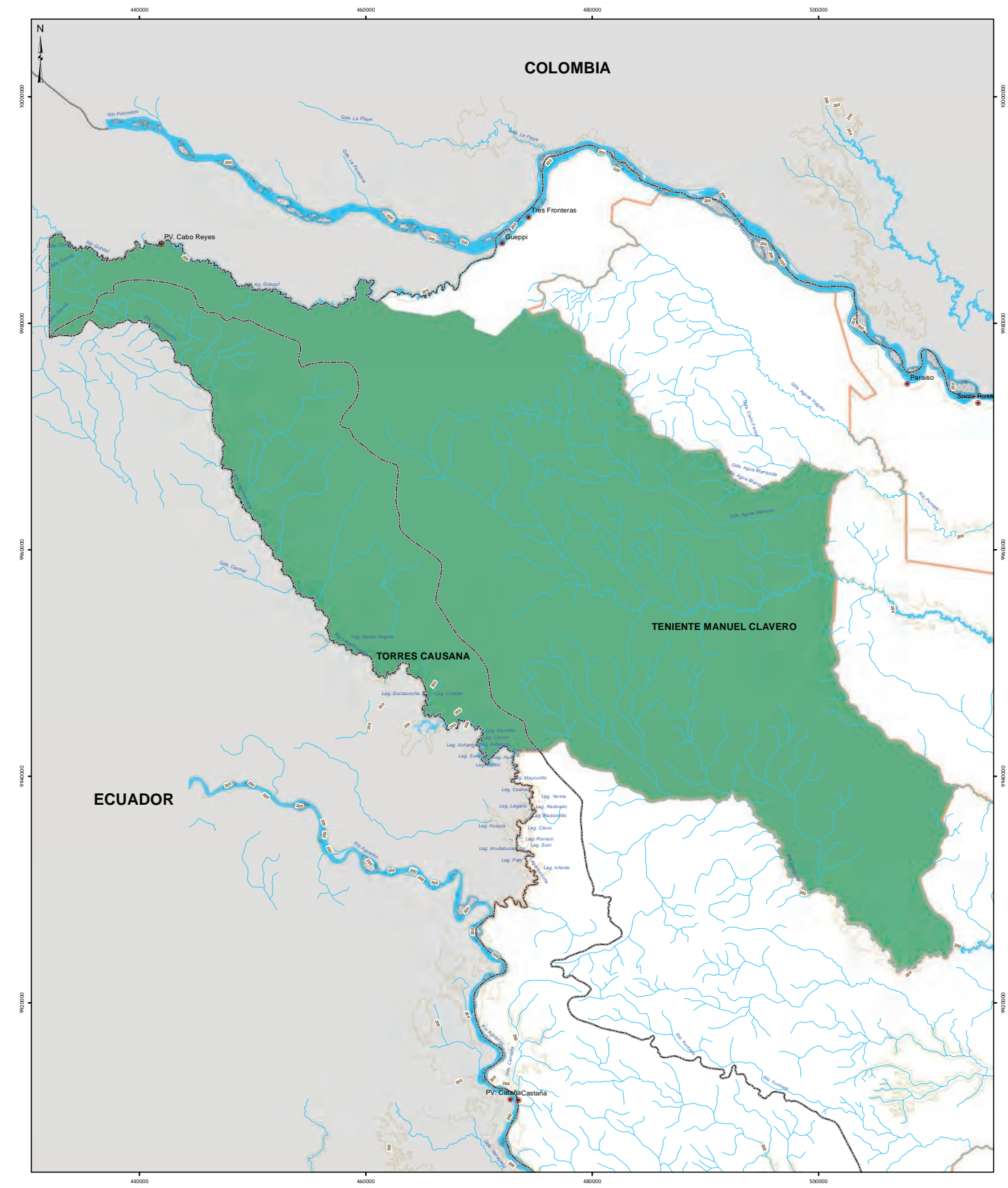

\begin{tabular}{|c|c|c|}
\hline SPER PEO & Ministerio & 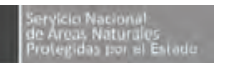 \\
\hline \multicolumn{3}{|c|}{$\begin{array}{l}\text { MAPA BASE } \\
\text { PARQUE NACIONALGUEPPI - SEKIME }\end{array}$} \\
\hline $\begin{array}{l}\text { UBICACIÓN } \\
\text { DEPARAMENTO } \\
\text { PROVINCIA } \\
\text { DISTRITOS }\end{array}$ & $\begin{array}{l}: \text { LORETO } \\
: \text { MAYNAS } \\
: \text { TORRES CAUSANA, } \\
\text { TENIENTE MANUELCLAVERO }\end{array}$ & \begin{tabular}{|ll} 
DATUM & $:$ WGS84 \\
ZONA & $: 18 \mathrm{~S}$ \\
ESCALA & $1: 250,000$ \\
\end{tabular} \\
\hline SUPERFIC IE: 203 & & Fecha de Elaboración: \\
\hline \multicolumn{2}{|c|}{ 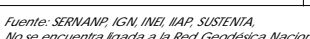 } & حumian: \\
\hline
\end{tabular}
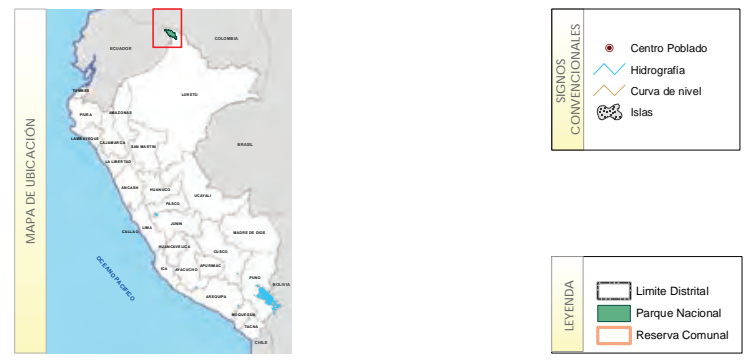
La administración de estas áreas protegidas está a cargo del Servicio Nacional de Áreas Naturales Protegidas por el Estado (SERNANP), organismo adscrito al Ministerio del Ambiente, el cual cuenta con el Sistema Nacional de Áreas Naturales Protegidas por el Estado (SINANPE), cuyo objetivo es contribuir al desarrollo sostenible de Perú, a través de la conservación de muestras representativas de la diversidad biológica. Las áreas naturales protegidas pueden ser públicas, privadas y comunitarias y están repartidas en diez categorías de manejo: reserva nacional, parque nacional, bosque de protección, coto de caza, reserva comunal, reserva paisajística, santuario histórico, santuario nacional, zona reservada y refugio de vida silvestre ${ }^{39}$.

La ley peruana reconoce el derecho de propiedad de las comunidades indígenas sobre las tierras que poseen dentro de las áreas protegidas, promoviendo la participación de dichas comunidades en la gestión de las áreas ${ }^{40}$ con un Régimen Especial de Administración de las Reservas Comunales. Este permite que los indígenas sean los responsables del manejo de la reserva tomando en cuenta el derecho consuetudinario. De acuerdo a la legislación peruana, los territorios indígenas son conocidos como "comunidades nativas".

Según el Artículo 1 del Régimen Especial para la Administración de las Reservas Comunales, la reserva comunal "es una categoría de área natural protegida, de uso directo, destinada a la conservación de la flora y fauna silvestre, en beneficio de las poblaciones locales y comunidades campesinas o nativas pertenecientes a los pueblos indígenas". En estas, el uso y comercialización de los recursos naturales (diferentes a la madera) de las reservas comunales se hace bajo planes de manejo aprobados y supervisados por la autoridad sectorial competente y conducidos por los mismos beneficiarios.

En el año 2013, el SERNANP trabajó en la elaboración del Plan Maestro del PN Güeppí-Sekime para el periodo 2014-201941. Este proceso contó con la participación de muchos actores locales de instituciones públicas y privadas, organizaciones indígenas y comunidades. Este documento de gestión está enfocado a la conservación de los ecosistemas, a la consolidación de espacios de gestión participativa del área y al desarrollo de activida- des económicas acordes al área. La instancia responsable de la elaboración del plan fue la jefatura del parque, la cual contó con la asistencia técnica de la Dirección de Desarrollo Estratégico del SERNANP.

Además, se realizó un diagnóstico del territorio donde está ubicado el parque, que describe sus características físicas, biológicas, socioculturales, actividades económicas y objetivos de conservación. Este insumo incluye los mecanismos para la implementación del Plan Maestro del PN Güeppí-Sekime. Los objetivos del plan se dividen en ambientales, socioculturales y económicos ${ }^{42}$ :

- Mantener el estado de conservación de los ecosistemas acuáticos y terrestres.

- Conservar poblaciones saludables de especies amenazadas como el manatí, paiche y cedro.

- Consolidar espacios para la gestión participativa del área (representados en un comité de gestión).

- Sentar las bases para el desarrollo de actividades económicas compatibles con la naturaleza del área (turismo de naturaleza).

Los principales actores de las RC Airo Pai y Huimeki formaron parte activa en la elaboración del Plan Maestro del PN Güeppí-Sekime. En los talleres participativos para la elaboración de dicho plan, se realizaron mapas de uso de los recursos y se identificaron e incluyeron sectores de usos ancestrales con significado cultural, cementerios y lugares sagrados. Con esta información, en base a las especificaciones técnicas establecidas por el SERNANP y según lo establecido en la normativa de áreas protegidas, se establecieron dos tipos de zonas en el PN Güeppí-Sekime: zona silvestre y zona de uso especial. ${ }^{43}$

\section{Sernanp.gob.pe}

40. Artículo 110, Ley General del Ambiente, Ley 28611.

41. Las actividades que constan en el plan se financian con recursos de fondos fiscales (SERNANP, Ministerio del Ambiente y sus Direcciones Estratégica y de Ordenamiento Territorial y el Programa Nacional de Conservación de Bosques para la mitigación del Cambio Climático), como también con cooperación internacional como WWF Alemania.

42. Tomado del Plan Maestro del Parque Nacional Güeppí-Sekime 2014-2019

43. Fuente: Diagnóstico del Parque Nacional Güeppí-Sekime 2014-2019 
Zona silvestre

Constituye la mayor parte del parque $(99,99 \%)$

Son áreas con poca o nula intervención humana, donde se permiten actividades de poco impacto, como patrullajes turismo sin infraestructura e investigación científica. Se subdivide en tres, de acuerdo a las características

\section{Zona de uso especial (0,01\%)}

S1. Espacios contiguos a los ríos usados regularmente por personal militar para abastecimiento y mantenimiento de puestos de vigilancia de frontera e hitos fronterizos. Se cuenta con regulaciones especiales para el tráfico fluvial en los ríos principales y prohibición para acceder a quebradas o cochas.

S2. Es la margen izquierda del río Huiririma, la cual tiene tránsito esporádico de los miembros del pueblo secoya en los viajes que realizan entre las cuencas de los ríos Putumayo y Napo.

S3. Espacios donde no se permite ningún tipo de actividad antrópica, excepto patrullajes, investigación científica y turismo sin la construcción de infraestructura.

Zonas donde están ubicados los puestos de vigilancia de frontera e hitos fronterizos, con infraestructura permanente, lo cual implica la presencia de personal dentro del parque.
En Perú, en la zona de Güeppí, la presencia del Estado es limitada por lo complicado que es el acceso. Los poblados indígenas y de colonos mestizos ubicados en el área de amortiguamiento del parque, las reservas y las zonas de amortiguamiento son considerados por el Estado peruano como "de extrema pobreza" y por ello son beneficiaros del "Programa Juntos", un programa social del Estado que tiene como fin promover el desarrollo humano y las capacidades de los niños. El programa consiste en la entrega de un incentivo monetario bimestral (200 soles) a hogares catalogados en extrema pobreza en la zona rural. Las madres beneficiarias deben comprometerse a cumplir con requisitos relacionados a salud, nutrición, educación e identidad y a llevar a sus hijos menores de 5 años al control de peso y talla; las mujeres embarazadas deben ir a controles periódicos en los centros de salud y obtener un Seguro Integral de Salud. En lo relacionado a educación, las madres deben enviar a los menores en edad escolar a los centros educativos donde, además, reciben almuerzo escolar. Adicionalmente, los beneficiarios tienen la obligación de obtener su documento nacional de identidad.

El Estado peruano está construyendo en la localidad Cabo Pantoja44 un edificio que va a congregar a las principales instituciones públicas que brindan servicios a la población; una de esas oficinas se asignará al SERNANP, lo que le dará más presencia en la zona.

En el Parque Nacional Natural Güeppí-Sekime se conformaron, a la par de la declaratoria de esta zona como parque nacional, dos reservas comunales: Airo Pai y Huimeki, para dar reconocimiento y respuesta a las demandas de legalización de territorio de ocupación ancestral de nacionalidades indígenas siona, secoya, huitoto (murui) y de ocupación más reciente, como es el caso de las poblaciones mestizas.

\section{Programa Trinacional ${ }^{45}$}

El paisaje norte cuenta con el Programa Trinacional, un modelo de gestión regional de integración fronteriza amazónica a nivel gubernamental entre Ecuador, Perú y Colombia para promover el desarrollo de la región con lineamientos de conservación de la biodiversidad y desarrollo sostenible.

44. Cabo Pantoja es la capital del distrito Torres Causana, en la provincia de Maynas. Está ubicada en las orillas del río Napo en la desembocadura del río Aquarico, en la zona de amortiguamiento de la Reserva Airo Pai. Es un lugar considerado de extrema pobreza por el Estado peruano.

45 Usma JS. C Ortega P S Valenzuela J Deza \& J Rivas (Eds. 2016. Diversidad biológica y cultural del Corredor Trinaciona de áreas protegidas La Paya - Cuyabeno - Güeppí Sekime. Colombia - Ecuador - Perú. WWF. Bogotá D.C., Colombia. 333p.

\section{.}




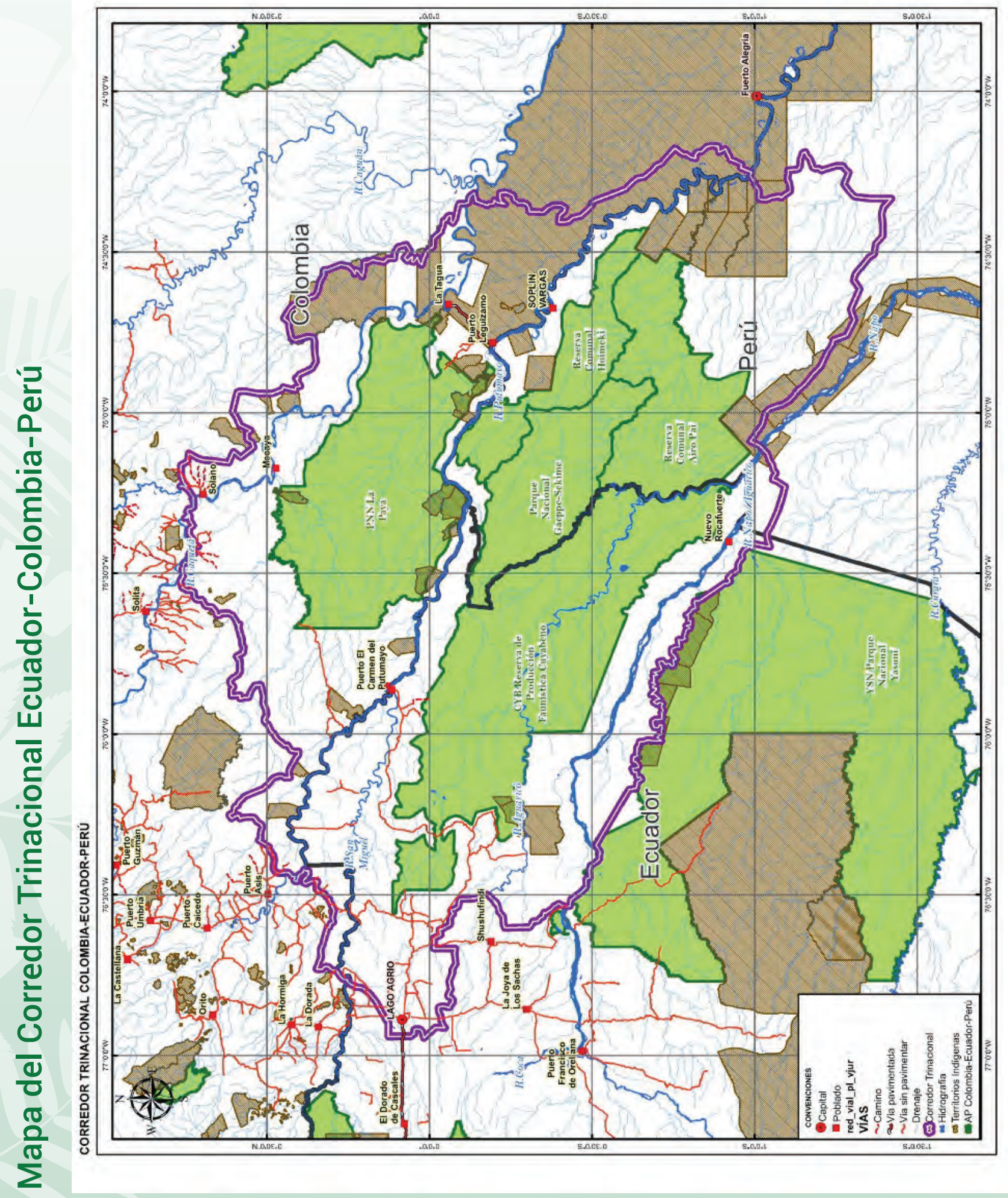




\section{Paisaje norte}

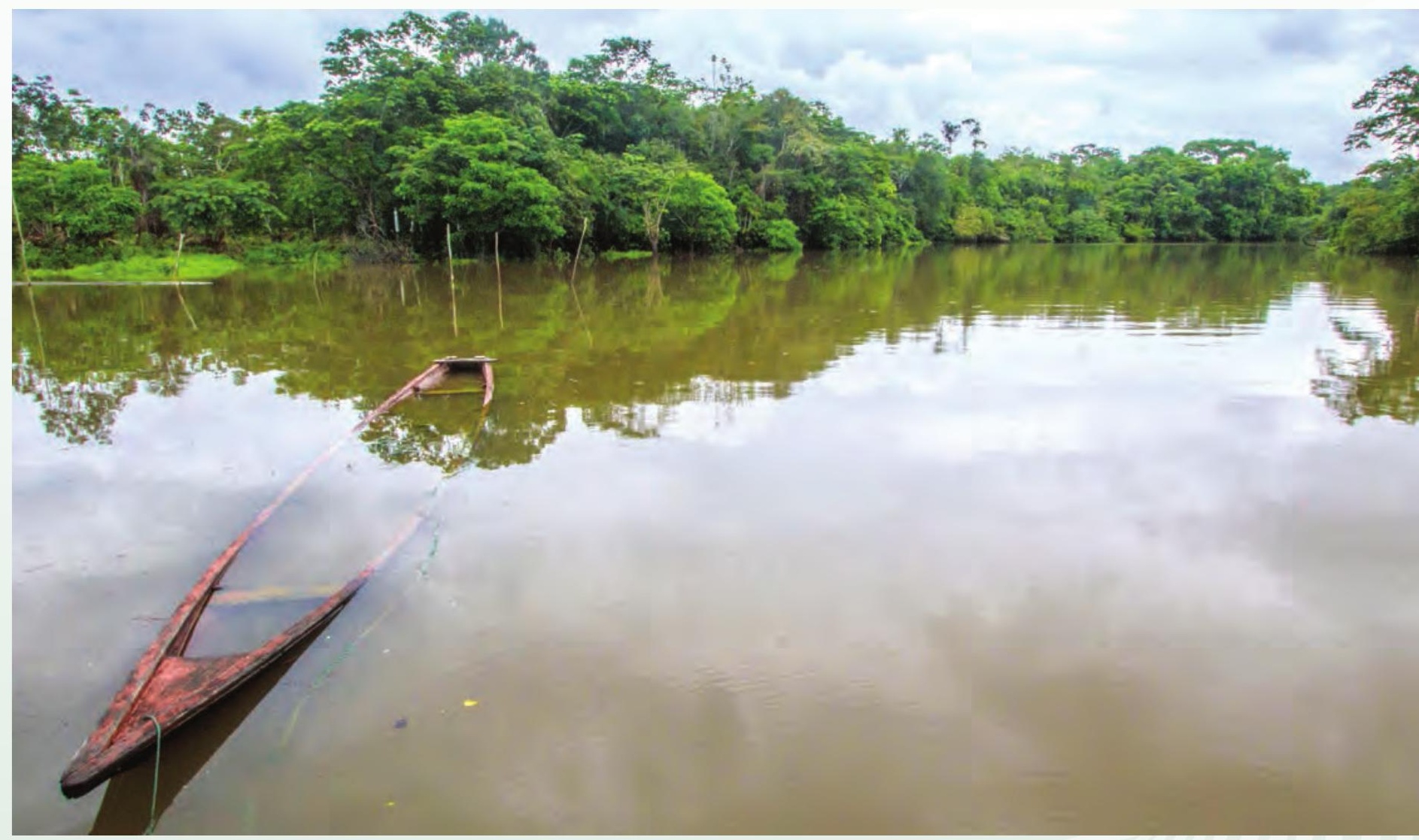

La propuesta del programa surgió de los administradores de las áreas protegidas de los tres países en el año 2005 tras hallar varios puntos de encuentro sobre su gestión. Su propuesta fue aunar las iniciativas técnicas y operativas y buscar los recursos para alcanzar mejores resultados, incidiendo en políticas públicas tanto a nivel local como regional.

El Programa Trinacional inició sus actividades en el año 2009, sin embargo, en 2011 se formalizó con la firma de un Memorando de Entendimiento entre los Ministerios de Ambiente, que involucra a su vez a las cancillerías de los Gobiernos de Ecuador, Perú y Colombia. Con la firma del memorando, los tres países ratificaron su compromiso para trabajar coordinadamente y reconocieron el Corredor Trinacional como una iniciativa de cooperación para la conservación en zonas de frontera.

Su estructura organizativa está conformada por: un comité coordinador, integrado por las autoridades nacionales de la administración de los sistemas de área protegida; un comité técnico, integrado por los tres jefes de las áreas protegidas y un funcionario de nivel nacional de cada una de las autoridades nacionales; y una secretaría técnica, integrada por las autoridades ambientales del país de turno, esta instancia rota cada dos años entre los tres países.

El Programa Trinacional tiene 4 líneas de acción:

- Gestión de las áreas protegidas y sus zonas de amortiguamiento

- Participación social

- Fortalecimiento del corredor de conservación

- Fortalecimiento de las capacidades institucionales

El Programa Trinacional implementó dos proyectos en el período 2009-2013:

- "Apoyo al Programa Trinacional"46, que fortaleció el modelo de gestión coordinada de las áreas protegidas. El apoyo incluyó un programa de aprendizaje para los actores del corredor en temas relacionados a normativas, manejo de recursos, solución de conflictos, ordenamiento

46. Proyecto financiado por OTCA/GIZ/CAN y OAPN de España 
territorial, desarrollo de proyectos, entre otros A su vez, contó con un Plan de Control y Monitoreo a través del cual se establecieron los lineamientos para el Corredor Trinacional.

- "Putumayo Tres Fronteras"47, que trabajó en el fortalecimiento de capacidades de las comunidades indígenas y campesinas y las autoridades locales, nacionales y regionales en gobernanza y en el manejo sostenible de los recursos naturales a través de:

- Acuerdos de integración y sistemas de coordinación técnicos para incrementar las áreas de conservación y una mayor efectividad de manejo y gobernanza sobre los ecosistemas amazónicos.

- Mejoras en alternativas económicas pesqueras y forestales y los mecanismos económicos para mejorar la calidad de vida y la sostenibilidad financiera de las áreas de conservación.

- Políticas públicas ambientales y sectoriales para valorar la biodiversidad, los derechos indígenas y los bienes y servicios ambientales.

Estos proyectos fortalecieron las capacidades operativas y técnicas de los actores de las áreas protegidas, logrando una mayor presencia institucional por parte de los administradores de las áreas, dentro de cada una y a nivel regional, donde ahora hay una relación de colaboración entre los actores.

Putumayo Tres Fronteras trabajó directa e indirectamente con poblaciones locales, incluyendo autoridades comunales y organizaciones regionales que se beneficiaron de una gestión participativa, más integrada y efectiva de las áreas protegidas colindantes $y$, sobre todo, que vieron fortalecida su capacidad para la gestión de los recursos naturales de su entorno, la gestión de sus comunidades y el liderazgo de procesos de integración con poblaciones de frontera vecinas.

Tomado de "Diversidad Biológica y Cultural del Corredor Trinacional de Áreas protegidas La Paya-Cuyabeno-Güeppí-Sekime", 2016. Pág.
Entre los logros del Programa Trinacional se destacan:

- La firma del memorando de entendimiento entre Ecuador, Colombia y Perú y la consolidación de la propuesta de plan estratégico.

- La categorización del nuevo Parque Nacional (PN) Güeppí-Sekime y dos reservas comunales, Airo Pai y Huimeki, que anteriormente conformaban la Zona Reservada Güeppí; y, el saneamiento físico-legal de territorios de comunidades nativas en dichas reservas, con lo que se solventaron los conflictos existentes en cuanto a tenencia de tierra de esos pueblos indígenas.

- Una mayor capacidad instalada para control y monitoreo con adecuación de infraestructura y equipamiento además del fortalecimiento institucional y relacionamiento con las comunidades.

- El desarrollo de iniciativas locales y de uso sostenible de recursos naturales. (Reservas Airo Pai y Huimeki y RPF Cuyabeno)

- El fortalecimiento de cadenas productivas y de la gestión turística (RPF Cuyabeno)

- Incremento de la gobernabilidad propia de comunidades locales y proceso del "Conversatorio de Acción Ciudadana (PNN La Paya)".

- Apoyo a la participación de comunidades indígenas en el Programa Socio Bosque (RPF cuyabeno)

También se destaca el compromiso con el Convenio de Diversidad Biológica (CDB) y su programa de trabajo en áreas protegidas, que busca un manejo eficiente de los sistemas de dichas áreas y el establecimiento de mecanismos de coordinación para conservar ecosistemas comunes.

Hoy existen acuerdos de manejo de recursos naturales con comunidades traslapadas, mayor participación comunitaria en las instancias de toma de decisión relacionadas con el manejo del territorio y su ordenamiento, iniciativas de monitoreo comunitario de la biodiversidad, desarrollo de iniciativas productivas amigables con el medioambiente, entre otros elementos de trabajo entre autoridades ambientales y comunidades locales.

47. Proyecto financiado por la Unión Europea y WWF Alemania 


\section{Paisaje sur}

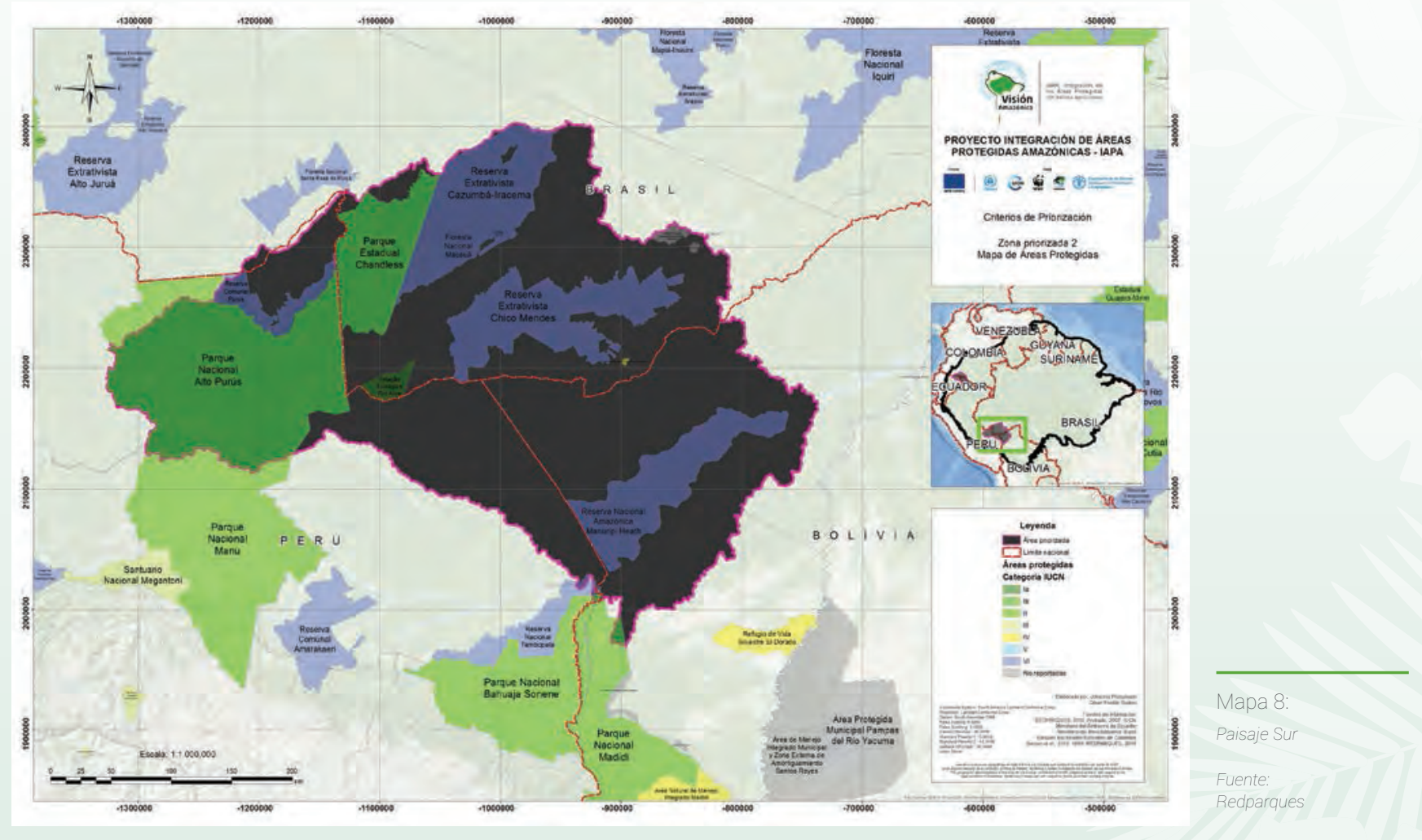

El paisaje sur está conformado por las áreas Chandless (Brasil), Reserva Extractivista Caprotegidas: Reserva Nacional de Vida Silvestre zumbá-Iracema (Brasil), Parque Nacional Alto Amazónica Manuripi (Bolivia), Parque Estadual Purús y Reserva Comunal Purús (Perú).
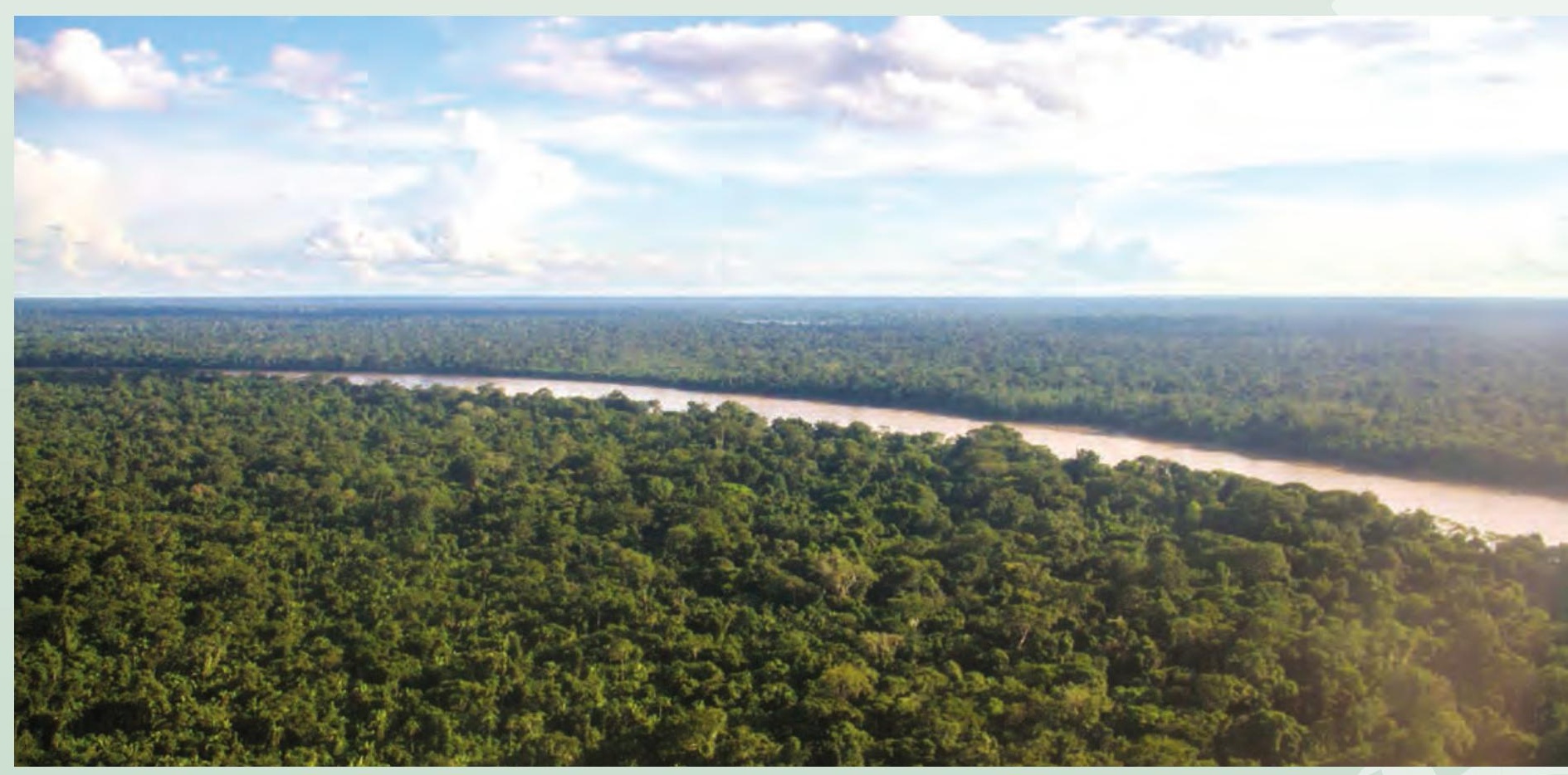


\begin{tabular}{|c|c|c|c|c|c|}
\hline $\begin{array}{l}\text { Nombre del } \\
\text { área } \\
\text { protegida }\end{array}$ & $\begin{array}{c}\text { Reserva Nacional } \\
\text { de Vida Silvestre } \\
\text { Amazónica } \\
\text { Manuripi }\end{array}$ & $\begin{array}{l}\text { Parque Estadual } \\
\text { Chandless }\end{array}$ & $\begin{array}{c}\text { Reserva } \\
\text { Extractivista } \\
\text { Cazumbá-Iracema }\end{array}$ & $\begin{array}{l}\text { Parque } \\
\text { Nacional Alto } \\
\text { Purús }\end{array}$ & $\begin{array}{l}\text { Reserva Comunal } \\
\text { Purús }\end{array}$ \\
\hline $\begin{array}{l}\text { Año de } \\
\text { constitución }\end{array}$ & 1973 & 2004 & 2002 & 2004 & 2004 \\
\hline Ubicación & $\begin{array}{l}\text { Al sudoeste del } \\
\text { departamento de } \\
\text { Pando } \\
\text { Municipios de } \\
\text { Filadelfia y Puerto } \\
\text { Rico1 }\end{array}$ & $\begin{array}{l}\text { Estado de Acre, en el } \\
\text { límite con Perú }\end{array}$ & $\begin{array}{l}\text { Estado de Acre } \\
\text { Municipio Sena } \\
\text { Madureira y } \\
\text { municipio de } \\
\text { Manoel Urbano }\end{array}$ & $\begin{array}{l}\text { Departamento } \\
\text { Ucayali y } \\
\text { departamento } \\
\text { Madre de Dios, } \\
\text { frontera con } \\
\text { Brasil }\end{array}$ & $\begin{array}{l}\text { Distrito de Iñapari, } \\
\text { provincia de } \\
\text { Tahuamanu, } \\
\text { departamento de } \\
\text { Madre de Dios y } \\
\text { distrito de Purús, } \\
\text { provincia de Purús, } \\
\text { departamento de } \\
\text { Ucayali }\end{array}$ \\
\hline $\begin{array}{l}\text { Extensión } \\
\text { total }\end{array}$ & 747000 ha & 695304 ha & 750794,70 ha & $\begin{array}{l}2510694,41 \\
\text { ha }\end{array}$ & 202033,21 ha \\
\hline $\begin{array}{l}\text { Extensión } \\
\text { del área } \\
\text { traslapada }\end{array}$ & & & $\begin{array}{l}\text { Más de la mitad } \\
\text { del área de la } \\
\text { reserva está } \\
\text { deshabitada }\end{array}$ & $\begin{array}{l}\text { No se cuenta } \\
\text { con registros } \\
\text { por las } \\
\text { características } \\
\text { particulares de } \\
\text { los pueblos que } \\
\text { la habitan }\end{array}$ & 26 comunidades \\
\hline Población & $\begin{array}{l}\text { Aproximadamente } \\
1700 \text { habitantes, } \\
374 \text { familias. } \\
230 \text { familias en las } \\
10 \text { comunidades } \\
\text { campesinas } \\
144 \text { familias en las } \\
37 \text { barracas }\end{array}$ & $\begin{array}{l}11 \text { familias colonas } \\
\text { mestizas (95 } \\
\text { habitantes aprox.) } \\
\\
\text { Por el lado sur, } \\
\text { se han registrado } \\
\text { la existencia de } \\
\text { etnias aisladas } \\
\text { no contactadas } \\
\text { (Mashco Piro) que } \\
\text { tienen su territorio } \\
\text { tradicional a lo } \\
\text { largo de la frontera } \\
\text { internacional } \\
\text { Brasil-Perú, en la } \\
\text { Tierra Indígena } \\
\text { Mamoadate }\end{array}$ & $\begin{array}{l}350 \text { familias } \\
\text { (aproximadamente } \\
1800 \text { personas) }\end{array}$ & $\begin{array}{l}\text { Entre } 200 \text { y } \\
600 \text { habitantes } \\
\text { de pueblos en } \\
\text { aislamiento } \\
\text { voluntario }\end{array}$ & $\begin{array}{l}\text { Aproximadamente, } \\
150 \text { familias no } \\
\text { indígenas viven en } \\
\text { Puerto } \\
\text { Esperanza } \\
\\
\text { Alrededor de } 80 \\
\text { familias indígenas } \\
\text { viven en Puerto } \\
\text { Esperanza }\end{array}$ \\
\hline
\end{tabular}




\begin{tabular}{|c|c|c|c|c|c|}
\hline $\begin{array}{l}\text { Nombre del } \\
\text { área } \\
\text { protegida }\end{array}$ & $\begin{array}{c}\text { Reserva Nacional } \\
\text { de Vida Silvestre } \\
\text { Amazónica } \\
\text { Manuripi }\end{array}$ & $\begin{array}{c}\text { Parque Estadual } \\
\text { Chandless }\end{array}$ & $\begin{array}{c}\text { Reserva } \\
\text { Extractivista } \\
\text { Cazumbá-Iracema }\end{array}$ & $\begin{array}{l}\text { Parque } \\
\text { Nacional Alto } \\
\text { Purús }\end{array}$ & $\begin{array}{l}\text { Reserva Comunal } \\
\text { Purús }\end{array}$ \\
\hline $\begin{array}{l}\text { Pueblos } \\
\text { indígenas }\end{array}$ & $\begin{array}{l}\text { Actualmente no } \\
\text { hay comunidades } \\
\text { indígenas } \\
\text { asentadas en el } \\
\text { área } \\
\text { Ancestralmente } \\
\text { Esse Ejja y } \\
\text { Pacahuara } \\
\text { Sin } \\
\text { autoidentificación. }\end{array}$ & $\begin{array}{l}\text { En el área de } \\
\text { amortiguamientno } \\
\text { del parque se } \\
\text { encuentran los } \\
\text { pueblos indígenas } \\
\text { madijá (o kulina), } \\
\text { kaxinawa (o juni- } \\
\text { kuin), machineri, } \\
\text { jaminawa }\end{array}$ & No aplica & $\begin{array}{l}\text { Pueblos } \\
\text { indígenas en } \\
\text { aislamiento. } \\
\text { 4 Reservas } \\
\text { Indígenas } \\
\text { Territoriales } \\
\text { (RT) para } \\
\text { Poblaciones } \\
\text { de Indígenas } \\
\text { en Aislamiento } \\
\text { Voluntario } \\
\text { (PIAV) y } \\
\text { Poblaciones de } \\
\text { Indígenas en } \\
\text { Aislamiento y } \\
\text { Contacto Inicial } \\
\text { (PIACI) }\end{array}$ & $\begin{array}{l}\text { Pueblos indígenas } \\
\text { (solamente } \\
\text { en zona de } \\
\text { amortiguamiento) } \\
\text { amahuaca, juni- } \\
\text { kuin, sharanahua, } \\
\text { mastanahua, } \\
\text { madijá, chaninahua, } \\
\text { asháninka y yine } \\
\text { PIAV y PIACI sin } \\
\text { verificar } \\
\text { Pequeño traslape } \\
\text { con RT Mashco Piro }\end{array}$ \\
\hline $\begin{array}{l}\text { Categoría de } \\
\text { manejo UICN }\end{array}$ & $\begin{array}{l}\text { Categoría VI: Áreas } \\
\text { protegidas con } \\
\text { uso sostenible de } \\
\text { recursos naturales } \\
\text { Combina } \\
\text { desarrollo con } \\
\text { conservación. } \\
\text { Permite el } \\
\text { aprovechamiento } \\
\text { de recursos no } \\
\text { maderables } \\
\text { (castaña, goma, } \\
\text { cacao, asaí, entre } \\
\text { otros) y limita } \\
\text { las actividades } \\
\text { agrícolas y } \\
\text { ganaderas }\end{array}$ & $\begin{array}{l}\text { Categoría II: Parque } \\
\text { Nacional (Sin } \\
\text { embargo, la gestión } \\
\text { de este parque es } \\
\text { estadual) }\end{array}$ & $\begin{array}{l}\text { Categoría VI: Áreas } \\
\text { protegidas con } \\
\text { uso sostenible de } \\
\text { recursos naturales }\end{array}$ & $\begin{array}{l}\text { Categoría } \\
\text { Il: Parque } \\
\text { Nacional, zona } \\
\text { de protección } \\
\text { estricta }\end{array}$ & $\begin{array}{l}\text { Categoría VI: Áreas } \\
\text { protegidas con } \\
\text { uso sostenible } \\
\text { de recursos (No } \\
\text { reportado en } \\
\text { Protected Planet) }\end{array}$ \\
\hline $\begin{array}{l}\text { Tipología de } \\
\text { gobernanza }\end{array}$ & $\begin{array}{l}\text { Gobernanza } \\
\text { compartida, } \\
\text { comanejo con } \\
\text { restricciones de } \\
\text { uso y disposición } \\
\text { de tierras }\end{array}$ & $\begin{array}{l}\text { Gobernanza por } \\
\text { parte del gobierno } \\
\text { y gobernanza } \\
\text { compartida con las } \\
\text { familias que viven en } \\
\text { el Parque }\end{array}$ & $\begin{array}{l}\text { Gobernanza por } \\
\text { parte del gobierno } \\
\text { y gobernanza } \\
\text { compartida con las } \\
\text { familias que viven } \\
\text { en la reserva }\end{array}$ & $\begin{array}{l}\text { Gobernanza } \\
\text { por parte del } \\
\text { gobierno y } \\
\text { gobernanza } \\
\text { por parte } \\
\text { de pueblos } \\
\text { indígenas }\end{array}$ & $\begin{array}{l}\text { Coadministración } \\
\text { entre el Estado } \\
\text { (SERNANP) y } \\
\text { ECOPURÚS, } \\
\text { ejecutor del } \\
\text { Contrato de } \\
\text { Administración de } \\
\text { la Reserva } \\
\text { Gobernanza } \\
\text { privada: } \\
\text { MABOSINFRON }\end{array}$ \\
\hline
\end{tabular}

La población del paisaje está compuesta por pueblos indígenas y migrantes campesinos que llegaron a la zona en busca de oportunidades, por lo que el paisaje es una mezcla de cultura amazónica con cultura rural campesina. En Perú, dentro del PN Alto Purús existen Po- blaciones de Indígenas en Aislamiento y Contacto Inicial (PIACI) y Poblaciones de Indígenas en Aislamiento Voluntario (PIAV). Dentro del parque se encuentra la Reserva Territorial Mashco Piro. En la Reserva Comunal Purús, zona de amortiguamiento del PN Alto Purús, 
habitan las etnias: juni-kuin, sharanahua, mastanahua, ashaninka, madijá, chaninahua, yine y algunas en contacto inicial, como los amahuacas, chitonahuas y "curanjeños".

En las zonas de amortiguamiento del PE Chandless hay territorios indígenas de los pueblos madijá (o kulina), kaxinawa (o juni-kuin), jaminawa y manchineri. En Brasil, dentro del parque, existen poblaciones (probablemente mascho piro) que están en proceso de cualificación; se realizó un primer registro de sus moradas temporales, en octubre de 2016, por un equipo compuesto por técnicos de la FUNAI Y SEMA.

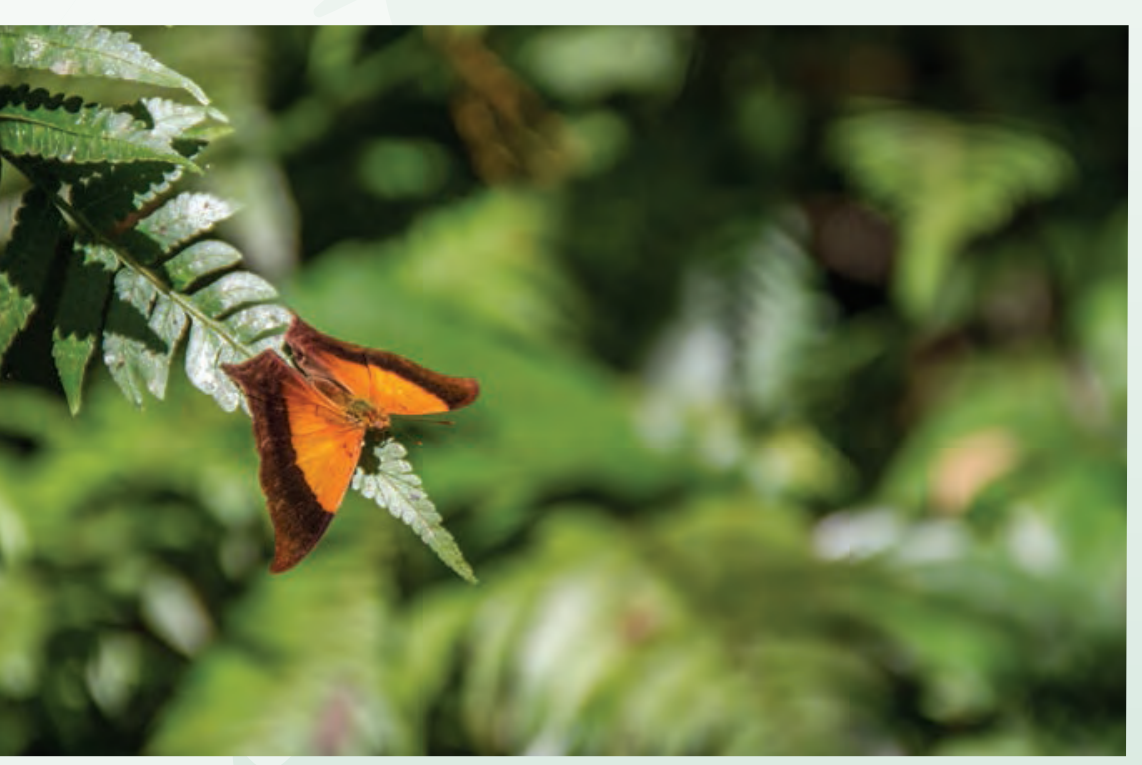

Dentro de la Reserva Extractivista CazumbáIracema, la mayor parte de la población son mestizos seringueiros.

En el AP Manuripi la población ancestral indígena fue severamente disminuida durante el auge cauchero. Según estudios de la zona (Dinah, 2012), existen pobladores de las culturas indígenas Esse Ejja, Tacana y Cavineño, aunque no se encuentran territorios exclusivamente indígenas en este AP ni en sus inmediaciones y es poca la población que se autoidentifica como indígena, siendo el mayor número de la población mestizos.

Las poblaciones de estas áreas viven de los recursos del bosque y sus actividades de autosustento están relacionadas a la pesca, caza, el cultivo de chacras y la recolección de frutos del bosque. La caza y la pesca están a cargo de los hombres y el cuidado de la chacra (roçado, en portugués) a cargo de las mujeres. La tala de madera está permitida para uso familiar y no para fines comerciales. La ganadería se encuentra como una actividad a menor escala.

Las chacras en la mayoría de áreas protegidas de este paisaje, a excepción de la Reserva Manuripi, se realizan en las tierras ribereñas e inundables, también llamados bajiales. Estas tierras son muy fértiles debido al arrastre de materia orgánica abundante como hojas, ramas, tallos, raíces, semillas y frutos que llegan con cada inundación. Así, los bajiales tienen un gran potencial para cultivos y son las tierras más productivas en la Amazonía con depósitos de sal y nutrientes. Las aves, entre ellas, guacamayos, buitre rey, loros rojos, verdes y azules y otras especies endémicas, encuentran su alimento ahí. En general, las chacras contienen una gran diversidad de productos, lo que asegura una buena fuente de alimentación a la fauna y la población local.

A nivel de paisaje se destacan actividades económicas relacionadas a la recolección de la almendra de castaña (Bertholletia excelsa), la recolección del fruto de asaí (Euterpe oleracea), el rescate de la goma o siringa (Hevea Brasiliensis) y la comercialización de semilla de caoba, ya sea por su significado cultural y/o social o por ser una importante fuente de ingresos económicos.

En la Reserva Manuripi y la zona del Alto Purús, algunos indígenas y campesinos emplean su mano de obra en trabajos temporales dentro del área protegida o en las urbes cercanas. En la actualidad, las grandes obras de infraestructura (como el puente sobre el río Madre de Dios, otro sobre el río Manuripi y la prospección petrolera en los límites con el departamento de La Paz) están empleando mano de obra de las comunidades de la Reserva Manuripi. En la época seca, algunas personas de la comunidad de Chivé (la más grande de la Reserva Manuripi) participan de la actividad aurífera aluvial en el río Madre de Dios. En Chivé se comercializan artículos de primera necesidad, principalmente con productos traídos de Brasil y Perú. A nivel de paisaje la comercialización se realiza principalmente por vía fluvial.

El PE Chandless no cuenta con recursos como el caucho y la castaña, por lo que sus moradores obtienen ingresos económicos con la 


\section{Paisaje sur}

venta de los excedentes de sus chacras. Los recursos que obtienen los emplean para comprar combustible, azúcar, sal, aceite y café en Manoel Urbano, que es la localidad más cercana y está ubicada a ocho horas por río. Los habitantes trabajan con la asesoría de la Secretaría de Producción del Estado de Acre para el desarrollo de proyectos productivos.

En la RESEX Cazumbá-Iracema, la principal fuente de ingresos de la población es la farinha de yuca y en las comunidades tienen "casas de farinha" para su elaboración. La comercializan en Sena Madureira y Rio Branco.

Los marcos jurídicos y la atención por parte del Estado en las áreas protegidas del paisaje sur difieren de un país a otro: las poblaciones de Bolivia y Perú tienen servicios básicos limitados al igual que la atención en salud y educación.

El Estado de Acre, denominado el Governo da Floresta y donde se encuentran ubicados el PE Chandless y la RESEX Cazumbá-Iracema, cuenta con una estrategia de desarrollo sostenible que influye en sus políticas públicas ambientales. En 2001 fue el primer estado de la Amazonía de Brasil en tener una ley forestal efectiva, que estableció directrices para el uso sostenible de sus bosques. ${ }^{48}$ Entre otras cosas, el Estado tiene un Sistema de Incentivos a Servicios Ambientales (SISA) para valorar los servicios ambientales prestados por campesinos, indígenas, habitantes de las riberas de los ríos (ribeirinhos) y poblaciones tradicionales, quienes promueven acciones legítimas de preservación, conservación, recuperación y uso sostenible de los recursos naturales. La herramienta denominada Zonificación Ecológicoeconómica del Estado de Acre (ZEE-AC) entrega subsidios para actividades relacionadas a la planificación del uso y ocupación del territorio, tomando en cuenta aspectos culturales, políticos, ecológicos y socioeconómicos. Esto ha dado como resultado, desde el año 2000, un aumento considerable de tierras destinadas a unidades de conservación de protección integral y uso sostenible. ${ }^{49}$ La ZEE-AC (desde 2006) apoya procesos de Ordenamiento Territorial Local (OTL); a las comunidades rurales con el desarrollo de Planes de Desarrollo Comunitarios (PDC); y a las comunidades indígenas con Planes de Gestión Territorial y Ambiental en Tierras Indígenas (PGTI). Todo esto en base a una metodología participativa que

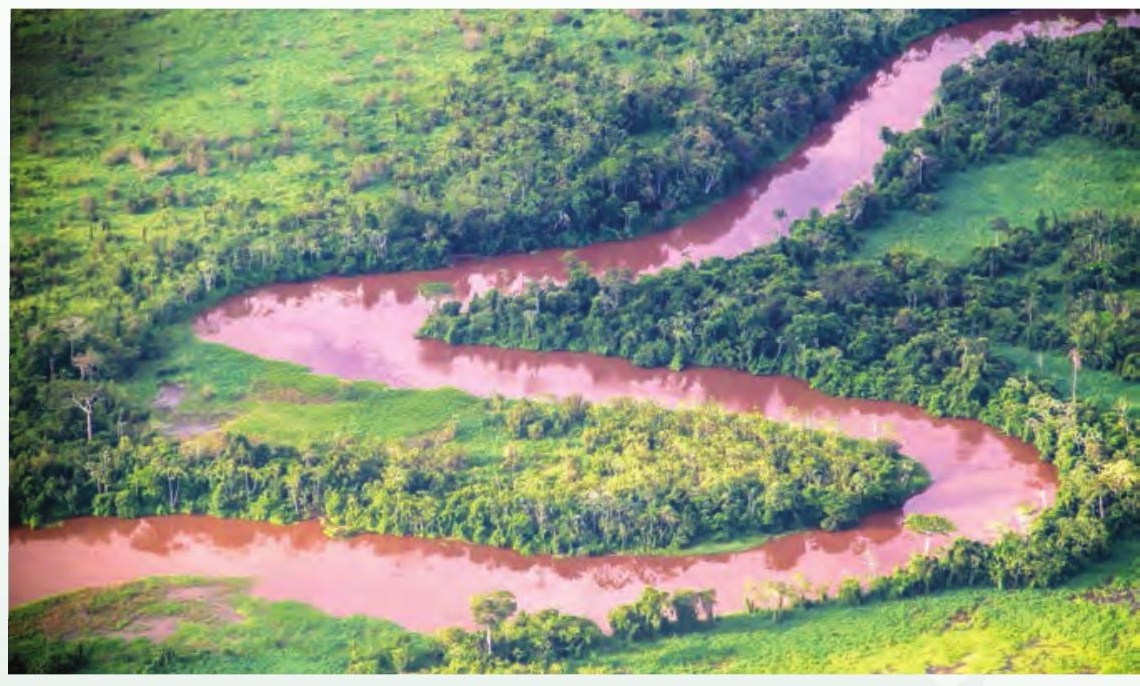

respeta las particularidades de cada región. ${ }^{5}$

Ambas áreas protegidas se ven beneficiadas de las iniciativas estatales.

En Manuripi, las comunidades que dan a la vía (pertenecientes al municipio de Filadelfia) están mejor atendidas que las comunidades a las cuales solo se puede acceder por vía fluvial (pertenecientes al municipio de Puerto Rico). El desayuno escolar y el subsidio de lactancia forman parte de las políticas nacionales de seguridad alimentaria de Bolivia.

El nivel de educación es similar en las áreas protegidas. La mayoría de comunidades tienen enseñanza primaria con modalidad de escuelas unidocentes. Para continuar con la educación secundaria los jóvenes salen a las ciudades más cercanas, que generalmente están alejadas de sus comunidades, motivo por el cual van a vivir fuera y regresan a la comunidad los fines de semana (en el mejor de los casos) o en vacaciones. Una vez terminados los estudios, los jóvenes tienen la opción de quedarse en la ciudad trabajando. Existe un gran interés por parte de los padres en garantizar a sus hijos una buena educación. En el paisaje se destaca la iniciativa de las comunidades en la Reserva Manuripi con la conformación de una junta escolar para mejorar el sistema educativo.

48. Según información del Gobierno estadual, el $83 \%$ del territorio de Acre es bosque sin deforestar.

49. En un $120 \%$ (de 2642672 a 5826232 ha), lo que corresponde al $43,7 \%$ del territorio, mientras que las tierras indígenas ocupan un $14,55 \%$.

50. Fuente: www.ac.gov.br 
En Brasil, el sistema de educación tiene tres niveles. La educación de $1^{\circ}$ a $5^{\circ}$ año es municipal, de $6^{\circ}$ a $9^{\circ}$ año es estatal y de ahí en adelante es federal (nacional). De acuerdo a los informantes, el problema radica en que los municipios no tienen recursos suficientes por lo que la educación básica no es lo bastante buena como para tener bases sólidas y poder cumplir con las exigencias académicas en los años siguientes.

En el Parque Estadual Chandless hay una escuela en la sede, donde viven la mayoría de familias. La escuela está a cargo del Municipio de Manoel Urbano y cuenta con un profesor permanente que vive en el parque. Para la educación secundaria, los jóvenes salen de la comunidad hacia Manoel Urbano y para los estudios superiores van a Sena Madureira o Rio Branco.

En la RESEX Cazumbá-Iracema los habitantes de Núcleo do Cazumbá tienen una escuela que cubre la educación primaria y media. Consideran que es necesario que la escuela cuente con un currículo propio relacionado al contexto y al hábitat en el que viven y que garantice una educación acorde a su realidad con opciones laborales para los jóvenes dentro de la reserva. Para ello, están trabajando en una propuesta para presentarla a las autoridades correspondientes.

Las escuelas en las comunidades de la Reserva Comunal Purús tienen problemas de presupuesto y hay bastante deserción escolar. Algunas escuelas tienen el sistema de Educación Bilingüe Intercultural (EBI), pero los docentes

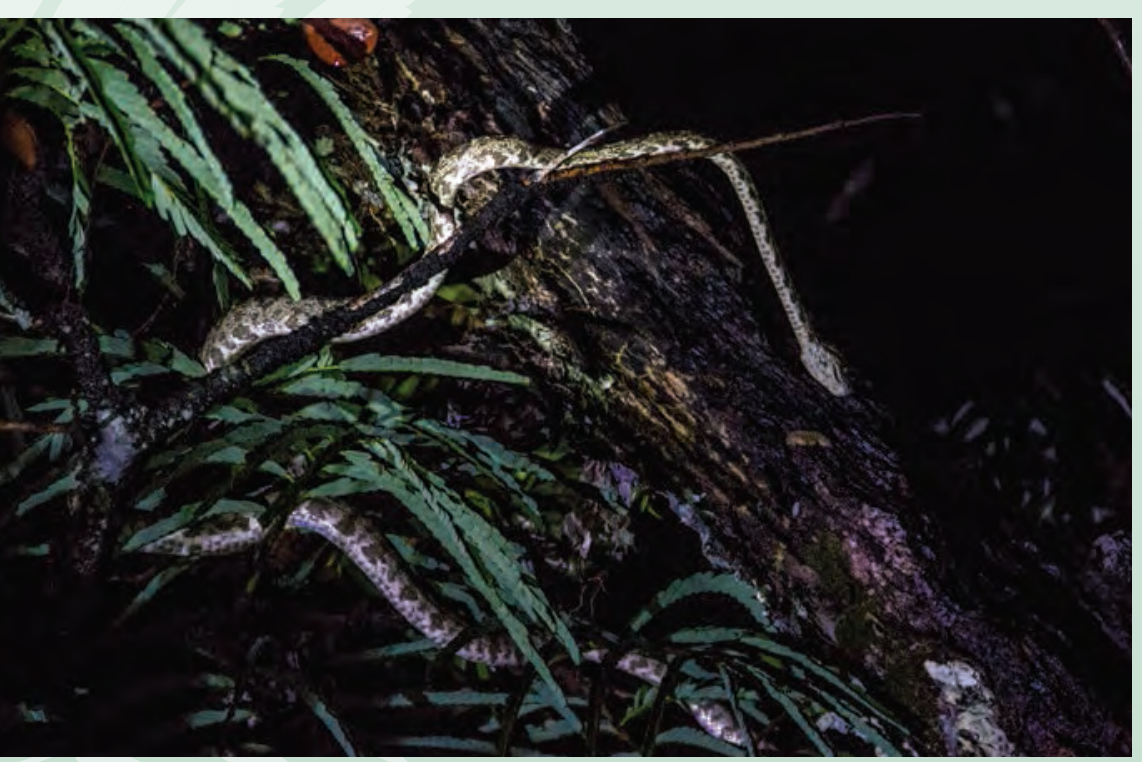

no son indígenas y no hablan el idioma local por lo que difícilmente se aplica la modalidad. La mayoría de los profesores viven en Puerto Esperanza por lo que las clases son irregulares. La educación secundaria es limitada.

En cuanto a la salud, a nivel de paisaje, las familias curan las enfermedades sencillas con plantas medicinales que tienen en sus chacras; cuando se trata de un problema grave salen al poblado más cercano. En general, a nivel de paisaje, la atención y prestación de servicio por parte de los Estados es insuficiente.

En la Reserva Manuripi las postas de salud son responsabilidad de los municipios ${ }^{51}$ y desde hace dos años las comunidades Chivé y Luz de América cuentan con este servicio. Los recursos disponibles son escasos, no cuentan con suficiente personal médico ni con medicinas básicas de botiquín ni de primeros auxilios. Periódicamente el Gobierno central envía brigadas de salud a las escuelas para chequeos dentales, desparasitación y vacunas para los niños

Lo mismo pasa en el PE Chandless, donde una vez al año llegan brigadas médicas de la Secretaria de Desarrollo para hacer un control de salud a las familias. De acuerdo a la conversación mantenida con Antonia Márquez de Souza, moradora del parque, los problemas de salud aparecen cuando salen a las ciudades y se contagian de enfermedades o consumen alimentos diferentes a los que están acostumbrados.

A la RESEX Cazumbá-Iracema Ilegan brigadas médicas, municipales y federales, una o dos veces al año. El puesto de salud en Núcleo do Cazumbá (el cual fue un logro gracias la organización de la población en 2004) ahora no funciona por falta de personal especializado. Ha habido algunas iniciativas esporádicas para el rescate de medicinas tradicionales, pero ninguna se mantiene. Un ejemplo de esto es el proyecto de plantas medicinales que en 2009 la RESEX Cazumbá-Iracema implemen-

51. De acuerdo a la Ley de Participación Popular, los municipios son los responsables de la salud en lo que se refiere a construcción, equipamiento y mantenimiento de la infraestructura de salud. En el caso de la Reserva Manuripi, esta responsabilidad recae en los Gobiernos municipales de Puerto Rico y Filadelfia. La Prefectura, a través del Servicio Departamental de Salud, provee el personal de salud e insumos. 


\section{Paisaje sur}

tó para tener una farmacia viva al alcance de los habitantes de la reserva. ${ }^{52}$

La Reserva Comunal Purús cuenta con un centro de salud, perteneciente al Ministerio de Salud, ubicado en la localidad de Puerto Esperanza y un hospital del Proyecto Integral de Salud Amazonía (PISAP), ubicado en Curanja y administrado por la Misión Católica. Algunas comunidades tienen puestos sanitarios y otras URO (unidades de rehidratación oral ${ }^{53}$ ), que generalmente no cuentan con medicinas ni implementos básicos. Los conocimientos tradicionales de los indígenas sobre las plantas medicinales son cada vez menos utilizados. Las enfermedades más recurrentes son las de la piel y parásitos. El alcoholismo es un problema latente y preocupante en la zona. ${ }^{54}$

En cuanto a las amenazas, en el paisaje sur hay actividad minera de oro, deforestación impulsada por la expansión de la frontera agrícola y venta de madera, ganadería y construcción de grandes proyectos como represas hidroeléctricas y carreteras.

Una de estas amenazas es la construcción de la carretera interoceánica, de común acuerdo entre los presidentes de los tres países que conforman el paisaje. Esta se terminó de construir en 2013, con más de 3000 km de recorrido desde Puerto Santos en Brasil hasta los puertos de Arica e Iquique en Chile. Incluye dos puentes en la frontera entre Brasil y Perú, uno sobre el río Acre y otro sobre el río Madre de Dios. De acuerdo a fuentes secundarias, esta carretera se encuentra en mal estado y ha generado un impacto ambiental y social negativo, ya que aumentó la deforestación, la frontera agrícola, las actividades ilegales como la tala ${ }^{55}$ y minería $y$, con ello, ha habido un aumento de poblaciones fluctuantes que migran hacia la zona en busca de oportunidades y trabajo. En esta zona no hay servicios básicos de luz y agua y los servicios de educación y salud son muy limitados. La carretera también ha facilitado la apertura de otras vías en la selva y la realización de otras actividades ilegales como el tráfico de drogas y el tráfico de personas ${ }^{56}$. Otra es la carretera Iñapari-Puerto Esperanza, la cual atravesaría dos millones de hectáreas de áreas protegidas, afectando, por el lado peruano, la biodiversidad del Parque Nacional Alto Purús, la Reserva Comunal Purús, el Parque Nacional Manu, la Reserva Comunal Amarakaeri y varias comunidades nativas como los mashco piro y las poblaciones indígenas aisladas que habitan la región. En Brasil, el Parque Estadual Chandless también se vería afectado (el trazado de la carretera está a 6 km de distancia del límite del parque), así como la Estación Ecológica Rio Acre y la Reserva Territorial Mamoadate. Este proyecto tiene mucha oposición de la población y las autoridades locales, porque consideran que facilitaría el tráfico ilegal de madera (caoba y cedro) y droga hacia Brasil y Bolivia ${ }^{5}$

Se menciona como un tema recurrente la contaminación de los ríos con mercurio como resultado de la minería de oro, principalmente en las comunidades de Manuripi y Purús, ubicadas en la ribera del río Madre de Dios. Esta información está respaldada por el informe realizado por el Ministerio del Ambiente de Perú y el Instituto de la Amazonía Peruana (2011), donde se hacen evidentes los niveles de contaminación del agua, los sedimentos en los ríos, los peces y las personas generados por la actividad minera, así como los impactos ambientales, sociales y económicos ${ }^{58}$.

Respecto a la variación del clima en el paisaje, durante la última década se han registrado inundaciones considerables en las ciudades ubicadas en la zona de frontera entre los tres países. Un ejemplo de ello es la inundación en febrero de 2015 del puente en Iñapari entre Perú y Brasil, Cobija (Bolivia) y Brasileia, Xapurí y Rio Branco (Brasil); ciudades que quedaron cubiertas de agua por el aumento del nivel del agua en el río Acre.

52. Proyecto ejecutado por la Empresa Brasileira de Pesquisa Agropecuária (EMBRAPA), alianza entre Brasil y el Gobierno de Italia

53. La URO es el lugar de la comunidad donde se atienden los casos de diarrea y se enseña a las madres a prevenir la diarrea y el cólera. Funciona en lugares comunales o en las casas de promotores de salud o líderes comunitarios.

54. Tomado del Plan de Desarrollo Integral de los Pueblos Indígenas del Alto Purús 2004-2009, desarrollado por FECONAPU.

55. Según fuentes secundarias, parte de la madera que se trafica en Perú proviene del lado boliviano, lo que genera muchos problemas entre ambos países

56. Fuente: Artículo "Buena vía, mala vida" http://www.connectas. org/amazonas/es/vias3.html

57. Fuente: elcomercio.pe, "Autoridades y nativos se oponen a la carretera Iñapari-Purús", julio, 2012

58. Fuente: "Minería aurífera en Madre de Dios y contaminación con mercurio". Informe elaborado por el Ministerio del Ambiente de Perú y el Instituto de la Amazonía Peruana en 2011. 
Reserva Nacional de Vida Silvestre Amazónica Manuripi (RNVSA Manuripi)
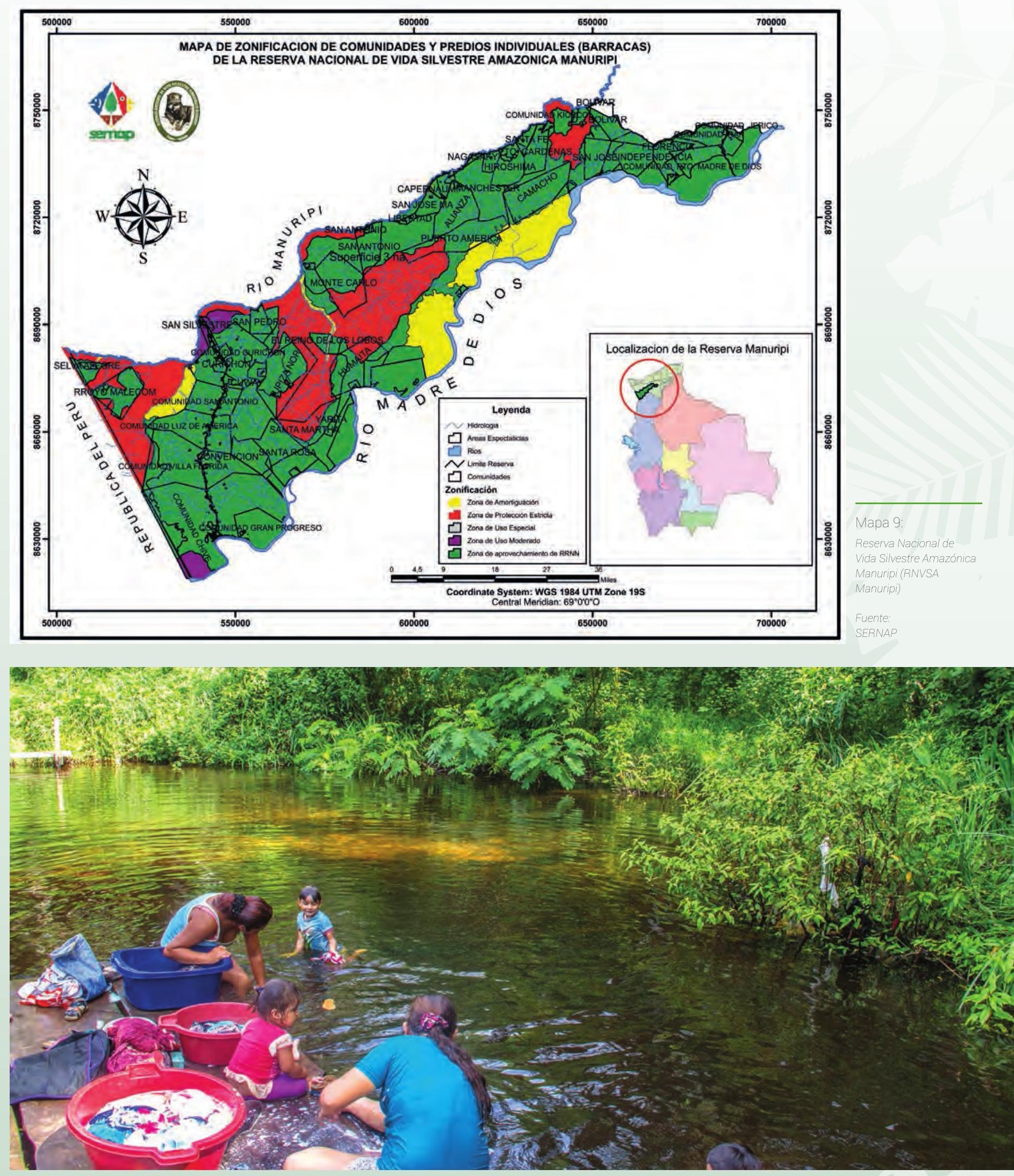


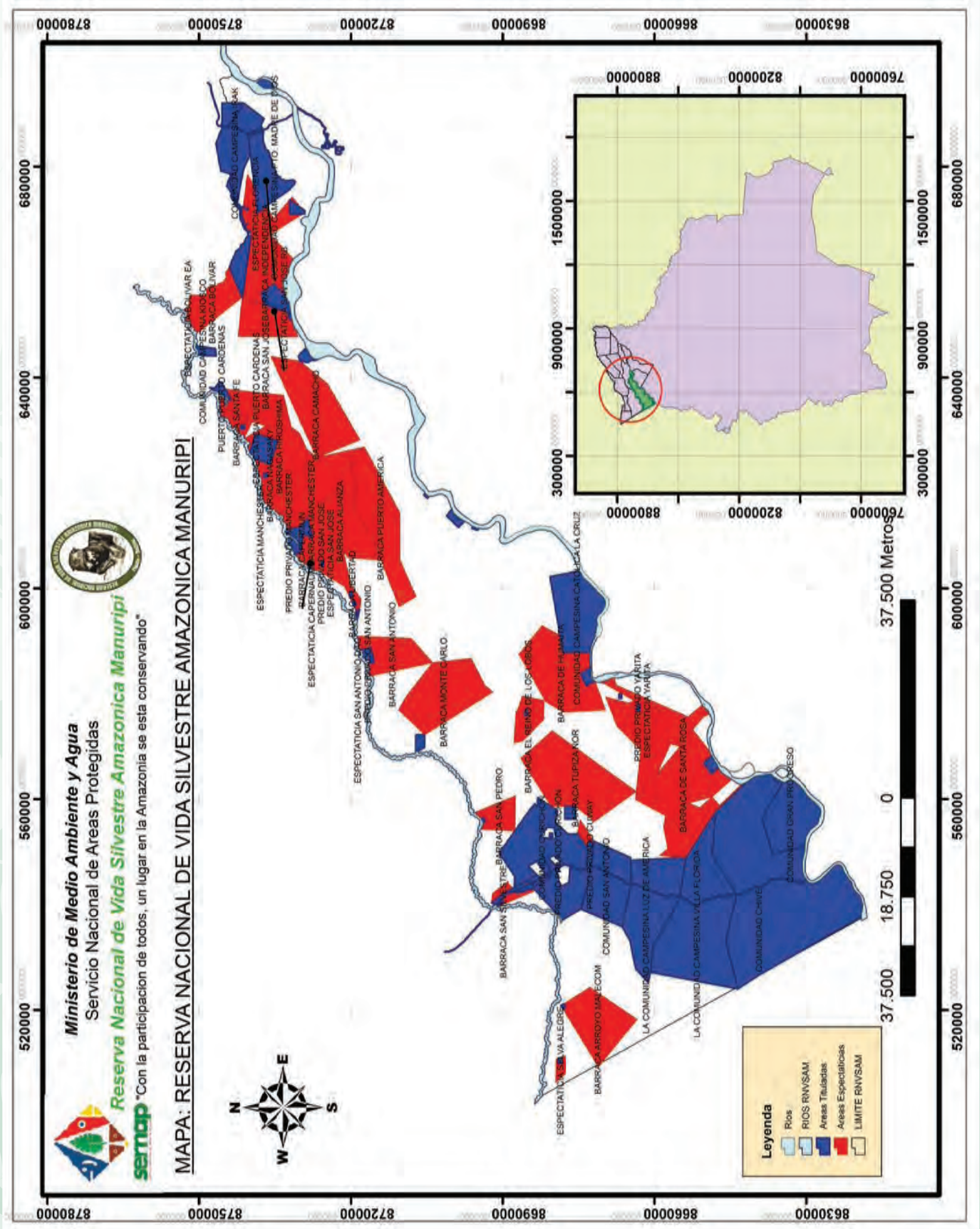




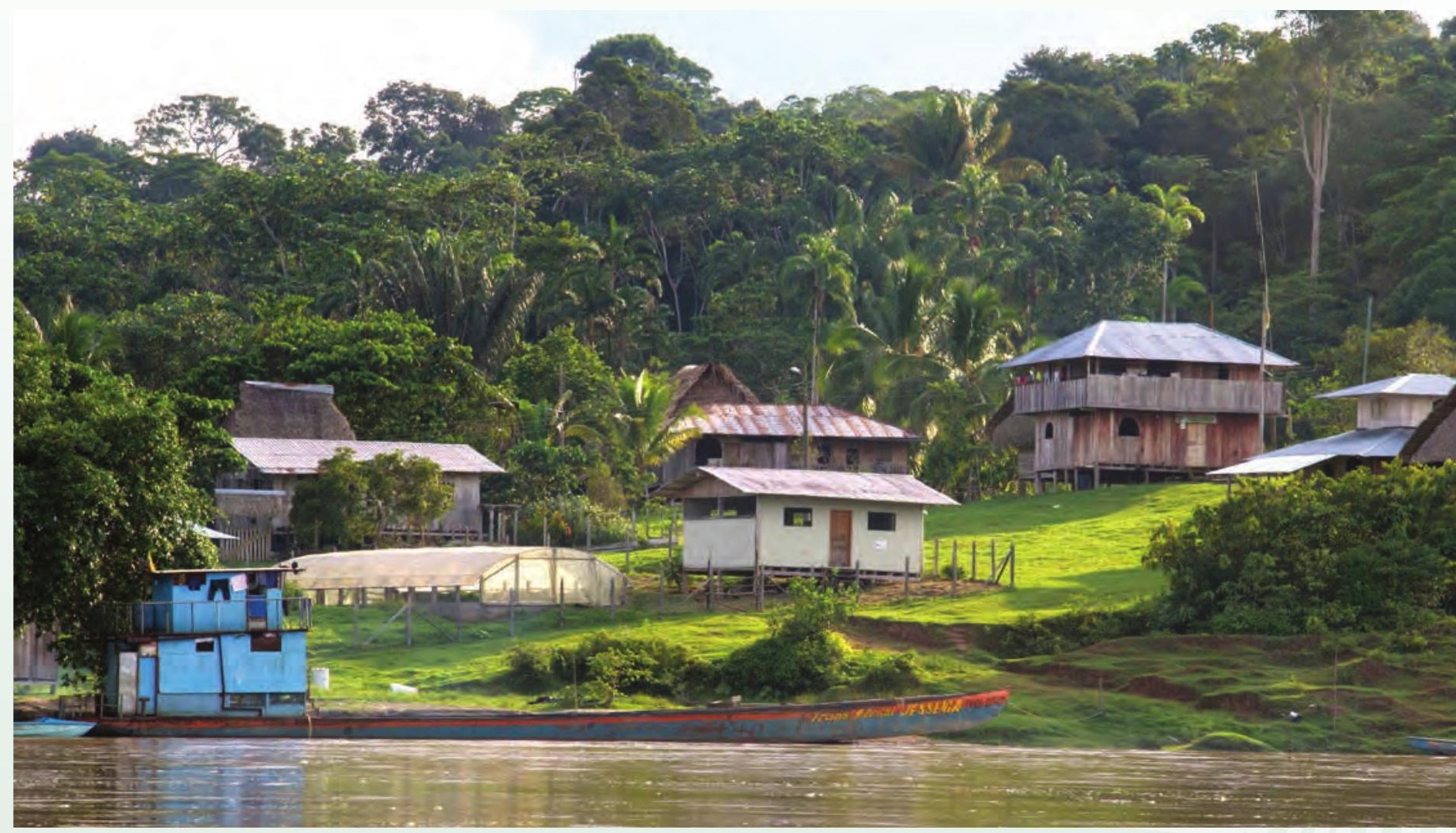

En Bolivia, el Servicio Nacional de Áreas Protegidas (SERNAP) coordina el funcionamiento del Sistema Nacional de Áreas Protegidas (SNAP) garantizando la gestión integral y la conservación de la diversidad biológica de estas áreas.

Las facultades del SERNAP son ${ }^{59}$

- Planificar, administrar y fiscalizar el manejo integral de las áreas protegidas

- Normar y regular actividades en el interior de las áreas protegidas, fiscalizarlas de acuerdo a su categoría, plan de manejo, zonificación y reglamentación específica.

- Promocionar la protección y conservación de los recursos naturales de las áreas protegidas.

- Establecer mecanismos de coordinación intersectorial para el tratamiento de la gestión integral de las áreas protegidas.

- Establecer procesos participativos para garantizar los objetivos de conservación y uso sostenible de la biodiversidad en las áreas protegidas.
- Ejercer las demás atribuciones que permitan el cumplimiento eficiente de su misión institucional.

- Financiar sus operaciones con recursos propios por prestación de servicios y otros, de conformidad a la reglamentación específica.

EI SERNAP, en su marco normativo institucional, cuenta con una política de gestión compartida entre el Estado y los campesinos. Cada comunidad campesina cuenta con un Plan de Gestión Integral de Bosques y Tierras, elaborado en base a normativas estatales. EI SERNAP, a través de la Dirección de la Reserva, tiene atribuciones de gestión del área protegida.

La Reserva Manuripi está conformada por dos tipos de asentamientos: comunidades campesinas y barracas. Tras la caída del precio de la goma (en la primera década del siglo XIX), los caucheros abandonaron las tierras, algunas de las cuales quedaron a cargo de los administradores. Otras pasaron a manos de los trabajadores, quienes, a su vez, conformaron comunidades campesinas.

59. Decreto Supremo No. 25158 de 4 de septiembre de 1998 y de D.S. No. 24781 de 31 de julio de 1997. 


\section{Paisaje sur}

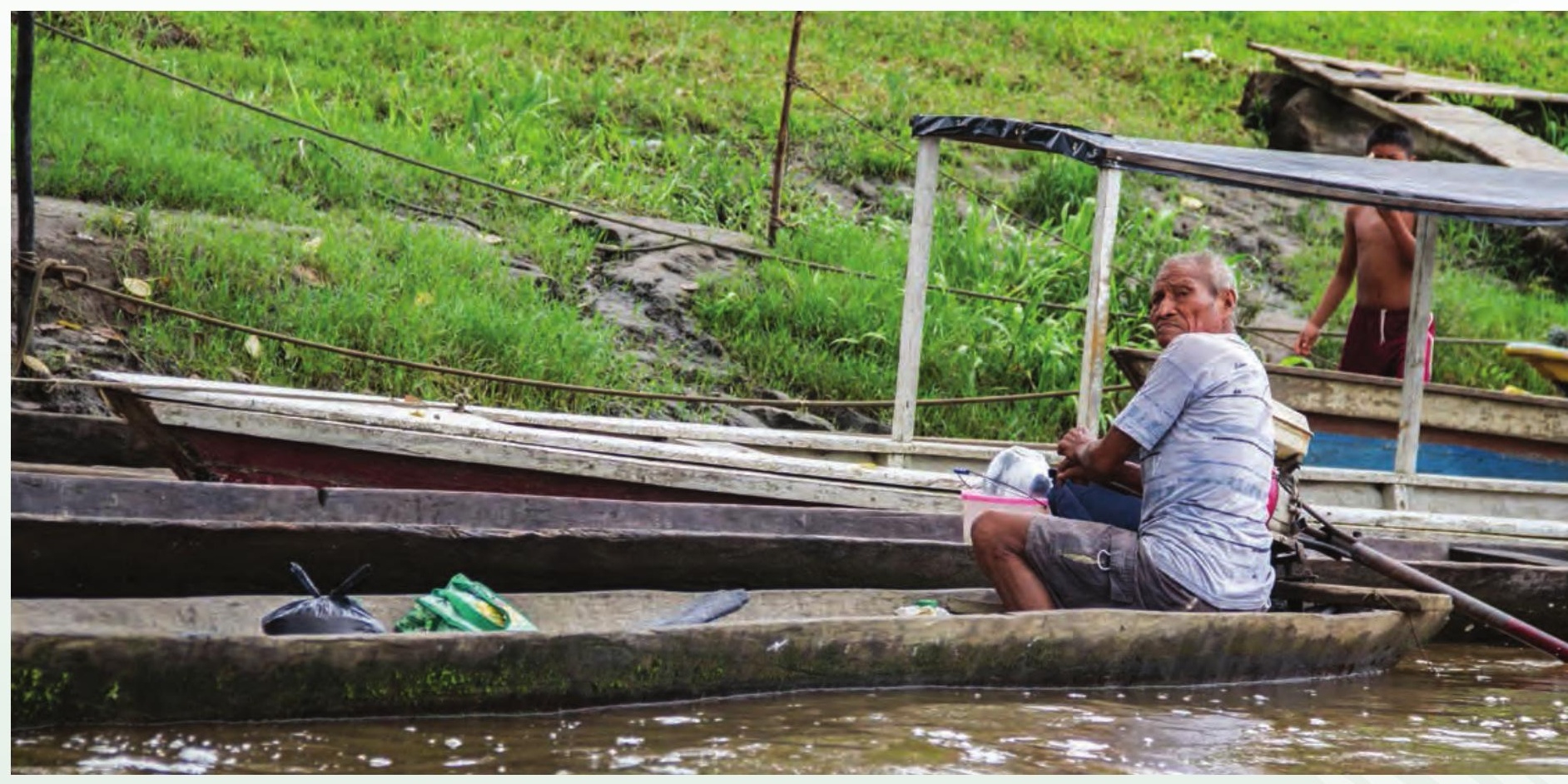

En el caso de la comunidad de Chivé, la más poblada de la reserva, existen asentamientos urbanos ilegales a donde llegan inmigrantes en busca de oportunidades. Si bien estos asentamientos han sido avalados por el sindicato de la comunidad, estas personas no tienen derecho a tierras para aprovechamiento de castaña. Ellos se dedican a comercializar la castaña, constituyéndose en actores clave para su intermediación. Por este motivo existe presión, por parte de la población de esta comunidad y de otras en la reserva, para legalizar el asentamiento de los comerciantes.

En 2010, el SERNAP impulsó la elaboración del Plan de Manejo de la Reserva Manuripi 20122022. Este se hizo de manera participativa con distintos actores sociales: la dirección del área protegida, el comité de gestión, técnicos de la unidad central del SERNAP y las autoridades municipales de Filadelfia y Puerto Rico, estos últimos pensados como una invitación para que lo estipulado en el plan de manejo se incluya en la planificación territorial de ambos municipios ${ }^{63}$

El Plan de Manejo de la Reserva Manuripi incluye acciones estratégicas para orientar la gestión del área protegida, busca conservar la diversidad biológica, el mantenimiento de la calidad ambiental y las condiciones de vida de los actores que viven dentro del área protegida, enmarcados en los objetivos y políticas del Sistema Nacional de Áreas Protegidas (SNAP).
En dicho plan se trabajó en la zonificación de la reserva, para lo cual se consideraron informes, datos, censos y planes de manejo de castaña, cartografía e imágenes satelitales disponibles, así como los puntos de vista y requerimientos de los actores locales a través de trabajo de campo, talleres y visita a las comunidades, además de un taller con los barraqueros ${ }^{64}$ Para la definición de la zonificación se tomaron en cuenta: los valores naturales, culturales, características socioeconómicas, usos de la tierra (actuales y potenciales) y objetivos de conservación y gestión del AP

Los actores sociales aprobaron la zonificación en reunión del comité de gestión en agosto de 2011.

\footnotetext{
63. En el Plan de Manejo Manuripi consta que la reserva "aún no está incluida en las políticas y estrategias departamentales y municipales de manera efectiva. Si bien la elaboración del plan de uso de suelo de pando (zonisig 1996a y 1996b), permitió de algún modo consolidar la existencia de la reserva, la misma contribuyó también a que sea excluida de estrategias y planes para el desarrollo de sus poblaciones, al considerarse una zona sin habitantes". Tomado del Plan de Manejo de la Reserva Ma nuripi 2012-2022, pág. 99

64. Las organizaciones responsables fueron SERNAP, la dirección y cuerpo de protección de la reserva, comité de gestión, el equipo técnico de MAPZA y WWF

65. Plan de Manejo de la Reserva Manuripi 2012-2022, pág. 135
} 


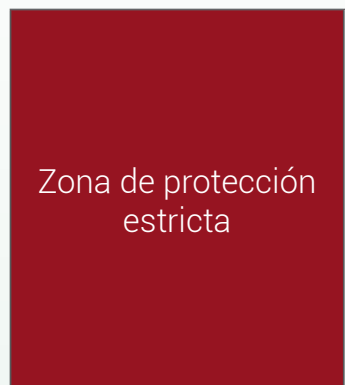

Zona de amortiguamiento

Zona de uso moderado

Zona de aprovechamiento de recursos naturales de productos forestales no maderables

Zona de aprovechamiento de recursos naturales para agroforestería. $(0,01 \%)$
Tierra propiedad del Estado. Zonas con poca intervención del hombre y ecosistemas muy frágiles.

Se permiten actividades de control y vigilancia e investigaciones científicas justificadas, autorizadas y reguladas.

No se permiten actividades turísticas ni recreativas, actividades extractivas ni de manejo de recursos, así como tampoco ningún tipo de modalidad de caza, ni pesca.

Zona que minimiza los impactos sobre el ambiente natural del AP. Se permite ecoturismo extensivo controlado e investigación científica.

Están prohibidas actividades consuntivas o extractivas.

Zona con alto valor paisajístico y de biodiversidad con cierto grado de intervención humana.

Se permiten actividades turísticas y recreativas.

Están prohibidas actividades extractivas, el manejo de recursos naturales, caza y pesca.

Es la zona más extensa de la reserva $(67,2 \%$, correspondiente a 502 125,59 ha). Aquí se encuentran tierras tituladas a favor de comunidades y barraqueros y tierras fiscales. Es una zona con gran importancia económica, fuente de empleo e ingresos para los habitantes de la reserva y zafreros que llegan para la temporada de zafra.

Se permite: la extracción de productos como castaña y goma dentro de tierras comunitarias y áreas expectaticias; actividades silviculturales para favorecer el crecimiento de las especies no maderables de aprovechamiento; reforestación con especies locales; investigación científica; turismo y educación ambiental; y el aprovechamiento de fauna silvestre en base a planes de manejo.

Están prohibidas actividades agrícolas y pecuarias, caza de fauna silvestre (excepto caza de subsistencia dentro de comunidades y siguiendo las normas para dicha actividad), extracción de madera y actividades extractivas de recursos no renovables, según normas ambientales vigentes.

Son tierras modificadas para uso agrícola y pecuario.

Se permite el aprovechamiento y uso de la fauna silvestre por parte de los habitantes permanentes de comunidades y barracas, aprovechamiento de maderables (en base a las normas forestales vigentes), investigación científica, turismo y educación ambiental.

No está permitido el uso de agroquímicos para agricultura, introducción y cultivo de semillas de especies exóticas y actividades extractivas de recursos no renovables (según normas ambientales vigentes).

Son las zonas donde se encuentran las poblaciones, la infraestructura para la protección y administración del área, servicios y obras públicas. 


\section{Paisaje sur}

La Reserva Nacional de Vida Silvestre Amazónica Manuripi tiene un traslape territorial con dos actores locales diferentes que se dedican a la extracción de la castaña y que tienen diferentes restricciones de uso del territorio: comunidades campesinas (10 comunidades tituladas) y barracas castañeras (27 barracas) (entrevista Walter Cano, 2016). El 25 \% de la Reserva Manuripi tiene algún tipo de título de propiedad, el $75 \%$ restante son tierras fiscales que pertenecen al AP y que, según el plan de manejo, aunque tienen diferentes formas de zonificación, su vocación es la conservación del ecosistema (entrevista WWF Bolivia, 2016)

Las comunidades campesinas de la RNVSA Manuripi tienen un uso histórico del territorio que inició con la extracción de goma y con la conformación de grandes barracas caucheras. Con la caída del precio de este producto, los empresarios abandonaron el lugar y se quedaron los trabajadores, quienes hicieron las gestiones necesarias para que el territorio se conformase en las actuales comunidades campesinas. La organización territorial interna de las comunidades se realizó a través de la repartición de 500 ha para cada una de las familias que integraban la comunidad. La justificación para la asignación de esta alta cantidad de superficie fue que el aprovechamiento principal en este territorio es la castaña y, según los censos realizados y el conocimiento de la población local, en cada hectárea de terreno se pueden encontrar, en promedio, entre uno o dos árboles de castaña (entrevistas a población local y técnico de castaña de la RNVSA Manuripi, 2016)

En la actualidad, estas comunidades tienen la posibilidad de extraer castaña y realizar cultivos de abastecimiento para el hogar (conocidos como "chacos"), aunque enfrentan un reto para el aprovechamiento del territorio: el crecimiento demográfico y la formación de nuevos hogares en las comunidades, lo que ha provocado que las 500 ha familiares sean insuficientes para el aprovechamiento de castaña y el abastecimiento de los nuevos hogares. Este contexto de crecimiento demográfico genera un problema de presión sobre las tierras fiscales del AP Manuripi, sobre todo para el aprovechamiento de la castaña.

Las barracas castañeras también son parte de la historia gomera de la zona de Manuripi, aunque estas propiedades no se disolvieron con la caída del precio de la goma, sino que, más

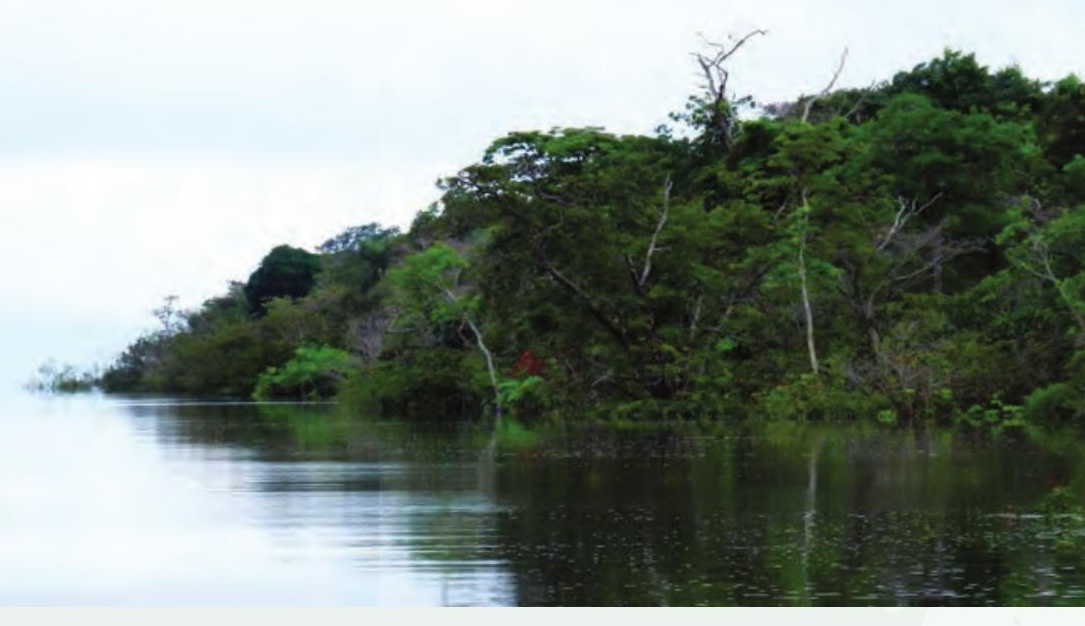

bien, cambiaron de dueños. En la actualidad, estas barracas tienen diferentes superficies y se ha visto limitado su crecimiento por la presencia del AP. Debido al aprovechamiento histórico de estas barracas (antes dedicadas a la extracción del caucho), se ha creado la figura del "derecho expectaticio" para que estas propiedades puedan hacer extracción de castaña en las zonas que se utilizaban históricamente, pero sin que la propiedad crezca y se afecte el uso del suelo de la reserva, reglamentado en el plan de manejo. Por ejemplo, la barraca castañera Puerto América tiene de propiedad 500 ha tituladas y, por derecho expectaticio, tiene la posibilidad de gestionar la extracción de castaña sobre 15000 ha adicionales, por lo cual debe pagar al Estado diferentes impuestos, siendo esto, un mecanismo de sostenibilidad financiera para el área protegida.

\section{Las áreas protegidas de Brasil}

Las áreas naturales protegidas de Brasil están ordenadas en tres niveles: federal, estatal y municipal y, desde 2002, se organizan en el Sistema Nacional de Unidades de Conservación de la Naturaleza (SNUC), conformadas por Unidades de Conservación (UC) de 8 tipos: Estación Ecológica (EE), Parque Nacional (PN), Parque Estadual (PE), Áreas de Relevante Interés Ecológico (ARIE), Áreas de Protección Ambiental (APA), Bosques Nacionales (Florestas Nacionais, FLONA), Bosques Estatales (Florestas Estaduais, FLOE) y Reservas Extractivistas (RESEX). EI SNUC establece que las UC deben ser gestionadas con participación social para cubrir los intereses de la sociedad. 


\section{Paisaje sur}

Programas estatales en Acre

El estado de Acre, donde se encuentran ambas áreas protegidas de Brasil del paisaje sur, es una de las regiones de más bajo Índice de Desarrollo Humano (IDH) del país. Cuenta con algunos programas estatales y proyectos:

- Programa Estatal de Certificación de Unidades Productivas Familiares, para fomentar el uso adecuado de los recursos naturales con alternativas sostenibles de producción, recuperación de áreas degradadas y regularización ambiental de las propiedades agrícolas familiares.

- Programa de atención de alimentos para agricultores, de la Secretaria Estatal de Agricultura, la cual compra a los productores su producción para proveer de alimento a los programas de ayuda social que llevan adelante las instituciones gubernamentales como hospitales, escuelas, etc. Este programa se implementa en el PE Chandless.
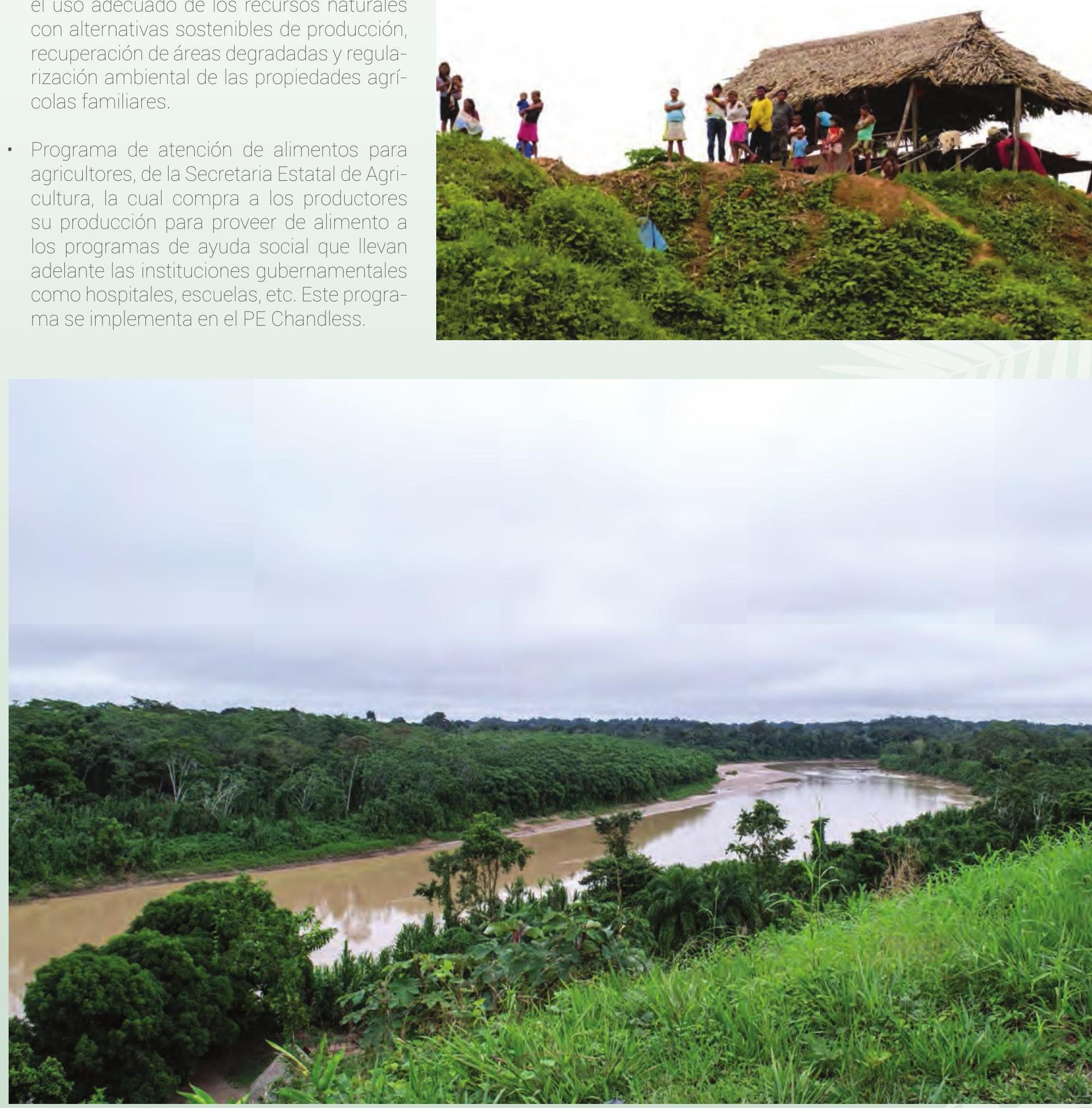


\section{Parque Estadual Chandless}

\section{(PE Chandless)}
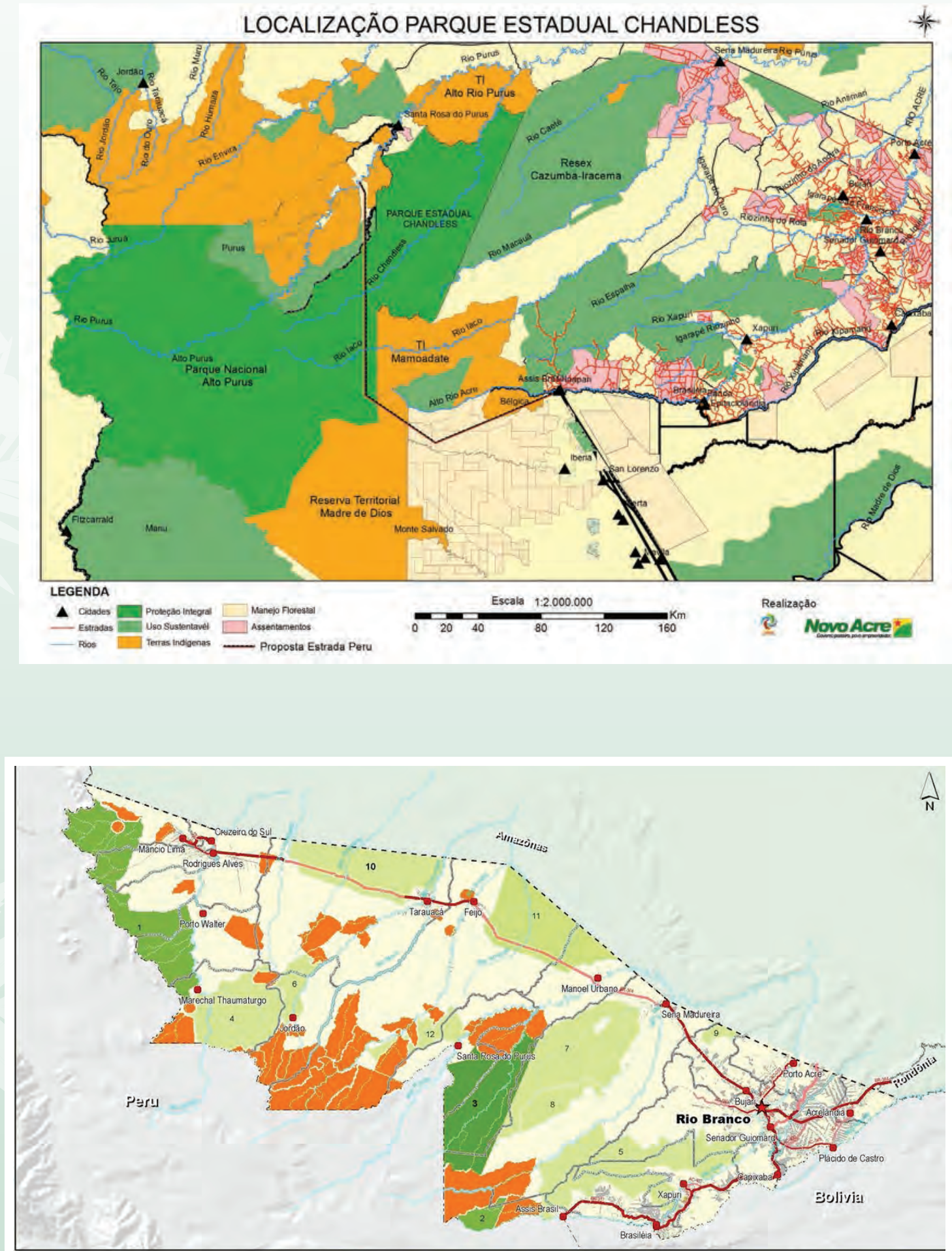

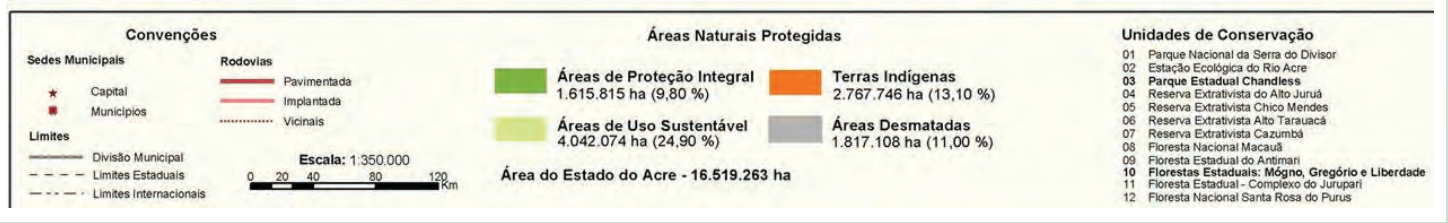


La gestión en el interior del Parque Estadual Chandless es competencia de la Secretaria de Estado de Medio Ambiente de Acre (SEMA), que formula las políticas públicas socioambientales para el Gobierno del estado de Acre. La SEMA tiene como objetivo la conservación de los recursos naturales a través de un sistema coherente de políticas y la consolidación de la Zonificación Ecológico-económica del Estado de Acre (ZEE) como instrumento de gestión. El parque limita con tierras indígenas y dentro existen indígenas no contactados que se movilizan por las cabeceras de los afluentes de los ríos Juruá y Purús, en territorio fronterizo entre Perú y Brasil.

En 2004, las tierras del río Chandless, a cargo del Instituto Nacional de Colonización y Reforma Agraria (INCRA), pasaron a ser una Unidad de Protección Integral conocida como el Parque Estadual Chandless.

En el parque hay una baja densidad humana, viven 11 familias campesinas que tienen lazos de parentesco entre sí. La gente proviene de poblados en las riberas del río Purús y de localidades cercanas. La mayoría de los adultos son analfabetos. Cuando se creó el parque, los habitantes de la zona que no querían formar parte del área protegida podían optar por una indemnización, sin embargo ninguna de las familias tomó esa opción. Estas familias se quedaron a vivir dentro del AP ya que no tuvieron otras opciones productivas que les atrajeran hacia otros lugares. En general, estas familias estuvieron relacionadas con el desarrollo de la hacienda, son extrabajadores o sus familiares (entrevistas a pobladores y al jefe de área, 2016)

Las poblaciones indígenas que transitan por el parque estadual Chandless son: pueblos en aislamiento voluntario, que se ubican en la zona más alejada del AP, casi en la frontera con Perú; y los pueblos indígenas madijá y jini kuin ubicados en la tierra indígena "Alto Río Purús". Esta tierra indígena fue reconocida por el Estado brasileño 20 años antes de la creación del parque y fue la primera tierra indígena con un proceso de delimitación clara (entrevista FUNAl, 2016). El PE Chandless también es transitado por los habitantes manchineri y jaminawa de la vecina tierra indígena "Mamoadate", ubicada al sur del parque.

Al inicio hubo conflicto con la comunidad local que no fue consultada sobre el establecimiento del área protegida. Desde hace algunos años las autoridades trabajan para establecer una relación con la población y acuerdos de trabajo conjunto en distintos programas de desarrollo social.

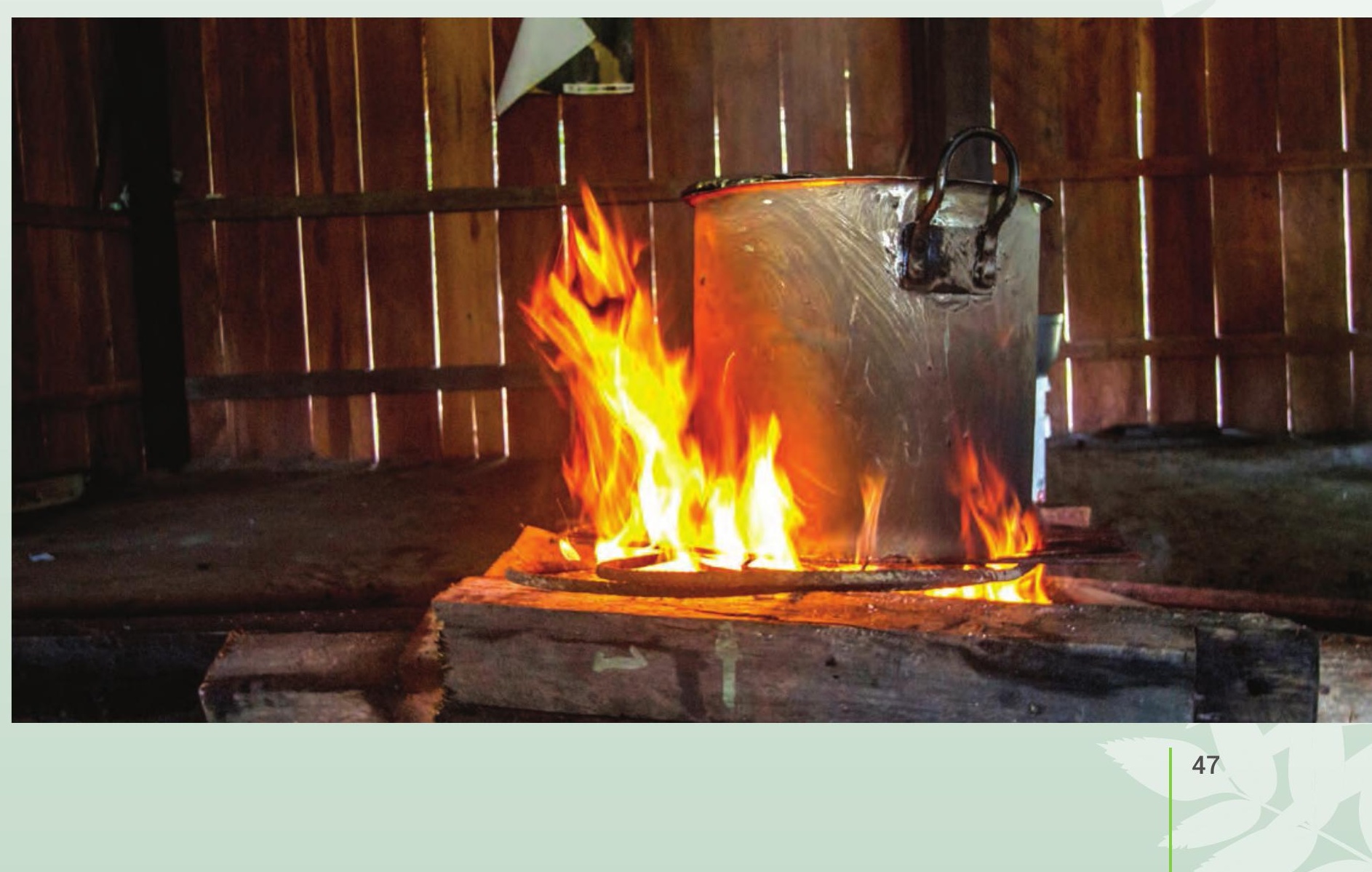


Actualmente, para los habitantes, el hecho de vivir dentro de un AP protege sus tierras y ríos de invasiones, ya que su establecimiento limitó la entrada de personas externas. Sin embargo, lamentan no poder incrementar su ganado, no poder cazar animales como el jaguar (que amenaza a los animales domésticos y al ganado) y no poder vender los excedentes de la pesca, que constituía su principal fuente de ingresos necesaria para la compra de combustible.

Desde 2008, el Parque Estadual Chandless cuenta con un plan de manejo donde se establece el uso del suelo y los recursos naturales dentro del área protegida. De acuerdo a la conversación mantenida con Jesús Rodríguez, jefe del parque, el plan de manejo no se diseñó con la participación de la comunidad, sino que fue realizado a nivel técnico. En 2017 se va a trabajar en la actualización del plan de manejo, donde se considerará a la población local como actor principal.

La zonificación para el PE Chandless se realizó de manera participativa en reuniones técnicas de planeación donde se tomaron en cuenta los diagnósticos temáticos de la UC. Se establecieron 4 zonas de manejo ${ }^{66}$
El parque Estadual Chandless posee una historia similar a la de la Reserva Manuripi, ya que esta zona era parte de grandes haciendas de extracción de goma. Cuando el precio de la goma cayó, los propietarios se retiraron dejando el cuidado de la hacienda a sus trabajadores. Después de esto, el Estado brasileño, a través del INCRA, realizó la discriminación del área: primero perteneciente a la Unión Federal, posteriormente donada a la Unión Estadual (estado de Acre), para finalmente ser categorizada como Parque Estadual. Por ello, se han generado procesos de concertación con la población que habita en esta zona.

Es importante considerar que las tierras indígenas en Brasil no son zonas de conservación, sino territorios para el uso de comunidades ancestrales según sus patrones culturales. En estas zonas no se permiten actividades productivas intensivas o comerciales a gran escala, lo que permite que estas tierras indígenas también contribuyan a la conservación de hábitats de la zona. Se pueden considerar áreas protegidas, pero no "unidades de conservación".

66. Información tomada del Plan de Manejo del Parque Estadual Chandless, enero de 2010.

\begin{tabular}{|c|c|}
\hline Zona de manejo & Definición \\
\hline Zona intangible & $\begin{array}{l}\text { Zonas con alto grado de conservación, con ecosistemas frágiles, donde la } \\
\text { intervención humana es casi nula. } \\
\text { Dedicadas a la protección integral de ecosistemas, de los recursos } \\
\text { genéticos y al monitoreo ambiental. } \\
\text { Funciona como matriz de repoblamiento de otras zonas. El objetivo es la } \\
\text { preservación, garantizando la evolución natural. }\end{array}$ \\
\hline Zona primitiva & $\begin{array}{l}\text { Zonas con poca intervención humana. } \\
\text { Zonas con flora y fauna con un alto valor científico. } \\
\text { Se pueden realizar actividades de educación científica y educación } \\
\text { ambiental. }\end{array}$ \\
\hline $\begin{array}{l}\text { Zona de ocupación } \\
\text { temporal }\end{array}$ & $\begin{array}{l}\text { Zonas donde está asentada la población. Se permite la fiscalización, } \\
\text { protección, educación ambiental y las actividades previstas en los } \\
\text { acuerdos y compromisos de las áreas de uso y establecimiento de la } \\
\text { población. }\end{array}$ \\
\hline $\begin{array}{l}\text { Zona de uso } \\
\text { especial }\end{array}$ & $\begin{array}{l}\text { Zona donde está ubicada la infraestructura necesaria para las actividades } \\
\text { de administración, fiscalización y mantenimiento del parque. }\end{array}$ \\
\hline
\end{tabular}




\section{Reserva Extractivista Cazumbá-Iracema (RESEX Cazumbá-Iracema)}

Anexo H

Ministério do Meio Ambiente

Ministério do Meio Ambiente Localização da Reserva Extrativista do Cazumbá-Iracema no Estado do Acre

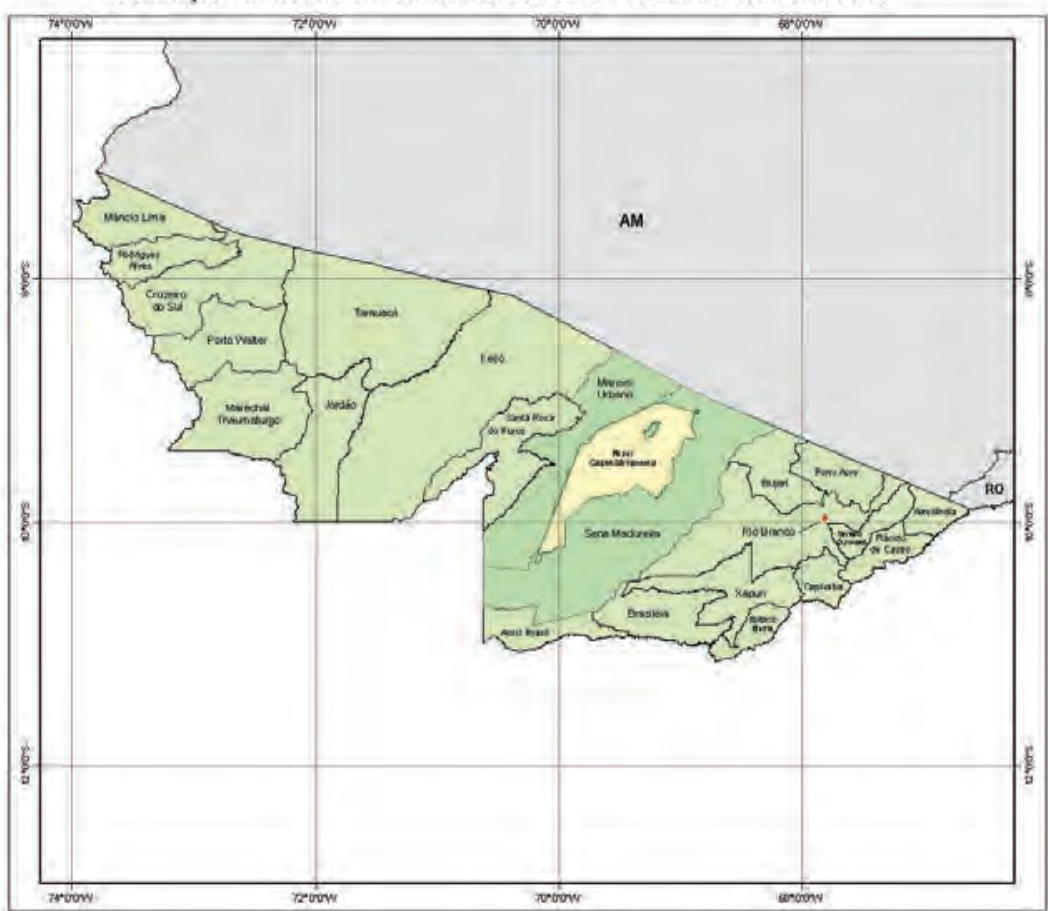

Mapa 1

Diretoria de Unidades de Conservação de Uso Sustentável e Populações Tradicionais - DIUSP

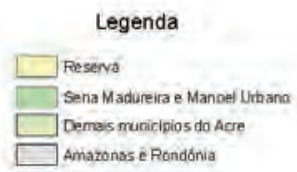

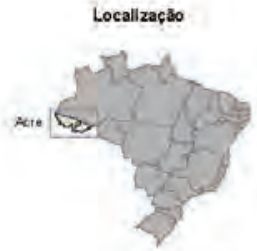

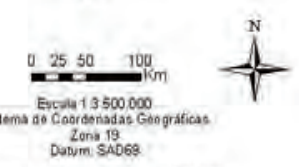

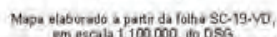

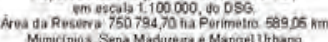

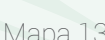

Reserva Cazumbá-Iracema Fuente

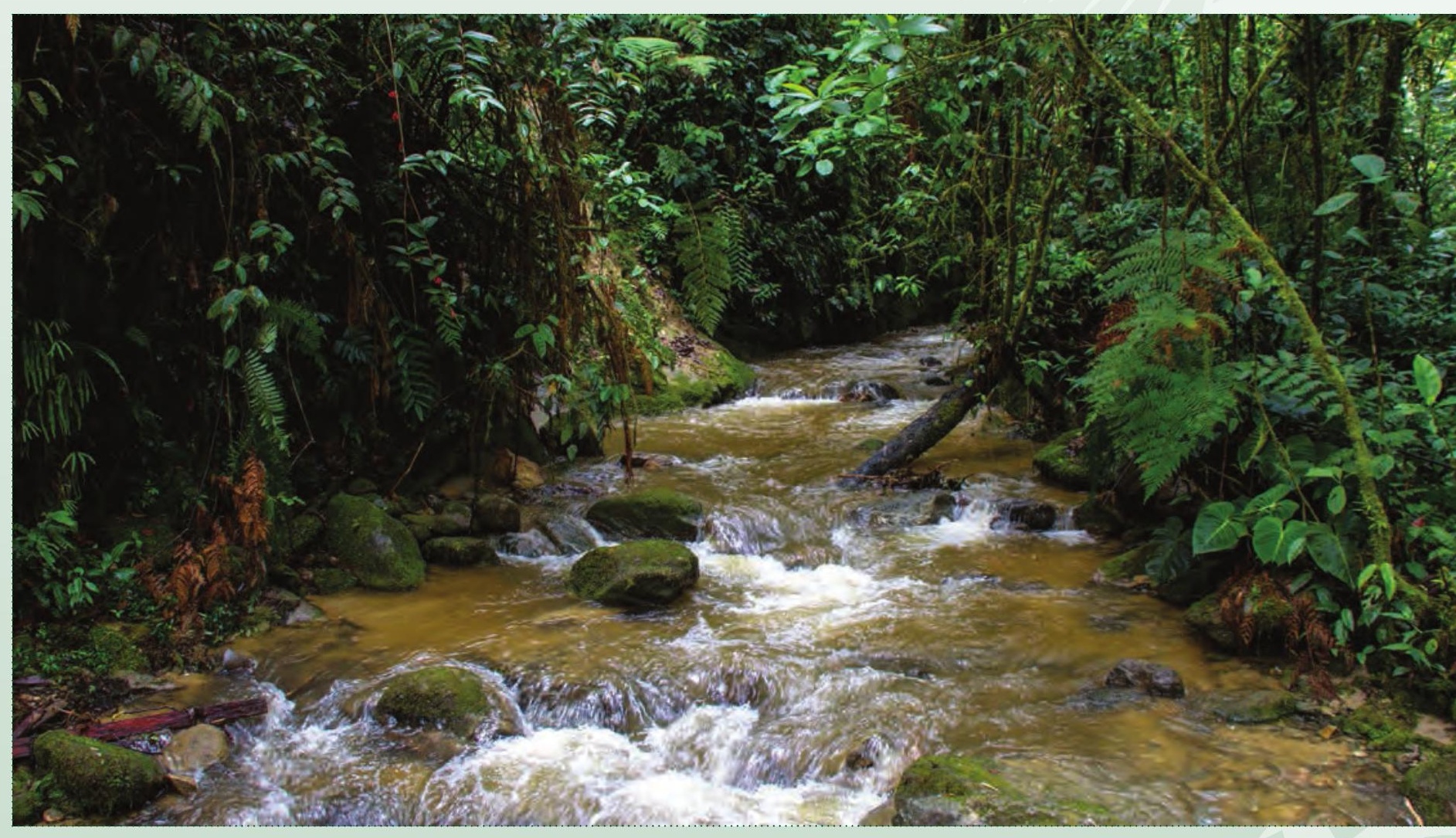




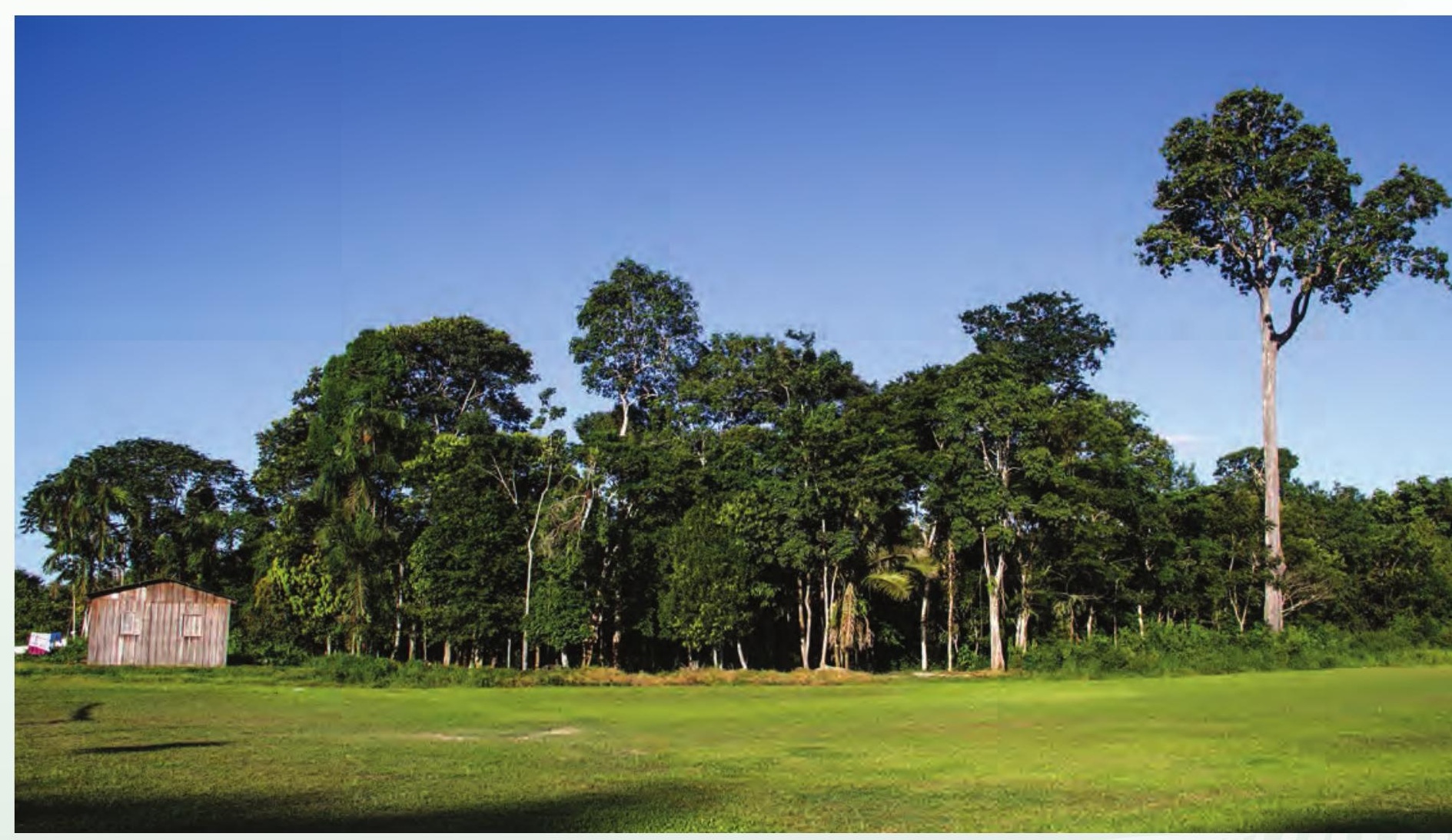

En 2007 se elaboró el Plan de Manejo de la Reserva Extractivista Cazumbá-Iracema de manera participativa con instituciones públicas y los moradores de la reserva.

Más de la mitad del área de la reserva está deshabitada. La parte habitada está conformada por unidades habitacionales familiares y productivas que se denominan colocaciones (colocação, en portugués). Estas colocações ${ }^{67}$ organizan el territorio a partir de estradas utilizadas históricamente por los pobladores de la reserva y que tienen las conexiones entre los hogares con los árboles de caucho y de castaña, con las chacras y con las casas de fariña. Cada familia tiene en promedio 300 ha. En Núcleo do Cazumbá existen algunas familias que ocupan un área comunitaria, el resto viven en colocaciones dentro de la reserva. Hay aproximadamente 145 colocaciones, distribuidas en cinco macro regiones: Cazumbá, Médio Caeté, Alto Caeté, Jacareúba-Redenção y RiozinhoCachoeira y doce en seringal.

Un conjunto de estradas de siringa forma una "colocação". Un conjunto de "colocações" forma un seringal y la reserva está dividida en 18 seringales.
La población de la reserva es mayoritariamente mestiza, en Cazumbá-Iracema existen muchas colocações ya que estas son propiedades de uso familiar, las cuales se agrupan en 11 comunidades grandes.

En la RESEX se establecieron tres niveles de uso ${ }^{68}$.

- Uso intensivo: se permite la ocupación y extracción de recursos maderables y no maderables, actividades de investigación, educación ambiental y ecoturismo.

- Uso extensivo: se permiten las mismas actividades que en la de uso intensivo, excepto la explotación maderera y pecuaria.

- Uso restringido: no se permiten actividades humanas, las investigaciones se permiten solo en casos excepcionales.

\footnotetext{
67. El término colocações hace referencia a una forma de organización del territorio a partir de los árboles de "seringa", árboles productores de caucho. Las estradas son los caminos que conectan entre árboles y son usados por las personas que extraen seringa o caucho.

68. Tomado del Plan de Manejo de la RESEX Cazumbá-Iracema diciembre de 2007.
} 


\begin{tabular}{|c|c|}
\hline $\begin{array}{c}\text { Zona de } \\
\text { conservación }\end{array}$ & $\begin{array}{l}\text { Zona donde nunca ha habido ocupación humana. } \\
\text { Se permiten investigaciones científicas con mínimo impacto e instalación } \\
\text { de infraestructura de apoyo para las investigaciones. } \\
\text { Nivel de uso: restringido }\end{array}$ \\
\hline $\begin{array}{c}\text { Zona con potencial } \\
\text { turístico }\end{array}$ & $\begin{array}{l}\text { Son áreas con especial belleza natural y escénica. } \\
\text { Se permiten actividades de ecoturismo y recreación. No se permite } \\
\text { la explotación de madera ni actividades de uso intensivo de recursos } \\
\text { naturales con fines comerciales. } \\
\text { Nivel de uso: extensivo }\end{array}$ \\
\hline Zona de caza & $\begin{array}{l}\text { Zonas acordadas en el plan de manejo con los moradores de la RESEX } \\
\text { para la realización de actividades de caza. } \\
\text { Nivel de uso: intensivo }\end{array}$ \\
\hline $\begin{array}{l}\text { Zona de manejo } \\
\text { de fauna }\end{array}$ & $\begin{array}{l}\text { Son áreas para manejo de fauna con fines comerciales, de subsistencia y } \\
\text { conservación. } \\
\text { Se permite la explotación económica de especies de fauna silvestre } \\
\text { seleccionadas por la comunidad, con prioridad sobre otras actividades } \\
\text { extractivas también permitidas. Se prohíbe el establecimiento de chacras. } \\
\text { Nivel de uso: extensivo }\end{array}$ \\
\hline $\begin{array}{c}\text { Zona } \\
\text { agroextractivista }\end{array}$ & $\begin{array}{l}\text { Áreas de uso comunitario, de recuperación y de uso no tradicional. } \\
\text { Se permiten actividades extractivas y de agricultura familiar con técnicas } \\
\text { tradicionales, para subsistencia y comercialización, ecoturismo, manejo } \\
\text { de fauna y pesca. } \\
\text { Nivel de uso: intensivo }\end{array}$ \\
\hline $\begin{array}{c}\text { Zona de expansión } \\
\text { extractivista }\end{array}$ & $\begin{array}{l}\text { Son áreas antes utilizadas por seringueiros, abandonadas por más } \\
\text { de } 30 \text { años, con potencial de uso extractivo que podría ser ocupada } \\
\text { eventualmente por el crecimiento demográfico dentro de la RESEX. } \\
\text { Se permiten proyectos productivos comunitarios y manejo comunitario } \\
\text { de pesca. } \\
\text { Nivel de uso: extensivo }\end{array}$ \\
\hline $\begin{array}{c}\text { Zona de } \\
\text { amortiguamiento }\end{array}$ & $\begin{array}{l}\text { Actividades compatibles descritas para este tipo de zonas en la } \\
\text { legislación ambiental. } \\
\text { Nivel de uso: intensivo }\end{array}$ \\
\hline
\end{tabular}




\section{Parque Nacional Alto Purús} (PN Alto Purús)

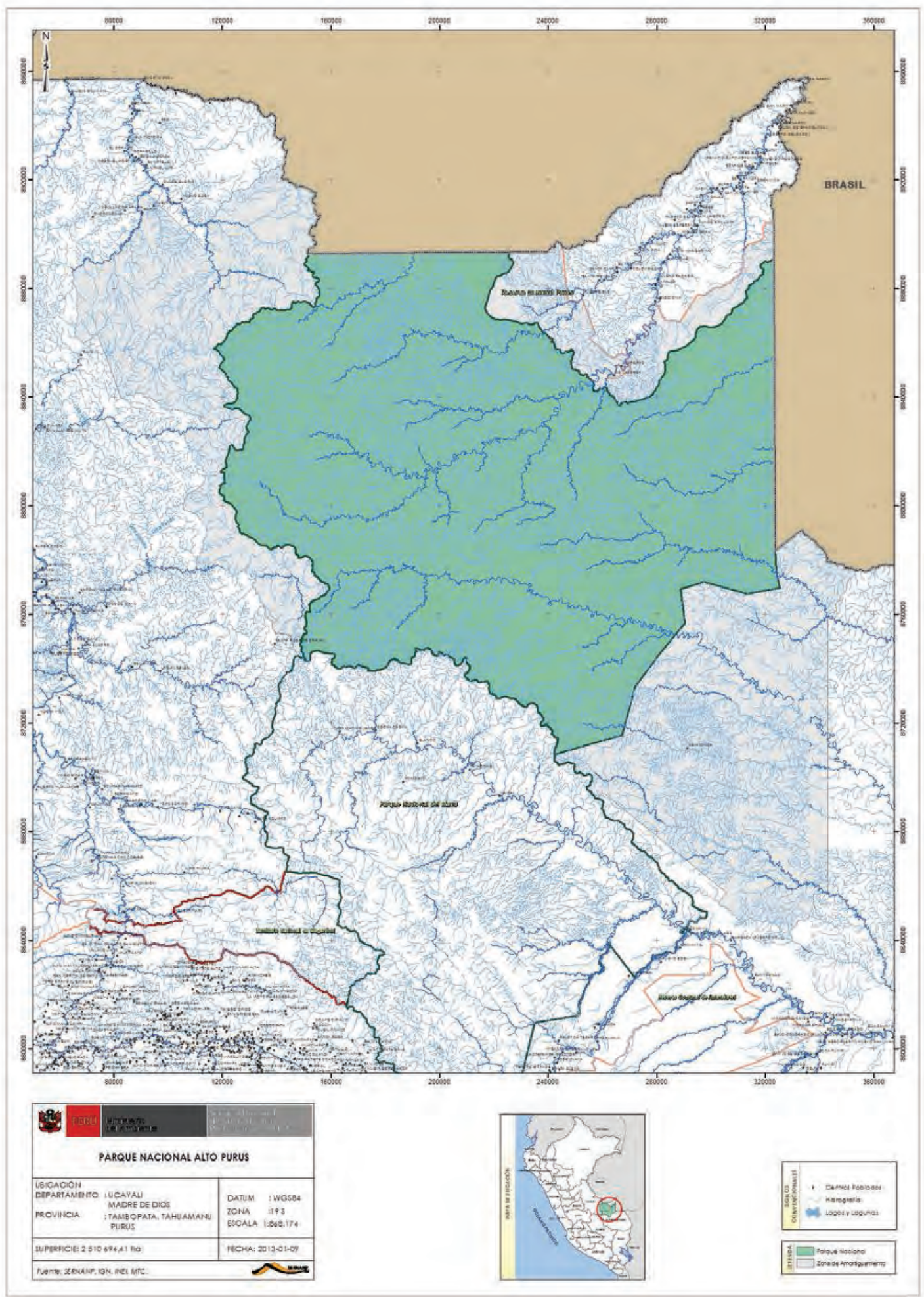




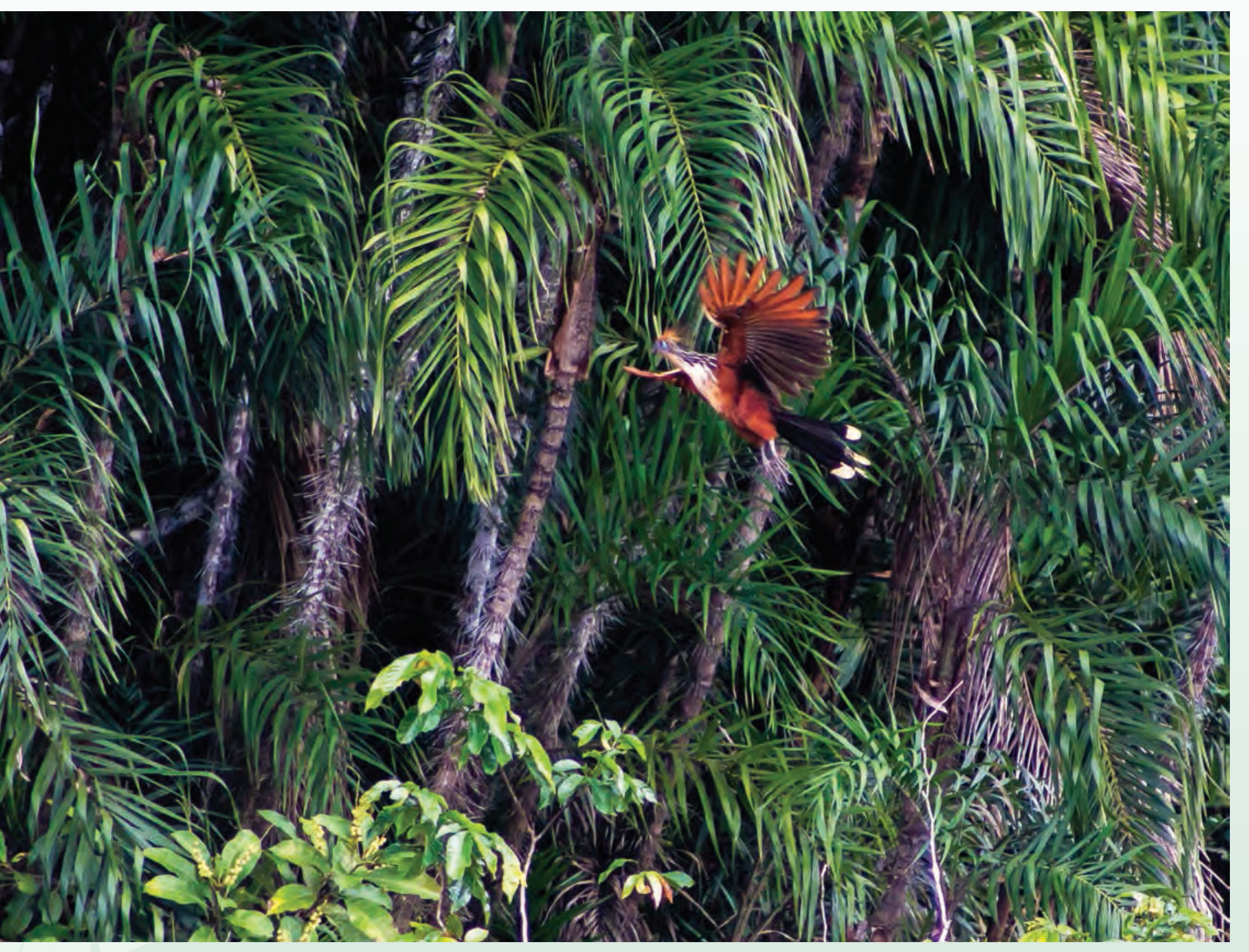

El PN Alto Purús es administrado y gestionado por el SERNANP, el cual promueve la realización de investigaciones científicas en temas
biológicos y ecológicos en las áreas aledañas al parque; están prohibidos los estudios previos y las actividades extractivas hidrocarburíferas como también la construcción de grandes obras de infraestructura.

El modelo de gestión del PNAP se basa en tres pilares: normatividad, biodiversidad y cogestión entre la jefatura del parque y los usuarios para el uso sostenible de los recursos naturales. Para que el modelo funcione, el plan de manejo propone fortalecer la institucionalidad, involucrar a la población en las actividades y decisiones que se tomen al interior del área protegida, sensibilizar a la población sobre la Por su difícil acceso, el Alto Purús es una zona muy rica en flora y fauna con un sinnúmero de especies endénicas, considerado el últino bosque con árboles de caoba y con grandes extensiones de bosques de bambú. Es un importante corredor ecológico tanto para la fauna de las áreas protegidas de Perú, Bolivia y Brasil como para los pueblos en aislamiento. Es el territorio recorrido por los pueblos indígehas en Aislamiento Voluntario (PIAV) ${ }^{69}$ desde hace miles de años, los cuales tienen una cosmovisión que refleja su sentido de identidad y pertenencia con el bosque. Estos indígenas están siendo amenazados por la presencia de grupos religiosos que buscan evangelizarlos, así como por actividades extractivas rea- 
lizadas por actores externos, principalmente madereros ilegales que cada vez se adentran más en el bosque en busca del recurso.

"Perú, cuenta desde el año 2006 con la Ley para la Protección de pueblos indígenas u Originarios en situación de Aislamiento y en situación de Contacto Inicial70, que garantiza el derecho a la vida y la integridad de dichos pueblos" (Ley No 28736).

El PN Alto Purús es catalogado como una Zona de Protección Estricta (ZPE) para garan- tizar su estado de conservación y protección. La ZPE, representa el 100 \% del PN Alto Purús y abarca más del 90 \% de la Reserva Territorial Mashco Piro donde existen PIAV. Cuenta además con medidas precautorias (Art. 91 del Reglamento de Ley de Áreas Naturales Protegidas) para que el personal del área protegida evite el contacto con los PIAV, un Plan Antropológico que establece las políticas y lineamientos generales de comportamiento con estas poblaciones y un protocolo de operaciones, que determina las acciones a seguir en caso de contacto ${ }^{7}$

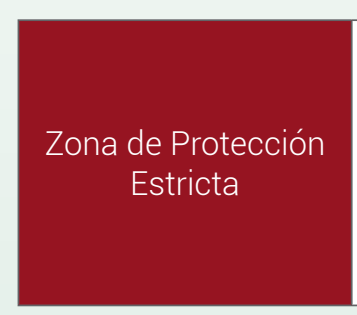

Se permiten solamente actividades de control y vigilancia con bajo impacto al ecosistema.

Las actividades extractivas permitidas dentro del parque son únicamente las tradicionales realizadas por los pueblos indígenas en aislamiento voluntario y por las comunidades indígenas de la Reserva Comunal Purús, ubicadas en el límite con el parque.

En la zona de amortiquamiento del PN Alto Purús se pueden realizar actividades como turismo, investigación, recuperación de flora y fauna y se reconocen Áreas de Conservación Privada (ACP) así como concesiones de conservación y de servicios ambientales. Aquí se encuentran las Reservas Territoriales Madre de Dios y Murunahua, para poblaciones aisladas voluntariamente; la Reserva Comunal Purús y el Parque Nacional Manu; y unidades de aprovechamiento forestal maderable en las cuencas de los ríos Sepahua y Tahuamanu, actividad que se realiza de acuerdo a los pla- nes de manejo forestal y el respeto de la normatividad vigente.

El Parque Nacional Alto Purús tiene a su alrededor territorios indígenas organizados como reservas territoriales, que son espacios de manejo territorial acorde a formas culturales indígenas y mestizas que se han adaptado a su entorno. Además, el Parque Nacional Alto Purús cuenta con la Reserva Comunal Purús y con la concesión forestal Manejo de Bosques Sin Fronteras (MABOSINFRON).

\begin{tabular}{|c|c|c|}
\hline PAISAJE & AP de referencia & Territorios Comunitarios \\
\hline \multirow{6}{*}{ Sur } & \multirow{6}{*}{ Parque Nacional Alto Purús } & Reserva Territorial Murunahua \\
\hline & & Reserva Territorial Kugapakori Nahua Nanti \\
\hline & & Reserva Territorial Madre de Dios \\
\hline & & Reserva Territorial Mashco Piro (PIAV) \\
\hline & & Reserva Comunal Purús \\
\hline & & MABOSINFRON \\
\hline
\end{tabular}


Reserva Comunal Purús (RC Purús)

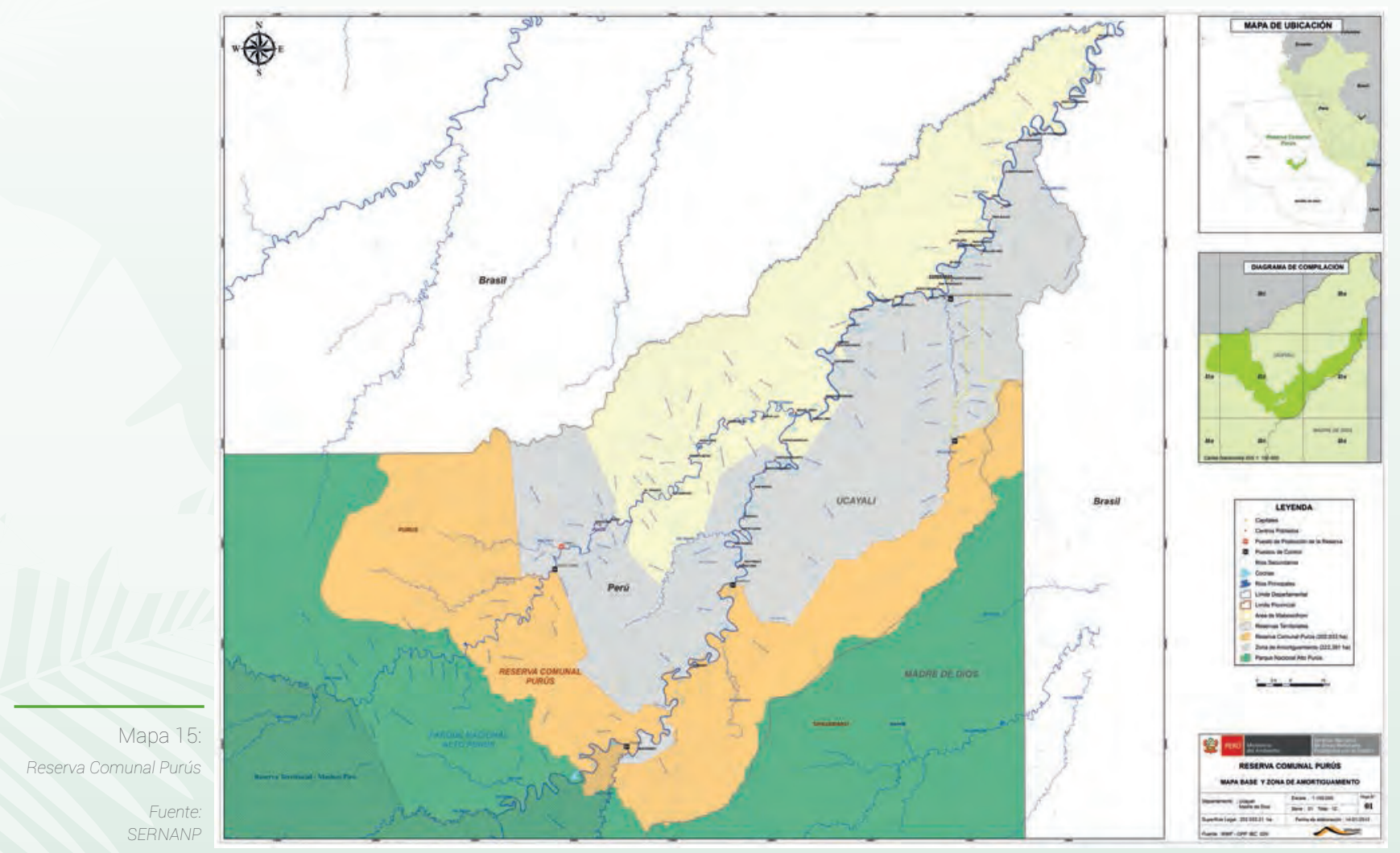




\section{Paisaje sur}

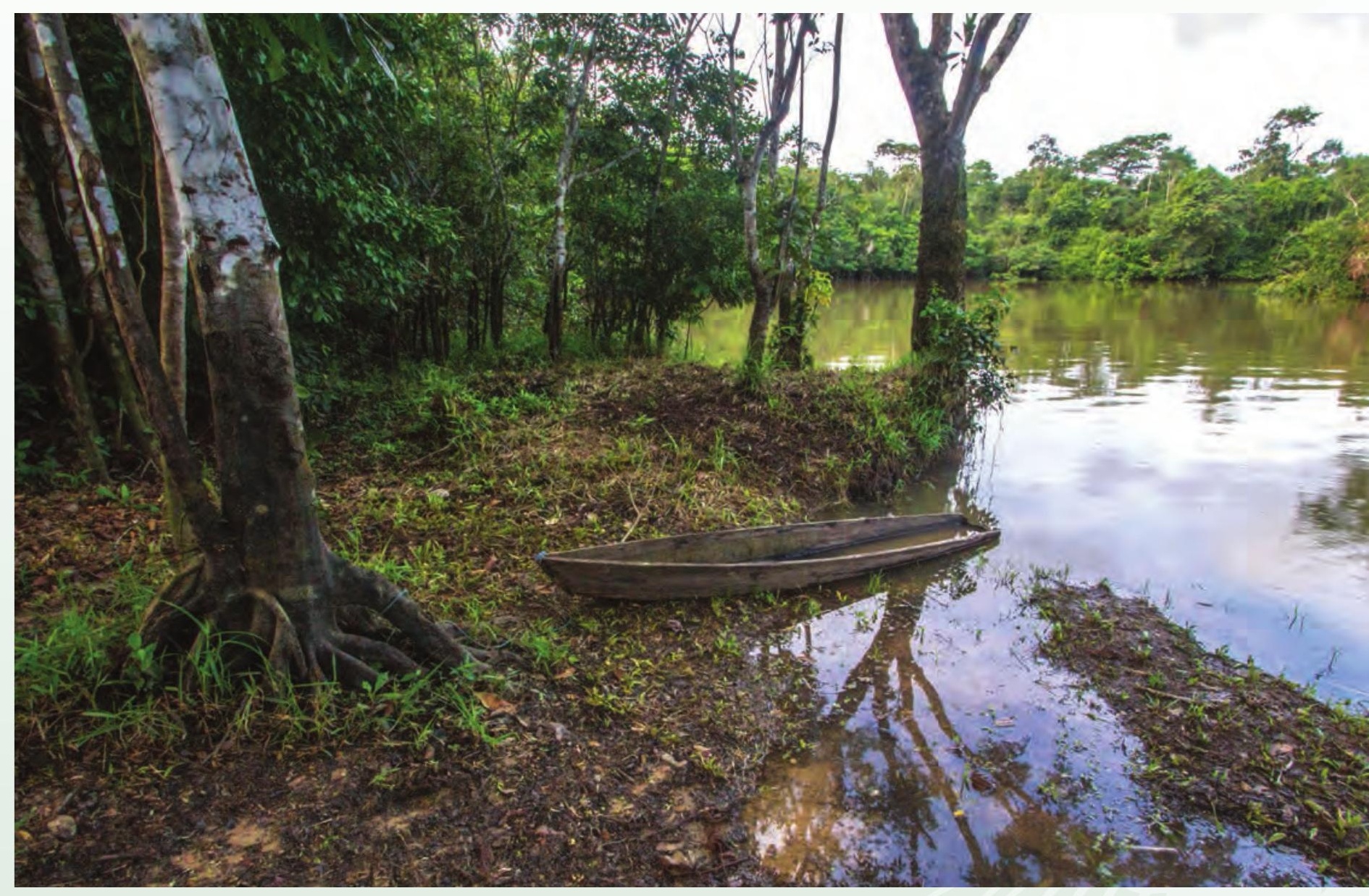

La Reserva Comunal Purús es administrada y gestionada por el SERNANP, representado por la jefatura de la reserva y por el Ejecutor del Contrato de Administración (ECA) como representante de la sociedad civil. La RC Purús es un área de uso directo que sirve como zona de amortiguamiento para el Parque Nacional Alto Purús ${ }^{72}$. La gestión de la RCP se rige por el Régimen Especial de Reservas Comunales ${ }^{73}$ e incluye cuatro sectores en la cuenca de los ríos Purús y Curanja: Alto Purús, Medio Purús, Bajo Purús y Curanja.

El proceso para establecer la reserva fue participativo, con autoridades públicas a nivel nacional, regional y local, los representantes de las poblaciones indígenas e instituciones de la sociedad civil. El establecimiento de la reserva ha hecho, entre otras cosas, que disminuya la tala ilegal de árboles de caoba.

La Reserva Comunal Purús cuenta con su segundo Plan Maestro para el periodo 2012-2017 con los siguientes objetivos:
- Mantener en buen estado los ecosistemas y sus procesos

- Asegurar el uso de los recursos naturales de acuerdo con un modelo que permita el ordenamiento de las actividades

- Promover la consolidación del compromiso de cogestión con los principales usuarios

En el proceso de consulta y validación del plan maestro se estableció la zonificación de la reserva, conformada por:

- Zona de protección estricta (PE)

- Zona silvestre (S)

- Zona de aprovechamiento directo (AD)

Ley de Áreas Naturales Protegidas (Ley N. ․ 26834) 73. Resolución de Intendencia N. ${ }^{\circ}$ 019-2005-INRENA-IANP 


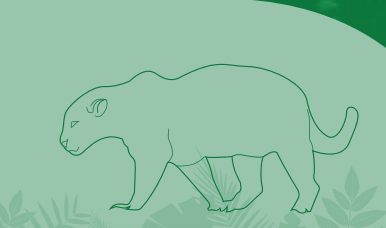

\begin{tabular}{|c|c|c|}
\hline & $\begin{array}{c}\text { Zona de protección } \\
\text { estricta }\end{array}$ & $\begin{array}{l}\text { Son zonas con ecosistemas muy frágiles que no han sido intervenidos. } \\
\text { Ocupan el } 12 \text { \% de la reserva. } \\
\text { Están permitidas actividades que no perturben el recurso hídrico, } \\
\text { actividades de control y vigilancia que generen bajo impacto en el área. } \\
\text { Tránsito de personas que habitan en áreas adyacentes de la reserva e } \\
\text { investigación científica en temas prioritarios para la reserva. } \\
\text { No se permiten actividades extractivas de recursos naturales, } \\
\text { construcción de infraestructuras de ningún tipo o que pongan en riesgo } \\
\text { a los pueblos indígenas en Aislamiento Voluntario y Contacto Inicial } \\
(\mathrm{PIACI})^{74} \text {. }\end{array}$ \\
\hline & Zona silvestre & $\begin{array}{l}\text { Son zonas con poca intervención humana. Ocupan el } 62 \text { \% de la reserva. } \\
\text { Se permiten actividades de administración, control, investigación } \\
\text { científica, educación y recreación sin infraestructura permanente ni } \\
\text { vehículos motorizados. Se pueden realizar patrullajes y monitoreo } \\
\text { ambiental, investigación científica, actividades de ecoturismo, } \\
\text { recreación y educación ambiental con bajo impacto y pesca y caza para } \\
\text { autosustento por parte de comunidades nativas. } \\
\text { No se permite la extracción de recursos forestales, construcción de } \\
\text { infraestructuras, actividad minera o extracción de hidrocarburos, } \\
\text { actividades que perturben el recurso hídrico. }\end{array}$ \\
\hline $\begin{array}{r}\text { Tabla 19: } \\
\text { Zonificación Reserva } \\
\text { Comunal Purús }\end{array}$ & $\begin{array}{c}\text { Zona de } \\
\text { aprovechamiento } \\
\text { directo }\end{array}$ & $\begin{array}{l}\text { Son zonas de aprovechamiento de recursos naturales utilizadas de manera } \\
\text { tradicional por las poblaciones locales. Representa el } 25 \text { \% de la reserva. } \\
\text { Se permite la utilización directa de flora o fauna silvestre, incluyendo } \\
\text { la pesca con fines de subsistencia, actividades para la educación, } \\
\text { investigación y recreación, actividades de control y vigilancia y monitoreo } \\
\text { ambiental así como proyectos pilotos para el aprovechamiento de } \\
\text { recursos naturales. }\end{array}$ \\
\hline
\end{tabular}

Las actividades productivas en la RC Purús van de la mano con el desarrollo sostenible, pero es necesario promocionarlas tanto en el interior del área como fuera de la reserva. Se considera necesario lograr la certificación ambiental de los productos extraídos del bosque para obtener más beneficios económicos y porque se sabe que es una puerta para introducirse en el mercado y dar salida a los productos que allí se producen.

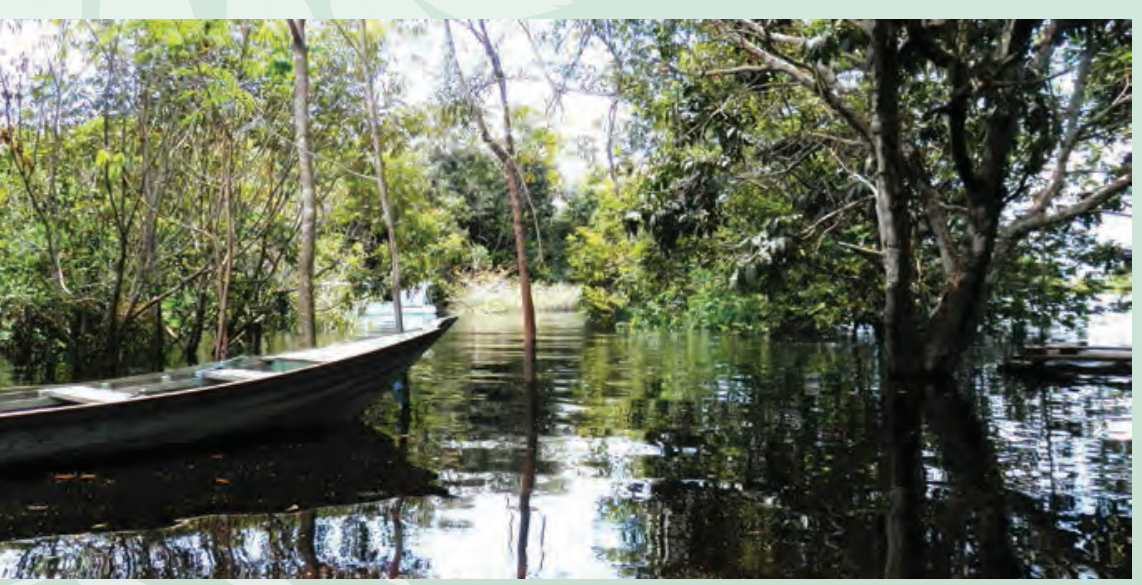

La Reserva Comunal Purús es parte del proceso de creación del Parque Nacional Alto Purús y, a diferencia de las reservas territoriales, fue planificada para que la población que se encuentra en el distrito de Purús pueda aprovechar, de manera directa, los recursos de los bosques del sector y, de manera indirecta, los recursos que se conservan en el parque nacional. Este se convierte en una "zona fuente" para la distribución de especies de fauna que son la base del consumo alimentario de la población de esta zona.

El proceso de concertación para la creación de la Reserva Comunal Purús se realizó con once comunidades nativas que se encuentran en la zona de influencia directa de la reserva y se logró asegurar la creación de una nueva AP que permita el aprovechamiento sostenible de los recursos naturales de la zona (entrevista Rafael Pino, 2016). 


\begin{tabular}{|c|c|c|}
\hline Paisaje & AP de referencia & Territorios comunitarios \\
\hline \multirow{11}{*}{ Sur } & \multirow{11}{*}{ Reserva Comunal Purús } & Santa Rey \\
\hline & & Santa Margarita \\
\hline & & Balta \\
\hline & & Laureano \\
\hline & & Gastabala \\
\hline & & San Marcos \\
\hline & & Cashuera \\
\hline & & Conta \\
\hline & & Canta Gallo \\
\hline & & Bola de Oro \\
\hline & & Catay \\
\hline
\end{tabular}

Por la categoría de manejo de la Reserva Comunal Purús y el trabajo coordinado de vigilancia y monitoreo del parque nacional, la creación de esta reserva permitió que la extracción ilícita de madera en la zona de Puerto Esperanza disminuyese sensiblemente y, además, asegurar que las comunidades de la zona no fuesen "estafadas" por los negociantes madereros. Estos, ofreciendo pagos mínimos en víveres y herramientas, hacían uso de las escrituras de los territorios de las comunidades para tramitar permisos de aprovechamiento forestal y, después de extraer la madera fina de las comunidades, desaparecían sin pagar los impuestos estatales de estos permiso. Por ello, las comunidades quedaron endeudadas con el Estado por una actividad de la que se beneficiaron de manera mínima (entrevistas comunidades, 2016, entrevista OSINFOR, 2016).

De manera complementaria, la Reserva Comunal Purús ha asegurado la protección de zonas de tránsito ancestral del pueblo indígena mashco piro que habita en el Parque Nacional Alto Purús. En la actualidad, en esta reserva se encuentra una familia indígena de tres miembros en contacto inicial.

Colindante con la Reserva Comunal Purús se encuentra la concesión forestal MA-
BOSINFRON (Asociación de Manejo de Bosques Sin Fronteras), en la cuenca del río La Novia, y es parte del área de amortiguamiento de la Reserva Comunal Purús. Trabaja en actividades de investigación junto con la reserva y con el Parque Nacional Purús.

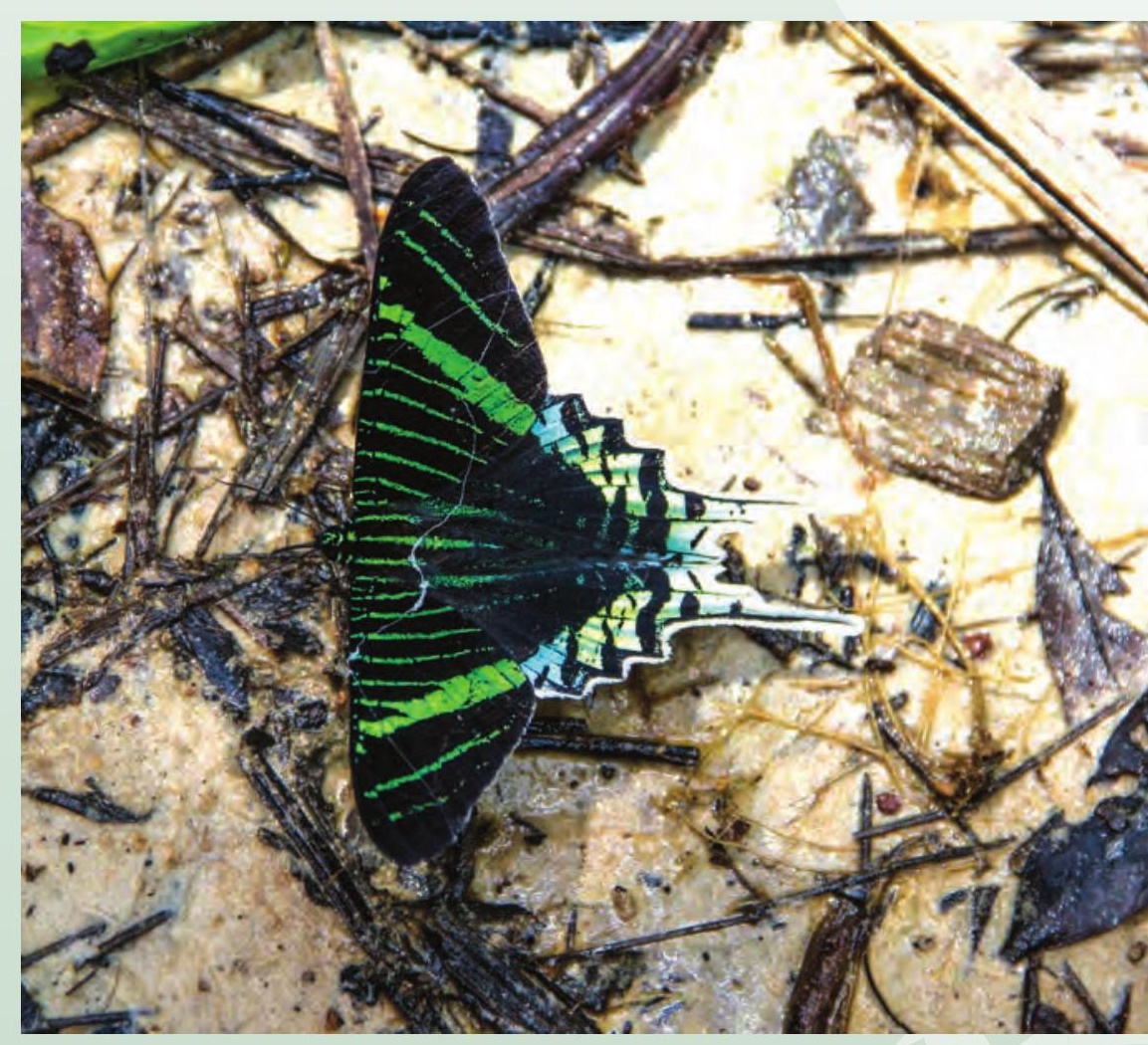




\section{Condiciones materiales de vida de la población de las áreas protegidas}

Las condiciones materiales de vida son los elementos con los que cuenta la población para el desarrollo cotidiano. Este concepto hace referencia a los elementos que están a disposición o de los que carece la población y que mejoran o dificultan sus condiciones de vida.

Estas condiciones materiales están vinculadas a la inversión pública que realiza el Estado como parte de su función de abastecer a la población de servicios básicos y también están vinculadas a las posibilidades de la población de abastecer su hogar y generar ingresos para satisfacer sus necesidades.

Las condiciones materiales analizadas para dar cuenta de las condiciones de vida de la población de las AP son los servicios básicos, realizando un breve análisis de las características económicas de las poblaciones locales de las AP.
Es importante analizar las condiciones materiales de las poblaciones locales ya que, si bien estas condiciones no están vinculadas a la gestión de las AP, definen la manera en que la población se relaciona con su entorno (en este caso los ecosistemas de las AP) y las expectativas que tienen sobre la gestión.

La provisión de servicios básicos en las AP puede ser un tema complejo de abordar ya que, en general, los indicadores vinculados al análisis de estos servicios y su interpretación mantienen un sesgo urbano. Sin embargo, incorporarlos en el análisis permite aproximarse a las condiciones de vida de la población. Todas las poblaciones de las AP consideradas toman agua para uso del hogar de vertientes o pozos. El abastecimiento de luz, en la mayoría de AP, se realiza a través de generadores con combustible lo que encarece el acceso a este

\begin{tabular}{|c|c|c|c|c|}
\hline Área protegida & Agua & Luz & Teléfono & Internet \\
\hline RPF Cuyabeno & De vertiente & $\begin{array}{l}\text { Generador con } \\
\text { combustible } \\
\text { Paneles solares }\end{array}$ & $\begin{array}{l}\text { Sí, en los } \\
\text { campamentos } \\
\text { para turistas }\end{array}$ & No \\
\hline PNN La Paya & De vertiente & $\begin{array}{l}\text { Sí, cerca de zonas } \\
\text { urbanas } \\
\text { Paneles solares al } \\
\text { interior del AP }\end{array}$ & $\begin{array}{l}\text { Celular cerca de } \\
\text { zonas urbanas }\end{array}$ & $\begin{array}{l}\text { Sí, en un puesto } \\
\text { de control }\end{array}$ \\
\hline RNVSA Manuripi & $\begin{array}{l}\text { De vertiente o } \\
\text { pozos }\end{array}$ & Sí, red pública & Celular & \\
\hline $\begin{array}{l}\text { RESEX } \\
\text { Cazumbá- } \\
\text { Iracema }\end{array}$ & De vertiente o pozo & $\begin{array}{l}\text { Sí, red pública } \\
\text { Generador con } \\
\text { combustible } \\
\text { Paneles solares }\end{array}$ & $\begin{array}{l}\text { Sí, en la casa de la } \\
\text { jefatura del parque } \\
\text { También en } 4 \\
\text { comunidades } \\
\text { (Cazumbá, Médio } \\
\text { Caeté, Alto Caeté y } \\
\text { Cachoreira) }\end{array}$ & $\begin{array}{l}\text { Sí, en la casa de } \\
\text { la jefatura del } \\
\text { parque }\end{array}$ \\
\hline PE Chandless & De vertiente & \begin{tabular}{|l} 
Generador con \\
combustible \\
Paneles solares \\
\end{tabular} & $\begin{array}{l}\text { En la oficina de } \\
\text { la jefatura del } \\
\text { parque. }\end{array}$ & No \\
\hline RC Purús & $\begin{array}{l}\text { De vertiente o } \\
\text { pozos }\end{array}$ & No & No & No \\
\hline PN Alto Purús & $\begin{array}{l}\text { De vertiente o } \\
\text { pozos }\end{array}$ & $\begin{array}{l}\text { Algunas } \\
\text { comunidades tienen } \\
\text { generador con } \\
\text { combustible }\end{array}$ & No & No \\
\hline
\end{tabular}


servicio. Únicamente la RNVSA Manuripi y la RESEX Cazumbá-Iracema poseen servicio eléctrico de red pública en las zonas amanzanadas

El servicio de teléfono es restringido en las AP, solamente en el PNN La Paya y en la RNVSA Manuripi tienen cobertura de telefonía celular, aunque este servicio también es limitado. En el PE Chandless y en la RESEX CazumbáIracema tienen acceso a teléfono en la oficina de la jefatura del parque y también en 4 comunidades (Cazumbá, Médio Caeté, Alto Caeté y Cachoreira). Además, los lodges de Cuyabeno también tienen acceso telefónico. Ninguna de las comunidades que se encuentran dentro de las AP cuenta con servicios de internet.

Como ya se ha visto en apartados anteriores, todas las poblaciones de las AP tienen acceso a servicios de educación y salud. Las escuelas se encuentran en las comunidades (o cerca de ellas) y para completar los estudios de secundaria los jóvenes deben trasladarse a lugares más lejanos. El servicio de salud que utiliza la población de las AP, cuando la medicina tradicional no es suficiente, es público en todos los casos analizados. El problema con el acceso a este servicio es que la población debe movilizarse hasta los lugares donde se encuentra disponible y, exceptuando el caso de la RNVSA Manuripi y la RESEX Cazumbá-Iracema, deben movilizarse vía fluvial para llegar, lo que supone un fuerte limitante de acceso, ya que conseguir combustible en estas zonas es difícil y las distancias que deben atravesar son amplias.

La economía de las poblaciones locales de las AP (indígenas y mestizas) se sustenta en la unidad familiar. Son economías familiares y las condiciones de trabajo e ingresos que tienen no se enlazan con formas de acumulación económica, sino más bien con la reproducción del hogar. Este tipo de economía se caracteriza, de manera primordial, por el uso de la mano de obra de la familia para las actividades económico-productivas (lo que implica que no son personas asalariadas -o lo son por temporadas-) y por el pluriingreso, es decir, por tener varias fuentes de ingresos económicos, por ejemplo, ingresos por agricultura, ganadería, manufactura de artesanías, de canoas, venta de presas de caza, etc. Por ello, los ingresos son variables, dependiendo de la actividad.
Debido a las características de la economía de las poblaciones rurales amazónicas y a las condiciones de abastecimiento de servicios básicos en estos territorios, se puede considerar que estas poblaciones tienen fuertes limitaciones. Sin embargo, estas limitaciones son difíciles de medir ya que la visión sobre el bienestar es muy compleja, sobre todo con la población indígena.

"Es importante destacar que no hay una visión indígena única sobre el bienestar o la pobreza. Por un lado, hay líderes e intelectuales indígenas que afirman que el concepto de pobreza es una manera de discriminar o desvalorizar la cultura indígena. El hecho de comparar la sociedad indígena con el resto de la sociedad nacional en términos de ingresos, escolaridad o saneamiento básico es injusto, ya que estos son indicadores propios de la sociedad nacional que no tienen la misma relevancia para los indígenas. Si fuera de comparar las dos en base a la solidaridad, la calidad de las interacciones sociales o la convivencia con la naturaleza sería la sociedad nacional que se consideraría pobre." (Renshaw y Wray, 2004: 1)

Sin embargo, existen necesidades de las poblaciones locales de las AP que requieren ser resueltas y que no pueden ser satisfechas completamente con los ingresos percibidos por los hogares. Jabón, aceite, ropa, tecnología, entre otros, son parte de los bienes de consumo de las poblaciones locales de las AP para los que requieren ingresos monetarios y a los que tienen dificultades de acceder.

Se debe puntualizar que la limitación principal que tienen estas poblaciones es la capacidad de consumir/comprar los bienes que requieren y que no pueden producir ${ }^{77}$. Estas limitaciones, en la posibilidad de consumo de las poblaciones locales de las AP, generan que se ejerza mayor presión sobre los recursos del bosque (mayor caza, por ejemplo) y que crezcan las expectativas sobre lo que debería ser la gestión de las AP para el beneficio de las poblaciones locales.

77. Para ampliar la discusión sobre el concepto de pobreza y su conceptualización se sugiere revisar: Spicker, P., Álvarez Lequizamón, S., \& Gordon, D. (2009). Pobreza un glosario internacional (No. 3 300.72). e-libro, Corp. 


\section{Condiciones materiales de vida de la población de las áreas protegidas}

Un mecanismo que desarrollan los Estados para reducir esta brecha entre lo que la población produce y lo que necesita comprar o consumir son las transferencias condicionadas, que son desembolsos directos a las personas que se encuentran en peores situaciones eco- nómicas y son consideradas pobres, a cambio de cumplir algunas condiciones (inscribir a los niños en la escuela, llevar controles médicos, etc.). Gran parte de las poblaciones locales de las AP reciben estas transferencias monetarias condicionadas.

\begin{tabular}{|c|c|c|c|c|}
\hline $\begin{array}{c}\text { Área } \\
\text { protegida }\end{array}$ & $\begin{array}{l}\text { Transferencias } \\
\text { condicionadas }\end{array}$ & Grupo meta & $\begin{array}{l}\text { Valor moneda } \\
\text { local }\end{array}$ & Valor USD \\
\hline Ecuador & $\begin{array}{l}\text { Bono de desarrollo } \\
\text { humano }\end{array}$ & $\begin{array}{l}\text { Familias } \\
\text { catalogadas } \\
\text { como pobres y } \\
\text { extremadamente } \\
\text { pobres }\end{array}$ & 50 USD & 50 USD \\
\hline Perú & $\begin{array}{l}\text { Programa Nacional } \\
\text { de Apoyo Directo } \\
\text { a los Más Pobres } \\
\text { "Juntos" }\end{array}$ & $\begin{array}{l}\text { Hogares en } \\
\text { situación de } \\
\text { pobreza extrema } \\
\text { con hijos } \\
\text { menores de } 14 \\
\text { años y mujeres } \\
\text { embarazadas }\end{array}$ & 200 PEN & 59,28 USD \\
\hline \multirow{3}{*}{ Bolivia } & Bono Juana Azurduy & $\begin{array}{l}\text { Mujeres } \\
\text { embarazadas } \\
\text { y niños hasta } \\
2 \text { años durante } \\
\text { todo el periodo de } \\
\text { gestación }\end{array}$ & $1820 \mathrm{BOL}$ & 257,15 USD \\
\hline & Bono Juancito Pinto & $\begin{array}{l}\text { Estudiantes } \\
\text { hasta } 8^{\circ} \text { año de } \\
\text { educación básica }\end{array}$ & $200 \mathrm{BOL}$ & 28,25 USD \\
\hline & Bono Renta Dignidad & $\begin{array}{l}\text { Personas mayores } \\
\text { de } 60 \text { años }\end{array}$ & $250 \mathrm{BOL}$ & 35,32 USD \\
\hline Brasil & Bolsa Familia & $\begin{array}{l}\text { Familias } \\
\text { consideradas } \\
\text { en condición de } \\
\text { pobreza y extrema } \\
\text { pobreza }\end{array}$ & $\begin{array}{l}\text { Según el número } \\
\text { de miembros } \\
\text { entre } 143,57 \mathrm{RBL} \\
\text { y } 236,47 \mathrm{RBL}^{78}\end{array}$ & $\begin{array}{l}\text { Entre } 40 \text { USD y } \\
66,71 \text { USD }\end{array}$ \\
\hline Colombia & $\begin{array}{l}\text { Más familias en } \\
\text { acción }\end{array}$ & $\begin{array}{l}\text { Familias con hijos } \\
\text { menores de } 7 \text { años }\end{array}$ & $\begin{array}{l}\text { Municipios con } \\
\text { Índice de pobreza } \\
\text { Multidimensional } \\
\text { de } 70 \% \text { o mayor } \\
\text { el incentivo es de } \\
71400 \text { COP } \\
719\end{array}$ & 22,53 USD \\
\hline
\end{tabular}

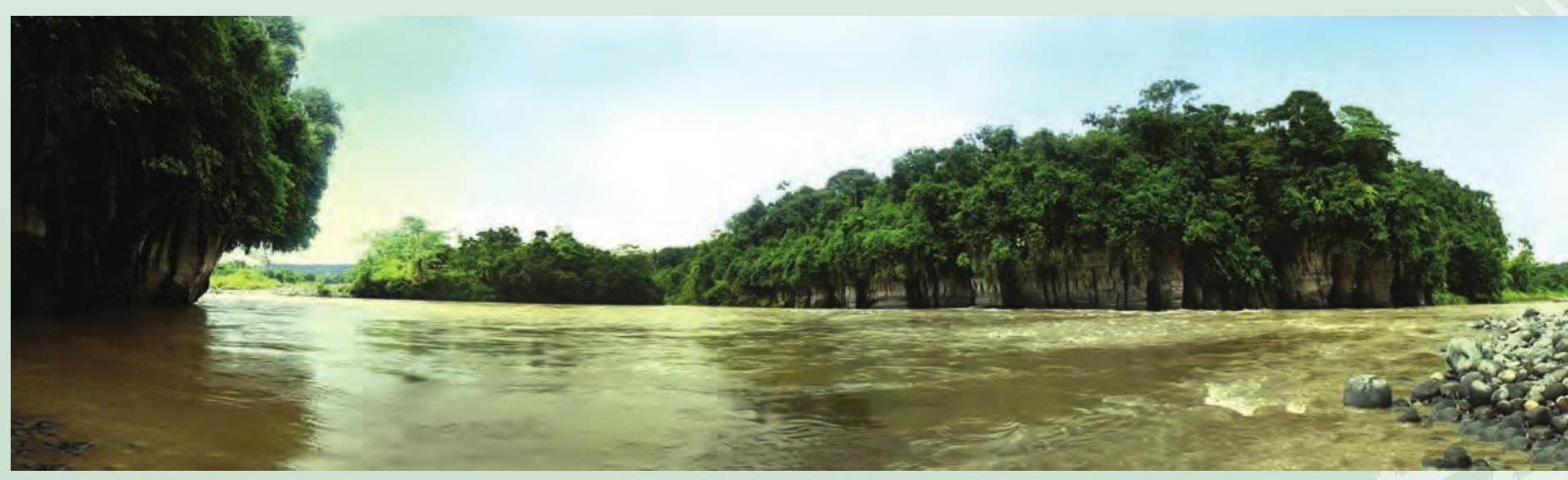




\section{El papel de los pueblos indígenas y las comunidades locales para la conservación de las áreas protegidas}

\section{Metodología}

\begin{abstract}
La información para la presente investigación se recopiló a través de fuentes secundarias (análisis de documentos, informes, artículos) y a través de fuentes primarias derivadas de entrevistas (vía teleconferencia y en persona) a actores estratégicos del paisaje. Además, se realizaron salidas de campo a ambos paisajes, lo cual permitió ampliar y validar la información obtenida en la primera fase de la investigación. Para esto se llevaron a cabo entrevistas, grupos focales y reuniones (observación no participante) realizadas con actores dentro de las áreas protegidas y en sus zonas de amortiguamiento.
\end{abstract}

\footnotetext{
Las entrevistas y grupos focales se realizaron en base a observación participante con preguntas guía. En las entrevistas se abarcaron los dos temas de las consultorías: "El papel de los pueblos indígenas y comunidades locales para la conservación tomando en cuenta su importancia ecológica, social y cultural" y "Los costos y los beneficios económicos y los impactos sociales y culturales derivados de la creación y el mantenimiento de áreas protegidas en los dos paisajes priorizados".
}

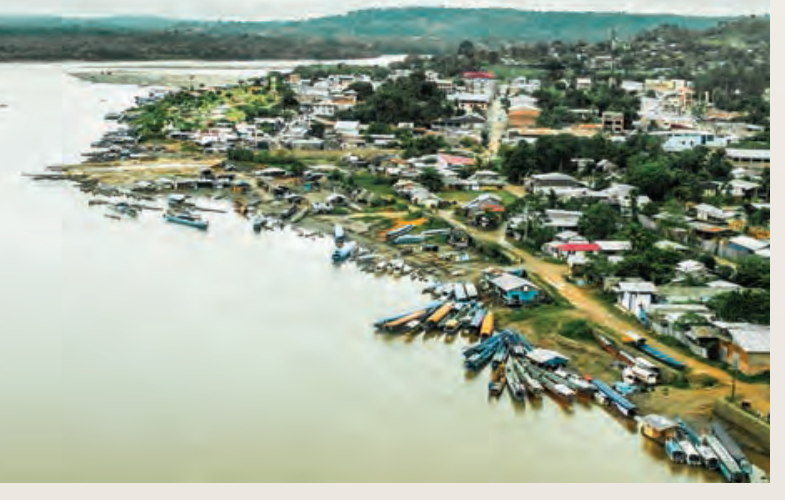

Antes de la salida de campo, se enviaron a los administradores de las áreas protegidas los temas, las preguntas guía a realizar a los entrevistados y una lista con los actores y representantes de sectores a ser tomados en cuenta, algunos de ellos indispensables y otros opcionales. Tanto en el paisaje norte como en el sur se mantuvieron reuniones con autoridades locales, representantes de asociaciones indígenas y campesinas, habitantes de las comunidades, empresarios y emprendedores. Se pidió incluir al menos una visita a una comunidad dentro de las áreas protegidas para poder realizar observación directa. Esto no fue posible en el PNN La Paya por motivos de seguridad relacionados con el conflicto armado que se vive en esa zona del país.

Una vez avalados los temas y los actores, los jefes de las áreas protegidas concertaron los días, horas y el lugar para las entrevistas. Esto, sin duda, facilitó la concreción del trabajo y permitió aprovechar al máximo el tiempo durante los días de visita. Ya en campo, la lista de entrevistados y los lugares de visita se fueron ajustando de acuerdo a las circunstancias existentes y a temas logísticos.

Por la dinámica local de cada una de las áreas protegidas, en algunas localidades se realizaron grupos focales, lo que facilitó que los entrevistados corroborasen sus opiniones sobre los distintos temas y, así, se enriqueció el levantamiento de información. Los lugares de las reuniones se establecieron tomando en cuenta la logística en la zona y la facilidad de acceso por parte de los entrevistados. Los temas que se trataron en los encuentros dependieron del sector al que representaron los actores. Se iniciaron estos encuentros con una breve explicación de los motivos de la entrevista, los objetivos de la misma y las expectativas de las 


\section{El papel de los pueblos indígenas y las comunidades locales}

consultoras; después se abordaron los temas, con las preguntas guía preestablecidas, a manera de conversación. Cada entrevista y grupo focal duró entre 30 minutos y una hora

Temas abordados

Ecológico:

- Uso y manejo de recursos naturales (RRNN) por parte de las comunidades indígenas en las AP

- Actividades tradicionales: caza, pesca, recolección y chacras

- Monitoreo de biodiversidad

- Control y vigilancia de las AP

- Percepción de las variaciones del clima

- Ordenamiento territorial

Social:

- Mecanismos de toma de decisión y espacios de participación local

- Presencia estatal/federal en las áreas protegidas

- Actividades productivas en las áreas protegidas y en las zonas de amortiguamiento

Cultural:

- Proyectos culturales, artesanías

- La participación de las mujeres, alimentación y plantas medicinales tradicionales

- La participación de los jóvenes

En el paisaje norte se visitó la Reserva de Producción de Fauna Cuyabeno en Ecuador. En el lado peruano se visitó el puesto de control del Servicio Nacional de Áreas Naturales Protegidas por el Estado de Perú (SERNANP) ubicado en Aguas Negras en el río Lagartococha, el centro poblado Puerto Estrella y la localidad Cabo Pantoja a orillas del río Napo. En Colom-

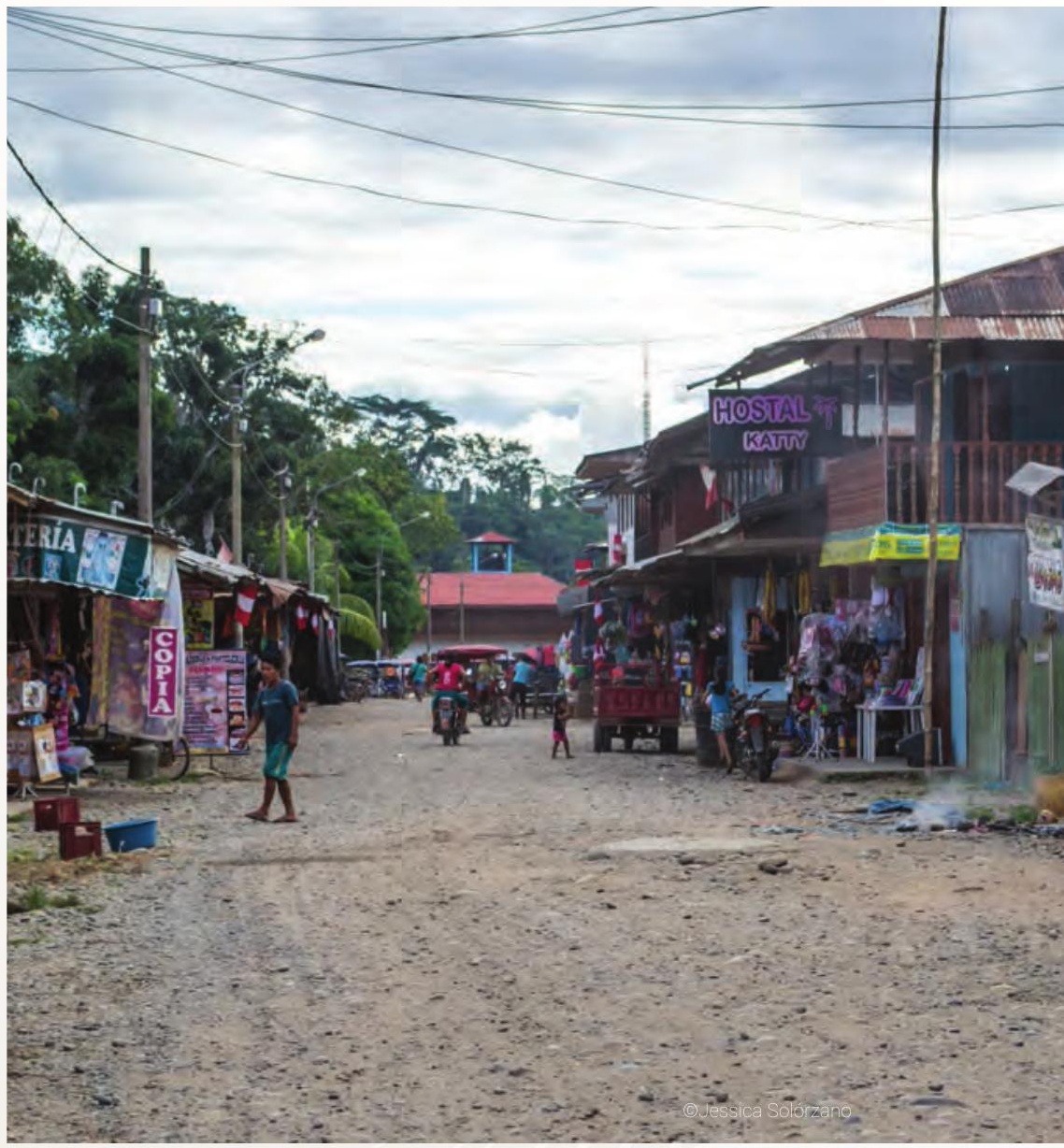

bia se visitó Puerto Leguízamo, donde están ubicadas las oficinas de Parque Nacional Natural (PNN) La Paya. Ahí se sostuvieron reuniones con representantes de diversos sectores de la zona con función amortiguadora del parque. Además, se visitó el Resguardo Indígena Jiri Jirí, a orillas del río Caquetá. La salida de campo al paisaje sur se realizó en la Reserva Nacional de Vida Silvestre Amazónica Manuripi, Bolivia, donde se visitaron las comunidades ubicadas a lo largo de la vía desde el cruce del río Manuripi hasta Chivé y la barraca Puerto América ubicada a orillas del río Madre de Dios. En Brasil se visitó la sede del Parque Estadual Chandless, a orillas del río Chandless y finalmente la Reserva Extractivista CazumbáIracema donde se visitó Núcleo do Cazumbá80.

La información que se presenta en el siguiente documento corresponde a junio de 2016.

80. La salida de campo al paisaje norte se realizó del 13 al 22 de marzo, 2016; la visita al paisaje sur fue del 21 de abril al 4 de mayo, 2016 


\section{Paisaje norte}

\section{Ámbito ecológico \\ Paiche y arawana, especies con manejo sostenible}

La arawana (Osteoglossum bicirrhosum) y el paiche (Arapaima gigas) son especies con un alto valor comercial y apetecidas en los mercados internacionales, lo que ha llevado a su sobreexplotación, principalmente por parte de pescadores ilegales.

"Si tumbamos mucha madera, se va a calentar el aire, nosotros cuidamos el bosque para que el aire no se caliente. Lo que necesitamos es apoyo".

Consejo de Abuelos, resguardo Jiri Jirí, Pueblo Indígena Murui. Marzo, 2016

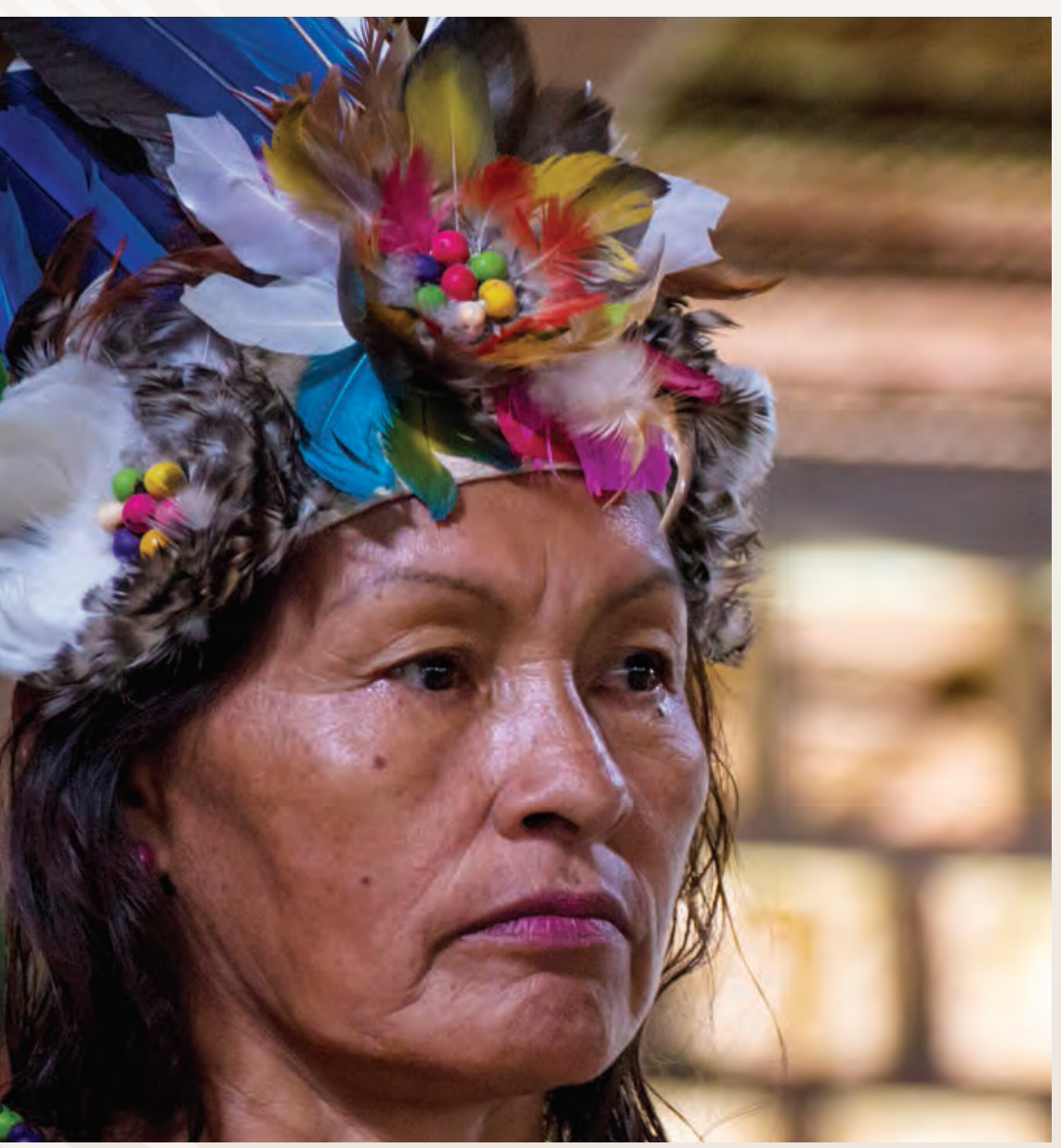

Desde el año 2009 en Perú, se desarrolló el proyecto "Manejo sostenible del Paiche y la Arawana"81 con comunidades indígenas kichwas, huitotos y secoyas, ubicadas en las zonas de amortiguamiento de las Reservas Airo Pai y Huimeki. El proyecto consistió en promover el manejo sostenible de estas especies, brindando capacitación técnica a la población y fortaleciendo el capital social de las comunidades a través de talleres participativos donde se desarrollaron planes de manejo para ambas especies y se conformaron grupos de manejo con miembros de las comunidades; los participantes también recibieron capacitación en aspectos relacionados a la comercialización ${ }^{82}$. En la comunidad secoya de Puerto Estrella se pudo conocer que 5 de sus miembros forman parte del equipo de monitoreo del paiche.

En el caso de la arawana, las prácticas empleadas anteriormente no eran sostenibles, pescaban indiscriminadamente y con técnicas que provocaban la destrucción de la especie. La pesca se realizaba en época de reproducción, se mataba a la madre con escopeta y se le extraían los alevines que guardaba en la boca pues, de la arawana, lo que se comercializa son las crías, las cuales permanecen en la boca de su progenitora hasta el momento de nacer. El proyecto modificó el mecanismo de pesca con escopeta a pesca de redes y rescató el conocimiento de los indígenas sobre los tiempos óptimos de captura (de acuerdo a la coloración de la boca) para lograr un aprovechamiento sostenible y la conservación de la especie.

Según Johana Deza ${ }^{83}$, a pesar de que es preciso desarrollar un monitoreo biológico constante, las comunidades han manifestado un aumento de la población de arawana. El proyecto logró el repoblamiento de ambas especies, además del involucramiento de las comunidades para su cuidado y manejo. Esto ha incidido positivamente en la disminución de la pesca ilegal así como en el fortalecimiento del trabajo coordinado entre el SERNANP y las comunidades locales.

\footnotetext{
81. La salida de campo al paisaje norte se realizó del 13 al 22 de marzo, 2016; la visita al paisaje sur fue del 21 de abril al 4 de mayo, 2016

82. El proyecto contó con el apoyo del proyecto "Putumayo Tres Fronteras" y WWF.

83. Los talleres contaron con el apoyo técnico y financiero de Dirección Regional de la Producción (DIREPRO), el SERNANP, el Centro para el Desarrollo del Indígena Amazónico (CEDIA) y WWF.
} 


\section{Paisaje norte: Ámbito ecológico}

El proyecto de la arawana constituye una primera experiencia de negocio viable y sostenible en la zona de Güeppír4. Las especies son comercializadas en Puerto Leguízamo ${ }^{85}$ (Colombia), debido a la cercanía y facilidad de acceso al mercado, desde donde las envían principalmente al sureste asiático. En la actualidad, no se cuenta con una normativa pesquera conjunta para ambos países por lo cual la venta desde Perú a Colombia se realiza de manera ilegalo6.

De acuerdo a información proporcionada por los entrevistados, se pudo conocer que en Puerto Leguízamo los precios son los mismos tanto para las especies que fueron producidas dentro de un proceso con plan de manejo y lineamientos de uso sostenible, como para las que no, por lo que los entrevistados ven la necesidad de que desde los Estados se promocione y favorezca la compra de productos certificados o manejados responsablemente a nivel comunitario.

\section{Repoblamiento de tortugas charapas}

En la RPF Cuyabeno, la comunidad cofán Zábalo lleva adelante desde el año 1989 el "Programa de manejo de tortugas charapas"87 (Podocnemis expansa), las cuales se encontraban en peligro de extinción porque tanto la tortuga como los huevos se usaban para consumo humano. El resultado es un repoblamiento significativo de la especie. Se calcula que desde los inicios del proyecto hasta el año 2009 se habían liberado alrededor de 100000 charapas a los ríos Zábalo, Aguarico y Cuyabeno ${ }^{88}$. Esto motivó al Ministerio del Ambiente de Ecuador (MAE) a ampliar el proyecto a las comunidades kichwas Playas de Cuyabeno y Zancudo Cocha para que, además de repoblar, tengan en la actividad un incentivo que genere ingresos económicos. La comunidad de Zábalo ahora tiene el objetivo de comercializar una parte de las tortugas a mercados internacionales. Para ello, el MAE elaboró un Plan de Negocios, el cual no arranca hasta el momento por falta de recursos ${ }^{89}$. Mientras tanto la comunidad se encuentra buscando alternativas de financiamiento y gestionando los permisos para poder exportar.

En el puesto de control de Aguas Negras, a orillas del río Lagartococha, los guardaparques de la RPF Cuyabeno y la RC Airo Pai, en trabajo conjunto, llevan adelante un proyecto de repoblamiento de charapas. Durante

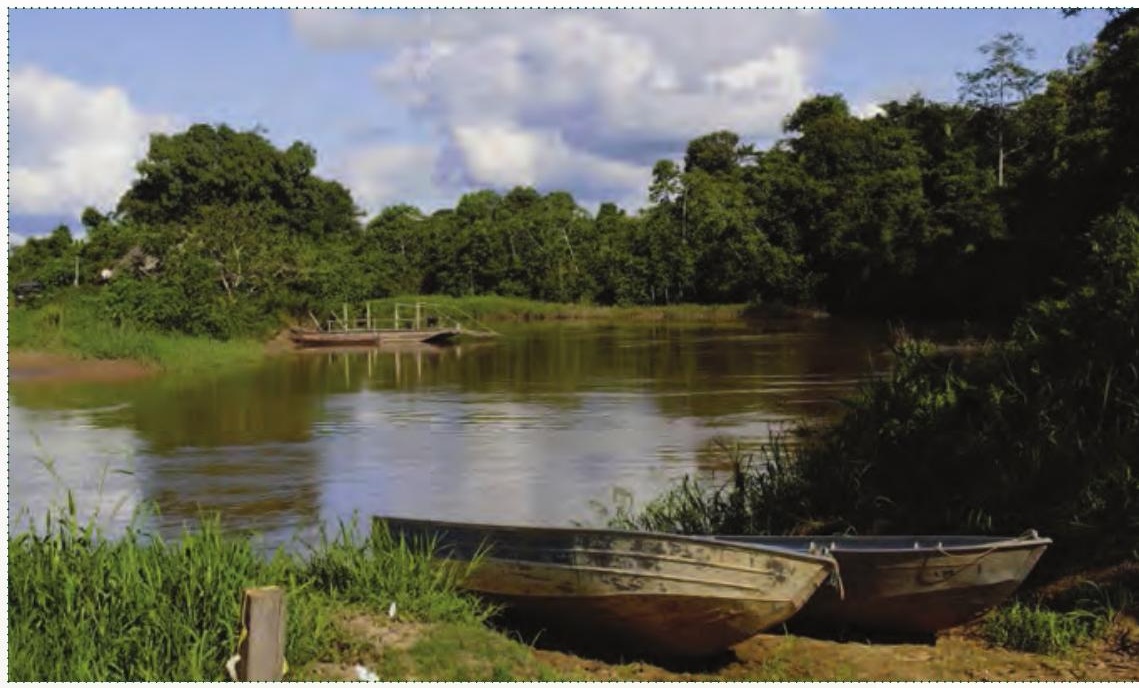

los días de visita a la zona (marzo, 2016) los guardaparques de Perú y Ecuador liberaron más de 2000 charapas en el río Lagartococha, las mismas que fueron criadas a orillas del río, en el lado peruano.

Pobladores locales monitoreando la biodiversidad

Las áreas protegidas que conforman el paisaje norte cuentan con un importante inventario de datos de flora y fauna de sus diferentes ecosistemas. Esto se realizó como parte del proyecto "Putumayo Tres Fronteras", en el cual se establecieron trece estaciones de muestreo en la cuenca del río Lagartococha, en su complejo de humedales en la frontera Perú-Ecuador y en la RPF Cuyabeno. Los muestreos fueron diurnos y nocturnos por lo que se pudieron registrar especies acuáticas y terrestres, anfibios, reptiles, aves y mamíferos. Además, se identificaron las especies endémicas y las amenazadas. El proyecto contó con participación comunitaria.

84. Usma, J.S., C. Ortega P., S. Valenzuela, J. Deza \& J. Rivas (Eds.) 2016. Diversidad biológica y cultural del Corredor Trinacional de áreas protegidas La Paya - Cuyabeno - Güeppí Sekime. Colombia - Ecuador - Perú. WWF. Bogotá D.C., Colombia. 333p.

85. Puerto Leguízamo es el enlace regional para proveer de arawana a centros de acopio y bodegas de exportación en Bogotá.

86 Usma, J.S., C. Ortega P., S. Valenzuela, J. Deza \& J. Rivas (Eds.) 2016. Diversidad biológica y cultural del Corredor Trinacional de áreas protegidas La Paya - Cuyabeno - Güeppí Sekime. Colombia - Ecuador - Perú. WWF. Bogotá D.C., Colombia. 333p.

87. Proyecto realizado con el apoyo inicial de The Field Museum de Chicago y Fundación Natura, años más tarde fue apoyado por Amaznor.

88. www.cofan.org

89. El MAE calculó que se necesitan 115000 USD para comenzar el proyecto, PetroAmazonas entregó 20000 USD. 
A través del proyecto "Putumayo Tres Fronteras" se establecieron los Lineamientos del Plan de Control y Vigilancia del Corredor Trinacional para fortalecer las actividades en las áreas protegidas, establecer objetivos comunes, alianzas y acuerdos de cooperación bi y trinacionales y analizar las amenazas existentes relacionadas a actividades ilegales de tala, caza, pesca y tráfico ilegal de fauna silvestre así como los impactos generados por las actividades hidrocarburíferas, minería, cultivos ilícitos y la presión por tierras en los límites de las áreas protegidas. El proyecto además dotó a las áreas protegidas con equipos especializados, nuevas infraestructuras y adecuación de las sedes existentes, con lo cual mejoraron su capacidad instalada ${ }^{92}$

La actividad de control y vigilancia es vista como un mecanismo de apoyo al manejo territorial. En las áreas protegidas de Ecuador y Perú, las actividades se hacen coordinadamente entre los guardaparques y las comunidades indígenas, las cuales participan para contrarrestar las actividades ilegales que se dan en sus territorios. En el PNN La Paya, las actividades de control y vigilancia se realizan principalmente por los guardaparques, con cierta dificultad, debido a la presencia de grupos al margen de la ley instalados ilegalmente dentro del parque.

En conversación mantenida con Luis Borbor, se pudo conocer que la RPF Cuyabeno asigna el mayor porcentaje de su presupuesto a la actividad de control y vigilancia. Cuenta con puestos de control en Tarapoa, Puente Cuyabeno y en el sector de la Laguna Grande. Desde 2012, la reserva cuenta con un Sistema de Control y Vigilancia que fue impulsado por el Sistema Nacional de Áreas Protegidas (SNAP) e incluye un diagnóstico y línea base, plan de acción y seguimiento. Esta área protegida fue la primera en implementarlo como un ejercicio piloto, y ha servido de ejemplo para otras áreas. Como resultado de este trabajo se establecieron los valores de conservación ${ }^{93}$, amenazas y zonas críticas de la reserva. El plan incluye una base de datos para control y vigilancia de recursos naturales y un formato único de recorridos que deben ser llenados por los guardaparques, que recibieron capacitación para completar los formatos y sistematizar la información. La información proporcionada por los guardaparques permite contar con datos relevantes para mejorar esta actividad.
El MAE mantiene Acuerdos de Uso y Manejo de Territorio con las comunidades indígenas que se encuentran dentro de la RPF Cuyabeno, donde se incluye, como parte de la responsabilidad del MAE, la implementación de un sistema comunitario de control y vigilancia para la reserva y se priorizan las zonas de mayor vulnerabilidad. Según los guardaparques de Cuyabeno, los mayores conflictos se dan en la cabecera de la reserva (localidad Puerto Nuevo) donde ocurren invasiones y un alto índice de infracciones forestales. Aunque existen los mecanismos legales no se dan las condiciones para enfrentar estas problemáticas y frenar las actividades ilícitas.

La comunidad cofán Zábalo (Cuyabeno) fue la primera en implementar un Sistema de Control y Vigilancia Local en $2003^{94}$ con el Programa de Guardaparques Cofanes, mediante el cual se entrenaron guardaparques comunitarios para la protección de su tierra (60 participantes hasta 2013). Estos se organizan en grupos de monitoreo ambiental y control y vigilancia, realizan recorridos por rutas preestablecidas y trabajan de manera rotativa en todo el territorio cofán; cuentan con varias estaciones a lo largo de su territorio y con formatos únicos para registrar

\footnotetext{
92. Ibídem, pág. 73

93. Entre los valores de conservación se encuentran las comunidades indígenas que habitan dentro de la reserva, con sus culturas y saberes, como también especies de fauna como el delfín rosado, manatí, nutria gigante y el jaguar. Están también las cuencas de los ríos Cuyabeno, Lagartococha y las lagunas de alrededor.

94. Proyecto ejecutado por la Fundación Sobrevivencia Cofán con el apoyo del Global Conservation Fund.
}

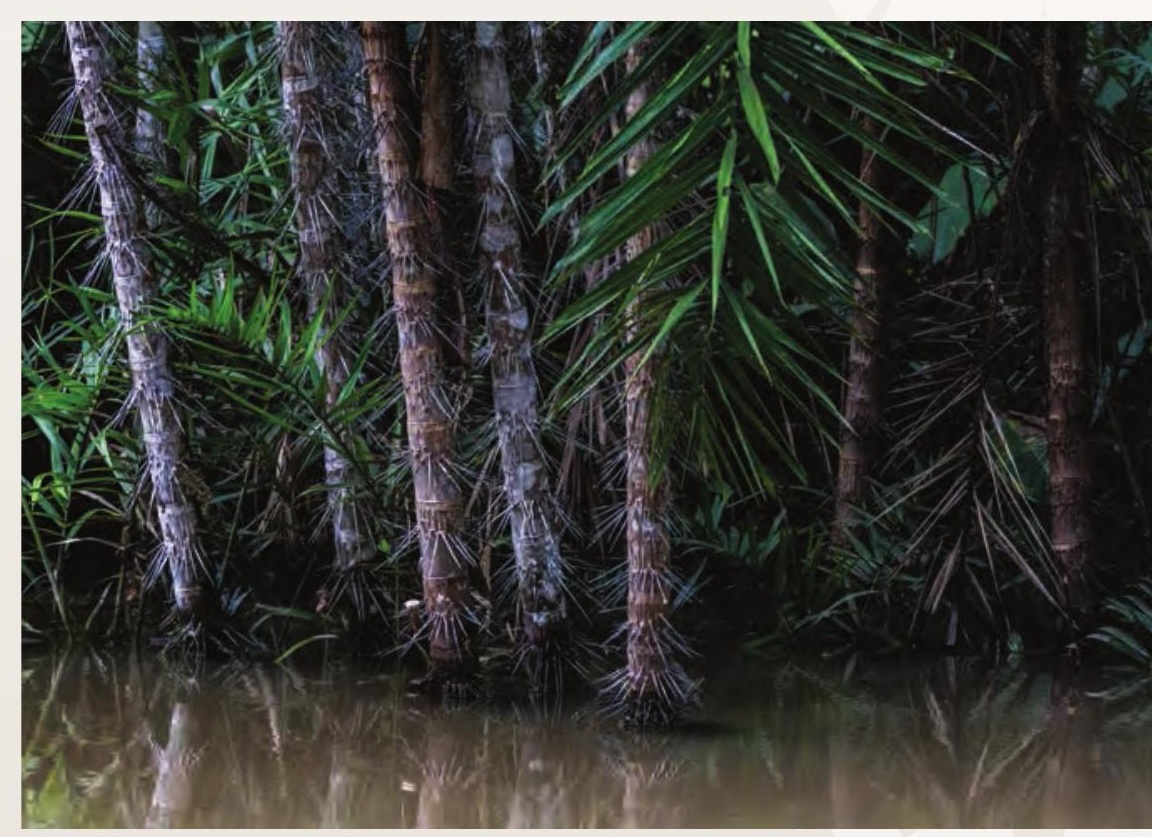


los datos, los cuales se usan para la generación de reportes y sistematización de información ${ }^{95}$. En 2013 hubo un curso de actualización de conocimientos, uso de GPS y legislación ambiental. Los guardaparques se capacitaron en una nueva herramienta de control y monitoreo desarrollada por la Escuela Latinoamericana de Áreas Protegidas de Costa Rica (ELAP) para sistematizar, organizar y generar información. Este proyecto es una de las pocas iniciativas en Ecuador donde un grupo indígena es reconocido oficialmente por el MAE (mediante Acuerdo Ministerial en el año 2002) como guardaparques de sus territorios ancestrales y las áreas protegidas estatales ${ }^{96}$. El MAE les otorgó una credencial de "guardaparques indígenas comunitarios" que les acredita para trabajar en su territorio.

Por su parte, el PNN La Paya tiene una balsa móvil ubicada en el río Caucayá, una sede operativa a $30 \mathrm{~km}$ de Puerto Leguízamo con una cabaña habilitada para servir de alojamiento a los funcionarios del PNN La Paya y otra cabaña en el sector de la Laguna La Apaya (a 60 km de Puerto Leguízamo río arriba por el Putumayo) en una finca de propiedad del parque. El PNN La Paya estableció acuerdos con diversas instituciones con las que se conformó el Comité Local de Prevención, Control y Vigilancia de Recursos Naturales de Puerto Leguízamo. Posterior a ello, el parque tuvo un papel relevante en la conformación del Comité Regional de Prevención, Control y Vigilancia de Recursos Naturales del Putumayo.

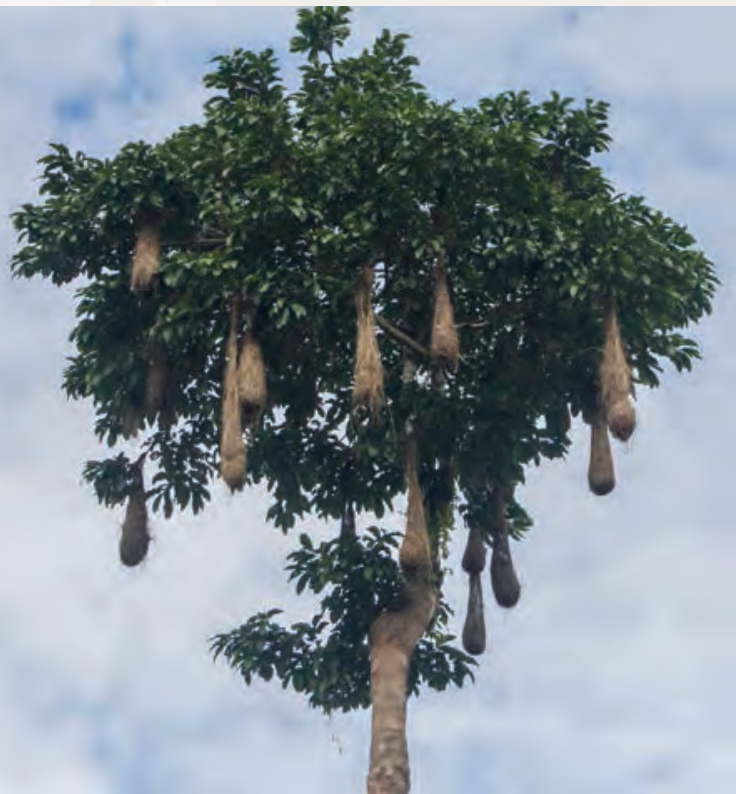

El PN Güeppí-Sekime y las RC Airo Pai y Huimeki cuentan, desde 2012, con un Plan de Control y Vigilancia. EI SERNANP, como una estrategia de conservación, trabaja en coordinación con la población local a través de grupos de control y vigilancia comunitaria, los cuales fueron capacitados por la DIREPRO (Dirección Regional de la Producción). Los comités de vigilancia comunitaria están conformados y reconocidos oficialmente por el SERNANP. Los guardaparques son indígenas de las comunidades, elegidos en asamblea comunitaria y avalados por la Organización Indígena Secoya del Perú (OISPE).

El SERNANP tiene una sede en Soplín Vargas, capital del distrito Teniente Manuel Clavero, ubicada frente a la sede del PNN La Paya, con la cual realizan actividades conjuntas. Tiene puestos de vigilancia ubicados en sitios estratégicos: uno en la cuenca del río Peneya, considerado un punto crítico de tala ilegal; otro en Aguas Negras, a orillas del río Lagartococha (que comparten con los guardaparques de Ecuador); y otro puesto de control en Mashunta, en la ribera del río Angusilla. El puesto de control en el río Peneya realiza un trabajo conjunto con la comunidad Santa Teresita de la etnia huitoto y los puestos de control en Aguas Negras y Mashunta trabajan con comunidades secoyas. Estos esfuerzos han resultado en más presencia del Estado en la zona, disminución de las actividades ilícitas y el establecimiento de compromisos y acuerdos entre las comunidades y el SERNANP para controlar y vigilar la zona y proteger los recursos naturales.

En la zona de amortiguamiento del PN GüeppíSekime, los pobladores de Cabo Pantoja tienen un acuerdo verbal con el SERNANP para colaborar en control y vigilancia, pero admiten que con los recursos que cuentan no pueden hacer una acción efectiva. Mencionan a la Dirección Nacional de Pesquería en lquitos como el órgano regulador en lo relacionado a pesca y con la cual se relacionan para actividades de control y vigilancia.

Para Luis Borbor, el trabajo que se realiza en la zona de Lagartococha es la "carta de presentación" del Programa Trinacional, principalmente

\footnotetext{
95. Este curso contó con el apoyo de USAID y la Iniciativa para la Conservación de la Amazonía Andina (ICAA). Fuente: www.cofan.org/blog Cofan Ranger Program.

96. Tomado de Boletín IICA, 9 de abril de 2009
} 
por el trabajo coordinado y la cooperación que hay entre los guardaparques de Ecuador y Perú. Menciona que los patrullajes coordinados y planificados entre las áreas protegidas Cuyabeno y Güeppí-Sekime han resultado en una disminución de las actividades ilegales de tala, caza y pesca. Además, cuenta que existe la propuesta para hacer una normativa entre los tres países con puestos de control trinacional. Las tres áreas protegidas coinciden con un déficit de guardaparques, lo cual les dificulta cumplir a cabalidad las tareas de control y vigilancia. Para Wilma Lucero, guardaparque de la RPF Cuyabeno, es necesario un reglamento trinacional ya que las leyes entre los tres países son distintas, lo cual impide un control más integrado de la zona.

\section{Incentivos para la conservación: Programa Socio Bosque}

\footnotetext{
El Programa Socio Bosque es un programa de conservación de los bosques promovido por el Estado ecuatoriano a través del MAE, el cual ha servido de apoyo a la actividad de control y vigilancia. Contribuye a disminuir la presión sobre los recursos naturales a través de la entrega de incentivos económicos a comunidades indígenas y campesinos que se comprometen a la conservación y protección de los bosques primarios, páramos y manglares que se encuentran en su territorio ${ }^{97}$.
}

Alrededor del $89 \%$ de los beneficiarios del programa pertenecen a comunidades indígenas de la Amazonía ecuatoriana. Uno de los requisitos para ingresar como socio es contar con título de propiedad comunitario y plan de manejo comunitario. Cuatro comunidades indígenas de la RPF Cuyabeno son socias de este programa: Zancudo Cocha (kichwa), Charap (shuar), Taikiua (shuar) y Zábalo (cofán), cubriendo una extensión total de casi 84000 ha. Las comunidades participantes, además de aportar a la conservación de la biodiversidad, se benefician económicamente, lo que incide en su calidad de vida. En Cuyabeno se benefician un total de 108 familias, las cuales reciben un ingreso anual de más de 240000 dólares $^{98}$. En 2011 el proyecto "Putumayo Tres Fronteras" apoyó a las comunidades en la preparación de información para ser socias de este programa con recopilación de información, reuniones periódicas y elaboración y seguimiento de los planes de inversión.

A través de este programa, el MAE entrega a las comunidades socias GPS para hacer control y monitoreo de su territorio. Llevan un registro y monitoreo de especies de flora y fauna y controlan las invasiones y las actividades ilícitas como tala y caza, información que se entrega al MAE.

\footnotetext{
97. Hasta diciembre 2016 contaba con 1489271,74 has conservadas y con 2759 socios a nivel nacional. 58 \% corresponde a bosque húmedo tropical
}

98. Información proporcionada por Jorge Rivas, WWF Ecuador, 2015

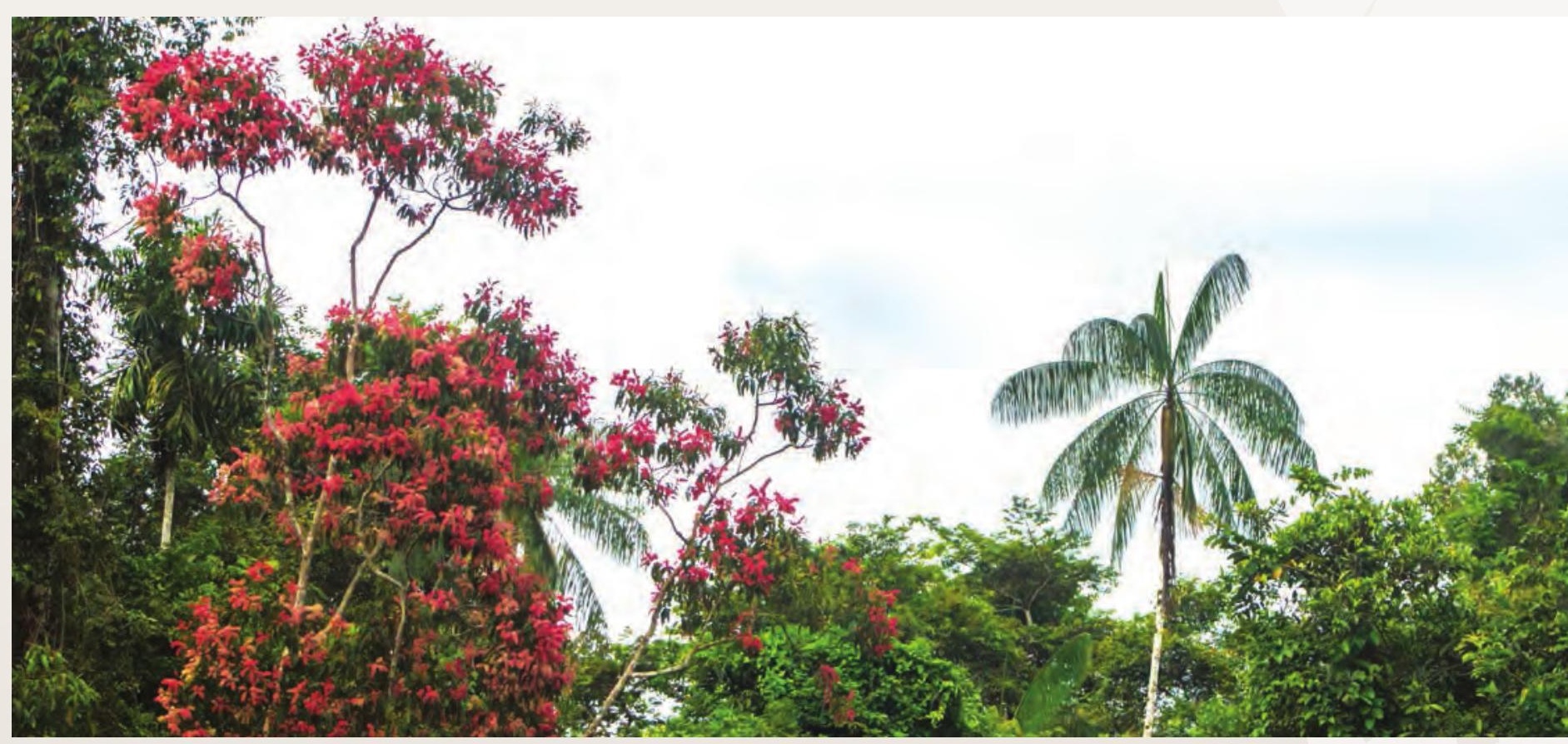




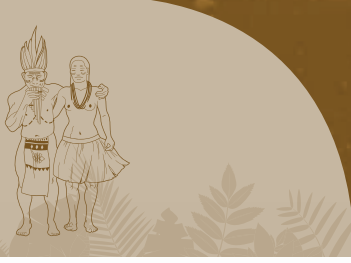

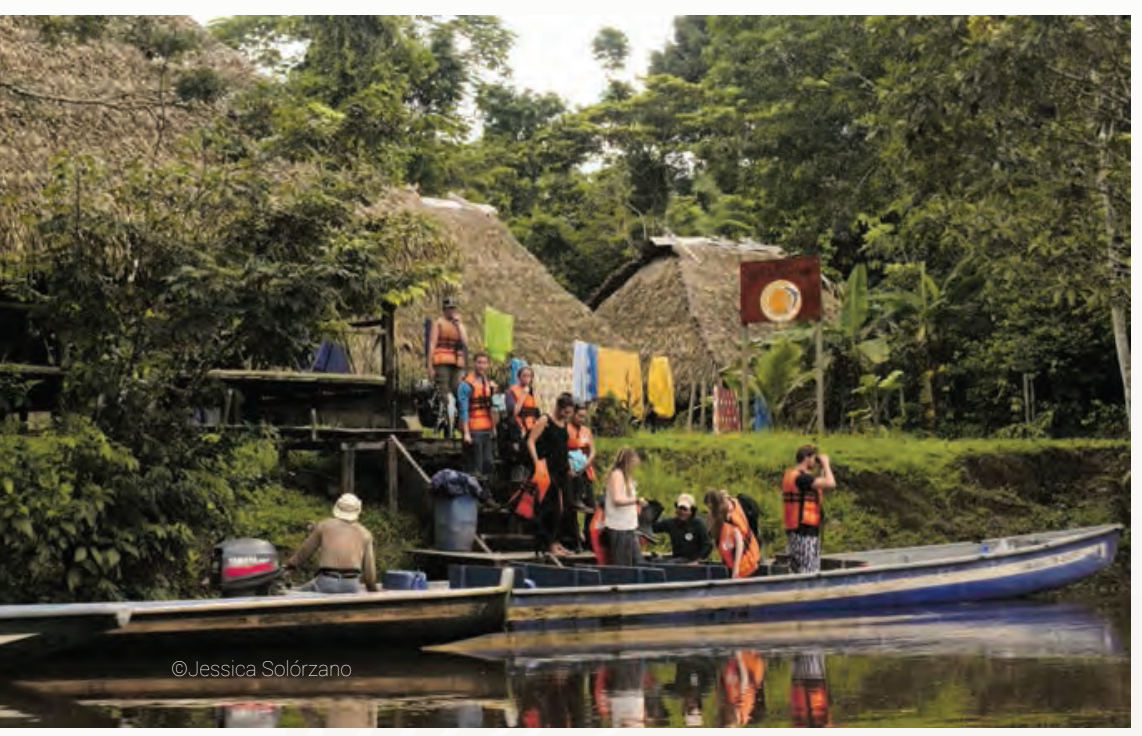

Julio Tangoy, miembro de la comunidad kichwa Zancudo Cocha y a cargo del puesto de control de la comunidad en el sector Pookoya, comenta que la comunidad se turna para hacer guardia por un mes en los dos puestos de control que mantiene (el otro puesto de control está en Sachaurco) y que los guardianes reciben un pago mensual. Explica que, antes de que la comunidad formase parte de este programa, se dedicaban a la caza tanto para autoconsumo como para comercialización en las localidades de Rocafuerte, Tiputini y Francisco de Orellana (conocida como El Coca). Desde que son socios, en el año 2010, cambiaron su economía de subsistencia por el pago que reciben del programa, cuidan el bosque y controlan la tala ilegal, en ocasiones con la ayuda de los militares ecuatorianos y el batallón peruano cercano a Pookoya. Tangoy manifiesta que no lleva registro escrito de los hallazgos, sino que memoriza las especies de maderables, árboles caídos, animales y aves que encuentra en sus recorridos por el bosque y después lo relata en su comunidad para el registro periódico al Ministerio del Ambiente.

De acuerdo a la información proporcionada por miembros de Zancudo Cocha, la comunidad está preparada, pues recibieron capacitación para manejar los recursos ${ }^{99}$. El pago que reciben del Programa Socio Bosque se realiza en base a su plan de inversión, el cual incluyó mejoras de infraestructura comunitaria, compra de medicinas y el mantenimiento de un medio de transporte fluvial propio, que usan principalmente para la actividad de turismo que ofrece la comunidad.
Ordenamiento territorial:

iniciativas a nivel de paisaje

Existe una iniciativa de los municipios de Puerto Leguízamo (Colombia), Puerto del Carmen (Ecuador) y Teniente Manuel Clavero (Perú) para desarrollar y trabajar de manera conjunta en un esquema asociativo de ordenamiento territorial trifronterizo. En este sentido, el Departamento Nacional de Planeación (DNP) y Parques Nacionales Naturales de Colombia han elaborado un plan de trabajo para adelantar las acciones necesarias que favorezcan la conformación del modelo de esquema asociativo. La primera jornada se realizó en diciembre de 2015 y tuvo como objetivo iniciar el acercamiento entre los Gobiernos de los tres municipios.

En marzo de 2016, se llevó a cabo en Puerto Leguízamo la "Jornada de intercambio de conocimientos y experiencias sobre planificación del desarrollo, ordenamiento territorial y gestión de áreas protegidas en Colombia, Ecuador y Perú hacia la construcción conjunta de un esquema asociativo de ordenamiento territorial trifronterizo". En esta reunión participaron los alcaldes y otras autoridades locales y nacionales de los tres países, quienes debatieron sobre los instrumentos de planeación del desarrollo, ordenamiento territorial y áreas protegidas con los que se cuenta para el diseño, ejecución, seguimiento y evaluación de políticas públicas que integran las áreas protegidas en esta zona de frontera.

El objetivo del encuentro fue socializar el estado del arte sobre aspectos conceptuales metodológicos, instrumentales (políticos, normativos y técnicos), procedimentales y competencias para la planeación del desarrollo, ordenamiento territorial y gestión de áreas protegidas en Colombia, Ecuador y Perú. Esto sirvió como insumo para la estructuración de un esquema asociativo de ordenamiento territorial trifronterizo a partir de los avances alcanzados a nivel político, técnico y operativo en los procesos de Acuerdo de Hermandad entre el Gobierno Autónomo Descentralizado (GAD) de Putumayo (Ecuador) y los Municipios de Soplin Vargas (Perú) y Puerto Leguízamo (Colombia). Otro tema fue el Memorando de Entendimiento para la ejecución del Programa Trinacional de Con-

99. Asesoría técnica de WWF a pedido del MAE 


\section{Paisaje norte: Ámbito ecológico}

servación y Desarrollo Sostenible del Corredor de Áreas Protegidas PNN La Paya, PN Güeppí y RPF Cuyabeno entre ministerios de ambiente de Colombia, Perú y Ecuador y la planeación del desarrollo y ordenamiento territorial en cada uno de los países. Posteriormente, se ha avanzado en:

- Inclusión del Esquema Asociativo en la Agenda Binacional Colombia-Ecuador en el eje medioambiente

- Socialización de las acciones, avances y desafíos del Esquema Asociativo al Programa Trinacional de Conservación

- Inclusión del municipio de Puerto Leguízamo en el Programa POT Modernos y el CONPES de Catastro multipropósito

\section{- Ejercicios de Prospectiva Territorial}

\section{Iniciativas de ordenamiento en las áreas protegidas}

\section{RPF Cuyabeno}

Los Acuerdos de Uso y Manejo de Territorio entre el MAE y las comunidades indígenas que se ubican dentro de la RPF Cuyabeno son un mecanismo para la conservación, gestión y manejo del territorio y han servido como un instrumento de confianza entre las partes, ya que, según algunos informantes, cuando se establecieron las áreas protegidas, algunos indígenas se sintieron despojados de sus territorios y limitados en el uso de los recursos.

Estos acuerdos reconocen la situación de tenencia de tierras por parte de las comunidades, la zonificación de uso (la misma que consta en el plan de manejo comunitario, parte integrante de estos convenios), los linderos y límites entre las comunidades y los procesos de comanejo de los territorios. El 88 \% del total de la superficie de la reserva está protegida bajo estos acuerdos, los cuales tienen una duración de diez años, renovables. El primer convenio suscrito bajo esta modalidad (autoridad ambiental-comunidad indígena) se dio en 1992 con la comunidad de Zábalo ${ }^{100}$; en este se reconoce "la posesión del territorio" y la jurisdicción de la comunidad. Este convenio es una excepción ya que Ecuador reconoce el derecho y posesión de uso de recursos naturales, pero no de propiedad dentro del AP; sin embargo, esto cambiará con la nueva Ley de Tierras, aprobada en enero 2016, que incluye la titularización global de territorios ancestrales.

Existen algunos conflictos de tenencia de tierra dentro de la reserva: los kichwas de Zancudo Cocha, los secoyas (en el sector de Pookoya) y los cofanes de Zábalo se atribuyen mutuamente el ingreso a cazar en territorio ajeno y la invasión a su territorio, a pesar de que los límites entre comunidades están bien establecidos. También hay conflictos entre los indígenas y las poblaciones de colonos ubicadas en el límite de la reserva. La zona más conflictiva está en la cabecera de la reserva donde, además, hay vías de acceso que la atraviesan (Nueva Loja-Puerto El Carmen), lo cual facilita la llegada de nuevos campesinos y la extracción de madera ilegal. La administración de la RPF Cuyabeno actúa como facilitadora para solucionar los conflictos relacionados con la posesión de la tierra, pero las decisiones finales las toman los implicados.

En la zona de amortiguamiento ${ }^{101}$, y a través del proyecto "Cuyabeno AMAZNOR", se realizaron los trámites legales para la entrega de títulos de propiedad a los finqueros con los cuales el MAE mantiene acuerdos para respetar y mantener los límites de la reserva. Los acuerdos entre la reserva y los colonos sirvieron para marcar los límites, aunque aún hay zonas con límites no definidos, lo cual genera conflictos. Según algunas opiniones de los entrevistados en la reunión mantenida en Tarapoa, los títulos individuales pusieron límites a las actividades ilícitas.

100. "Convenio entre el Ministerio de Agricultura y Ganadería y la Asociación de Comunidades Indígenas de la Nacionalidad Cofán (ACOINCO) y la Comunidad Cofán de Zábalo para la conservación, usos y servicios de los recursos de la Reserva de Producción Faunística Cuyabeno en la jurisdicción de la Comunidad de Zábalo", de 15 de abril de 1992.

101. Financiado por el gobierno de Ecuador, con fondos del Banco Interamericano de Desarrollo, ejecutado por UDENOR y el Ministerio del Ambiente y administrado por la UAP/AMAZNOR y la GTZ como su Operador Supervisor. Entre sus actividades está la linderación y legislación de la tenencia de la tierra, sensibilización y control y vigilancia de la RPF Cuyabeno. Infoandina.org 


\section{Zona de Güeppí}

En el año 2001, en la zona de Güeppí hubo un primer intento para categorizar el área protegida y establecer alianzas de cogestión con los pueblos indígenas colindantes. De acuerdo a la conversación mantenida con Lelis Rivera, del Centro para el Desarrollo del Indígena Amazónico (CEDIA), se requería un proceso previo de información para que las comunidades comprendieran el proceso. La falta de dicho proceso generó dificultades. ONG como CEDIA hicieron un trabajo de comunidad en comunidad para explicar en qué consistía la categorización y así, en 2012, con el apoyo del proyecto "Putumayo Tres Fronteras", se logró la categorización del Parque Nacional GüeppíSekime, de la Reserva Comunal Huimeki y la Reserva Comunal Airo Pai.

El PN Güeppí-Sekime se estableció como un área nacional protegida de uso indirecto, en esta se respetan los usos tradicionales de los pueblos indígenas, los cuales fueron tomados en cuenta para establecer los criterios y condiciones para el uso de las zonas. Allí no se permite hacer uso de los recursos naturales para comercio sino solo para autoabastecimiento.

Las Reservas Comunales Huimeki y Airo Pai son de uso directo y está permitido el uso de los recursos naturales para subsistencia. En el año 2012, se inició un proceso de saneamiento físico-legal del territorio en seis comunidades nativas kichwas, ubicadas en la zona de amortiguamiento de las RC Airo Pai y Huimeki. El resultado fue la entrega de títulos de propiedad comunitarios, que les otorga el derecho a ser consultados sobre actividades que pretendan realizarse en sus territorios y que puedan afectarles. En Perú, de acuerdo a la ley, los suelos forestales son propiedad del Estado y la tierra productiva se entrega a las comunidades. Existe la figura de "cesión de uso", la cual se otorga a las comunidades dependiendo del tipo de suelo (previo a un estudio de suelos).

La comunidad kichwa Tres Fronteras, en la RC Huimeki, y la comunidad secoya Puerto Estrella, en la RC Airo Pai, son las dos únicas comunidades nativas que colindan con el PN GüeppíSekime. La primera está inscrita oficialmente y tiene personería jurídica, su territorio está delimitado y cuenta con su respectivo título de propiedad. Puerto Estrella es una comunidad conformada por 5 familias que llegaron en 2003 desde Guajoya, promovidos por un proyecto de linderación de IBIS Dinamarca ${ }^{104}$. Esta no está inscrita, no cuenta con títulos de propiedad. Por lo tanto, sus representantes no son reconocidos legalmente y no están en capacidad de suscribir documentos por lo que la relación con las autoridades del parque son informales ${ }^{105}$

\section{Ámbito social}

\section{Las chacras, una prioridad de conservación}

Entre las actividades tradicionales se destaca la chacra (chagra en Colombia) como un elemento de conservación fundamental y como una unidad de producción familiar importante dentro de la cultura indígena. La chacra se ubica dentro del bosque y forma parte de este, es transitoria, se mezcla con árboles y arbustos, lo que le proporciona las condiciones necesarias para generar alelopatías ${ }^{106}$

Se maneja bajo un sistema agroforestal, con base en la sabiduría ancestral y prácticas tradicionales de cultivo y cosecha que resultan en una buena producción, diversidad, abundancia y evitan la erosión del suelo. Para instalar una chacra se escoge el terreno tomando en cuenta su disposición, la topografía y tipo de suelo, la dirección del viento, la presencia de árboles grandes para dar sombra, entre otros factores. Una vez seleccionado el espacio, en época seca se tala y quema la madera para enriquecer el suelo con los nutrientes de la ceniza. Después se prepara el terreno para sembrar tomando en cuenta la asociación de cultivos. En la chacra se encuentran plantas medicinales, frutales y los principales productos de la dieta familiar como maíz, yuca, plátano, maní, etc., además de plantas silvestres útiles para medicina, alimentación y otros usos. Los indígenas emplean un sistema de rotación periódico cada 2

104. "Convenio entre el Ministerio de Agricultura y Ganadería y la Asociación de Comunidades Indígenas de la Nacionalidad Cofán (ACOINCO) y la Comunidad Cofán de Zábalo para la conservación, usos y servicios de los recursos de la Reserva de Producción Faunística Cuyabeno en la jurisdicción de la Comunidad de Zábalo", de 15 de abril de 1992

105. Tomado del Decreto 622 del 16 de marzo de 1977, Capítulo III. Reserva y Delimitación, Artículo 7.

106. Fenómeno biológico a través del cual un organismo produce compuestos bioquímicos que benefician a otros organismos en su crecimiento o reproducción. 


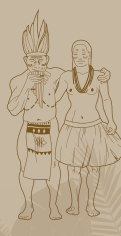

- 3 años, después del cual buscan otro espacio para cultivar

En conversación con el Consejo de Abuelos en Jiri Jirí del PNN La Paya, se pudo conocer que los indígenas muruis curan la chagra para controlar la entrada de ciertos animales que la dañan y para incentivar el regreso de otros animales que ayudan a que en ella haya una interrelación favorable entre especies. Así, un buen manejo de la chacra, además de proveer el alimento a la familia, también provee de alimento a la fauna del bosque: mamíferos, insectos, reptiles, aves..., generando una simbiosis de la que se aprovechan todas las especies. Este intercambio de beneficios entre las especies es una forma proteger los ecosistemas y reducir los impactos y riesgos de fenómenos naturales.

En el área de influencia del PNN La Paya se desarrolló un monitoreo local para analizar el consumo y manejo de recursos naturales con el fin de determinar alternativas productivas y de uso

"Las chagras constituyen la prioridad de conservación para las áreas protegidas ya que generan importantes dinámicas ecosistémicas primordiales para la conservación de semillas y especies".

Jeferson Rojas, Jefe del PNN La Paya.

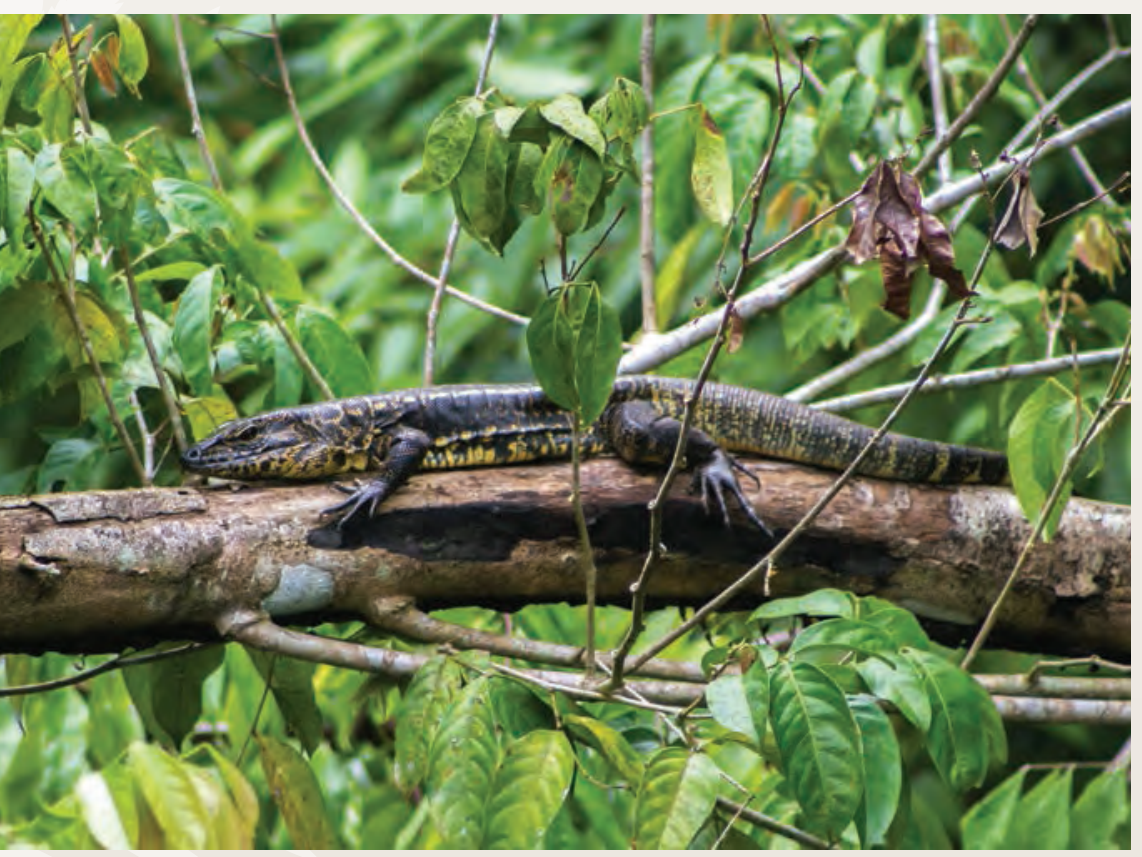

sostenible de los recursos ${ }^{108}$. En este monitoreo, participaron 42 familias asentadas a lo largo del río Putumayo, quienes llevaron, por un periodo de 9 meses, un registro de su consumo diario, que incluía productos de la chacra, del bosque, pesca, caza y productos comprados fuera de sus comunidades. Entre los principales resultados de este monitoreo se encontró que los sistemas de producción agrícola y los bosques ofrecen una gran variedad de productos y que un alto porcentaje de los productos obtenidos por siembra y recolección (91 \%) son para consumo familiar. Además, se destaca el consumo de frutas y verduras (principalmente plátano, yuca y papaya). Por ello, se pone de manifiesto la importancia de mantener las chacras como una unidad de producción importante para el consumo familiar

En 2014 se desarrolló el proyecto "Recuperación y Fortalecimiento de Prácticas Tradicionales Sostenibles de Seguridad Alimentaria en las Comunidades Indígenas Muruis del Municipio de Leguízamo, Departamento del Putumayo"110, que tuvo como objetivo recuperar y fortalecer las prácticas tradicionales sostenibles encaminadas a la preservación y conservación de biodiversidad asociado a la seguridad alimentaria ${ }^{111}$. Como parte de este proyecto se fomentó la recuperación de áreas disturbadas y se brindó capacitación en sistemas agroforestales tipo chagra, abonos orgánicos y conservación, restauración y sostenibilidad de los ecosistemas dentro de las chagras indígenas.

\footnotetext{
7. Tradicionalmente los Pueblos Indígenas se movilizaban por su territorio para no agotar los recursos de un solo sitio y dejar que la tierra de las chacras y el bosque se recuperasen para así mantener el equilibrio en el ecosistema.

108. Parte del proyecto "Putumayo Tres Fronteras" implementado por PNN Colombia, Tropenbos y WWF Colombia, con financiamiento de UE y WWF Alemania.

109. Fuente: Usma, J.S., C. Ortega P., S. Valenzuela, J. Deza \& J Rivas (Eds.). 2016. Diversidad biológica y cultural del Corredor Trinacional de áreas protegidas La Paya - Cuyabeno - Güeppí Sekime. Colombia - Ecuador - Perú. WWF. Bogotá D.C., Colombia. 333p

110. Proyecto ejecutado por ACILAPP y CORPOAMAZONIA

111. Tomado de: "Identificar alternativas productivas sostenibles social, económica y ambientalmente con potencial de desarrollo dentro del corredor de conservación La Paya- Cuyabeno- Güeppí", documento elaborado por Jorge Enrique Capto Cuchón, febrero 2015. Consultoría realizada en el marco del Programa Trinacional de Conservación y Desarrollo Sostenible del Corredor de Gestión Transfronteriza La Paya- Cuyabeno- Güeppí.
} 


\section{Paisaje norte: Ámbito social}

\section{Principales actividades productivas sostenibles}

Un proyecto exitoso en el paisaje norte es el que llevan adelante los indígenas kichwa de Zancudo Cocha, desde 2010, con la producción de cacao fino de aroma. Este proyecto inició con capacitación en aspectos técnicos para producción y manejo de cacao orgánico y fortalecimiento organizativo. Hoy se ha generado una cadena productiva, cuentan con producción de cacao orgánico, certificación "Cacao Arriba" otorgada por el Instituto Ecuatoriano de Propiedad Intelectual (IEPI) y marca registrada bajo el nombre "Nativo", la cual les acredita para exportar su producto ${ }^{172}$. El proyecto también incluye a otras comunidades ubicadas en la zona de amortiguamiento, en la cabecera de la reserva (Juan Montalvo, Las Palmas, Cristóbal Colón, San Rafael y Rey de los Andes). Los indígenas de Zancudo Cocha mencionan que la producción de cacao bajó (2014) por la plaga de la monilia'113 (Moniliophthora roreri) y que por falta de recursos para contrarrestarla, se perdió una buena parte del cultivo pero que, sin embargo, planean seguir con la producción e incursionar en la elaboración de chocolate para comercializarlo como producto terminado y no solo como materia prima.

La comunidad de Zancudo Cocha entrega su producto a centros de acopio de cacao fuera del área protegida, entre estos se destaca la Asociación de Mujeres El Porvenir de Pacayacu, en la zona de amortiguamiento, la cual produce pasta de cacao. Dicha asociación es un caso exitoso que vale la pena mencionar. Está conformada por 12 mujeres que se unieron dada la necesidad de generar recursos económicos para apoyar a la economía familiar. Conformaron una caja común con 100 USD cada una y empezaron a trabajar en la producción de la pasta de cacao sin ningún conocimiento técnico. Después, por gestión de las socias, recibieron capacitación en elaboración de chocolate, fortalecimiento organizacional y manejo financiero. Han recibido además aportes económicos para compra de equipos, maquinaria, para construcción de infraestructura ${ }^{114}$, la compra de un código de barras, apoyo en el diseño de la imagen para el empaque, como también asesoría en temas de gestión para el registro de su marca "Aroma Nacional del Cuya-

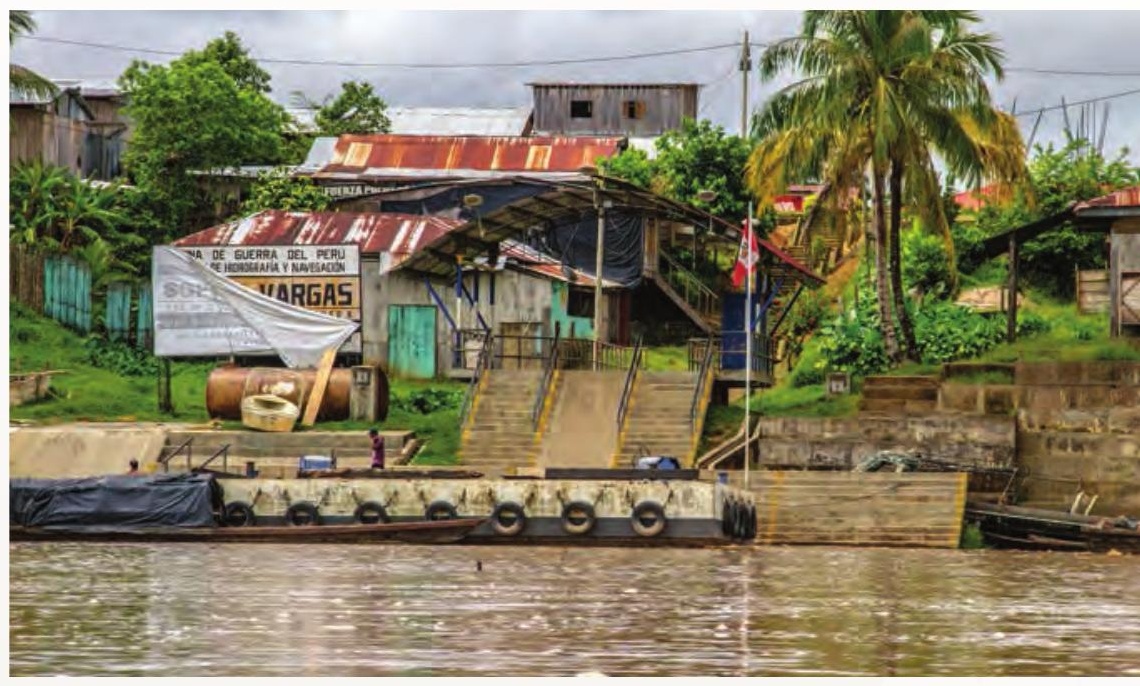

beno" en el IEPI115. Desde 2011, la asociación cuenta con personería jurídica y cumple con los requisitos que exige la ley: registro sanitario, patente municipal, permiso de los bomberos, etc. En conversación mantenida con Johana Rivera, presidenta de la Asociación El Porvenir, se pudo conocer que la asociación es manejada bajo lineamientos de comercio justo, pagando sobre la media del mercado a los productores de cacao. Las socias perciben un salario mensual, comercializan sus productos en Lago Agrio, Shushufindi, Quito y en Puerto Asís (Colombia) y han participado en ferias a nivel nacional donde han ganado algunos premios

En la comunidad Zábalo (Cuyabeno), los indígenas cofán fabrican canoas de fibra de vidrio desde 1998 con el apoyo inicial de la Comunidad Europea. En la actualidad venden aproximadamente 100 canoas al año (cada una a un costo aproximado de 3500 USD). Los clientes son los mismos indígenas e instituciones públicas como el Gobierno provincial, que compra las canoas para dotar de movilidad a las comunidades. Una de las ventajas del producto es que las canoas de fibra de vidrio tienen un tiempo de vida útil mucho más

112. Proyecto realizado con el aporte técnico y financiero de WWF Ecuador.

113. Es un tipo de hongo, la plaga es más propensa a aparecer en época de lluvias. Suele afectar más a la variedad de cacao nacional y se la debe combatir con un mejor manejo del cultivo y la aplicación de fungicidas químicos.

114. Aportes del Gobierno Provincial de Sucumbíos y Petroecuador por gestión de la Asociación.

115. Convenio de cooperación con WWF Ecuador. 


\section{Paisaje norte: Ámbito social}

El turismo que se realiza en la reserva no es de tipo comunitario, aunque los indígenas y sus familias se vinculan en diferentes momentos y formas. La actividad es manejada por operadoras turísticas que trabajan con los indígenas mediante contratos de prestación de servicios en diferentes funciones: cocineros, guías, motoristas, etc.

En términos de los aportes público-privados al tema de turismo, el MAE junto con la ONG Rain Forest Alliance, a partir de 2008, desarrollaron un proyecto para la mejora de prácticas turísticas responsables, en el que se incluyeron nuevas tecnologías como energía con paneles solares, tratamiento de aguas, manejo de residuos sólidos, que culminó con la entrega de una certificación ambiental. En el periodo de 2006 a 2011, el Consorcio Paisajes Sostenibles ${ }^{119}$ desarrolló junto con la administración de la RPF Cuyabeno un nuevo modelo para turismo en áreas protegidas basado en un manejo sostenible para reducir los impactos del turismo, proteger las especies y dar alternativas económicas a las comunidades indígenas ubicadas dentro de la reserva. Como resultado de ese trabajo conjunto, donde también participaron actores locales, se desarrolló una Metodología de Gestión de Destino con la cual se desarrolló el Plan de Manejo de Visitantes, validado por el MAE. Otra herramienta con la que cuentan es el Manual de Operaciones Turísticas, un instrumento piloto para áreas protegidas de la Amazonía. Personal de la RPFC menciona que aún se tienen que afinar estos documentos ya que hay casos en que estos se contradicen con lo estipulado en el plan de manejo de la reserva, el cual deberá incorporar estos criterios al momento de su actualización (por ejemplo, el manual de operaciones prohíbe la pesca deportiva mientras que el plan de manejo sí la permite).

Así también, el MAE, a través de la administración de la reserva, realizó capacitaciones para guías naturalistas indígenas y mestizos, certificándolos para guiar en la zona.

Los operadores en zona del Cuyabeno están organizados. Actualmente, hay 14 operadores turísticos privados en la reserva, 9 de los cuales son parte de la Asociación de Operadores Turísticos de Cuyabeno, aún sin personería jurídica. Los lodges tienen patentes de manejo anuales que les concede el MAE.

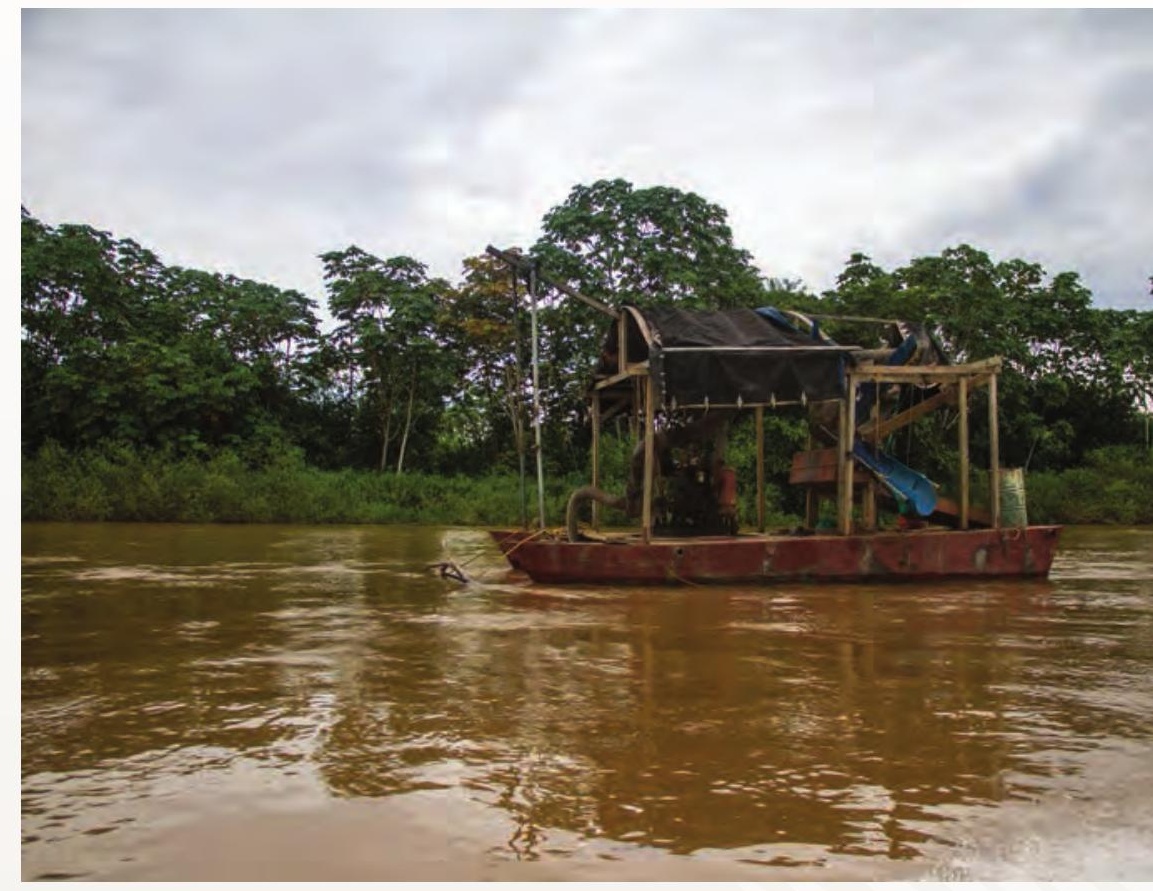

Todos los lodges operan de la misma manera Tienen acuerdos de contrato privados con los indígenas por el uso de sus tierras (arriendos), que oscilan entre 10 y 20 años. Los paquetes incluyen un día de visita a una comunidad siona o secoya que consiste en visitar una casa donde las mujeres muestran el proceso de preparación del casave de yuca y la elaboración de sus artesanías; y luego la visita al shamán para observar una curación y conocer acerca de la cultura y de las plantas medicinales. Los operadores turísticos entrevistados coinciden que entre un $30 \%$ a $40 \%$ de los indígenas se benefician del turismo.

Los lodges tienen paneles solares, plantas de tratamiento de agua, biodigestores especiales para aguas servidas, trampas de grasa y tanques separadores de sólidos y líquidos. Cada lodge se ha organizado individualmente para el manejo de desechos sólidos, sacan los desechos cada vez que salen a recibir turistas al Puente Cuyabeno, y también pagan el servicio de recolección municipal que recoge la basura 1 ○ 2 veces al mes. Todos los lodges trabajan con 2 guías indígenas de la zona como mínimo.

119. El Consorcio Paisajes Sostenibles está formado por la organización internacional Rain Forest Alliance, la Asociación para la Investigación y el Desarrollo Integral (AIDER) de Perú y la Corporación Gestión y Derecho Ambiental (ECOLEX) de Ecuador. 


\section{Paisaje norte: Ámbito social}

gratuita, semillas e insumos. Hay aportes puntuales como el del Ministerio de Agricultura, Ganadería, Acuacultura y Pesca (MAGAP) que brinda capacitación técnica en las comunidades para el óptimo aprovechamiento de los recursos; sin embargo, mencionan que falta capacitación para tecnificar las prácticas agrícolas $^{12}$

En la comunidad Rey de los Andes, en la parte alta de la RPF Cuyabeno, hay un proyecto de producción y comercialización de café tostado y molido de la Asociación Agropecuaria Expreso de Oriente. La asociación funciona desde 2002122, la conforman 15 socios propietarios de fincas y beneficia indirectamente a 150 familias. En sus inicios vendían el café en grano a una empresa acopiadora en Guayaquil, la cual enviaba el café al extranjero. Después la producción tuvo un descenso por la afectación de la plaga broca (Hypothenemus hampei) que acabó con la producción y degeneró la semilla. Así, en 2007 la asociación paró la producción de café.

En 2010, el Programa Trinacional dio un nuevo impulso a este negocio y se reanudó la producción y comercialización de café con la asignación de recursos para equipos y materia prima, mejoras en infraestructura, fortalecimiento en la comercialización y el capital social. Actualmente la asociación produce, acopia y comercializa café a nivel local (en Lago Agrio) y en Quito bajo la marca "El sabor del Cuyabeno". Se menciona, además, que la asociación enfrenta algunas dificultades administrativas: el negocio no repunta, la demanda ha bajado, hay mucha competencia, las alianzas con los lodges de la reserva no funcionaron y la capacidad de producción en su fábrica está siendo subutilizada ya que se producen 1000 fundas al mes cuando con la máquina que tienen se podrían producir hasta 16000 fundas

Pedro Díaz, socio de Expreso de Oriente, menciona que, a futuro, la asociación quiere obtener un sello y certificado de origen y aprovechar el hecho de estar en la zona de amortiguamiento de la RPF Cuyabeno, como un valor agregado para promocionar su café. Considera que la asociación es un aporte al cuidado del área protegida y de las cuencas hídricas, ya que la producción de café no genera riesgo ni presión al área protegida y que, además, la explotación de madera, que antes era común en la zona,

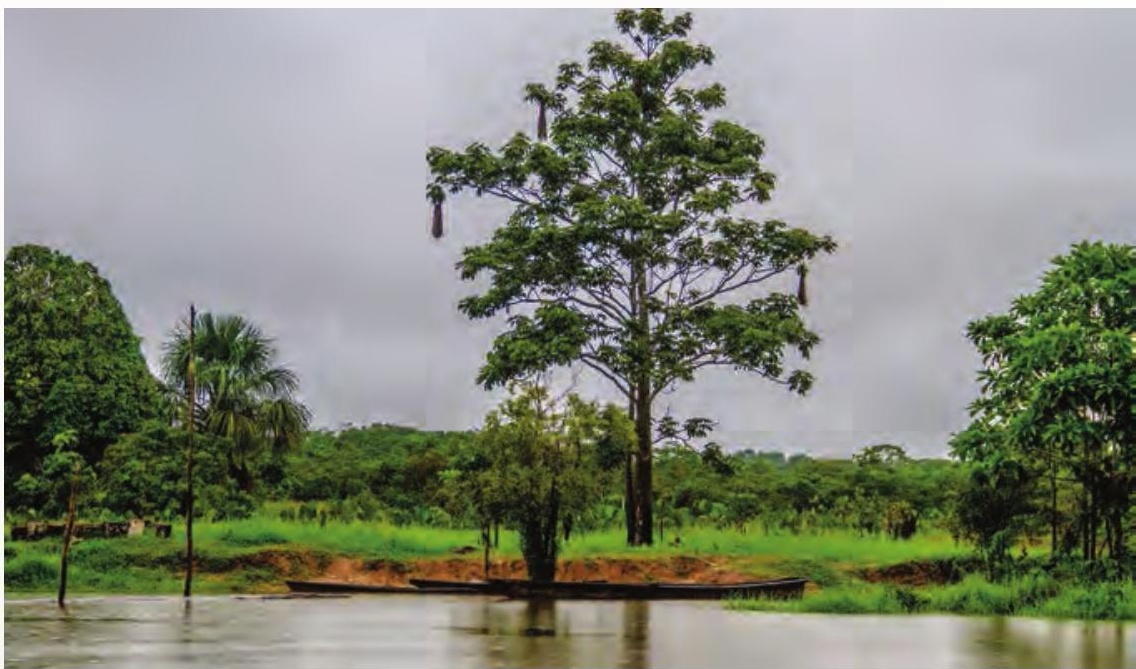

ha bajado considerablemente ya que ahora la población está dedicada a la producción de café como una alternativa económica.

En la zona de amortiguamiento del PNN La Paya, se encuentran algunas experiencias de fincas agroecológicas demostrativas, las cuales plantean un nuevo modelo de desarrollo con el cambio del sistema productivo tradicional a un sistema agroecológico integral, como contrapeso al modelo ganadero de la región, el cual se teme que aumente por los procesos de colonización resultado de los Acuerdos del Proceso de Paz.

En otra iniciativa, en 2014, los indígenas de la zona de amortiguamiento del PNN La Paya, recibieron apoyo de FUPAR (Fundación Pacífico Renaciente) para formar un centro de acopio de productos amazónicos tradicionales. La necesidad se dio por la informalidad y los bajos precios que pagan los intermediarios cuando individualmente llegan a la galería (mercado) de Puerto Leguízamo para vender sus productos. El proyecto se conformó con 24 comunidades de las etnias murui, coreguaje y kichwa y consistía en el acopio de productos de las veredas participantes para llevarlos al centro de acopio, ubicado en Puerto Leguízamo (en terreno concesionado por el municipio). Ahora el proyecto está detenido por discusiones internas y falta de gestión ya que, según Consuelo

121. El Consorcio Paisaies Sostenibles está formado por la orTérmino utilizado por entrevistados en Puerto Leguízamo, Colombia para referirse a grandes extensiones de pastos para el ganado en zonas donde antes era bosque.

122. El proceso organizativo fue apoyado por la Fundación YANPAZ, la empresa ENCANA, Pronorte-AMAZNOR, el Municipio de Cuyabeno y el Gobierno provincial de Sucumbíos. 


\section{Paisaje norte: Ámbito social}

puestos participativos y rendición de cuentas. Tienen directivas comunitarias conformadas por un presidente, vicepresidente, secretario, tesorero y vocales. La mayoría de cargos están ocupados por hombres. La directiva tiene una duración de dos años y la máxima instancia de decisión es la asamblea comunitaria, la cual se realiza periódicamente con la participación de toda la comunidad. Los acuerdos a los que se llega son por el voto de la mayoría y se amparan en las leyes existentes en cada país. En Cuyabeno las comunidades están amparadas en la Ley de Juntas Parroquiales.

La comunidad secoya de Puerto Estrella (RC Airo Pai), aunque su junta directiva no está reconocida legalmente por su situación irregular, se reúne periódicamente para tratar los temas de interés comunitario.

Al nivel de paisaje, los representantes indígenas tienen un liderazgo importante tanto al interior de sus comunidades como hacia fuera. Son muy activos y proactivos en el ejercicio de sus derechos colectivos, el manejo de su territorio y en las relaciones con otros actores. En la RPF Cuyabeno, por ejemplo, se evidencia que los pueblos indígenas cuentan con información sobre el derecho a la remediación ambiental, debido a los daños causados hace décadas por la actividad petrolera.

\footnotetext{
El Programa Trinacional, a través del proyecto "Putumayo Tres Fronteras", trabajó en el fortalecimiento del capital social con líderes locales, administradores de áreas protegidas y gobiernos locales en mecanismos de participación, defensa de derechos, metodologías prácticas para desarrollo de proyectos y en temas relacionados a la gestión ambiental para sentar las bases de autoconcepción de ciudadanía, de sentido de pertenencia al Estado y del ejercicio de reivindicación de derechos ${ }^{126}$.
}

\section{Acuerdos de participación entre el Estado y los pueblos indígenas}

La legislación de cada país contempla mecanismos formales de participación. En Colombia, PNNC tiene Acuerdos Políticos de Voluntades con las asociaciones de los pueblos indígenas que se encuentran traslapados en áreas protegidas para el establecimiento de una agenda conjunta que articule y coordine la implementación de componentes temáticos, programas, estrategias de salvaguarda y líneas de acción, en los que se consideraron los Planes de Vida y los Planes de Salvaguarda. En 2015, PNNC firmó acuerdos con los pueblos murui, kichwa y siona ubicados al interior y en el área de amortiguamiento del PNN La Paya, con lo cual se han podido desarrollar acciones para avanzar en la construcción e implementación de Acuerdos de Manejo y el Régimen Especial de Manejo.

El gobierno del pueblo murui se fundamenta en la "Ley de Origen" que es el legado de la ley ancestral, la cual establece que los Pueblos nacen de un Padre Creador -Moo Buinaima- y una Madre Divina, quienes asignan un espacio para vivir, un territorio ordenado que debe ser usado y dejado tal como les fue dado ya que si se hace algo en contra de la naturaleza, eso trae consecuencias y castigos.

Consejo de Abuelos, Resguardo Jiri Jirí, Abril 2016.

En el año 2013 se trabajó en un nuevo modelo de gestión del PNN La Paya, en el cual se definieron tres ámbitos de gestión: local o de área protegida, de la zona de amortiguamiento y de los procesos subregionales o ámbito regional, organizados en cuatro sectores de gestión: Putumayo (cuenca media del río Putumayo), Caquetá (cuenca media del río Caqueta), Eje Carreteable (Eje carreteable Puerto Leguízamo-La Tagua) y Caucayá (cuenca del río Caucayá, corazón del área protegida).

En el Conversatorio de Acción Ciudadana en Puerto Leguízamo se contó con la participación de 31 personas, entre ellos, indígenas, campesinos y demás actores del Municipio de Puerto Leguízamo, relacionados de una u otra manera con el PNN La Paya. Fue un pro-

126. Usma, J.S., C. Ortega P., S. Valenzuela, J. Deza \& J. Rivas (Eds.). 2016. Diversidad biológica y cultural del Corredor Trinacional de áreas protegidas La Paya - Cuyabeno - Güeppí Sekime. Colombia - Ecuador - Perú. WWF. Bogotá D.C., Colombia. 333p. 
ceso de participación muy activo que duró alrededor de un año. Se trataron temas como el relacionamiento de las comunidades con el parque, salud pública, manejo de residuos sólidos, comercialización de productos y acceso a mercados. Uno de los resultados de este conversatorio fue un acuerdo de cooperación entre PNN La Paya y las tres organizaciones indígenas de la zona -APKAC, ACILAPP y ACIPS - para coordinar actividades con las comunidades campesinas ubicadas en la zona de amortiguamiento.

Adicionalmente el PNN La Paya y el Municipio de Puerto Leguízamo están trabajando en un Proceso participativo de integración de la biodiversidad con especial énfasis en áreas protegidas en el Plan de Desarrollo Territorial del municipio de Puerto Leguízamo-Putumayo, con el fin de incluir los temas de biodiversidad y áreas protegidas en el Plan de Desarrollo 2016-2019 "Leguízamo Teje". En este proceso participan líderes comunitarios e indígenas quienes discuten temas ambientales, prevención y gestión de conflictos por tierras, gestión de riesgo y cambio climático, servicios públicos, desarrollo agropecuario y rural, así como los temas relacionados con la propuesta del Esquema Asociativo.

En las tres áreas protegidas, las comunidades indígenas cuentan con Planes de vida como un instrumento de planeación que se elabora de forma participativa y en consenso, a partir de un autodiagnóstico con el que se define qué es

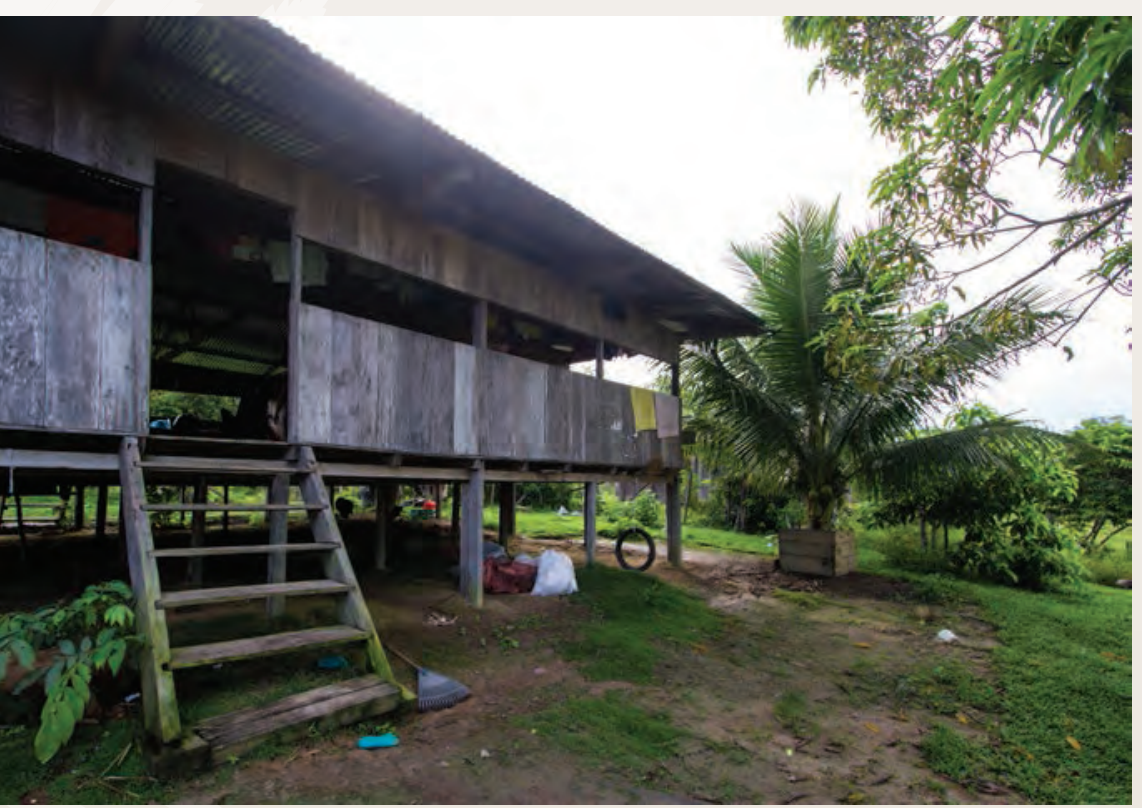

la comunidad, qué quiere y qué hacer para lograrlo. El proyecto "Putumayo Tres Fronteras" apoyó en Perú la construcción de planes de vida de las comunidades nativas Santa Teresita (huitoto), Mashunta (secoya) y Nueva Esperanza (kichwa).

El plan de vida de la etnia murui es su reglamento interno, una redacción en términos de su conocimiento y palabra con las normas de la comunidad. El lema del plan de vida de los muruis es "un territorio donde todos podamos vivir", donde consta que el territorio no está establecido por los límites políticos, sino por el espacio organizado donde se desarrolla la vida y la continuidad cultural.

Las comunidades dentro de la RPF Cuyabeno cuentan con planes de gestión comunitaria, los cuales están articulados al plan de manejo de la reserva. En estos incluyen la caracterización del área, un diagnóstico situacional, propuesta de manejo territorial con zonificación, normas comunitarias de caza, pesca y uso de recursos del bosque, sanciones en caso de incumplimiento y estrategias de desarrollo social, cultural y económico acordes al reglamento de uso del área protegida. Incluyen un marco estratégico con programas de manejo y alternativas de financiamiento para concretar los objetivos.

Los planes de vida y los de gestión comunitaria constituyen una herramienta importante para el desarrollo de los planes de manejo de las áreas protegidas (conocidos como Plan Maestro, en Perú) como una guía técnica para ejecutar las actividades dentro del área. Estos se elaboran a través de talleres en los que participan los principales actores implicados en el área protegida, quienes realizan un diagnóstico situacional que incluye información física, biológica, social, cultural y económica; se identifican los problemas y amenazas, sus posibles soluciones, se aplican herramientas de planificación como la zonificación, se incluyen mapas, se trabaja en la visión, misión, objetivos, programas y proyectos a desarrollarse en el área protegida (para un periodo de 5 años), con estrategias, compromisos y las fuentes de financiamiento. Con toda esta información se arma el documento. Los planes de manejo de las áreas protegidas son validados técnicamente y socializados con los participantes, antes de su divulgación. 


\section{Paisaje norte: Ámbito social}

\section{Comités de gestión como mecanismo de participación}

En Ecuador, si bien los comités de gestión están contemplados en la ley, las comunidades indígenas en Cuyabeno no aplican este mecanismo, sino que se amparan en la Ley Orgánica de Comunas y en la Ley de Participación Ciudadana, reconocidas por el Estado.

El nuevo modelo de gestión del PNN La Paya propone un Comité Interinstitucional de Gestión para lo cual se identificaron los actores para la reformulación del plan de manejo entre los que están: organizaciones indígenas (APKAC-Asociación de Autoridades Tradicionales del Pueblo Kichwa de la Amazonia Colombiana, ACIPS-Asociación de Cabildos Indígenas del Pueblo Siona y ACILAPP-Asociación de Cabildos Indígenas de Leguízamo y Alto Predio Putumayo, Murui y Koreguaje); organizaciones campesinas (mestizos amazónicos) (ASOJUNTAS-Asociación de Juntas de Acción Comunal del Municipio de Leguízamo, ASTRACAM-Asociación Campesina del Mecaya, ASCAP-Asociación Campesina Agrícola del Putumayo, ATCAL-Asociación de Trabajadores Campesinos de Leguízamo); afrodescendientes, instituciones públicas vinculadas al área protegida como PNN La Paya, Corpoamazonía, Municipio de Leguízamo, Gobernación de Putumayo, Armada Nacional, Ejército Nacional, Fiscalía General de la Nación y Policía Nacional. Instituciones públicas de Perú y Ecuador, SERNANP y MAE, también están incluidas. Estas intervienen específicamente en lo relacionado a actividades conjuntas de control y vigilancia para las áreas protegidas.

En Perú, en las reservas comunales, existe la figura de los Ejecutores de Contratos de Administración (ECA) que son personas jurídicas que se responsabilizan de los planes de manejo y de la ejecución de proyectos sostenibles en las áreas protegidas. Este ente ejecutor está conformado por gente de la comunidad, para quienes los recursos de la reserva son su fuente de subsistencia, siendo estos los beneficiarios directos. Estos contratos son por tiempo indefinido. La ley establece que la participación debe realizarse a través de un comité de gestión, que es un paso posterior a los Contratos de Administración. De acuerdo a información proporcionada por Lelis Rivera,

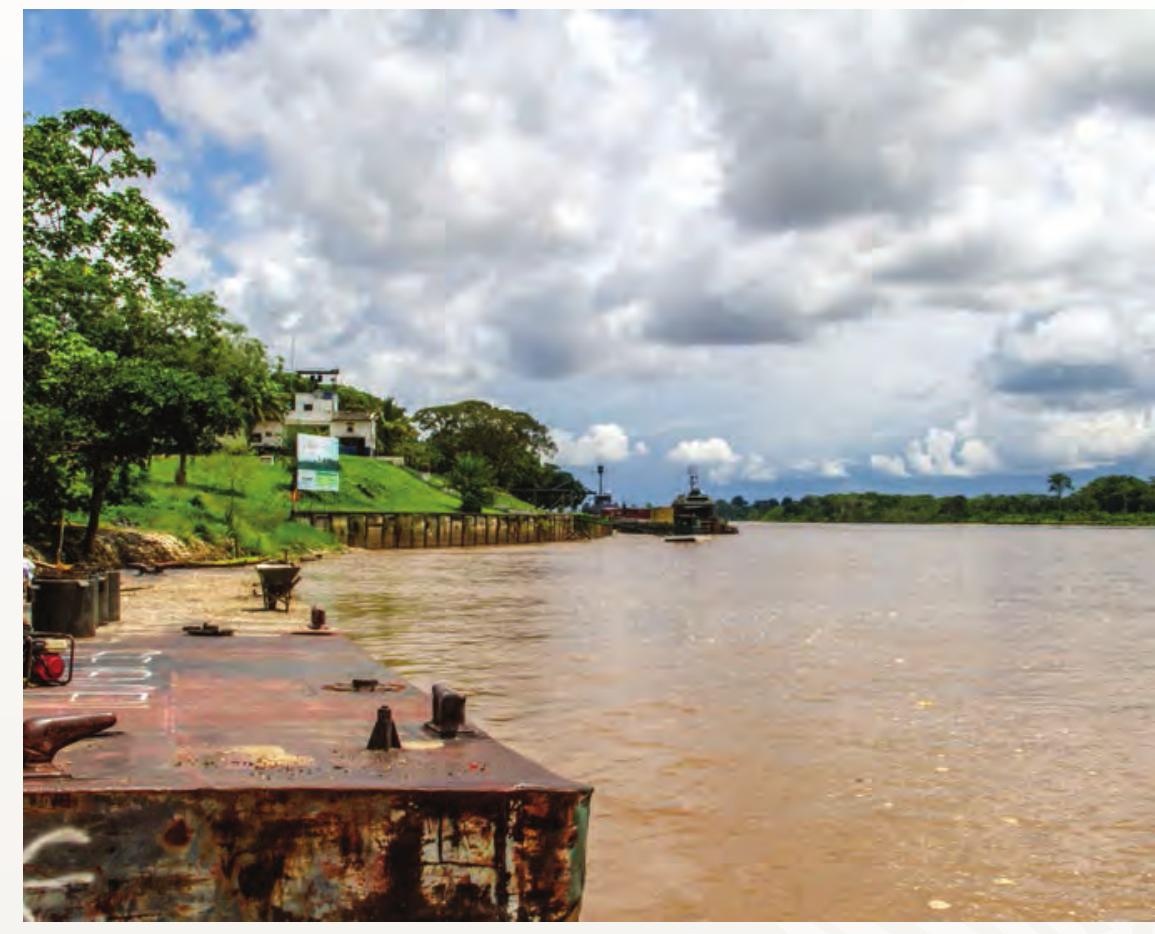

representante del CEDIA (Centro para el Desarrollo del Indígena Amazónico), las RC Airo Pai y Huimeki, hasta el momento, no cuentan con un comité de gestión ni ejecutores de contrato de administración, principalmente por los altos costos que representa la logística de las reuniones previas a su conformación.

\section{Consulta Previa}

Para abordar el análisis formal de los mecanismos de toma de decisión y participación se debe referir al derecho de Consulta Previa, reconocido en el Convenio 169 de la Organización Internacional del Trabajo (OIT).

"La Consulta Previa prevista en el Convenio se refiere principalmente a medidas legislativas y administrativas que puedan afectar directamente a los pueblos indígenas, o a aquellas relacionadas con la exploración o explotación de recursos minerales o del subsuelo en los territorios donde habitan"127. Es un proceso de diálogo y concertación intercultural que busca garantizar la participación real, oportuna y legítima de los grupos étnicos en la toma de decisiones, proyectos o actividades que los afecten con el fin de proteger su integridad étnica y cultural.

127. Definición de la OIT en su página web www.ilo.org 


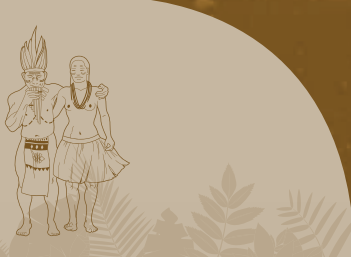

En Ecuador, el mecanismo de Consulta Previa se aplica exclusivamente como parte de los estudios de impacto ambiental contemplado en la ley de gestión ambiental. De acuerdo a información proporcionada por los entrevistados para esta investigación, en Cuyabeno se han realizado consultas a las comunidades indígenas en procesos vinculados a actividades extractivas; sin embargo, existe la percepción en las comunidades de que sus opiniones no influyen sobre estos procesos.

En el caso de Colombia, la consulta previa se adelanta de acuerdo con la Directiva presidencial N 10 de noviembre de 2013, la cual señala que es deber del gobierno nacional y del Estado garantizar el goce efectivo de los derechos de las comunidades étnicas y la implementación de la Consulta Previa como mecanismo para la protección y supervivencia de los pueblos étnicos que se vean afectados positiva o negativamente por una actividad ajena a sus costumbres, tradiciones y uso del territorio. Es necesario establecer disposiciones que permitan una mejor coordinación interinstitucional para la garantía de este derecho, bajo los principios de eficacia, economía y celeridad administrativas, mediante el acoplamiento de las autoridades encargadas de llevar a cabo el proceso de consulta previa con las comunidades étnicas. En la actualidad, están haciendo trabajo de consulta en las comunidades indígenas vinculadas al PNN La Paya, acerca de proyectos de hidrocarburos.

En Perú, en 2011, se promulgó la Ley de Derecho a la Consulta Previa a los pueblos indígenas u Originarios, la cual constituye un paso significativo y un hecho clave a resaltar a los demás países ya que con esta ley se garantiza y fortalece el ejercicio de consulta, participación y toma de decisiones. La ley ha generado muchos beneficios a los pueblos indígenas cuyos representantes forman parte de los consejos consultivos y comités de supervisión ambiental. En el caso específico de Güeppí-Sekime la ley de Consulta Previa a los pueblos indígenas no se aplica por tener la categoría de Parque Nacional, donde están prohibidas las actividades extractivas; esta ley sí aplica a las reservas comunales.

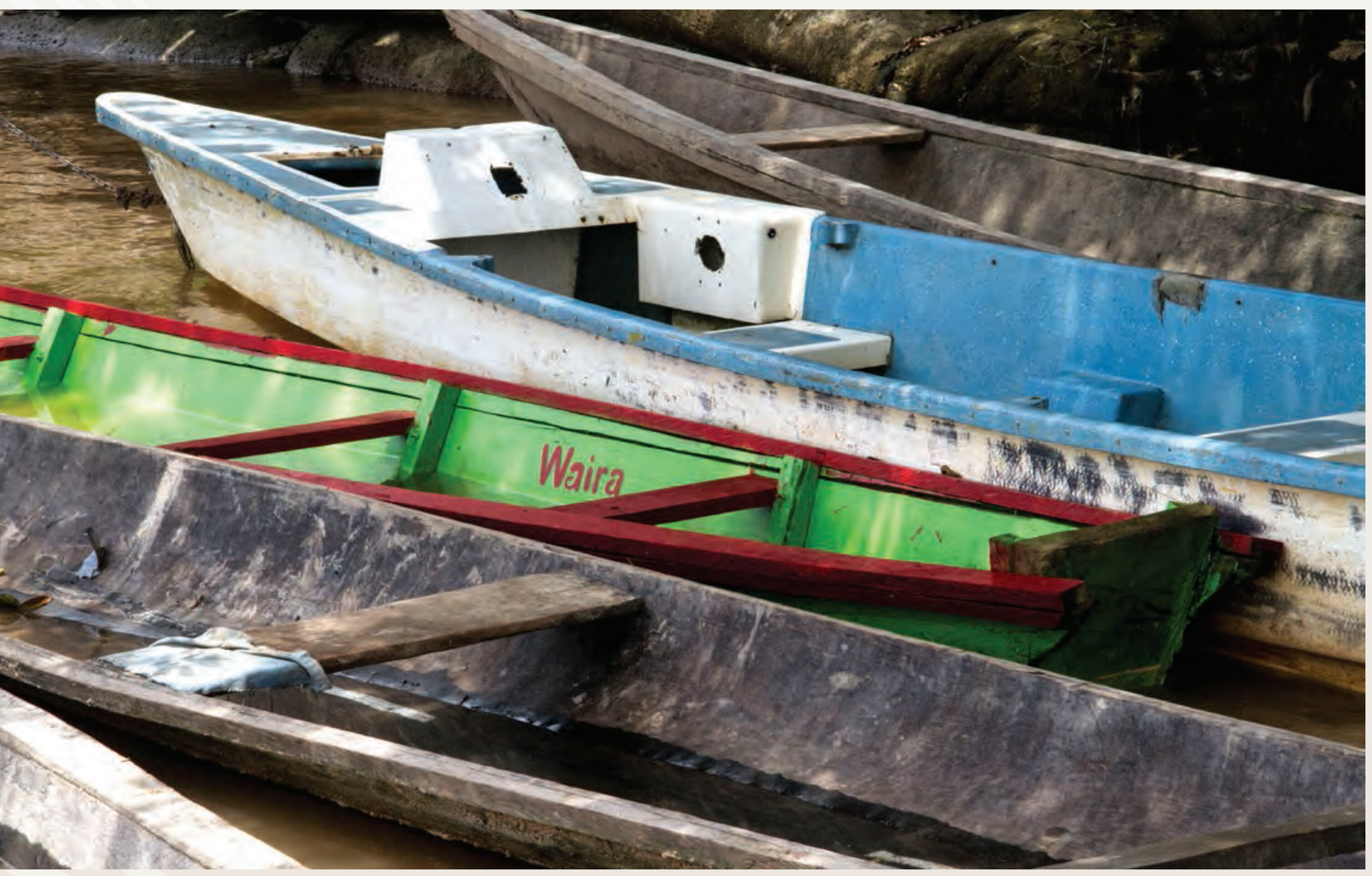




\section{Ámbito cultural}

En las tres áreas protegidas del paisaje norte, los lugares donde se encuentra una gran diversidad de flora y fauna son considerados por los indígenas como sitios sagrados, lugares que incluyen aspectos culturales y espirituales. Mencionan que, anteriormente, a estos sitios los hombres iban por varios días para realizar las actividades de caza y pesca y, mientras permanecían ahí, realizaban rituales y ceremonias para que la madre tierra les permitiese realizar esas actividades. Además, mencionan como sagrados los salares, las lagunas - principalmente La Apaya (PNN La Paya) y la Laguna Grande (Cuyabeno), donde se encuentran plantas medicinales- y los ríos, que para los abuelos son las venas de la madre tierra. En La Paya los indígenas mencionan un sitio sagrado fuera del área del parque, que tiene un poder, temido por muchos, donde todavía nadie ha sabido cómo entrar.

En las áreas protegidas de Ecuador y Perú, se encuentran algunos proyectos de plantas medicinales y objetivos culturales a nivel comunitario. En las comunidades existen muestras de sus prácticas culturales como danza, artesanías y gastronomía, las cuales se promocionan en los proyectos de turismo comunitario.

En el PNN La Paya hay algunas iniciativas de rescate de aspectos culturales, como la de los campesinos ubicados en la zona de amortiguamiento quienes desarrollaron un espacio denominado "Escuelas de la Selva", que es el lugar donde se reúne la gente alrededor del fuego para contar las historias de vida. Por otro lado, el programa "Canastos de Sabiduría" con la etnia murui constituye un proceso importante que se está desarrollando de forma participativa.

\section{Aspectos que fortalecen los procesos culturales de los pueblos indígenas}

\section{Canastos de Sabiduría}

El programa "Canastos de Sabiduría" busca la recuperación de la cosmovisión y las prácticas tradicionales culturales del pueblo murui en los resguardos Jiri Jirí, Progreso y La Primavera. Este proceso empezó en 2013 y tiene como fin registrar por escrito las tradiciones y conocimientos de la etnia murui y de su lengua, que tradicionalmente se transmitía de forma oral. Para el Consejo de Abuelos, "la narración es un elemento fundamental para poder avanzar, siempre recordando la historia"128.

Este programa cuenta con el apoyo técnico y financiero de la Agencia Colombiana para la Reintegración (ACR) ${ }^{129}$ y PNN La Paya que les brinda asesoría en el fortalecimiento de su autonomía y capital social. Los muruis consideran que este proceso es muy importante, no solo para ellos, sino para todos los pueblos de la zona de Caquetá, ya que muestra una forma de vivir la paz que se busca.

El programa incluye el desarrollo de 14 canastos temáticos, cada uno con distintos módulos:

\footnotetext{
128. Consejo de Abuelos de Jiri Jirí, marzo 2016.

129. ACR se creó en 2011 como una Unidad Administrativa Especial del Departamento Administrativo de la Presidencia de la República, encargada de fortalecer la implementación de la Política de Reintegración en Colombia.
}

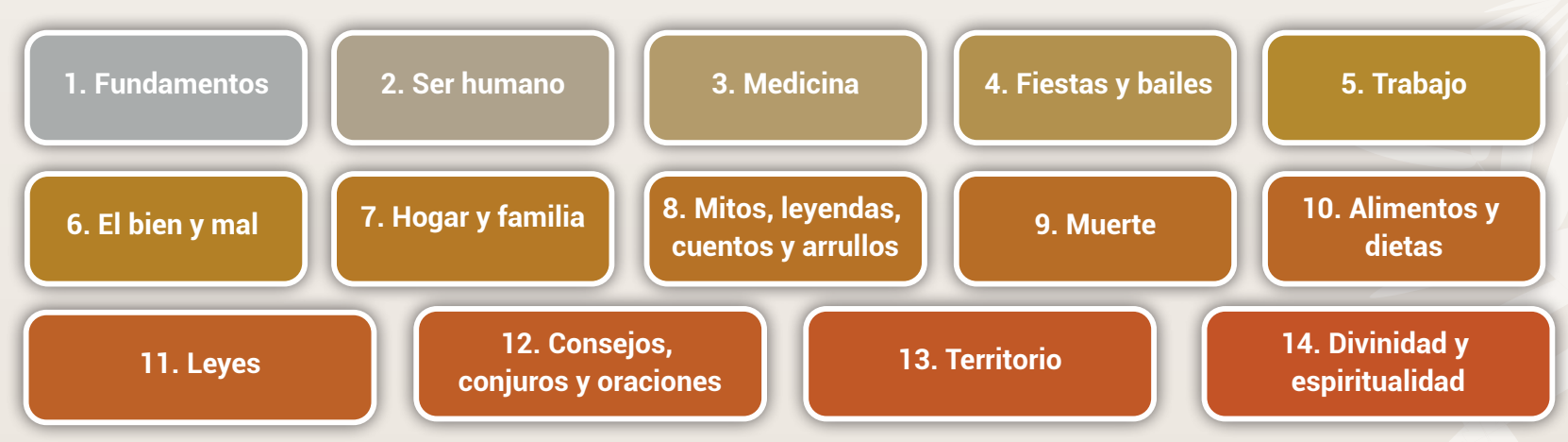


La maloca se construye en minga (trabajo colectivo y gratuito para algún fin de utilidad social) con la participación de toda la comunidad. Su parte estructural está compuesta por 4 pilares que representan los conocimientos ancestrales que han sido pasados de generación en generación. Son espacios grandes con vigas de madera. Anteriormente el techo era de hoja de palma, que ahora ha sido reemplazado por techo de zinc por considerarse más práctico. La construcción de la maloca toma algunos meses, tiempo después del cual se festeja la construcción con comida, bebida y bailes tradicionales. El festejo dura cerca de una semana, asiste la gente de la comunidad e invitados de afuera.

Información obtenida en conversación con Abuelo Oliverio, maloca de ACILAPP en marzo, 2016

En marzo de 2016, en el Resguardo de Jiri Jirí, concluyó el trabajo del primer canasto temático "Fundamentos" que incluyó los módulos:

- Las deidades del Padre creador, Moo Buinaima

- Plantas sagradas: manifestación, inspiración y poder en la Ley de Origen

- Patrimonios culturales sagrados en la Ley de Origen

- Valor, ética y moral tradicional sagrada

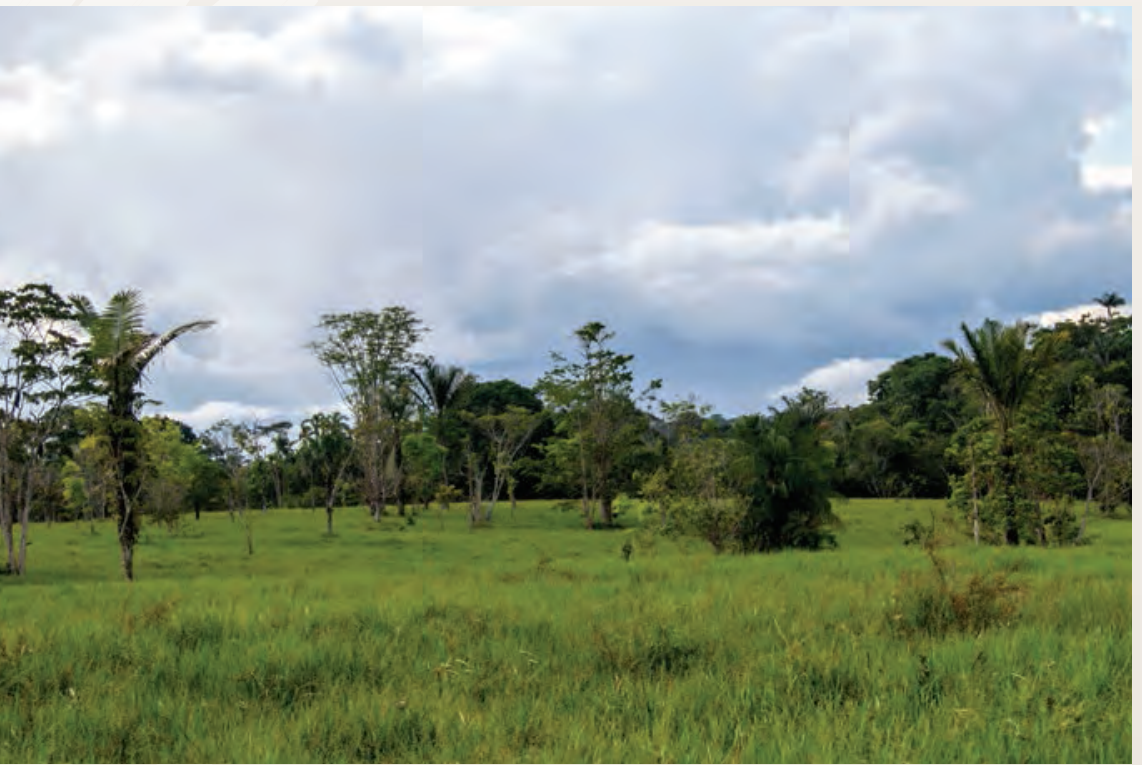

- Filosofías tradicionales en la Ley de Origen

La parte operativa de este proceso está a cargo de los "Guardianes indígenas del territorio", Naginallimaira, grupo conformado por los jóvenes de los resguardos participantes.

La cosmovisión de los muruis y su interrelación con el manejo sostenible del bosque

Para los pueblos indígenas amazónicos de Colombia, la maloca es considerada un sitio fundamental dentro de su cultura. En 2007, en vista de que estos espacios se estaban perdiendo, el Gobierno colombiano, a través del Ministerio de Cultura, impulsó el Proyecto "Fortalecimiento de Malocas" para fomentar la transmisión de la cultura y tradiciones dentro de las comunidades, en especial a los niños y jóvenes.

En la cosmovisión murui, la maloca es una mujer sabia, es el vientre donde se formó el ser. Es un espacio de encuentro con el espíritu, de limpieza y sanación del cuerpo y la mente, un lugar para la palabra dulce ${ }^{130}$.

La maloca es un espacio de hombres que se reúnen a conversar, desde que cae la tarde hasta altas horas de la noche. Los hombres más viejos de la comunidad forman el "Consejo de Abuelos" y son los que guían a la comunidad en sus decisiones. Uno de los abuelos guía el encuentro abre el espacio y, una vez concluido el diálogo, lo cierra con cantos de agradecimiento.

En estos encuentros se transmiten oralmente las costumbres y tradiciones, se aconseja, se enseña, se analiza, se reflexiona, se planifica, se establecen las reglas y se articula todo lo que pasa en la comunidad y la relación de esta con el bosque. Es un espacio para tomar decisiones, pero también se habla de temas cotidianos, se discuten los roles, las funciones e intereses de las personas de la comunidad y de los que llegan de afuera; se reflexiona acerca del territorio y los recursos y la gobernanza.

130. Información recogida en la maloca del Resguardo Jiri Jirí con el Consejo de Abuelos. abril, 2016. 


\section{Paisaje norte: Ámbito cultural}

Para los muruis, los que llegan a la maloca son "seres que tenían que llegar" y con quienes se comparte el conocimiento de los abuelos. La participación de los mestizos en estos espacios ha servido para complementar las visiones de los muruis con las visiones occidentales, que "hasta hace poco eran como agua y aceite"131.

Mientras se dialoga en la maloca, los hombres mambean, actividad que consiste en introducir polvo de hoja de coca (mambe) en un costado de la boca acompañada de ambil (una jalea oscura hecha a base de tabaco) y mantenerlos ahí hasta que se diluyan. Esta combinación tiene un efecto que potencia la capacidad de percepción y transmisión del pensamiento que dirige los asuntos tratados en la discusión. Los abuelos cuentan que los jóvenes se inician en el mambeo cuando sienten el llamado y están listos, ya que mambear es un acto que conlleva mucha responsabilidad.

Para los muruis, las plantas sagradas que constituyen su esencia son la coca, el tabaco y la yuca dulce, a través de las cuales establecen una conexión espiritual para premiar, aconsejar, educar y corregir. Antiguamente la economía tradicional empleaba estas tres plantas como una "forma de pago"; ahora esto es regulado a través de los espacios culturales.

El uso tradicional de la hoja de coca se hace en un contexto ritual, el proceso es guiado por un maestro que establece una intención y pone la palabra bonita. La manera tradicional para hacer el mambe consiste en tostar las hojas de coca en una vasija de barro hasta llegar al punto exacto, luego se ciernen las hojas tostadas junto con las cenizas de hoja de yarumo ${ }^{132}$ (Cecropia peltata) para liberar los alcaloides.

El tabaco es una planta muy delicada que se siembra en las chagras dejando que crezca sola, sin cuidados. Se cocina mezclándolo con maraca (la baya del cacao) para endulzarlo y luego con sal de monte ${ }^{133}$. Esta mezcla se la conoce como ambil, que también es usado en pequeñas cantidades como purgante, para desparasitar.

En cuanto a la yuca, las hay de muchos tipos y se usan dependiendo de la necesidad. La yuca dulce es la que se emplea para la elaboración de la caguana, la bebida tradicional que consumen los hombres en la maloca.

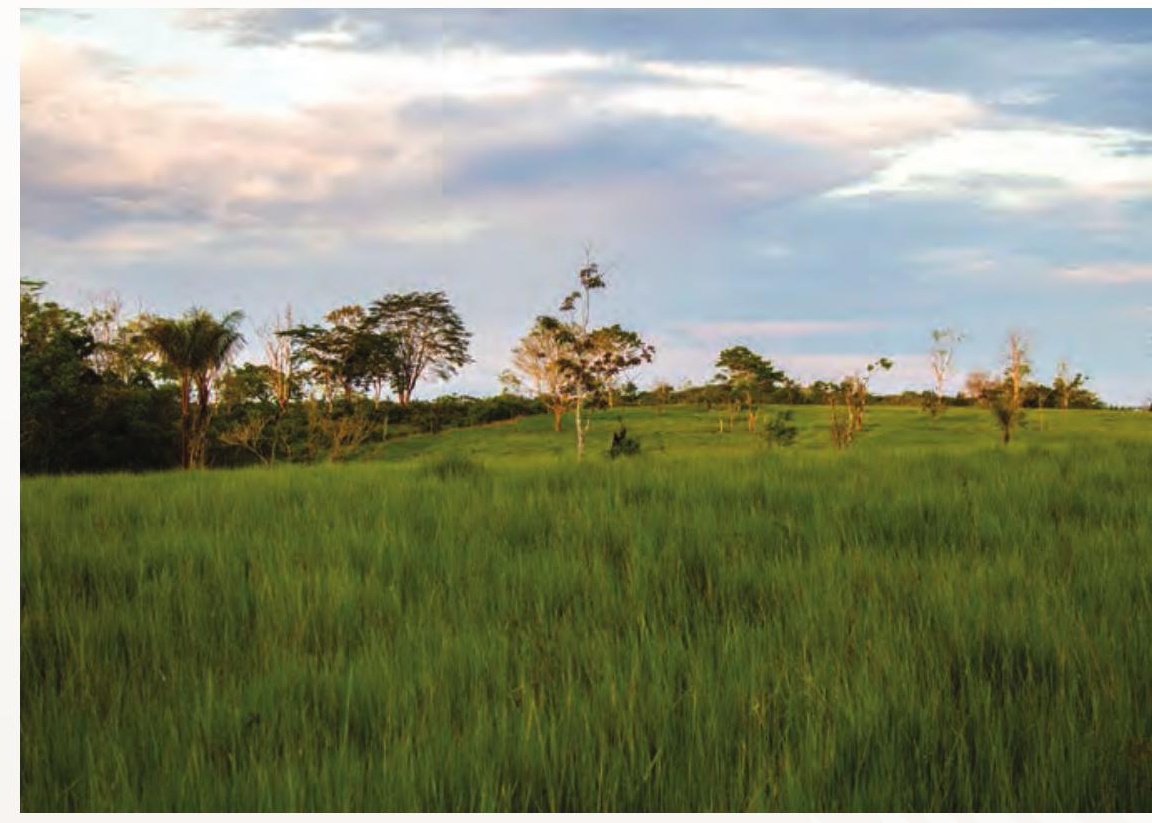

"En la maloca se cantan canciones de alegría para calmar el espíritu, como rituales sagrados que ayudan al equilibrio. Es un espacio donde apareció la palabra, donde los abuelos dejan su palabra y las madres entierran su placenta".

Los abuelos consideran que el uso occidental de la coca ha profanado esta planta sagrada ${ }^{134}$ Además de la elaboración de cocaína, mencionan el mambeo como una nueva tendencia entre los jóvenes mestizos.

"A través de las plantas establecemos contacto con los abuelos para que nuestra palabra no ofenda ni incomode a nadie".

Consejo de abuelos, Resguardo Jiri Jirí, marzo 2016.

131. Consejo de Abuelos, maloca de Jiri Jirí, abril 2016.

132. El yarumo es un árbol, cuyo rastrojo se encuentra en las chacras que se dejan descansar después de usarlas por un periodo aproximado de 3 años

133. La sal de monte se obtiene quemando la hojarasca, la ceniza que se obtiene se filtra con agua caliente y el agua que queda se seca y queda la sal. La sal de monte se usa para conservar los alimentos.

134. 134. Se conoce que dentro del PNN La Paya todavía hay cultivos ilícitos de coca, a pesar de que muchas hectáreas fueron fumigadas tras la implementación del Plan Colombia. 
Manifiestan que la comercialización de hierbas medicinales podría ser un buen ejercicio para insertarse en el mercado. Sin embargo, dicen que existen algunas plantas que sí se podrían comercializar y otras que prefieren mantener para uso local ya que, por sus características sagradas, son consideradas hierbas para una medicina más profunda y merecen un uso delicado.

En conversación con Jorge Larrarte y John Ronquillo, funcionarios de ACILAPP, se pudo conocer que el mambe se está convirtiendo en una actividad productiva, que ahora se puede comprar por cucharadas o kilos; la comercialización se hace boca a boca y, en algunos casos, participa toda la comunidad para cumplir con los pedidos. Consideran necesario trabajar en un control para regular la venta y que esta se haga desde los indígenas y no desde los blancos. Adicionalmente, como parte del ejercicio de reivindicación cultural, comentan que los muruis están trabajando en la preservación de la coca original ya que han encontrado que algunas plantas están dando hojas más grandes y con un sabor diferente.

\section{Mujeres: guardianas del territorio}

Tanto en las áreas protegidas del paisaje norte como en las zonas de amortiguamiento, las mujeres tienen un rol muy importante.

Los roles tradicionales de hombres y mujeres están bien definidos y se mantienen, especialmente, entre los indígenas muruis. La mujer educa a la hija y el hombre educa al hijo; la mujer se encarga de la chagra desde la siembra hasta la cosecha y el hombre prepara la chagra antes de la siembra, bota el bosque, desmonta y prepara el terreno; la mujer cultiva la coca, mientras que el hombre cosecha el tabaco. Las mujeres son además parteras, matronas y sobanderas. Todo esto lo aprenden de sus abuelas y madres en la cotidianidad ${ }^{135}$. En la maloca se encuentran muchos símbolos que representan armónicamente lo masculino y femenino. El ambil representa al hombre y el mambe representa a la mujer, al igual que la caguana y el casave representan lo femenino y la presencia de la mujer en el mambeo. Para los muruis, la palabra de la mujer es muy importante dentro del grupo. Luis Cote, indígena murui, manifiesta: "las decisiones del abuelo las consulta con la abuela, si el hombre empieza a fallar, la mujer es quien tiene que hacerlo recapacitar".

A raíz de la creación de los "Canastos de Sabiduría", se organizó un grupo de mujeres muruis pertenecientes a los resguardos Jiri Jirí, Progreso y La Primavera, con el fin de recordar y rescatar su cultura, lo que ha dado como resultado un mayor compromiso por parte de las mujeres para transmitir sus conocimientos a las jóvenes de sus comunidades.

Para Luz Mery Narváez, lideresa murui, la relación con otras culturas ha traído aspectos positivos, pero también negativos, como la degradación de la mujer indígena. Menciona casos de prostitución de niñas indígenas entre 12 y 15 años que salen de su comunidad a la ciudad en busca de trabajo.

Los indígenas de Zancudo Cocha (Cuyabeno) y los campesinos de Cabo Pantoja (zona de amortiguamiento de la RC Airo Pai) manifiestan que en sus comunidades los roles de hombres y mujeres ahora se comparten por practicidad y por la incorporación de proyectos con perspectiva de género que se desarrollan a nivel local. Las mujeres cuentan que, si bien ellas son las responsables de mantener la chacra, a veces los hombres les ayudan y que ellas, a su vez, ayudan a los hombres en la caza y pesca.

Aunque hay diferencias entre los pueblos indígenas de la zona, en términos generales las mujeres participan activamente en los diferentes ámbitos de toma de decisión dentro de las comunidades. Algunas comunidades han tenido dirigentes mujeres ${ }^{136}$.

Como parte de las responsabilidades de las mujeres están la siembra, el cuidado de la chacra, la cosecha de los alimentos y la preparación de los mismos. La transmisión de conocimientos relacionados a la alimentación se da en la práctica y en la cotidianidad, principalmente entre las mujeres, quienes se reúnen para preparar los alimentos para las festividades.

135. Información proporcionada por Luz Mery Narváez, lideresa murui.

136. Como en la comunidad de Zancudo Cocha (Cuyabeno) con la presidencia de Barbarita Tagoy en 1983, quien hasta ahora es una lideresa activa a nivel comunitario. 
Tanto dentro de las áreas protegidas como en las zonas de amortiguamiento, las mujeres cultivan las chacras con productos como la yuca, plátano, arroz, maíz, cacao, papa china, camote, zapallo, palmito, maní de tierra, ají, frutales y plantas medicinales.

La yuca es uno de los productos más importantes en la dieta familiar por su gran contenido nutricional. Mencionan que hay de diferentes tipos ${ }^{137}$ y en base a este producto elaboran bebidas y platos tradicionales de dulce y de sal. En Cuyabeno, los kichwas elaboran la chicha de yuca para refrescarse durante el trabajo y la fermentan para las fiestas. En PNN La Paya mencionan el casave, una tortilla de yuca dulce, y la cahuana, una bebida hecha de almidón de yuca dulce mezclada con fruta. Las mujeres cuentan que para hacer esta bebida se pela la yuca, se ralla, se exprime, se decanta el agua y queda el almidón. Aparte se pone a hervir un poco de agua en la que se pone el almidón, se bate y, cuando llega al punto, se añade el jugo de fruta. Esta bebida se toma en la maloca durante el mambeo.

Las mujeres en Cabo Pantoja cuentan que usan la yuca amarga para preparar la fariña o mañoco, una base de yuca hecha grano para preparar distintos platos. Cuentan que la preparación de la fariña toma tiempo, ya que primero hay que remojar la yuca por 3 días en la quilla (canoa tradicional de madera, alargada y angosta), luego prensarla para sacar toda el agua y ponerla a cocinar por varias horas en la capirona (leña) hasta que se seque.

Forma parte de su alimentación la carne (de monte, gallina y chancho) y el pescado, con el que elaboran el maito, un plato de pescado aderezado con sal, envuelto en hoja de bijao (Calathea lutea) y cocinado en leña. También forman parte de su alimentación las gallinas y chanchos, como parte de su actividad de crianza de animales menores.

Se pudo conocer que, en algunas comunidades, la práctica de cultivar la chacra se está perdiendo ya que las familias ahora prefieren comprar alimentos y medicinas en los mercados. Manifiestan que el cambio de cultura ha llevado al facilismo sin medir las consecuencias, como la aparición de nuevas enfermedades, cada vez a más temprana edad ${ }^{138}$. Para los muruis, la enfermedad es un desequilibrio espiritual y aparece cuando el alma está derrotada, cuando la persona se ha separado del Padre Creador y la Madre Divina; el desacato trae enfermedades y estas se generan por la conducta inapropiada de la persona o por la intención de otra. Su sanación corresponde al chamán.

Los muruis cuentan que su alimentación ha variado por la incorporación a su dieta de alimentos procesados y bebidas artificiales, lo que ha afectado a la salud de la población. Mencionan que antes era común encontrar las plantas curativas en la chacra y el bosque. Tradicionalmente hacían un ritual especial en el cual pedían permiso a las plantas antes de arrancarlas y les rezaban pidiéndoles la cura para la persona enferma. Ahora esto se está perdiendo y mencionan la importancia de recuperar las chacras como la base de su cultura.

\footnotetext{
137. Algunas con bastante almidón, unas moradas, otras amarillas, otras blancas, otras muy delicadas que al prepararse de manera errónea pueden ser venenosas.
}

138. Conversación mantenida con el Consejo de abuelos en la comunidad de Jiri Jirí.

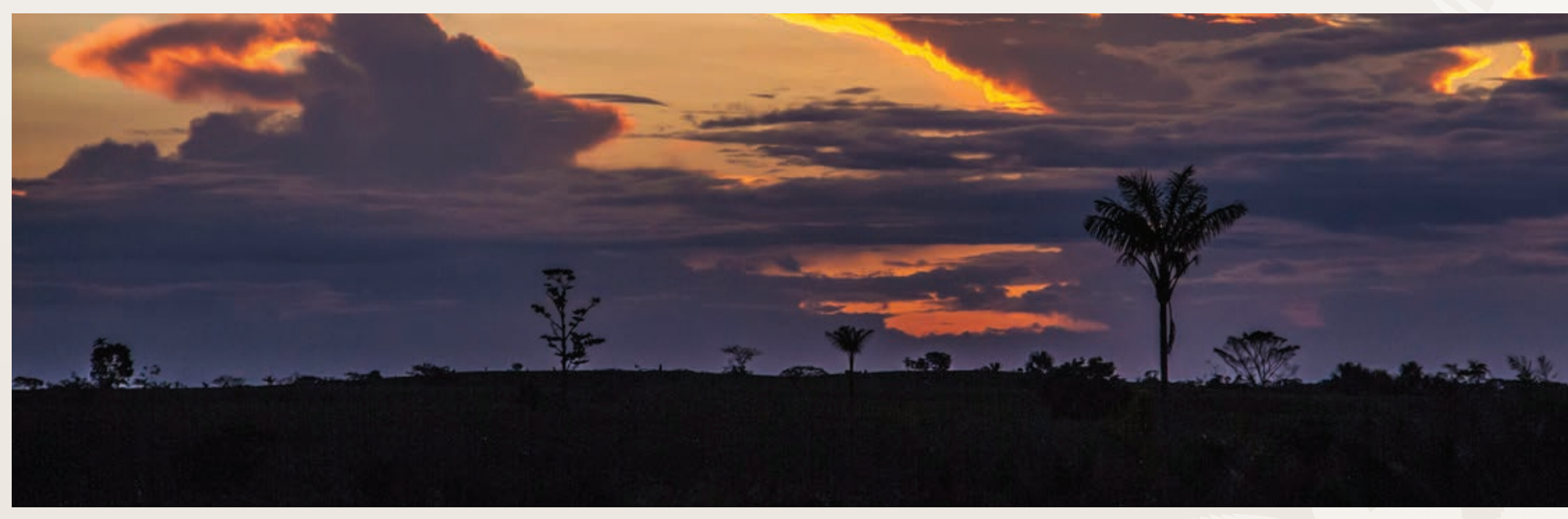


"Nosotros no somos de números, por eso necesitamos que los jóvenes aprendan de eso, se preparen, que estudien para que trabajen y no se vayan".

Consejo de Abuelo. Maloca Jiri Jirí.

\section{Jóvenes actores en la conservación}

En el paisaje norte se menciona la participación de los jóvenes en actividades puntuales impulsadas, en la mayoría de casos, por actores externos.

En la RPF Cuyabeno, los jóvenes sionas y secoyas participan en la actividad turística, lo que les ha brindado otras oportunidades, como aprender idiomas, relacionarse con foráneos, adquirir ciertas habilidades para relacionarse con otras culturas y desenvolverse bien en otros ámbitos.

En Güeppí, los niños y adolescentes de las instituciones educativas de las comunidades Santa Teresita (huitoto), Mashunta (secoya) y Santa Rosa de Escalante (kichwa), ubicadas en la zona de amortiguamiento de las RC Airo Pai y Huimeki, participaron en los talleres de sensibilización y concientización sobre la importancia de conservar el lobo de río, que se llevó a cabo como parte de la investigación realizada sobre esta especie en 2012. Posteriormente, con la participación activa de los docentes de las comunidades y los guardaparques del SERNANP, se elaboró un Plan de Educación Ambiental (PAE) en torno a la protección del lobo de río y al manejo sostenible de los recursos.

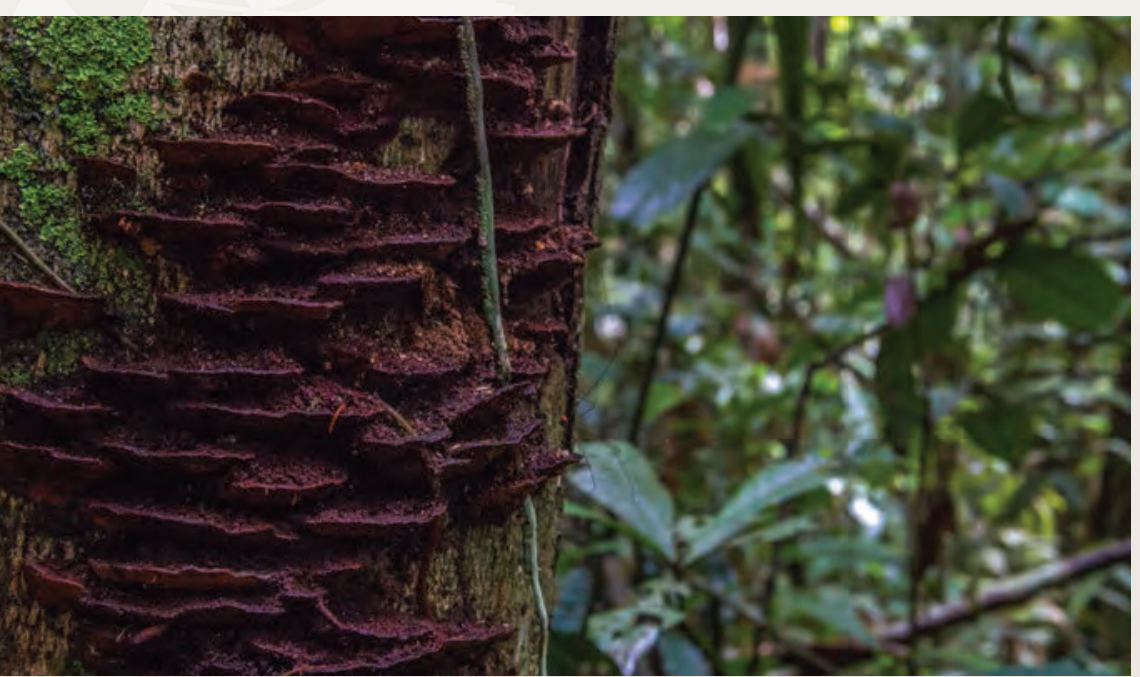

Para los abuelos, la participación de los jóvenes en los temas de la comunidad es fundamental para que se apropien de su cultura y mantengan su esencia ${ }^{139}$. Manifiestan que una manera de hacerlo es entregándoles su conocimiento. En este contexto, los abuelos trabajan junto a los jóvenes para enseñarles acerca de la maloca, los calendarios de cosecha, las tradiciones y su cosmovisión. Confían en que los jóvenes sean los que ayuden a la comunidad a integrarse en la dinámica del mercado para el desarrollo económico local.

Se conoce de una experiencia binacional interesante donde participaron jóvenes de $8^{\circ}$ y $9^{\circ}$ grado de instituciones educativas ubicadas en la zona de amortiguamiento del PNN La Paya y la zona de Güeppí. La experiencia se desarrollóa través del proyecto "Modelos Prácticos de Producción Piscícola de Consumo Humano y Uso Ornamental para el Desarrollo de la Zona de Integración Fronteriza de Perú y Colombia"140, que tuvo como objetivo "promover una piscicultura amazónica sencilla en la región fronteriza, mediante el establecimiento de centros piscícolas piloto en cada país y la transferencia de técnicas sencillas para el manejo de peces"141. Los jóvenes se beneficiaron con alevines de cachama (Piaractus brachypomus) y gamitana (Colossoma macropomun) y recibieron capacitación teórico práctica para su cuidado y crianza.

\section{Retos en el ámbito artesanal}

La elaboración de artesanías por parte de los pueblos indígenas es una forma de la reproducción cultural de las prácticas tradicionales vinculadas a los valores estéticos, sus costumbres y cosmovisión y, al mismo tiempo, contribuyen al uso sostenible de los recursos naturales de las áreas protegidas.

139. Consejo de Abuelos, maloca Jiri jirí, marzo 2016.

140. Proyecto ejecutado por el Instituto Amazónico de Investigaciones Cientificas SINCHI en Colombia y el Proyecto Especial Binacional Desarrollo Integral Cuenca del Putumayo (PEDICP) en Perú, con el apoyo financiero de la Unión Europea y de la Comunidad Andina de Naciones, en el marco del proyecto "CESCAN III Apoyo a la Cohesión Económica y Social" de 2012 a 2015

141. Tomado de: "Identificar alternativas productivas sostenibles social, económica y ambientalmente con potencial de desarrolla dentro del corredor de conservación La Paya-Cuyabeno-Güeppí", documento elaborado por Jorge Enrique Capto Cuchón febrero 2015. Consultoría realizada en el marco del Programa Trinacional de Conservación y Desarrollo Sostenible del Corredor de Gestión Transfronteriza La Paya-Cuyabeno-Güeppí. 
En general, en las áreas protegidas del paisaje norte, las mujeres elaboran collares y pulseras con semillas que recolectan del bosque, ollas de barro y bolsos con fibras como el cumare (Astrocaryum aculeatum), mientras que los hombres realizan trabajos en madera, principalmente lanzas y figuras de animales. En conversación con Oliverio López, artesano murui, se pudo conocer que anteriormente hacían sus artesanías en el mambeadero, el sitio sagrado de la maloca. Elaboraban el bastón de mando, lanzas de chonta, morteros de madera para moler el mambe, asientos para mambeadero y el manguaré (instrumento de percusión de madera utilizado para convocar a reuniones y anunciar mensajes cuyo sonido puede escucharse a kilómetros de distancia).

Don Oliverio cuenta que se inició en el tallado de figuras de animales hace 15 años. El oficio lo aprendió de su suegro quien, a su vez, lo aprendió de su padre. Perfeccionó la técnica participando en un taller de capacitación técnica y de comercialización, organizado por las entidades públicas Corporación para el Desarrollo sostenible del Sur de la Amazonia (CORPOAMAZONIA ${ }^{142}$ ) y Artesanías de Colombia ${ }^{143}$, en el año 2004 en Puerto Asís. Ese mismo año participó en 4 ferias organizadas por esta institución en las que tuvo la oportunidad de vender sus artesanías y promocionar su cultura. Ahora talla animales de madera bajo pedido. Usa madera de granadillo (Dalbergia melanoxylon), cedro (Cedrus), palo sangre (Corymbia gummifera) y polvillo (Handroanthus serratifolius). Manifiesta que ahora las artesanías en madera son producidas por pocos artesanos ${ }^{144}$.

A nivel de paisaje, la comercialización de artesanías no se considera una fuente de ingreso importante. Los indígenas las comercializan en sus propias localidades a los turistas que llegan. De acuerdo con la información recibida, esta es una actividad que se está perdiendo ya que antes tanto hombres como mujeres elaboraban las artesanías con los abuelos y, según los entrevistados, ahora los jóvenes no se interesan por aprender.

\section{Interrelación de actores}

A continuación, se presenta un mapa de interrelación de los actores identificados para cada una de las áreas protegidas del paisaje norte y un mapa de las interrelaciones a nivel de paisa- je. Estos mapas son una adaptación de la herramienta desarrollada por la Fundación Futuro Latinoamericano (FFLA) para la elaboración de mapas de relaciones y poder. La forma sugerida para la ubicación de los actores y el alcance han sido adaptados, mientras que las relaciones de poder se mantienen tal como presenta la FFLA.

El área protegida está representada por el rectángulo verde ubicado en el centro del mapa donde, a su vez, se ubican los actores que están dentro del área protegida; los actores de la zona de amortiguamiento están alrededor, en el cuadro de color marrón claro. Hay actores que pueden estar en el área protegida y en la zona de amortiguamiento, estos están ubicados en el medio de las dos. Los actores con alcance local están enmarcados en un rectángulo verde y los actores con alcance nacional en rectángulo de color marrón claro.

Hay cuatro tipos de relación que se describen a continuación.

Relación de colaboración: relación estrecha entre actores, ambos se reconocen, legitiman, comparten información, entienden y atienden necesidades y actúan coordinadamente. Está representada por una línea continua negra.

Relación de confrontación: existen enfrentamientos pasados o actuales, las necesidades e intereses de los actores no se legitiman entre ambos. Está representada por una línea continua roja.

Relación de coordinación: relaciones puntuales de interacción, dadas por el cumplimiento de sus mandatos institucionales o de acciones y requisitos que tienden a satisfacer necesidades de una de las partes. Está representada por una línea entrecortada negra.

142. Autoridad ambiental regional que se encarga de ejecutar las políticas, planes y programas nacionales en materia ambiental definidos por la ley aprobatoria del Plan Nacional de Desarrollo y del Plan Nacional de Inversiones o por el Ministerio de Ambiente y Desarrollo Sostenible, así como los del orden regional que le hayan sido confiados conforme a la ley, dentro del ámbito de su jurisdicción.

143. Es una entidad del Estado que tiene como objeto la promoción y el desarrollo de todas las actividades económicas, sociales educativas y culturales, necesarias para el progreso de los artesanos del país y del sector artesanal.

144. Según el documento elaborado por Jorge Enrique Catpo, otro artesano en madera en Puerto Leguízamo, es el Sr. Hanz Lanaro Acosta, en el marco del Programa Trinacional de conservación y Desarrollo Sostenible del Corredor de Gestión Transfronteriza La Paya-Güeppí-Cuyabeno, febrero, 2015. 
Relación distante: refleja poca coordinación entre actores. Ambos se visualizan, pero no tienen trabajo conjunto. Son indiferentes entre sí, pero no necesariamente tienen una relación de enfrentamiento. Está representada por una línea entrecortada roja.
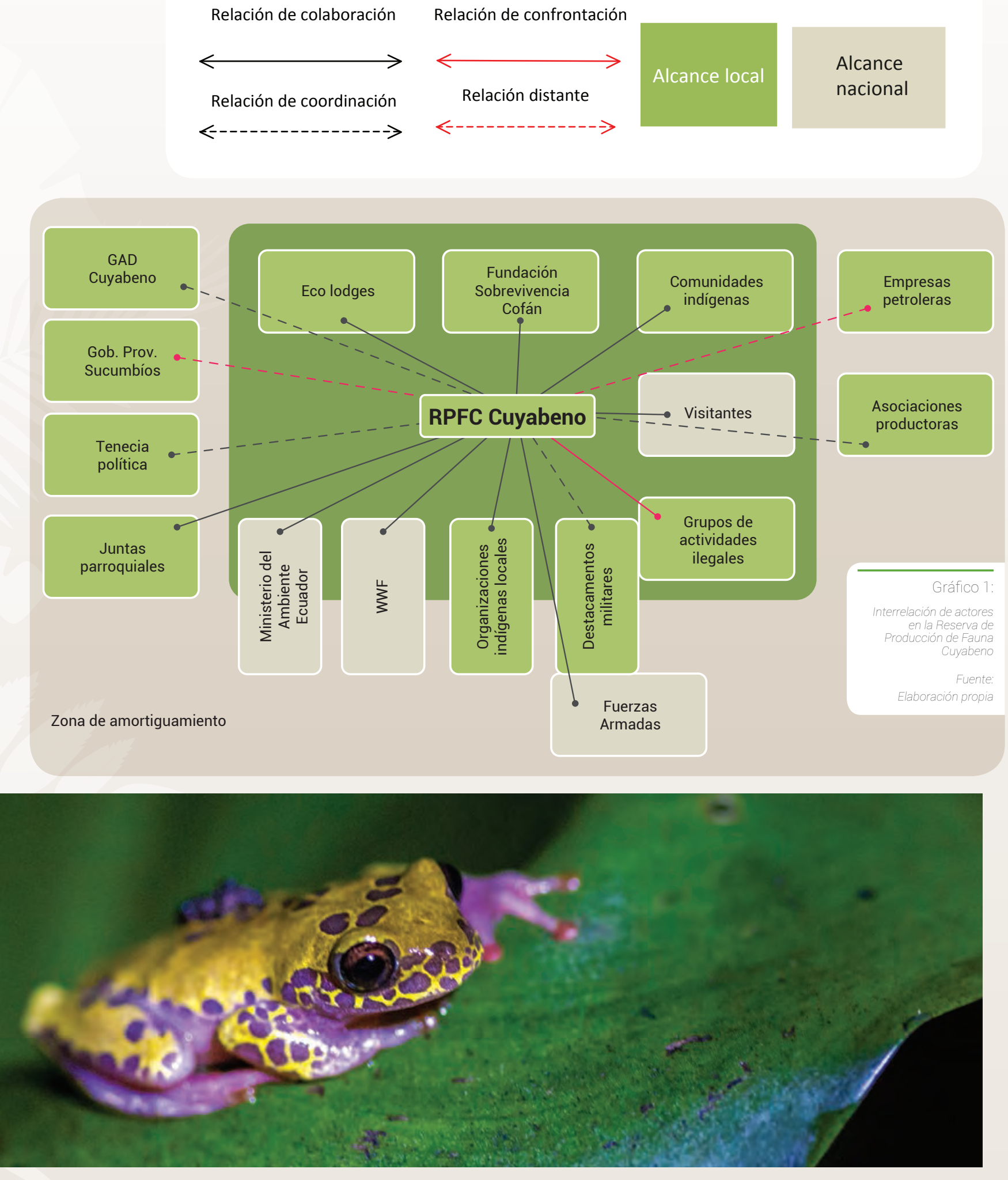


\begin{tabular}{|c|c|c|c|c|c|c|c|c|c|}
\hline \multirow[b]{2}{*}{ Actor } & \multirow[b]{2}{*}{ Sector } & \multicolumn{3}{|c|}{ Ámbito } & \multicolumn{2}{|c|}{ Ubicación } & \multicolumn{2}{|c|}{ Alcance } & \multirow[b]{2}{*}{ Rol / situación } \\
\hline & & $\begin{array}{l}\text { 은 } \\
\frac{0}{0} \\
\text { O }\end{array}$ & $\begin{array}{l}\overline{\frac{\pi}{0}} \\
0 \\
0\end{array}$ & 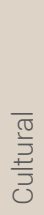 & 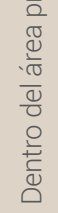 & 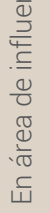 & $\begin{array}{l}\bar{\pi} \\
0 \\
0\end{array}$ & $\begin{array}{l}\bar{\sigma} \\
\frac{\tilde{O}}{0} \\
\frac{\pi}{Z}\end{array}$ & \\
\hline Ministerio del Ambiente & Público & $x$ & $x$ & & $x$ & $x$ & & $x$ & $\begin{array}{l}\text { Administración de los RRNN. } \\
\text { Promueve el Programa Socio Bosque. }\end{array}$ \\
\hline $\begin{array}{l}\text { Administración de la Reserva } \\
\text { (jefe de reserva, guardaparques y } \\
\text { personal administrativo) }\end{array}$ & Público & $x$ & $x$ & $x$ & $x$ & & $x$ & & $\begin{array}{l}\text { Coordinación de actividades entre los } \\
\text { actores, facilita procesos. } \\
\text { Control y Vigilancia. }\end{array}$ \\
\hline Organizaciones indígenas & Pueblos indígenas & $x$ & $x$ & $x$ & $x$ & $x$ & $x$ & & $\begin{array}{l}\text { Organización entre etnias, reivindicación } \\
\text { delos derechos indígenas. }\end{array}$ \\
\hline Comunidades indígenas & Pueblos indígenas & $x$ & $x$ & $x$ & $x$ & & $x$ & & $\begin{array}{l}\text { Organización local, uso del territorio, } \\
\text { cultura ancestral, manejo de RRNN. }\end{array}$ \\
\hline GAD Cuyabeno & Público & $x$ & $x$ & $x$ & & $x$ & $x$ & & $\begin{array}{l}\text { Control del uso del suelo, provee } \\
\text { servicios públicos, hacen los planes de } \\
\text { desarrollo del cantón. }\end{array}$ \\
\hline $\begin{array}{l}\text { Gobierno Autónomo Provincial de } \\
\text { Sucumbíos }\end{array}$ & Público & $x$ & $x$ & $x$ & & $x$ & $x$ & & $\begin{array}{l}\text { Planificación y ejecución de obras } \\
\text { públicas. }\end{array}$ \\
\hline $\begin{array}{l}\text { Junta Parroquial de Cuyabeno, } \\
\text { Tarapoa, Aguas Negras }\end{array}$ & Público & & $x$ & & $x$ & & $x$ & & $\begin{array}{l}\text { Planificación de desarrollo parroquial, } \\
\text { ordenamiento territorial, incentivar } \\
\text { actividades productivas. }\end{array}$ \\
\hline Tenencia Política Cuyabeno & Público & & & & & $x$ & $x$ & & $\begin{array}{l}\text { Dirección, coordinación y control de la } \\
\text { aplicación de las políticas públicas del } \\
\text { Gobierno nacional en el territorio. } \\
\text { Entregan permisos para portar armas. }\end{array}$ \\
\hline Fuerzas Armadas & Público & & $x$ & & & $x$ & & $x$ & $\begin{array}{l}\text { Protección y defensa de las fronteras, el } \\
\text { territorio, los RRNN y la población. }\end{array}$ \\
\hline Destacamentos militares & Público & & $x$ & & $x$ & $x$ & $x$ & & $\begin{array}{l}\text { Coordinación de actividades con } \\
\text { guardaparques y comunidades para } \\
\text { la protección de RRNN y apoyo en } \\
\text { movilización de la población. }\end{array}$ \\
\hline $\begin{array}{l}\text { Empresas privadas de turismo, } \\
\text { ecolodges }\end{array}$ & Privado & $x$ & $x$ & $x$ & $x$ & & $x$ & & $\begin{array}{l}\text { Inversión en infraestructura. } \\
\text { Actividad turística en la Reserva. } \\
\text { Fuentes de trabajo para indígenas locales. }\end{array}$ \\
\hline Visitantes & Privado & & $x$ & & $x$ & $x$ & $x$ & & $\begin{array}{l}\text { Realizan actividades de turismo y } \\
\text { promocionan la Reserva. } \\
\text { Actividades de investigación científica, } \\
\text { social. } \\
\text { Dejan recursos económicos. }\end{array}$ \\
\hline Asociación de Mujeres El Porvenir & Microempresa & & $x$ & & & $x$ & $x$ & & $\begin{array}{l}\text { Compra de cacao a comunidad indígena, } \\
\text { elaboración y venta de cacao orgánico } \\
\text { de Cuyabeno. }\end{array}$ \\
\hline Asociación Expreso de Oriente & Microempresa & & $x$ & & & $x$ & $x$ & & $\begin{array}{l}\text { Siembra y comercialización de café de } \\
\text { Cuyabeno. }\end{array}$ \\
\hline Empresas petroleras & Privado & $x$ & $x$ & $x$ & & $x$ & $x$ & & $\begin{array}{l}\text { Actividad extractiva. } \\
\text { Fuente de empleo. }\end{array}$ \\
\hline Fundación Sobrevivencia Cofán & ONG & $x$ & $x$ & $x$ & $x$ & & $x$ & & $\begin{array}{l}\text { Desarrollo de proyectos de desarrollo en } \\
\text { comunidades Cofán. }\end{array}$ \\
\hline WWF Ecuador & $\begin{array}{l}\text { Cooperación } \\
\text { internacional }\end{array}$ & $x$ & $x$ & $x$ & $x$ & & $x$ & $x$ & $\begin{array}{l}\text { ONG de conservación. Apoyo en } \\
\text { proyectos comunitarios. }\end{array}$ \\
\hline $\begin{array}{l}\text { Personas que realizan actividades } \\
\text { ilegales }\end{array}$ & Privado & $x$ & $x$ & & $x$ & $x$ & $x$ & & $\begin{array}{l}\text { Realizan de manera ilegal actividades de } \\
\text { turismo, tala, pesca y caza dentro de la } \\
\text { reserva. }\end{array}$ \\
\hline
\end{tabular}




\begin{tabular}{|c|c|c|c|c|c|c|c|c|c|}
\hline \multirow[b]{2}{*}{ Actor } & \multirow[b]{2}{*}{$\begin{array}{l}\bar{o} \\
\text { ò } \\
\infty\end{array}$} & \multicolumn{3}{|c|}{ Ámbito } & \multicolumn{2}{|c|}{ Ubicación } & \multicolumn{2}{|c|}{ Alcance } & \multirow[b]{2}{*}{ Rol / situación } \\
\hline & & $\begin{array}{l}8 \\
\frac{0}{7} \\
\frac{0}{8} \\
\\
\end{array}$ & $\begin{array}{l}\bar{c} \\
0 \\
\infty \\
\infty\end{array}$ & 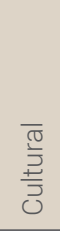 & 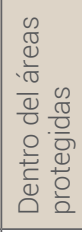 & 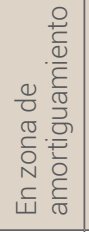 & $\begin{array}{l}\bar{\sigma} \\
\stackrel{్}{్} \\
\end{array}$ & $\begin{array}{l}\bar{\sigma} \\
\overline{0} \\
\frac{0}{0} \\
\frac{\pi}{z}\end{array}$ & \\
\hline $\begin{array}{l}\text { Ministerio del Ambiente y } \\
\text { Desarrollo Sostenible }\end{array}$ & Público & $x$ & $x$ & $x$ & x & $x$ & & $x$ & $\begin{array}{l}\text { Define la política ambiental a nivel } \\
\text { nacional y promueve la conservación y } \\
\text { el uso sostenible de los RRNN. }\end{array}$ \\
\hline $\begin{array}{l}\text { Parques Nacionales Naturales } \\
\text { de Colombia }\end{array}$ & Público & $x$ & $x$ & $x$ & $x$ & $x$ & $x$ & $x$ & $\begin{array}{l}\text { Entidad perteneciente al Ministerio } \\
\text { de Ambiente y Desarrollo Sostenible, } \\
\text { encargada de la administración y } \\
\text { manejo del Sistema de Parques } \\
\text { Nacionales Naturales y la coordinación } \\
\text { del Sistema Nacional de Áreas } \\
\text { Protegidas. }\end{array}$ \\
\hline $\begin{array}{l}\text { Oficina PNN La Paya (iefe } \\
\text { de parque, guardaparques, } \\
\text { personal administrativo) }\end{array}$ & Público & $x$ & $x$ & $x$ & x & $x$ & $x$ & & $\begin{array}{l}\text { Responsable de la conservación de la } \\
\text { flora y fauna del AP y del uso sostenible } \\
\text { de los recursos. Coordina actividades } \\
\text { entre los actores, facilita procesos, } \\
\text { realiza control y vigilancia del AP. }\end{array}$ \\
\hline Fuerzas Militares & Público & & $x$ & & & $x$ & & $x$ & $\begin{array}{l}\text { Defensa del territorio colombiano y } \\
\text { lucha contra el narcotráfico. }\end{array}$ \\
\hline Bases militares & Público & & $x$ & & & $x$ & $x$ & & $\begin{array}{l}\text { En Puerto Leguízamo tienen bases } \\
\text { militares de la Armada y el Ejército. }\end{array}$ \\
\hline Municipio de Puerto Leguízamo & Público & $x$ & $x$ & $x$ & & $x$ & $x$ & & $\begin{array}{l}\text { Garantizar la participación ciudadana } \\
\text { para el desarrollo local, dotar de } \\
\text { servicios públicos a los leguizameños. } \\
\text { Apoyo a las iniciativas comunitarias } \\
\text { de manejo y uso sostenible de la } \\
\text { biodiversidad. } \\
\text { Se autodenomina municipio ecológico. }\end{array}$ \\
\hline $\begin{array}{l}\text { Instituto Amazónico de } \\
\text { Investigación cientifica (Sinchi) }\end{array}$ & Público & $x$ & $x$ & & $x$ & $x$ & & $x$ & $\begin{array}{l}\text { Apoyo con asistencia técnica y } \\
\text { recursos para recuperación del bosque } \\
\text { en La Paya y proyectos productivos. Es } \\
\text { una entidad del Ministerio de Ambiente } \\
\text { y Desarrollo Sostenible. }\end{array}$ \\
\hline $\begin{array}{l}\text { Agencia Colombiana para la } \\
\text { Reintegración, ACR }\end{array}$ & Público & & $x$ & $x$ & & $x$ & & $x$ & $\begin{array}{l}\text { Asistencia técnica al proyecto } \\
\text { "Canastos de Sabiduría", etnia murui }\end{array}$ \\
\hline $\begin{array}{l}\text { Corporación para el Desarrollo } \\
\text { Sostenible del Sur de la } \\
\text { Amazonia, CORPOAMAZONIA }\end{array}$ & Público & & $x$ & & & x & & $x$ & $\begin{array}{l}\text { Planificación del uso del suelo y de los } \\
\text { RRNN. } \\
\text { Facilita la participación comunitaria, } \\
\text { fomenta la conservación de la } \\
\text { biodiversidad y el desarrollo sostenible. }\end{array}$ \\
\hline $\begin{array}{l}\text { Servicio Nacional de } \\
\text { Aprendizaje, SENA } \\
\text { Ministerio de Trabajo }\end{array}$ & Público & & $x$ & & & $x$ & & $x$ & $\begin{array}{l}\text { Cursos de capacitación profesional } \\
\text { para actividades productivas. } \\
\text { Apoyo al desarrollo comunitario a nivel } \\
\text { urbano y rural. }\end{array}$ \\
\hline $\begin{array}{l}\text { MINGA, Asociación para la } \\
\text { promoción social alternativa }\end{array}$ & Privado & & $x$ & & & $x$ & & $x$ & $\begin{array}{l}\text { En Putumayo acompañan procesos } \\
\text { sociales afectados por el Plan } \\
\text { Colombia. }\end{array}$ \\
\hline
\end{tabular}




\begin{tabular}{|c|c|c|c|c|c|c|c|c|c|}
\hline \multirow[b]{2}{*}{ Actor } & \multirow[b]{2}{*}{$\begin{array}{l}\overline{0} \\
\text { to } \\
\text { ¿ }\end{array}$} & \multicolumn{3}{|c|}{ Ámbito } & \multicolumn{2}{|c|}{ Ubicación } & \multicolumn{2}{|c|}{ Alcance } & \multirow[b]{2}{*}{ Rol / situación } \\
\hline & & $\begin{array}{l}8 \\
\frac{0}{7} \\
\frac{.0}{8} \\
\dot{U}\end{array}$ & $\begin{array}{l}\bar{\pi} \\
\overline{0} \\
\infty\end{array}$ & $\begin{array}{l}\overline{\frac{\pi}{J}} \\
\frac{\vec{J}}{3} \\
0\end{array}$ & 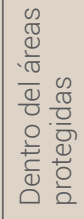 & 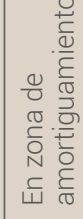 & $\overline{\widetilde{\delta}}$ & $\begin{array}{l}\bar{\pi} \\
\frac{0}{0} \\
\frac{0}{Z}\end{array}$ & \\
\hline FUPAR & Público & & $x$ & & & $x$ & & $x$ & $\begin{array}{l}\text { Apoyo financiero para comercialización } \\
\text { de productos agrícolas y artesanales. } \\
\text { Participación en ferias. }\end{array}$ \\
\hline $\begin{array}{l}\text { ACILAPP } \\
\text { Asociación de Autoridades } \\
\text { Tradicionales y Cabildos de los } \\
\text { Pueblos indígenas del Municipio } \\
\text { de Leguízamo y Alto Resguardo } \\
\text { Predio Putumayo }\end{array}$ & $\begin{array}{l}\text { Pueblos } \\
\text { indígenas }\end{array}$ & $x$ & $x$ & $x$ & & $x$ & $x$ & & $\begin{array}{l}\text { Organización interétnica, reivindicación } \\
\text { de los derechos indígenas }\end{array}$ \\
\hline Resguardo Indígena Jiri Jirí & $\begin{array}{l}\text { Pueblos } \\
\text { indígenas }\end{array}$ & $x$ & $x$ & $x$ & & $x$ & $x$ & & $\begin{array}{l}\text { Organización local, uso del territorio, } \\
\text { cultura ancestral, manejo de RRNN. } \\
\text { Llevan adelante el proyecto de } \\
\text { "Canastos de Sabiduría". }\end{array}$ \\
\hline $\begin{array}{l}\text { Asociación de Autoridades } \\
\text { Tradicionales del Pueblo Kichwa } \\
\text { de la Amazonia Colombiana }\end{array}$ & $\begin{array}{l}\text { Pueblos } \\
\text { indígenas }\end{array}$ & $x$ & $x$ & $x$ & & $x$ & $x$ & & $\begin{array}{l}\text { Organización local, reivindicación de } \\
\text { los derechos indígenas. }\end{array}$ \\
\hline Campesinos & Campesinos & $x$ & $x$ & & $x$ & $x$ & $x$ & & $\begin{array}{l}\text { Tienen monocultivos, interés en tierras } \\
\text { para agricultura, están incursionando en } \\
\text { proyectos de agroecología. } \\
\text { Incentivan ampliación de frontera agrícola. }\end{array}$ \\
\hline Ganaderos & Ganaderos & $x$ & $x$ & & & $x$ & $x$ & & $\begin{array}{l}\text { Crían ganado para venta de carne, en } \\
\text { propiedades de hasta } 500 \text { ha donde } \\
\text { talan el bosque para tener potreros. }\end{array}$ \\
\hline WWF Colombia & $\begin{array}{l}\text { Cooperación } \\
\text { internacional }\end{array}$ & $x$ & $x$ & $x$ & & $x$ & $x$ & $x$ & $\begin{array}{l}\text { Apoyo en fortalecimiento de capital } \\
\text { humano, caracterización territorial. }\end{array}$ \\
\hline Poblaciones desplazadas & & & & & & & & & $\begin{array}{l}\text { Poblaciones rurales, principalmente } \\
\text { indígenas y campesinos, presionadas } \\
\text { por la guerrilla con reclutamiento } \\
\text { forzado de personas, la expropiación } \\
\text { de terrenos y las amenazas contra sus } \\
\text { vidas. Llegan a Puerto Leguízamo en } \\
\text { busca de oportunidades y tierra. } \\
\text { Ejercen control sobre los límites del } \\
\text { parque para acceso a tierra. }\end{array}$ \\
\hline $\begin{array}{l}\text { Personas que realizan } \\
\text { actividades ilegales }\end{array}$ & Privado & $x$ & $x$ & & $x$ & $x$ & $x$ & & Minería artesanal (oro), tala y caza. \\
\hline Grupos paramilitares & Independiente & & $x$ & & $x$ & $x$ & $x$ & $x$ & $\begin{array}{l}\text { Se ubican en la zona del río Caquetá, en } \\
\text { la zona de influencia del PNN La Paya }\end{array}$ \\
\hline $\begin{array}{l}\text { Fuerzas Armadas } \\
\text { Revolucionarias de } \\
\text { Colombia-FARC }\end{array}$ & Independiente & $x$ & $x$ & & $x$ & $x$ & $x$ & $x$ & $\begin{array}{l}\text { Cultivos ilícitos de coca dentro del AP } \\
\text { para la producción de pasta de coca y } \\
\text { cocaína. Al estar en zona de frontera } \\
\text { realizan contrabando de armas, } \\
\text { municiones e insumos químicos. }\end{array}$ \\
\hline
\end{tabular}




\begin{tabular}{|c|c|c|c|c|c|c|c|c|c|}
\hline \multirow[b]{2}{*}{ Actor } & \multirow[b]{2}{*}{$\begin{array}{l}\text { के } \\
\text { ठ্ } \\
\infty\end{array}$} & \multicolumn{3}{|c|}{ Ámbito } & \multicolumn{2}{|c|}{ Ubicación } & \multicolumn{2}{|c|}{ Alcance } & \multirow[b]{2}{*}{ Rol / situación } \\
\hline & & $\begin{array}{l}\frac{\pi}{0} \\
\frac{0}{0} \\
\frac{0}{0} \\
\dot{U} \\
\end{array}$ & $\begin{array}{l}\frac{\pi}{0} \\
0 \\
\infty\end{array}$ & 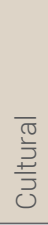 & 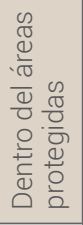 & 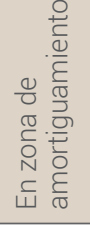 & $\begin{array}{l}\overline{0} \\
0 \\
\end{array}$ & $\begin{array}{l}\bar{\pi} \\
\frac{0}{0} \\
\frac{0}{0} \\
\frac{\pi}{2}\end{array}$ & \\
\hline Ministerio del Ambiente & Público & $x$ & $x$ & & $x$ & $x$ & & $x$ & $\begin{array}{l}\text { Órgano rector en materia de } \\
\text { ambiente a nivel nacional. }\end{array}$ \\
\hline $\begin{array}{l}\text { SERNANP, Servicio } \\
\text { Nacional de Áreas } \\
\text { Naturales Protegidas por } \\
\text { el Estado. }\end{array}$ & Público & $x$ & $x$ & $x$ & $x$ & $x$ & & $x$ & $\begin{array}{l}\text { Entidad adscrita al Ministerio } \\
\text { del Ambiente. Dirige y } \\
\text { establece los criterios técnicos } \\
\text { y administrativos para la } \\
\text { conservación de las AP y la } \\
\text { diversidad biológica. }\end{array}$ \\
\hline $\begin{array}{l}\text { Administración del Parque } \\
\text { Güeppí-Sekime y las } \\
\text { reservas comunales }\end{array}$ & Público & $x$ & $x$ & $x$ & $x$ & $x$ & $x$ & & $\begin{array}{l}\text { Coordinación de actividades } \\
\text { dentro y fuera de las AP entre } \\
\text { los actores. }\end{array}$ \\
\hline $\begin{array}{l}\text { Municipalidad Distrital } \\
\text { Torres Causana }\end{array}$ & Público & & $x$ & & & $x$ & $x$ & & \multirow{2}{*}{$\begin{array}{l}\text { Administrar los ingresos } \\
\text { económicos y desarrollar } \\
\text { labores en beneficio y progreso } \\
\text { de la comunidad local. }\end{array}$} \\
\hline $\begin{array}{l}\text { Municipalidad Distrital } \\
\text { Teniente Manuel Clavero }\end{array}$ & Público & & $x$ & & & $x$ & $x$ & & \\
\hline Fuerzas Armadas & Público & & $x$ & & $x$ & $x$ & $x$ & $x$ & $\begin{array}{l}\text { Defensa del territorio y la } \\
\text { soberanía. }\end{array}$ \\
\hline $\begin{array}{l}\text { Puesto de Vigilancia de } \\
\text { Frontera } \\
\text { Soplín Vargas y Aguas } \\
\text { Negras } \\
\text { Ejército Peruano }\end{array}$ & Público & $x$ & $x$ & & $x$ & $x$ & $x$ & & $\begin{array}{l}\text { Control y vigilancia en los } \\
\text { puntos de frontera, trabajo } \\
\text { conjunto con guardaparques de } \\
\text { la Reserva Airo pai. }\end{array}$ \\
\hline $\begin{array}{l}\text { Federación Indígena } \\
\text { Kichwa del Alto Putumayo } \\
\text { Inti Runa (FIKAPIR) }\end{array}$ & $\begin{array}{l}\text { Pueblos } \\
\text { indígenas }\end{array}$ & $x$ & $x$ & $x$ & & $x$ & $x$ & & $\begin{array}{l}\text { Representa a } 27 \text { comunidades } \\
\text { indígenas del Alto Putumayo. }\end{array}$ \\
\hline $\begin{array}{l}\text { Organización Indígena } \\
\text { Secoya del Perú (OISPE) }\end{array}$ & $\begin{array}{l}\text { Pueblos } \\
\text { indígenas }\end{array}$ & $x$ & $x$ & $x$ & & $x$ & $x$ & & $\begin{array}{l}\text { Agrupa a las comunidades } \\
\text { indígenas secoyas. }\end{array}$ \\
\hline $\begin{array}{l}\text { Asociación interétnica } \\
\text { de Desarrollo de la Selva } \\
\text { Peruana (AIDESEP) }\end{array}$ & $\begin{array}{l}\text { Pueblos } \\
\text { indígenas }\end{array}$ & $x$ & $x$ & $x$ & $x$ & & $x$ & & $\begin{array}{l}\text { Apoyo técnico en la elaboración } \\
\text { del Plan Maestro del Parque } \\
\text { Nacional Güeppí-Sekime. }\end{array}$ \\
\hline $\begin{array}{l}\text { Organización Kichwaruna } \\
\text { Wangurina del Alto Napo } \\
\text { (ORKIWAN) }\end{array}$ & $\begin{array}{l}\text { Pueblos } \\
\text { indígenas }\end{array}$ & $x$ & $x$ & $x$ & & & & & $\begin{array}{l}\text { Defensa de los derechos de los } \\
\text { Pueblos indígenas. }\end{array}$ \\
\hline $\begin{array}{l}\text { Organización Regional de } \\
\text { los Pueblos indígenas del } \\
\text { Oriente (ORPIO) }\end{array}$ & $\begin{array}{l}\text { Pueblos } \\
\text { indígenas }\end{array}$ & $x$ & $x$ & $x$ & & $x$ & $x$ & & $\begin{array}{l}\text { Defensa de los derechos de los } \\
\text { Pueblos indígenas. }\end{array}$ \\
\hline $\begin{array}{l}\text { Centro para el Desarrollo } \\
\text { del Indígena Amazónico } \\
\text { (CEDIA) }\end{array}$ & ONG & $x$ & $x$ & $x$ & $x$ & & $X$ & & $\begin{array}{l}\text { Apoyo técnico en la elaboración } \\
\text { del Plan Maestro del Parque } \\
\text { Nacional Güeppí-Sekime. }\end{array}$ \\
\hline WWF Perú & $\begin{array}{l}\text { Cooperación } \\
\text { internacional }\end{array}$ & $x$ & $x$ & $x$ & $x$ & & $x$ & & $\begin{array}{l}\text { Apoyo a poblaciones locales } \\
\text { para el desarrollo sostenible de } \\
\text { sus comunidades, certificación } \\
\text { de manejo forestal, mejores } \\
\text { prácticas extractivas, entre otros. }\end{array}$ \\
\hline $\begin{array}{l}\text { Personas que realizan } \\
\text { actividades ilegales }\end{array}$ & Privados & & $x$ & & $x$ & & $x$ & & $\begin{array}{l}\text { Actividades relacionadas } \\
\text { principalmente a la tala del bosque, } \\
\text { cazay pesca indiscriminada. }\end{array}$ \\
\hline
\end{tabular}



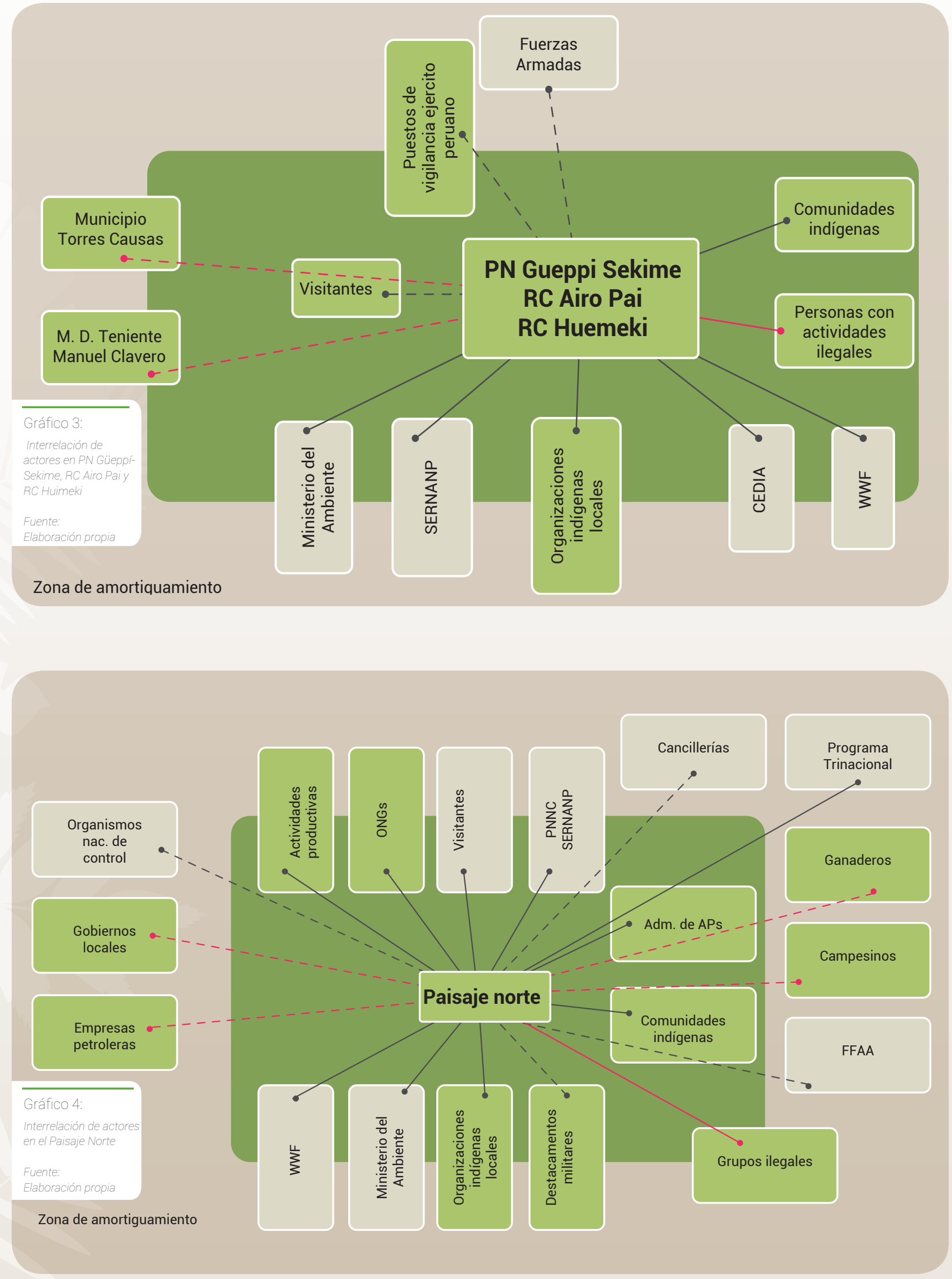


\section{Paisaje sur}

\section{Ámbito ecológico}

\section{Gestión y conservación de la biodiversidad}

Las administraciones de las áreas protegidas del paisaje sur trabajan coordinadamente junto con las poblaciones locales para realizar el monitoreo de la biodiversidad existente.

El Parque Nacional Alto Purús y la Reserva Comunal Purús, de acuerdo a los planes de manejo, gestionan el aprovechamiento sostenible de la caza y cuentan con planes de manejo de charapas, taricayas y bagres en las zonas de amortiguamiento. Los pobladores cuentan con capacitación en educación ambiental para liderar proyectos relacionados con los recursos naturales y con la revalorización del conocimiento local. Las comunidades indígenas son las promotoras de la caza y pesca sostenible y quienes realizan el monitoreo de recursos. Cuentan con dos sistemas de monitoreo, uno para el manejo sostenible de la caza de subsistencia en la reserva y otro para las variables climáticas y la calidad del agua.

En la Reserva Comunal Purús, se está trabajando, junto con las comunidades indígenas, para que las actividades tradicionales como la caza y pesca se aprovechen de manera ordenada y sostenible, a través de la implementación de un Sistema de Monitoreo de Fauna.
Desde 2012, la asociación civil MABOSINFRON, en la cuenca del río La Novia y conformada por líderes campesinos de Puerto Esperanza, tiene la concesión para administrar 6700 ha de bosque de tierras bajas que limitan con la Reserva Comunal Purús y con tierras indígenas tituladas. Esta fue la primera concesión entregada para conservación en la provincia de Purús, tiene un periodo de 10 años y es renovable. Allí se realizan investigaciones científicas y proyectos que promuevan la conservación de especies de flora y fauna vulnerable como la caoba, el cedro y el águila arpía. MABOSINFRON trabaja junto con los guardianes de la reserva y con las comunidades indígenas vecinas para proteger la biodiversidad.

En la zona de Purús, en 2014, se dio una importante pérdida de producción de maní de cultivos del pueblo indígena jini-kuin por la creciente de los ríos fuera de la temporada de lluvias. La FECONAPU (Federación de Comunidades Nativas del Río Purús) adaptó mecanismos de prevención a través de la reubicación de las plantaciones en sectores más altos, alejados de las orillas en los ríos. Además, establecieron acuerdos con otras comunidades para poder sembrar en terrenos que no corran ese peligro. Esta medida les hizo acreedores al Premio Nacional Ambiental 2014 por "Buenas Prácticas Frente al Cambio Climático", otorgado por el Ministerio del Ambiente de Perú.

En el PE Chandless, debido a su categorización de área protegida estricta y por sus características únicas con alto valor ecológico, la SEMA tiene entre sus prioridades la promoción

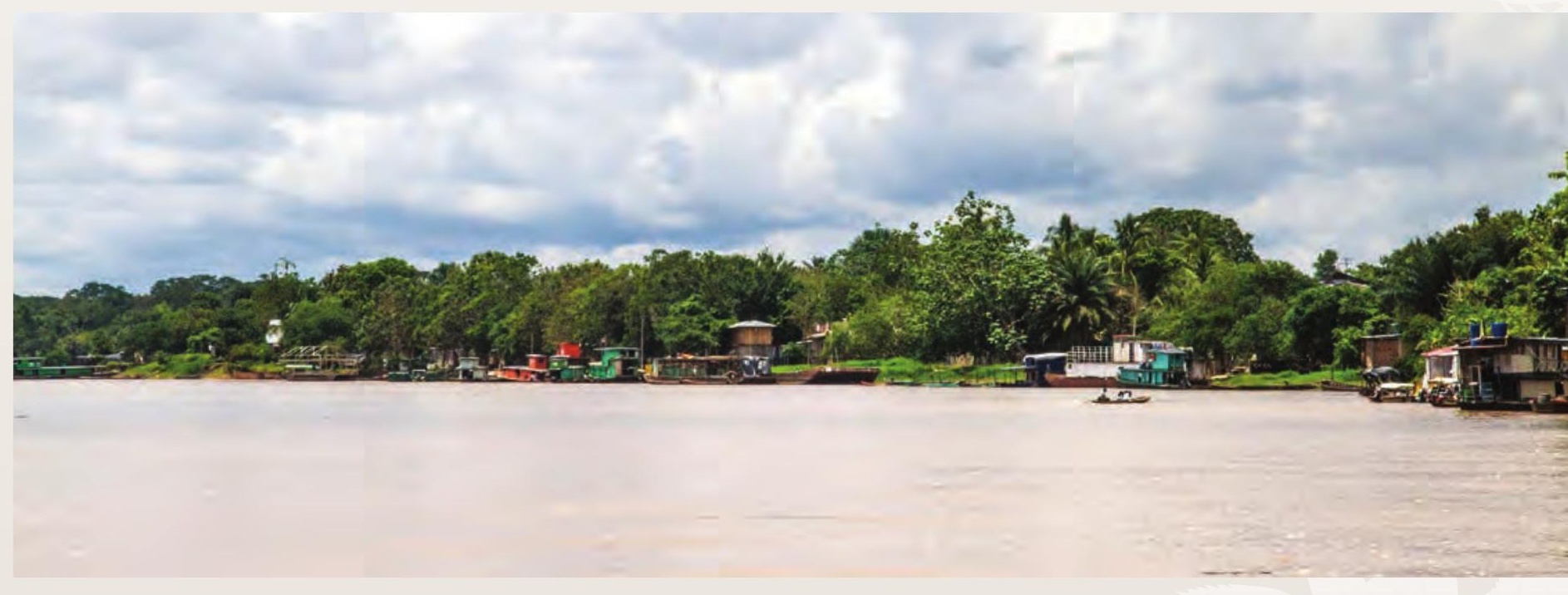




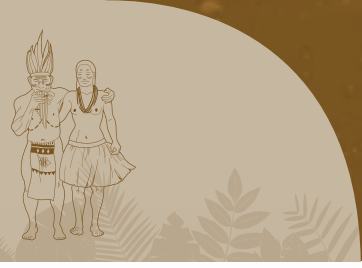

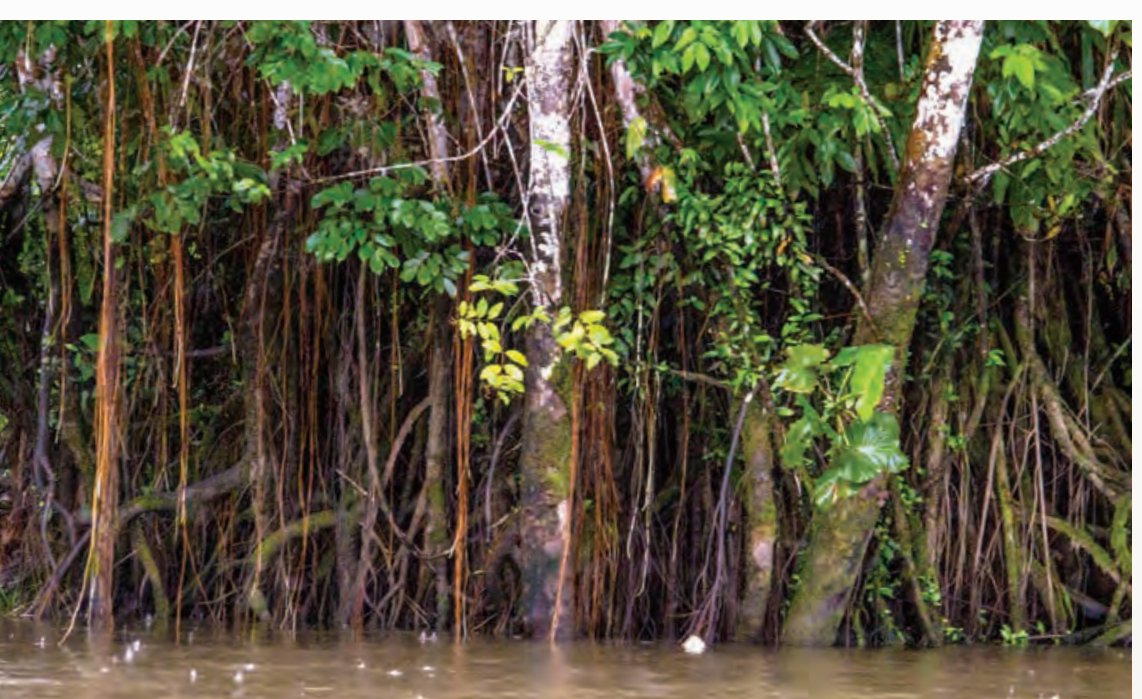

y desarrollo de investigaciones científicas. En este contexto se priorizó la implementación de infraestructura que facilite el acceso y permanencia de investigadores en la unidad de conservación para el desarrollo de estudios científicos, en los que participan académicos de universidades nacionales y extranjeras realizando investigaciones en distintos temas. Los habitantes del parque son los guías locales, quienes apoyan a los investigadores.

Adicionalmente, la administración del parque y los pobladores tienen establecidas zonas de transectos $^{145}$ para el levantamiento de información de flora y fauna. El monitoreo en estos transectos está establecido para un periodo de 5 años, tiempo en el cual los habitantes tienen prohibido realizar actividades de caza en estas zonas.

En 2008 la SEMA estableció un acuerdo de cooperación con el Instituto Nacional de Meteorología (INMET) para la instalación de una estación automática en el PE Chandless, la

"El proyecto de Monitoreo de Biodiversidad nos ha permitido tener otra visión de las cosas. Antes cazábamos sin saber qué estaba sucediendo ni las consecuencias que eso podía traer. Ahora ya es diferente, conocemos cómo funciona, qué se puede hacer y qué no, y cómo debemos manejar los recursos naturales".

Francisco de Souza Carvalho Monitor de biodiversidad de la RESEX Cazumbá-Iracema. cual cuenta con tecnología punta que arroja datos meteorológicos en tiempo real. En 2011 se estableció un acuerdo con la Agencia Nacional de Agua (ANA) para la instalación de una estación hidrológica que mide diariamente la pluviosidad, la temperatura y la profundidad del río. Esta información ayuda a planificar expediciones científicas y a construir escenarios de cambio climático para la región a mediano y largo plazo.

Antes del establecimiento del Plan de Manejo de 2007 en la RESEX Cazumbá-Iracema, Núcleo do Cazumbá ya tenía un acuerdo de caza para preservar las especies en peligro. En base a esta experiencia se incorporó en el plan la importancia de involucrar a la población local en las actividades de monitoreo de la biodiversidad y de contar con acuerdos de caza en las comunidades para proteger las especies en peligro y controlar las actividades que están generando un alto impacto ambiental, como la caza con perros y la pesca indiscriminada. En ese mismo año y hasta 2009, se llevó a cabo el proyecto "Gestión de Recursos Hídricos de la microcuenca de los ríos Caeté, Macauã, laco e Purus"146. cuyo propósito fue realizar procesos de capacitación, fortalecimiento e intercambios de experiencias comunitarias para la formación y acciones de agentes ambientales voluntarios en la reserva. Este fue el preámbulo para el trabajo que actualmente se desarrolla en la RESEX Cazumbá-Iracema en lo que tiene que ver con el monitoreo de biodiversidad.

\section{El monitoreo comunitario en la RESEX Cazumbá-Iracema}

La Reserva Extractivista Cazumbá-Iracema, desde 2013, forma parte del Proyecto de "Monitoreo Participativo de Biodiversidad en Unidades de Conservación de la Amazonía", desarrollado por el Instituto de Pesquisas Ecológicas (IPE) como parte de la iniciativa para la estructuración del Sistema Brasileiro de Monitoramento da Biodiversidade del ICMBio (Instituto Chico Mendes de Conservación de Biodiversidad)

\footnotetext{
145. Muestreo caracterizado por la toma de datos en determinados recorridos prefijados

146. Proyecto ejecutado por la ONG Amigos de la Amazonía y Petrobras en asociación con ICMBio e IBAMA.
} 


\section{Paisaje sur. Ámbito ecológico}

Este proyecto tiene como uno de sus objetivos involucrar a las comunidades locales en la gestión de las áreas protegidas como monitores de biodiversidad, para apoyar el manejo adecuado de recursos naturales. El proyecto está siendo implementado en siete unidades de conservación de la Amazonía de Brasil.

En la RESEX Cazumbá-Iracema, el IPE trabaja con tres macroregiones de la reserva: Núcleo do Cazumbá, Medio Caeté y Alto Caeté. El IPE realiza anualmente un curso de "Capacitación de Protocolos Mínimos para el Monitoreo in situ de la Biodiversidad" en el cual, durante el año 2014 participaron jóvenes de la reserva elegidos por votación, quienes se certificaron como monitores de biodiversidad. La capacitación no se limita a enseñar a los jóvenes a registrar los datos, sino que brinda conocimientos técnicos como un complemento a sus conocimientos tradicionales, además de instrumentos y herramientas para realizar el monitoreo. Los que obtienen las mejores calificaciones son los escogidos para trabajar como monitores mientras que los otros participan cuando se requiere más personal. Además de la capacitación, el proyecto provee una consultora contratada para coordinar, hacer seguimiento y trabajar de cerca con los monitores, quienes reciben una remuneración por su trabajo.

En Cazumbá-Iracema se realiza el monitoreo de mamíferos, plantas, aves y mariposas. En 2015 se inició el monitoreo de la castaña por decisión de la comunidad ya que cayeron en cuenta de que el castañal no se estaba reproduciendo. La RESEX cuenta con tres estaciones de muestreo y está comenzando su segundo año de registro de datos. En el proyecto trabajan 10 jóvenes: 6 monitores de protocolos mínimos y 4 monitores de castaña, de un total de 25 capacitados.

En conversación con Francisco de Souza Carvalho, monitor del proyecto que, además, forma parte del Consejo Deliberativo de la Reserva ${ }^{147}$, se supo que al inicio del proyecto se realizaba el monitoreo en base al conocimiento tradicional de la flora y fauna. Este se complementó con los cuadernos guía de identificación de especies que se recibieron después.

Para el monitoreo de mamíferos y aves, se marcan transectos de $5 \mathrm{~km}$ de distancia en línea recta en lugares cercanos a las comunidades.

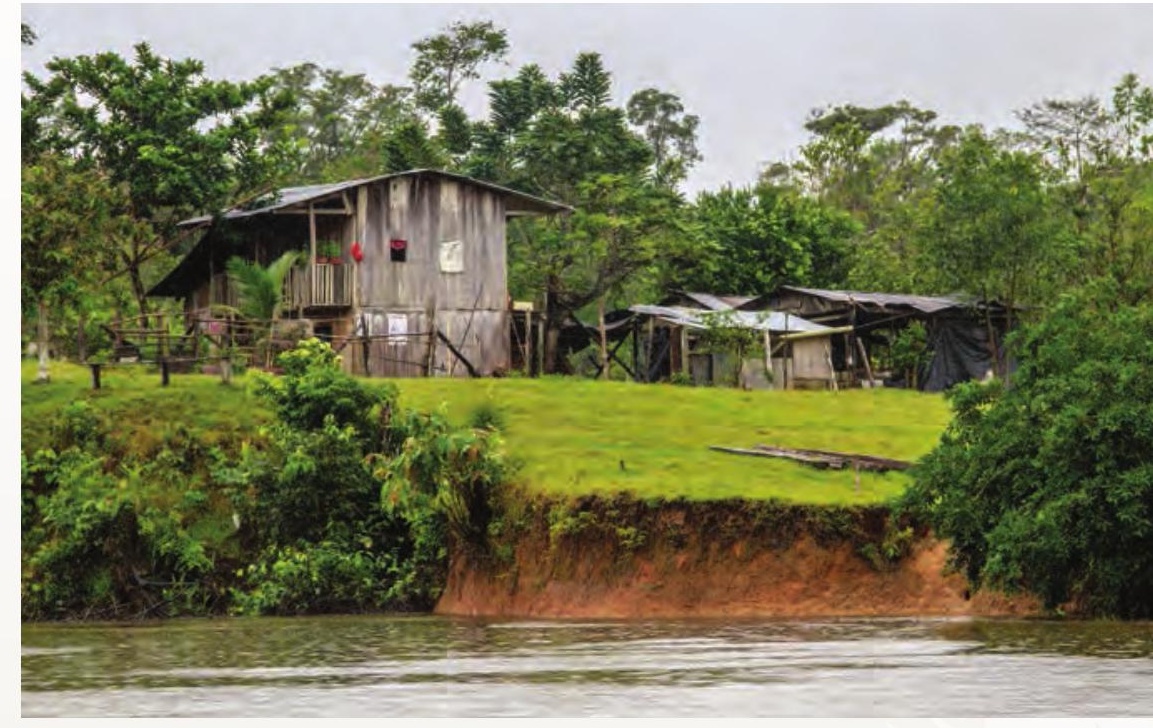

Actualmente, cuentan con tres transectos, uno en cada comunidad participante. Para el registro de los hallazgos, los monitores asignan una hora por kilómetro. Hay un límite mínimo de tamaño para registrar especies, así, los mamíferos más pequeños que monitorean son las ardillas.

El monitoreo de mariposas toma más tiempo (alrededor de 7 días). Este se realiza a los lados del transecto de $5 \mathrm{~km}$. Primero se arman las trampas con caña de azúcar en puntos predeterminados, se espera un día hasta que esta se fermente para provocar que las mariposas se perturben, se queden en la red y sea más fácil la recolección. Después de un día se repite el procedimiento para recolectar otra muestra adicional. Según Francisco de Souza Carvalho, se han encontrado algunas especies de mariposas que no constan en el cuaderno guía, ampliando así la cantidad de especies registradas.

El monitoreo de mamíferos, aves y mariposas se realiza dos veces al año, uno en época seca y otro en época de lluvia. Para el monitoreo de flora se traza con GPS una cruceta llamada cruz de malta ${ }^{148}$ donde se registran y marcan todas las plantas y árboles que se encuentran en los cuatro cuadrantes ubicados en los extremos de la cruz. Este monitoreo se hace cada cinco años.

147. El Consejo Deliberativo de la RESEX Cazumbá-Iracema es un espacio donde se crean normas y reglas mientras que el Consejo Consultivo no tiene poder de decisión.

148. Cuatro brazos iquales, más ensanchados en los extremos que en e cruce, y limitados por una línea recta. Los cuadrantes en los extremos de la cruz son de $50 \mathrm{~m} \times 20 \mathrm{~m}$ y registran las plantas y árboles que encuentran hasta $1 \mathrm{~m}$ de altura. 


\section{Paisaje sur. Ámbito ecológico}

\section{Control y vigilancia comunitaria}

Las actividades de control y vigilancia que se desarrollan en el interior de las áreas protegidas del paisaje sur, así como en sus zonas de influencia, tienen el objetivo de disminuir el registro de actividades ilegales para proteger la biodiversidad y las especies amenazadas.

En el caso de actividades ilegales dentro de la Reserva Manuripi - principalmente las relacionadas con la tala, pesca, explotación de oro, tráfico y aprovechamiento de animales y tráfico de drogas-, los guardaparques trabajan coordinadamente con la policía. El jefe del área es el responsable de decomisar los equipos, máquinas y productos encontrados en la actividad ilegal, lo que se conoce como secuestro preventivo. En caso de que lo confiscado no pueda trasladarse, se procede a realizar un acta depositaria en la cual el infractor se hace responsable de todo lo confiscado y se abre un proceso administrativo en contra del acusado, quien tiene el derecho a la defensa. En caso de ser culpable, los bienes confiscados se donan a instituciones sociales o a la iglesia.

La administración de la Reserva Manuripi cuenta con el apoyo de la cancillería, la Policía y de ADEMAF (Agencia para el Desarrollo de las Macroregiones y Zonas Fronterizas) para los operativos de control de la reserva en zonas de frontera. Las actividades de patrullaje rutinario se realizan con el apoyo de la Fuerza Naval y la Armada. En estos operativos se han decomisado bienes y destruido campamentos y aserraderos ilícitos, pero hasta el momento no se han podido establecer acuerdos binacionales para el control de fronteras.

Los guardaparques de Manuripi explican que la zona de frontera entre Perú y Bolivia es un terreno agreste, lleno de pantanos, lo que dificulta las actividades de control y convierte a la zona en conflictiva y peligrosa donde inclusive ha habido muertes. En 2008 se dio un incidente de tala ilegal por parte de madereros peruanos en tierras bolivianas lo cual generó problemas entre las cancillerías de ambos países. A raíz de esto, se reconocieron los límites y se establecieron nuevos hitos; sin embargo, la actividad ilegal continúa. El límite de la reserva colinda con la carretera transoceánica de Perú, lo que facilita la extracción de madera ilícita por el lado peruano. También son comu- nes los conflictos relacionados a actividades de explotación de oro en el río Madre de Dios.

En la Reserva Manuripi, para el caso específico de la actividad de la castaña, los guardaparques juegan un papel muy importante en el control y vigilancia antes, durante y después de la época de zafra en las comunidades, barracas, tierras fiscales (cuyo aprovechamiento es definido por instrumentos legales del Estado) y zonas de protección estricta. En el caso de extracción de castaña en tierras fiscales contiguas a tierras comunitarias, la Dirección de la Reserva logró un acuerdo verbal con los hijos de los comuneros que no disponen de tierras propias. Pueden recolectar castaña en tierras fiscales, con la condición de que no realicen actividades de tala, caza, agricultura de subsistencia, ni construcción de viviendas o infraestructuras productivas. Previamente deben presentar a la reserva una lista de quiénes entran y el tiempo de permanencia. Los guardaparques hacen el seguimiento de este acuerdo durante la época de zafra.

En las comunidades y barracas los guardaparques realizan visitas y hacen seguimiento a la actividad en los lugares de recolección y payoles ${ }^{151}$. En caso de encontrar irregularidades tienen la facultad para suspender temporalmente la autorización para la zafra.

En la Reserva Manuripi, la actividad de control y vigilancia no se limita a las poblaciones y actores dentro de la reserva, sino a cualquier otra actividad implementada por instituciones públicas dentro de los límites de la reserva, como construcción de obras de infraestructura (caminos o puentes). Esto se denomina monitoreo ambiental.

En Brasil no existe la figura de guardaparque, por lo tanto, el PE Chandless y la RESEX Cazumbá-Iracema mantienen acuerdos de vigilancia con las comunidades. En la RESEX Cazumbá-Iracema, los gestores del ICMBio también realizan actividades de protección y control, como autoridad administrativa, en conjunto con el Pelotón Forestal de Acre.

151. Los payoles son los lugares donde se almacena la castaña, necesitan tener una buena ventilación y la temperatura adecuada. 


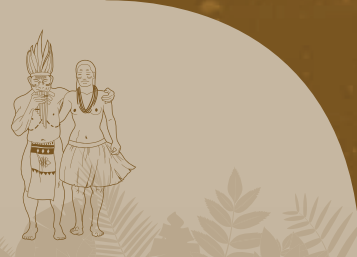

Las actividades de protección y control desarrolladas en el PE Chandless son coordinadas y realizadas por la SEMA, que trabaja en conjunto con el Instituto de Medio Ambiente de Acre (IMAC) y el Pelotón Forestal de Acre. La actividad abarca generalmente dos etapas: la de sobrevuelo y la de expedición en campo. En los sobrevuelos se identifican actividades ilegales, registrando sus coordenadas con GPS para luego realizar la expedición en campo. Este trabajo se realiza en las riberas del río Purús y del río Chandless, incluyendo trechos de su afluente, el Igarapé Cuchichá. El tramo oeste del parque, localizado en la frontera con Perú y en las cercanías del municipio de Santa Rosa de Purús, es monitoreado solo con sobrevuelos. Los indígenas ubicados en la zona de amortiguamiento del PE Chandless realizan actividades de prevención y fiscalización en coordinación con los militares.

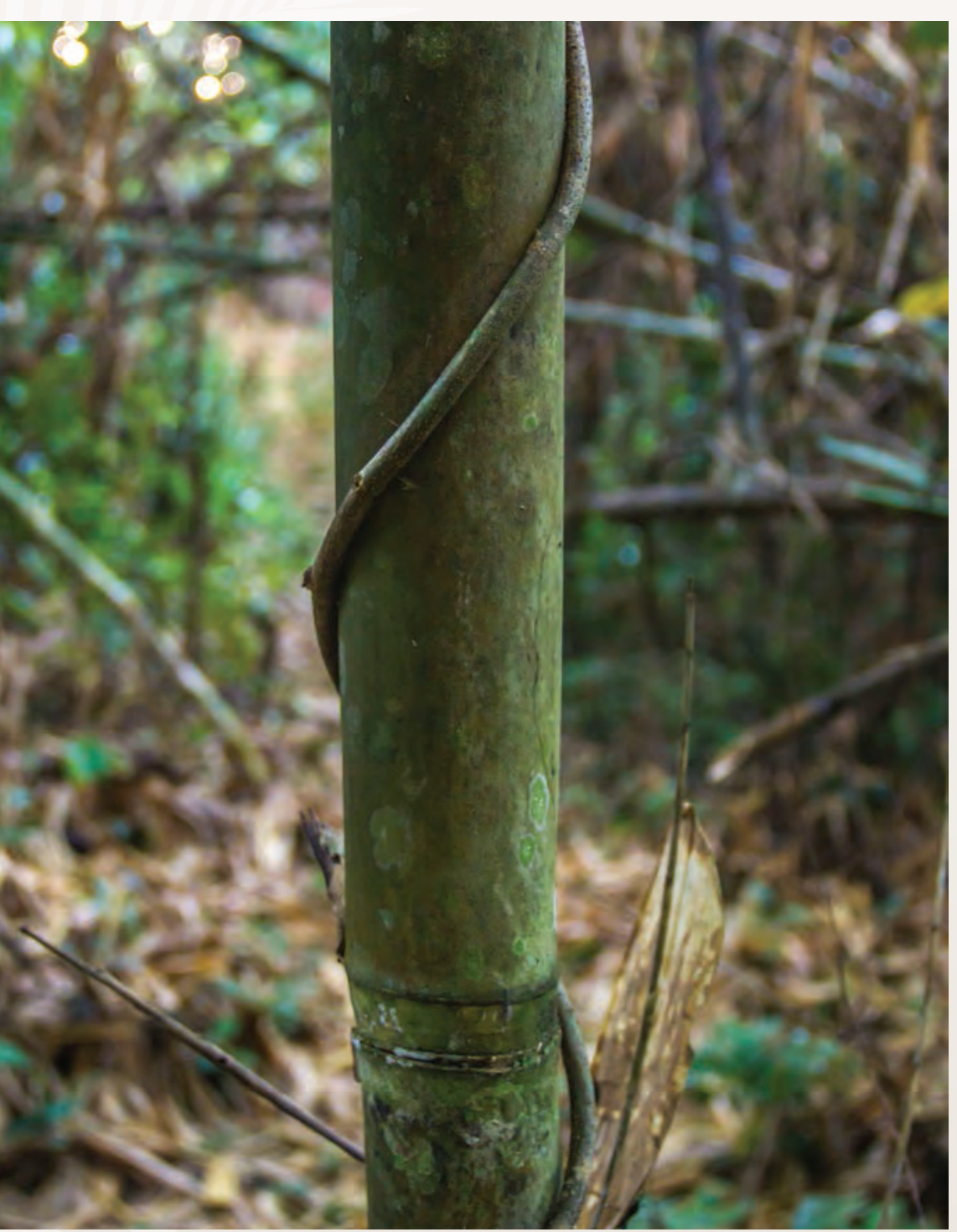

El Plan Maestro del Parque Nacional Alto Purús incluye la implementación y ejecución del Plan de Control y Vigilancia, que incluye la aplicación de lineamientos en contra de las actividades ilegales, así como el monitoreo de los desplazamientos poblacionales y de la actividad minera ilegal. El parque cuenta con un sistema de control y vigilancia en el que participa la población local, a través de los Comités de Vigilancia comunales, para reforzar el trabajo de los guardaparques contratados y voluntarios, que son personas de las comunidades locales. El PN Alto Purús, al ser Zona de Protección Estricta (ZPE), realiza sus actividades de control y vigilancia por las zonas aledañas y no en el interior del parque. Periódicamente se realizan sobrevuelos para controlar que no haya incidentes o amenazas en el área protegida y, en caso de que existan, se programa el ingreso al parque.

La RC Purús estableció como uno de los objetivos del Plan Maestro, el fortalecimiento del sistema de control y vigilancia de la reserva, con especialistas capacitados, la dotación de recursos a los guardaparques, construyendo instalaciones y promoviendo la participación de guardaparques voluntarios y de población local.

Desde 2004, ECOPURÚS (ejecutor del contrato de administración de la Reserva Comunal Purús) y las comunidades indígenas de los pueblos jini-kuin y sharanahua se encuentran trabajando en actividades de control y vigilancia junto con las administraciones del Parque $\mathrm{Na}$ cional Alto Purús y la Reserva Comunal Purús. Cuentan con instrumentos, establecieron siete puntos estratégicos de vigilancia y disponen de un equipo de guardaparques integrado por técnicos e indígenas locales, quienes además han asumido el rol de promotores de pesca y caza sostenible y monitorean el uso de recursos ${ }^{152}$.

En 2014, cinco miembros de MABOSINFRON fueron acreditados como "custodios del patrimonio forestal" por la Dirección Ejecutiva Forestal y de Fauna Silvestre (DEFFS Ucayali). Esta acreditación les faculta a tomar acciones de inmovilización y desalojo frente a actos ilegales dentro del área concesionada.

\footnotetext{
152. Proyecto realizado en conjunto entre WWF Perú, Asociación Peruana para la Conservación de la Naturaleza (APECO), ProNaturaleza, Sociedad Zoológica de Francfort, Federación de Comunidades Nativas del Purús (FECONAPU).
} 


\section{Paisaje sur: Ámbito ecológico}

Ordenamiento territorial en las áreas protegidas del paisaje sur Acuerdos locales para el uso del territorio en el PE Chandless

En el PE Chandless y las tierras indígenas vecinas, hasta hace poco la caza se realizaba con escopeta, poniendo trampas a los animales en las chacras u otros sitios donde se proveen de alimento y siguiendo sus huellas, sonidos o cualquier otro rastro que pudiera llevarlos hasta su escondite. Ahora estas formas se han cambiado por la caza con perros, ya que es una forma más rápida, fácil y económica y no se necesitan armas ni permisos.

Según conversaciones con habitantes del PE Chandless, para obtener el permiso de portar armas para la caza hay que realizar una serie de trámites, presentar el registro de residencia en el área protegida (como respaldo de que la actividad que realizan es para caza de subsistencia) y registrar las armas en el servicio federal. Para los habitantes del parque, estos trámites implican tiempo, dinero y traslados hacia Santa Rosa de Purús (a 8 horas por vía fluvial desde la sede del parque). Las armas que se compran en Perú son más asequibles, pero no se pueden registrar en Brasil. Estos son algunos de los motivos por los cuales, aunque todos tienen armas, muy pocos tienen los papeles en regla y por eso prefieren la caza con perros, la cual está generando un desequilibrio ecológico en el ecosistema y un maltrato innecesario al animal cazado, además de problemas entre vecinos.

Como la caza, otras formas tradicionales del uso del territorio deben establecerse con acuerdos entre la población para un manejo adecuado y sostenible de los recursos.

Así, en abril de 2016, se llevó a cabo en la sede del PE Chandless el primer "Taller de acuerdos de uso del territorio" entre los habitantes del parque y los indígenas madijás, ubicados en el área de amortiguamiento. Este encuentro tuvo como propósito dialogar acerca de las preocupaciones e intereses de ambas partes, principalmente en lo relacionado al aprovechamiento de recursos, la caza, pesca y el uso de las tierras asignadas para chacras. En este encuentro participaron alrededor de 30 personas,

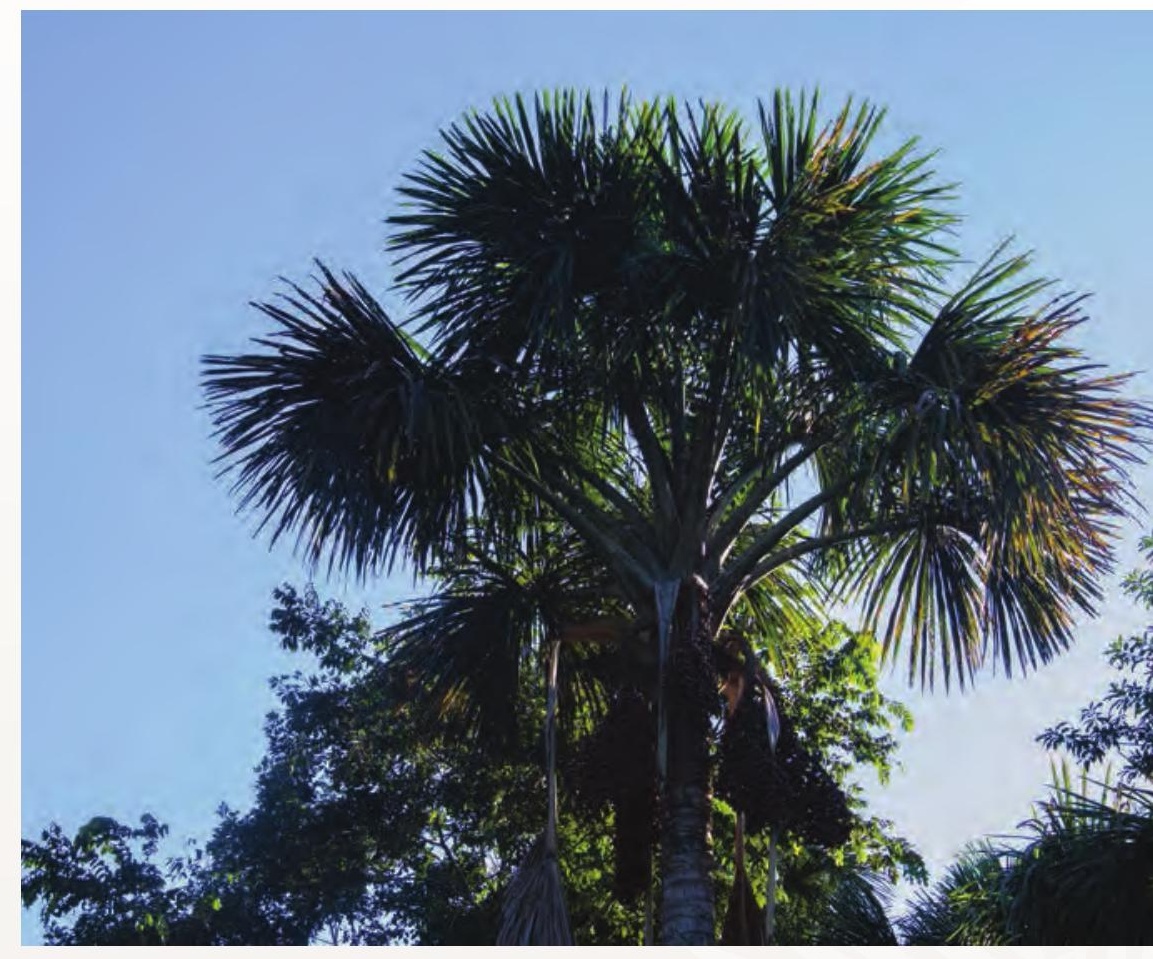

fue facilitado por la Secretaría de Estado de Medio Ambiente de Acre (SEMA) y contó además con representantes de la Fundación Nacional del Indio (FUNAI) y la jefatura del parque.

Los acuerdos a los que llegaron fueron:

- Las actividades de caza y tala solo se pueden realizar en territorio propio, así los moradores del parque podrán talar y cazar en el área del parque y los indígenas madijás dentro de los límites de su territorio.

- En ambos territorios la tala de madera está permitida solamente para construcción de casas; se prohíbe la tala para construcción de canoas (ya que estas eventualmente se podrían comercializar).

- La pesca en el río Chandless y en los lagos está permitida para los dos grupos (moradores del parque e indígenas madijás) siempre y cuando sea para autoconsumo y no para venta.

- Se permite tener chacras en las tierras de los vecinos siempre y cuando se llegue a un acuerdo entre las partes involucradas.

- Se prohíbe la entrada de personas ajenas tanto al parque como a las tierras indígenas. 
El comité de gestión también participó en la aprobación del Reglamento de la Castaña, el cual incluye, además de los aspectos ecológicos, el cumplimiento de aspectos laborales y el respeto a los derechos de los zafreros, que estaban expuestos a condiciones precarias de alojamiento por los contratistas de predios privados

A partir de 2010, el comité de gestión perdió fuerza ya que la relación con el área protegida era ocasional. De acuerdo a conversación con Walter Cano, director de la reserva, a inicios de marzo de 2016 se reconformó el comité de gestión, el cual cumple la función de aportar con nuevas perspectivas e ideas desde la realidad de cada sector para mejorar la gestión del área. Están apoyando el proyecto de aprovechamiento de asaí y las mejoras en las condiciones de acopio de castaña, así como el desarrollo de investigaciones específicas para el aprovechamiento de otros recursos naturales como el paiche (Arapaima gigas)

En cuanto a la participación a nivel comunitario, en Manuripi, las comunidades están conformadas por grupos de familias campesinas organizadas que, a partir de 1995, adquirieron su personería jurídica como Organizaciones Territoriales de Base (OTB) representados en sindicatos, de acuerdo a la Ley de Participación Popular. Forman parte de la Federación Departamental de Campesinos de Pando.

La instancia de representación del sindicato está compuesta por una directiva que se elige cada dos años, con presidente, vicepresidente y varias carteras de trabajo que se reúnen una vez por mes para rendir cuentas. Cuentan con un fondo común, que se genera con el aporte anual de los encarpetados y que se destina a cubrir gastos administrativos y sirve también para otorgar préstamos a los afiliados exclusivamente para enfermedades. De estos sindicatos también pueden formar parte los "no encarpetados", con una tarifa de aportes diferenciada. Entre los no encarpetados están las personas que llegan a la comunidad, sin derecho a tierras, y que se dedican al comercio y a la prestación de servicios; dentro de este grupo también están los hijos de los encarpetados, a los cuales se les permite el aprovechamiento de la castaña en tierras fiscales contiguas a las tierras comunitarias.
Existen, además, otras organizaciones como la Junta de Vecinos en zonas urbanas, el Comité de Agua, el Comité de Luz, el Comité de Salud, el Sindicato de Comerciantes, el Sindicato de Zafreros y la Subcentral de Campesinos de la Reserva Manuripi. Se destaca la conformación de la Junta Escolar formada por las escuelas de las comunidades que están al borde del camino San Silvestre-Chivé. La junta es una organización social de base para gestionar recursos y dotar a las escuelas con una mejor infraestructura y recursos educativos para reforzar la enseñanza primaria. A mediano plazo, su objetivo es hacer gestiones para contar con educación secundaria para que sus hijos no tengan que salir a los centros urbanos donde se dispone de este servicio. Hoy por hoy los jóvenes, para acceder a educación secundaria, van al único colegio en la reserva ubicado en la comunidad Luz de América (municipio de Filadelfia). Otros optan por ir a colegios en la ciudad de Cobija, a $180 \mathrm{~km}$ de distancia de las comunidades ubicadas en el municipio de Puerto Rico y a 30 km de distancia de las comunidades del municipio de Filadefia, por vías en mal estado en las que solo se puede transitar en época seca. En las barracas (predios privados) la situación no es diferente ya que la mayoría no cuentan con escuelas. Solamente en las comunidades se puede garantizar el servicio de educación primaria todo el año.

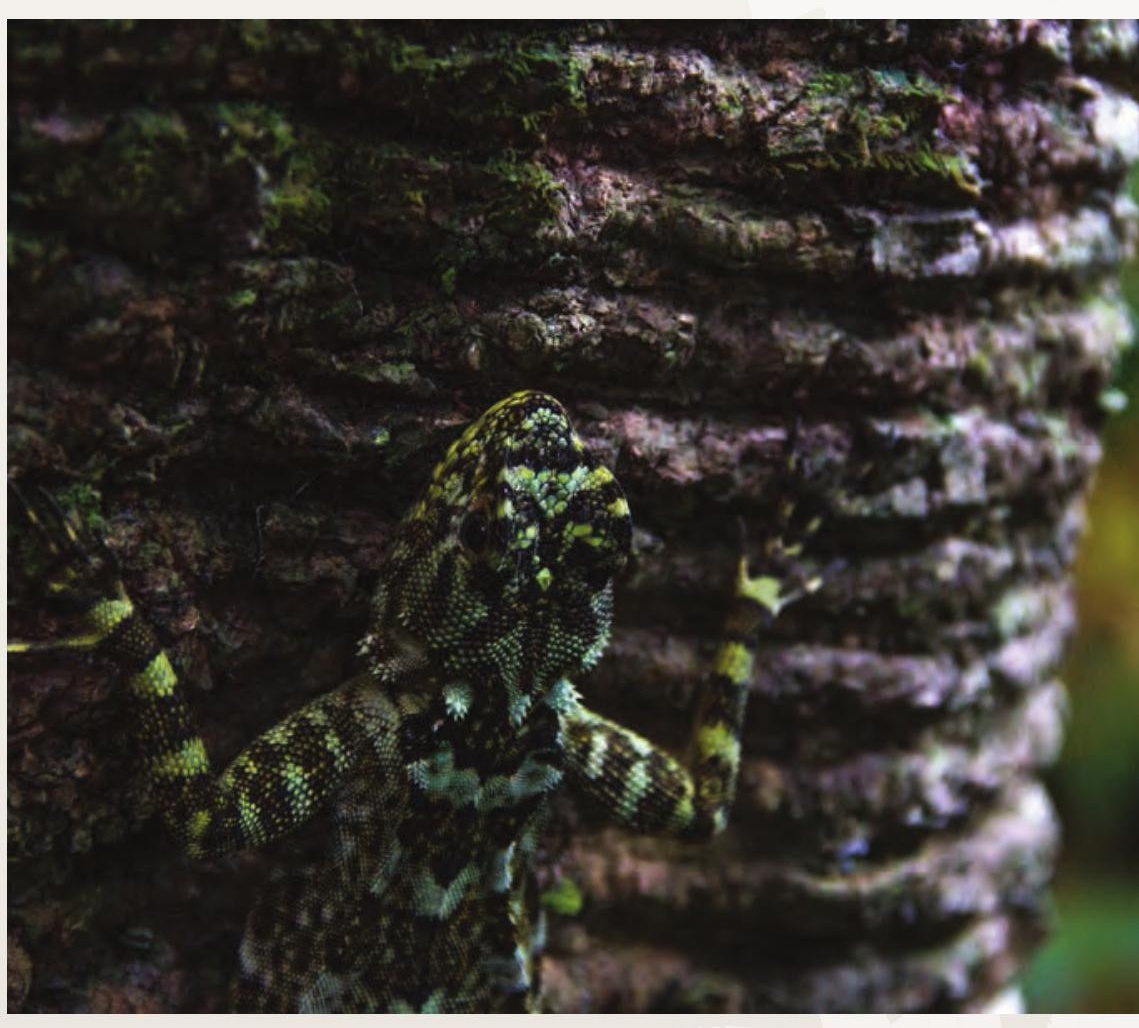


Consejo Consultivo PE Chandless

Presidido por: Secretaria de Estado do Medio Ambiente - SEMA

\begin{tabular}{|l|l|}
\multicolumn{1}{|c|}{ Instituciones del Gobierno } & \multicolumn{1}{c|}{ Sociedad civil } \\
\hline Instituto Chico Mendes de Conservação da & SOS AMAZÔNIA \\
Biodiversidade - ICMBio/Reserva Extractivista & Colônia dos Pescadores do Município de \\
Cazumbá-Iracema & Manoel Urbano \\
Fundação Nacional do Índio - FUNAl & Sindicato dos Trabalhadores Rurais de Manoel \\
Fundação Nacional de Saúde - FUNASA & Urbano - STR-MU \\
Universidade Federal do Acre - UFAC & Cooperativa do Alto Purus, Município de \\
Instituto Nacional de Pesquisas Amazônicas - & Manoel Urbano \\
INPA & \\
Secretaria de Estado de Extensão Agroflorestal e & \\
Produção Familiar - SEAPROF & \\
Instituto de Meio Ambiente do Acre - IMAC & \\
Secretaria de Estado de Turismo - SETUR & \\
Prefeitura Municipal de Sena Madureira/AC & \\
Prefeitura Municipal de Manoel Urbano/AC & \\
Prefeitura Municipal de Santa Rosa do Purus/AC & \\
\hline
\end{tabular}

En Manuripi, 3 de las 10 comunidades están bajo la dirección de mujeres. En cada comunidad, las mujeres han conformado clubes de madres, algunos de los cuales se han convertido en organizaciones comunales de carácter sindical.

\section{Consejo Consultivo del PE Chandless}

El PE Chandless cuenta con un consejo consultivo a través de una asociación técnica entre SEMA y SOS Amazonia, en el ámbito de los proyectos "Conectando Comunidades Forestales y Paisaje para el Desarrollo sustentable del Sudoeste da Amazonia Brasileña - Consorcio Amazonia" y "Cluster Comunidades y Mercado"154

El Consejo Consultivo del PE Chandless fue creado el 8 de septiembre de 2009155. La SEMA preside el consejo que además está conformado por quince organizaciones más, once gubernamentales y cuatro de la sociedad civil. El Consejo Consultivo del PEC es heterogéneo, está compuesto por 30 consejeros, residentes en 4 municipios del Estado: Rio Branco, Sena Madureira, Manoel Urbano y Santa Rosa do Purús. Los habitantes del parque no forman parte del consejo consultivo porque no existe una asociación de moradores del parque y la participación en consejo de las áreas protegidas en Brasil es permitida solamente a organizaciones con personería jurídica.

\section{Participación en la RESEX Cazumbá-Iracema}

En términos generales, existe un buen nivel de organización en las comunidades que conforman la RESEX, por motivaciones propias y por proyectos de fortalecimiento organizacional, entre los que se destaca el proyecto "Estructura de Gestión de la Reserva Extractivista Cazumbá-Iracema"156, que se llevó a cabo en 2003. Este tuvo como objetivos contribuir al establecimiento de una estructura de gestión participativa en la reserva a través de la creación de nuevas asociaciones y el fortalecimiento de las ya existentes, fomentar la sensibilización y movilización social, la creación e implementación de un "consejo deliberativo" y la capacitación a los actores locales para que participen como consejeros.

154 Proyectos financiados por USAID a través del apoyo del Programa Áreas Protegidas de la Amazonía (ARPA).

155. Portaria № 068. A, publicado en el Diario Oficial el 10 de septiembre de 2009

156. Proyecto financiado por la Fundación Nacional de Medio Ambiente-FNMA y ejecutado por IBAMA en asociación con ASSC. 


\section{Paisaje sur. Ámbito social}

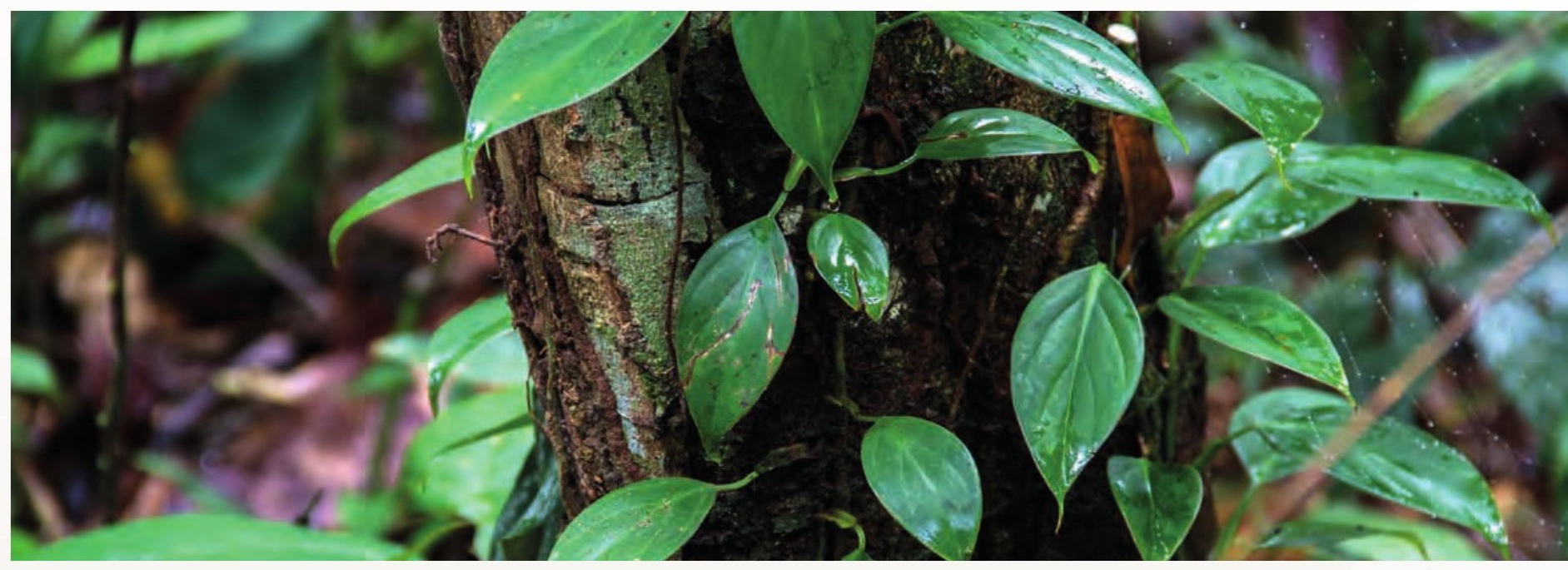

Por ley, las RESEX son manejadas por un consejo deliberativo, presidido por la entidad responsable de su administración y constituido por representantes de instituciones públicas, sociedad civil y las comunidades locales. Fue así como, en marzo de 2006, se conformó el Consejo Deliberativo como la máxima autoridad en la reserva. Este se reúne ordinariamente tres veces al año y, cuando amerita, tiene reuniones extraordinarias. Las reuniones del consejo son públicas, al igual que sus resoluciones, por lo tanto cualquier persona natural o jurídi- ca puede participar. En las reuniones, tratan temas con implicaciones para toda la reserva, discuten y aprueban programas a ser implementados, discuten políticas públicas que afectan a la unidad, revisan el plan de manejo y la relación de la reserva con otras áreas protegidas. El consejo acompañó en la elaboración, implementación y revisión del Plan de Manejo de 2007

Actualmente el consejo deliberativo de la reserva está compuesto por siete instituciones del Gobierno y ocho no gubernamentales.

\begin{tabular}{|c|c|}
\hline \multicolumn{2}{|c|}{$\begin{array}{c}\text { Consejo Deliberativo RESEX Cazumbá-Iracema } \\
\text { Presidido por: ICMBio }\end{array}$} \\
\hline Instituciones del Gobierno & Sociedad Civil \\
\hline $\begin{array}{l}\text { 1. Instituto Chico Mendes de Conservação da } \\
\text { Biodiversidade (ICMBio) } \\
\text { 2. Secretaria de Extrativismo e Produção } \\
\text { Familiar (SEPROF) } \\
\text { 3. Parque Estadual do Chandless } \\
\text { 4. Secretaria Municipal de Saúde de Sena } \\
\text { Madureira - SMS } \\
\text { 5. Secretaria Municipal de Educação e Cultura } \\
\text { de Sena Madureira - SEMEC } \\
\text { 6. Instituto Federal de Educação, Ciência e } \\
\text { Tecnologia do Acre - IFAC } \\
\text { 7. Secretaria Estadual de Educação }\end{array}$ & $\begin{array}{l}\text { 1. Comunidad Alto Caeté } \\
\text { 2. Comunidad Médio Caeté } \\
\text { 3. Comunidad Cazumbá } \\
\text { 4. Comunidad Riozinho-Cachoeira } \\
\text { 5. Comunidad Jacareuba Redencao } \\
\text { 6. Sindicato dos Trabalhadores Rurais de Sena } \\
\text { Madureira - STR } \\
\text { 7. Cooperativa Agroextractivista do Vale do Rio } \\
\text { laco - Cooperiaco } \\
\text { 8. Conselho Nacional dos Seringueiros - CNS }\end{array}$ \\
\hline
\end{tabular}



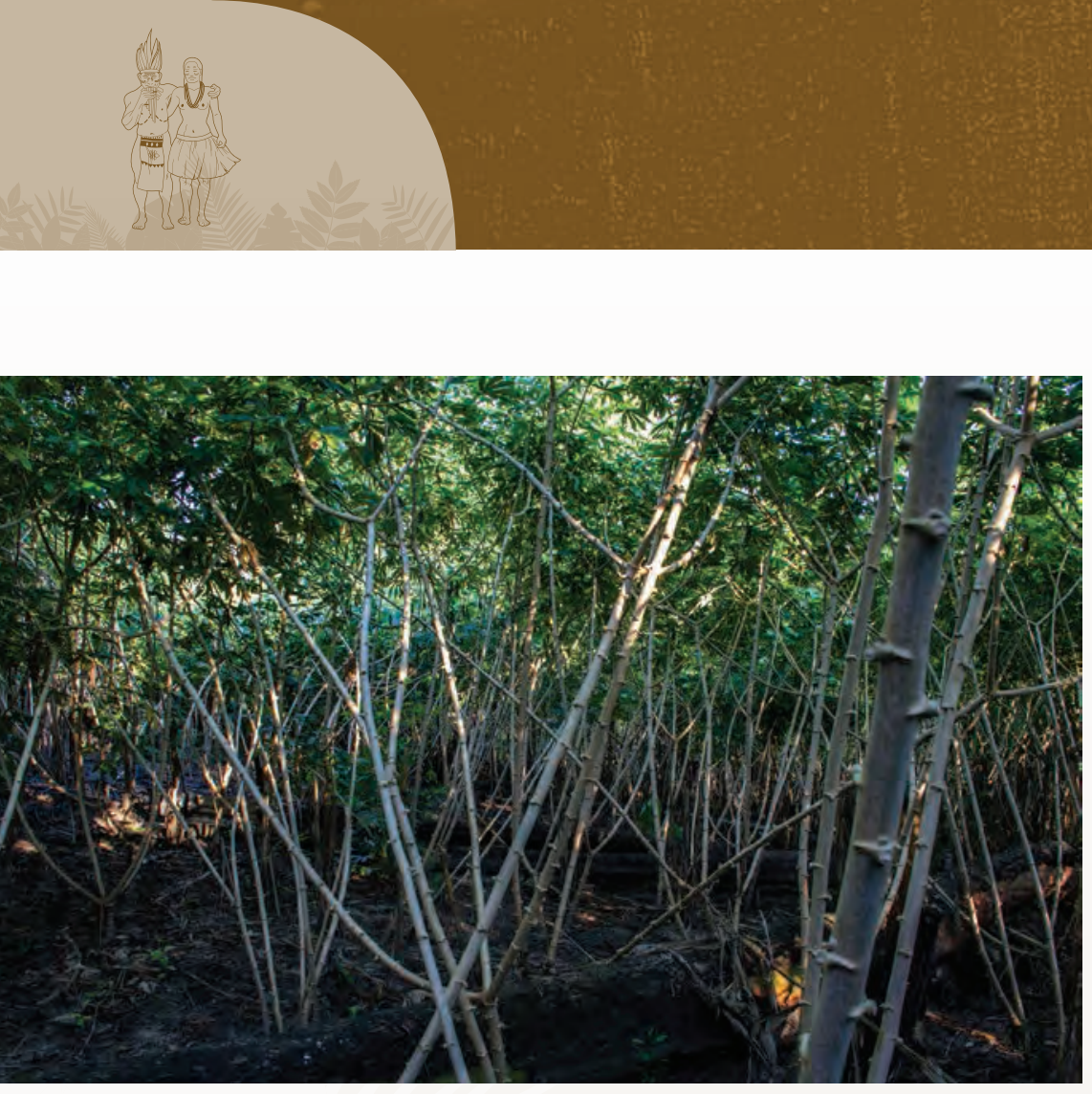

En la RESEX existen diferentes instancias de gestión:

- El Consejo Deliberativo

- ICMBio, como la institución gestora y la responsable legal para la Unidad

- Asociaciones de habitantes

- Grupos de habitantes sin organización formal

La RESEX Cazumbá-Iracema cuenta con la Associação dos Seringueiros do Seringal Cazumbá157 (ASSC), organización formal con personería jurídica que representa a las comunidades. Núcleo do Cazumbá se caracteriza por su buen nivel de organización, involucramiento y participación en la gestión de la reserva. Los habitantes trabajan junto con ICMBio y otras instituciones, lo que ha influido positivamente sobre las demás comunidades. Esta organización y compromiso les ha llevado, desde 1994, a tener sus propias reglas de convivencia, que son reconocidas y validadas por el plan de manejo de la RESEX. Estas incluyen: compra y venta de mejoras en la comunidad, uso comunitario de los recursos naturales, un área de agricultura dividida para cada familia, regulaciones para el uso de bebidas alcohólicas dentro de la comunidad, entre otras.

Las mujeres de la RESEX Cazumbá-Iracema forman parte de la ASSC y organizaron el Grupo de Formación de la Mujer (GFM) para ampliar

su participación en las decisiones de la comunidad. Desde 2012, la gestión de la reserva incentiva la creación de grupos de mujeres en otras comunidades, sin embargo la participación femenina aún es reducida; en el equipo de ICMBio no se cuenta con la presencia de mujeres.

La única área protegida del paisaje sur que tiene conformado un grupo de jóvenes es la RESEX Cazumbá-Iracema. El grupo se conformó hace tres años para contrarrestar los vicios y las drogas, a través de la Iglesia católica158. Los jóvenes explican que en su tiempo libre ayudan en los quehaceres del hogar, en la chacra y en la elaboración de la farinha de mandioca. Su anhelo es ir a la universidad para estudiar - según los informantes- carreras como Derecho, Biología o Física, para luego volver a la RESEX. Tanto los hombres como las mujeres jóvenes tienen conformado un equipo de fútbol.

\section{Comité de gestión del Parque Nacional Alto Purús}

El PNAP cuenta con un comité de gestión y un comité asesor. El comité de gestión fue conformado en 2010 por representantes de la población en la zona de amortiguamiento del PNAP y representantes de instituciones públicas, privadas, locales, nacionales o internacionales interesadas en colaborar en la gestión del PNAP. Entre estas se encuentran: FECONAPU (Federación de Comunidades Nativas del Río Purús), SENAMHI (Servicio Nacional de Meteorología e Hidrología), Asociación de Carpinteros Industriales de Iberia (ASCARIB), GOREU (Gobernación Regional de Ucayali), ARPAU (Asociación Regional del Pueblo Asháninka de Ucayali), la Gobernación de Sepahua y el propio parque. Cuenta con una directiva conformada por presidente, vicepresidente, secretario, tesorero, un fiscal y vocales. Su objetivo es fomentar el trabajo conjunto

157. La ASSC fue creada para fortalecer el movimiento siringuero que estaba en contra de la reforma agraria promovida por el INCRA. Fue la primera asociación creada en Sena Madureira; en 2002 y 2004 recibió el Premio Chico Mendes de Medio Ambiente, otorgado por el Ministerio de Ambiente por su trabajo a favor de conservación de la Amazonía.

158. La Iglesia católica tiene mucha influencia en la zona de Acre gracias al italiano Padre Paolino Baldassari, miembro de la Orden de los Siervos de María, que falleció a los 90 años en abril de 2016. El Padre Paolino se radicó en Acre por más de 50 años e hizo una gran labor en lugares donde el Estado no llegaba, se unió a la lucha de los siringueros por las tierras y en contra la deforestación. Fue un gran conocedor de la medicina ancestral practicada por los indígenas y siringueros. 


\section{Paisaje sur. Ámbito social}

entre la población y las autoridades por medio de la concertación, la participación y el empoderamiento para planificar y supervisar las actividades que se desarrollan en la zona de amortiguamiento. El comité de gestión divide su trabajo en cuatro sectores: Purús, AtalayaSepahua, Yurúa y Madre de Dios.

La participación de la población indígena y mestiza de la zona de amortiguamiento en las actividades del parque se observa en los Comités de Vigilancia Comunitarios (CVC), que son parte del comité de gestión y apoyan directamente las acciones operativas del área.

El Comité Asesor del Plan de Manejo del Parque Nacional Alto Purús está conformado por organizaciones locales (Federación de Comunidades Nativas de Purús, PROPURÚS), ONG locales (Pronaturaleza, Asociación Peruana para la Conservación de la Naturaleza APECO) y organismos de cooperación internacional (WWF, Ayuda para Vida Silvestre Amenazada, Sociedad Zoológica de Fráncfort Perú AVISASZF y Acuerdo para la Conservación de Bosques Tropicales ACBT).

\section{Contrato de administración para la participación en la Reserva} comunal Purús

En la Reserva Comunal Purús, el Ejecutor del Contrato de Administración (ECA) es
ECOPURÚS, asociación civil con personería jurídica sin fines de lucro, que representa a 26 comunidades de los pueblos indígenas jini-kuin, sharanahua y asháninka, dueños de parte del territorio. ECOPURÚs tiene la misión de coadministrar los recursos naturales de manera sostenible para beneficiar a la población. Cuenta con un Consejo Directivo conformado por cinco líderes indígenas, los cuales son elegidos por votación. ECOPURÚS y las ONG ejecutan los proyectos que se desarrollan en el interior de la reserva. Actualmente las ONG con las que están ejecutando los proyectos son APECO y PROPURÚS.

Otro actor importante es la Federación de Comunidades Nativas de Purús (FECONAPU), la cual tiene la función de garantizar la participación directa de los actores de la zona de amortiguamiento de la Reserva Comunal Purús en los proyectos de manejo sostenible y uso tradicional de los recursos naturales.

Los pueblos indígenas que habitan la Reserva Comunal Purús cuentan con planes de vida, planes de acción y comités de vigilancia comunal, así como un Comité de Gestión con la participación voluntaria de actores interesados en aportar al manejo de la reserva. En el Comité de Gestión los actores que participan son:

\begin{tabular}{|c|c|c|c|}
\hline Públicos & Privados & Pueblos indígenas & Asesores \\
\hline $\begin{array}{l}\text { Jefatura de la } \\
\text { Reserva Comunal } \\
\text { Purús } \\
\text { UGEL, Dirección } \\
\text { Regional de } \\
\text { Educación de Ucayali } \\
\text { como autoridad en } \\
\text { educación ambiental } \\
\text { AAP y PEPP, } \\
\text { autoridades en } \\
\text { agricultura } \\
\text { Gobierno regional de } \\
\text { Ucayali (GOREU) } \\
\text { Municipalidad } \\
\text { provincial de Purús }\end{array}$ & $\begin{array}{l}\text { MABOSINFRON, } \\
\text { concesión de } \\
\text { conservación }\end{array}$ & $\begin{array}{l}\text { Juni-Kuin } \\
\text { Sharanahua } \\
\text { Comunidad indígena } \\
\text { San Martín } \\
\text { Comunidad indígena } \\
\text { Santa Margarita } \\
\text { Comunidad indígena } \\
\text { Nuevo Progreso }\end{array}$ & $\begin{array}{l}\text { FECONAPU (Federación } \\
\text { de Comunidades Nativas } \\
\text { del Río Purús) } \\
\text { WWF } \\
\text { PROPURÚS } \\
\text { APECO (Asociación } \\
\text { Peruana para la } \\
\text { Conservación de la } \\
\text { Naturaleza) } \\
\text { ACBT (Acuerdo para la } \\
\text { conservación de Bosques } \\
\text { Tropicales) }\end{array}$ \\
\hline
\end{tabular}




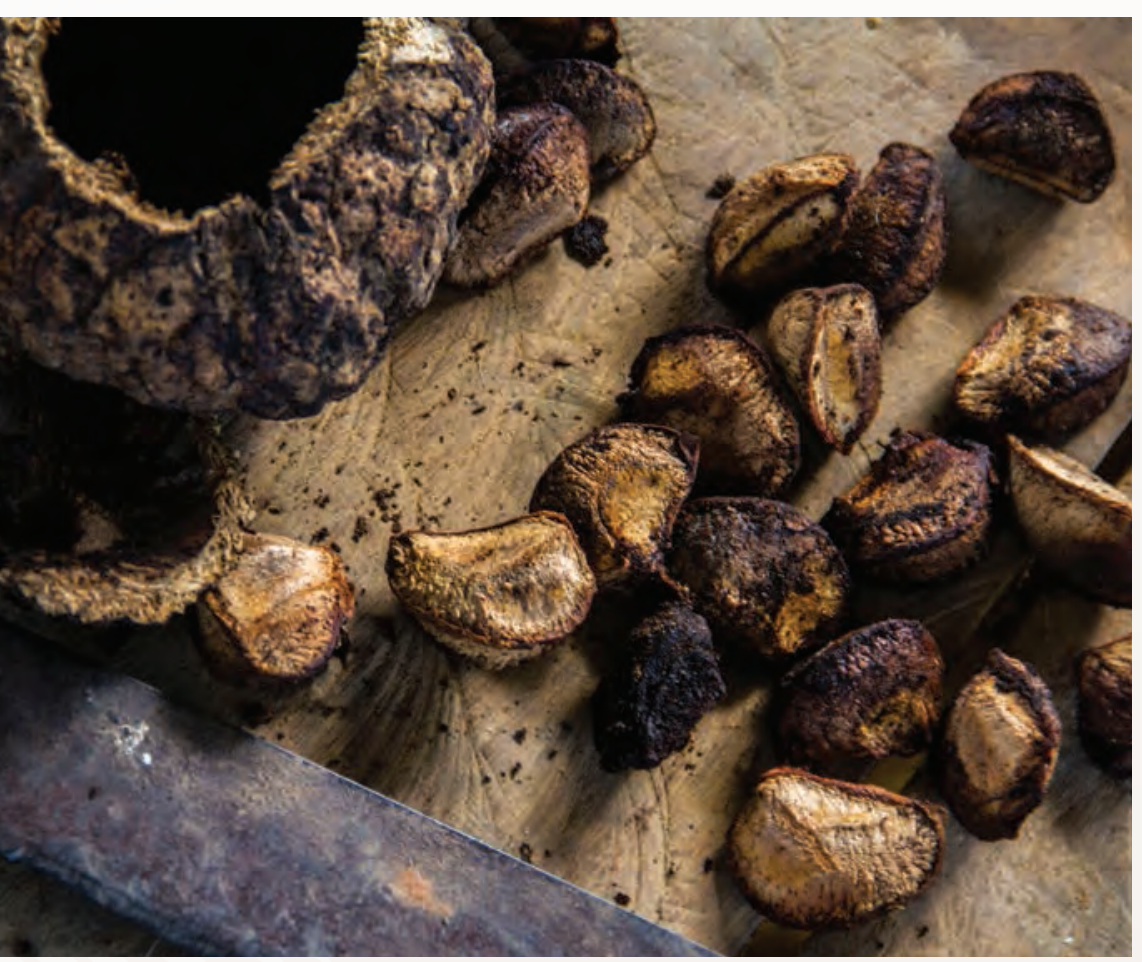

Actividades productivas

sostenibles

Certificación de la castaña de Manuripi

La zafra de castaña

La cosecha de la castaña se realiza durante la época de Iluvia. Los padres e hijos recolectan los cocos de castaña en el bosque, una tarea considerada masculina que les toma desde tempranas horas de la mañana hasta el atardecer. En algunos casos, según los informantes, esta actividad se comparte con las mujeres de carácter e inclusive afirman que "algunas cargan igual que el marido". Durante la recolección, se toman los cocos que por maduros ya han caído al suelo; esta debe hacerse pronto para evitar que el fruto se contaminen de toxinas. Se clasifican los cocos por

\section{La castaña}

El árbol de castaña crece en tierras bajas de suelos secos en los bosques del sur de la Amazonía. La castaña es el fruto de un árbol longevo que puede vivir hasta 500 años, alcanza hasta $60 \mathrm{~m}$ de altura y $2 \mathrm{~m}$ de diámetro. Es un árbol tan alto que sobresale en el bosque y que puede ser apreciado desde largas distancias. Crece de manera silvestre y dispersa en promedio 2 árboles por ha.

Los árboles de castaña no pueden reproducirse sin abejas, las cuales son sus únicas polinizadoras. Una vez realizada la polinización, los árboles florecen de octubre a diciembre, el fruto demora 15 meses en desarrollarse y una vez maduro cae al suelo. Su fruto crece dentro de un coco, mide aproximadamente $15 \mathrm{~cm}$ de diámetro y pesa entre 1 a $2 \mathrm{~kg}$. El coco contiene entre 10 y 25 semillas y en su interior es-

La cosecha de la castaña se realiza entre enero y marzo. Los cocos tienen una corteza dura que requiere de cierta técnica para abrir y no lastimar las almendras. La guatusa es el único animal que puede abrirlos y alimentarse de estos. Las semillas que no comen las entierran, estas germinan a los 18 meses y el árbol empieza a dar fruto a los 20 años. Así ambas especies juegan un rol importante como simbiontes, ya que de ellos depende la proliferación de la castaña.

Un árbol de castaña en plena producción y buenas condiciones puede dar en promedio 200 cocos por año.

Fuente: "Monitoreo de castaña a través de parcelas permanentes en la Reserva Nacional de Vida Silvestre Amazónica Manuripi, Pando -Bolivia". 


\section{Paisaje sur. Ámbito social}

tamaño y luego se abren para sacar las pepas y cargarlas hasta el lugar de acopio (denominado payol en Bolivia), donde están las mujeres, encargadas del almacenamiento, limpieza y secado de las pepas que deben secarse bajo sombra aproximadamente durante dos días.

El aprovechamiento tradicional de la castaña ha sido influenciado por los aportes de organismos externos, quienes han capacitado a los campesinos en mejores prácticas para la recolección, acopio y almacenamiento en payoles. Algunas comunidades en Manuripi recibieron financiamiento para la construcción de payoles individuales y un payol comunitario (en la comunidad Villa Florida). Esto garantiza la calidad del producto, ya que estos espacios cumplen con las condiciones de ventilación y temperatura adecuada para un buen manejo de la castaña ${ }^{159}$

La cáscara de los cocos se deja en el bosque y algunas personas llevan una parte para aprovecharla como leña. Otros zafreros explican que ahora tienen motos para entrar y salir del bosque.

Después de la zafra, la actividad en el interior del bosque baja. De acuerdo a conversaciones con los campesinos y los guardaparques en Manuripi, si bien el número de cocos decrece considerablemente después de marzo, los campesinos de las comunidades y barraqueros, continúan con el aprovechamiento de la castaña durante los meses siguientes al periodo autorizado, actividad conocida como zafrilla.

La zafrilla deja en el bosque un porcentaje muy bajo de cocos que podría afectar sustancialmente la regeneración natural. Según información proporcionada por los entrevistados, la zafrilla en las comunidades se extiende hasta por un periodo de 4 meses. En las barracas o predios privados, los barraqueros contratan a los zafreros para la recolección de castaña por un periodo de tres meses. Una vez que los zafreros retornan a sus tierras, los empleados permanentes de la barraca realizan la zafrilla durante un mes más; después de este tiempo ya no ingresan al bosque para permitir su recuperación natural ${ }^{160}$. Esta presión sobre los bosques en tierras comunitarias se debe a que las poblaciones dependen todo el año del manejo del bosque y aprovechamiento de recursos naturales, al contrario de lo que sucede en las barracas donde el aprovechamiento de la castaña tiene fines de lucro económico y no de subsistencia.

Según los castañeros, la producción es buena cada dos años y el aprovechamiento de la castaña, tal como se ha venido manejando hasta ahora, no está mermando su producción y el crecimiento de nuevos árboles. Para ellos, una de las amenazas que enfrentan es la entrada de gusano en el árbol de castaña, el cual se come el cogollo del árbol y lo mata, dándole una apariencia quemada a la copa. Para acabar con el gusano es necesario fumigar el árbol con bomba, lo cual altera el ecosistema ${ }^{161}$ Hasta ahora, no se saben con certeza las razones para la aparición de este gusano.

Walter Cano, director de la reserva, menciona que el comportamiento cíclico de la capacidad productiva de los árboles de castaña guarda relación con el cambio climático, ya que cada uno o dos años la producción de castaña disminuye sustancialmente, lo cual coincide con años muy secos o muy húmedos. Sin embargo, hasta la fecha, esto no ha sido científicamente comprobado.

\section{Dinámica social en las barracas}

En las barracas hay algunas familias que viven de forma permanente mientras que otras llegan a las barracas contratados durante la época de zafra y se van una vez concluida la temporada. Durante el tiempo de zafra la población crece hasta 10 veces, lo que representa una gran presión para el área protegida. La cantidad de zafreros permitidos, de acuerdo al reglamento, es de 2 a 3 zafreros por cada 500 ha. Dependiendo del tamaño del predio, un barraquero puede contratar entre 150 a 200 zafreros, cada uno llega con su familia de 4 personas en promedio, lo cual indica que en época de cosecha ingresan cerca de 800 personas a un predio.

159. Proyecto promovido por la Cooperación Técnica de Dinamarca.

160. Jorge Valdivia, propietario de la Barraca Puerto América, estima que en las barracas el $20 \%$ de la producción no se recoge.

161. Una vez dado el tratamiento, el árbol recupera su follaje, pero no florece otra vez hasta después de 3 a 4 años. 
En las barracas, los zafreros Ilegan contratados desde Cobija y Riberalta. La época de zafra coincide con la de vacaciones escolares y la mayoría de zafreros va con sus familias Llegan sin nada, por lo que los barraqueros les adelantan dinero ( sistema conocido como habilito) para que puedan proveerse de lo necesario para empezar a trabajar ${ }^{162}$. comida, botas, ropa, mantas, medicinas, radios, licor, sombreros, hojas de coca para el boleo ${ }^{163}$, gasolina, motos, etc., que adquieren en las tiendas de las barracas de propiedad de los barraqueros. Al momento de recibir su remuneración cruzan cuentas con el número de cajas de castaña recolectada.

Las familias que llegan son distribuidas en grupos que quedan a cargo de los contratistas ${ }^{164}$ Cada contratista se hace cargo de un centro madre conformado por varios subcentros con viviendas rústicas construidas con materiales de la zona y ubicados cerca de arroyos, donde se alojan entre 3 o 4 familias, dependiendo de la extensión de bosque que deben recorrer. Los contratistas compran las cajas de castaña recolectadas a los zafreros. Los ingresos generados por la recolección de castaña durante el periodo de zafra permiten a los campesinos mantenerse durante los meses siquientes hasta la próxima cosecha, lo que muestra la gran cantidad de producción de este recurso y lo bien valorado que está en el mercado ${ }^{165}$.
De acuerdo a conversaciones con campesinos, los zafreros, en Bolivia, a pesar de que generan bastantes ingresos económicos, no distribuyen bien sus recursos y llegan hasta la siguiente zafra sin dinero y con deudas.

Los contratistas no reciben sueldo sino un monto, previamente acordado, por cada caja de castaña ${ }^{166}$. Además de controlar la producción, controlan que los zafreros cumplan con las normas para el cuidado del bosque, no porten armas (ya que es prohibido cazar), no talen árboles, hagan un buen manejo de desechos, cuiden las fuentes de agua, etc

Reglamento para el control de la zafra de castaña

Bolivia cuenta desde 2008 con el Reglamento para el Control de la Zafra de la Castaña en la Reserva Nacional de Vida Silvestre Amazónica Manuripi ${ }^{167}$, desarrollado por el SERNAP con la participación de las comunidades y barracas. El objetivo del reglamento es regular las actividades y las condiciones en las que se realiza la zafra con el fin de garantizar que los procesos ecológicos y evolutivos del ecosistema se mantengan y el aprovechamiento de la castaña sea sostenible a largo plazo ${ }^{168}$

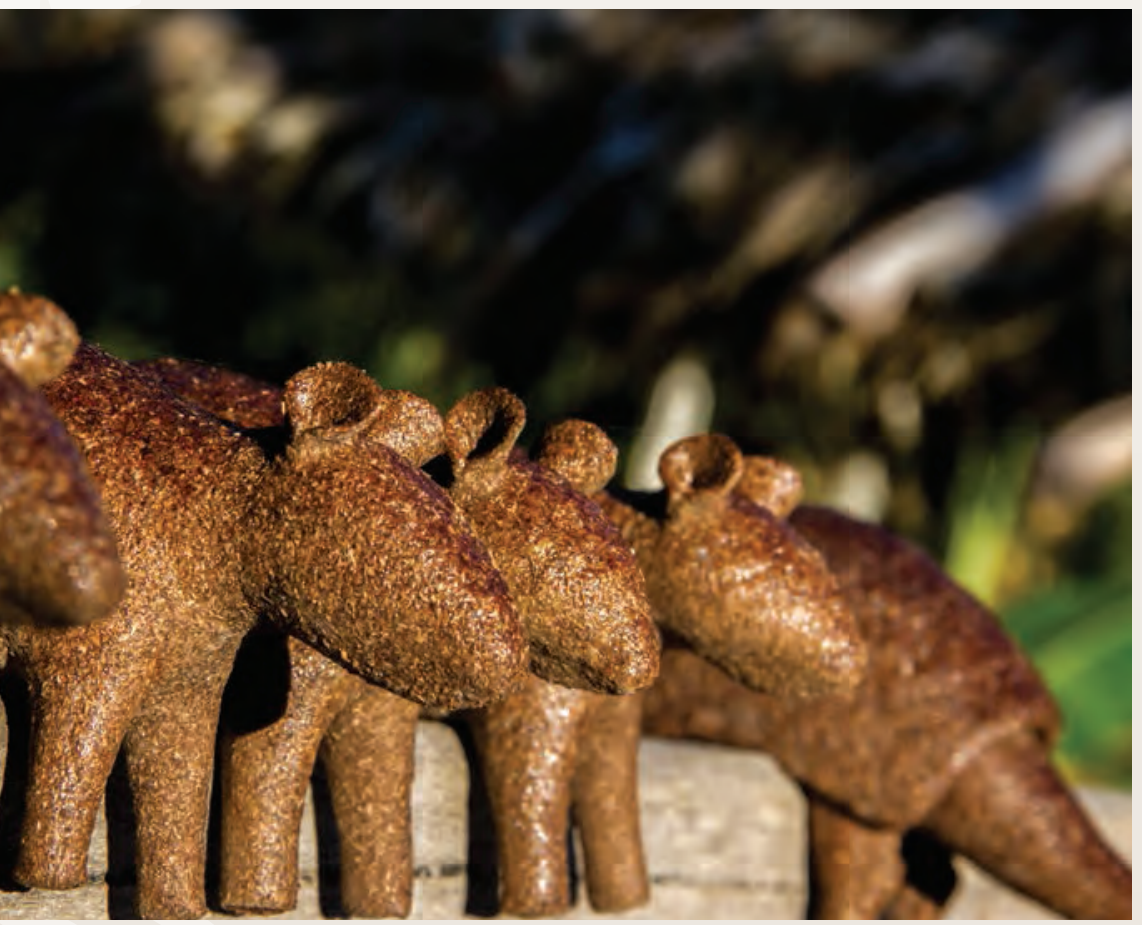

162. De acuerdo a conversación con Jorge Valdivia, el monto del habilito depende del número de miembros de la familia. Si un trabajador llega solo, recibe mil bolivianos de adelanto; para los que llegan con familia el habilito es mayor. La barraca se provee de estos bienes en Guayaramerín, en la zona de frontera con Brasil, a 83 km de distancia.

163. El bolo de hoja de coca es algo imprescindible para la zafra ya que los campesinos comentan que previene el sueño, el cansancio, el apetito y la sed. Bolear o masticar la hoja de coca es una costumbre muy arraigada entre los campesinos bolivianos. Para esto se seca la hoja de coca al sol, se envuelve y se coloca a un costado dentro de la boca. Se mezcla con un poco catalizador alcalino (cal, ceniza alcalina o bicarbonato de calcio) hasta formar un bolo y extraer de la hoja las sustancias activas y estimulantes.

164. Los contratistas son intermediarios que contratan a su vez zafreros y venden la castaña recolectada al barraquero con un margen sustancial de utilidad. Son el puente entre los zafreros y el barraquero.

165. El precio de la caja de castaña en la última zafra (marzo 2016) fue de 250 bolivianos.

166. Cada contratista recibe 5 bolivianos por cada caja de castaña. En promedio, según Jorge Valdivia, en la Barraca Puerto América cada contratista al final de la temporada ha recibido entre 12000 y 13 000 cajas de castaña

167. Reglamento aprobado por resolución administrativa DE-044/2008 del 19 de diciembre de 2008

168. Artículo 1 del Reglamento para el Control de la Zafra de la Castaña en la Reserva Nacional de Vida Silvestre Amazónica Manuripi. 


\section{Paisaje sur. Ámbito social}

El reglamento incluye: categorización, zonificación y normas de manejo del suelo, los requisitos para la entrega de autorizaciones, planes de manejo y reglamentos de uso, monitoreo y control de todas las actividades realizadas durante el proceso de recolección (como la caza). Incluye también temas relacionados a la protección de flora y fauna silvestre y la conservación de los ecosistemas, habilitación de sendas a fin de evitar impactos ambientales, normas relacionadas al transporte de la castaña dentro del bosque y hacia los centros de acopio y la habilitación de vertederos para el correcto manejo de desechos sólidos y líquidos generados durante la época de zafra, entre otros

El reglamento garantiza mejores condiciones para los zafreros ya que incluye compromisos que deben ser asumidos por los barraqueros como: la firma de contratos de trabajo para brindar seguridad a los trabajadores y garantizarles condiciones adecuadas para realizar su trabajo, la prohibición de niños en la actividad de recolección de castaña, el retorno de los hijos y las madres a inicios de marzo para el comienzo del año escolar, entre otros ${ }^{169}$.

\section{Planes de manejo de la castaña}

El $74 \%$ de la superficie de la reserva cuenta con planes de manejo de castaña que fueron elaborados por instituciones privadas autorizadas previamente por la reserva. Estas instituciones cubrieron el costo de la elaboración de los primeros planes de manejo; los siguientes fueron cubiertos por sus propietarios ${ }^{170}$. Los planes incluyen mapeo de árboles de cada predio con numeración y coordenadas.

\section{Comercialización de la castaña}

Desde hace más de tres décadas, la castaña es muy apetecida en el mercado internacional por sus propiedades nutritivas ${ }^{171}$. Desde 1996, Bolivia se convirtió en el primer productor y exportador de castaña, superando a Brasil, históricamente conocido como el mayor exportador y razón por la que la nuez es conocida como Brazil nut. Esta actividad representa más del 75 \% del movimiento económico familiar para los habitantes de la Amazonía boliviana. Dentro de la reserva, se estima que la producción de castaña llega a poco más de 11000 toneladas anuales y ocupa una superficie de 507731 ha
La Empresa Boliviana de Almendras y Derivados (EBA), empresa pública que busca mejorar las condiciones de vida de los productores de castaña, compra las almendras a nivel nacional, paga un mejor precio en el mercado y asume el costo de la certificación orgánica. Anteriormente, la diferencia de precios que pagaba la EBA frente a la que pagaban las empresas privadas era mayor debido a las subvenciones del propio gobierno, cuyo fin era tener el control del precio de la castaña en el mercado nacional. No obstante, esta medida no dio resultado por la falta de liquidez de la empresa estatal y por dificultades en la administración gerencial.

La EBA ha establecido tres tipos de castaña: convencional, orgánica y de origen (Reserva Manuripi). Las comunidades que certifican su castaña con sello orgánico reciben un pago adicional al finalizar la zafra, el cual representa el $12 \%$ del valor de sus ventas brutas. Para el caso de la castaña de origen o de la Reserva Manuripi, reciben un pago adicional del $22 \%$ por provenir de un área protegida ${ }^{172}$.

La EBA beneficia aproximadamente a 3000 familias de la reserva. Los recolectores de castaña en Manuripi venden una pequeña parte de su producción a la EBA y el mayor volumen de su producción la destinan a plantas procesadoras privadas en Riberalta y Cobija, como Urkupiña y Tahuamanu ${ }^{173}$. Esto se debe a que las empresas privadas pagan al contado mientras que la EBA paga el valor adicional (22 \%) meses después de entregado el producto (entre los meses de junio y agosto) como una estrategia para que los campesinos tengan otro ingreso meses después de terminada la zafra.

169. Según Jorge Valdivia, el rendimiento de los zafreros baja una vez que las familias se regresan a la ciudad; esto, si bien tiene relación con el hecho de que al final de la temporada hay menos frutos por recolectar, también se debe a la disminución de la mano de obra para recolectar los frutos y al abandono que sienten los zafreros, lo cual afecta su estado anímico y al hecho de que, una vez solos, deben, además de trabajar, realizar las tareas de hogar que antes estaba a cargo de la esposa y las hijas.

170. Información proporcionada por el Sr. Valdivia.

171. Se destaca el selenio, un oligoelemento que ayuda en la producción de enzimas antioxidantes que previenen el daño celular.

172. Boletín informativo El Castañero de la EBA, año 3, número 17. Enero a agosto de 2013. www.eba.com.bo

173. Según los informantes, la mano de obra es requerida cada vez menos ya que las plantas están automatizando los procesos. 
Si bien algunas de las barracas tienen beneficiadora propia, también venden a la EBA como una forma de mantener buenas relaciones con el Gobierno. Según los entrevistados, la EBA tiene una planta procesadora de castaña en Sena, la cual está siendo subutilizada y emplea principalmente a mujeres para el trabajo de descascarado y pelado de la almendra.

\section{Castaña certificada}

Desde 2012 la castaña de la Reserva Manuripi cuenta con algunas certificaciones:

- Certificación Sello de Origen denominado "Producto de Origen Castaña Manuripi", marca registrada que garantiza que esta ha sido aprovechada de forma sostenible, con responsabilidad social y ambiental para contribuir a la gestión del área protegida y mejora las condiciones de vida de la población local"174 Tiene como objetivos potenciar y valorar la castaña y el reconocimiento al valor de origen de la castaña, que proviene de un área protegida.

- Certificación Orgánica otorgada por CERES, Certification of Environmental Standars $\mathrm{GmbH}^{175}$, que garantiza la cualidad orgánica y ecológica del producto. El 55 \% de la superficie de aprovechamiento de castaña en la reserva (entre comunidades y barracas) cuenta con esta certificación.

- Certificación Fairtrade, o de comercio justo, un sello de garantía para el consumidor que resalta los valores éticos del producto.

A nivel nacional, las certificaciones han ayudado a llegar a acuerdos comerciales entre la Asociación de Productores de Almendra de la Reserva y la EBA; a nivel internacional han abierto las puertas a mercados europeos y americanos.
Sostenibilidad financiera en la reserva

En 2014, los actores de la reserva llegaron a un consenso para implementar un mecanismo de sostenibilidad financiera para el aprovechamiento, manejo y monitoreo de la castaña dentro de la reserva, que fue aprobado por el SERNAP. Incluyó un análisis del marco institucional y legal para la implementación del Sistema de Cobro (SISCO) por el aprovechamiento de la castaña y acuerdos de comercialización de la castaña de origen del área protegida. Así, el SERNAP recibe el equivalente al $2 \%$ de la venta de castaña que sale de la reserva y reinvierte los fondos en el sistema de certificación orgánica; los barraqueros pagan 4 bolivianos por cada hectárea y se cobran multas como sanciones por incumplimiento. El SISCO genera ingresos de 100000 dólares anuales, los cuales se reinvierten en la reserva ${ }^{176}$. En el SERNAP, los sistemas de cobro están ligados al turismo y aportan a la sostenibilidad financiera de las áreas protegidas. Con la certificación de la castaña, Manuripi ha demostrado que hay otros mecanismos viables para lograr la sostenibilidad financiera del área protegida.

\footnotetext{
174. Tomado de la presentación realizada por Víctor García de WWF Bolivia, marzo 2016

175. Certificadora alemana para agricultura orgánica/ecológica, procesado de alimentos ecológicos, buenas prácticas agrícolas y buenas prácticas de manejo en la industria alimenticia, textiles ecológicos, y biocarburantes sostenibles.

176. Información proporcionada por Víctor García, funcionario de WWF Bolivia, abril 2016.
}

\section{Barraca Puerto América}

La barraca Puerto América es un referente en la Reserva Manuripi, es una barraca grande con 15000 ha, a orillas del río Madre de Dios, donde viven algunas familias de manera permanente $y$, anualmente, llegan muchos zafreros con sus familias. Su actual dueño, el Sr. Jorge Valdivia, fue un exempleado de la barraca quien a principios de los años 70 se hizo cargo del predio. 
La barraca cuenta con todos los servicios básicos, radio, telefonía fija y celular así como servicios adicionales cuyos costos de operación y mantenimiento son asumidos por la barraca. Cuenta con escuela, puesto de salud, pista de aterrizaje, avioneta y dragas (6). Cuenta su dueño que, hace algunos años, funcionaron dos asientos electorales, un puesto de guardaparques del SERNAP y una base militar.

La barraca Puerto América brinda algunos beneficios para los zafreros que no se dan en otras barracas como: médico permanente, botiquín abastecido, vacuna de fiebre amarilla en cada inicio de zafra, subsidio materno con la entrega de provisiones a las mujeres embarazadas antes del alumbramiento, entre otros.

La barraca habilita durante todo el año a sus empleados, los cuales son gente de su confianza que trabaja en el lugar desde hace muchos años.

Además de la castaña propia, la barraca compra la castaña a las comunidades vecinas ofreciéndoles un mejor precio del mercado. Una parte vende a la EBA y otra exporta directamente a Europa y Rusia, mercados en los cuales se promociona la castaña como "Brazil nut made in Bolivia".

El Sr. Valdivia tiene una empresa importadora y exportadora, otra empresa procesadora de castaña, una máquina aceitera para aprovechar los desechos de la castaña, ganado, tierra destinada a la agricultura (5 ha de acuerdo a la ley). Cría animales menores y está incursionando en el asaí. En su predio tiene petróleo y oro. A mediano plazo tiene previsto un proyecto de turismo.

\section{El asaí como una alternativa} económica

\section{El asaí es otro de los productos amazónicos tradicionales que se está aprovechando como actividad productiva.}

Su época de recolección es de abril a julio. Anteriormente el fruto se conseguía tumbando la palma, la cual moría tras la recolección. Ahora se han incorporado nuevas técnicas de aprovechamiento que garantizan un ecosistema en equilibro.

Para recolectar el fruto se requiere un equipo de 3 o 4 personas, de las cuales 2 suben el tronco, otra, desde abajo, identifica e indica a dónde tienen que subir (conocido como matero) y la último es la encargada de desgranar el fruto. El fruto se baja de racimo en racimo ya que, por ser tan delicado, si cae al suelo se daña. El fruto queda colgado en un trípode construido para el efecto $y$, una vez desgranado, lo llevan a la despulpadora en el menor tiempo posible.

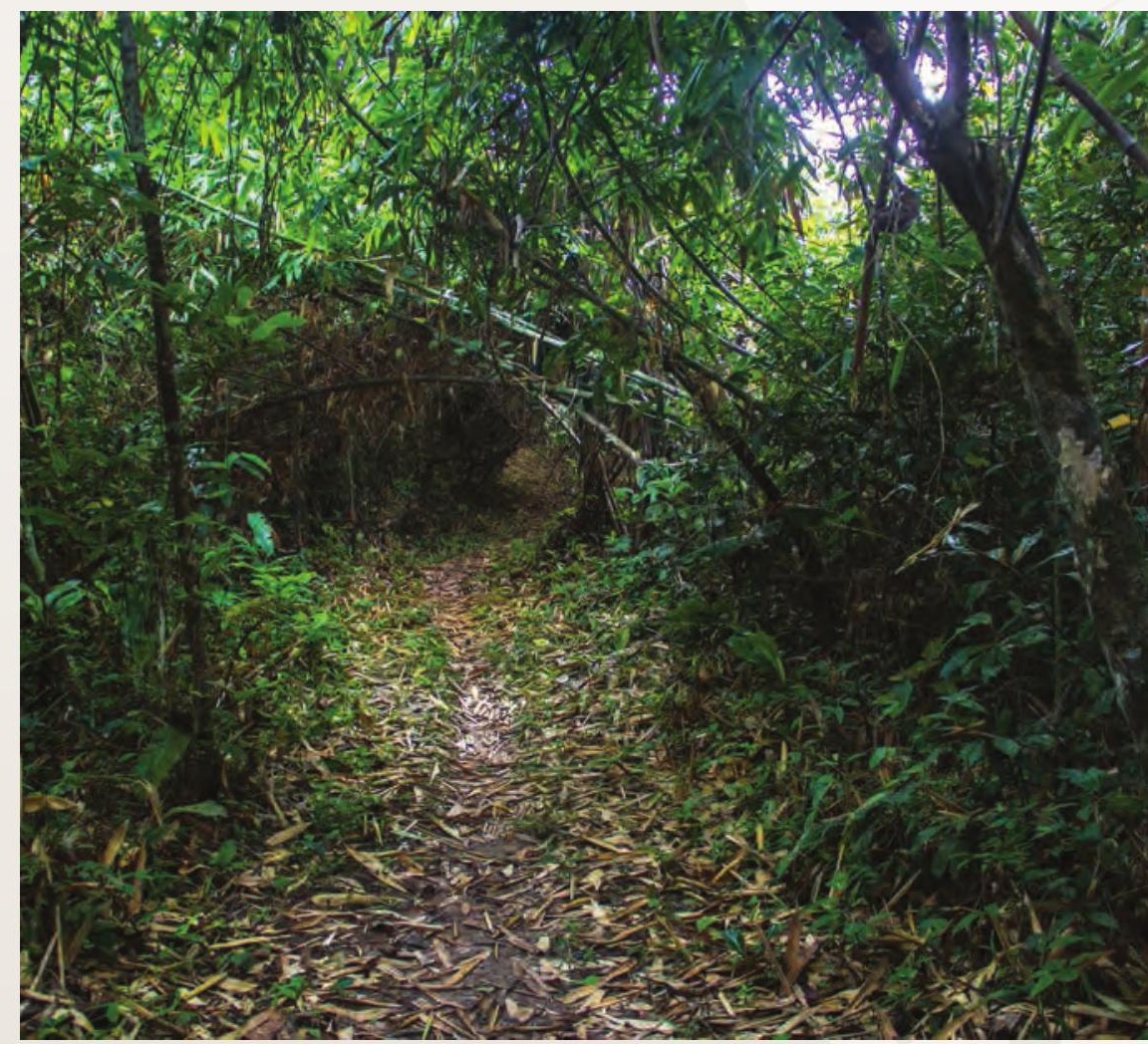


El asaí es un fruto amazónico de un tipo de palmera. Es una baya pequeña redonda de color morado oscuro de tamaño pequeño, $10 \mathrm{~mm}$ de diámetro aproximadamente, que crece en los racimos de una palma llamada asaiceiro, la cual alcanza 25 $\mathrm{m}$ de alto. Su pulpa corresponde solamente al 10 $\%$ del fruto. Su sabor es exótico, parecido a una mezcla de chocolate con canela, tiene propiedades antioxidantes y energizantes, es muy nutritivo contiene calcio, magnesio, zinc, hierro, potasio, vitaminas $\mathrm{E}, \mathrm{C}$ y B y omega 3,6 y 9.

En la RESEX Cazumbá-Iracema desde 2015, un grupo de habitantes forma parte del proyecto de agroindustria del asaí. Este grupo recibió capacitación técnica del (PRONATEC) - programa creado por el Gobierno federal en 2011, a cargo del Ministerio de Educación-. La construcción y equipamiento de la microempresa tuvo financiamiento de la Agencia de los Estados Unidos para el Desarrollo Internacional (USAID). Por ahora, el grupo cuenta con una planta para procesamiento de la pulpa, la cual fue inaugurada en agosto de 2015 y está incursionando en la comercialización. En 2015, con este proyecto, la reserva se hizo acreedora de un premio otorgado por el PRONATEC.

En la Reserva Manuripi, cinco comunidades están incursionando en el proyecto de aprovechamiento del asaí con el apoyo de la cooperación de Dinamarca como una alternativa productiva adicional a la castaña. Para fin de 2016 esperan contar con una planta de despulpado de asaí y tener consolidada la gestión de la comercialización de este producto.

En marzo de 2016, representantes del grupo organizado de recolectores de asaí de Núcleo do Cazumbá visitaron a los habitantes de las comunidades San Silvestre y Chivé en la Reserva Manuripi, para compartirles su experiencia con el asaí y enseñarles nuevas técnicas para el aprovechamiento sostenible de este fruto: cómo escalar por el tronco de la palma, cómo cortar los racimos, cómo recolectar y cómo bajar el fruto para no estropearlo. También compartieron su experiencia acerca de los estándares de seguridad (por ejemplo, utilización de cascos para evitar muertes por golpes en la cabeza), estándares de calidad para el despulpado del fruto y posibilidades de comercialización.
Charapas y taricayas para la conservación y promoción de la economía local

En la Reserva Comunal Purús, zona de amortiguamiento del parque, la asociación ASMANERAPU (Asociación de Manejo de Recursos Naturales del Alto Purús) trabaja desde 2004 en un plan de manejo de tortugas charapas (Podocnemis expansa) y taricayas (Podocnemis unifilis) con el respectivo registro de presión demográfica, crecimiento poblacional y transformación del uso de la tierra para estas actividades

Tanto la taricaya como la charapa tienen una importancia social y económica en las comunidades amazónicas. Ambas forman parte de la dieta alimenticia de estas comunidades, por lo que es importante que su estrategia de conservación integre la protección efectiva de la especie con el aprovechamiento sostenible del recurso y acciones estratégicas de gestión y manejo.

Los comuneros aprendieron la técnica de repoblamiento de la taricaya, que consiste en recolectar los huevos de los nidos naturales de las playas y reanidarlos en los bancos de arena de incubación construidos en las comunidades, de esta manera se logra rescatarlos de los depredadores naturales y aumentar así el índice de supervivencia al nacimiento.

El resultado ha sido el repoblamiento de estas especies, la liberación periódica de miles de tortugas en su hábitat natural, además de la sensibilización de la población con actividades de educación ambiental.

En términos económicos, las comunidades se han visto beneficiadas por la venta de tortugas, las cuales son proporcionadas a la empresa MF Turtles \& Tropical Fish, empresa privada con la que, desde 2015, tienen un compromiso de compra-venta. La empresa exporta las tortugas y las comercializa como mascotas con certificado del área protegida. Esta actividad además genera ingresos para el Estado por el pago de impuestos.

El Gobierno peruano catalogó a la charapa como especie "en peligro" y a la taricaya como especie "vulnerable". 


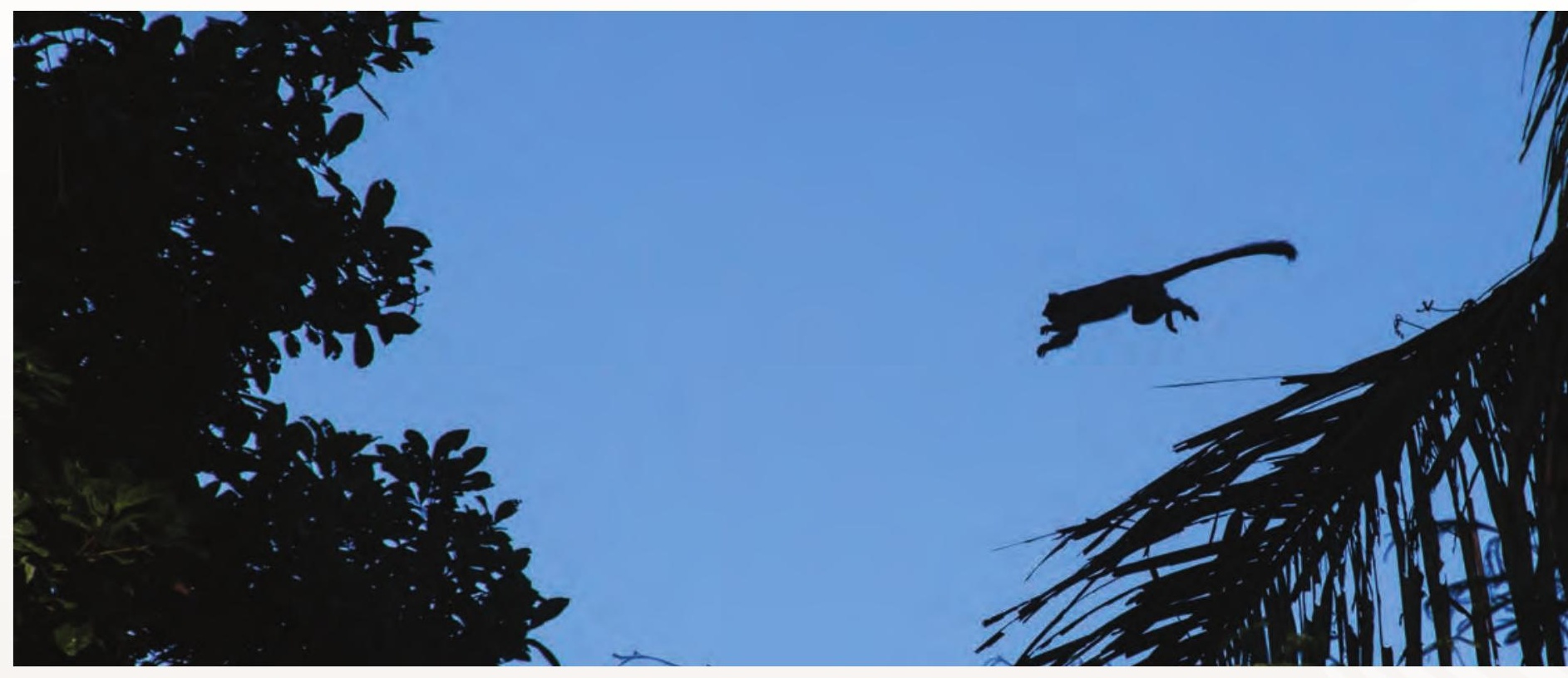

Aprovechamiento y comercialización de semillas de caoba

La caoba (Swietenia macrophylla) es uno de los recursos forestales de mayor valor económico en el mundo, razón por la cual, por décadas, ha sido talada de manera indiscriminada, llevando a su desaparición en algunos lugares.

En 2009, ECOPURÚS, Ejecutor del Contrato de Administración de la Reserva Comunal Purús, inició la ejecución del proyecto "Aprovechamiento sostenible de rodales semilleros de caoba en las comunidades del Purús"178, para el manejo sostenible de las semillas de caoba y su posterior comercialización con certificación del área protegida. El proyecto pone en práctica acciones de recuperación, enriquecimiento y agroforestería de caoba. En él participan 4 comunidades indígenas nativas (Laureano, Pozo San Martin, Santa Margarita y Gastabala). Como parte del proyecto, se desarrolló un plan de manejo que contó con la aprobación de la Dirección General Forestal y Fauna Silvestre (DGFFS) del Gobierno regional de Ucayali (GOREU).

Durante la implementación del proyecto se realizan reuniones entre los coordinadores del proyecto y la comunidad. Las comunidades participantes reciben capacitación en el manejo de semillas en las etapas de precosecha, cosecha y comercialización. Periódicamente se realizan inventarios forestales, monitoreo y evaluación de los rodales semilleros, cosecha y extracción de semillas, análisis de pureza, pruebas de germinación, adquisición de equipos de escalamiento para subir a los árboles y recolectar las semillas (lo que antes se hacía tumbando los árboles) y técnicas para conservación de la semilla ${ }^{1}$

El proyecto, además de los beneficios económicos, ha traído beneficios ambientales y sociales, como la conservación de la especie, fortalecimiento del manejo técnico local, el impulso a la organización comunitaria y alianzas estratégicas entre el Estado y las comunidades nativas como parte del proceso de cogestión de la Reserva Comunal Purús. En 2013, este proyecto se hizo acreedor del Premio Nacional de Ciudadanía Ambiental, en la categoría de Econegocios y biocomercio, otorgado por el Ministerio del Ambiente.

A pesar de ser un proyecto comunitario de aprovechamiento sostenible, ECOPURÚs es considerado por el Estado como un proveedor más de semillas de caoba. En los concursos públicos no importa cómo se haya recolectado ni el proceso empleado, ya que, según los informantes, el Estado solo considera el precio más bajo al elegir un proveedor.

178. ECOPURÚS ejecuta este proyecto con la Asociación Peruana de Conservación (APECO) y PROPURÚS

179. APECO (Asociación Peruana para la conservación de la naturaleza) da el apoyo técnico. 
Manejo de la Reserva: aceites vegetales, plantas medicinales, plantas insecticidas, abejas, goma, castaña, agricultura familiar y reordenamiento de la pesca. Este proyecto fortaleció las actividades tradicionales que realizan las familias y, además, las mujeres de la ASSC se organizaron para la producción, autoconsumo y comercialización de aceites de: asaí (Euterpe oleracea), castaña, patauá (Oenocarpus bataua o Jessenia bataua) y copaiba (Copaifera officinalis), este último usado como antiinflamatorio.

Las familias tienen una casa de farinha para la mandioca/yuca (Manihot esculenta), un alimento básico y tradicional que se consume en la dieta diaria y cuyo proceso de producción involucra a toda la familia. La casa de farinha es el lugar donde se transforma la mandioca en harina. Comienza con la cosecha de la mandioca y el traslado a la casa de farinha, responsabilidad de los hombres. Una vez ahí, las mujeres y los niños pelan y ponen a remojar la mandioca en agua para que se ablande. Después, se raya y se cuelga en un cedazo o chuspa de nylon para que caiga el exceso de líquido, también se exprime. Luego se pone la mandioca en una sábana a secar al sol para después tostarla en una paila hasta que esté a punto. Los excedentes de la producción de farinha, en el caso de la RESEX Cazumbá-Iracema, se destinan para la venta en Sena Madureira.

En abril de 2016, las comunidades Alto y Bajo Caeté en la RESEX iniciaron el proyecto "Etapas de desarrollo de una cadena productiva de tres aceites (asaí, castaña y copaiba) con potencial fitoterapéutico en la RESEX CazumbáIracema"182, con expectativas de que sea una nueva fuente de ingresos para la población.

En la RESEX se han realizado algunos esfuerzos para que la población se dedique a la extracción del aceite de copaiba ${ }^{183}$ (Copaifera spp.) e inclusive cuentan con un plan de manejo para este recurso. Sin embargo, los habitantes no aprovechan la copaiba por el esfuerzo que implica extraer el aceite que se encuentra dentro del tronco del árbol. Tradicionalmente el aceite de copaiba se extraía haciendo un corte profundo en forma de cuña, con hacha o motosierra, hasta llegar al corazón del árbol de donde empieza a brotar el aceite; otra forma de extracción consistía en derrumbar el árbol. Ninguna de estas formas era sostenible. La nueva técnica que se está promoviendo en las comunidades consiste en realizar un hueco en el tronco con una broca, a un metro de altura del suelo, para colocar un tubo del ancho del hueco y taparlo con tapa rosca, para así poder recolectar el aceite periódicamente y no en una sola vez. Del árbol se pueden extraer de 20 a 30 litros de aceite. Después de eso hay que dejar que el árbol descanse 3 años para que produzca aceite otra vez.

En la Reserva Manuripi, hay una experiencia exitosa de finca agroecológica en la comunidad de San Antonio ${ }^{184}$, que sirve como ejemplo para las otras comunidades. Su propietario destina para el cultivo 7 ha de su tierra en las que cultiva de forma orgánica frutas, tubérculos y diversos productos amazónicos. En esta actividad participa toda la familia.

\section{Ámbito cultural}

\section{El rescate de la tradición de la goma}

La goma es un recurso no maderable que se obtiene del árbol del caucho (Seringueira en portugués). Este árbol alcanza los $30 \mathrm{~m}$ de altura, su tronco alcanza un diámetro de hasta poco menos de un $1 \mathrm{~m}$. Los árboles comienzan a producir la goma -una leche blanca y espesa- cuando tienen entre 12 y 15 años de edad, durante todo el año y por un periodo aproximado de 35 años.

La goma se obtiene al hacer una incisión transversal en la corteza, con una herramienta parecida a un hacha diseñada (cabrita) y elaborada específicamente para esta actividad. Para su aprovechamiento se divide el tronco en cuatro segmentos y se aprovechan dos de estos, mientras los otros dos descansan para que se regenere la corteza. Las incisiones suelen hacerse comenzando des-

82. Provecto ejecutado con EMBAPRA e ICMBio.

183. Copaiba se deriva de kupay, palabra de origen quaraní que significa "árbol que cura". El árbol de copaiba puede alcanzar 25 m de altura y 7 m de diámetro.

184. Propiedad del Sr. Pedro Cabrera Ventura quien es además líder comunitario. Se sabe que la venta de estos productos agrícolas genera a su propietario un ingreso de alrededor de mil dólares mensuales. 
de la parte de arriba del tronco, bajando hacia la raíz y de izquierda a derecha, dejando que la goma resbale por el tronco (el siguiente corte en ese segmento se hace en sentido contrario al último corte y como mínimo, tres días después de este).

Fuente: http://www.lateinamerika-studien.at

La recolección de la goma es una tradición de los pueblos que habitan en los bosques amazónicos cuyo aprovechamiento con técnicas tradicionales no genera impactos negativos en el ecosistema. Esta actividad es realizada por los hombres, denominados siringueros o recolectores.

Para recolectar la goma, los siringueros inician el recorrido por sus estradas (sendas) muy temprano por la mañana para hacer el rayado de los árboles. Cada árbol de siringa está divido en 2 o 4 segmentos dependiendo del grosor del tronco (que va en relación a la edad del árbol), lo que muestra que los árboles viejos aún siguen produciendo goma. Una vez ubicado el árbol, realizan un corte transversal en cada uno de los segmentos, por donde, desde cada corte, empieza a brotar la goma para ser recogida en un recipiente colocado al final de la incisión. Toma alrededor de dos horas que el recipiente se llene y la goma deje de brotar. Los siringueros recogen la goma de los árboles que forman parte de un circuito (el que hace la estrada). El trabajo es individual, cada siringuero recorre las sendas ubicadas en su propio predio ${ }^{185}$

En los inicios, la goma era empleada para fabricar el calzado que usaban para caminar en

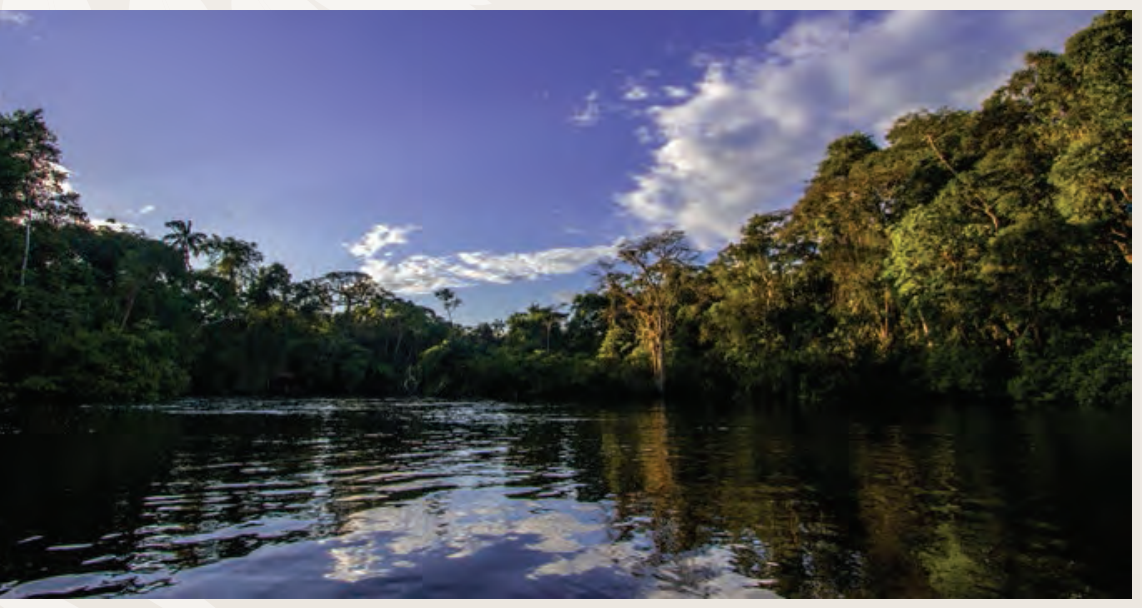

la selva, por su característica impermeable y resistente. La confección se hacía con la técnica tradicional de ahumado (defumado, en portugués) que quita la humedad y sella el material. Luego, por la bajada del precio en el mercado, esta actividad dejó de realizarse. Sin embargo, existen algunas iniciativas dentro de las áreas protegidas del paisaje sur para la conservación del recurso ${ }^{186}$ y otras para el rescate de la actividad.

En la Reserva Manuripi, en 2009, se implementó el proyecto "Aprovechamiento Sostenible de la Goma en la Reserva Manuripi"17", para recuperar la tradición y la producción de la goma y como una alternativa sostenible adicional a la castaña. Miembros de seis comunidades de la reserva -Curichón, San Antonio, Luz de América, Villa Florida, Católica, La Cruz y Sacrificio-, conformaron la Asociación de Gomeros de la Reserva Manuripi (ASGOMA), quienes se dedicaban a la actividad de la goma en los meses de abril a julio. El proyecto incluyó capacitación y organización además del desarrollo de un "Protocolo siringuero" con normas de rayado y recolección, mapeo de árboles, apertura de estradas, extracción de la goma, hasta la elaboración de los bloques con el respectivo control de calidad y registro. El producto se entregaba a dos empresas de Cochabamba para la producción de sandalias y plantillas para zapatos. Sin embargo este proyecto no prosperó aunque los socios confían en retomar la actividad ${ }^{188}$.

En el Plan de Manejo de la RESEX CazumbáIracema se señala la extracción de la goma como una de las actividades extractivas con potencial. De acuerdo a dicho plan, el 32 \% de familias de la reserva se dedican a la extracción de goma como actividad económica. Los siringueiros tienen mucho respeto por el bosque y en especial por el árbol de goma, pues

185. En la RESEX Cazumbá-Iracema, el área donde habita una familia tiene aproximadamente 300 ha, cada estrada de siringa es de 100 ha y cada hectárea tiene 100 árboles aproximadamente. Esta es la medida usual en Acre. Información proporcionada por Tiago Juruá.

186. En Bolivia el árbol de goma está protegido por Ley Forestal Artículo 39 del Decreto Supremo \# 27572 del 17 de junio de 2004.

187. Proyecto ejecutado con fondos de la Cooperación Financiera Alemana, a través del programa Biodiversidad y Áreas Protegidas, en colaboración con el Programa Manejo de Áreas Protegidas y Zonas de Amortiguamiento, el SERNAP y WWF.

188. En 2012, la producción total fue de 12378 kg de goma seca que obtuvo un precio de venta que osciló entre 14 y 18 bolivianos por kilo. 


\section{Paisaje sur. Ámbito cultural}

es un recurso que se obtiene durante todo el año. Manifiestan que tratando el árbol delicadamente y con respeto puede producir goma para toda la vida.

En 2002 se llevó a cabo un proyecto piloto de artesanías de goma y desde 2008 este tomó un nuevo impulso con el proyecto "Encauchados de Vegetais", con el apoyo del Gobierno de Acre, para desarrollar nuevas técnicas de uso del material. Forma parte del proyecto "Acre Latex Design Lab", en alianza con el Instituto Europeo de Diseño (IED) e ICMBio, entre otras instituciones. El proyecto tuvo como objetivo conjugar la tradición de la goma con nuevas técnicas para el aprovechamiento de este recurso, lo que ha dado como resultado el diseño de nuevos productos artesanales con estándares de calidad que se comercializan a nivel nacional e internacional.

Los artesanos cuentan con una colección propia de artesanías que representan la flora y fauna local. Un grupo de 25 mujeres artesanas se dedican, desde 2011, a la elaboración de réplicas de hojas de goma en base a la técnica de encauchados de vegetales ${ }^{189}$; como parte de este grupo hay 4 seringueiros, que recolectan la goma para las mujeres. Otro artesano se dedica a la elaboración de animales del bosque, con base en la técnica de ahumado. Tanto el grupo de mujeres como el artesano comercializan sus productos en ferias artesanales dentro y fuera del país con el apoyo del Gobierno de Acre y SEBRAE (Serviço Brasileiro de Apoio às Micro e Pequenas Empresas). En 2014, el grupo de mujeres expuso su trabajo en la Feria Internacional de Diseño en Milán-Italia. El proyecto de artesanías de hojas de goma ha dado un impulso a las mujeres. Según Leonora Maia, coordinadora del grupo de artesanas, antes del proyecto, las mujeres se dedicaban solamente a la chacra y a los quehaceres del hogar, no generaban recursos económicos y dependían exclusivamente de sus maridos. A raíz del proyecto de artesanías, explica que la generación de recursos económicos les ha dado independencia, lo cual ha influido en su autoestima, ya que aportan a la economía del hogar, además del gran aporte que están haciendo al rescate cultural de la tradición de la goma.

A pesar de estas iniciativas puntuales, parece que la tradición de la goma no se está pasando de generación en generación. Se pudo evidenciar la falta de interés de los jóvenes por apren-

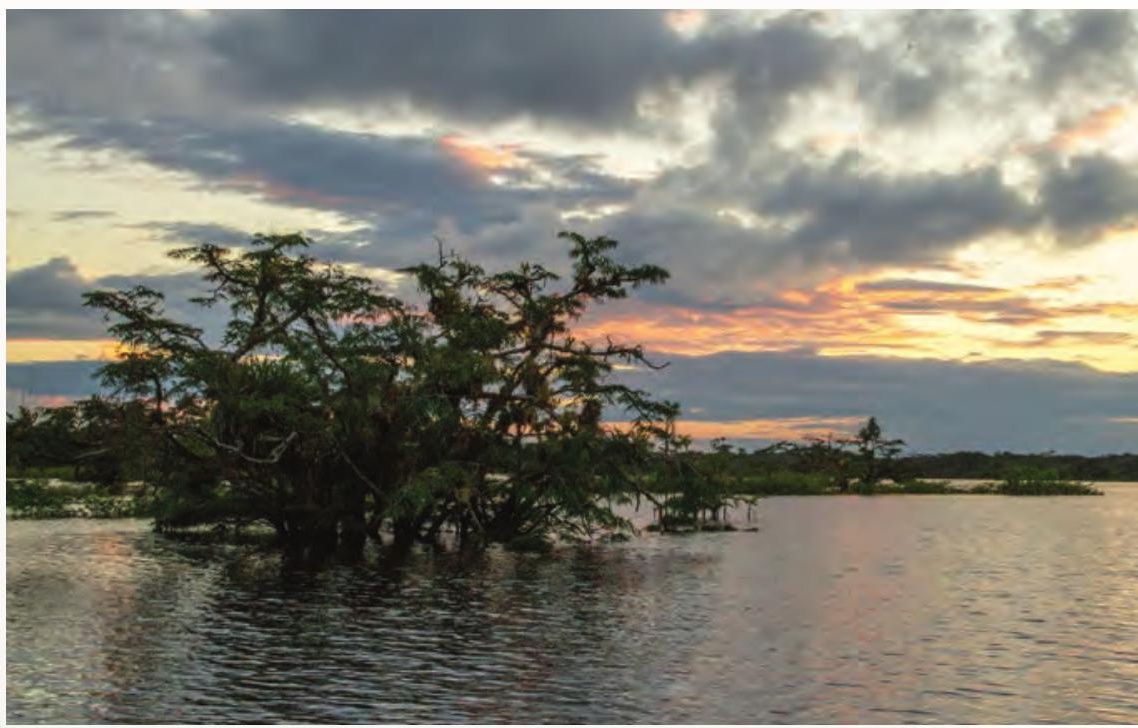

"Yo considero a la siringa como mi madre, porque fue con ella que mi padre me crió, fue con ella que yo crié a mis hijos y aún extraigo de ella mi sustento diario".

Jilberto Miranda Maia, Mayo 2016

der el oficio y su inclinación por recibir capacitación técnica y educación en otros temas Además se recogieron opiniones de los padres sobre las limitaciones que este tipo de actividad tiene: es un trabajado sacrificado y de bajo retorno económico.

\section{Las contribuciones de las} mujeres a la conservación

A nivel de paisaje, la responsabilidad de las mujeres recae en el cuidado de la familia, los hijos y de la chacra. En general, las mujeres son las responsables de la salud de su familia, usan las plantas medicinales de la chacra y las que se encuentran en el bosque. Entre las más comunes mencionan la sangre de drago (Croton lechleri) y el cirarí como cicatrizantes y para la gastritis; matico (Buddleja globosa) para aliviar el dolor de estómago y el vómito: la uña de gato (Uncaria tomentosa) para infec- 


\section{Interrelación de actores}

A continuación, se presenta un mapa de interrelación de los actores identificados para cada una de las áreas protegidas del paisaje sur, que guarda la misma metodología presentada en el paisaje norte en la sección "Interrelación de actores".

\begin{tabular}{|c|c|c|c|c|c|c|c|c|c|}
\hline \multirow[b]{2}{*}{ Actor } & \multirow[b]{2}{*}{ 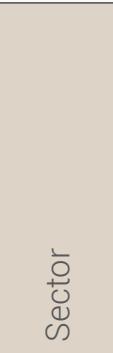 } & \multicolumn{3}{|c|}{ Ámbito } & \multicolumn{2}{|c|}{ Ubicación } & \multicolumn{2}{|c|}{ Alcance } & \multirow[b]{2}{*}{ Rol/situación } \\
\hline & & $\begin{array}{l}0 \\
\frac{0}{5} \\
0 \\
\frac{0}{0} \\
0 \\
0\end{array}$ & $\begin{array}{l}\overline{\frac{\pi}{0}} \\
0 \\
\infty\end{array}$ & $\frac{\overline{\frac{\pi}{J}}}{\frac{ \pm}{J}}$ & 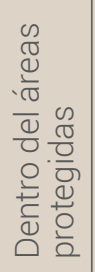 & 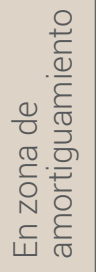 & $\begin{array}{l}\overline{\mathscr{U}} \\
0 \\
\end{array}$ & $\begin{array}{l}\bar{\sigma} \\
\frac{0}{0} \\
\frac{0}{0} \\
\frac{\pi}{Z}\end{array}$ & \\
\hline Ministerio del Ambiente & Público & $x$ & $x$ & $x$ & $x$ & $x$ & & $x$ & $\begin{array}{l}\text { Responsable de la política nacional del } \\
\text { medioambiente }\end{array}$ \\
\hline $\begin{array}{l}\text { ICMBio } \\
\text { Instituto Chico Mendes }\end{array}$ & Público & $x$ & $x$ & $x$ & $x$ & $x$ & $x$ & & $\begin{array}{l}\text { Protege el patrimonio natural y promueve } \\
\text { el desarrollo socioambiental. Gestiona las } \\
\text { Unidades de Conservación Federales. } \\
\text { Es el órgano gestor en la RESEX } \\
\text { Cazumbá-Iracema }\end{array}$ \\
\hline $\begin{array}{l}\text { INCRA (Instituto } \\
\text { Nacional de Colonización } \\
\text { y Reforma Agraria) }\end{array}$ & Público & $x$ & $x$ & & $x$ & $x$ & & $x$ & $\begin{array}{l}\text { Trabaja en reforma agraria y } \\
\text { ordenamiento territorial, acceso a la tierra } \\
\text { y titulación, participación social, entrega } \\
\text { créditos para proyectos en las AP. }\end{array}$ \\
\hline $\begin{array}{l}\text { EMBRAPA } \\
\text { (Empresa Brasilera } \\
\text { de Investigación } \\
\text { Agropecuaria) }\end{array}$ & Público & $x$ & $x$ & & $x$ & $x$ & & $x$ & $\begin{array}{l}\text { Entidad adscrita al Ministerio de } \\
\text { Agricultura, Pesca y Suministros que } \\
\text { trabaja en innovación tecnológica para } \\
\text { generar conocimiento y tecnología en el } \\
\text { tema agropecuario. } \\
\text { En Acre realiza investigaciones en las } \\
\text { áreas de producción sostenible pecuaria } \\
\text { y forestal, sistemas integrados y áreas } \\
\text { degradadas, frutales y plantas nativas } \\
\text { agroindustriales. } \\
\text { Implementa el Programa PBBI (Programa } \\
\text { Biodiversidade Brasil-Italia) }\end{array}$ \\
\hline $\begin{array}{l}\text { Gobierno del Estado de } \\
\text { Acre }\end{array}$ & Público & $x$ & $x$ & & & $x$ & $x$ & & $\begin{array}{l}\text { Entidad autónoma organizada que } \\
\text { administra el Estado. Tienen sus propios } \\
\text { recursos y además recibe la asignación } \\
\text { regular de una parte de los impuestos } \\
\text { recolectados localmente por el gobierno } \\
\text { federal. El Gobierno del estado de Acre } \\
\text { tiene una política ambiental como su eje } \\
\text { transversal. } \\
\text { La primera dama apoya el proyecto de } \\
\text { artesanías "Acre Latex Design" en la } \\
\text { RESEX. }\end{array}$ \\
\hline $\begin{array}{l}\text { SEMA (Secretaría } \\
\text { de Estado de Medio } \\
\text { Ambiente) }\end{array}$ & Público & $x$ & $x$ & & $x$ & $x$ & $x$ & & $\begin{array}{l}\text { Realizan planeamiento, elaboración, } \\
\text { ejecución, promoción, implementación, } \\
\text { monitoreo de programas, proyectos, } \\
\text { herramientas de gestión de políticas } \\
\text { públicas ambientales y territoriales en el } \\
\text { estado de Acre. }\end{array}$ \\
\hline $\begin{array}{l}\text { IBAMA (Instituto Brasileiro } \\
\text { do Meio Ambiente e } \\
\text { Recursos Naturais } \\
\text { Renováveis) }\end{array}$ & Público & $x$ & $x$ & & $x$ & $x$ & & $x$ & $\begin{array}{l}\text { Es una entidad federal responsable de la } \\
\text { ejecución, reglamentación y control de las } \\
\text { políticas ambientales en Brasil. } \\
\text { Implementa el Programa PBBI }\end{array}$ \\
\hline
\end{tabular}




\begin{tabular}{|c|c|c|c|c|c|c|c|c|c|}
\hline \multirow[b]{2}{*}{ Actor } & \multirow[b]{2}{*}{$\begin{array}{l}\overline{0} \\
0 \\
0 \\
\mathscr{D}\end{array}$} & \multicolumn{3}{|c|}{ Ámbito } & \multicolumn{2}{|c|}{ Ubicación } & \multicolumn{2}{|c|}{ Alcance } & \multirow[b]{2}{*}{ Rol/situación } \\
\hline & & 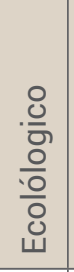 & \begin{tabular}{|l|}
$\bar{\pi}$ \\
0 \\
0 \\
$i$
\end{tabular} & $\frac{\bar{\pi}}{\frac{\pi}{2}}$ & 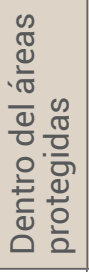 & 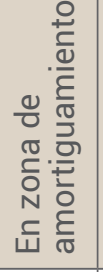 & $\begin{array}{l}\overline{\widetilde{J}} \\
\text { ○्త }\end{array}$ & $\begin{array}{l}\bar{\pi} \\
\check{L} \\
. \frac{0}{0} \\
\frac{\pi}{Z}\end{array}$ & \\
\hline $\begin{array}{l}\text { ARPA (Programa Áreas } \\
\text { Protegidas da Amazônia) }\end{array}$ & $\begin{array}{c}\text { Alianza } \\
\text { público-privada }\end{array}$ & $x$ & $x$ & $x$ & $x$ & $x$ & & $x$ & $\begin{array}{l}\text { Programa del Gobierno federal, } \\
\text { coordinado por el Ministerio de Medio } \\
\text { Ambiente (MMA), gestionado por el Fondo } \\
\text { Brasileño para la Biodiversidad (FUNBIO) } \\
\text { y financiado con recursos del Fondo } \\
\text { Mundial para el Medio Ambiente (FMMA), } \\
\text { a través del Banco Mundial, el Gobierno } \\
\text { alemán, el Banco Alemán de Desarrollo } \\
\text { (KfW), WWF Brasil y el Fondo Amazonia a } \\
\text { través del Banco Nacional de Desarrollo } \\
\text { Económico y Social de Brasil (BNDES.) } \\
\text { Las áreas protegidas que apoya reciben } \\
\text { bienes, obras y contratación de servicios } \\
\text { para llevara a cabo actividades de } \\
\text { integración con las comunidades vecinas, } \\
\text { formación de consejos, planes de manejo, } \\
\text { estudios sobre la titularidad de las tierras, } \\
\text { vigilancia. }\end{array}$ \\
\hline Visitantes & Privado & $x$ & $x$ & $x$ & $x$ & $x$ & $x$ & & $\begin{array}{l}\text { Realizan actividades de investigación } \\
\text { científica, social y promocionan la reserva. } \\
\text { Dejan recursos económicos. }\end{array}$ \\
\hline $\begin{array}{l}\text { Personas que realizan } \\
\text { actividades ilegales }\end{array}$ & Privado & $x$ & $x$ & & $x$ & $x$ & $x$ & & $\begin{array}{l}\text { Realizan de manera ilegal actividades de } \\
\text { tala, pesca y caza dentro de la reserva. }\end{array}$ \\
\hline
\end{tabular}

\begin{tabular}{|c|c|c|c|c|c|c|c|c|c|}
\hline \multicolumn{10}{|c|}{ Parque Estadual Chandless } \\
\hline Moradores del PEC & Campesinos & $x$ & $x$ & $x$ & $x$ & & $x$ & & $\begin{array}{l}11 \text { familias que viven cerca de la sede del } \\
\text { PEC a orillas del río Chandless. Están ahí } \\
\text { desde antes de que se declarara AP. }\end{array}$ \\
\hline Territorios indígenas & $\begin{array}{l}\text { Pueblos } \\
\text { indígenas }\end{array}$ & $x$ & $x$ & $x$ & $x$ & & $x$ & & $\begin{array}{l}\text { Están ubicados alrededor del PEC, son } \\
\text { de los Pueblos indígenas mastanahuas, } \\
\text { chaninahuas, junikuin, ashaninka, madijá, } \\
\text { sharanahuas, yine e amahuaca. }\end{array}$ \\
\hline $\begin{array}{l}\text { Pueblos indígenas no } \\
\text { contactados }\end{array}$ & $\begin{array}{l}\text { Pueblos } \\
\text { indígenas }\end{array}$ & $x$ & $x$ & $x$ & $x$ & & $x$ & & $\begin{array}{l}\text { Tienen su territorio tradicional a lo largo } \\
\text { de la frontera internacional Brasil-Perú, se } \\
\text { encuentran dentro del PEC. }\end{array}$ \\
\hline Consejo Consultivo & Mixto & $x$ & $x$ & $x$ & $x$ & & $x$ & & $\begin{array}{l}\text { Es presidido por el SEMA, está compuesto } \\
\text { por } 11 \text { instituciones gubernamentales y } 4 \\
\text { de la sociedad civil. }\end{array}$ \\
\hline $\begin{array}{l}\text { FUNAI (Fundação } \\
\text { Nacional do Índio) }\end{array}$ & Público & & $x$ & $x$ & & $x$ & & $x$ & $\begin{array}{l}\text { Actúa en la zona de amortiguamiento } \\
\text { del PEC. Establece y desarrolla las } \\
\text { políticas relacionadas con los pueblos } \\
\text { indígenas. Protege y demarca las tierras } \\
\text { tradicionalmente habitadas y usadas por } \\
\text { estas comunidades. } \\
\text { Se encarga de evitar que los foráneos } \\
\text { invadan territorios indígenas. }\end{array}$ \\
\hline
\end{tabular}


Interrelación de actores

\begin{tabular}{|c|c|c|c|c|c|c|c|c|c|}
\hline \multirow[b]{2}{*}{ Actor } & \multirow[b]{2}{*}{$\begin{array}{l}\overline{0} \\
\text { 巳 } \\
\dot{\infty}\end{array}$} & \multicolumn{3}{|c|}{ Ámbito } & \multicolumn{2}{|c|}{ Ubicación } & \multicolumn{2}{|c|}{ Alcance } & \multirow[b]{2}{*}{ Rol/situación } \\
\hline & & $\begin{array}{l}\frac{8}{5} \\
\frac{0}{0} \\
\frac{0}{0} \\
\text { บ }\end{array}$ & $\begin{array}{l}\bar{\pi} \\
\frac{\pi}{0} \\
0 \\
\infty\end{array}$ & $\begin{array}{l}\overline{\frac{\pi}{0}} \\
\frac{3}{5} \\
0\end{array}$ & 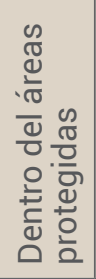 & 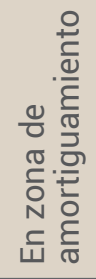 & $\begin{array}{l}\overline{\widetilde{J}} \\
\text { O }\end{array}$ & $\begin{array}{l}\bar{\pi} \\
\frac{0}{0} \\
\frac{\pi}{Z} \\
Z\end{array}$ & \\
\hline $\begin{array}{l}\text { SETUL (ACRE } \\
\text { Secretaria de Estado de } \\
\text { Turismo) }\end{array}$ & Público & & $x$ & & $x$ & $x$ & $x$ & & $\begin{array}{l}\text { Estudio para la implementación de } \\
\text { proyecto de turismo científico en el PEC, } \\
\text { con técnica de escala de árboles. }\end{array}$ \\
\hline $\begin{array}{l}\text { Comissao Pro Indio do } \\
\text { Acre }\end{array}$ & ONG & & $x$ & $x$ & & $x$ & $x$ & & $\begin{array}{l}\text { Actúa en la zona de amortiguamiento } \\
\text { del PEC. Apoya a los pueblos indígenas } \\
\text { del estado de Acre en la lucha de sus } \\
\text { derechos colectivos. }\end{array}$ \\
\hline SOS AMAZONIA & ONG & $x$ & $x$ & & $x$ & & & $x$ & $\begin{array}{l}\text { Coordinación técnica para la elaboración } \\
\text { del plan de manejo. ONG que trabaja en } \\
\text { defensa de la Amazonía, apoyando las } \\
\text { poblaciones tradicionales y promoviendo } \\
\text { la conservación del medioambiente. }\end{array}$ \\
\hline
\end{tabular}

\begin{tabular}{|c|c|c|c|c|c|c|c|c|c|}
\hline \multicolumn{10}{|c|}{ RESEX Cazumbá-Iracema } \\
\hline Consejo Deliberativo & Mixto & $x$ & $x$ & $x$ & $x$ & & $x$ & & $\begin{array}{l}\text { Es la máxima autoridad de decisión } \\
\text { en la RESEX, está compuesto por } \\
8 \text { instituciones del Gobierno y } 9 \text { no } \\
\text { gubernamentales. }\end{array}$ \\
\hline Grupo de Artesanos & Privado & $x$ & $x$ & $x$ & $x$ & & $x$ & & $\begin{array}{l}\text { Conformado por mujeres de Núcleo do } \\
\text { Cazumbá que hacen hojas de los árboles } \\
\text { con goma, su trabajo ha sido reconocido } \\
\text { a nivel internacional. }\end{array}$ \\
\hline $\begin{array}{l}\text { Grupo de agroindustria } \\
\text { de asaí }\end{array}$ & Privado & $x$ & $x$ & & $x$ & & $x$ & & $\begin{array}{l}\text { Pertenecen a Núcleo do Cazumbá, es un } \\
\text { proyecto que inició en } 2014 \text {, cuentan con } \\
\text { una planta de despulpado de asaí. }\end{array}$ \\
\hline $\begin{array}{l}\text { SEBRA (Servicio } \\
\text { Brasileño de Apoyo a } \\
\text { las Micro y Pequeñas } \\
\text { empresas) }\end{array}$ & Privado & & $x$ & & $x$ & $x$ & & $x$ & $\begin{array}{l}\text { Promueve la competitividad y el } \\
\text { desarrollo sostenible de micro y } \\
\text { pequeños emprendimientos. Apoya } \\
\text { proyectos en la RESEX Cazumbá- } \\
\text { Iracema con capacitación. }\end{array}$ \\
\hline $\begin{array}{l}\text { Programa Biodiversidade } \\
\text { Brasil-Itália (PBBI) }\end{array}$ & $\begin{array}{l}\text { Cooperación } \\
\text { internacional }\end{array}$ & $x$ & $x$ & & $x$ & & $x$ & & $\begin{array}{l}\text { Apoyó a la RESEX Cazumbá en proyectos } \\
\text { de desarrollo a través de un modelo } \\
\text { de conservación y uso sostenible de la } \\
\text { biodiversidad. }\end{array}$ \\
\hline WWF Brasil & $\begin{array}{l}\text { Cooperación } \\
\text { internacional }\end{array}$ & $x$ & $x$ & $x$ & & $x$ & & $x$ & $\begin{array}{l}\text { Apoyo a poblaciones locales para } \\
\text { el desarrollo sostenible de sus } \\
\text { comunidades. }\end{array}$ \\
\hline
\end{tabular}



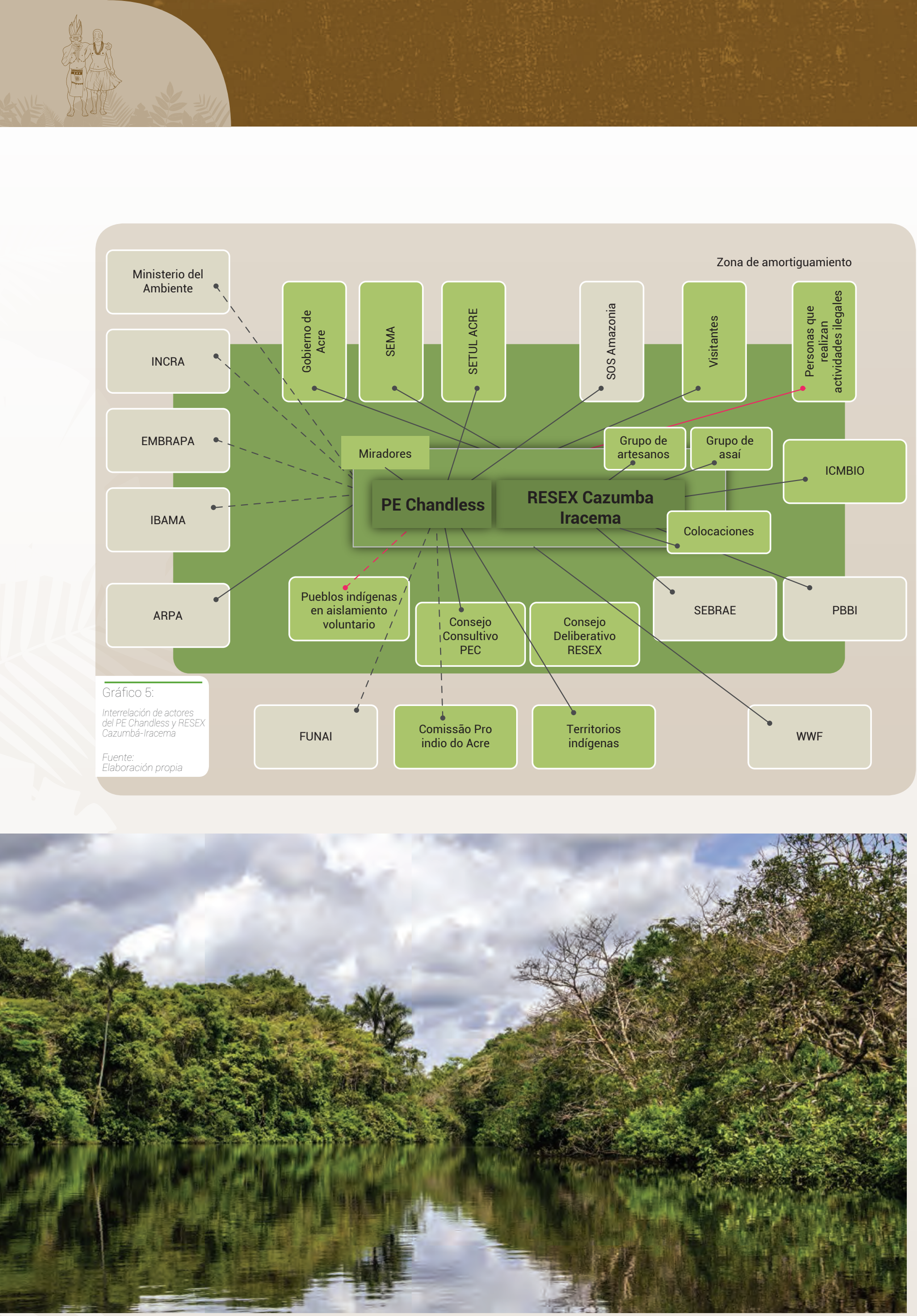
Interrelación de actores

\begin{tabular}{|c|c|c|c|c|c|c|c|c|c|}
\hline \multirow[b]{2}{*}{ Actor } & \multirow[b]{2}{*}{ 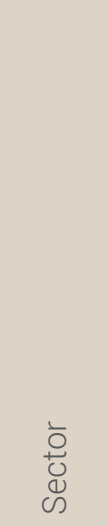 } & \multicolumn{3}{|c|}{ Ámbito } & \multicolumn{2}{|c|}{ Ubicación } & \multicolumn{2}{|c|}{ Alcance } & \multirow[b]{2}{*}{ Rol/situación } \\
\hline & & $\begin{array}{l}8 \\
\frac{0}{8} \\
0 \\
0 \\
\\
\end{array}$ & 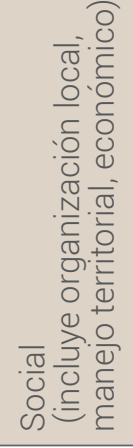 & $\begin{array}{l}\overline{\frac{\pi}{5}} \\
\stackrel{\overrightarrow{3}}{J} \\
0\end{array}$ & $\begin{array}{l}\frac{0}{0} \\
\frac{0}{0} \\
0 \\
0 \\
\frac{0}{0} \\
0 \\
\end{array}$ & 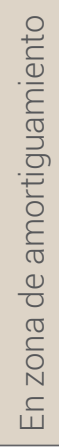 & $\begin{array}{l}\overline{\widetilde{J}} \\
\text { O }\end{array}$ & $\begin{array}{l}\bar{\sigma} \\
\frac{0}{0} \\
0 \\
\frac{\pi}{2} \\
\end{array}$ & \\
\hline $\begin{array}{l}\text { Ministerio de Ambiente y } \\
\text { Desarrollo Sostenible }\end{array}$ & Público & $x$ & $x$ & $x$ & $x$ & $x$ & & $x$ & $\begin{array}{l}\text { Define la política ambiental a nivel } \\
\text { nacional y promueve la conservación y el } \\
\text { uso sostenible de los RRNN. }\end{array}$ \\
\hline $\begin{array}{l}\text { SERNAP (Servicio Nacional } \\
\text { de Areas Protegidas) }\end{array}$ & Público & x & $x$ & $x$ & $x$ & $x$ & $x$ & $x$ & $\begin{array}{l}\text { Entidad perteneciente al Ministerio } \\
\text { de Ambiente y Desarrollo Sostenible, } \\
\text { encargada de la administración y manejo } \\
\text { del Sistema de Parques Nacionales } \\
\text { Naturales y la coordinación del Sistema } \\
\text { Nacional de Áreas Protegidas. }\end{array}$ \\
\hline Municipio de Puerto Rico & Público & & $x$ & & & $x$ & $x$ & & $\begin{array}{l}\text { Uno de los municipios donde se } \\
\text { encuentra la Reserva Manuripi. Entre } \\
\text { otras cosas, es el responsable de la } \\
\text { educación y salud. }\end{array}$ \\
\hline Municipio de Filadelfia & Público & & $x$ & & & $x$ & $x$ & & $\begin{array}{l}\text { Uno de los municipios donde se } \\
\text { encuentra la Reserva Manuripi. Entre } \\
\text { otras cosas, es el responsable de la } \\
\text { educación y salud. }\end{array}$ \\
\hline $\begin{array}{l}\text { Administración Reserva } \\
\text { Manuripi }\end{array}$ & Público & $x$ & $x$ & $x$ & $x$ & $x$ & $x$ & & $\begin{array}{l}\text { Responsable de la conservación } \\
\text { de la flora y fauna del AP, y del uso } \\
\text { sostenible de los recursos. Coordina } \\
\text { actividades entre los actores, facilita } \\
\text { procesos, realiza control y vigilancia } \\
\text { del AP. } \\
\text { Tiene la potestad de otorgar licencias } \\
\text { y autorizaciones de extracción de } \\
\text { castaña a comunidades y barracas. }\end{array}$ \\
\hline $\begin{array}{l}\text { EBA } \\
\text { (Empresa Boliviana de } \\
\text { Almendra y Derivados) }\end{array}$ & Público & & $x$ & & & $x$ & & $x$ & $\begin{array}{l}\text { Empresa del Estado dedicada a acopiar } \\
\text { la castaña de productores comunitarios } \\
\text { y privados para la exportación. Su } \\
\text { propósito es incentivar la producción } \\
\text { nacional con valor agregado, generando } \\
\text { mayores fuentes de trabajo, desarrollo } \\
\text { y soberanía productiva en la amazonia } \\
\text { boliviana. Cuenta con una planta } \\
\text { industrial en El Sena. }\end{array}$ \\
\hline CERES & Privada & $x$ & $x$ & $x$ & $x$ & & & $x$ & $\begin{array}{l}\text { Otorga la certificación de producto } \\
\text { orgánico a la castaña }\end{array}$ \\
\hline
\end{tabular}




\begin{tabular}{|c|c|c|c|c|c|c|c|c|c|}
\hline & & & Ámbito & & Ubia & ación & Alcéc & nce & \\
\hline Actor & $\begin{array}{l}\overline{0} \\
\text { गे } \\
\& \\
\infty\end{array}$ & $\begin{array}{l}0 \\
\frac{0}{8} \\
0 \\
0 \\
\\
\end{array}$ & 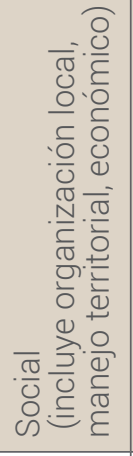 & 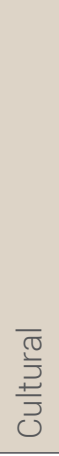 & $\begin{array}{l}\frac{0}{\pi} \\
\frac{0}{0} \\
0 \\
\frac{0}{0} \\
\frac{0}{0} \\
0\end{array}$ & 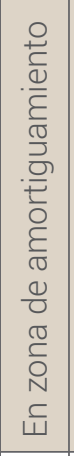 & $\begin{array}{l}\overline{\widetilde{J}} \\
\text { О } \\
\end{array}$ & $\begin{array}{l}\bar{\pi} \\
\frac{0}{0} \\
\frac{0}{0} \\
\frac{\pi}{2} \\
\end{array}$ & Rol/situación \\
\hline $\begin{array}{l}\text { ABT (Autoridad de } \\
\text { Fiscalización y Control social } \\
\text { de Bosques y Tierras) }\end{array}$ & Público & $x$ & $x$ & & $x$ & $x$ & & $x$ & $\begin{array}{l}\text { Otorga la autorización de inicio de zafra a la } \\
\text { Dirección de la Reserva Manuripi. Protege, } \\
\text { regula, fiscaliza y controlalas actividades } \\
\text { humanas en los bosques y tierras, } \\
\text { promoviendo el desarrollo y manejo integral } \\
\text { sostenible. }\end{array}$ \\
\hline Comité de Gestión & $\begin{array}{l}\text { Público y } \\
\text { privado }\end{array}$ & $x$ & $x$ & $x$ & $x$ & & $x$ & & $\begin{array}{l}\text { Instancia donde se discute, se fiscaliza, se } \\
\text { planifica y soluciona los problemas de la } \\
\text { gestión del área. Es la mayor instancia de } \\
\text { decisión dentro del AP, está formado por } \\
\text { las comunidades, las barracas y el SERNAP } \\
\text { y conformada por representantes de la } \\
\text { sociedad civil. }\end{array}$ \\
\hline Comunidades extractivas & Privado & $x$ & $x$ & $x$ & $x$ & & $x$ & & $\begin{array}{l}10 \text { comunidades asentadas dentro de la } \\
\text { reserva, tienen personería jurídica y están } \\
\text { conformadas por encarpetados quienes } \\
\text { legitimamente tienen derecho a tierras. }\end{array}$ \\
\hline Barraqueros & Privado & $x$ & $x$ & $x$ & $x$ & & $x$ & & $\begin{array}{l}\text { Dueños de los predios privados que } \\
\text { combinan titulos de propiedad sobre } \\
\text { superficies pequeñas y derechos } \\
\text { expectaticios sobre grandes superficies }\end{array}$ \\
\hline $\begin{array}{l}\text { Empresas comercializadoras } \\
\text { de castaña }\end{array}$ & Privado & & $x$ & & & $x$ & $x$ & & $\begin{array}{l}\text { Empresas privadas (Urcupiña y Tahuamanu) } \\
\text { que compran la castaña a las comunidades } \\
\text { y la comercializan al exterior. }\end{array}$ \\
\hline $\begin{array}{l}\text { AARENARMAPA } \\
\text { (Asociación Agroindustrial y } \\
\text { de Recursos Naturales del } \\
\text { Río Manuripi, Pando) }\end{array}$ & Privado & & $x$ & & $x$ & & $x$ & & $\begin{array}{l}\text { Asociación comercializadora de castaña } \\
\text { que representa a los barraqueros del río } \\
\text { Manuripi, tiene incidencia política en la zona. }\end{array}$ \\
\hline WWF Bolivia & $\begin{array}{l}\text { Cooperación } \\
\text { Internacional }\end{array}$ & $x$ & $x$ & $x$ & & $x$ & $x$ & $x$ & $\begin{array}{l}\text { Apoyo proceso de certificación de la } \\
\text { castaña, fortalecimiento de capital humano, } \\
\text { sostenibilidad financiera. }\end{array}$ \\
\hline Visitantes & Privado & x & $x$ & $x$ & $x$ & $x$ & $x$ & & $\begin{array}{l}\text { Algunos realizan actividades de turismo; } \\
\text { otros investigación cientifica y social. }\end{array}$ \\
\hline $\begin{array}{l}\text { Personas que realizan } \\
\text { actividades ilegales }\end{array}$ & Privado & $x$ & $x$ & & $x$ & $x$ & $x$ & & $\begin{array}{l}\text { Realizan de manera ilegal actividades de } \\
\text { tala, pesca y caza dentro de la reserva. }\end{array}$ \\
\hline
\end{tabular}




\section{Interrelación de actores}

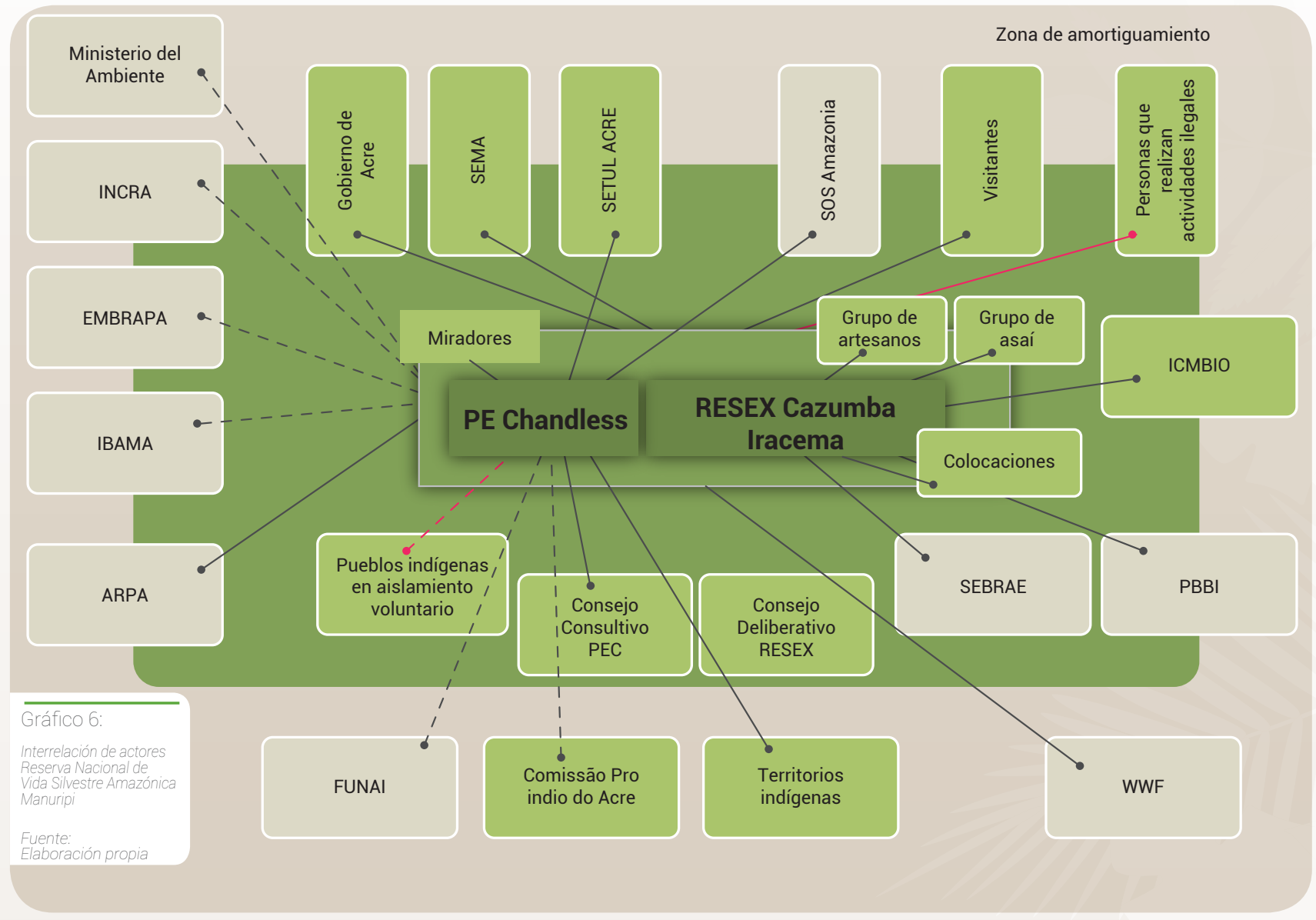

\begin{tabular}{|c|c|c|c|c|c|c|c|c|c|}
\hline \multirow[b]{2}{*}{ Actor } & \multirow[b]{2}{*}{$\begin{array}{l}\overline{0} \\
\overline{0} \\
\infty \\
\infty\end{array}$} & \multicolumn{3}{|c|}{ Ámbito } & \multicolumn{2}{|c|}{ Ubicación } & \multicolumn{2}{|c|}{ Alcance } & \multirow[b]{2}{*}{ Rol/situación } \\
\hline & & $\begin{array}{l}\frac{0}{0} \\
\frac{0}{0} \\
0 \\
\\
\end{array}$ & $\begin{array}{l}\overline{\frac{\pi}{U}} \\
0 \\
\infty\end{array}$ & $\begin{array}{l}\overline{\frac{\pi}{J}} \\
\frac{ \pm}{J} \\
\bar{J}\end{array}$ & 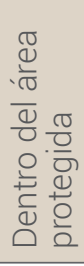 & 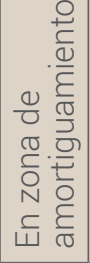 & $\begin{array}{l}\bar{ர} \\
0 \\
\end{array}$ & $\begin{array}{l}\bar{\sigma} \\
\frac{\bar{C}}{0} \\
\frac{0}{Z} \\
Z\end{array}$ & \\
\hline Ministerio del Ambiente & Público & $x$ & $x$ & & $x$ & $x$ & & $x$ & $\begin{array}{l}\text { Órgano rector en materia de ambiente a } \\
\text { nivel nacional. }\end{array}$ \\
\hline $\begin{array}{l}\text { SERNANP (Servicio } \\
\text { Nacional de Áreas Naturales } \\
\text { Protegidas por el Estado) }\end{array}$ & Público & $x$ & $x$ & $x$ & $x$ & $x$ & & $x$ & $\begin{array}{l}\text { Entidad adscrita al Ministerio del Ambiente. } \\
\text { Dirige y establece los criterios técnicos y } \\
\text { administrativos para la conservación de las } \\
\text { AP y la diversidad biológica. }\end{array}$ \\
\hline $\begin{array}{l}\text { Administración del parque y } \\
\text { las reservas comunales }\end{array}$ & Público & $x$ & $x$ & $x$ & $x$ & $x$ & $x$ & & $\begin{array}{l}\text { Coordinación de actividades dentro y fuera } \\
\text { de las AP entre los actores. }\end{array}$ \\
\hline $\begin{array}{l}\text { Gobernación Regional de } \\
\text { Ucayali (GOREU) }\end{array}$ & Público & $x$ & $x$ & & & $x$ & $x$ & & $\begin{array}{l}\text { Aprueba las concesiones de conservación. } \\
\text { Entregó la primera a MABOSINFRON en } \\
2012 \text {. }\end{array}$ \\
\hline
\end{tabular}

\section{Tabla 28:}

Descripción de actores del PN Alto

Purús y RC Purús 


\begin{tabular}{|c|c|c|c|c|c|c|c|c|c|}
\hline \multirow[b]{2}{*}{ Actor } & \multirow[b]{2}{*}{$\begin{array}{l}\overline{0} \\
0 \\
0 \\
\infty\end{array}$} & \multicolumn{3}{|c|}{ Ámbito } & \multicolumn{2}{|c|}{ Ubicación } & \multicolumn{2}{|c|}{ Alcance } & \multirow[b]{2}{*}{ Rol/situación } \\
\hline & & $\begin{array}{l}\frac{\pi}{5} \\
\frac{0}{0} \\
\\
\end{array}$ & $\begin{array}{l}\bar{c} \\
\overline{0} \\
\text { ¿ }\end{array}$ & 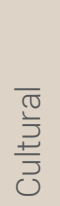 & 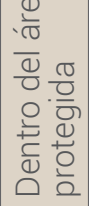 & 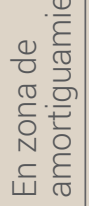 & $\begin{array}{l}\overline{\widetilde{J}} \\
\text { O }\end{array}$ & $\begin{array}{l}\bar{\pi} \\
\stackrel{0}{0} \\
\frac{0}{0} \\
\frac{\pi}{2}\end{array}$ & \\
\hline $\begin{array}{l}\text { OSINFOR (Organismo de } \\
\text { supervisión de los recursos } \\
\text { forestales y de fauna } \\
\text { silvestre) }\end{array}$ & Público & $x$ & $x$ & & $x$ & $x$ & & $x$ & $\begin{array}{l}\text { Encargado a nivel nacional, de supervisar y } \\
\text { fiscalizar el aprovechamiento sostenible y } \\
\text { la conservación de los recursos forestales } \\
\text { y de fauna silvestre, así como de los } \\
\text { servicios ambientales provenientes del } \\
\text { bosque otorgados por el Estado a través de } \\
\text { diversas modalidades de aprovechamiento. } \\
\text { Son los que entregan las concesiones } \\
\text { forestales, supervisan y fiscalizan los } \\
\text { planes de manejo a los forestales, hacen } \\
\text { control y vigilancia. }\end{array}$ \\
\hline $\begin{array}{l}\text { FECONAPU (Federación de } \\
\text { Comunidades Nativas del } \\
\text { Río Purús) }\end{array}$ & $\begin{array}{l}\text { Pueblos } \\
\text { indígenas }\end{array}$ & $x$ & $x$ & & $x$ & & $x$ & & $\begin{array}{l}\text { Organización de los Pueblos indígenas } \\
\text { de Purús. Recibió el Premio Nacional } \\
\text { Ambiental } 2014 \text { por Buenas Prácticas } \\
\text { Frente al Cambio Climático, otorgado por } \\
\text { el Ministerio del Ambiente en diciembre de } \\
2014 \text {. }\end{array}$ \\
\hline $\begin{array}{l}\text { AIDESEP (Asociación } \\
\text { Interétnica de Desarrollo de } \\
\text { la Selva Peruana) }\end{array}$ & $\begin{array}{l}\text { Pueblos } \\
\text { indígenas }\end{array}$ & $x$ & $x$ & & $x$ & $x$ & $x$ & $x$ & $\begin{array}{l}\text { Organización vocera de los pueblos } \\
\text { indigenas de la Amazonía peruana, } \\
\text { que trabaja en la defensa y respeto } \\
\text { de los derechos colectivos, expone su } \\
\text { problemática y presenta las propuestas } \\
\text { alternativas de desarrorllo que plantean } \\
\text { según su cosmovisión y estilo de vida. } \\
\text { Forma parte del Comite de Gestión del } \\
\text { PNAP. }\end{array}$ \\
\hline PROPURÚS & ONG & $x$ & $x$ & & $x$ & & $x$ & & $\begin{array}{l}\text { Dedicada a la conservación de la diversidad } \\
\text { biológica y yultural de las cabeceras } \\
\text { Amazónicas en los departamentos de } \\
\text { Ucayalicy yadre de Dios en la selva peruana, } \\
\text { específicamente entre las nacientes de los } \\
\text { rís Alto Purús y Yurúu. Apoyan proyectos } \\
\text { de fortalecimiento en áreas protegidas } \\
\text { y en el desarrollo de la capacidad de } \\
\text { conservación de los habitantes locales }\end{array}$ \\
\hline $\begin{array}{l}\text { APECO (Asociación Peruana } \\
\text { para la Conservación de la } \\
\text { Naturaleza) }\end{array}$ & ONG & $x$ & $x$ & & $x$ & & & $x$ & $\begin{array}{l}\text { Fomenta la toma de conciencia de temas } \\
\text { como la conservación de la biodiviversidady y } \\
\text { el desarrollo sostenibleen Perú. Promueveel } \\
\text { desarrollo de capacidades locales y regionales } \\
\text { para consolidar la gestión pública de las áreas } \\
\text { protegidas nacionales y regionales y la cogestión } \\
\text { de reservas comunales; asícomola gestión } \\
\text { comunal deáreas de conservación privada. } \\
\text { Apoya a la RCP con capacitación en } \\
\text { aprovechamiento de semillas de caoba }\end{array}$ \\
\hline $\begin{array}{l}\text { ACBT Perú (Acuerdo para la } \\
\text { conservación de Bosques } \\
\text { Tropicales) }\end{array}$ & $\begin{array}{l}\text { Cooperación } \\
\text { Internacional }\end{array}$ & $x$ & $x$ & $x$ & $x$ & & & $x$ & $\begin{array}{l}\text { Es un fondo de canje de deuda por } \\
\text { naturaleza entre Perú y los Estados } \\
\text { Unidos. Apoyó el desarrolloo del Manual } \\
\text { de Procedimiento administrativo de } \\
\text { ECOPURÚ, el estudio de producción y } \\
\text { comercialización de semillas de caoba, } \\
\text { proyecto de artesanías con fibras naturales. }\end{array}$ \\
\hline
\end{tabular}




\section{Interrelación de actores}

\begin{tabular}{|c|c|c|c|c|c|c|c|c|c|}
\hline \multirow[b]{2}{*}{ Actor } & \multirow[b]{2}{*}{$\begin{array}{l}\overline{0} \\
0 \\
\text { ¿ } \\
\infty\end{array}$} & \multicolumn{3}{|c|}{ Ámbito } & \multicolumn{2}{|c|}{ Ubicación } & \multicolumn{2}{|c|}{ Alcance } & \multirow[b]{2}{*}{ Rol/situación } \\
\hline & & $\begin{array}{l}0 \\
\frac{0}{5} \\
\frac{0}{0} \\
\dot{U}\end{array}$ & $\begin{array}{l}\frac{\pi}{8} \\
0 \\
\infty\end{array}$ & $\begin{array}{l}\overline{\frac{\pi}{5}} \\
\frac{2}{\overline{2}} \\
0\end{array}$ & 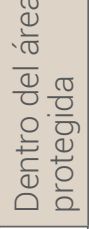 & 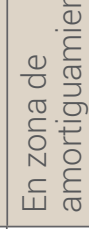 & $\overline{0}$ & $\begin{array}{l}\bar{\sigma} \\
\frac{\tilde{O}}{0} \\
\frac{\pi}{Z} \\
\end{array}$ & \\
\hline WWF Perú & $\begin{array}{l}\text { Cooperación } \\
\text { Internacional }\end{array}$ & $x$ & $x$ & $x$ & $x$ & & $x$ & & $\begin{array}{l}\text { Apoyo a poblaciones locales para el } \\
\text { desarrollo sostenible de sus comunidades, } \\
\text { certificación de manejo forestal, mejores } \\
\text { prácticas extractivas, entre otros. }\end{array}$ \\
\hline $\begin{array}{l}\text { Vicariato Apostólico de } \\
\text { Puerto Maldonado }\end{array}$ & Iglesia & & $x$ & & $x$ & $x$ & $x$ & & 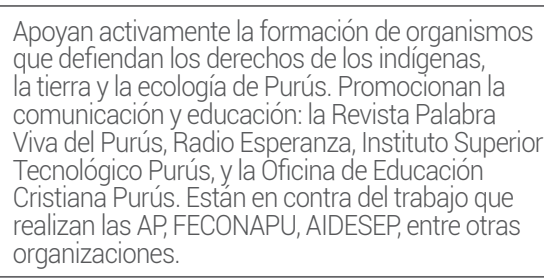 \\
\hline Visitantes & Privados & $x$ & $x$ & $x$ & $x$ & $x$ & $x$ & & $\begin{array}{l}\text { Realizan actividades de turismo, } \\
\text { investigación científica, social y } \\
\text { promocionan el AP } \\
\text { Dejan recursos económicos }\end{array}$ \\
\hline $\begin{array}{l}\text { Personas que realizan } \\
\text { actividades ilegales }\end{array}$ & Privado & & $x$ & & $x$ & & $x$ & & $\begin{array}{l}\text { Actividades relacionadas principalmente } \\
\text { a la tala del bosque, caza y pesca } \\
\text { indiscriminada. }\end{array}$ \\
\hline
\end{tabular}

\begin{tabular}{|c|c|c|c|c|c|c|c|c|c|}
\hline \multicolumn{10}{|c|}{ Parque Nacional Alto Purús } \\
\hline Comité de Gestión & $\begin{array}{l}\text { Público- } \\
\text { privado }\end{array}$ & $x$ & $x$ & $x$ & $x$ & & $x$ & & $\begin{array}{l}\text { Representa a la sociedad civil y es el } \\
\text { mecanismo de participación de la población } \\
\text { en el área protegida. }\end{array}$ \\
\hline $\begin{array}{l}\text { ARPAU (Asociación Regional } \\
\text { del Pueblo Ashaninka de } \\
\text { Uyacayali) }\end{array}$ & $\begin{array}{l}\text { Pueblos } \\
\text { indígenas }\end{array}$ & $x$ & $x$ & $x$ & $x$ & & $x$ & & $\begin{array}{l}\text { Representa a las comunidades ashaninka } \\
\text { en Uyacayali }\end{array}$ \\
\hline $\begin{array}{l}\text { Pueblos indígenas en } \\
\text { aislamiento voluntario }\end{array}$ & $\begin{array}{l}\text { Pueblos } \\
\text { indígenas }\end{array}$ & $x$ & $x$ & $x$ & $x$ & & $x$ & & $\begin{array}{l}\text { Tienen su territorio tradicional a lo largo } \\
\text { de la frontera internacional Brasil-Perú, se } \\
\text { encuentran dentro de la zona del Alto Purús. }\end{array}$ \\
\hline $\begin{array}{l}\text { ProNaturaleza, } \\
\text { Fundación Peruana para } \\
\text { la Conservación de la } \\
\text { Naturaleza }\end{array}$ & ONG & $x$ & $x$ & & $x$ & $x$ & & $x$ & $\begin{array}{l}\text { Realizan acciones de manejo sostenible } \\
\text { de los recursos naturales renovables, } \\
\text { asegurando la conservación de las } \\
\text { Áreas Naturales Protegidas y procesos } \\
\text { relacionados a la conservación de la } \\
\text { biodiversidad de Perú. Miembros del Comité } \\
\text { de Gestión. }\end{array}$ \\
\hline $\begin{array}{l}\text { AVISA-SZF } \\
\text { (Ayuda para Vida Silvestre } \\
\text { Amenazada, Sociedad } \\
\text { Zoológica de Frankfurt Perú) }\end{array}$ & $\begin{array}{l}\text { Cooperación } \\
\text { internacional }\end{array}$ & & $x$ & $x$ & $x$ & & $x$ & $x$ & $\begin{array}{l}\text { Promueve actividades en defensa del } \\
\text { territorio, la vida de los pueblos indígenas, } \\
\text { la protección de la reserva territorial en } \\
\text { AP donde existan pueblos indígenas en } \\
\text { aislamiento y contacto inicial. }\end{array}$ \\
\hline
\end{tabular}




\section{Interrelación de actores}

Zona de amortiguamiento
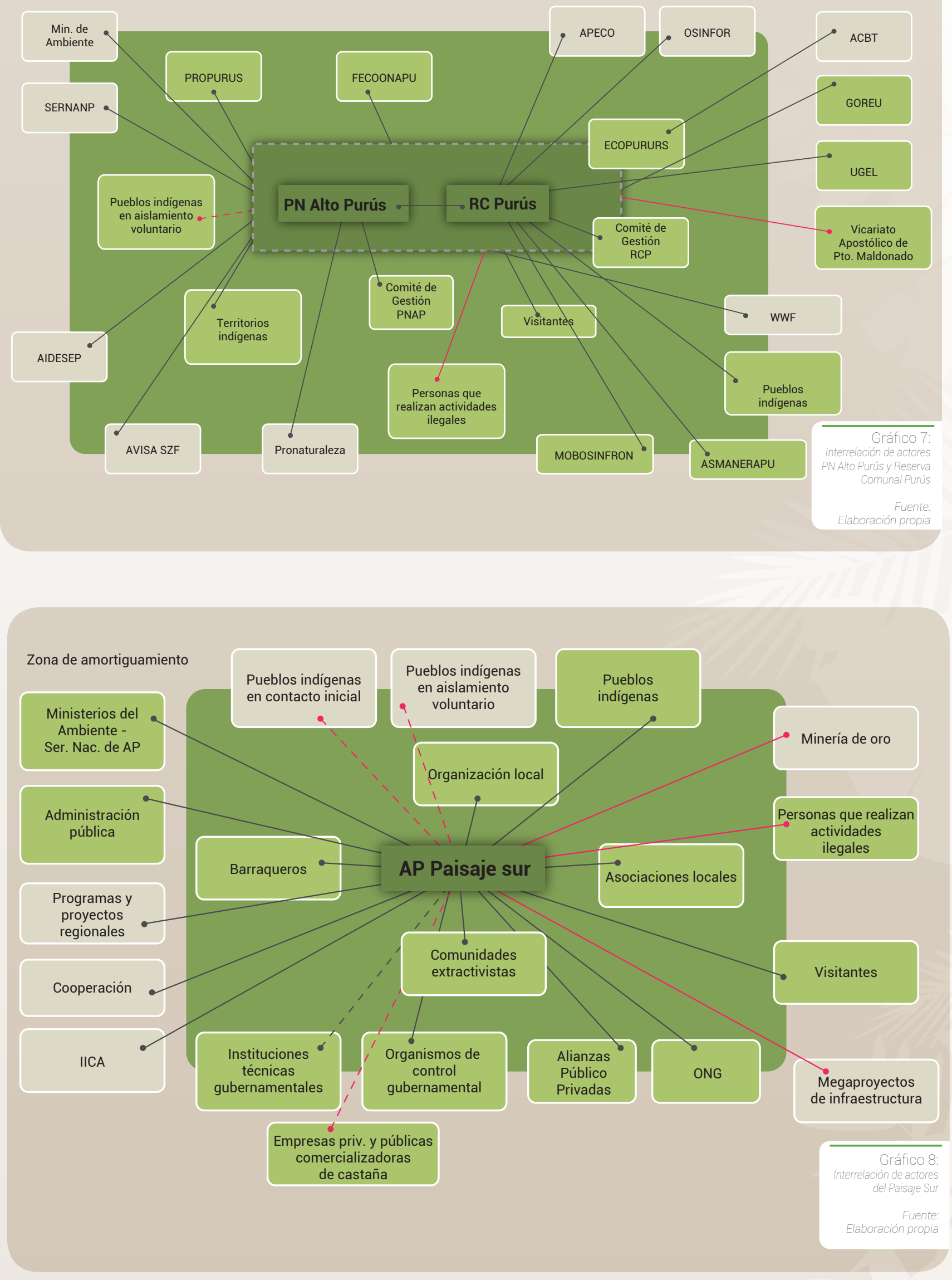


\section{Costos y beneficios económicos de las áreas protegidas para las poblaciones locales}

\section{Consideraciones metodológicas}

La información que se presenta fue obtenida a través de fuentes primarias y secundarias. Para la recolección de información primaria se realizó trabajo de campo con las directivas de cada una de las AP, con excepción de la directiva de Güeppí-Sekime, Airo Pai y Huimeki. La información secundaria utilizada se basa en textos producidos por cada una de las AP, iniciativas trasnacionales, organismos internacionales y científicos de diferentes campos de conocimiento, entre otros.

El análisis y descripción se enfoca en comprender la dinámica local de uso de los recursos naturales de las AP y en cómo esto representa un costo o un beneficio para la población local. En este interés se sustenta la escala de análisis que se utiliza: las comunidades locales y, en algunos casos, por la calidad de la información existente, se eleva el análisis a la circunscripción político-administrativa más cercana.

Para organizar los elementos que son parte del análisis se priorizaron los servicios ecosistémicos que son más relevantes en las diez AP consideradas en ambos paisajes. Tomando como referencia el texto How much is an ecosystem worth? Assessing the economy value of conservation (Banco Mundial, et al. 2014), se espera comprender cómo los costos y beneficios de las acciones de conservación llevadas a cabo por las AP se distribuyen como impactos económicos, sociales y culturales en la población local.
Se toma la perspectiva de las comunidades locales para comprender la forma de distribución de costos y beneficios ya que, a esta escala, es posible comprender una porción de los impactos que generan las AP. La priorización de servicios ecosistémicos se realiza considerando que no todos los SE que provee un ecosistema se aprovechan a escala local, sino que trascienden los espacios delimitados por las personas y se convierten en beneficios para el ecosistema, el paisaje o el bioma

Los SE priorizados en este análisis son los servicios de aprovisionamiento y los servicios culturales. Esta priorización permite delimitar con más precisión la escala de análisis, aunque también impide que se pueda diferenciar claramente qué pertenece a uno u otro servicio. Por ejemplo, ¿cómo clasificar a las chacras de los pueblos indígenas si cumplen a la vez una función de aprovisionamiento y de reproducción de formas culturales propias?

Esta dificultad puede ser superada en la medida en que se comprenda que los elementos que se analizan tienen esta doble función: una actividad de aprovisionamiento también está asentada sobre bases de conocimiento cultural e histórico al igual que una actividad cultural puede generar ingresos económicos en una comunidad específica.

Dicho esto, la priorización y división que se realiza para el presente análisis es metodológica: busca comprender de manera separada elementos que, en la vida cotidiana de las poblaciones locales, están imbricados y se alimentan unos a otros.

\begin{tabular}{|c|c|}
\hline Servicios Ecosistémicos & Categoría de análisis \\
\hline \multirow{6}{*}{ Servicio de aprovisionamiento } & Agricultura \\
\hline & Pesca \\
\hline & Caza \\
\hline & Ganadería \\
\hline & $\begin{array}{l}\text { Aprovechamiento de productos forestales no maderables } \\
\text { (PFNM) }\end{array}$ \\
\hline & Aprovechamiento de productos forestales maderables (PFM) \\
\hline \multirow{2}{*}{ Servicios culturales } & Turismo \\
\hline & Investigación científica \\
\hline
\end{tabular}




\section{Consideraciones metodológicas}

Para el análisis de costos y beneficios económicos e impactos sociales y culturales derivados de la creación y mantenimiento de las AP, se aborda el proceso de creación de las AP para dar cuenta de los cambios que ha supuesto el antes y después de la declaratoria y cómo esto se traduce en impactos directos en las formas de aprovechamiento de los recursos de los bosques amazónicos y en la canalización de recursos económicos (a través de las jefaturas de las AP) para el desarrollo local.

Después, se discute sobre el proceso de operación de las AP para dar cuenta de las formas diferenciadas de aprovechamiento de bienes y servicios ecosistémicos y cómo las diferentes formas de aprovechamiento, según las categorías de manejo de las AP, generan costos y beneficios económicos para las poblaciones locales.
Impactos identificados

La identificación de impactos de las AP sobre las poblaciones locales -indígenas y mestizas - se realizó en función de la atribución de causalidad que se puede derivar de la implementación de políticas de conservación y uso sostenible del territorio, vinculada a la creación y funcionamiento del AP. La atribución de causalidad hace referencia a la identificación de una causa para un fenómeno observable. Para este caso, los impactos de las AP sobre las poblaciones locales se constituyen en la explicación de "fenómenos observables" en la creación y funcionamiento de las AP, que requieren ser interpretados para dar cuenta de sus efectos o consecuencias (deseadas y no deseadas)

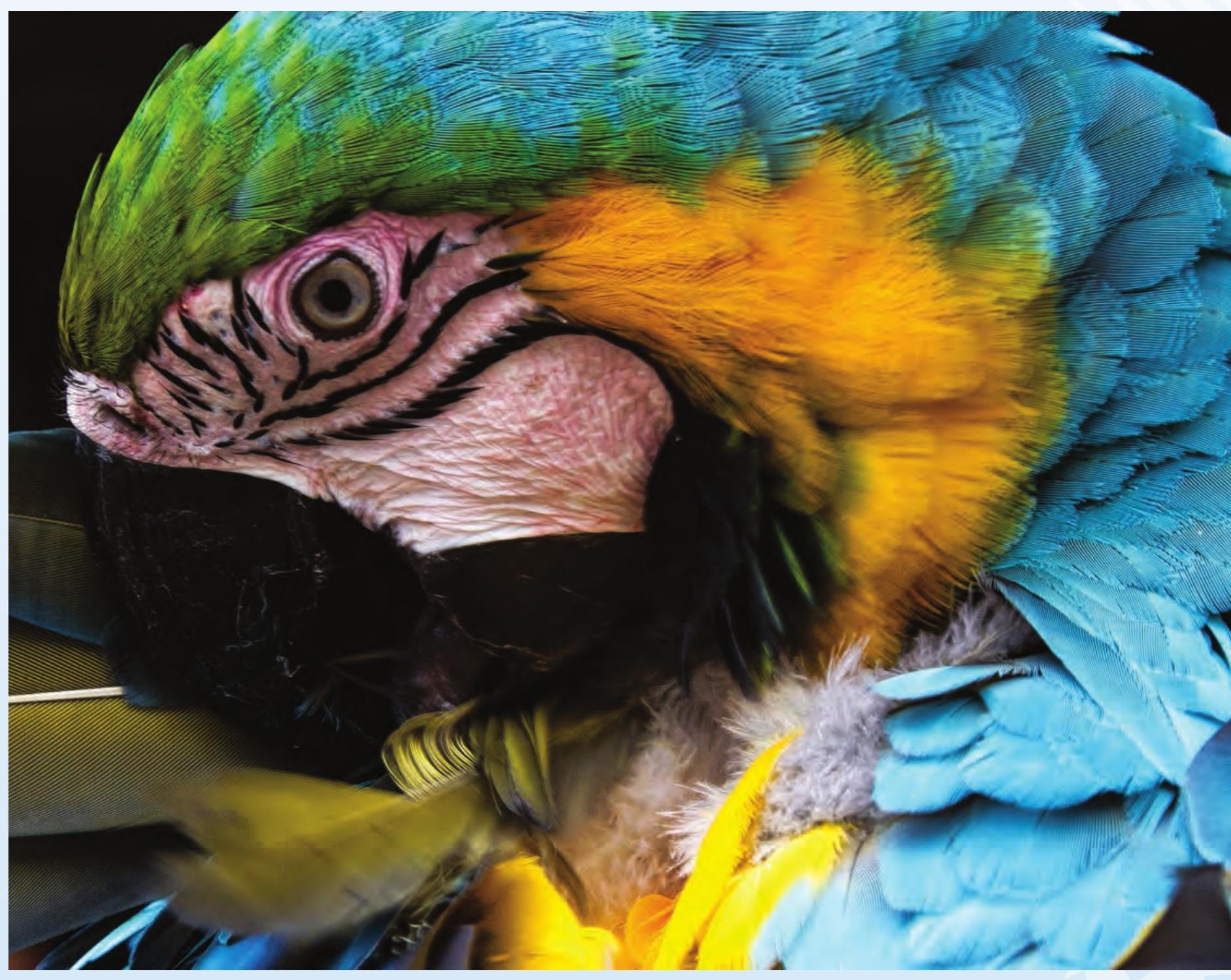


A continuación, se presenta una sistematización de los impactos identificados para todas las AP que fueron consideradas. La intensi- dad del impacto y sus efectos es diferente en cada AP y esta explicación se realizará en el siguiente apartado.

\begin{tabular}{|c|c|c|c|}
\hline Fase & Fenómeno observable & Impacto & Valoración \\
\hline \multirow[b]{2}{*}{ Creación } & \multirow[b]{2}{*}{$\begin{array}{l}\text { Políticas públicas e inversión } \\
\text { económica enfocada en la } \\
\text { conservación de servicios } \\
\text { ecosistémicos. }\end{array}$} & $\begin{array}{l}\text { Posibilidad de construcción } \\
\text { de agendas de gobernanza } \\
\text { desde marcos culturales/ e } \\
\text { históricos propios. }\end{array}$ & Beneficio \\
\hline & & $\begin{array}{l}\text { La creación de las AP significó } \\
\text { para las poblaciones locales } \\
\text { un cambio radical en la } \\
\text { forma de aprovechamiento } \\
\text { económico de los recursos } \\
\text { naturales de la Amazonía. } \\
\text { Esto se transversaliza a todo } \\
\text { el proceso de funcionamiento } \\
\text { del AP. }\end{array}$ & $\begin{array}{l}\text { Costo de } \\
\text { oportunidad }\end{array}$ \\
\hline \multicolumn{4}{|c|}{ Servicios ecosistémicos de aprovisionamiento } \\
\hline \multirow{4}{*}{ Funcionamiento } & \multirow{2}{*}{$\begin{array}{l}\text { Estímulo de actividades } \\
\text { agrícolas sostenibles (de } \\
\text { autosustento). }\end{array}$} & $\begin{array}{l}\text { Modificación del } \\
\text { aprovechamiento de recursos } \\
\text { del territorio con criterios de } \\
\text { sostenibilidad (restricciones } \\
\text { para la apertura de chacras, } \\
\text { actividades de caza y pesca, } \\
\text { uso de barbechos, etc.) }\end{array}$ & Costo \\
\hline & & $\begin{array}{l}\text { Inversión para capacitación y } \\
\text { ejecución de emprendimientos } \\
\text { productivos, lo que ha } \\
\text { generado empleo remunerado } \\
\text { y no remunerado. }\end{array}$ & Beneficio \\
\hline & \multirow[b]{2}{*}{$\begin{array}{l}\text { Aprovechamiento } \\
\text { controlado de productos } \\
\text { forestales. }\end{array}$} & $\begin{array}{l}\text { Posibilidad de emprendimiento } \\
\text { de procesos productivos para } \\
\text { comercialización de productos } \\
\text { agrícolas y del bosque, de } \\
\text { manera sostenible. }\end{array}$ & Beneficio \\
\hline & & $\begin{array}{l}\text { Regulación de actividades } \\
\text { de aprovechamiento de } \\
\text { materiales del bosque } \\
\text { mediante normativas que } \\
\text { exigen características } \\
\text { mínimas para estas } \\
\text { actividades. }\end{array}$ & $\begin{array}{l}\text { Costo en permisos } \\
\text { (lo asumen ONG) }\end{array}$ \\
\hline \multicolumn{4}{|c|}{ Servicios ecosistémicos culturales } \\
\hline \multirow{2}{*}{ Funcionamiento } & $\begin{array}{l}\text { Desarrollo de actividades } \\
\text { turísticas. }\end{array}$ & $\begin{array}{l}\text { Generación de ingresos } \\
\text { económicos para las } \\
\text { poblaciones locales. }\end{array}$ & Beneficio \\
\hline & $\begin{array}{l}\text { Desarrollo de actividades de } \\
\text { investigación. }\end{array}$ & $\begin{array}{l}\text { Dinamización de la producción } \\
\text { de conocimientos sobre las AP } \\
\text { y sus bienes y servicios. }\end{array}$ & Beneficio \\
\hline
\end{tabular}




\section{Consideraciones metodológicas}

Esta identificación de impactos se ha realizado en base a dos elementos: la perspectiva de las poblaciones locales que aportaron a este análisis a través de su participación en entrevistas y la perspectiva técnica, desde las herramientas de investigación y valoración de servicios ecosistémicos y su aprovechamiento. Es importante recalcar que esta no es una evaluación de servicios ecosistémicos, pero se toman como referencia para dar cuenta de la relación entre ecosistema y población local.

\section{Valoración de costos y beneficios económicos}

La valoración de costos y beneficios económicos se realiza para visualizar, en lenguaje monetario, las formas en que se manifiestan costos y beneficios para las poblaciones que habitan o están relacionadas con las áreas protegidas. Esta valoración se realiza a través de la referencia de precios de mer- cado para aquellos elementos que pueden ser monetizados. Para los que no pueden ser monetizados se realiza una valoración cualitativa, resaltando la importancia local que existe sobre aquello que se está valorando.

Las valoraciones de los costos o beneficios económicos dependen de que se generen restricciones de uso o aprovechamiento de los servicios ecosistémicos priorizados para este análisis. Esto supone que, en función de las preferencias, intereses y restricciones existentes sobre el uso y el control de los servicios ecosistémicos, a la población local le supone un costo o un beneficio económico.

Para esta evaluación se utilizan las siguientes valoraciones: valor de uso directo, costos evitados, costos directos por implementación de medidas de conservación y costos de oportunidad para bienes que no se extraen o no se utilizan actualmente.

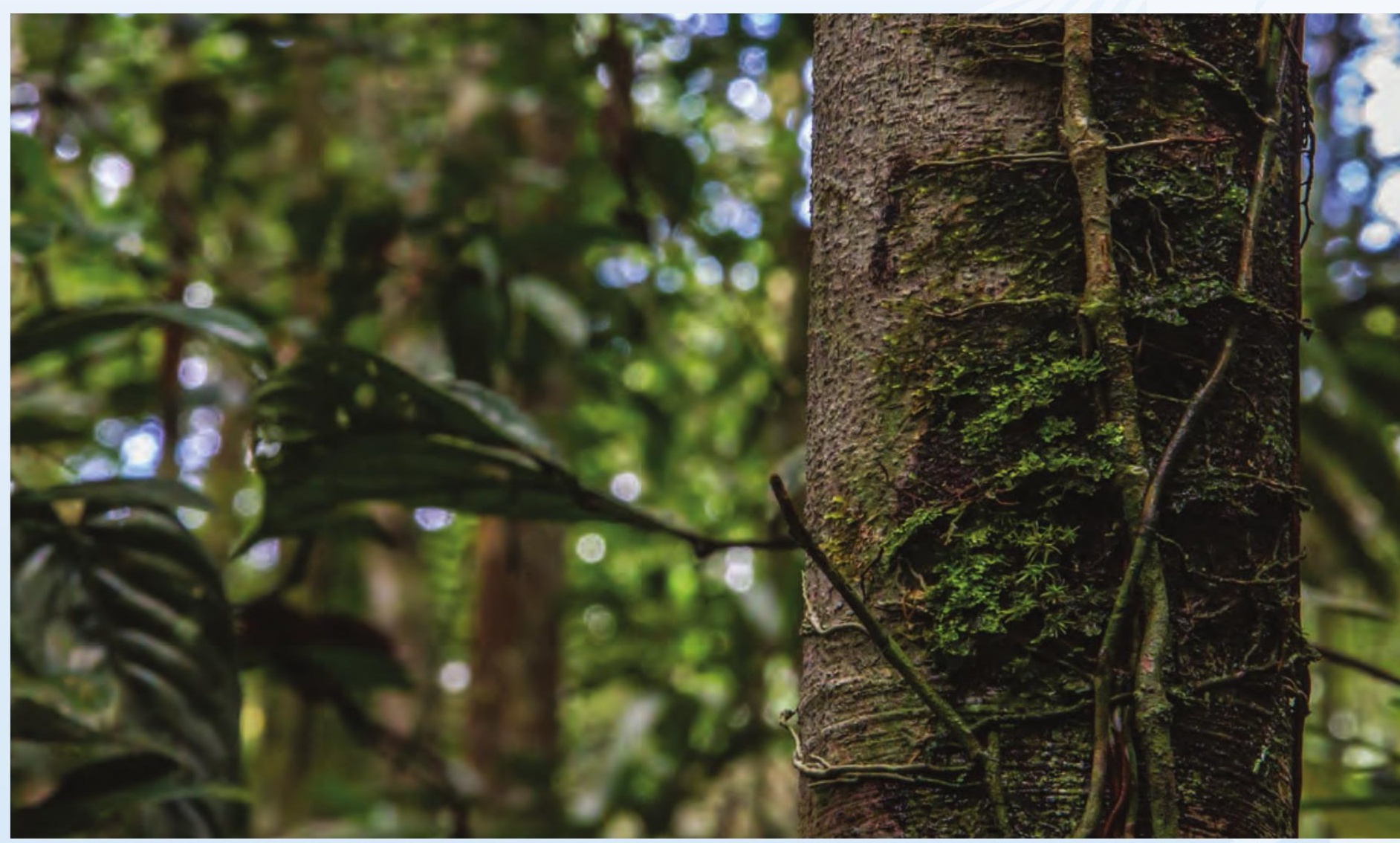




\section{Impacto por la creación de}

las áreas protegidas

fomento del retorno a sistemas agrícolas tradicionales y en el análisis de la economía para insertarse en circuitos de mercado que permitan la comercialización de los productos que se producen en las comunidades.

En el PNN La Paya, la negociación de proyectos y la gestión de la gobernanza se ha realizado sobre la base de una estructura cultural local: el espacio de mambeo, al que se ha hecho referencia en apartados anteriores Este es un espacio de toma de decisiones políticas tradicional, que apunta hacia el diálogo y la eliminación de la confrontación, generando confianza. La base de esta actividad es que se "haga amanecer la palabra" cumpliendo lo que se dice y acoplando las actividades a la realidad de las comunidades. Es una forma de negociación circular, no lineal, lo que permite superar la visión de proyecto con un inicio y un fin, donde en cada vuelta del proceso se retroalimenta de un proceso de construcción colectiva.

En esta construcción, el principal objetivo ha sido revalorizar las culturas locales del PNN La Paya y generar procesos que permitan el desarrollo cultural (pero también económico) de la población local. En estos procesos se ha identificado que falta estructuración en las cadenas productivas de comercialización y transformación de lo que se produce, para que pueda existir una venta directa y así obtener un valor agregado.

Es importante considerar que existen elementos que permiten comprender la gobernanza local de este parque nacional y las posibilidades de intervención en el territorio, tanto de la población local como de la jefatura del parque: el conflicto armado y los cultivos de uso ilícito. Estos elementos han impedido que se realicen mayores intervenciones productivas en el territorio

El caso de la RPF Cuyabeno, antes de su declaratoria como AP, también enfrentaba problemas de tala de madera y de comercio de fauna silvestre y pieles. Otro problema que existía antes de la declaratoria es que ingresaban pescadores de otros lugares en busca del paiche (Arapaima gigas), lo que afectaba a la población local, ya que sus recursos se veían reducidos sensiblemente.

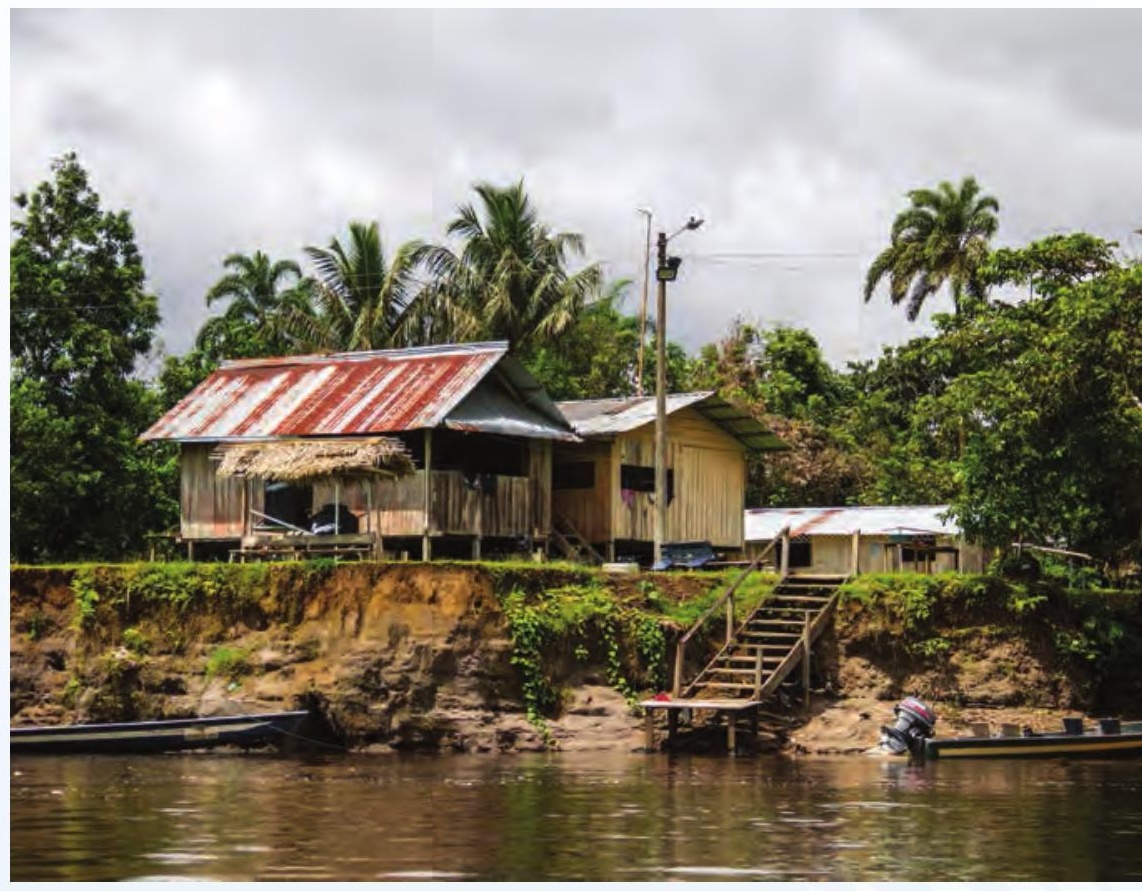

El trabajo de construcción de gobernanza en esta AP fue liderado por la jefatura de la RPF Cuyabeno y el motivo que hizo dialogar a los diferentes actores fue el proceso de linderación del territorio. Este proceso fue pionero entre las AP ecuatorianas y logró generar consensos sobre las formas de aprovechamiento del territorio y de los recursos que aquí se encuentran

Esta diferencia entre el antes y el después de la creación del AP y el proceso de gobernanza liderado por la jefatura de esta área ha beneficiado a las comunidades locales, que ven los beneficios de vivir en un área protegida a través del aprovechamiento turístico que aquí se realiza. En la actualidad, con la presencia de la jefatura, hay un mayor control del área en temas de conservación, lo que ha sido importante para el control de las actividades de caza y pesca y, también, para el control de las actividades turísticas.

En el PN Alto Purús y en la RC Purús, según los testimonios de las personas entrevistadas, antes de la declaratoria de estas dos AP el contexto era muy diferente. Entraban personas de otros lugares o personas de las mismas comunidades a aprovechar los recursos del bosque, pero sin criterios de sostenibilidad. En estas dos AP muchas veces ingresaban a la fuerza personas externas para extraer recursos, principalmente madera y pescado. 
Las personas (los patrones madereros) que ingresaban a las AP para aprovechar la madera, fiaban a los habitantes de las comunidades locales tanto comida como cartuchos de escopeta, creando círculos de endeudamiento continuo para los pobladores de estas zonas y pagando lo mínimo por el aprovechamiento de la madera. La pesca, sobretodo en la RC Purús, ocurría sin ningún tipo de control o permiso, por lo que los recursos se manejaban de manera irracional. Similar fue el caso de las tortugas charapas, taricayas y motelos, las cuales desaparecieron de la zona.

Con la creación de las áreas protegidas PN Alto Purús y RC Purús, se generaron procesos que fortalecieron el control y vigilancia del aprovechamiento de los recursos del bosque. A través de estos procesos, la gobernanza local se afianzó en la relación de colaboración entre las jefaturas de las AP y las comunidades, en contra del ingreso de personas extrañas al territorio, rompiendo así los círculos de endeudamiento, los enfrentamientos entre comunidades y con madereros o pescadores.

El cambio fundamental se encuentra en que la población local de estas dos AP peruanas reconoce que el control de aprovechamiento de recursos se ha incrementado, por lo que las poblaciones de fauna también se han in-

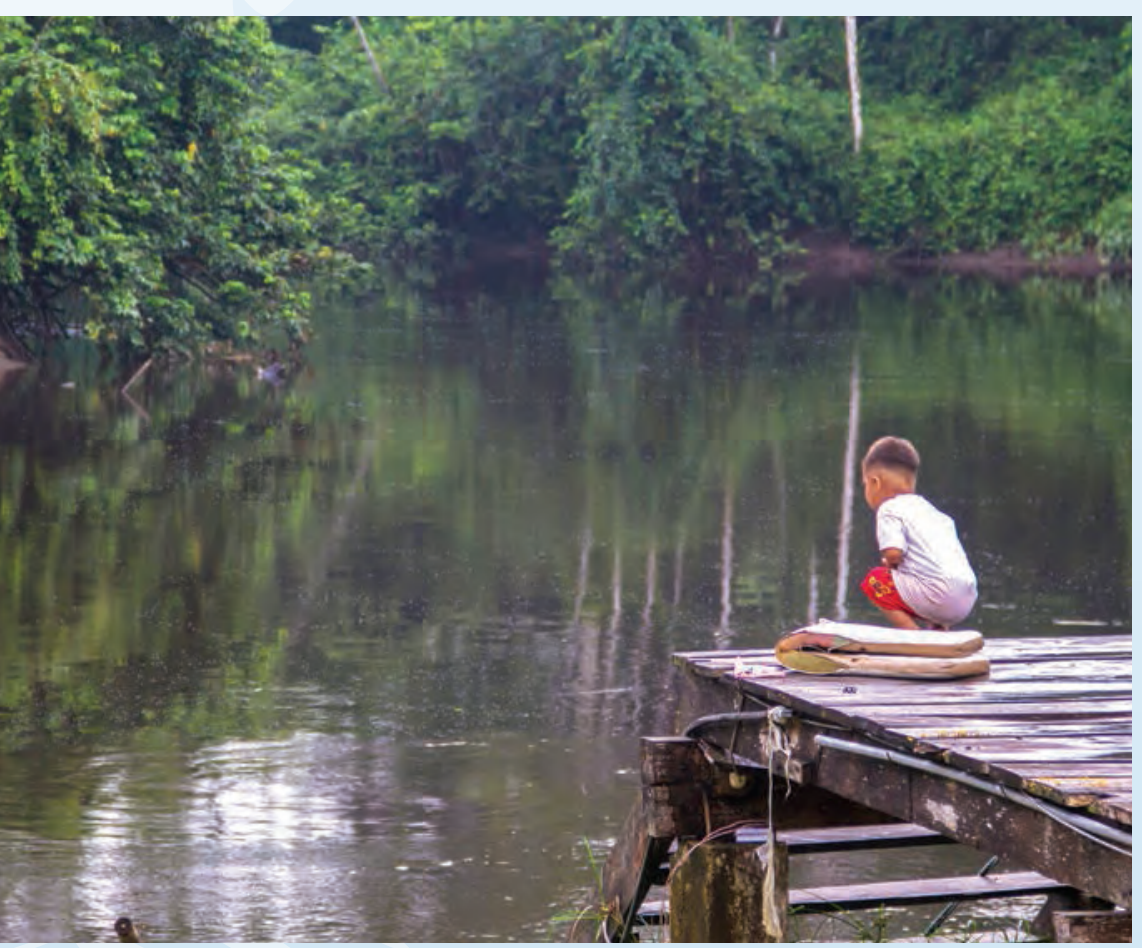

crementado en espacios cercanos a las AP. Además, ahora, para la venta de productos forestales maderables y no maderables del bosque, según la normativa forestal de Perú y su reforzamiento por las jefaturas de estas dos AP, se requiere hacer planes de manejo, lo que permite asegurar la sostenibilidad de las actividades que se realizan. En estos planes de manejo participan las comunidades locales de las dos AP y son las principales beneficiarias del aprovechamiento sostenible de madera.

En la RNVSA Manuripi, el proceso de construcción de gobernanza ha estado vinculado, de manera principal, a la regulación de la extracción de la castaña, enfocada en detener el crecimiento de la propiedad de las barracas privadas; lograr la sustentabilidad del aprovechamiento de la castaña en los territorios comunitarios; y normar las consecuencias de los procesos de zafra: la caza intensiva de fauna silvestre. Un avance importante en este proceso ha sido el proceso de certificación orgánica de la castaña para lograr mejores precios en el mercado.

En el PE Chandless, la construcción de gobernanza se ha realizado a partir de la necesidad de normar el uso de los recursos naturales del AP con la población que habita en su interior. Además, ha sido necesario generar diálogo y acuerdos entre las familias que viven dentro del parque y las familias de las tierras indígenas vecinas.

Un impacto positivo importante que ha recibido la población a partir de la declaratoria del AP se vincula con la imposibilidad actual de que ingresen personas para aprovechar o adueñarse del territorio. Antes de que esta zona fuese parque estadual era de propietarios privados que compraban y vendían la tierra, por lo que la población estaba sujeta a desalojos. En la actualidad, a través de la gestión del AP, la población que vive en Chandless tiene claridad sobre el aprovechamiento de los recursos y sobre la posesión de sus tierras.

La RESEX Cazumbá-Iracema inicia su proceso de declaratoria desde el año 1998 e inicia su proceso de gobernanza local a partir de la interrupción del proceso de ordenamiento territorial del INCRA, ya que este proceso iba en contra de la forma de organización territorial 


\section{Impacto por la creación de las áreas protegidas}

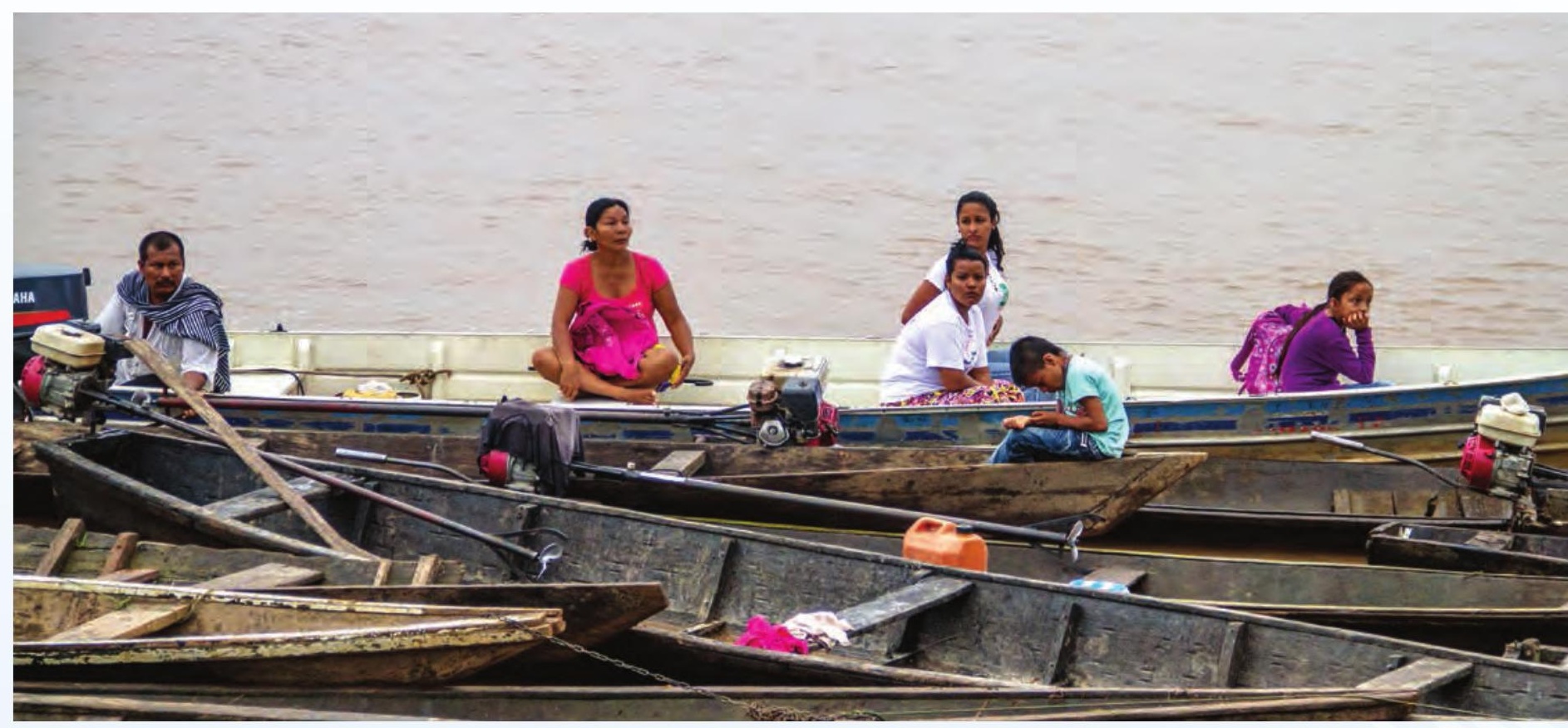

cultural e histórica de la población de la zona que se construía a partir de las estradas de seringa, que se organizan de acuerdo al aprovechamiento de los árboles de caucho, la ubicación de las chacras y las casas de fariña.

Con la creación del AP, la población de la RESEX Cazumbá-Iracema aseguró que su forma tradicional de ordenamiento del territorio se incluya en la forma de ordenamiento estatal de las AP e impidió el avance de la frontera agrícola a través de la linderación de unidades productivas individuales, que era uno de los objetivos del INCRA.

A partir de todos estos procesos de construcción de gobernanza local, se ha afianzado parte del bienestar y desarrollo de los pueblos indígenas y mestizos que viven en estas AP. Siguiendo la Declaración de Kimberley (2002) -en la que se priorizan líneas temáticas que hacen énfasis en la visión de bienestar y desarrollo de los pueblos indígenas - se puede enlazar un impacto importante de las AP para las poblaciones locales. La Declaración de Kimberley prioriza:

- El control sobre las tierras y territorios indígenas, base espiritual y material de la existencia indígena.

- El respeto y la conservación del medioambiente.
- El reconocimiento y el respeto a la identidad y a las culturas indígenas desde una visión pluricultural.

- La participación (...) que incluye la incorporación de la perspectiva indígena en las decisiones que se toman a nivel nacional e internacional (Renshaw y Wray, 2004:2)

Con diversa intensidad, en cada una de las áreas analizadas, uno de los principales impactos de la declaratoria de las AP para las poblaciones locales es el alcance generado, de manera progresiva, en conquistas sobre el territorio y sobre espacios de toma de decisiones. Esto asegura espacios de vida para la población y, de esta manera, se rompen relaciones asimétricas de poder (patrones del caucho, de la madera, comerciantes de pieles, entre otros) que, aunque en ciertos momentos permitían ingresos monetarios para la población, la mantuvieron en incertidumbre sobre la propiedad de la tierra y los recursos de los bosques.

Si bien la declaratoria de estas AP ha sido un beneficio para las poblaciones locales a través del avance en la construcción de gobernanza territorial local desde perspectivas tradicionales, el proceso mismo de gobernanza ha significado un cambio radical en las formas de aprovechamiento económico de los recursos naturales. 


\section{Modificación del aprovechamiento económico de los recursos del AP}

Si antes de la creación de las AP cualquier persona podía ingresar a aprovechar los recursos, la creación de las AP genera una serie de lineamientos y normativas que regulan con mayor intensidad las actividades que las poblaciones locales realizan así como el ingreso a las AP y territorios comunitarios. Esto modifica el aprovechamiento directo de los recursos del bosque.

Todas las AP analizadas tienen ahora restricciones de aprovechamiento forestal, caza y pesca, es decir, la población de las AP no puede aprovechar los recursos como lo hacía en años anteriores, con fines comerciales. Antes de la declaratoria de las AP, los principales ingresos de los hogares estaban relacionados con actividades de extracción de recursos del bosque: animales de caza, pieles, pescados y maderas, siendo la agricultura una actividad más enfocada al autosustento. Con la declaratoria de las AP, estos ingresos económicos son severamente disminuidos y las fuentes principales de ingreso de la población pasan a ser las actividades agrícolas y proyectos de uso sostenible de los recursos, más relacionados con su forma de vida ancestral.

Pero ¿cuál es la diferencia entre las fuentes de ingresos de la población local de las AP, antes y después de la declaratoria? Esta diferencia se puede analizar desde algunos ángulos: el aprovechamiento individual frente al aprovechamiento comunitario, el sentido común de la población local, las fuentes de financiamiento de las actividades y el acceso a los mercados.

El proceso de aprovechamiento sin control de los recursos del bosque antes de las declaratorias de las AP estaba definido por características individuales de las personas que habitaban estos territorios: la capacidad de caza, el conocimiento del bosque y su acceso a herramientas o armas. Estas actividades podían realizarse, en términos generales, en cualquier momento según las necesidades del hogar y suponían un ingreso seguro, ya que pieles, carne de monte y madera son bienes que siempre tienen mercados asegurados. En caso de que la persona conociera el bosque, pero no tuviera herramientas o armas, los habilitadores ${ }^{194}$ estaban siempre dispuestos a financiar estas actividades a cambio de la repartición de las ganancias de los productos extraídos y, aunque esta repartición no fuera justa para la persona que realizara la actividad, era una forma de acceso al dinero que le permitía sostener el hogar y realizar inversiones en sus unidades productivas.

La sostenibilidad de estas actividades no era evaluada por la población local ya que, el sentido común de la población amazónica siempre ha estado vinculado a la abundancia y a que la provisión de recursos del bosque está desligada de la intervención humana ${ }^{195}$.

En este contexto zalgún poblador local de la Amazonía, hace treinta años, podía suponer que las guanganas u otras especies, animales o forestales se acabarían? Además, la forma en que la Amazonía se ha articulado a los circuitos de mercado y la manera en que la población local ha generado ingresos monetarios para los hogares se han realizado, históricamente, a través del uso intensivo de los recursos del bosque, por las dinámicas desiguales en zonas que se han caracterizado por ser comercializadoras de bienes primarios.

Con la declaratoria de las AP, la población local ha visto modificadas sus formas de aprovechamiento de recursos y ha debido modificar los productos que ofertan en el mercado, suponiendo un impacto significativo. Al no tener la posibilidad de extraer recursos del bosque para comercializar como se hacía antes, las chacras, que servían para el autosustento del hogar, reciben la presión de ser la fuente de ingresos de la familia. Por ello, se convierten en "unidades productivas", lo que implica que estos espacios ya no deben solamente proveer recursos alimenticios diversos para el hogar (con un componente de reproducción cultural), sino que también deben ser espacios de

194. Personas que cuentan con capital para invertir en actividades productivas. En el contexto de este análisis, los habilitadores han estado vinculados a los procesos de caza y aprovechamiento forestal, prestando dinero a la población local, generando círculos de endeudamiento. En la producción de castaña, en Manuripi, todavía existen habilitadores

195. Para profundizar la comprensión sobre cosmovisiones amazónicas y su visión de los recursos naturales, revisar: Sahlins, 1974 
Impacto por la creación de las áreas protegidas

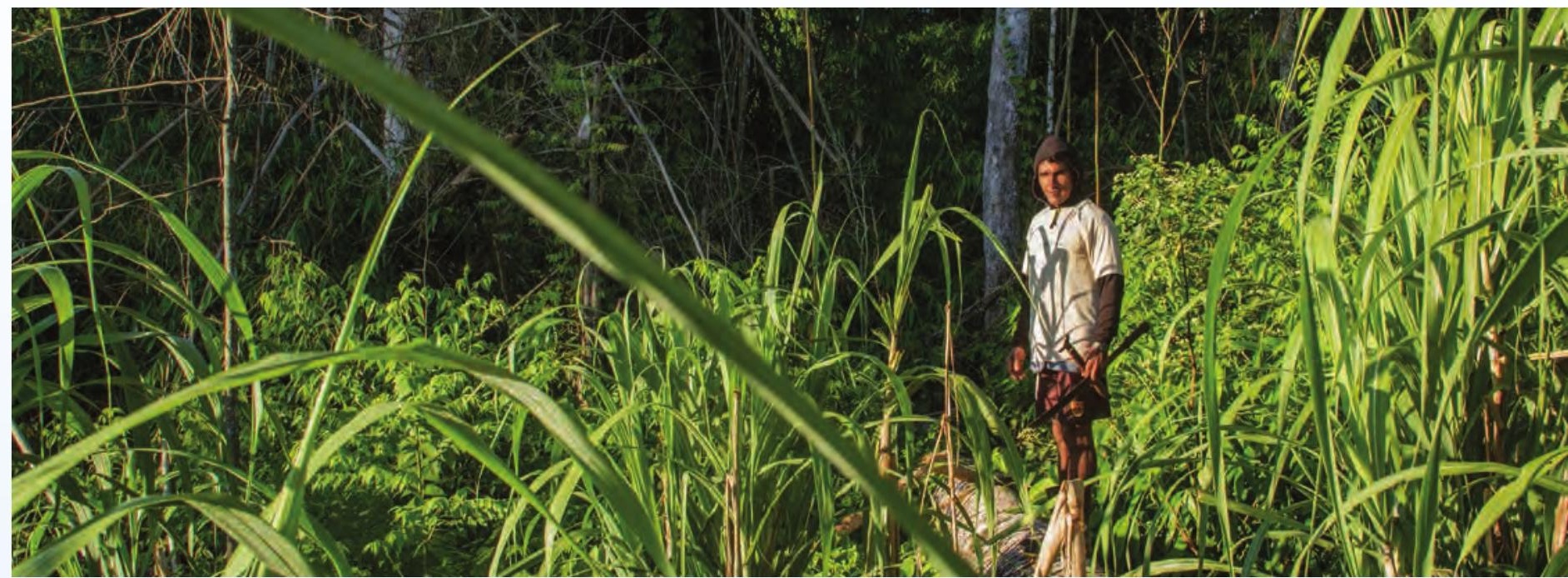

producción de mercancías que sean recibidas por el mercado.

Aunque este cambio en el uso productivo de las chacras puede tener varias fuentes, por ejemplo, el cambio de las necesidades de las poblaciones locales o el contacto con otras formas de producción, no se debe desconocer que la declaratoria de las AP ha generado modificaciones en las formas productivas y de conexión con los mercados de la población de las AP. Cabe destacar que la mayoría de entrevistados en este estudio reconocieron la disminución de la diversidad de las chacras de autosustento cuando tuvieron que vincularse al mercado de productos agrícolas.

En este contexto, las chacras que se mantienen dentro de las AP han sufrido un impacto por la declaratoria y su funcionamiento y la población ha debido intensificar la producción de alimentos que pueden ser comercializados. Este impacto ha afectado, de manera directa, a la biodiversidad tradicional en las chacras amazónicas ya que es necesario incrementar, en las superficies que permite el AP, la producción de especies que puedan ser comercializadas en los mercados locales, en detrimento de otros productos de consumo familiar.

Además, las actividades de caza y pesca también han tenido un impacto: han disminuido y quedan restringidas a ser realizadas, de manera exclusiva, como actividades de autoabastecimiento del hogar. Esto, aunque evita gastos en el hogar, no genera ingresos monetarios. En algunos casos, la población aprovecha los cupos establecidos de autoabastecimiento para comercializar carne de monte y pescado lo que les permite tener ingresos monetarios que permiten cubrir ciertas necesidades del hogar. Sin embargo, estas actividades, aunque en ocasiones necesarias, son ilícitas.

Todas estas restricciones, en términos económicos, se convierten en costos de oportunidad que han sido asumidos por la población local de las AP, siendo el resultado de esta modificación un impacto para los ingresos de las poblaciones locales. Los costos de oportunidad están relacionados con la elección de una actividad sobre otra y la pérdida económica que se deriva de esta decisión.

En el caso de la población local de las AP, el impacto económico está relacionado a los costos de oportunidad. El costo de oportunidad que han asumido, sin que necesariamente lo hayan elegido, es lo que dejan de ganar con las restricciones de aprovechamiento que generan las normativas asociadas a las categorías de manejo de las AP. Por este motivo, después de la creación de estas áreas, las poblaciones locales reconocen los avances que han tenido en temas de gobernanza y capacidad de decisión sobre su territorio, la defensa y protección de fauna para su autoconsumo (que en otros lugares ya no está presente), la calidad de vida superior a la que se puede tener en las ciudades por el contacto con la naturaleza $y$, en los casos que corresponde, la posibilidad de mantener sus saberes ancestrales y prácticas cotidianas propias. Sin embargo, aún se preguntan ¿Cuál es el beneficio económico que obtenemos? 


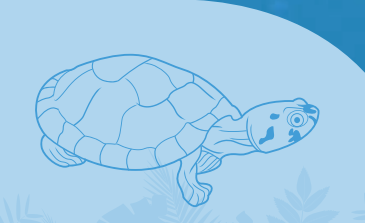

Las actividades de aprovechamiento sostenible que impulsan las directivas de las AP están relacionadas con la apertura de nuevas opciones productivas sostenibles para que la población genere beneficios económicos a partir de la creación y funcionamiento de las AP. Estas actividades suponen nuevos retos para la población: la organización comunitaria para acceder a permisos de aprovechamiento de recursos y a capacitaciones para realizar estas actividades de manera sostenible; la búsqueda de canalización de inversiones económicas para iniciar los proyectos; el empoderamiento de toda la población hacia estos; y la paciencia para esperar mientras permisos y conocimientos se ajustan hasta que la iniciativa empiece a producir.

Otros elementos que se tornan en retos para lograr la comercialización de la pro- ducción de las AP son externos, pero influyen sustancialmente; por ejemplo, la distancia con los mercados, las cadenas de comercialización y el precio de los combustibles para el transporte de la producción, las brechas culturales y el rol de los mercados, que continúan siendo, de forma mayoritaria, regulados por los principios del libre mercado. Pocos son los espacios que se han abierto para procesos de comercio justo que permitan mejorar las condiciones económicas de las poblaciones locales de las AP.

En este ámbito, la RNVSA Manuripi ha tenido un gran avance con la certificación orgánica de la castaña, al igual que la Reserva de Producción de Fauna Cuyabeno, con el apoyo al comercio justo a través de procesos de producción orgánica de café y cacao.

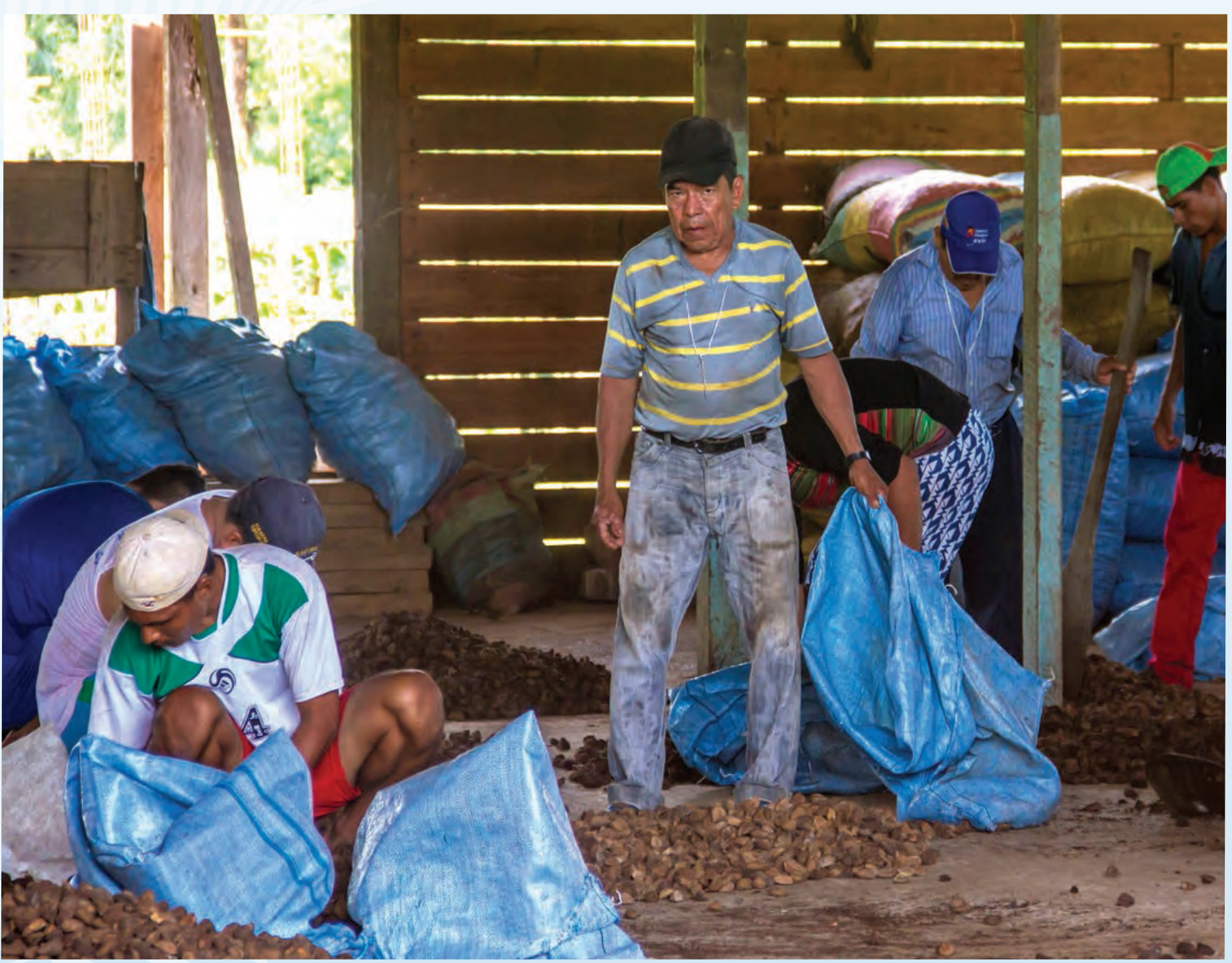


Impactos por el funcionamiento de las áreas protegidas

El funcionamiento de las áreas protegidas implica una gestión continua del territorio a partir de las normativas de uso (planes de manejo, acuerdos comunitarios, entre otros instrumentos). Se pueden identificar los siguientes impactos para las poblaciones locales:

- Modificación del aprovechamiento de recursos del territorio con criterios de sostenibilidad

- Estímulo de procesos productivos para el aprovechamiento sostenible y la comercialización de productos del bosque, que abarca también el control ambiental de las actividades productivas que se realizan y las inversiones para capacitación y ejecución de emprendimientos productivos.

Es importante considerar cómo se realiza la siguiente descripción de los impactos por el funcionamiento de las AP. Primero se observa cómo, por criterios de sostenibilidad, las AP han modificado actividades que no tienen relación con la operación del $A P$, pero que reciben impactos: las formas en las que se aprovechaban antes los recursos y los cambios que han operado en las actividades que antes se hacían sin ninguna restricción.

Después se analiza cómo se "mitigan" estos impactos a través del impulso hacia nuevas actividades productivas sostenibles que buscan el aprovechamiento económico con criterios de sostenibilidad.

Este análisis se realiza a través de la construcción de modelos típico-ideales para dar cuenta de las formas en que se gestiona la economía de las familias de las áreas protegidas.
"Un tipo ideal es un recurso para comprender mejor los fenómenos sociales y consiste en la composición de un modelo, deliberadamente exagerado, de un conjunto de rasgos o factores que parecen detectarse en procesos análogos de diferentes culturas o en diversos periodos históricos de una misma civilización. (...) Un tipo ideal nunca se corresponde exactamente con ninguna realidad histórico-social, pero permite ayudar a entender interacciones e instituciones sociales" (Weber, 2007: 179).

\section{Modificación del}

aprovechamiento de recursos

del territorio con criterios de sostenibilidad ${ }^{196}$

El impacto por la modificación del aprovechamiento de recursos en los territorios declarados como AP - a partir de criterios de aprovechamiento sostenible- se da a partir de las restricciones que se generan por las categorías de manejo. La categoría de manejo "parque nacional" modifica el aprovechamiento restringiendo su uso. En este caso algunas AP son excepción, por ejemplo, el PE Chandless, por tener en su interior once

\footnotetext{
196. Se presentan los datos de las AP, de manera conjunta, ya que las actividades de las poblaciones son muy similares y no se requiere realizar una diferenciación entre las AP del paisaje norte y del paisaje sur.
}

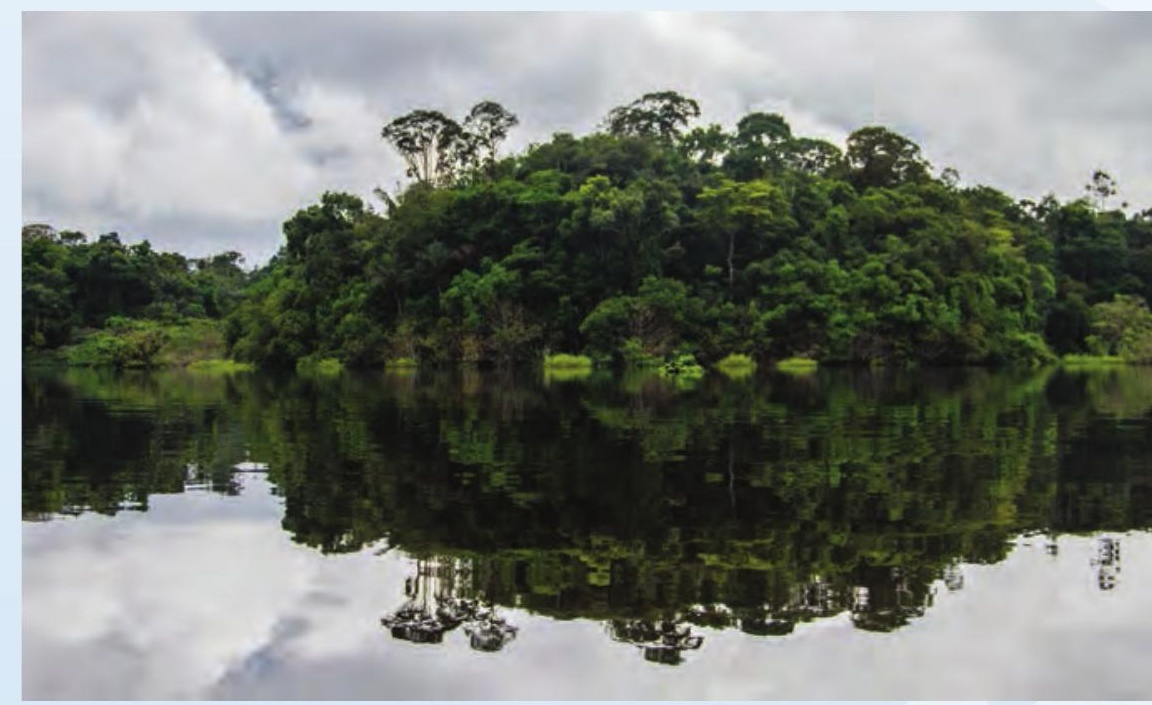


familias a las que se permite un aprovechamiento sostenible de los productos del bosque, al igual que el PNN La Paya, donde viven familias -en las riberas del río Caucayá- con las que se tiene un proceso sostenido para relocalizarlas en sectores fuera del parque. En el PN Alto Purús solamente vive población mashco piro en situación de aislamiento voluntario.

Las categorías de manejo "áreas de gestión de hábitats/especies" y "áreas protegidas con uso sostenible de los recursos naturales" -que permiten un aprovechamiento controlado de los recursos y en las que se encuentran las demás AP consideradas- generan restricciones sobre la intensidad de las actividades. De esta manera el impacto de las AP sobre las poblaciones locales se manifiesta en restricciones sobre el uso del suelo, el aprovechamiento de frutos del bosque y la caza y pesca, como es el caso de la Reserva de Producción de Fauna Cuyabeno, la Reserva Comunal Purús, las Reservas Comunales Airo Pai y Huimeki y la Reserva de Vida Silvestre Amazónica Manuripi.

Sobre el uso del suelo, el principal impacto es la limitación al crecimiento de las chacras y la posibilidad de ampliar/abrir potreros para ganado. Este impacto afecta directamente a la posibilidad de generar ingresos económicos para los hogares que viven dentro de las AP ya que, al ser las chacras el nuevo espacio

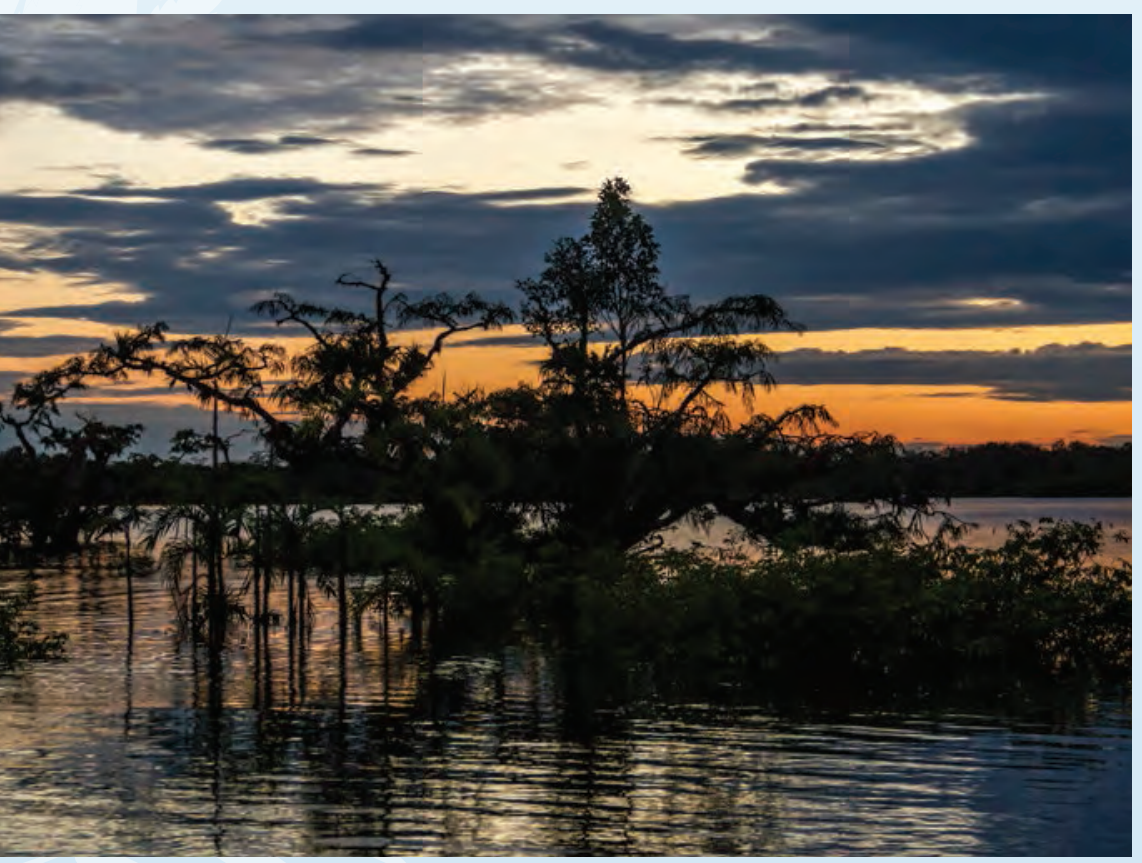

productivo de la familia para producir y vender -y, por tanto, para generar ingresos económicos- y al no poder extender las unidades productivas, no es posible aumentar los ingresos económicos a través de esta actividad ${ }^{19}$

Además, la declaratoria de las AP ha generado un cambio en la economía de la población local: lo que antes era una ganancia económica por comercialización de fauna silvestre y productos forestales maderables y no maderables se convierte en un costo evitado por el consumo para autosustento que realiza la población local de los productos del bosque. Sin embargo, ha supuesto una pérdida de ganancias económicas inmediatas. Las ganancias actuales de la población de las AP se han diversificado y están vinculadas a agricultura y al desarrollo de proyectos de aprovechamiento sostenible de los recursos naturales del bosque.

Uno de los ingresos de la población local de las AP es la venta de los excedentes productivos de las actividades agrícolas que se desarrollan para el autoabastecimiento del hogar $y$, aunque esta actividad no tiene relación directa con la gestión del $A P$, sí existe una relación con la forma de uso del suelo que se realiza dentro de las AP.

En el PNN La Paya, las actividades agrícolas se mantienen en la chacra, que tiene entre una y dos hectáreas y donde se producen alimentos como: plátano, yuca, papaya, cilantro, piña, copoazú, papaya y guanábana, cuyos excedentes se comercializan. Se realizan actividades de pesca (boquichico, bagre) y de recolección de frutos del bosque como el milpeso, la canangucha, la cocona, el arazá, chontaduro, camu-camu, uva caimarona, chonta, o achiote ${ }^{198}$. Además, se comercializan productos que se preparan en el hogar, por ejemplo, el casabe, el ají negro, la fariña y la caguana (chicha de yuca).

197. Se realiza este análisis únicamente desde la perspectiva del análisis económico, dejando de lado los criterios ecológicos y de conservación por los que son importantes las restricciones al crecimiento de las chacras. De igual manera, no se discute en esta descripción la vocación agrícola o ganadera que pueden tener las poblaciones amazónicas, ni tampoco se analiza la posible falta de mano de obra disponible para ampliar el trabajo agrícola.

198. Al final del documento se presentan en anexo tablas que muestran los nombres científicos de las especies mencionadas en el texto. 


\section{Impactos por el funcionamiento de las áreas protegidas}

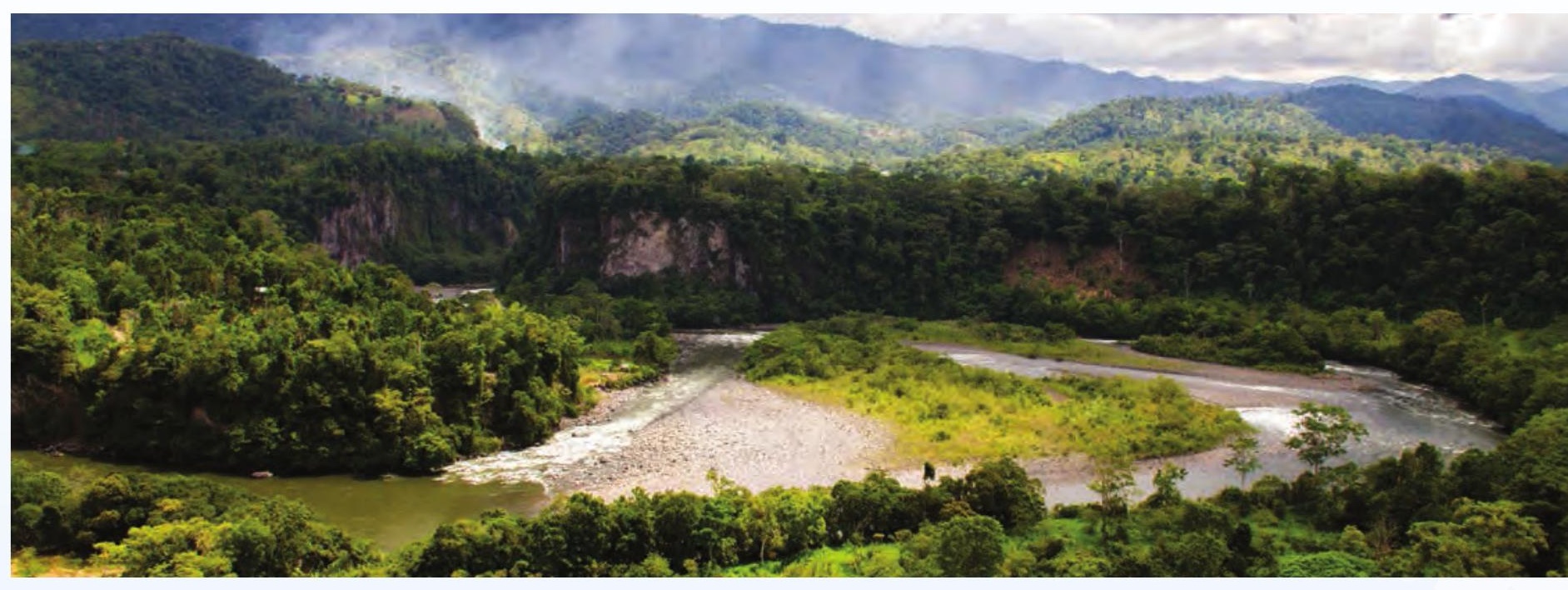

En este parque nacional, indígenas muruis también han empezado a comercializar el mambe ${ }^{99}$, como una oportunidad de generar ingresos económicos. Este se vende, de manera mayoritaria, a las personas que ya no tienen chacras o que ya no lo preparan por diferentes motivos

Un reflejo de la presión que se ha puesto sobre las chacras, que pasaron de ser fuentes de alimentación del hogar a unidades productivas para la comercialización de productos, es la pérdida de diversidad alimenticia que, según información entregada en la entrevista realizada con ACILAPP, es menor que en otros lugares de Colombia. Un ejemplo de este proceso es el paso hacia un único cultivo de yuca de la variedad que más se comercializa, perdiéndose así otras siete diferentes variedades de este tubérculo. Dentro del PNN La Paya no hay actividades ganaderas, aunque su presencia en las zonas de influencia genera una gran presión sobre el territorio del AP.

Las chacras en la RPF Cuyabeno también son una fuente de ingreso para la población local a través de la venta de los excedentes producidos. Aunque en este caso, por la presencia de actividades empresariales (turismo e hidrocarburos) relativamente cercanas, la población se ha volcado al trabajo asalariado, para asegurar mayores ingresos económicos.

En las chacras de la reserva se produce café, cacao, arroz, maíz, yuca, plátano, maní, papaya y zapallo, entre otros. El tamaño máximo de las chacras es de dos hectáreas ya que falta mano de obra agrícola y, además, las condiciones eco- lógicas (suelo y plagas) no permiten que estos cultivos se extiendan más. Como una forma de diversificar la producción y la venta interna en las comunidades se crían gallinas y chanchos.

En la RPF Cuyabeno se realizan, también actividades de caza de subsistencia; parte de esa carne se vende o intercambia en el mercado comunitario. Los animales que se cazan son: saíno y guangana, principalmente. Las actividades de pesca se hacen en quebradas de la reserva. Se pesca: piraña, tucunare, bocachico, palometa, carachama, tucsi, entre otros pescados de la zona. De forma mayoritaria, el producto de la pesca no se vende, sino que se comparte entre los miembros de la comunidad.

Un ingreso complementario para los hogares de la RPF Cuyabeno es la elaboración de artesanías para los turistas que visitan este AP. Se elaboran: bolsos, collares o aretes, todo con semillas y fibras del bosque. También fabrican ollas de barro para cocinar y para hacer chicha.

Las poblaciones del área de amortiguamiento del PN Alto Purús ${ }^{200}$ que no están dentro de territorios comunales (zona de Sepahua) también modificaron su forma de aprovechamiento de recursos y la producción de sus chacras a partir de la declaratoria. En

199. Preparado de hojas de coca con ceniza de hojas de yarumo (Cecropiapeltata)

200. Se toma como referencia esta zona del PNAP ya que dentro del AP solo existen Pueblos en Aislamiento Voluntario. Otras zonas que son áreas de amortiguamiento de esta AP son territorios comunales. 
esta zona se produce: yuca, arroz, plátano, algo de maní, sandía y maíz, que son los productos que más salida tienen en el mercado local, además de pequeñas cantidades de camote, papaya, achojcha, pepino, ají dulce y frejol para el consumo del hogar.

En la zona de Sepahua no hay un espacio físico de mercado, por eso es más difícil comercializar; lo que se vende como excedente agrícola es menor a lo que se vende en otros lugares. Además, por la presencia de empresas hidrocarburíferas en la zona, la población se moviliza hacia estas en busca de trabajo o salen de las comunidades a trabajar en empresas palmicultoras.

La elección de trabajar en las empresas petroleras o palmicultoras está vinculada a que el trabajo asalariado tiene una mejor retribución económica que las actividades agrícolas. Este cambio implica también una mayor dependencia de productos que deben ser comprados, por ello se convierte en un círculo que asegura el acceso a ciertos productos de consumo básico, pero también va desgastando la posibilidad de soberanía alimentaria de los hogares. Por otra parte, la falta de tiempo para la producción tradicional en

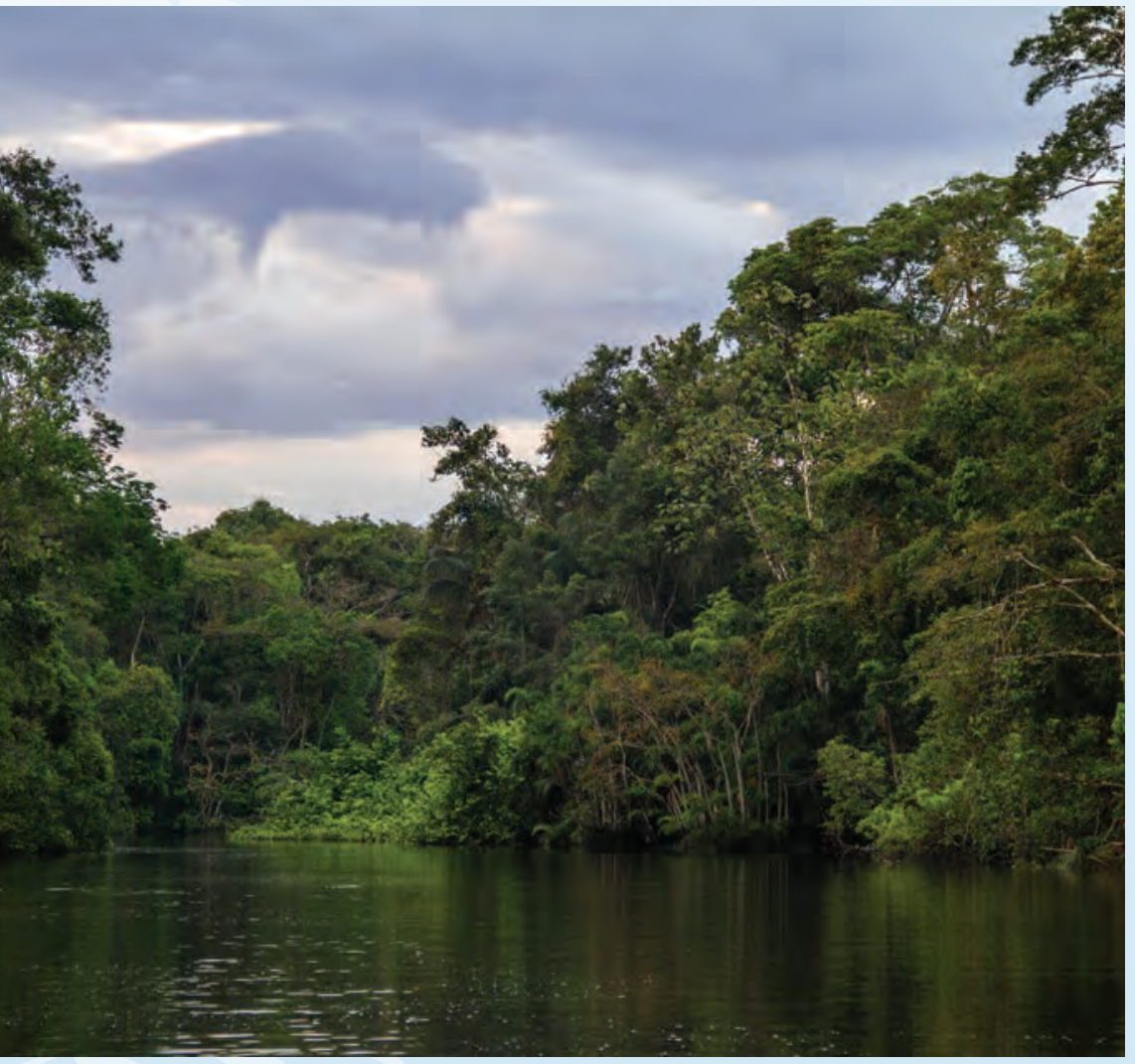

sus chacras y el uso de productos del bosque conllevan un proceso de pérdida de prácticas culturales tradicionales, importantes para la conservación de la diversidad de formas de producción y el aprovechamiento de bosques amazónicos.

Algunas comunidades de la zona de Sepahua participan en el proyecto productivo "Pichis Palcazú", impulsado por el Gobierno regional de Ucayali, que ha abastecido de animales menores (gallinas y patos) a las poblaciones de esta zona para que puedan diversificar sus ingresos.

Por las actividades industriales que se desarrollan en la zona de amortiguamiento del PN Alto Purús y por la distancia física que existe con el AP, las comunidades ubicadas en Sepahua no tienen disponible caza en las proximidades. Por este motivo, estas poblaciones viajan varias horas en bote para acercarse a los límites del parque: "La cacería en la zona cercana al parque es muy buena. Se invierte un poco más de gasolina, pero se trae buena caza. Se cazan: majas, venado, saíno, guangana, sachavaca, tapir, monos" (entrevista poblador local, 2016)

La pesca cerca de los límites del PN Alto Purús también es abundante. Lo que más se pesca es: paco, sábalo, doncella, lisa, palometa. En el PN Alto Purús no se realizan actividades de aprovechamiento forestal. En las zonas de influencia que no son territorios comunales existen varias concesiones forestales entregadas a empresas, por lo que la población local no realiza un aprovechamiento extensivo de los recursos maderables.

Para las comunidades de Sepahua, el oficio vinculado a la extracción de madera es una actividad de subsistencia más que no reporta grandes ingresos económicos. Antes de la creación y funcionamiento del AP, el aprovechamiento de madera era libre y se trabajaba con habilitadores de la madera (que eran los mismos compradores) y, aunque el precio unitario era bajo, debido a la cantidad de madera extraída, los pobladores locales que se dedicaban a esta actividad obtenían importantes ingresos económicos. "Se pasaba todo el verano trabajando con ellos y se lograba vivir todo el año hasta el siguiente verano que empezaba de nuevo el trabajo. 
Pagaban bajo, pero había bastante madera, por lo que era buen negocio. Además, daban víveres" (entrevista poblador local, 2016).

En la RC Purús, todas las personas de las comunidades hacen chacras, aunque por la distancia entre algunas comunidades y al centro poblado Puerto Esperanza, sumado al precio del combustible que deben consumir para llegar a este lugar, se dificulta comercializar los excedentes. En las chacras producen: plátano, yuca, maíz, maní, sandía, zapallo, frejol, papaya, sachapapa. Algunas comunidades mantienen el cultivo del algodón, con el que hacen artesanías como: hamacas, mochilas, coronas, vestidos y faldas, que venden en Puerto Esperanza. No hay un lugar en Puerto Esperanza habilitado como mercado, lo que limita la comercialización de productos. El tamaño promedio de las chacras en la RC Purús es de media hectárea hasta una hectárea, dependiendo de la mano de obra disponible en la familia.

Al igual que en el PN Alto Purús, las comunidades de la RC Purús también participan en el proyecto "Pichis Palcazú", que ha entregado gallinas y patos a las comunidades. Estos animales también se venden en Puerto Esperanza. Este proyecto también ha entregado ganado vacuno a las comunidades que, por el momento, aprovechan la leche, sin embargo esperar comercializar la carne en un futuro.

Las actividades de caza en la RC Purús están limitadas para el autoabastecimiento de los hogares y la población local reconoce que existe abundante fauna. Los animales que se cazan son: motelo, saíno, venado, perdíz, paujil, sachavaca, maja y mono (negro y blanco). De igual forma sucede con los productos de la pesca, que se realiza en los ríos y lagunas de la zona. Lo que más se consigue en las faenas de pesca es: bocachico, carachama, doncella, paco, bagre, maparate, corvina, yambina, mota, paña, pasaco, cunchi y maparate. De manera complementaria, se realizan actividades de recolección de productos del bosque como: chonta, chimicua, chirimoya de monte, asaí, zapote de monte, shapaja, cacao, yarina y ungurahui, entre otros frutos.

El aprovechamiento de recursos forestales en la RC Purús para comercialización solo está permitido con plan de manejo, pues solamente se pueden utilizar productos forestales, de manera libre, para el autoabastecimiento del hogar; se utilizan madera y hojas para construir casas y para hacer botes.

En la RNVSA Manuripi se permite el aprovechamiento forestal, la pesca y la agricultura para el autosustento. Solamente la castaña está permitida para la extracción comercial. Aquí también existe el oficio de extracción de caucho, pero esta actividad ha decaído de manera sensible por el precio actual de la goma.

Las actividades agrícolas se realizan en forma de chacras, pero la frontera agrícola en Manuripi ha decrecido en los últimos 5 años por el incremento del precio de la castaña. La población local prefiere dedicarse a la castaña y con las ganancias de esta actividad comprar los alimentos. En las chacras que se mantienen se produce: plátano, yuca, arroz, piña y maíz. La población también se dedica a criar chanchos y gallinas.

En Manuripi se aprovechan poco los productos del bosque y los frutos del bosque que se recolectan son el majo, chonta, aguaje, la tagua y el asaí. La caza que se realiza es, de igual manera, para la subsistencia. En la zona se caza saíno y mono.

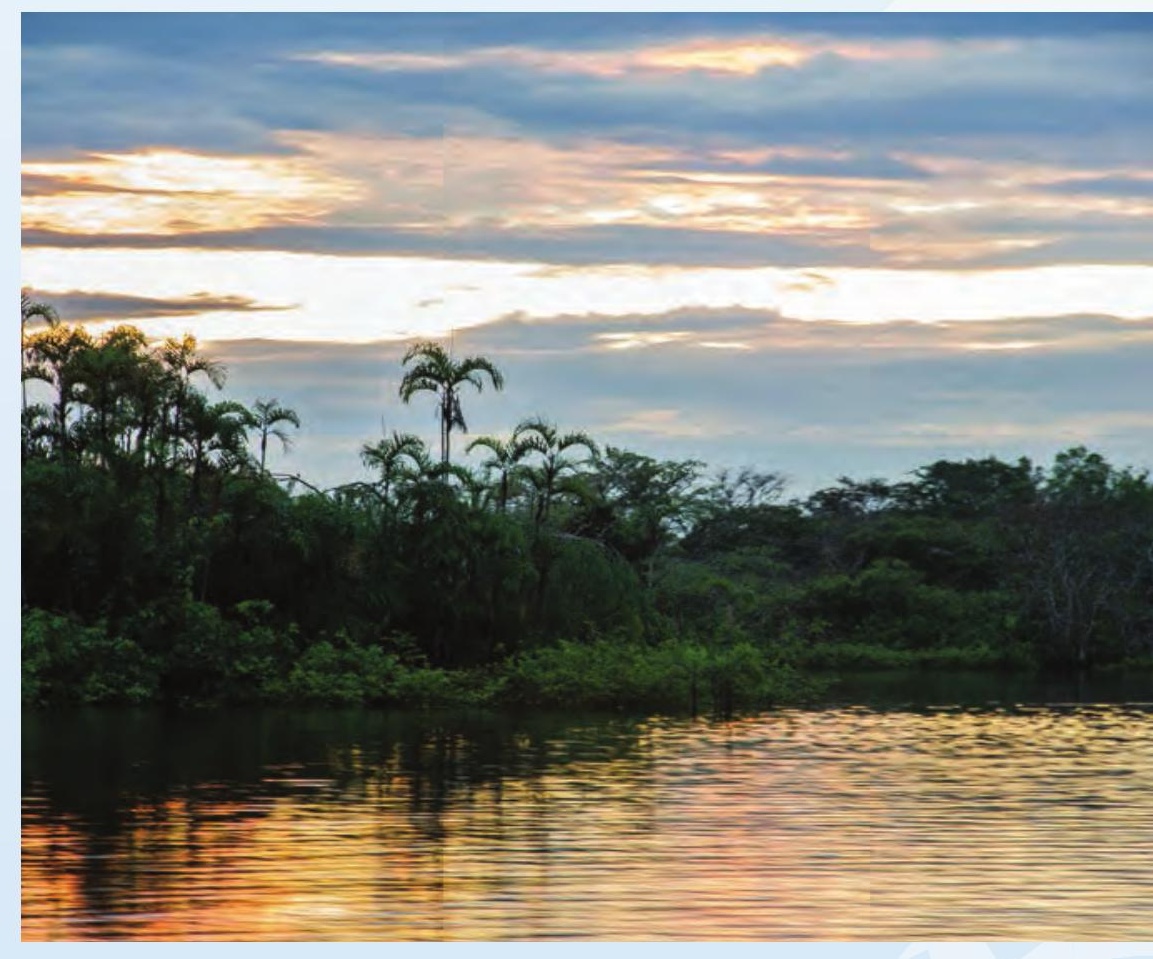


Las actividades de caza están limitadas también para el autoconsumo y depende del gusto y tiempo del cazador: saíno y paca es lo que más se caza. Hay un acuerdo en el Núcleo do Cazumbá para no cazar con trampas ni con perros. Las actividades de caza se hacen dependiendo del tamaño de la familia, se puede ir una o dos veces al mes. Aun cuando se tiene acceso a carne de res o pollo, se prefiere la carne de caza porque "tiene más sabor". Se cazan también algunos tipos de aves, monos, guatusas y tortugas.

En la RESEX se aprovechan productos forestales no maderables como el aceite de copaiba, el asaí y cacao. También hay castañales privados y castañales comunitarios. En la recolección de castaña comunitaria participan entre 17 y 18 personas de Núcleo do Cazumbá. También se aprovecha el caucho, aunque por el precio actual en el mercado, es una actividad menor. Cada estrada contiene alrededor de 100 árboles de caucho, de los que obtienen en total entre 15 y 20 litros de caucho diario dependiendo de la intensidad de la recolección

La pesca se realiza en el río 3 o 4 veces al mes y existe muchísima variedad de peces: tambaquí, surubí, paiche y paco entre otros.

El uso de madera se realiza, principalmente para la construcción de casas y para hacer canoas

Estímulo de procesos productivos para aprovechamiento sostenible y comercialización de productos del bosque

Una de las características principales sobre el impulso de actividades sostenibles dentro de las AP es que requieren de organización, es decir, son proyectos de tipo comunitario, con todas las dificultades que esto puede conllevar. Los costos de tiempo invertido, compromiso, etc. son asumidos por la población.

En el paisaje norte, las AP Parque Nacional Natural La Paya, Reserva Comunal Airo Pai y la Reserva de Producción de Fauna Cuya-

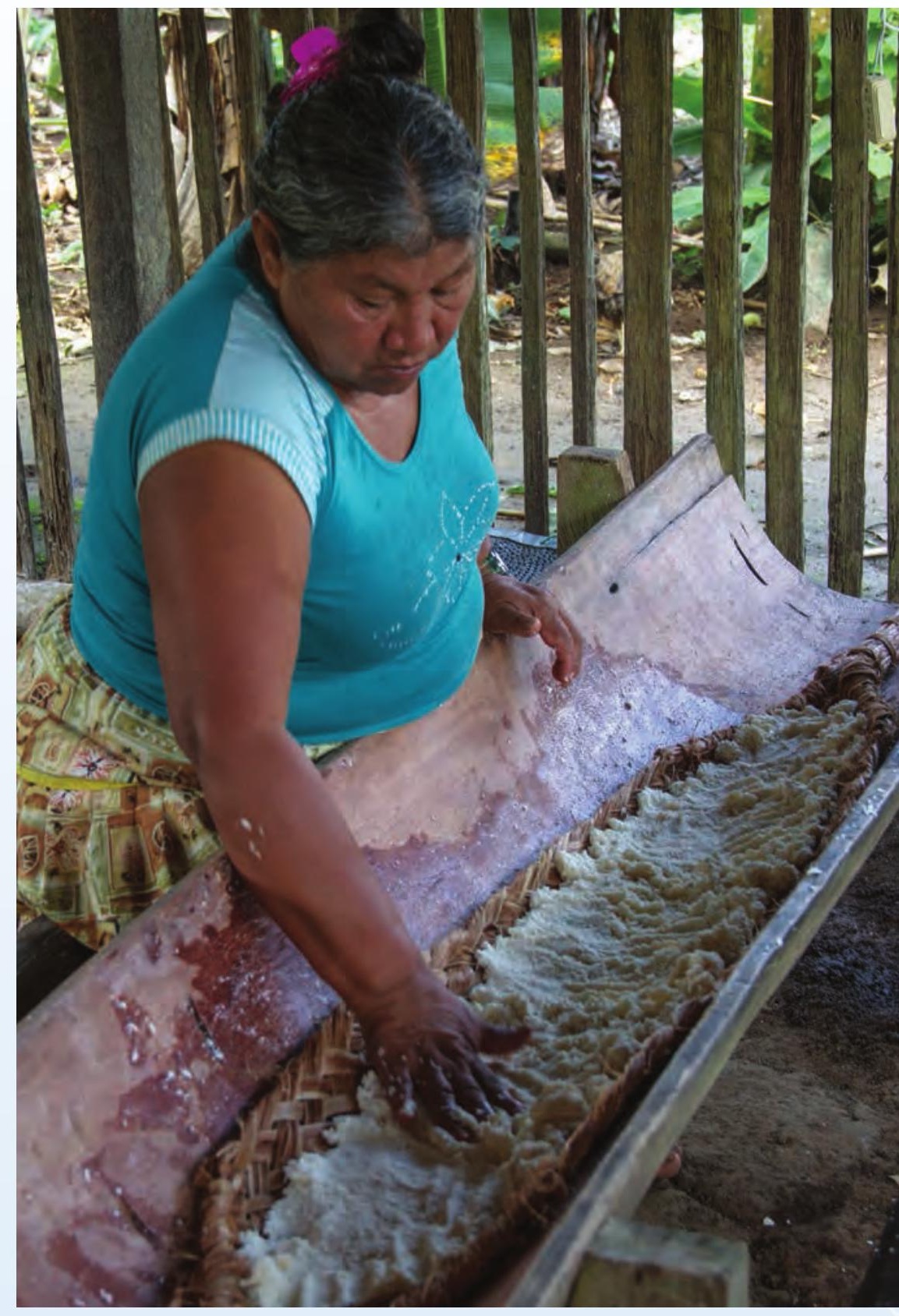

beno se han enfocado en el fortalecimiento cultural, la reproducción de tortugas, el comercio de cacao y la regulación de las actividades turísticas.

En el paisaje sur, las AP Reserva de Vida Silvestre Amazónica Manuripi, el Parque Nacional Alto Purús, la Reserva Comunal Purús, el Parque Estadual Chandless y la Reserva Extractivista Cazumbá-Iracema han privilegiado el aprovechamiento de productos forestales no maderables y el repoblamiento de poblaciones de tortugas. 


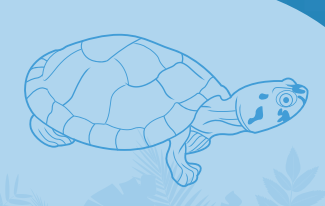

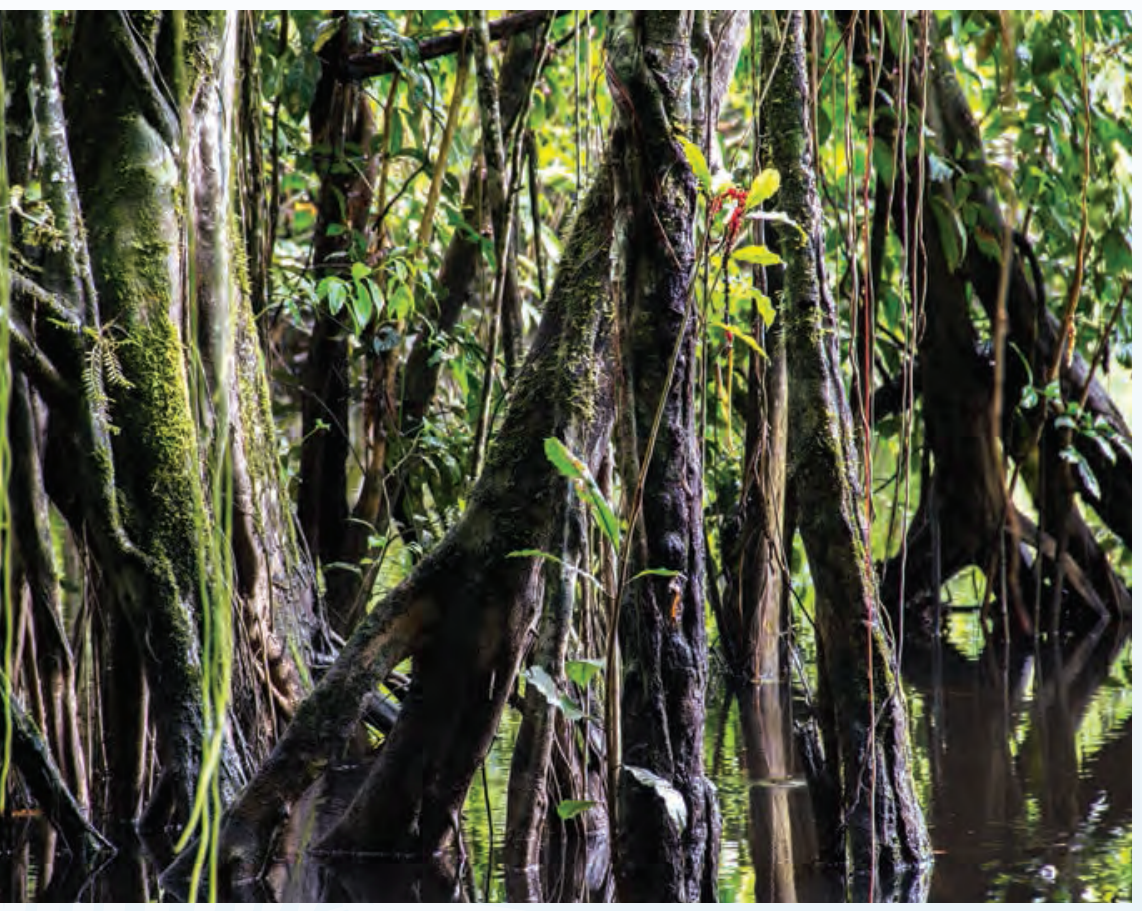

Estas iniciativas productivas impulsadas desde las jefaturas y organizaciones internacionales han sido una apuesta por construir procesos de aprovechamiento sostenible de recursos, ya sea a través de producción agrícola como el cacao, o de actividades de recolección, como el manejo de tortugas, asaí o castaña. En todos los casos se busca lograr ingresos económicos para la población y, de esta manera, disminuir la presión sobre los bosques consecuencia de un aprovechamiento intensivo y sin planificación.

Se debe considerar que algunos de los emprendimientos productivos sostenibles vin- culados al aprovechamiento de recursos del bosque tienen una temporalidad, lo que hace que no puedan ser aprovechados durante todo el año. Esto puede ser una desventaja ya que no es un ingreso continuo para la población, pero si se logra realizar dos o más de estas actividades en los hogares de las AP, se podría mantener un ingreso continuo, de diferentes fuentes. Esto supondría una forma productiva compatible con una economía familiar rural que permita que las familias aseguren ingresos durante el transcurso del año.

A continuación, se presentan cada una de las iniciativas que se han desarrollado en las áreas protegidas de los paisajes. Se describen las ventajas (beneficios) y costos que la participación en estos proyectos ha supuesto para las poblaciones locales y la manera en que las AP contribuyen a que los beneficios para las poblaciones locales sean mayores.

Un reto en el momento de realizar análisis económicos que den cuenta de cuán beneficiosa es una actividad para un grupo familiar es la posibilidad de comparar los ingresos de la actividad con un valor referencial que permita conocer el beneficio real de dicha actividad. Para contar con una referencia sobre los beneficios económicos que tienen las poblaciones locales por el desarrollo de procesos productivos para aprovechamiento sostenible y comercialización de productos del bosque en las AP, se presenta un cuadro que muestra el sueldo básico nacional (mensual) y se contrasta con los beneficios económicos de estas actividades con indicadores económicos nacionales.

\begin{tabular}{|c|c|c|c|c|c|c|c|c|c|}
\hline \multirow[b]{2}{*}{$\begin{array}{l}\text { Valor } \\
\text { sueldo } \\
\text { básico } \\
\text { nacional }\end{array}$} & \multirow{2}{*}{$\begin{array}{c}\text { Ecuador } \\
\text { RPF } \\
\text { Cuyabeno }\end{array}$} & \multicolumn{2}{|c|}{$\begin{array}{c}\text { Perú } \\
\text { PN Alto Purús y } \\
\text { RC Purús }\end{array}$} & \multicolumn{2}{|c|}{$\begin{array}{c}\text { Colombia } \\
\text { PNN La Paya }\end{array}$} & \multicolumn{2}{|c|}{$\begin{array}{c}\text { Brasil } \\
\text { PE Chandless y } \\
\text { RESEX Cazumbá- } \\
\text { Iracema }\end{array}$} & \multicolumn{2}{|c|}{$\begin{array}{c}\text { Bolivia } \\
\text { RNVSA Manuripi }\end{array}$} \\
\hline & & 850 PEN & 257,57 USD & $689455 \mathrm{COP}$ & 226,54 USD & $880 \mathrm{BRL}$ & 252,65 USD & $1656 \mathrm{BOL}$ & 259,00 USD \\
\hline
\end{tabular}

Tabla 31 


\section{Impactos por el funcionamiento de las áreas protegidas}

Actividades productivas sostenibles en el paisaje norte

\section{Parque Nacional Natural La Paya}

En este parque nacional la dirección de la gestión del AP ha estado muy enfocada en la gestión de la gobernanza territorial. Elementos como el conflicto armado y los cultivos de uso ilícito han sido motivos que limitan la acción activa en el territorio y, además, generan otras necesidades; por ejemplo, fortalecer procesos de gobernanza local con los actores afectados por estos conflictos.

Sin embargo, este contexto de conflicto en el PNN La Paya ha generado procesos de impulso a la elaboración de artesanías. Corpoamazonía ha trabajado en la zona, facilitando una capacitación de 80 horas en artesanías de Colombia. Tropembos también ha trabajado en esta temática con la población local. El inconveniente con estas actividades, según los entrevistados, es que es difícil conseguir recursos para viajar a ferias para presentar las artesanías y, en el mercado local, la población no se interesa por comprar los objetos que se producen. Por este motivo, varias personas que realizaban artesanías han dejado de hacerlo.

Otro proyecto que busca el beneficio de la población del PNN La Paya es el "centro de acopio" en Puerto Leguízamo. Esta fue una iniciativa coordinada con la jefatura del AP y con fondos de la Fundación Panamericana para el Desarrollo (FUNPAD) para mejorar las condiciones de comercialización de la población que vive dentro o en la zona de influencia del parque. La dificultad que enfrenta este proyecto es que no todas las personas vinculadas al proyecto entregan su producción y, en algunos casos, prefieren entregarla a intermediarios que comercializan productos en el mercado de Puerto Leguízamo. Por este motivo, una vez más, el limitante del proyecto es el mecanismo de comercialización de los productos.

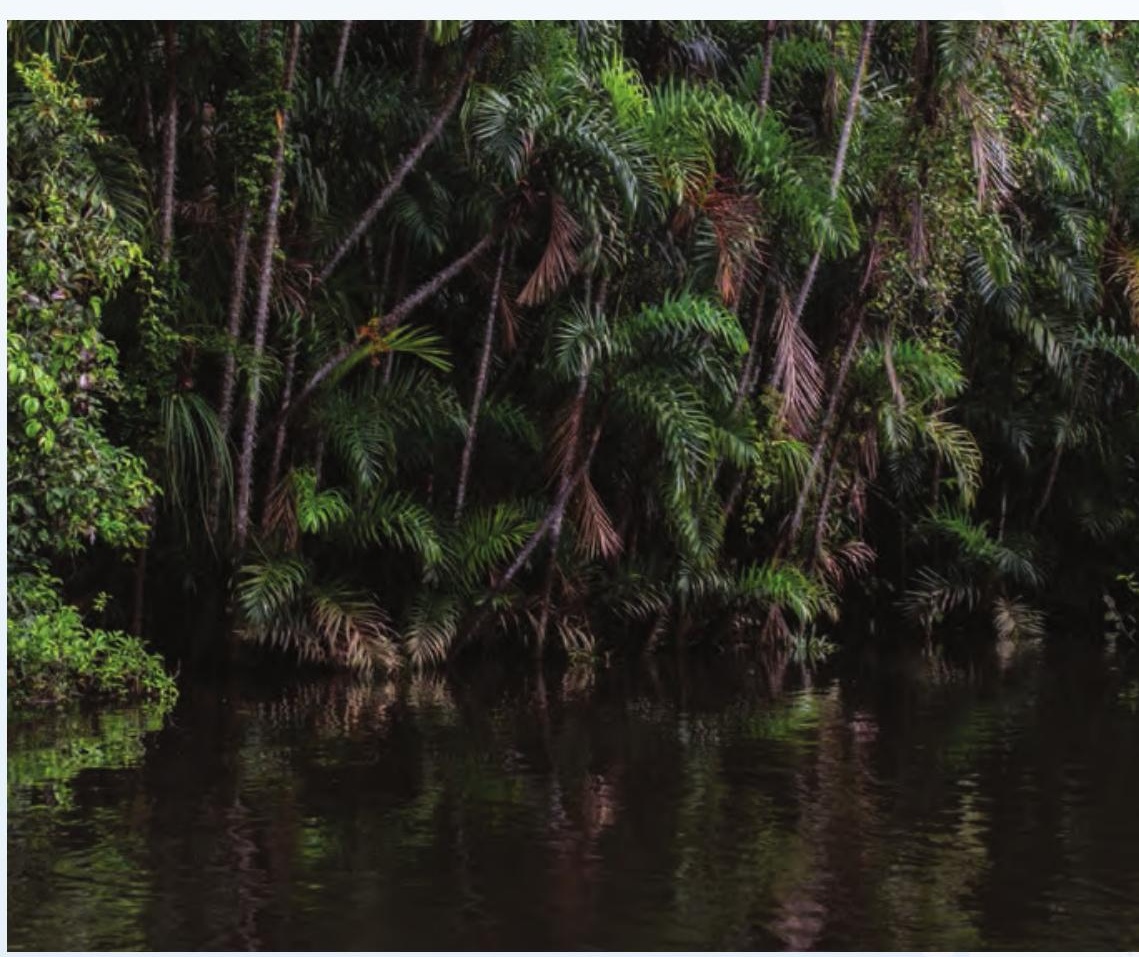

\begin{tabular}{|l|l|l|}
\hline \multicolumn{1}{|c|}{ Proyecto } & \multicolumn{1}{|c|}{ Costos asumidos por la población } & \multicolumn{1}{c|}{ Beneficio } \\
\hline Artesanías & $\begin{array}{l}\text { Costos de movilización para } \\
\text { presentaciones de productos. }\end{array}$ & $\begin{array}{l}\text { Ingresos económicos por venta de } \\
\text { las artesanías. }\end{array}$ \\
\hline Centro de acopio & $\begin{array}{l}\text { Costos de producción de los productos } \\
\text { agrícolas. } \\
\text { Cambio del uso del suelo de las chacras } \\
\text { para el mercado. }\end{array}$ & $\begin{array}{l}\text { Ingresos económicos por venta de } \\
\text { productos agrícolas. }\end{array}$ \\
\hline
\end{tabular}




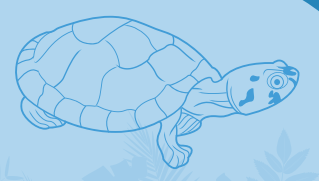

Los proyectos desarrollados en el PNN La Paya no han logrado consolidarse como opciones productivas y económicas para la población local, ya que la distancia de las comunidades, la dificultad y el costo de la movilización de productos artesanales y agrícolas han desestimulado que la población se empodere de los proyectos.

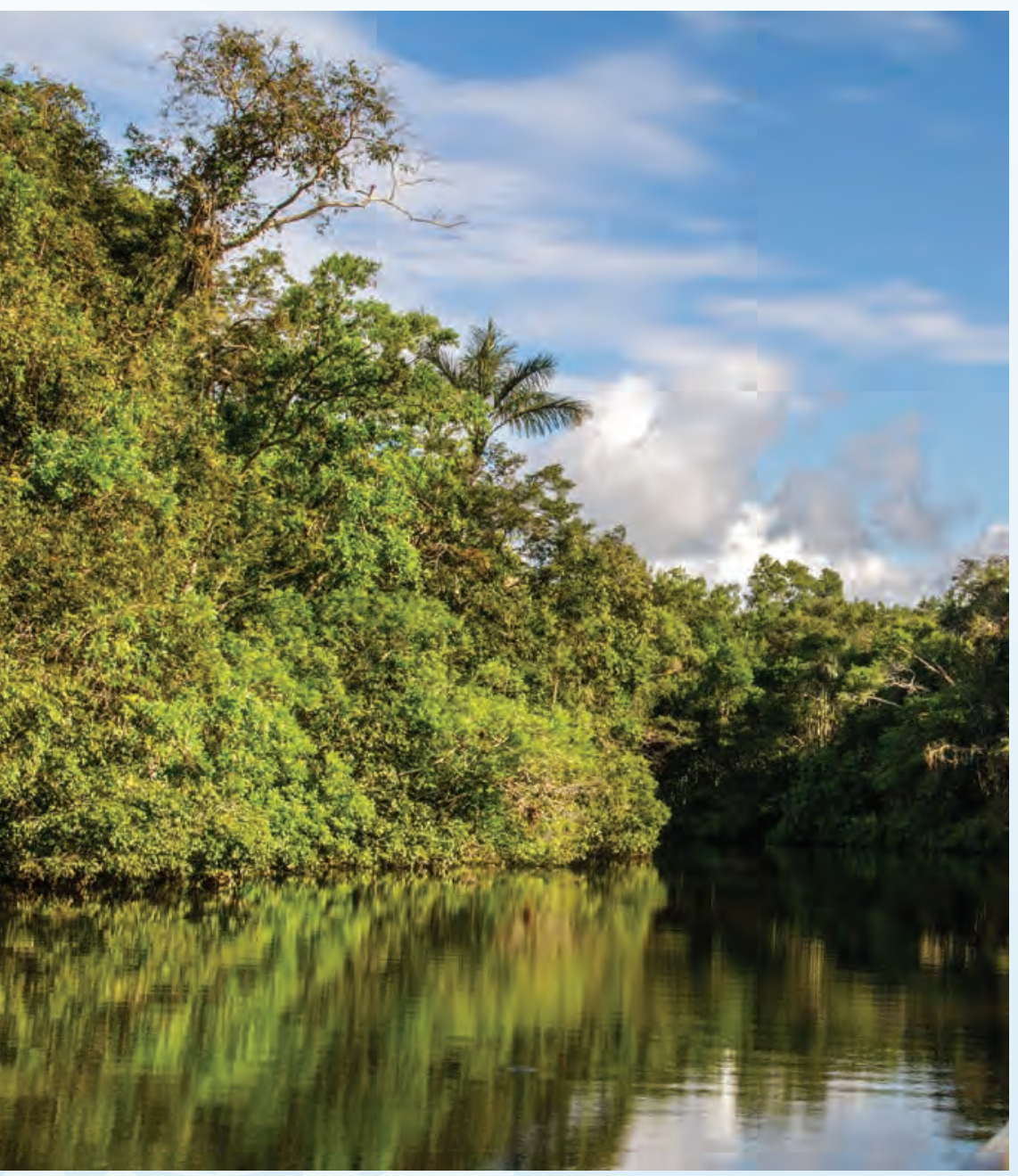

Reserva de Producción de Fauna Cuyabeno

En la RPF Cuyabeno se han realizado proyectos de venta de materias primas, producción de artículos con valor agregado y fortalecimiento de las actividades turísticas en el AP.

La producción de artículos con valor agregado y su comercialización se ha logrado a través de la coordinación de la jefatura, actores sociales involucrados y la organización WWF Ecuador. Este es el caso de la comercialización de cacao, producido dentro del AP, hacia la organización de mujeres productoras de chocolate "El Porvenir", en Pacayacu.

La comunidad que realiza la comercialización de cacao es Zancudo Cocha. Esta comunidad tiene sembradíos de cacao que se realizaron con el acompañamiento de WWF Ecuador y, en la actualidad, tienen un centro de acopio para almacenar el producto en la comunidad. Son 25 familias y todas producen entre un cuarto de hectárea y una hectárea. En el centro de acopio, el cacao se ensaca y se almacena cada 15 días. Cada año se agrupan, aproximadamente, 140 quintales anuales que son vendidos a la asociación de Pacayacu y a otros compradores de la zona, fuera del área protegida. En la comunidad Zancudo Cocha, de las ganancias que se obtienen por la venta de cacao, una parte se reparte entre los productores y otra se reinvierte en el centro de acopio. Como proyección a futuro, esperan poder hacer barras de chocolate en la misma comunidad, para no comercializar la materia prima, sino darle el valor agregado

\begin{tabular}{|c|c|c|c|c|c|}
\hline & \multirow[b]{2}{*}{ Producto/actividad } & \multirow[b]{2}{*}{ Producción total } & \multirow[b]{2}{*}{$\begin{array}{l}\text { Valor de venta } \\
\text { por unidad }\end{array}$} & \multirow[b]{2}{*}{$\begin{array}{l}\text { Valor total de } \\
\text { ganancias }\end{array}$} & \multirow[b]{2}{*}{$\begin{array}{l}\text { Ingreso familiar } \\
\text { promedio }\end{array}$} \\
\hline & & & & & \\
\hline $\begin{array}{r}\text { Beneficios por } \\
\text { comercialización de cacao, } \\
\text { comunidad Zancudo Cocha } \\
\text { Fuente: } \\
\text { Elaboración propia en base a } \\
\text { información de entrevistas en } \\
\text { campo (2016) }\end{array}$ & $\begin{array}{l}\text { Cacao } \\
\text { Comunidad Zancudo } \\
\text { Cocha (2015) }\end{array}$ & 140 qq/año & 160 USD/qq & 22400 USD/año & $\begin{array}{l}\text { 896,00 USD/año } \\
\text { 74,66 USD/mes }\end{array}$ \\
\hline
\end{tabular}

201. El valor que se presenta es un valor referencial para visualizar las ganancias potenciales de cada familia participante en esta actividad ( 25 familias). Este valor varía en función de cuánto cacao produce y entrega, cada familia, al centro de acopio. 


\section{Impactos por el funcionamiento de las áreas protegidas}

La participación de las familias de Zancudo Cocha en este proyecto les ha dado la posibilidad de enlazar su producto con un mercado de precio justo y de recibir mayores ganancias por la comercialización del cacao. A través de esta actividad, las familias que participan en este proyecto recibieron en el año 2015, en promedio, 74,66 USD mensuales, lo que supone un 20,39 \% del sueldo básico ecuatoriano.

La asociación de producción de chocolate El Porvenir lleva trabajando cinco años como organización jurídica y cuenta con 12 miembros. Al contrario de lo que ocurre habitualmente en el contexto local, donde muchas organizaciones terminan por disolverse, esta asociación ha mantenido su producción. Tiene firmado un convenio con la comunidad Zancudo Cocha para comprar el cacao a un precio fijo que fue consensuado entre las partes y que se revisa de manera anual.

La asociación compra cada año, aproximadamente, treinta quintales de cacao a la comunidad Zancudo Cocha y de cada quintal, en promedio, obtienen 500 barras de chocolate de 250 g. Cada barra de 250 g es comercializada a 3 USD en diferentes comercios locales y redes de comercio justo.
El trabajo de elaboración y comercialización de chocolate de la Asociación El Porvenir es un ejemplo de los resultados de la organización. A través de esta asociación, 12 familias logran, en promedio, ingresos mensuales de 279,16 USD, lo que supone un 76,22 \% del sueldo básico en Ecuador.

Tanto para la comunidad Zancudo Cocha como para las mujeres de la Asociación El Porvenir, el comercio y manufactura del cacao no son actividades exclusivas, sino que son una actividad económica más que genera ingresos y recursos para los hogares.

Otro proyecto que ha trabajado la jefatura de la reserva es, desde el año 2008, el repoblamiento de tortugas. Este proyecto se inició en la comunidad Zábalo y, aunque el objetivo del proyecto fue la recuperación de la especie, se espera poder comercializarla, aunque aún no se ha conseguido asegurar un mercado para este producto.

Las actividades de turismo en la RPF Cuyabeno se pueden dividir en dos grupos: las iniciativas turísticas privadas y las iniciativas turísticas comunitarias. Estas actividades, en principio, no fueron estimuladas por la jefatura del AP, sino que iniciaron por interés de empresas privadas. En la actualidad, el vín

\begin{tabular}{|l|l|}
\hline \multicolumn{1}{|c|}{ Producto/Actividad } & \multicolumn{1}{c|}{ Venta de chocolate "El Porvenir" } \\
\hline Producción total & 15000 unidades de $250 \mathrm{~g}$ al año \\
\hline Valor de venta por unidad & 3 USD \\
\hline Valor total de ingresos & 45000 USD/año \\
\hline Costo materia prima & 4800 USD/año \\
\hline Ganancia total & 40200 USD/año \\
\hline Ingreso familiar promedio202 & 3350 USD/año \\
& 279,16 USD/mensual \\
\hline
\end{tabular}

\section{Tabla 34:}

Beneficios por comercialización de chocolate, Asociación El Porvenir

\section{Fuente:}

Elaboración propia en base a información de entrevistas en campo (2016)

202. Ibídem. 
culo que tienen los prestadores de servicios turísticos (privados o comunitarios) con la jefatura se realiza a través del control y vigilancia de estas actividades, para evitar degradar el ambiente del AP y promover el avistamiento de fauna y flora que fue disminuida históricamente por las malas prácticas de manejo.

Las iniciativas privadas realizan la inversión económica en el AP y deben recuperar sus costos a través de la operación turística. Estas iniciativas generan beneficios para las comunidades ya que se coordinan con las familias indígenas locales la prestación de algunos servicios, entre ellos: gestionar el transporte fluvial dentro del AP y preparar demostraciones culturales para los turistas visitantes. Aun cuando estas actividades privadas generan mayores ganancias para sus propietarios, este funcionamiento libra a las comunidades locales de los costos de inversión en infraestructura mercadeo y permisos (entre otros), ya que son altos y, difícilmente, podrían ser asumidos por todas las comunidades.

Las actividades turísticas privadas se concentran en 12 campamentos (lodges) repartidos en tres comunidades sionas: Puerto Bolívar, San Victoriano y Tarabeaya. En 2015 ingresaron 16966 turistas. Si, efectivamente, 15 000 personas fueron a estas comunidades, en total, ingresaron aproximadamente 195000 USD. A continuación, se desglosan los conceptos para este ingreso:

\begin{tabular}{|c|c|c|c|c|}
\hline $\begin{array}{l}\text { Producto/ } \\
\text { Actividad }\end{array}$ & $\begin{array}{l}\text { Total de turistas } \\
\text { atendidos }\end{array}$ & $\begin{array}{l}\text { Demostración } \\
\text { cultural: casabe }\end{array}$ & $\begin{array}{l}\text { Demostración } \\
\text { cultural: shamán }\end{array}$ & Venta de artesanías \\
\hline $\begin{array}{l}\text { Atención a } \\
\text { turistas }\end{array}$ & 15 000/año & 4 USD c/turista & 4 USD c/turista & 10 USD c/artesanía promedio \\
\hline \multicolumn{2}{|c|}{ Ingreso total generado } & 60000 USD/año & 60000 USD/año & 75000 USD203/año \\
\hline \multicolumn{2}{|c|}{ Ganancia total (2015) } & \multicolumn{3}{|c|}{195000 USD/año } \\
\hline
\end{tabular}

Tabla 35: Estas ganancias se obtienen por las visitas de ingresos para las los turistas a las comunidades para conocer comunidades por atención a turistas

Fuente: Elaboración propia en base a información de entrevistas en campo directamente relacionadas con las actividades turísticas, para aproximar un valor promedio de ingresos para cada comunidad, se divide entre tres el valor de la ganancia total por estas actividades, lo que da como resultado que cada comunidad pudo ganar en el año 2015, 65000 USD, lo que se traduce en un ingreso mensual de 5416,66 USD.
Sin embargo, la repartición de estas ganancias entre los miembros de las comunidades no siempre es equitativa ya que la atención de los turistas en las comunidades no la realizan todas las familias, sino solamente algunas, lo que hace que este beneficio no sea aprovechado por toda la población comunitaria. Existen también otros ingresos por la vinculación a la actividad turística que tienen un corte más individual y que están vinculados a la prestación directa de servicios para los lodges. A continuación, se desagregan estos ingresos, aunque no se pueden aproximar ganancias mensuales ya que son actividades individuales y, en algunos casos, ocasionales:

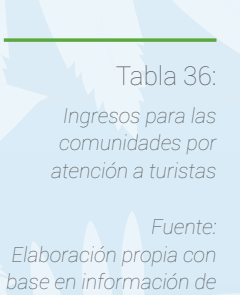
base en información de entrevistas en campo (2016)

\begin{tabular}{|l|l|}
\hline \multicolumn{1}{|c|}{ Producto/Actividad } & \multicolumn{1}{c|}{ Prestación de servicios a lodges } \\
\hline Renta de espacio para el lodge & Entre 400 USD y 1000 USD/mes \\
\hline Contratación de canoa & 85 USD $204 /$ día \\
\hline Guía local & 60 USD/día \\
\hline Trabajo (cocina, limpieza) & 366 USD/mes \\
\hline
\end{tabular}

203. Para generar este valor se asume que solo la mitad de visitantes de año 2015 (7500 personas) compraron una artesanía de 10 USD.

204. Este valor incluye el costo del combustible que debe utilizar el transporte al día. 


\section{Impactos por el funcionamiento de las áreas protegidas}

Todos los lodges que se ubican en la RPF Cuyabeno pagan una renta a los dueños por el predio en el que se ubican (los lodges utilizan entre media y una hectárea aproximadamente). Esta es una ganancia para la familia propietaria de ese terreno, ya que hay acuerdo dentro de las comunidades sobre la repartición del territorio (no son acuerdos con escrituras, son acuerdos comunitarios). Además, todos los lodges contratan los servicios de transporte fluvial con los miembros de la comunidad, lo que supone un ingreso diario de 85 USD para la persona que presta el servicio. Por otra parte, están incorporar en sus paquetes turísticos la participación de guías locales, lo que significa un ingreso de 60 USD. Además, contratan personas de las comunidades para los servicios de cocina y limpieza, lo que puede significar un ingreso de un sueldo básico para las personas que prestan este servicio.

Con el apoyo de WWF Ecuador, también existen algunos emprendimientos turísticos comunitarios en otras comunidades de la RPF Cuyabeno, aunque el funcionamiento del mercado turístico es muy complejo y costoso para que pueda ser asumido por las comunidades.

Las actividades turísticas en la zona, sean estas comunitarias o privadas, se realizan a través de operadoras turísticas que trabajan en la zona. Se ofertan tours de diferente duración (entre tres y cinco días de visita), con caminatas nocturnas y pesca deportiva. También se realizan visitas a las chacras de cacao, hacen una ruta por el río Lagartococha y, algunos tours, llegan incluso hasta Puerto Estrella (Perú).

La RPF Cuyabeno participa de las actividades turísticas a través de la gestión de la calidad del servicio turístico que se desarrolla en el AP. Dictan criterios de no contaminación, sostenibilidad del aprovechamiento a través del monitoreo de los senderos que se utilizan, etc.

En la RPF Cuyabeno las actividades que se han impulsado desde la jefatura del área han generado la conexión entre productores y procesadores de cacao y se ha logrado que los dos actores generen una cadena

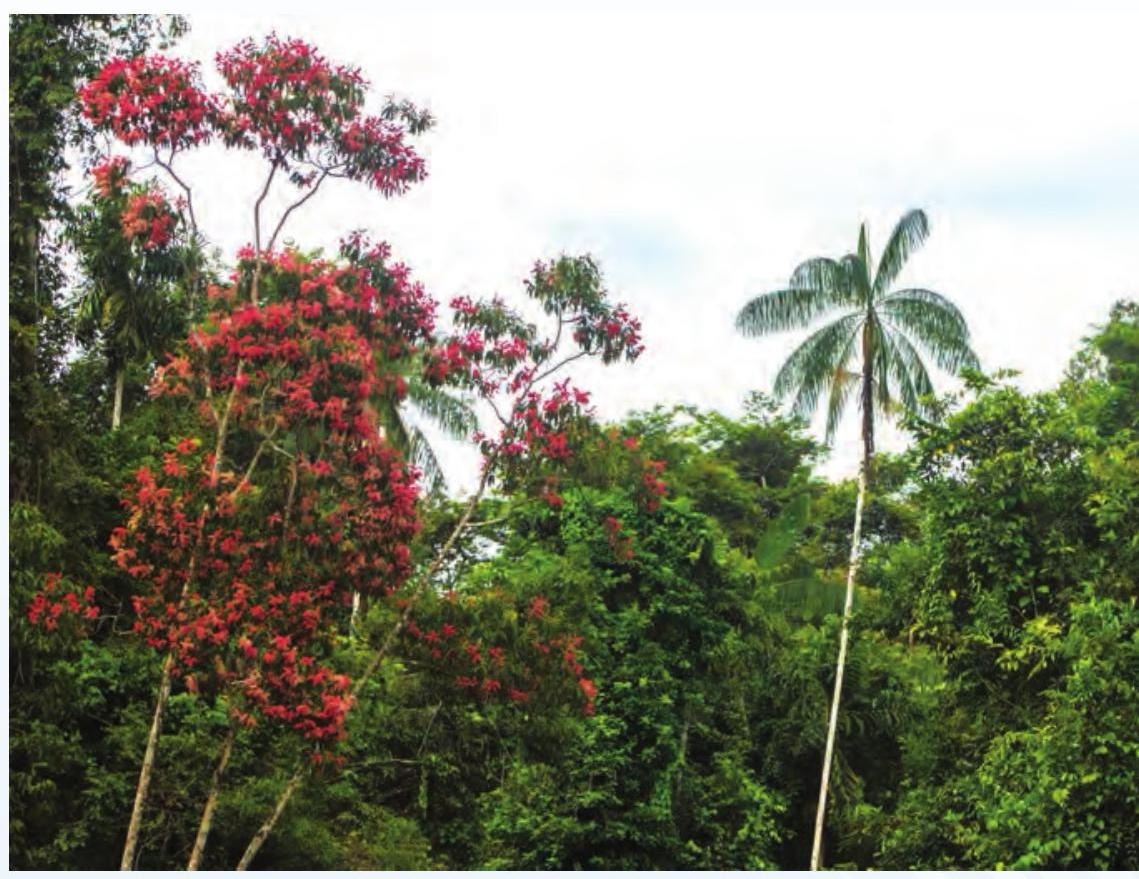

productiva importante, algo que ha sido di-

fícil para las otras AP del paisaje norte.

El control y vigilancia de las actividades turísticas es un impacto positivo para el desarrollo de estas actividades ya que, por un lado, se asegura calidad del servicio y, por otro, se hace un uso sostenible de los recursos del AP.

\section{PN Güeppí-Sekime y Reservas}

Comunales Airo Pai y Huimeki

En el caso de estas AP y, en general en Perú, el SERNANP legaliza organizaciones con registro público y planes de manejo para el comercio de los recursos del bosque. Las personas que quieren inscribirse en el registro público, en el caso del PN Güeppí Sekime y las Reservas Comunales Airo Pai y Huimeki, deben ir a lquitos para legalizarse. La lejanía de estas AP con Iquitos desestimula a la población, impidiendo que puedan aprovechar los recursos del bosque para el comercio y, en algunos casos, se mantiene un aprovechamiento ilegal.

En la Reserva Comunal Airo Pai, el aprovechamiento de las tortugas taricayas sirve, por ahora, para el consumo del hogar y se hace solo con los huevos que no son viables (fisurados o suaves). Aún no se han 
realizado procesos de comercialización porque no figura ninguna comunidad en el registro público para el aprovechamiento de este recurso, por lo que las comunidades están participando con la jefatura del AP, únicamente, en el repoblamiento de esta especie.
Otro recurso que se espera aprovechar en esta reserva es el paiche, un pescado muy cotizado. Hay dos grupos de manejo que trabajan con el SERNANP para proteger el paiche y las tortugas. El primer grupo está conformado por 18 personas y el segundo por 12 pero, por el momento, estos grupos no tienen beneficios económicos.

\begin{tabular}{|l|l|l|}
\hline \multicolumn{1}{|c|}{ Proyecto } & \multicolumn{1}{|c|}{ Costo } & \multicolumn{1}{|c|}{ Beneficio } \\
\hline $\begin{array}{l}\text { Repoblación de } \\
\text { tortugas }\end{array}$ & $\begin{array}{l}\text { Movilización para legalizar actividades } \\
\text { productivas, lo que desestimula a la población } \\
\text { para emprender proyectos sostenibles. } \\
\text { Costos de preparación de elementos necesarios } \\
\text { para el proyecto (armado de playas artificiales, } \\
\text { cuidado de estos espacios) } \\
\text { Trabajo no remunerado en la ejecución del } \\
\text { proyecto. }\end{array}$ & $\begin{array}{l}\text { Garantía del consumo en el hogar de huevos } \\
\text { de tortuga que no son viables para el proceso } \\
\text { de repoblamiento. }\end{array}$ \\
\hline $\begin{array}{l}\text { Movilización para legalizar actividades } \\
\text { productivas, lo que desestimula a la población } \\
\text { para emprender proyectos sostenibles. } \\
\text { Trabajo no remunerado en la ejecución del } \\
\text { proyecto. } \\
\text { Costos de movilización y pago de permisos para } \\
\text { emprender en esta actividad. }\end{array}$ & $\begin{array}{l}\text { No existen beneficios económicos para los } \\
\text { participantes del proyecto, ya que actualmente } \\
\text { no se está comercializando el producto. } \\
\text { El beneficio que recibe la población es la } \\
\text { garantía de consumo en el hogar de este } \\
\text { recurso. }\end{array}$ \\
\hline
\end{tabular}

Tabla 37: Costos y beneficios. $\mathrm{PN}$ Güeppi-Sekime

Fuente:

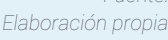

En los proyectos que se han desarrollado en estas AP, los beneficios obtenidos están vinculados al autoabastecimiento de la población local. No se han logrado aún beneficios económicos, ya que, entre otros elementos del contexto de la zona, se debe cumplir con requisitos específicos que dicta la normativa vigente en Perú.

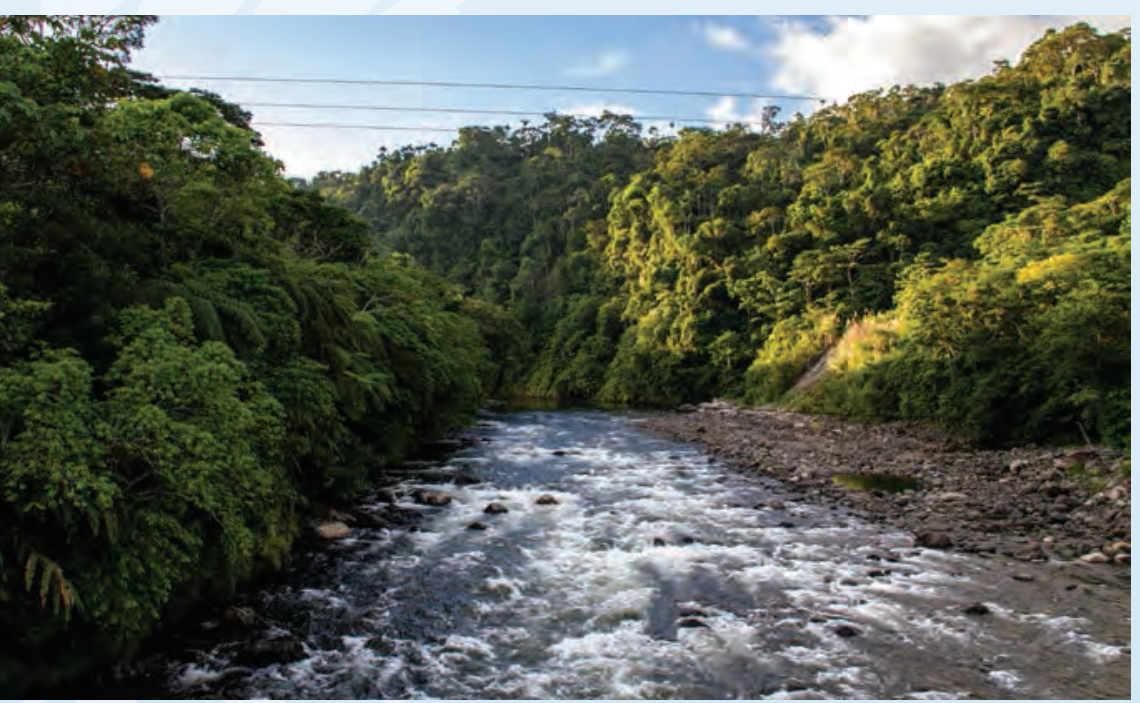

Además, si bien en otras AP de Perú se realiza la comercialización de tortugas, en esta zona aún no hay compradores para este producto, por lo que no se ha logrado consolidar una cadena de comercialización. En cambio, el paiche tiene mercado en la ciudad de Iquitos, sin embargo la falta de los permisos requeridos impide su comercialización.

\section{Actividades productivas} sostenibles en el paisaje sur

\section{PN Alto Purús y RC Purús}

En el PN Alto Purús se han realizado diferentes proyectos atendiendo a las necesidades del AP y de las poblaciones locales de las áreas de amortiguamiento. En el río Tahuamanu, se ha trabajado un plan de manejo de pesquería. En el departamento Madre de Dios se han hecho actividades de control y vigilancia para impedir que se asienten dragas mineras. La fuerza de la 


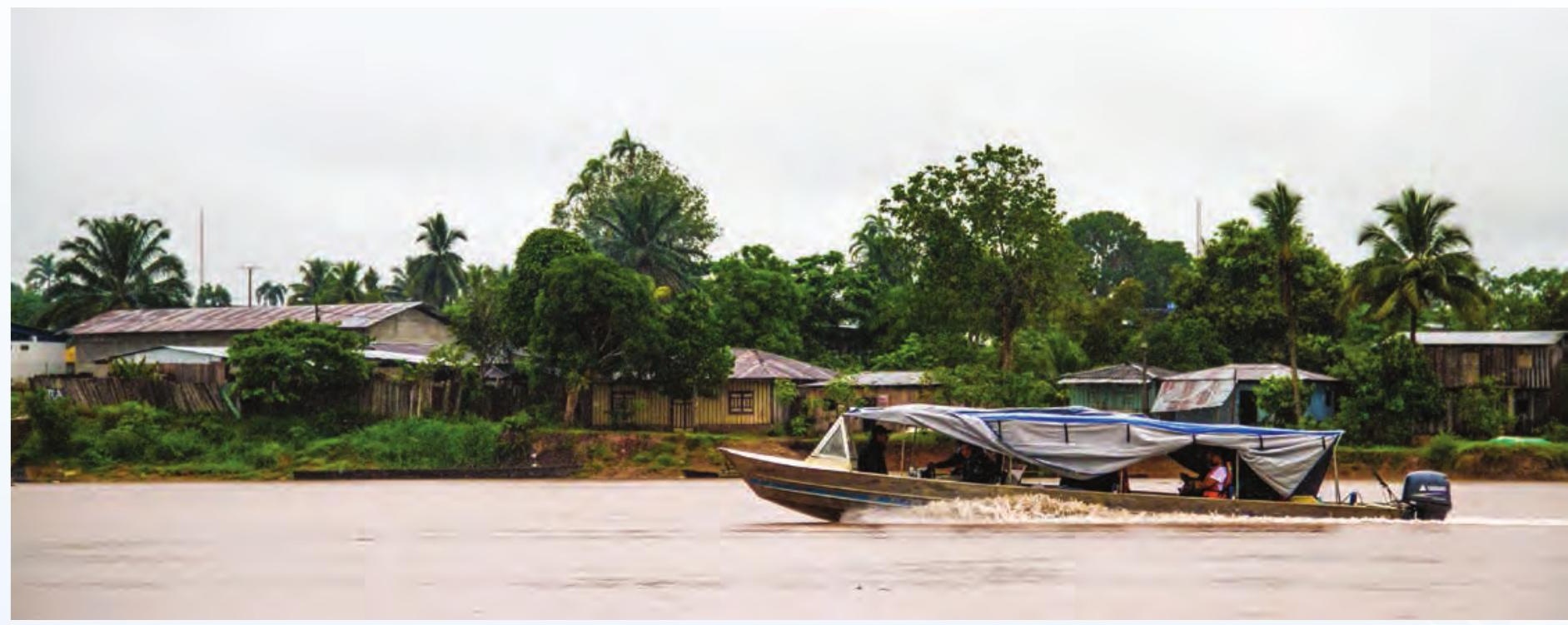

gobernanza y gestión del parque es priorizada en las zonas de amortiguamiento y en las zonas de influencia, ya que, trabajando en estas zonas, se evita que la población ingrese, de manera ilegal, a actividades madereras o de aprovechamiento indiscriminado de fauna.

En colaboración entre el parque nacional y WWF Perú, se han trabajado proyectos de género, educación ambiental, títeres con niños y repoblación de tortugas acuáticas (en el río Tahuamanu). La mayor intervención en apoyo a iniciativas locales del PN Alto Purús se encuentra focalizada en la Reserva Comunal Purús.

En la RC Purús se han realizado iniciativas relacionadas con:

\section{- Proyecto de frutales}

- Recolección y venta de semillas de caoba

- Comercialización de tortugas taricayas y motelos

Dos son los elementos que intervienen en el éxito o fracaso de estas iniciativas para las comunidades: la capacidad de organización local y la conexión que se ha logrado con el mercado de los productos ofertados. Los costos operativos y de capacitación han sido asumidos por organizaciones cooperantes, mientras que las comunida- des han asumido costos de trabajo, como mano de obra propia, y los costos propios de organización (dedicación de tiempo para las actividades). El reto mayor ha sido generar y mantener el interés de la población en los proyectos, lo que, a largo plazo, es difícil.

En el futuro se espera lograr la comercialización del aceite de copaiba, actualmente en proceso de estudio para su correcta planificación.

En la RC Purús, el proyecto de frutales surge debido a la falta comunitaria de frutas cultivadas, pues solamente se aprovechan las frutas del bosque. Si bien consume proteína, la población no consume suficientes verduras o frutas, por lo que este proyecto busca el mejoramiento de la dieta de las comunidades y también bajar la presión sobre los recursos de la reserva, a través de la búsqueda de nuevas opciones productivas y económicas. En este proyecto participan aproximadamente veinte comunidades de la zona de amortiguamiento de la RC Purús

Otra iniciativa que se ha impulsado en la RC Purús es el manejo de cochas ${ }^{205}$. Este proyecto se ha desarrollado con el apoyo de APECO, donde participan las siguientes comunidades: Colombiana, Nueva Vida y Miguel Grau.

205. Denominación peruana para las lagunas 


\section{Impactos por el funcionamiento de las áreas protegidas}

Para la asociación del río Curanja, en caso de cubrir el cupo total que le asigna su plan de manejo, las ganancias anuales ascenderían a 29860 PEN (8 947,41 USD), lo que dividido entre las cinco comunidades participantes, da como resultado un beneficio anual por producción y comercialización de 5972 PEN o 1 789,48 USD para cada comunidad.

\begin{tabular}{|c|c|c|c|c|}
\hline $\begin{array}{c}\text { Producto/ } \\
\text { Actividad }\end{array}$ & $\begin{array}{c}\text { Producción } \\
\text { total anual } \\
\text { (Unidades) }\end{array}$ & $\begin{array}{c}\text { Valor de venta por } \\
\text { unidad } \\
\text { (Soles peruanos) }\end{array}$ & $\begin{array}{c}\text { Valor total de } \\
\text { ganancias anual } \\
\text { (Soles peruanos) }\end{array}$ & $\begin{array}{c}\text { Valor total de } \\
\text { ganancias anuales } \\
\text { (Dólares americanos) }\end{array}$ \\
\hline $\begin{array}{c}\text { Quelonios- } \\
\text { taricaya }\end{array}$ & 2152 & 5 Pen & 10760 Pen & 3224,45 USD \\
\hline $\begin{array}{c}\text { Quelonios- } \\
\text { teparos }\end{array}$ & 3752 & 8 Pen & 30016 Pen & 8994,91 USD \\
\hline \multicolumn{2}{|c|}{ Total ganancias } & 40776 Pen & 12219,36 USD \\
\hline
\end{tabular}

\section{Tabla 39: \\ ingresos por venta de quelonios, comunidades de la cuenca del Río Alto Purús Fuente: Elaboración propia con datos de entrevistas en campo (2016) e información del Plan de Manejo de quelonios de} Purús
El caso de la Asociación Río Alto Purús también es alentador. Las ganancias totales de la asociación por la producción y comercialización de tortugas, según el cupo de aprovechamiento establecido en el plan de manejo, es de 40776 PEN (12 219,36 USD) lo que, dividido entre las cuatro comunidades que son parte de esta asociación, da como resultado un beneficio anual de 10 194PEN (3054,84USD) para cada asociación.
Los ingresos por la producción y venta son repartidos entre los miembros de las asociaciones, de acuerdo a su participación en el proyecto: se reparte entre las personas que han recogido los huevos y las que han hecho y dado mantenimiento a las playas artificiales. El saldo restante es reinvertido en la asociación. Sin embargo, es necesario recordar que estas son proyecciones sobre los cupos permitidos de producción y comercialización,

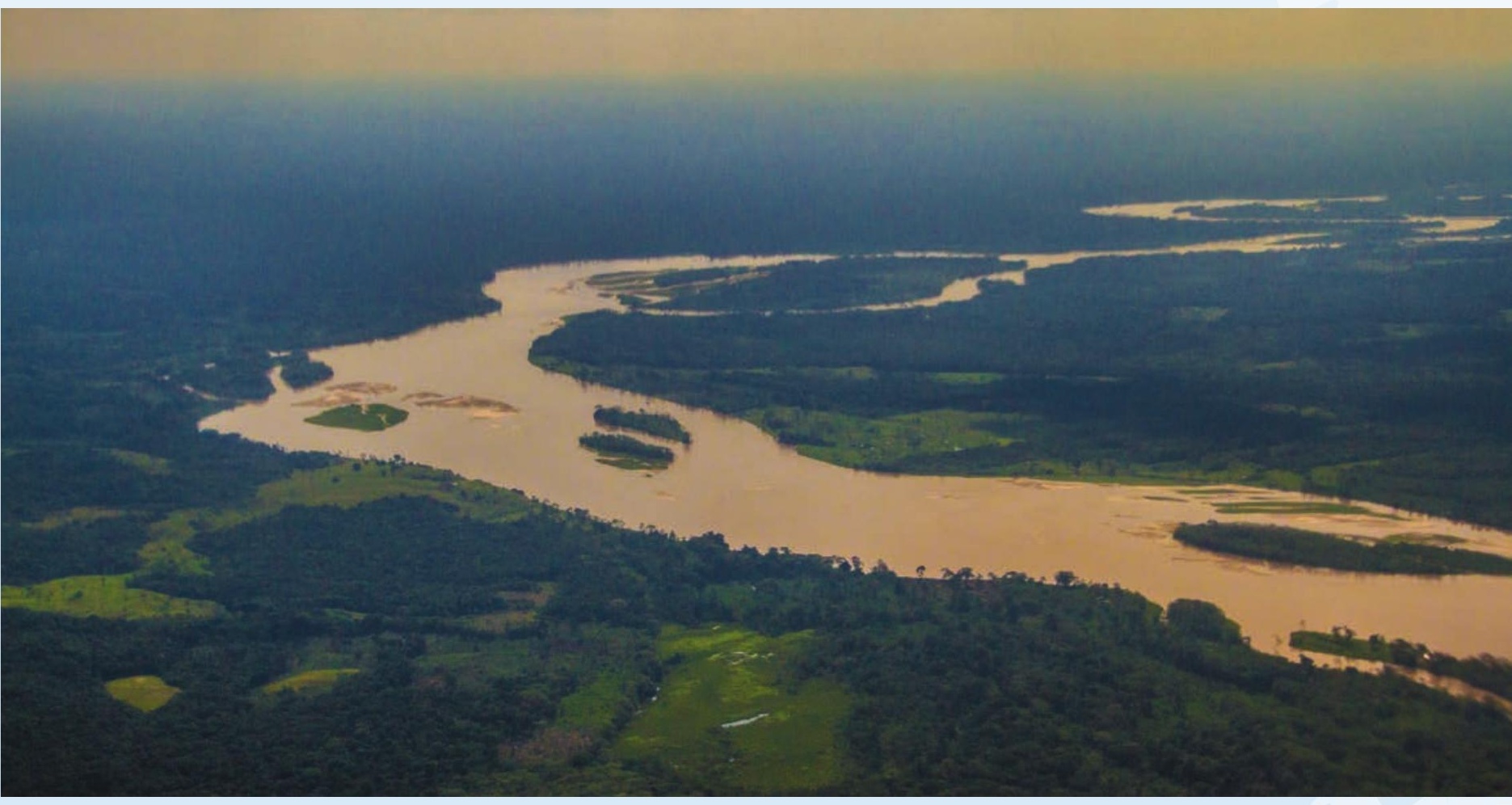


por lo que es muy importante que las asociaciones y la jefatura de la RC Purús trabajen para cumplir estos cupos.

Las actividades de este proyecto están reguladas a través de contratos de aprovechamiento firmados entre las comunidades y la jefatura del AP. El éxito de este proyecto radica en que existe una empresa que se ha vinculado al desarrollo del proyecto y asegura la compra de la producción. Esta empresa, MF Tropical Turtles \& Fishes, aportó económicamente a la elaboración de los planes de manejo necesarios para la venta de las tortugas. Esto ha asegurado un mercado para la producción, lo que hace que este producto sea vendido directamente y no se requiera buscar compradores.

El proyecto de recolección y venta de semillas de caoba también se desarrolla en la RC Purús. El aprovechamiento de semillas se realiza sin cortar el árbol, práctica generalizada en otras zonas de Perú. Para realizar esta actividad se utiliza equipo de escalada y tijeras telescópicas. En el año 2009 se realizó la primera cosecha. Se realiza una recolección de semillas al año y se hacen pruebas de germinación para garantizar la cosecha

Las comunidades de la RC Purús que participan en este proyecto son: Gastabala, Pozo San Martín, Santa Margarita y Monterrey. El apoyo a este proyecto lo realizó APECO a través del financiamiento de gastos operativos y de capacitación para las comunidades participantes. Las comunidades par- ticipantes aportaron con la alimentación para las actividades del proyecto.

Cada comunidad puede producir 10 kilos de semillas al año. La elección de los árboles que serán semilleros es muy importante por algunos factores, por ejemplo, para asegurar la calidad y cantidad de las semillas. Este último factor es muy importante ya que cada árbol tiene ciclos que hacen que un año produzca más semillas que otro, o bien, un año produzca semillas y otro no.

Los beneficios económicos de esta actividad se reparten de la siguiente manera: se realiza el acopio de todas las semillas recolectadas, se secan y almacenan para la venta. Al darse la venta de las semillas se paga progresivamente a todas las comunidades participantes, las que, a su vez, primero pagan a los que han trabajado de manera directa en la recolección de semillas y, el saldo restante, se invierte en actividades o instrumentos que requiera la comunidad. Es importante conocer que la venta de los volúmenes de producción total no se realiza de una sola vez, sino que depende de la demanda de los compradores por lo que el pago a las comunidades, por las semillas, se da de manera paulatina, en la medida en que se va vendiendo este producto.

A continuación, se presentan las ganancias económicas que generan la recolección y venta de semillas para las comunidades y para las personas que están relacionadas con esta actividad.

\begin{tabular}{|c|c|c|c|c|}
\hline $\begin{array}{c}\text { Producto/ } \\
\text { actividad }\end{array}$ & $\begin{array}{c}\text { Producción } \\
\text { total anual }\end{array}$ & $\begin{array}{c}\text { Valor de } \\
\text { venta por } \\
\text { unidad }\end{array}$ & $\begin{array}{c}\text { Ganancia anual } \\
\text { Soles peruanos } \\
\text { (2015) }\end{array}$ & $\begin{array}{c}\text { Ganancia anual } \\
\text { Dólares Americanos } \\
(2015)\end{array}$ \\
\hline $\begin{array}{c}\text { Kilo de semilla de } \\
\text { caoba }\end{array}$ & $20 \mathrm{~kg}$ & 300 Pen & 6000 Pen $^{206}$ & 1798,02 USD \\
\hline
\end{tabular}

206. En el momento en que se realizó esta investigación, en campo, no se había vendido aún toda la producción del año 2016 . Hasta ese momento se habían vendido $20 \mathrm{~kg}$ de semillas de caoba. Sobre los $20 \mathrm{~kg}$ vendidos se realiza este análisis de ganancias ya que es lo que efectivamente han ganado las comunidades. 


\section{Impactos por el funcionamiento de las áreas protegidas}

Durante el año 2015 se comercializaron $20 \mathrm{~kg}$ de semillas secas de caoba. Esto significó ingresos de 6000 PEN (1 798,02 USD) para los participantes de esta actividad. Por tanto, a cada comunidad participante (cuatro comunidades) le reportó un beneficio de 1500 PEN o 449,50 USD.
Estas ganancias se reparten entre las personas que participaron en la actividad de recolección de caoba (elección de semillero, recolección de las semillas y transporte de las semillas) y el saldo restante se reinvierte en necesidades de la comunidad.

\begin{tabular}{|l|l|l|}
\hline \multicolumn{1}{|c|}{ Producto/Actividad } & \multicolumn{1}{|c|}{$\begin{array}{c}\text { Ganancia } \\
\text { Soles peruanos }\end{array}$} & $\begin{array}{c}\text { Ganancia } \\
\text { Dólares americanos }\end{array}$ \\
\hline $\begin{array}{l}\text { Jornal diario por recolección de caoba } \\
\text { Pago diario a subidores a árboles de } \\
\text { caoba }\end{array}$ & Entre 30 Pen y 40 Pen & 8,80 Usd y 11,84 Usd \\
\hline
\end{tabular}

Tabla 41: Ingresos individuales por trabajo en proyecto recolección de semillas de caoba

Fuente Elaboración propia con datos de entrevistas en campo (2016)
Una de las empresas que compra las semillas de caoba de la reserva es Ramsa S.A. (Reforestadora Amazónica) pero, en general, las instituciones públicas y otros potenciales compradores no consideran la procedencia de las semillas para hacer las compras y existen otros proveedores que son competencia para esta iniciativa de aprovechamiento sostenible.

\begin{tabular}{|c|c|c|}
\hline Proyecto & Costos & Beneficios \\
\hline Frutales & Costos de mantenimiento de los cultivos. & Soberanía alimentaria. \\
\hline $\begin{array}{l}\text { Recolección y } \\
\text { venta de semillas } \\
\text { de caoba }\end{array}$ & $\begin{array}{l}\text { Contraparte de la realización de este } \\
\text { proyecto: alimentación para participantes, } \\
\text { movilización. }\end{array}$ & $\begin{array}{l}\text { Ingresos anuales por venta de semillas. } 1 \text { kg se vende } \\
\text { entre } 300 \text { Pen y } 400 \text { Pen (entre } 88,85 \text { USD y } 118,46 \\
\text { Usd) cada comunidad puede recolectar hasta } 10 \mathrm{~kg} \\
\text { de semillas secas. } \\
\text { Ingresos económicos como sueldos para las } \\
\text { personas que trabajan directamente en la recolección } \\
\text { de semillas. }\end{array}$ \\
\hline $\begin{array}{l}\text { Comercialización } \\
\text { de tortugas }\end{array}$ & $\begin{array}{l}\text { Costos de preparación de elementos } \\
\text { necesarios para el proyecto (armado de } \\
\text { playas artificiales donde se ubican los } \\
\text { huevos recolectados, cuidado de estos } \\
\text { espacios) } \\
\text { Trabajo no remunerado en la ejecución del } \\
\text { proyecto. }\end{array}$ & $\begin{array}{l}\text { Ingresos económicos por la venta de quelonios. } \\
\text { Ejemplo, la comunidad San Ramón recibió } 2923 \text { Pen } \\
\text { ( } 885 \text { Usd) en } 2015 \text { por la venta de tortugas. Esto se } \\
\text { destina a sueldos de los participantes y compras para } \\
\text { mejoras en la comunidad. }\end{array}$ \\
\hline
\end{tabular}

Los impactos de los proyectos que se han realizado en la $R C$ Purús están vinculados al fortalecimiento de la pluriactividad de la población local, lo que en términos económicos, se traduce en la diversificación de las fuentes de ingresos económicos de la población.

Este impacto es representativo ya que permite que la población local genere ingresos por diferentes actividades en diferentes momentos del año, de manera que siempre ten- gan algún tipo de ingreso económico para abastecer el hogar.

La limitación para que este beneficio sea general en toda el AP es la dificultad que existe para mantener a la población motivada y participativa, más aún al inicio de los proyectos. Al iniciar nuevos emprendimientos, que no necesariamente tienen un mercado asegurado, la población debe hacer una inversión de tiempo y recursos organizativos para impulsarlo, lo

\section{Tabla 42}

Costos y beneficios RC Purús Fuente: Elaboración propia 
que no sucede en todos los casos, por lo que los proyectos o iniciativas no tienen una participación masiva.

Un ejemplo es el proceso de venta de tortugas que inició hace diez años con el repoblamiento de la especie. En ese momento pocas fueron las personas que mostraron interés. Ahora, se puede considerar este proyecto como un éxito en la comercialización sostenible y más población de la RC Purús desea integrarse al mismo, lo que trae dilemas a los que han participado desde el inicio.

\section{RNVSA Manuripi}

La RNVSA Manuripi es la primera de las AP involucradas en el proyecto IAPA y ha consolidado un sistema que aporta a la mejora de las condiciones de sostenibilidad financiera a través del uso sostenible de los recursos del bosque, en este caso, la castaña (entrevista Víctor García, WWF, 2016). De forma paralela, se están impulsando dos nuevos proyectos de aprovechamiento de asaí y de paiche, aunque estos aún no están generando aportes económicos a la población local o al AP. La importancia del desarrollo de estos proyectos radica en que apoyan al ingreso familiar de las poblaciones locales.

La castaña de Manuripi cuenta con certificación orgánica y de origen. Es la única castaña en toda la Amazonía boliviana que cuenta con estas certificaciones, lo que da una ventaja comparativa al producto (entrevista Víctor García, WWF Bolivia, 2016). Los costos anuales de estas certificaciones han sido cubiertos, en un inicio, por WWF Bolivia y, en la actualidad, con la tasa que cobra el AP por el aprovechamiento de la castaña para una parte de estas certificaciones. Con estas certificaciones se están creando los cimientos para la competitividad del producto en el mercado. En caso de oscila- ciones de precios, la castaña de Manuripi tiene más posibilidades de mantener el precio, ya que tiene un mejor manejo.

La producción total de castaña de la RNVSA Manuripi es de 10000 toneladas anuales. El primer año de certificación (2012) se vendieron 200 toneladas con precio diferenciado por las certificaciones. Estos números han ido creciendo y todavía hay producto que se vende sin certificaciones; esto sucede porque aún faltan procesos estandarizados para aprovecharlas al máximo.

El aprovechamiento de la castaña dentro de la reserva se da bajo dos sistemas: barracas castañeras (de propietarios privados) y comunidades locales. Las barracas castañeras contratan mano de obra para el tiempo de zafra, mientras que, en la zona comunitaria, se trabaja con mano de obra familiar, lo que permite bajar los costos de producción y generar más ganancias para los hogares. Sin duda alguna, la zafra de castaña en Manuripi es un gran dinamizador del empleo en la zona.

Un impulso importante que existe para la producción de castaña certificada en Manuripi es la intervención de la Empresa Boliviana de Almendra y Derivados (EBA) que compra a los productores con un precio mejorado por la certificación orgánica del producto. Además, cuenta con un sistema de pagos que permite que la población local no tenga que recurrir a habilitadores para realizar las labores de recolección de castaña.

\footnotetext{
207. Este $20 \%$ es el sobreprecio que reconoce la Empresa Boliviana de Almendra y Derivados (EBA) por las certificaciones que tiene la castaña de la RVSA Manuripi: $10 \%$ por certificación orgánica, $10 \%$ por certificación de origen. Este sobreprecio es pagado en los meses de septiembre u octubre y esto evita, en parte, el endeudamiento de los campesinos recolectores de castaña al inicio de la zafra.

208. Barricas de $70 \mathrm{~kg}$. El número de barricas que se contabilizan para este análisis consideran el descuento de peso por desperdicio. Es decir, es el número total de barricas sin desperdicio que se comercializan directamente.
}

\begin{tabular}{|c|c|c|c|c|c|c|}
\hline Producto & $\begin{array}{c}\text { Producción } \\
\text { familiar anual }\end{array}$ & $\begin{array}{c}\text { Valor de } \\
\text { venta por } \\
\text { unidad } \\
\text { (Bolivianos) }\end{array}$ & $\begin{array}{c}\text { Valor de } \\
\text { ganancias } \\
\text { (Bolivianos) }\end{array}$ & $\begin{array}{c}20 \% \text { Eba } 207 \\
\text { (Bolivianos) }\end{array}$ & $\begin{array}{c}\text { Valor total de } \\
\text { ganancias } \\
\text { anuales } \\
\text { (precio de } \\
\text { mercado + 20 \% } \\
\text { eba) } \\
\text { (Bolivianos) }\end{array}$ & $\begin{array}{c}\text { Valor total de } \\
\text { ganancias anuales } \\
\text { (Dólares } \\
\text { americanos) }\end{array}$ \\
\hline Castaña & 130 barricas $^{208}$ & $\begin{array}{c}450 \mathrm{BOB} / \\
\text { barrica }\end{array}$ & $58500 \mathrm{BOB}$ & $11700 \mathrm{BOB}$ & $70200 \mathrm{BOB}$ & $10074,7 \mathrm{USD}$ \\
\hline
\end{tabular}




\section{Impactos por el funcionamiento de las áreas protegidas}

Para analizar los beneficios de la extracción de castaña en la RNVSA Manuripi y su influencia en la población local, se toma como referencia un valor promedio de producción familiar. Una familia que posee terreno para extraer castaña puede obtener 130 barricas durante los meses que dura la zafra. El precio de cada barrica es de 450 BOB, lo que supone un ingreso total de 58500 BOB.

Si esta familia vende su castaña a la EBA obtendrá un 20 \% complementario sobre el precio por la certificación orgánica y de origen, que le será entregado en el mes de septiembre y lo que le permitirá iniciar el nuevo proceso de zafra el siguiente año. En total, una familia de la RNVSA Manuripi, produciendo 130 barricas obtendrá como beneficio anual 70200 BOB, equivalentes a 10 074,7 USD.

El mecanismo de transferencia de la EBA, que paga el sobreprecio de las certificaciones de producción orgánica y de origen desde el mes de septiembre, aunque ha sido visto con recelo, es un mecanismo muy importante para evitar el endeudamiento de los campesinos zafreros que no tenían otra opción para iniciar la zafra cada año. Un zafrero podía endeudarse entre 5000 BOL y 10 000 BOL (706,47 USD y 1412 USD), lo que era un problema para la economía de estos campesinos.

El proyecto de fomento para la recolección de asaí se está iniciando en la RNVSA Manuripi y cuenta con la participación de cinco comunidades cercanas a vías de acceso carrozable. Se están realizando los estudios para viabilizar este proyecto, ya que el asaí es un fruto rápidamente perecedero, por lo que requiere ser procesado en un corto tiempo para su comercialización. La reserva tiene un potencial de producción de 60 000 toneladas anuales en las cinco comunidades que están participando en el proyecto, con la posibilidad de vender en 30 BOB aproximadamente cada racimo, aunque las oscilaciones del mercado pueden afectar a la comercialización de este producto. Dinamarca está invirtiendo recursos económicos para el desarrollo de esta iniciativa.

El aprovechamiento de la goma es una actividad que, históricamente, se ha desarrollado en esta zona. En la actualidad está desapareciendo por la baja cotización que tiene en el mercado, aun cuando se ha intentado generar procesos de comercialización de artesanías de este material.

Las actividades turísticas en la RNVSA Manuripi se realizan, específicamente, en Lago Bay. Este aprovechamiento turístico dentro del AP es individual y no se han generado proyectos desde la jefatura del AP.

La gestión de la jefatura de la RNVSA Manuripi se ha concentrado en la producción de la castaña y su ordenamiento se realiza a través de normativa específica para el desarrollo de esta actividad. Este enfoque se justifica, sobre todo, por ser una actividad con un mercado fijo y muy rentable que genera ingresos para la población local y para la operación del AP.

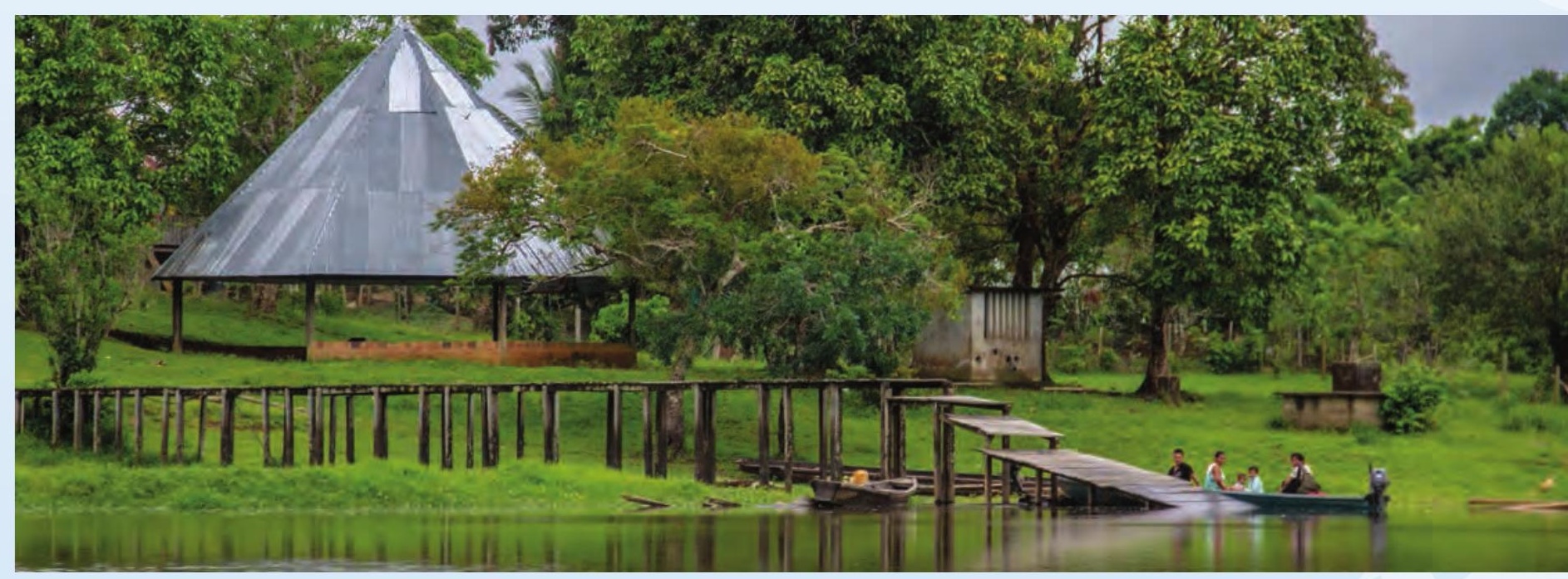


El beneficio de esta gestión es claro: ingresos económicos para la población de manera directa, para aquellos que son parte de las comunidades asentadas dentro del AP y, de manera indirecta, para aquellos que llegan a buscar trabajo en los tiempos de la zafra de castaña

Una limitación de las actividades de esta área protegida es la especialización hacia un solo producto en un contexto de economías familiares que requieren diversificar su ingreso para lograr la sostenibilidad durante el año. Este es uno de los grandes problemas que enfrenta la población de la RNVSA Manuripi: se han centrado en la recolección de castaña y han abandonado otras actividades productivas. Las ganancias por la comercialización de la castaña, aunque son abundantes, se producen solamente durante el tiempo de la zafra (entre 4 y 5 meses al año). Durante los siguientes meses, la familias no tienen otros ingresos económicos, por lo que se dan algunos casos donde se endeudan para continuar manteniendo el hogar, migran temporalmente hacia poblados consolidados cercanos para buscar empleo temporal o deben endeudarse en valores altos para volver a iniciar la zafra de castaña del siguiente año. Esto es lo que convierte a esta actividad en un negocio de subsistencia del hogar, ya que las deudas no permiten que se forme una economía de acumulación.

Sin embargo, el impacto de las intervenciones de la jefatura del AP (con apoyo de WWF Bolivia) sobre la producción de castaña y su certificación orgánica y de origen han permitido que las familias que se vinculan al mercado de la castaña certificada logren un precio justo por el producto y, además, que se generen parte de los pagos meses después de la entrega del producto (antes del inicio del siguiente ciclo de zafra), lo que evita el endeudamiento de los hogares.
Además, a través del impulso a la producción y procesamiento del asaí se estarán dando nuevas opciones económico-productivas para la población, lo que ayudará a que se diversifique la economía local y mejoren las condiciones económicas de la población local de esta área protegida.

\section{PE Chandless}

En el caso del PE Chandless, sus objetivos de creación (desarrollo de turismo y promover la investigación científica) han limitado el desarrollo de proyectos que, a partir del aprovechamiento del bosque, beneficien a la población que vive en esta AP.

Como una forma de apoyo a la población local, se ha planificado realizar una capacitación técnica profesional relacionada al apoyo en servicios vinculados al funcionamiento del AP (eventos, visita de investigadores, etc.), para que exista una opción económica alternativa.

Debido a la distancia que existe entre la población del PE Chandless y los centros urbanos, existe dificultad para colocar los excedentes de la agricultura en los mercados. Con el objetivo de solventar esto, se ha planificado un proyecto desde el Estado para comprar los excedentes agrícolas directamente y utilizarlos para diferentes programas sociales. Para esto, se realizará un catastro de producción agrícola y así se conocerá qué se produce en la zona.

Las actividades turísticas en el PE Chandless son un paso pendiente en la gestión de este AP. Esperan abrir el parque para el turismo de aves y, para esto, el Ministerio de Turismo está empezando a posicionar a las AP del estado de Acre como destinos que atraigan el turismo local.

\begin{tabular}{|c|c|c|}
\hline Iniciativas & Costos & Beneficios \\
\hline Producción agrícola & Mantenimiento de cultivos & Soberanía alimentaria \\
\hline Producción pecuaria & $\begin{array}{c}\text { Mantenimiento de potreros y de } \\
\text { animales }\end{array}$ & Ingresos económicos \\
\hline
\end{tabular}




\section{Impactos por el funcionamiento de las áreas protegidas}

\section{RESEX Cazumbá-Iracema}

En la RESEX Cazumbá-Iracema, las iniciativas que se han desarrollado a través de la coordinación o con el visto bueno de la jefatura del AP son: producción artesanal a partir de la recolección de goma, recolección y procesamiento de asaí, recolección de aceite de copaíba, mejora de la calidad de la harina, cursos profesionales para mejorar la producción agrícola y extractivista, programa de monitoreo de la biodiversidad, etc. Se está gestionando, desde la jefatura del parque, el inicio de dos proyectos priorizados por la población local del AP. construcción de viveros y lecciones de corte y confección.

Aun cuando se han gestionado y se continúan gestionando proyectos, el apoyo económico que llega a la población local a través de "Bolsa Familia" es muy importante para evitar que la población caiga en la pobreza y puedan así complementar sus ingresos económicos.

Un elemento importante a considerar es la dinámica de participación de la población en los proyectos impulsados por el AP. La participación de la población en los proyectos se da en función de que los productos o procesos cuenten con un mercado consolidado; cuando es un proyecto o producto nuevo, las personas no participan en la misma cantidad y con la misma motivación.

El proyecto de artesanías a partir de la recolección de goma inicia en 2002 con una investigación para mejorar la calidad de la goma. En el año 2008, se empiezan a fabricar réplicas de hojas (que sirven como salva-manteles) con el caucho mejorado, lo que abrió la posibilidad de la comercialización de estos productos procesados. Para la fabricación de las hojas de goma se hacen moldes con aluminio y hojas del

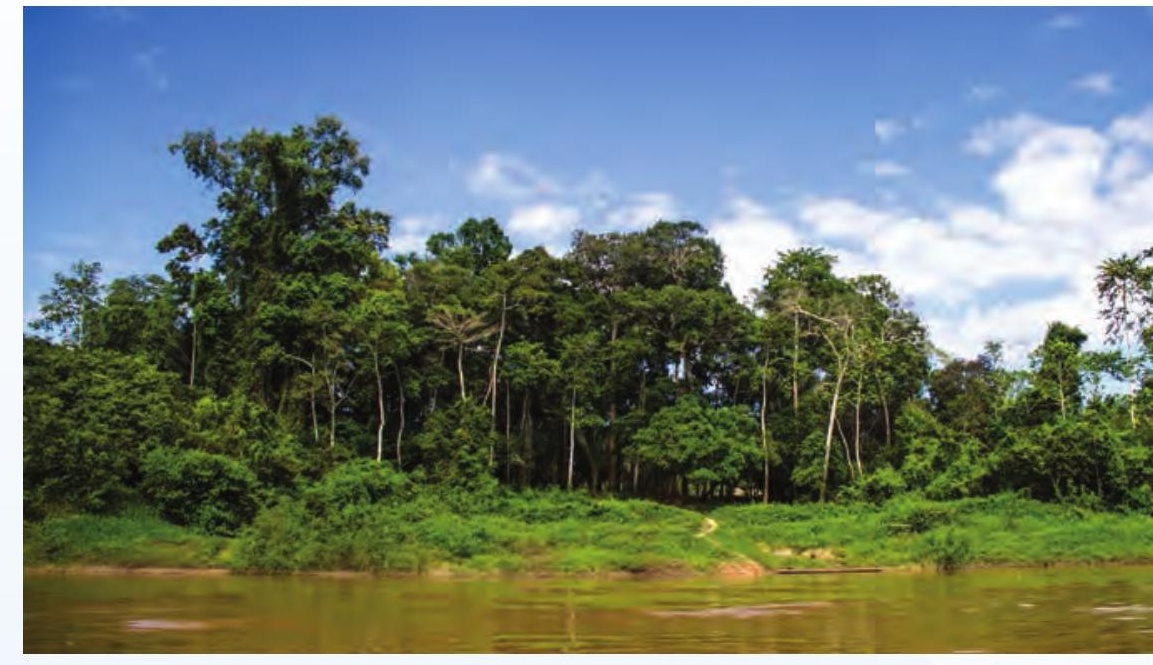

bosque. Esta iniciativa la iniciaron catorce personas y ahora participan veinticinco. Una ventaja es que, gracias a las estradas de seringa y al estado de conservación del bosque, pueden realizar el ciclo productivo completo: recolección-transformacióncomercialización.

La comercialización de estas hojas de goma es más sencilla con el apoyo de la jefatura del AP, ya que apoya en la asistencia a ferias y hace de interlocutora con el Estado y las empresas a favor de las artesanías. Los ingresos económicos por esta actividad se presentan a continuación:

El precio del kilogramo de caucho sin procesar, en el momento de esta investigación, se ubicó en 1,40 BRL (0,39 USD) sin subsidio estatal y en 3,70 BRL (1,04 USD) con subsidio. De esta materia prima, según la cantidad de árboles a los que se tenga acceso, se pueden obtener $15 \mathrm{~kg}$ diarios. De cada kilogramo de caucho se pueden obtener 8 artesanías de, aproximadamente, 4 onzas. De esta manera, de $15 \mathrm{~kg}$ de caucho se pueden obtener 120 artesanías. El precio de estas artesanías puede oscilar entre $5 \mathrm{BRL}$ y $15 \mathrm{BRL}$.

\section{Tabla 45:}

Ingresos económicos

por venta de artesanías de caucho

Fuente:

Elaboración propia con campo (2016) base en entrevistas de

\begin{tabular}{|c|c|c|c|c|}
\hline Producto/Actividad & Unidad & $\begin{array}{c}\text { Valor promedio de venta } \\
\text { por unidad } \\
\text { (Real brasileño) }\end{array}$ & $\begin{array}{c}\text { Valor total de } \\
\text { ganancias } \\
\text { (Real brasileño) }\end{array}$ & $\begin{array}{c}\text { Valor total de ganancias } \\
\text { (Dólares americanos) }\end{array}$ \\
\hline $\begin{array}{c}\text { Artesanías de } \\
\text { seringa (caucho) }\end{array}$ & 120 & $10 \mathrm{BRL}$ & $1200 \mathrm{BRL}$ & 343,84 USD \\
\hline
\end{tabular}




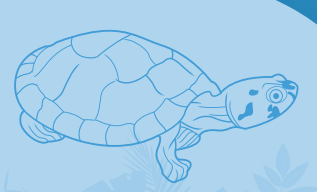

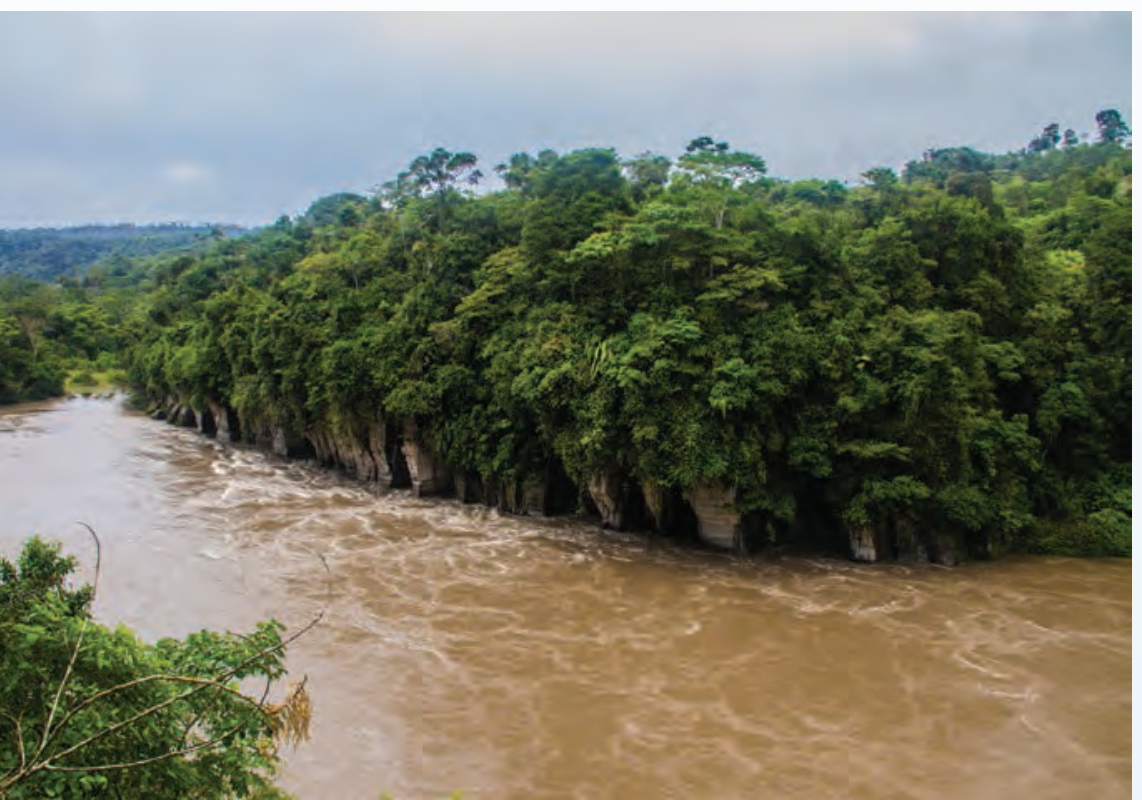

Las ganancias que se obtienen por cada kilo (o litro) de caucho que se procesa en artesanías pueden alcanzar los 1200 BRL (343,84 USD). Según manifestaron las personas de la asociación entrevistada, las ganancias por la venta de artesanías de caucho cubren, aproximadamente, el 70 \% de los gastos mensuales de sus hogares.

En esta actividad, son muy importantes los costos evitados que se tienen por producir dentro de su área protegida. En ella se aseguran una provisión de agua sin costo, muy necesaria para el procesamiento de las artesanías.

El proyecto de asaí de la RESEX Cazumbá-Iracema inicia de manera artesanal Tabla 46: siendo parte del consumo familiar. Más Costos y beneficios tarde, empezaron a crecer las familias in-
RESEX Cazumbáteresadas en el asaí y se impartió una capacitación para comenzar a industrializar Elaboración propia el producto, además de la construcción de una agroindustria para el procesamiento del asaí, financiada con recursos externos (USAID)

Con esta iniciativa se espera mejorar la alimentación y la seguridad alimentaria de las familias así como acrecentar los ingresos. Este es un producto del bosque cuyo aprovechamiento no requiere mucho trabajo y es abundante, lo que permite que se piense en la comercialización. De este modo, el proyecto cumple dos propósitos: primero, cubrir la alimentación de la población local; y, segundo, fomentar el comercio con ciudades como Sena Madureira, Manoel Urbano o Rio Branco.

El grupo de asaí está conformado por 8 personas, 6 hombres y 2 mujeres, y se espera que más personas se unan a esta iniciativa. En 2015 se organizó el grupo y en la actualidad se están realizando los ensayos.

Para comercializar el asaí de la RESEX aún se necesita una certificación sanitaria (este trámite no tiene un alto costo), pero para obtenerlo, posiblemente, se requieran mejoras en el proceso de industrialización. La presentación para la comercialización del producto se realizará en función de lo que exija el mercado.

Entre 2002 y 2004, se impulsó la incursión de la población en actividades de turismo, para lo que se construyeron cabañas en Núcleo do Cazumbá, pero este proyecto y la infraestructura han sido abandonados. El abandono de este proyecto, en gran medida se debió a que esta oferta turística no pudo vincularse con algún circuito de mercado, motivo por el cual la población optó por volcarse a otras actividades que, tal vez, brinden mejores ingresos económicos.

\begin{tabular}{|l|l|l|}
\hline \multicolumn{1}{|c|}{ Iniciativa } & \multicolumn{1}{c|}{ Costos } & \multicolumn{1}{c|}{ Beneficios } \\
\hline $\begin{array}{l}\text { Producción artesanal a partir de la } \\
\text { recolección de goma. }\end{array}$ & $\begin{array}{l}\text { Trabajo no remunerado al inicio del } \\
\text { proyecto }\end{array}$ & $\begin{array}{l}\text { Ingresos económicos por } \\
\text { comercialización de las artesanías de } \\
\text { goma. }\end{array}$ \\
\hline Recolección y procesamiento de asaí. & $\begin{array}{l}\text { Trabajo no remunerado al inicio del } \\
\text { proyecto }\end{array}$ & $\begin{array}{l}\text { Aún no se perciben beneficios } \\
\text { económicos. El principal beneficio } \\
\text { es la contribución a la seguridad } \\
\text { alimentaria de la población de la } \\
\text { RESEX Cazumbá-Iracema. }\end{array}$ \\
\hline
\end{tabular}


Los beneficios que ha recibido la población local de la RESEX Cazumbá-Iracema están relacionados con el valor agregado de los productos derivados del aprovechamiento de la goma, lo que permite generar mayores ingresos económicos por el aprovechamiento de este recurso.

Además, esta generación de valor agregado no solo sucede con la goma, sino con la producción de asaí. Aunque todavía no se comercializa, este proceso se está realizando en una infraestructura que está dentro del AP, lo que les ayuda a evitar los costos que se generarían por estar ubicados en otro lugar más alejado (transporte, arriendo, etc.)

Otro beneficio importante es la conexión con mercados que se ha logrado consolidar para la venta de artesanías de goma a través de la colaboración de la jefatura del AP y socios como WWF Brasil. Esto les ha permitido concursar en procesos en otros lugares de Brasil y del mundo, lo que se traduce en mayores posibilidades de ingresar a mercados de comercio justo.

Transferencias económicas por actividades de conservación

Un proceso importante que se desarrolla en Ecuador, Perú, Brasil y Bolivia son las transferencias económicas desde el Estado hacia las poblaciones que habitan dentro de áreas protegidas. Estas transferencias económi- cas, con diferentes mecanismos en cada país, benefician directamente a las poblaciones locales de las AP y son un estímulo para la conservación, el uso sostenible de los recursos y, además, son un impacto positivo para la economía familiar y comunitaria.

En Ecuador, este apoyo ocurre a través del programa Socio Bosque, del Ministerio del Ambiente. Se trata de una transferencia económica anual que asigna valores económicos proporcionales a la cantidad de territorio que se destina para conservación. En la RPF Cuyabeno, la aplicación del programa Socio Bosque ha sido posible gracias al trabajo de linderación que ha realizado la jefatura del AP y por las medidas de conservación que se han aplicado. Todo esto ha permitido que las comunidades se beneficien de las transferencias económicas que genera este programa, posicionando a la RPF Cuyabeno como el AP de Ecuador con más zonas del programa Socio Bosque del país.

Las comunidades de la RPF Cuyabeno que se han adscrito a Socio Bosque deben presentar un plan de inversión para el dinero que obtienen. Además, deben establecer un plan de control y vigilancia del territorio para asegurar la conservación de las áreas bajo protección de este programa. Los recursos económicos que ingresan a las comunidades que participan en Socio Bosque se destinan para equipamiento de la comunidad y también se reparten, como sueldos, entre las familias de la comunidad a través de la

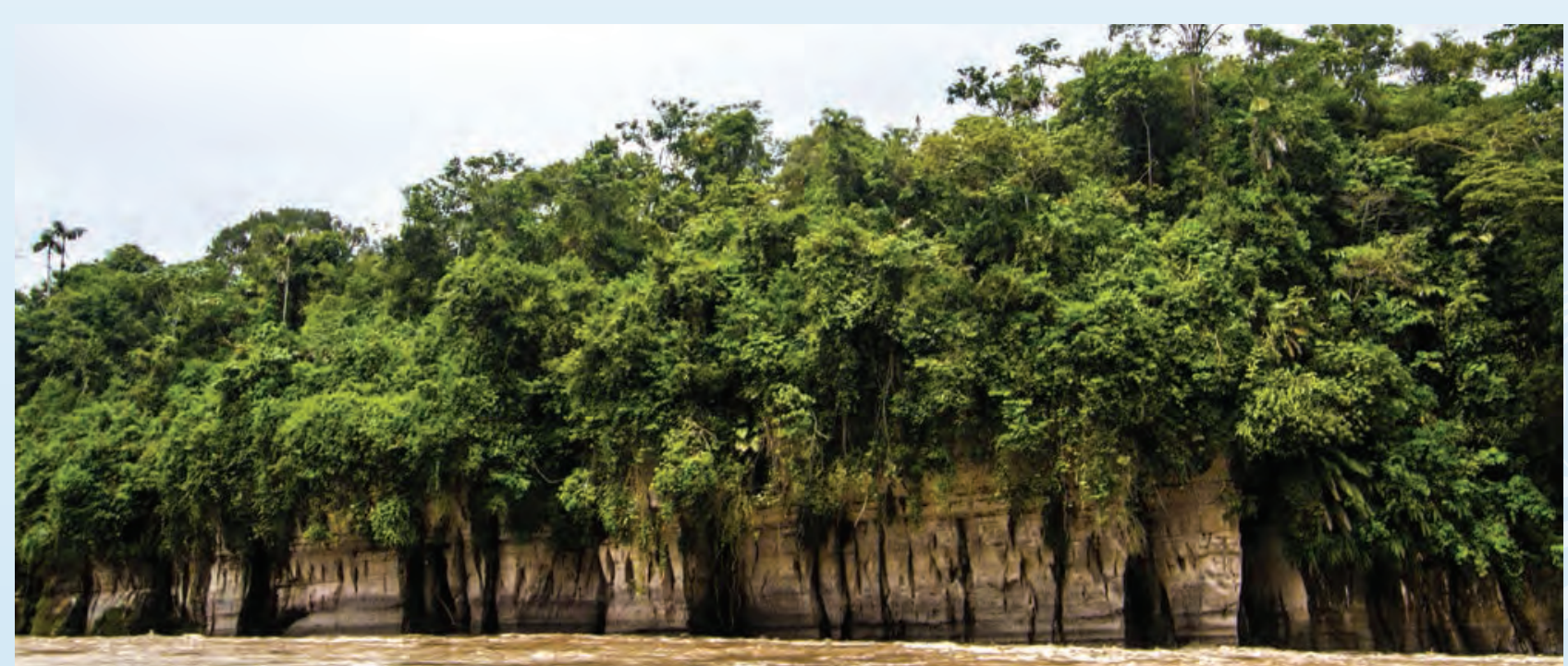

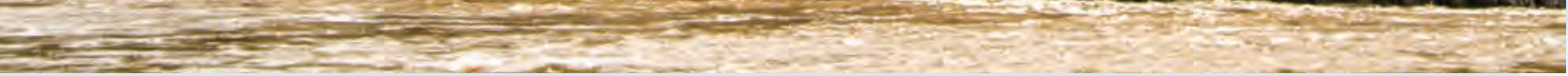


que viven dentro del AP, a través de la construcción de casas con baño, agua entubada y placa solar, pero sin perder el modelo local de la arquitectura. Para la construcción de estas casas se utilizará la madera que haya sido confiscada de tala ilegal.

En el caso de Perú, el Organismo de Supervisión de los recursos forestales (OSINFOR) planifica dar un estímulo a las comunidades por realizar aportes a la conservación. Este proyecto está destinado, de manera específica, a las comunidades que tienen deudas con el Estado por impuestos forestales. Para ser parte de esta iniciativa las comunidades deben presentar un plan de conservación simple para los bosques comunitarios y deben cancelar una parte de la deuda que mantienen con el Estado.

Hay comunidades que, en la actualidad, tienen deudas de hasta 121000 PEN (36 659 USD) debido a las estafas que sufrieron por parte de los habilitadores que extrajeron madera de sus territorios pero no pagaron los impuestos derivados de permisos forestales. Con este proyecto se espera trabajar en periodos de cinco años en los siguientes ejes: estímulo a la conservación de los bosques, reducción de la presión sobre los bosques por el endeudamiento de las comunidades y aprovechamiento de recursos del bosque que puedan ser utilizados por la comunidad. Esto se realizará a través de planes de manejo que aseguren la sostenibilidad de las actividades.

En el caso de Bolivia, la transferencia por actividades de conservación está enfocada directamente en la producción de castaña orgánica certificada. Esta transferencia económica es liderada por la Empresa Boliviana de Almendra y Derivados (EBA) y es un impacto muy beneficioso para la población de la RNVSA Manuripi.

Esta transferencia se realiza como un reconocimiento a las buenas prácticas ambientales en la extracción de la castaña y se realiza de la siguiente manera: cuando empieza a salir la producción de la zafra de castaña (entre marzo y mayo), la EBA compra el producto certificado a los campesinos y paga el precio justo de mercado (450 BOB por cada barrica de 70 kg de castaña, 63,28 USD, a la fecha) y a partir del mes de septiembre paga un $20 \%$ del valor total, de retorno o sobreprecio por la certificación orgánica de cada barrica vendida por el productor en el momento de la zafra.

Con este mecanismo, la EBA fomenta las buenas prácticas en la recolección de la castaña y, además, desmonta el sistema de "habilitación" que está vinculado a los inicios de periodos de zafra castañera, donde la población debe endeudarse para realizar esta actividad, lo que les impide que los réditos económicos de la producción de castaña sean realmente una ganancia, sino que se conviertan en un salvavidas de las deudas. Con la transferencia que realiza la EBA, los recolectores de castaña aseguran tener dinero para el inicio del nuevo proceso de zafra y así pueden también lograr una mejor distribución del gasto de las ganancias por la esta actividad.

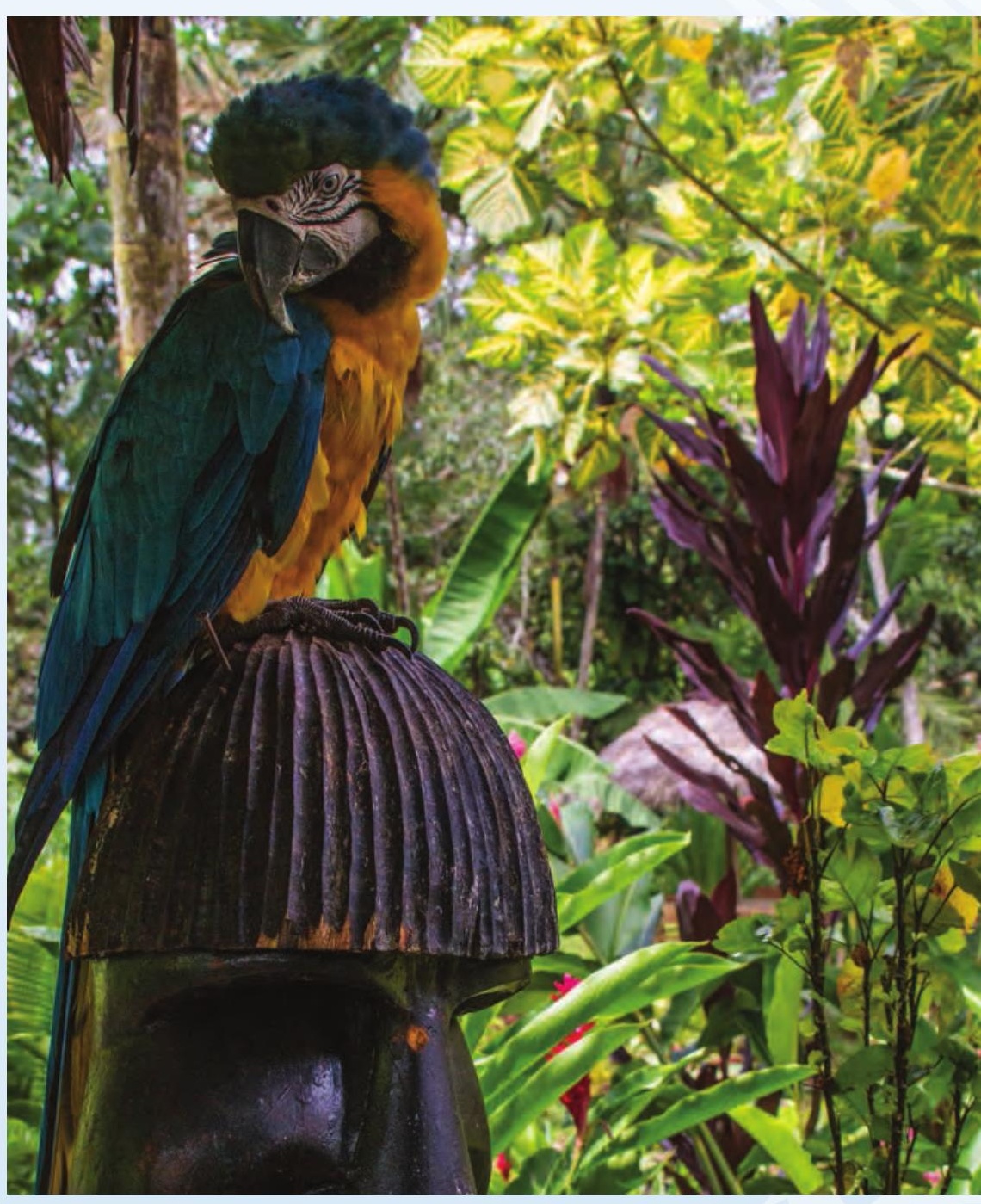




\section{Conclusiones}

\section{Sobre el aprovechamiento sostenible de los recursos naturales de las áreas protegidas}

Las poblaciones locales que habitan las áreas protegidas analizadas mantienen conocimientos importantes sobre el aprovechamiento de los recursos naturales amazónicos. Tanto las poblaciones indígenas (con sus conocimientos ancestrales) como las poblaciones campesinas colonas (con prácticas que se han adaptado al espacio amazónico) son los actores base para generar políticas de conservación de las áreas protegidas. Aquí radica la importancia de las intervenciones de jefaturas de área, Estados, organismos internacionales y organizaciones sociales de base, entre otras, que impulsan prácticas sostenibles de aprovechamiento de los recursos de los bosques.

La Amazonía es un espacio de gran diversidad y resiliencia, aunque procesos históricos de aprovechamiento intensivo de sus recursos han puesto en riesgo poblaciones de flora y fauna y la preservación cultural. La disminución de la caza y de espacios boscosos es una realidad para las poblaciones locales de las áreas protegidas, lo que hace que emerja una preocupación desde espacios locales por generar acciones encaminadas hacia la conservación.

Esta preocupación por la conservación está vinculada a la protección de espacios de vida importantes para la reproducción social, económica y cultural de las poblaciones locales. Estas acciones de conservación suponen también un cambio importante en la forma en que debe ser visto el bosque y los recursos que en este existen. Esta es una de las dificultades a las que se enfrentan las acciones de conservación frente a prácticas cotidianas de sustento de los hogares.

A través de los años, las poblaciones locales de las áreas protegidas han abastecido sus hogares a través de actividades de autosustento, las cuales, de manera progresiva, han ido incrementando la necesidad de incor- porar productos externos, como alimentos procesados, medicina, tecnología de comunicación, etc., lo que ha generado un proceso de crecimiento de la relación con el mercado y, por ende, de relación con la moneda.

Esta relación exige que las poblaciones locales tengan necesidades que superan la capacidad de provisión de sus espacios de vida, ya que hay cosas que no pueden producir. Por este motivo, deben vender aquello con lo que cuentan para tener ingresos económicos y, de esta manera, comprar lo que necesitan.

En un primer momento, lo que la población local vendía eran los productos silvestres del bosque, ya fuera directamente o a través de "habilitadores". Con la declaratoria de las AP, esta dinámica cambió, por la normativa vigente y por el impulso de actividades sostenibles para el aprovechamiento de los materiales del bosque. Aunque este cambio es beneficioso en términos de conservación de espacios de vida social, cultural y ambiental, los ingresos económicos de la población han tenido un descenso y la presión para el abastecimiento económico del hogar ha recaído sobre las chacras.

Antes de la creación de las AP, los espacios productivos de la población local (las chacras) estaban enfocados, específicamente, en preservar la diversidad de productos alimenticios, medicinales y artesanales vinculados a la reproducción de prácticas culturales propias. Después de la creación de las AP y tras la expedición de normativa ambiental para la comercialización de productos del bosque, las chacras toman la forma de unidades productivas, en las que se deben producir alimentos para la comercialización. Por este motivo, en la actualidad, es generalizada la producción agrícola para el mercado, dando como resultado un proceso de disminución de la diversidad de las chacras 
de las AP analizadas, ya que estas unidades productivas ya no solo deben atender al abastecimiento de productos para el hogar sino abastecer necesidades comerciales para generar ingresos monetarios.

En algunas comunidades se han perdido las chacras (por ejemplo, hay casos en la RVSA Manuripi o en parte del PNN La Paya), debido a que las actividades agrícolas para comercialización no generan los ingresos económicos que se esperan. Por el esfuerzo que implica esta actividad y la baja remuneración que obtienen por sus productos, la población prefiere migrar hacia otras actividades productivas (asalariadas) que, aunque no brinden ninguna seguridad alimentaria, dan un mayor acceso a ingresos monetarios, lo que les permite un mayor consumo de bienes y servicios que provee el mercado.

por actividade. producción sostenible

Fuente: Elaboración propia con datos de entrevistas en campo (2016) productos del bosque además de para procurar minimizar la presión sobre los recursos de las AP a causa de ilícitos ambientales -, las jefaturas de las áreas protegidas (con el apoyo de organizaciones internacionales) han trabajado en dar opciones económicas a las poblaciones locales de las áreas protegidas, mediante el uso sostenible de los recursos del bosque. De esta manera, aparecen proyectos importantes de comercialización de cacao orgánico, castaña orgánica, recolección de semillas de caoba, procesamiento de asaí, venta de tortugas y transformación del caucho en artesanías, entre otros.

Estos proyectos generan ingresos para las poblaciones locales de las AP a mediano y largo plazo, con criterios de sostenibilidad, dando opciones complementarias a la producción agrícola, para el abastecimiento de los hogares de las áreas protegidas. Por ejemplo:

\begin{tabular}{|l|l|}
\hline \multicolumn{1}{|c|}{ Actividad de producción sostenible en las AP } & Ingreso económico \\
\hline $\begin{array}{l}\text { Venta de cacao orgánico en la comunidad Zancudo Cocha (RPF } \\
\text { Cuyabeno) }\end{array}$ & 896 USD/año para la comunidad \\
\hline Venta de pasta de cacao Asociación El Porvenir (RPF Cuyabeno) & 3350 USD/año para cada familia participante \\
\hline Venta de quelonios, taricayas y teparos (PN Alto Purús y RC Purús) & $\begin{array}{l}\text { Entre } 8947,41 \text { USD/año y 12 219,36 USD/año para } \\
\text { cada asociación que participa en el proyecto. }\end{array}$ \\
\hline Venta de semillas de Caoba (RC Purús) & 1798,02 USD/año para la asociación \\
\hline Venta de castaña certificada (RVSA Manuripi) & 10 074,7 USD/año para cada familia \\
\hline Venta de artesanías de goma (RESEX Cazumbá-Iracema) & 343,84 USD/lote de 15 kg de goma \\
\hline
\end{tabular}

Todos estos productos cuentan con certificaciones orgánicas y de origen, como el "Sello de Origen" de la castaña en Manuripi, las tortugas charapas en la RC Purús, "Cacao Arriba", artesanías de caucho en la RESEX Cazumbá-Iracema y la actividad de turismo responsable en Cuyabeno. Estos certificados dan un valor agregado a los productos y servicios; garantizan un manejo sostenible que toma en cuenta aspectos ecológicos sociales y culturales; abren las puertas a mercados internacionales; permiten mejores condiciones para la negociación; y benefician a las áreas protegidas.
Además, estos proyectos productivos de las áreas protegidas buscan potenciar y recuperar las prácticas tradicionales y generar una fuente de ingresos para las familias que habitan en el área. En la mayoría de casos, estos proyectos se han dado por intervención y asesoría de actores externos: Estado (área protegida), ONG, cooperación internacional y empresa privada. Uno de los logros importantes de estos proyectos es la diversificación de las fuentes de ingresos de la población con diferente periodicidad (dependiendo del producto). De esta manera, es posible que la población tenga ingresos 
en varios momentos del año permitiendo el sustento económico de los hogares. Además, esto permite cierto nivel de resiliencia de la economía familiar ya que, al no depender de un solo ingreso, si alguna de las actividades económicas falla, se pueden esperar los beneficios de la siguiente actividad.

Para esto, se recomienda continuar abriendo nuevas actividades de aprovechamiento sostenible en las áreas protegidas. La investigación de formas de aprovechamiento de recursos del bosque ambientalmente amigables y la agregación de valor a los productos es un gran paso para que, después, estos elementos puedan ser conectados con mercados a nivel local, regional y/o mundial. La experiencia de la RESEX Cazumbá-Iracema sobre la agregación de valor a las artesanías que se realizan con caucho es muy importante y puede ser tomada como modelo, o replicada, por otras áreas protegidas que cuenten con este recurso.

De manera conjunta a la investigación, es importante que se aceleren los procesos de legalización para la comercialización de productos que se extraen/producen dentro de las áreas protegidas. Estos permisos son los que avalan la producción sostenible para que, de esta manera, la población se pueda beneficiar a corto plazo del desarrollo de estos proyectos y, más importante aún, que la población se motive a trabajar en coordinación con el área protegida, ya que, en muchos casos, los largos tiempos de espera para la implementación del proyecto desaniman a la población a participar.

El turismo en áreas protegidas es una actividad potencial que requiere contar con una combinación de condiciones ambientales, sociales, jurídicas e institucionales para que su desarrollo sea sostenible. El caso más desarrollado en los paisajes es el que se realiza en la RPF Cuyabeno, donde los indígenas presentan su cultura como un atractivo, aunque esta actividad no sea manejada directamente por ellos, pero sí por operadores turísticos especializados. El atractivo mayor es, sin duda, la fauna y flora de la reserva.

Los ingresos que puede generar las actividades turísticas, sean directamente comunitarias o a través de la prestación de servicios en iniciativas privadas, son importantes:
Tabla 48:

Ingresos por actividades turísticas RPF Cuyabeno Fuente:

Elaboración propia con datos de entrevistas en campo (2076)

\begin{tabular}{|c|c|}
\hline Reserva de Producción Faunística Cuyabeno & Ingreso \\
\hline $\begin{array}{l}\text { Ingresos anuales generados, dentro del AP, por iniciativas } \\
\text { turísticas privadas (participación comunitaria) }\end{array}$ & 195000 USD/año \\
\hline \multicolumn{2}{|l|}{ Ingresos por prestación individual de servicios: } \\
\hline Renta de espacio para el lodge & Entre 400 USD y 1000 USD/mes para la familia \\
\hline Contratación de canoa & 85 USD/día para el conductor de la canoa \\
\hline Guía local & 60 USD/día para el guía local \\
\hline Trabajo (cocina, limpieza) & 366 USD/mes para la persona que trabaja \\
\hline
\end{tabular}

En este caso, la experiencia de la Reserva de Producción de Fauna Cuyabeno es un importante referente en el desarrollo de actividades turísticas dentro de un área protegida. Aunque su contexto es particular por la cercanía a vías que la conectan con una ciudad de fácil acceso y por su categoría de manejo, que permite que las actividades de hospedaje se realicen dentro del área protegida, la RFP Cuyabeno es un ejemplo claro de las posibilidades que se generan en las alianzas comunitarias y privadas para rea- lizar emprendimientos que, aunque no sean comunitarios, generan grandes beneficios para las poblaciones locales que se vinculan a estas actividades.

Por este motivo, es importante recomendar que las AP que estén interesadas en desarrollar actividades turísticas consideren la posibilidad de realizar alianzas similares a las que existen dentro de la Reserva de Producción de Fauna Cuyabeno, ya que esto permite la inversión de capital para iniciar el 
proyecto y, además, da la posibilidad de que la comunidad no asuma los riesgos económicos que implica este tipo de negocio. A largo plazo, esto se puede convertir en un ejercicio de transferencia de conocimientos sobre el manejo turístico, lo que abre la posibilidad de que, en el futuro, la población también pueda realizar emprendimientos turísticos propios.

A través del trabajo realizado y del análisis de estas actividades -y de otras actividades que no han tenido éxito en las áreas protegidas-, se puede derivar que los proyectos que más éxito tienen son aquellos que se conectan con circuitos de mercado, que ofrecen productos que ya están valorizados y que permiten ingresos económicos, a mediano plazo, a las poblaciones locales de las AP. Este contexto se convierte en una dificultad para la comercialización de la producción sostenible actual y para incursionar en la comercialización de nuevos productos.

Por ejemplo, para aquellos productos que no tienen mercados fijos, como las semillas de caoba certificadas de la RC Purús, o las artesanías de caucho de la RESEX Cazumbá-Iracema, las variaciones en los compradores de estos productos dificultan que las comunidades puedan tener una producción fija que les permita también proyectar sus beneficios económicos

De esta manera, es necesario que se impulsen procesos de apertura de mercados para los productos de las áreas protegidas que permitan asegurar la venta de la producción local sostenible. También es necesario que las poblaciones locales reciban capacitación, no solamente en técnicas de producción sostenible, sino también en el manejo de los ingresos que generan, fortaleciendo una visión de acumulación y ahorro que les permita dar un paso más allá del autoabastecimiento.

Para finalizar, este tipo de iniciativas que fomentan el intercambio de experiencias de gestión entre áreas protegidas con amplias similitudes son fundamentales para fortalecer las capacidades y el intercambio de conocimientos sobre aprovechamiento sostenible y formas variadas de resolver limitaciones del día a día. Por este motivo, se insta a continuar con este trabajo y el acercamiento entre líderes de diferentes áreas protegidas con diferentes productos o experiencias, para que se puedan generar espacios de conocimiento que partan desde las experiencias locales y, de las cuales, se puedan extraer nuevas ideas para el beneficio económico y cultural de las poblaciones de las áreas protegidas.

\section{Sobre la gobernanza territorial de las poblaciones locales en las áreas protegidas}

Los pueblos indígenas que habitan las áreas protegidas descritas aportan a la conservación de los ecosistemas y los recursos naturales con la práctica de sus actividades tradicionales. Entre estas se pueden mencionar diferentes mecanismos de uso de recursos naturales y de gobernanza territorial, que ha generado procesos favorables para la conservación del ecosistema en su conjunto.

Un mecanismo de incorporación de la población a actividades de gestión de las áreas protegidas se realiza a través de personas de las comunidades que pueden monitorear las condiciones de la biodiversidad porque están en al día de lo que acontece, conocen su territorio, realizan prácticas tradicionales, además del conocimiento ancestral con el que cuentan. Adicionalmente, la sistematización de la información, para la cual han sido capacitados, les permite notar los cambios con mayor claridad y así tomar decisiones acertadas en el debido momento (vedas, controles, elaboración de reglamentos) apropiándose de las condiciones del territorio.

Respecto a las variaciones del clima, los indígenas coinciden en que estas forman parte de los cambios de la naturaleza. Sin embargo, existe una percepción de la variación por experiencias particulares relacionadas a inundaciones y sequías. En el caso de los indígenas, los muruis están realizando adaptaciones a sus calendarios de caza, pesca y siembra basados en sus conocimientos tradicionales asociados; las comunidades nativas del río Purús, adaptaron mecanismos 
de prevención y establecieron acuerdos con otras comunidades para salvar sus cultivos de maní los cuales estaban en peligro por la creciente del río fuera de temporada.

La conformación de comités locales para control y vigilancia (como el de Puerto Leguízamo), los comités de vigilancia comunitaria (en Güeppi), las concesiones forestales en la RCP, acuerdos de vigilancia con las comunidades en Brasil y los sistemas de control y vigilancia en Alto Purús son una excelente manera de organizar y empoderar a las comunidades, poniendo más dificultades al desarrollo de actividades ilegales en las áreas protegidas. Otras maneras efectivas de involucrar a las comunidades en las actividades de control y vigilancia son el Programa Socio Bosque (Ecuador) y la acreditación como custodios del patrimonio forestal a miembros de la Asociación MABOSINFRON de la RC Purús, la única que faculta a sus miembros (líderes campesinos) a tomar acciones frente a actos ilegales dentro del área concesionada. Se evidencia mayor dificultad para actividades ilegales en los territorios indígenas y las reservas territoriales por la apropiación del territorio, lo que, entre otras cosas, garantiza los derechos a los pueblos indígenas en Aislamiento Voluntario y Contacto Inicial que se movilizan entre Brasil y Perú. En la zona de frontera compartida entre los tres países del paisaje norte hay mucha presencia de fuerzas armadas y destacamentos militares a lo largo de los ríos Putumayo y Aguarico, principalmente en Colombia y Ecuador, debido al conflicto armado colombiano, el cual da una dinámica particular a este paisaje e influye en la actividad de control y vigilancia.

Los planes de vida de los pueblos indígenas son herramientas para plasmar por escrito sus formas de vida tradicional, la visión a futuro sobre su territorio y el uso de recursos, que antes se hacía de manera oral. Ahora, los planes de manejo comunitarios se vinculan a los planes de vida lo que les permite hacer seguimiento y medir los avances de las actividades y proyectos.

El capital social de las áreas protegidas es fundamental para fortalecer la participación y toma de decisión. El Programa Trinacional, en el paisaje norte, ha sido un impulso im- portante para el desarrollo participativo de las áreas protegidas de manera individual y de forma colectiva. Existen casos como la RESEX Cazumbá-Iracema y la RC Purús donde se evidencia mucha organización y las comunidades cuentan con capacidad de gestión y poder de negociación. Este no es el caso de todas las áreas protegidas de los paisajes.

La toma de decisiones consuetudinarias de los pueblos indígenas está vinculada a su cosmovisión y modo de vida en equilibrio con la naturaleza y constituye una importante herramienta para llegar a acuerdos de uso y manejo de los recursos naturales. La toma de decisiones en relación a la exploración y explotación de recursos debe contemplar aspectos de consentimiento ya que se realiza dentro de sus territorios. En el caso de Perú, con la Ley de Derecho a la Consulta Previa a los pueblos indígenas u Originarios, los indígenas son actores fundamentales en la toma de decisiones. En el caso de Brasil y Bolivia la consulta a los pueblos indígenas también es vinculante. En el caso de Ecuador y Colombia los pueblos indígenas son consultados pero los resultados no tienen carácter vinculante, por lo que es necesario fortalecer estos procesos que amparan los derechos fundamentales de los pueblos indígenas.

Los comités de gestión son los mecanismos a través de los cuales la participación comunitaria se expresa en las áreas protegidas. Constituyen el espacio donde se realiza la toma de decisiones con actores relevantes que participan de forma permanente permitiendo la continuidad de los procesos para que estos sean sostenibles en el tiempo. En el paisaje norte, la participación en estos comités es limitada y los actores no se han apropiado de los mismos. Por el contrario, es a través de otras instancias legítimas donde se llegan a acuerdos y a acciones concretas tales como los Conversatorios de Acción Ciudadana, los procesos participativos promovidos por el Municipio de Puerto Leguízamo (Colombia) o la elaboración de los planes de manejo comunitarios y del área protegida en Cuyabeno. En el paisaje sur, los comités de gestión o sus equivalentes -Comité de Gestión Manuripi y PNAP, Consejo Consultivo PEC, Consejo De- 
mité Asesor (Alto Purús) y los Ejecutores de Contratos de Administración (RCP) - son los mecanismos de participación y toma de decisión relevantes para la zona.

Los pueblos indígenas y las comunidades locales cuentan con conocimientos particulares sobre el territorio, el uso de los recursos y las condiciones generales de los ecosistemas. El establecimiento del ordenamiento territorial de estas áreas se ha basado en los conocimientos provistos por estas poblaciones, lo cual ha permitido establecer la zonificación de las áreas protegidas y el uso adecuado del territorio, contribuyendo así a la conservación de las áreas protegidas en base a estos conocimientos. Se evidencia presión por acceso y uso de tierras en ambos paisajes tanto al interior de las áreas protegidas (como el caso de los hijos de los encarpetados en Manuripi o los conflictos de límites entre comunidades de Cuyabeno) como desde las zonas de amortiguamiento (tierras indígenas que limitan con el PE Chandless o ganaderos y campesinos ubicados en los límites de las áreas protegidas). Los espacios de diálogo y acuerdos entre los involucrados, como el taller que se realizó en el PE Chandless con moradores del parque e indígenas madijás, son formas efectivas de alcanzar consensos en base a las necesidades reales de cada parte.

Los conocimientos tradicionales son una fuente importante de información sobre la cual se basan muchas de las prácticas que los pueblos indígenas y las comunidades locales realizan para el manejo de los recursos naturales. Por ejemplo, la recuperación de los conocimientos tradicionales y modos de vida que está llevando a cabo el pueblo murui es una manera de apropiarse, defender su territorio y sentir orgullo de sus raíces. También destaca el caso de Cuyabeno, donde las prácticas culturales son un valor turístico de relevancia. Esto no es lo que sucede en todas las áreas protegidas, ya que en algunos casos existen procesos de aculturación que están transformando estos conocimientos en prácticas menos tradicionales, como la utilización del mambe fuera del uso tradicional ligado a lo espiritual o el abandono de las chacras y la incorporación de alimentos procesados que se obtienen fuera de la comunidad.
Contrariamente al valor de estas prácticas tradicionales, también se puede concluir que varias de las actividades productivas de aprovechamiento de los recursos del bosque, identificadas dentro de las áreas protegidas, se aprovechan mejor con la implementación de nuevas técnicas y tecnologías y la asesoría de especialistas con una visión global, dando un giro a la actividad. Este es el caso de las artesanías de goma o las nuevas formas de aprovechar el asaí, el aceite de copaiba, etc. en la RESEX Cazumbá-Iracema.

Las mujeres están presentes tanto a nivel familiar como a nivel comunitario, su aporte a la conservación de las áreas protegidas se da desde el ámbito cultural, con la transmisión de conocimientos y rescate de tradiciones; en el ámbito ecológico, con el cuidado de la chacra y la manutención del cultivo de plantas tradicionales (medicinales); y en el ámbito social, con su participación en las decisiones comunitarias y la generación de recursos económicos para su familia, entre otros.

Los jóvenes de los pueblos indígenas y comunidades locales tienen muchas limitaciones en la gestión comunitaria y en el escenario de las áreas protegidas. Se evidencia con preocupación su falta de involucramiento en actividades tradicionales $y$, adicionalmente, se promueve que los jóvenes se involucren en actividades fuera de las áreas protegidas, procurando nuevas alternativas económicas para su futuro. Esto los desvincula, no solo culturalmente, de estos procesos y de la transmisión de la responsabilidad sobre los recursos a futuro. El pueblo murui en la zona de amortiguamiento del PNN La Paya y los pobladores de Núcleo do Cazumbá tienen expectativas y apuestan por que los jóvenes, una vez culminados sus estudios universitarios, regresen a la comunidad para apoyar al desarrollo comunitario y dinamizar la economía local.

La conservación de las áreas protegidas es un trabajo conjunto de aportes, alianzas público-privadas, diálogos y acuerdos entre todos los involucrados, donde los pueblos indígenas y comunidades locales tienen un rol fundamental. Los logros alcanzados y las buenas prácticas constituyen ejemplos para la región y deben ser replicados. 


\section{Anexos}

Tablas con nombres científicos de especies nombradas en el texto

\begin{tabular}{|l|l|}
\hline Nombre común & Nombre científico \\
\hline Achiote & Bixa orellana \\
\hline Achojcha & Cyclanthera pedata \\
\hline Ají dulce & Capsicum annuum \\
\hline Algodón & Gossypium spp. \\
\hline Arazá & Eugenia stipitata \\
\hline Arroz & Oryza sativa \\
\hline Cacao & Theobroma cacao \\
\hline Café & Coffea spp. \\
\hline Camote & Ipomoea batatas \\
\hline Cilantro & Coriandrum sativum \\
\hline Coca & Erythroxylum coca \\
\hline Frejol & Phaseolus vulgaris \\
\hline Guanábana & Annona muricata \\
\hline Maíz & Zea mays \\
\hline Maní & Arachis hypogaea \\
\hline Papaya & Carica papaya \\
\hline Pepino & Cucumis sativus \\
\hline Piña & Ananas comosus \\
\hline Plátano & Musa paradisiaca \\
\hline Sachapapa / Name & Dioscore atrifida \\
\hline Sandía & Citrullus lanatus \\
\hline Yuca / Mandioca & Manihot esculenta \\
\hline Zapallo / Calabaza & Cucurbita maxima \\
\hline
\end{tabular}

\begin{tabular}{|l|l|}
\hline Nombre común & Nombre científico \\
\hline Aguaje & Mauritia flexuosa \\
\hline Asaí/Açaí & Euterpe oleracea \\
\hline Bacaba & Oenocarpus bacaba \\
\hline Canangucha & Mauritia flexuosa \\
\hline Camu-camu & Myrciaria dubia \\
\hline Chimicua & Perebea guianensis \\
\hline Chirimoya de monte & Annona \\
\hline Chonta/chontaduro & Bactris gasipaes \\
\hline Cocona & Solanum sessiliflorum \\
\hline Copoazú & Theobroma grandiflorum \\
\hline Copaiba & Copaifera langsdorffii \\
\hline $\begin{array}{l}\text { Majo/Milpeso/ } \\
\text { Ungurahua/ }\end{array}$ & Oenocarpus bataua \\
\hline Shapahui & Attalea phalerata \\
\hline Tagua/Yarina & Phytelephas macrocarpa \\
\hline Uva caimarona & Pourouma cecropiifolia \\
\hline Zapote de monte & Casimiroa edulis \\
\hline
\end{tabular}

Tabla 49:

Especies cultivadas

Fuente:

Elaboración propia

\begin{tabular}{|l|l|}
\hline Nombre común & Nombre científico \\
\hline Bagre & Siluriforme \\
\hline Bocachico & $\begin{array}{l}\text { Prochilodus } \\
\text { magdalenae }\end{array}$ \\
\hline Branquinha & Potamorhina spp. \\
\hline Carachama & $\begin{array}{l}\text { Pseudorinelepis } \\
\text { genibarbis }\end{array}$ \\
\hline $\begin{array}{l}\text { Doncella/Zúngaros/ } \\
\text { Surubí }\end{array}$ & Pseudoplatystoma \\
\hline Lisa & Rhytiodus microlepis \\
\hline Maparate & $\begin{array}{l}\text { Hypophthalmus } \\
\text { marginatus }\end{array}$ \\
\hline Mota & $\begin{array}{l}\text { Calophysus } \\
\text { macropterus }\end{array}$ \\
\hline Paco & $\begin{array}{l}\text { Piaractus } \\
\text { brachypomus }\end{array}$ \\
\hline
\end{tabular}

\begin{tabular}{|l|l|}
\hline Nombre común & Nombre científico \\
\hline Paiche & Arapaima gigas \\
\hline Palometa & Mylossoma duriventre \\
\hline Paña & Serrasalmus rhombeus \\
\hline Piraña & Serrasalminae \\
\hline Tambaquí & $\begin{array}{l}\text { Colossoma } \\
\text { macropomum }\end{array}$ \\
\hline Tucsi & Chaetostoma \\
\hline Tucunare & Cichla \\
\hline Yatorana & Brycon melanopterus \\
\hline Sábalo & Prochilodus lineatus \\
\hline
\end{tabular}




\section{Bibliografía}

\section{Bibliografía}

Araujo N. y Casavecchia C. (2014). Reserva de Producción de Fauna Cuyabeno, estudio de caso Ecuador. En: Amazonía más allá de las fronteras: lecciones aprendidas en áreas protegidas. Casavecchia C. (Editora). UICN, Quito, Ecuador

Banco Mundial, et.al (2014) How much is an ecosystem worth? Assessing the economy value of conservation.

Bolivia (17 de junio de 2004). Decreto Supremo No. 27572.

Borrini-Feyerabend, G., N. Dudley, T. Jaeger B. Lassen, N. Pathak Broome, A. Phillips y T. Sandwith (2014) Gobernanza de áreas protegidas: de la comprensión a la acción. No. 20 de la Serie: directrices para buenas prácticas en áreas protegidas, Gland, Suiza: UICN.

Burgos R., R. de la Cruz y T. Granizo. (2014) Construcción de una Estrategia para Manejo Holístico de Territorios de Vida Plena en la Cuenca Amazónica. Una contribución a la reflexión regional sobre la integridad de territorios indígenas amazónicos. Alianza COICA-WWF/TNC. Quito-Ecuador.

Candelo, C. (abril 2014). Historia: Liberando la palabra. Proyecto marco: Putumayo Tres Fronteras, WWF Colombia.

Capto Cuchón, J. (febrero 2015) Identificar alternativas productivas sostenibles social, económica y ambientalmente con potencial de desarrollo dentro del corredor de conservación La Paya-Cuyabeno-Güeppí. Consultoría realizada en el marco del Programa Trinacional de Conservación y Desarrollo Sostenible del Corredor de Gestión Transfronteriza La Paya-Cuyabeno-Güeppí

Cisneros P. y Mc Breen J. (2010). Superposición de territorios indígenas y áreas protegidas en América del Sur. UICN, Quito, Ecuador.

Código Nacional de Recursos Naturales Renovables y del Medio Ambiente, Colombia

Convenio entre el Ministerio de Agricultura y Ganadería y la Asociación de Comunida- des Indígenas de la Nacionalidad Cofán (ACOINCO) y la Comunidad Cofán de Zábalo para la conservación, usos y servicios de los recursos de la Reserva de Producción Faunística Cuyabeno en la jurisdicción de la Comunidad de Zábalo (15 de abril de 1992)

Decreto 622 (16 de marzo de 1977), por el cual se reglamentan parcialmente el Decreto Ley No. 2811 de 1974 sobre "Sistema de Parques Nacionales"; la Ley 23 de 1973 y la Ley $2^{\text {a }}$ de 1959, Colombia, Capítulo III, Reserva y Delimitación, Artículo 7.

Decreto Supremo No. 25158 Perú (4 de septiembre de 1998) y del D.S. No. 24781 (31 de julio de 1997)

Dinah Shelton, AntenorVaz, Beatriz Huertas Castillo, Carlos Camacho Nassar, Luis Jesús Bello, Paola Colleoni, José Proaño, Dany Mahecha R. (ed.), Carlos Eduardo Franky C. (ed.) y la Unión de Nativos Ayoreo de Paraguay e Iniciativa Amotodie (2012) pueblos indígenas en aislamiento voluntario y contacto inicial. IWGIA-IPES.

Dudley Nigel and Sue Stolton (ed.) (2008). Defining protected areas: an international conference in Almeria, Spain. Gland, Switzerland: IUCN. 220 pp.

Evaluación Nacional Ecuador del Proyecto "Un paisaje integrado de conservación y desarrollo sostenible: Fortalecimiento de un Sistema Regional de Áreas Protegidas y Territorios indígenas en la cuenca trinacional del Río Putumayo (Putumayo tres fronteras)". Mentefactura (agosto 2013).

Fagan, Chris y Diego Shoobridge (2005) Una investigación de la extracción ilegal de madera en el Parque Nacional Alto Purús y alrededores. Parkswatch.

Falla, Patricia. (1992) Historias de trocha y río. Un viaje por el Caucayá. Tesis de pregrado.

Fundación Futuro Latinoamericano, "Manual de Capacitación en Diálogo y Negociación Colaborativa para la Transformación de Conflictos 
Socioambientales", Quito, 2010.

Informe Avances en el Desarrollo del Programa de Trabajo Sobre Áreas Protegidas. Región Bioma Amazónico, REDPARQUES, (octubre 2010)

Ley de Áreas Naturales Protegidas de Perú (Ley N.․ 26834)

Ley General del Ambiente, Perú, Ley 28611 Artículo 110.

Memorando de entendimiento para la ejecución del Programa Trinacional de Conservación y Desarrollo Sostenible del Corredor de Áreas Protegidas PNN La Paya-ZR Güeppí-RPF Cuyabeno (13 de julio de 2011). Ministerio de Medio Ambiente, Vivienda y Desarrollo Territorial de Colombia, Ministerio del Ambiente de Ecuador y Ministerio del Ambiente de Perú. Bogotá.

Ministerio del Ambiente de Perú y el Instituto de la Amazonía Peruana, Informe: Minería aurífera en Madre de Dios y contaminación con mercurio (2011)

Ministerio del Ambiente de Ecuador (2006). Políticas y Plan Estratégico del Sistema Nacional de Áreas Protegidas de Ecuador 2007-2016. Proyecto GEF: Sistema Nacional de Áreas Protegidas. Quito, Ecuador

Ministerio del Ambiente Ecuador (abril, 2008). Plan de Manejo Comunitario del Centro Kichwa Zancudo Cocha, Reserva de Producción Faunística Cuyabeno. Ministerio del Ambiente, Secretaría Plan Ecuador, Programa de Desarrollo Sostenible de la Frontera Amazónica Norte de Ecuador, AMAZNOR. Préstamo BID No 1420 / OCEC.

- Ministerio del Ambiente Ecuador (diciembre, 2008). Plan de Manejo Comunitario del Centro Cofán Zábalo, Reserva de Producción Faunística Cuyabeno. Ministerio del Ambiente, Secretaría Plan Ecuador, Programa de Desarrollo Sostenible de la Frontera Amazónica Norte de Ecuador, AMAZNOR. Préstamo BID No 1420 / OC-EC.

Ministerio del Ambiente Ecuador (2008). Convenio de Cooperación entre el Ministerio del Medio Ambiente y el Centro Kichwa Zancudo Cocha para la conservación, gestión y manejo del territorio del Centro
Kichwa Zancudo Cocha en la Reserva de Producción Faunística Cuyabeno.

Ministerio del Ambiente Ecuador (2012). Plan de Manejo de la Reserva de Producción de Fauna Cuyabeno. Quito, Ecuador. $56 \mathrm{p}$.

Ministerio del Ambiente Perú, SERNANP Plan Maestro de la Reserva Comunal Purús 2012-2017

Ministerio del Ambiente Perú, SERNANP Plan Maestro del Parque Nacional Alto Purús 2012-2017.

Ministerio del Ambiente Perú, SERNANP. Primera edición (junio 2015). Diagnóstico del Parque Nacional Güeppí-Sekime 20142019.

Ministerio del Ambiente Perú, SERNANP. Primera edición (junio 2015). Plan Maestro del Parque Nacional Güeppí-Sekime 20142019.

Modelo de Gestión Organizativa del PNN La Paya, Parques Nacionales Naturales de Colombia (2013)

Morales, E. (diciembre 2014). Proyecto: Putumayo Extensión. WWF Perú.

Oviedo, G. (julio 2007) Territorios Indígenas y Conservación. Taller de Gobernanza para la Conservación de la Cordillera Real Oriental, Colombia, Ecuador y Perú.

Parques Nacionales Naturales de Colombia. Plan de Manejo del Parque Nacional Natural La Paya. Línea Base para la formulación del Plan de Manejo del Parque Nacional Natural La Paya -2007 -2011.

Polanco Ochoa, R. (2013). Leguízamo: hacia una construcción histórica del territorio. Proyecto Putumayo Tres Fronteras del Programa Trinacional de conservación y desarrollo sostenible del corredor de áreas protegidas, La Paya (Colombia), Cuyabeno (Ecuador) y Güeppí (Perú). Tropenbos Internacional. Colombia, Bogotá.

Propuesta de Proceso de Revisión del Plan de Manejo Participativo de la Reserva Extractivista Cazumbá-Iracema. SOS Amzonia, ICMBio, WWF-Brasil. (Enero 2014)

Reglamento para el Control de la Zafra de 


\section{Bibliografía}

la Castaña en la Reserva Nacional de Vida Silvestre Amazónica Manuripi, resolución administrativa DE-044/2008 del 19 de diciembre del 2008, Bolivia.

Renshaw, J., \& Wray, N. (2004). Indicadores de pobreza indígena. Documento inédito.

Resolución de Intendencia N. ${ }^{\circ}$ 019-2005-INRENA-IANP, Perú

Resolución No. 031, del 26 de enero del 2007 del Ministerio de Ambiente, Vivienda y Desarrollo Territorial, Unidad Administrativa Especial del Sistema de Parques $\mathrm{Na-}$ cionales Naturales, Colombia

Sahlins, Marshall (1974). Stone AgeEconomics. TavistockPress, London

Spicker, P., Álvarez Lequizamón, S., \& Gordon, D. (2009). Pobreza un glosario internacional (No. 3 300.72). e-libro, Corp.

Suárez, L., y Cohanoff, C. (2013). ¿Cómo evaluar un área protegida? VII Congreso de Medio Ambiente.

Ormaza, Paulina y Fernando Bajaña (s/f) Territorios A'icofan, SiekóyaPâi, Siona, Shuar Y Kichwa Zona Baja De La Reserva De Producción Faunística Cuyabeno. Ecuador

Usma, J.S., C. Ortega P., S. Valenzuela, J. Deza \& J. Rivas (Eds.) (2016). Diversidad biológica y cultural del Corredor Trinacional de áreas protegidas La Paya - Cuyabeno Güeppí Sekime. Colombia - Ecuador - Perú. WWF. Bogotá D.C., Colombia. 333p.

Weber, Max (2007) La ciencia como profesión. La política como profesión. Espasa Calpe, Madrid.

Planes de ordenamiento, desarrollo territorial y manejo consultados:

Plan de Desarrollo Integral de los pueblos indígenas del Alto Purús 2004-2009, FECONAPU

Plan de Desarrollo y Ordenamiento Territorial del Cantón Cuyabeno 2015-2020

Plan de Desarrollo y Ordenamiento Territorial La Paya (2000)

Plan de Manejo Ambiental del Parque Estadual Chandless (2010)
Plan de Manejo Ambiental de Manuripi (2010)

Plan de Manejo de la Reserva de Producción Faunística Cuyabeno (2012)

Plan de Manejo de la Reserva Extractivista Cazumbá-Iracema (2007)

Plan de Manejo de la Reserva Nacional de Vida Silvestre Amazónica Manuripi 2012 2022.

Plan de Manejo de Quelonios de la Asociación de la cuenca del Río Alto Purús "ASMARENAPU" (2014-2018)

Plan de Manejo de Quelonios de la Asociación de la cuenca del Río Curanja "ASMARENAC" (2014-2018)

PDOT (2000). Plan de ordenamiento territorial del Municipio de Leguízamo

Plan de Vida de Purús, FECONAPU (2009)

Plan Maestro de Alto Purús (2005-2010)

Plan Maestro de la Reserva Comunal Purús (2012-2017)

\section{Páginas web consultadas:}

http://fidagh.org/joomlafidagh/salarioslatinoamericanos

http://plataformacelac.org/es/progra$\mathrm{ma} / 481$

http://wiki.sumaqperu.com/es/Parque_ Nacional_Alto_Pur\%C3\%BAs

http://www.biobol.org/index.php/apsnacionales/300-reserva-de-vida-silvestreamazonicamanuripi

http://www.calendariobolsafamilia2016. net/valor-bolsa-familia-2016/

www.cofan.org

http://www.lostiempos.com/actualidad/ economia/20150725/alistan-sismicados-areas-junto-al-parque-manuripi

http://www.programatrinacional.com/ Programa-Trinacional/Cinco-areas-protegidas/Reserva-Comunal-Huimeki

https://www.protectedplanet.net https://ppbio.inpa.gov.br/ Programa de 
Pesquisa em Biodiversidade - PPBio

www.ac.gov.br Gobierno del Estado de Acre

www.agricultura.gob.ec/ Ministerio de Agricultura de Ecuador.

www.amazonia-andina.org/amazonia-activa/noticias/paisajes-sostenibles-conservacion-biodiversidad-mejora-los-mediosvida

www.ambiente.gob.ec Ministerio del Ambiente Ecuador

http://bdpi.cultura.gob.pe// Base de datos de pueblos indígenas u originarios. Ministerio de Cultura de Perú

www.connectas.org/amazonas/es/vias3. html. Artículo Buena vía, mala vida.

www.corteconstitucional.gov.co

http://www.asambleanacional.gob.ec/es/ publicaciones-asamblea-nacional

www.eba.com.bo Boletín informativo El Castañero de EBA, año 3, número 17. Enero a agosto del 2013.

www.elcomercio.pe / Autoridades y nativos se oponen a la carretera Iñapari-Purús. Julio, 2012

www.embrapa.br Empresa Brasileira de Pesquisa Agropecuária

WWW.fieldmuseum.org

WWW.ICMBio.gov.br

www.ilo.org Organización Internacional del trabajo

www.Infoandina.org

www.inredh.org

www.legislacionambientalspda.org.pe

www.parquesnacionales.gov.co

http://www.profonanpe.org.pe/proyectosy-programas Programas y proyectos financiados en algunas áreas protegidas de Perú

www.programatrinacional.com

https://raisg.socioambiental.org/ Red Amazónica de Información Socioambiental
Georreferenciada (RAISG)

wwW.redparques.com

www.sernanp.gob.pe

http://sinchi.isometri.co/ Instituto Sinchi Colombia, Investigación Científica para el desarrollo sostenible de la Amazonía de colombia y su protección.

http://sociobosque.ambiente.gob.ec/

www.territorioindigenaygobernanza.com

www.youtube.com WWF Bolivia. Videos: Castaña (nuez amazónica) Manuripi, Castaña (Nuez Amazónica), Origen de Área Protegida, Reserva Nacional de Vida Silvestre Amazónica MANURIPI, Siringa (goma) Manuripi.

www.webiica.iica.ac.cr Boletín electrónico Información IICA, 9 de abril de 2009 



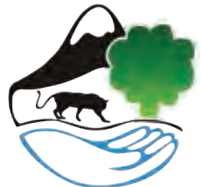

redparques

\section{REDPARQUES}

Red Latinoamericana de Cooperación

Técnica en Parques Nacionales, otras

Áreas Protegidas, Flora y Fauna Silvestres

www.redparques.com

Facebook de Redparques:

facebook.com/redparquesAL

Twitter: @redparques

\section{ONU \\ medio ambiente}

Programa de las Naciones

ONU Medio Ambiente - Oficina para América Latina y el Caribe

Avenida Alberto Tejada, Edificio 103

Clayton, Ciudad del Saber - Ciudad de

Panamá, PANAMÁ

Telf:: (507) 305-3100

Fax: (507) 305-3105

Apto. Postal: 0843-03590

www.pnuma.org

Twitter: @ONUMedioAmb

Facebook ONU Medio Ambiente:

facebook.com/ONUMedioAmbiente

www.unep.org

Alberto.pacheco@unep.org

\section{UICN}

Unión Internacional para la

Conservación de la Naturaleza

Av. República de El Salvador N34-127 y Suiza Edificio Murano Plaza, piso 12; 170515 Quito,

Ecuador

Telf. (593 2) 3330684

www.lucn.org/sur

www.portalces.org

Twitter: @UICN_SUR

Facebook UICN-Sur: facebook.com/UICN.SUR www.iucn.org

samerica@iucn.org

Organización de las Naciones Unidas para la Alimentación y la Agricultura

Oficina Regional de la FAO para América Latina y el Caribe

Av. Dag Hammarskjöld 3241, Vitacura,

Santiago de Chile

Telf: (56 2) 29232100

www.fao.org/americas/es

Twitter: @FAOnoticias

Facebook FAO: facebook.com/UNFAO/

www.fao.org

Jose.gomez@fao.org

\section{0 \\ WWF}

\section{WWF-Colombia}

Sede principal

Carrera 35 No. 4A-25

Cali, Colombia

Telf: (57 2) 5582577

www.wwf.org.co

Twitter: @WWFColombia

Facebook WWFColombia:

facebook.com/WWFColombia

www.wwf.org

areasprotegidas@wwf.org.co 


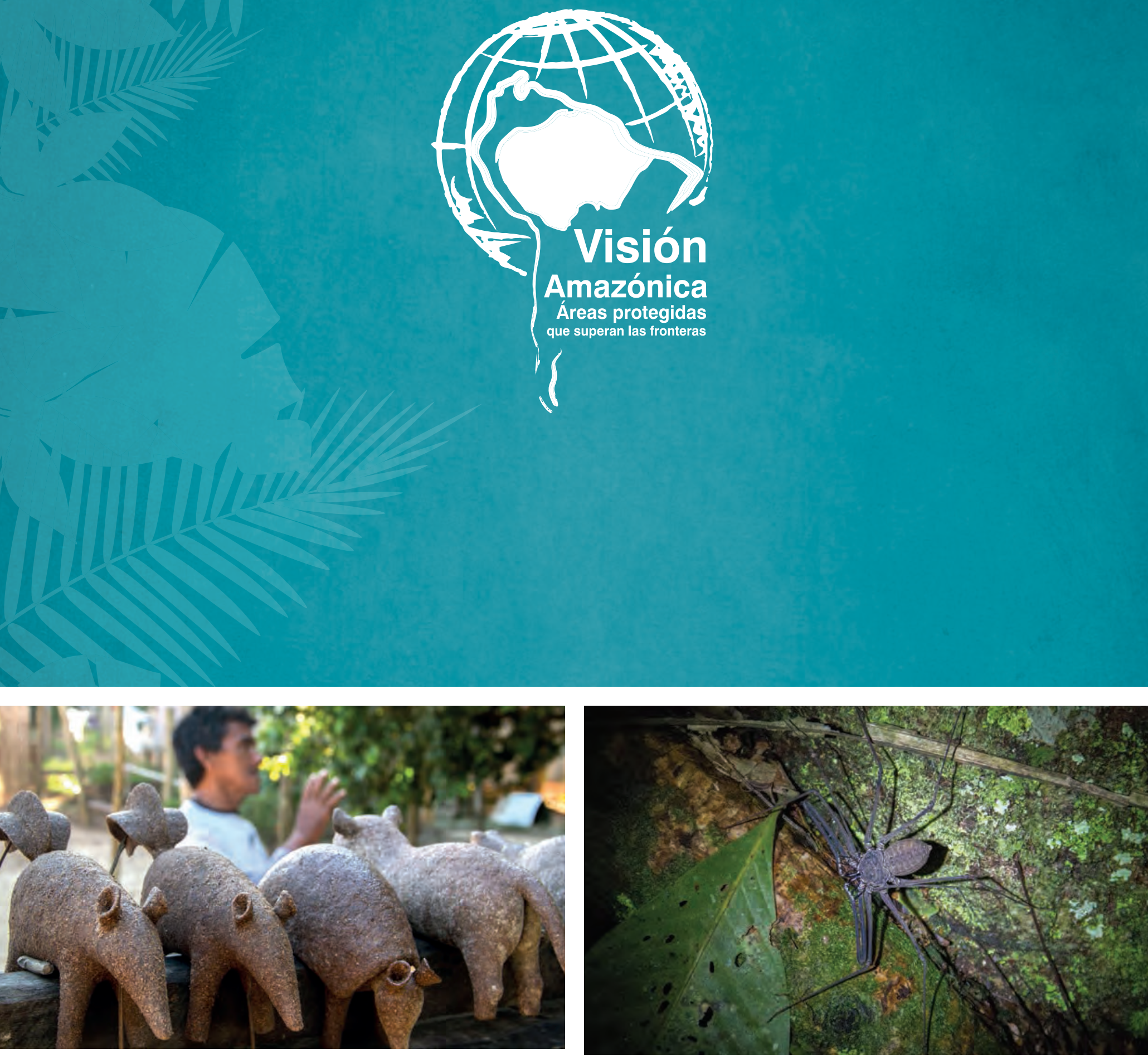

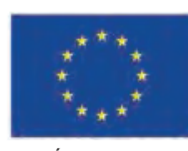

UNIÓN EUROPEA
ONU

medio ambiente

Proorame de las Naciones
Unidas para ei Medio Ambient

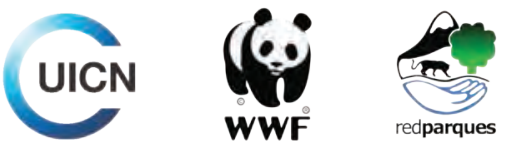

$(F)$

Organización de las Naciones

Unidas para la Alimentación y la Agricultura 